\title{
RIDING \\ AND \\ IIUNTING
}

OAPTAIN M. H. HAYES 


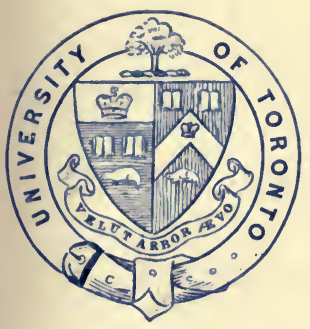

Dreseliteo to

\section{The Library}

of the

\section{University of Toronto}

by

Executors of Mrs. Hume Blake 
Digitized by the Internet Archive in 2007 with funding from Microsoft Corporation 


$$
\text { - }
$$





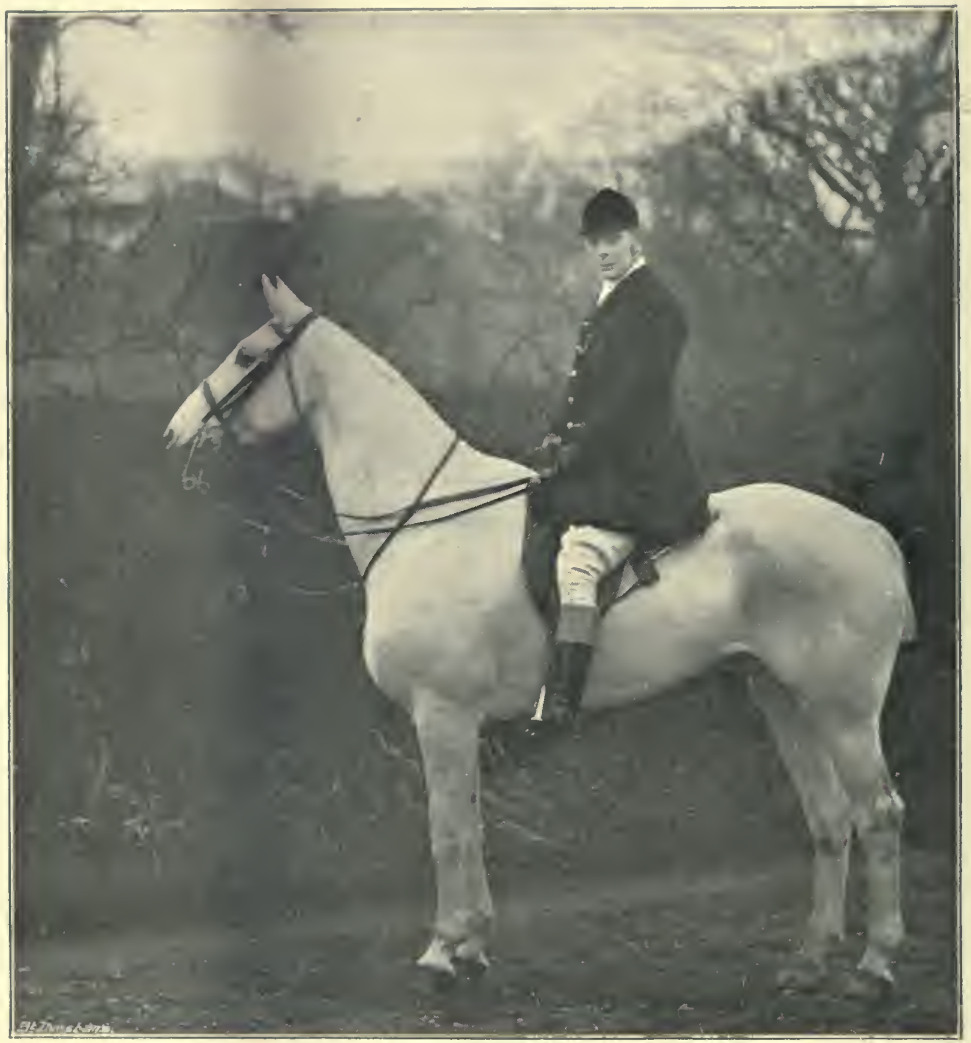

Photo by

Clarence Halley, Newmarket.

THE EARL OF LONSDALE. Late Master of the Quorn. 


\section{RIDING AND HUNTING}

BY

M. HORACE HAYES, F.R.C.V.S.

\section{(Late Captain "The Buffs")}

AUthor OF "Points OF THE Horse," "Veterinary NOTE'; lor Horse-Owners," "Stable Management and Exercise,"

“Ili.ustrated Horse-Breaking," “Among Horses in Russia," etc.

WITH ILLUSTRATIONS

\section{0$$
31.3 .49
$$

LONDON

HURST AND BLACKETT, LIMITED

I 3 GREAT MARLBOROUGH STREET

I90I

All rights reserved 
PRINTED BY KELLY'S DIRECTORIES LIMITED, LONDON AND KINGSTON. 


\section{P R E F A C E.}

ABout three-quarters of this book is new; the remaining quarter having appeared in the last (third) edition of Riding on the Flat and Across Country, 47 illustrations of which have been utilised. The present work contains 260 illustrations.

In the former book I made no mention of hunting; because, when I wrote it, my riding experience, except when I was a boy in Ireland, had been chiefly confined to steeplechasing, racing, schooling and pig-sticking in India, and to military riding when I was a subaltern in a field battery. On my return to England in 1892, after teaching Boers and other residents in South Africa how to break in horses, I was fortunately able to spend two seasons in Leicestershire and one in Cheshire. The knowledge gained during these three years impressed me so much with the fact that riding in England is almost inseparable from hunting, that I determined to combine the two subjects as soon as I could collect sufficient fresh material and new illustrations to justify the change of the former title to Riding and Hunting. During the last four years, I made a special study of the Continental system of military riding. Being in no way a hound man, I sought and obtained the valuable aid of Captain King-King, late I 3 th Hussars, whom I had the pleasure of knowing at Melton Mowbray. His deep knowledge of hunting is the result of 
an enthusiastic love of the sport, keen observation, and a life-long experience both in the Shires and in the Provinces. Any merit there may be in the remarks I have made about hunting belongs to him.

I have to thank Mr. Scarth Dixon for some of the instances I have mentioned in the chapter on race riding; Messrs. Champion and Wilton, Mr. T. U. Clarke and Mr. Ford for their valuable professional advice on the subjects of bridles and saddles, and Mr. Carl Norman, of the Photochrom Company, for the great trouble he took with the half-tone blocks.

All the photographs, with the exception of the frontispiece and Figs. 8 I, 88 and 243, were taken by my wife or by myself.

Yew Tree House, Crick, Rugby, 20th December, I 900 


\section{O N T E N T S.}

PREFACE.

CHAPTER I.

General View of Riding

CHAPTER II.

Beginning to Ride . 5 to 8

CHAPTER III.

The Horse as a Riding Machine.

CHAP'TER IV.

Bits and Bridle Gear 24 to 108

CHAPTER V.

SADDLERY •

\section{CHAPTER VI.}

How to Hold the Reins

CHAPTER VII.

Mounting And Dismounting . 169 to 186

CHAPTER VIII.

The Seat . I 87 to 203

CHAPTER IX.

Riding Without Reins

CHAPTER $\mathrm{X}$.

Hands ANd Legs

CHAPTER XI.

Guidance and Control . 
CHAPTER XIJ.

Riding and Bridling Horses with Vices - 252 to 277

CHAPTER XIII.

Riding Over a Country . 278 to 294

CHAP'TER XIV.

Hunting Preliminaries.

CHAPTER XV.

The Shires and their Fences - $35^{\circ}$ to $35^{8}$

CHAPTER XVI.

With Hounds . 359 to $37 \mathrm{I}$

CHAPTER XVII.

RACE RIDING 372 to 409

CHAPTER XVIII.

SteEplechasing . 410 to 424

CHAPTER XIX.

RACING SADDLERY 425 to $43 \mathrm{I}$

CHAPTER XX.

Keeping Down Weight - 432 to 447

CHAPTER XXI.

Military Riding $44^{8}$ to $45^{I}$ INDEX - $45^{2}$ to 460 


\section{LIST OF ILLUSTRATIONS.}

Frontispiece--The Earl of Lonsdale, Late Master of the Quorn.

FIG.

PAGE

I to r6. The Gallop . . . . . . . ro and I I I 7 to 26 . The Canter . . . . . I I I I5, I 7 and I9

27. Side view of horse's lower jaw . . . . . . $\quad$ I9

28. Turning horse to the right on his fore-hand . . 22

29. Racing snaffle . . . . . . . 30

30. Ordinary snaffle with cheeks . . . . . 3 I

3r. Double-jointed snaffle . . . . . . 3 I

32. Elevation of unjointed snaffle . . . . . 3 I

33. Plan , , . . . . . 3 I

34. Twisted snaffle . . . . . . . 32

35. Thin racing snaffle . . . . . . . 32

36. Chain snaffle . . . . . . . . 33

37. Double-ringed snaffle . . . . . . 33

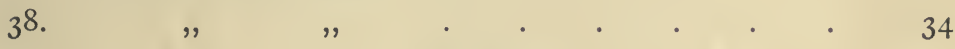

39. , ", with cheeks . . . . 34

40. Bridoon gag snaffle . . . . . . . 35

4I. Elevation of gag snaffle . . . . . . . 35

42. Plan of Fig. $4 \mathrm{I}$. . . . . . . . 35

43. Double-mouthed snaffle . . . . . . 36

44. Newmarket,$\quad$. . . . . . . 37

45. Hancock's "curl bit mouth cover" . . . . 39

46. Ordinary curb . . . . . . . . 40

47. Chin-strap unbuckled . . . . . . $4 \mathrm{I}$

48. " " . . . . . . . 4 4 I

49. Ward Union Curb Bridle, with half-moon snaffle . $4^{2}$

50. ", , , , with sliding mouth-piece . 43

5 . Curb with sliding mouth-piece . . . . 43 
FIG.

PAGE

52. Ben Morgan bit

53. Chifney bit

54. Gridiron bit

55. Lord 'Thurlow's bit .

56. Military bit : one ring is turned up to show that the rings are movable

57. Segundo bit

58. " " with lower end of off cheek drawn back, to show that the cheeks and port are movable . 45

59. Curb with arched mouth-piece . . . . 45

6o. Mamluke bit . . . . $\quad$. . . 46

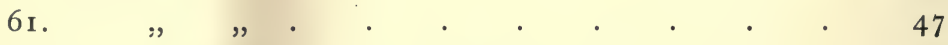

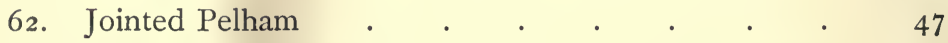

63 Pelham with movable mouth-piece and short chain on port

64. Pelham (same as that shown in Fig. 63) with movable mouth-piece having port inclined forward.

65. Hanoverian Pelham.

66. Side view of Hanoverian Pelham folded up . . 49

67. "Head" of single bridle . . . . . . 50

68. Bridoon head . . . . . . . . $55^{2}$

69. Stud billets . . . . . . . . . . . 53

70. Spring hook . . . . . . . . 53

7 I. "Head" of bridle for rough work . . . . 54

72. Mr. Langham-Reed's head-stall . . . $\quad 5^{6}$

73. Stop to prevent ring of martingale catching on buckle

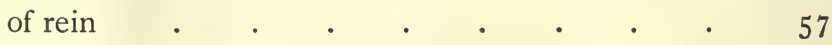

74. Ring of martingale caught on buckle of rein . . 57

75. Improvised stop on rein . $\quad . \quad$. $\quad . \quad 58$

76. Loose ring of curb attached horizontally . . $\quad 5^{8}$

77. Reins laced to prevent hands slipping . . . 59

78. Ordinary nose-band with rubber tube . . . 60

79. Caveson nose-band . . . . . . . 6 I

8०. Gillard's nose-band . . . . . . . 62

81. I Frank Gillard and the Belvoir Hounds . . . 63 
FIG.

82. Bucephalus nose-band

83. Curb reversed .

84. Chin-strap with hooks at each end . . . . 67

85. Action of unjointed snaffle on horse's mouth . . 68

86. Nutcracker action of jointed snaffle on horse's mouth 68

87. Groom on Leicestershire hunter . . . . . 69

88. Kalmuck on Russian remount . . . . . 70

89. Cheek of snaffle connected to cheek-piece of bridle . 72

90. Snaffle with cheeks solidly connected to mouth-piece 73

91. Action of curb as a lever . . . . . . 73

92. View of under surface of lower jaw . . . . 74

93. Action of a curb which has no curb-chain . . . 77

94. Properly constructed curb for ordinary hunter . . 78

95. Angle made by the cheeks of a curb, when the reins are taken up . . . . . . . . 8 I

96. Side view of curb which has its port inclined forward at an angle of $45^{\circ} \quad . \quad . \quad . \quad . \quad .8 \mathrm{I}$

97. Curb-chain covered with india-rubber tube . $\quad 84$

98. " " $"$. . . . . 85

99. Ordinary curb-hook . . . . . . . $\quad$. 85

ı००. Patent "circle curb-hook" . . . . . 85

гог. Standing martingale buckled to caveson nose-band . 87

102. " " , , rings of a snaffle . 88

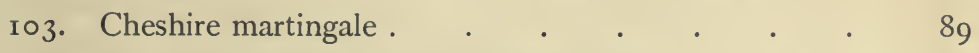

104. Maximum length of standing martingale . . . 9 I

105. Minimum ", " ",$\quad$. 93

106. Improvising a standing martingale by means of a

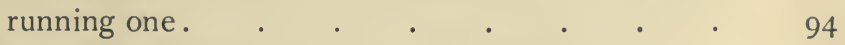

I07. Lord Lonsdale's registered running martingale . . 95

I08. A "web martingale" . . . . . . . 96

I09. Natural position of head in canter . . . . 98

I Iо. Measuring minimum length of running martingale . 99

I I . Irish martingale or "spectacles" . . . . 100

I 2. Running martingale improvised by means of a branched standing martingale and two rings . . 
FIG.

PAGE

II3. Bridling a horse . . . . . . . 103

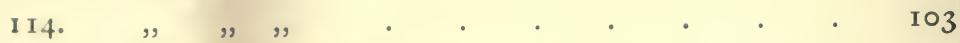

I 5. Upper aspect of the bones of the lower jaw which form the bearing surface of the mouth-piece of the bit

I16. Correct position of bit and bridoon .

104

I05

I I 7. Half-moon snaffle with cheeks solidly connected to the mouth-piece . . . . . . . . 108

I 18 . Hunting saddle with a nearly straight head . . $\quad$ Iog

I I 9. Military saddle . . . . . . . . . $\quad$ I Io

I 20. Racing saddle . . . . . . . . $\quad$ I IO

I 2 I. Buck-jumping saddle $\quad$. $\quad$. $\quad$. $\quad$. $\quad . \quad$. I I

I 22. Tree of hunting saddle . $\quad$. $\quad$. $\quad . \quad$. . III

I23. View of under surface of saddle tree . $\quad . \quad$. $\quad$ II2

I 24. , , , , , , , , , with bar plates .

I 3

I 25. Saddle tree with narrow twist and a good deal of dip in seat . . . . . . . . . . . $\quad$ I 18

I 26. View of under surface of saddle tree, Fig. I25 . . I I9

I 27. Hunting saddle with half-cut back head . . . I 20

I 28. Upper surface of tree, with webs . . . . I 2 I

I 29. Under ,, , , , , , , . . . . . I 22

I30. Saddle with short panel and open gullet . . $\quad$ I 24

I 3 . Lord Lonsdale's system of girthing . . . . $\quad$ I 28

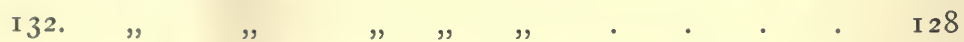

133. Side view of Austrian officers' jointed saddle tree $\quad$ I32

134. Plan of Austrian officers' jointed saddle tree on a broad-backed horse . . . . . .

I35. Plan of Austrian officers' jointed saddle tree on a narrow-backed horse . . . . . . . . $\quad$ r 133

I36. Nolan's saddle . . . . . . . . . . $\quad$ I34

I37. Rough-rider in buck-jumping saddle . . . . $\quad$ I35

I38. Messrs. Champion and Wilton's gauge for the withers 136

I39. :, , , , , , back . I 37

I40. Mr. T. U. Clarke's gauge for the withers . . . $\quad$ I $3^{8}$

I 4 I to I44. Stirrup leather buckles . . . . . . $\quad$ I 39 
FIG.

PAGE

45. Persian side iron

140

I45. Spade side iron

140

147. Round leg iron

140

148. Weston's patent safety bar and buckle

I 4 I

I49. Girth buckle with cross bar . . . . . 143

I50. " " without cross bar . . . . . 143

I5I. Horse properly saddled and bridled . . . . 147

I52. Twisting stirrup leather . . . . . . 149

r53. Shortening a girth . . . . . . ${ }_{50}$

I54. Tightening the girths when mounted. . . . I $_{5} \mathrm{I}^{\mathrm{I}}$

r55. Using a stirrup leather, the sewing of which has become undone . . . . . . . $\mathrm{r}_{52}$

r56. Drawing up iron on leather . . . . $\mathrm{r}_{52}$

157. A rein in each hand . . . . . . . 154

158. Single reins crossed in both hands . . . . I55 $_{55}$

I59. Single reins crossed in one hand . . . . ${ }_{5} 6$

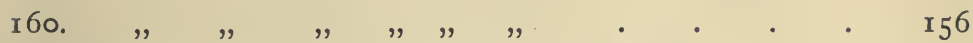

I6r. Double reins held separately in two hands . . $\quad 157$

162. ", " crossed in both hands with the little fingers between them

$\mathrm{r}_{5} 8$

163. Double reins crossed in both hands with the ring (third) finger between them . . . . . $\quad$ r 59

r64. Holding double reins crossed in one hand . . r6o

165. Double reins in left hand: one crossed, the other

hooked up on middle finger . . . . 16r

r66. Shortening single reins held in one hand . . . $\quad$ r62

36. Reins held in one hand in military fashion . . $\mathrm{r}_{5}$

168. Off rein taken up by right hand from position shown

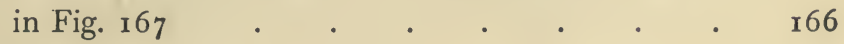

r69. Tying up one rein . . . . . . . . 167

I 70. Measuring length of stirrup leathers . . . . 170

I 7 r. Preparing to mount . . . . . . . I I I

172. 'Bringing horse's head round to near side when mounting . . . . . . . . 173

173. Covering a horse's near eye with cap . . . $\quad$ r75 
FIG.

174. Preparing to mount hog-maned pony

175. , , , , in military fashion

s76. Riding lad preparing to mount

I 77. , " bearing his weight on horse's neck when mounting

I 7 8. Getting a leg-up

I 80

179. Preparing to dismount

I80. Dismounting .

18r. Stopping short

182. Sitting easily .

183. Back hollowed out .

190

184. Daylight showing between knees and saddle

I85. No daylight between knees and saddle

r86. Hunting seat at a walk

195

195

199

187. $, \quad, \quad$, a gallop.

200

188. Clearing the pommel to see if the stirrups are the right length

r89. Riding without reins

190. Out hunting .

19r. Shortening the reins before using the whip with the right hand .

192. Swinging the whip forward before bringing it up

193. Bringing the whip up before using it

194. Shortening the reins with the right hand before using the whip with the left hand .

195. Drawing the whip through the right hand .

197. Rising at the trot

198. Turning a horse with outward hand raised . $\quad 239$

199. " , , , , , , , , , ,

200. $, ", \quad, \quad, \quad, \quad$, kept low

201.

,", , , , ,

, , , ,

243

202. Passage to the right . 
FIG.

205. Picking up an object off the ground .

250

206. Showing a horse the whip .

254

207. Maori method of riding a buck-jumper . . . 259

208. Plan of preventing a horse throwing down his head .

209. Plate to prevent horse getting his tongue over the bit.

2 ro. Side view of plate shown in Fig. 209

2 I r. Position of snaffle over plate shown in Fig. 209 .

2 12 . Taking off

282

213. Dollery on Cloister and Mawson on Horizon . . 283

2I4. Leaning well back . . . . . . . 284

215. Clearing the water-jump at Sandown Park . . $\quad 285$

2I6. Hands down and reins a good length . . . 286

2I 7. Sitting too far back; reins too short; and hands too high . . . . . . . . .

218. View from Gartree Hill; the cover in the foreground, and Little Dalby Hall on the right in the distance

2 ró. Wire

220. Garter straps .

221. View, from the road near Buckley Folly, of the country in the direction of Daventry

22 2. Hedge newly cut and laid

223. A second season cut-and-laid hedge .

224. Old cut-and-laid hedge

225. A practicable bullfinch

226. Topped hedge .

227. Hedge

228 .

230. Single oxer

23I. Double ,

232. Posts and rails 
FIG.

236. Double posts and rails

237. Railway posts and rails

238. Stone wall

239. Midland stile .

240. Gate

24I. Hedge with ditch on one side .

242. Ridge and furrow

243. J. H. Martin on Joe Chamberlain

244. Knot on end of rein

245. Plan of G. N. Steeplechase Course .

247. Landing side of Beecher's Brook . . . . 413

248. Seventh fence . . . . . . . . $4 \mathrm{I} 3$

249. Valentine's Brook fence . . . . . . 4 I 4

250.,$"$ (landing side) . . . . 4 4 5

25I. Thirteenth fence . . . . . . . 415

252. Side view of fifteenth fence . . . . . $4 \mathrm{I} 6$

253. View of fifteenth fence from landing side . . . 4 i 7

254. Usual open ditch with guard rail . . . . 417

255. Water jump in front of Grand Stand . . . 418

256. First fence (taking off side) after race . ‘ . 419

257. " " (landing side) " , . . . 420

258. Second ," ", ",$" \quad$. . . 42 I

259. Beecher's Brook (taking off side) after race . . 422

260. Eighth fence

" $, \quad, \quad$,

$4 \approx 3$ 


\section{R I D I N G.}

CHAPTER I.

\section{GENERAL VIEW OF RIDING.}

THERE are several varieties of riding, which are respectively the outcome of circumstances that differ greatly from each other. Thus, in military riding, uniformity of style and control over the animal are the chief objects kept in view. As high school equitation is practically restricted to the manege and circus, its professors have naturally to depend for variety on exaggerated movements, the majority of which can seldom if ever be usefully applied in the field or even on the road. Custom and conditions of ground cause Continental horsemen as a rule to ride out of doors in a manner suitable only to the school or the parade ground. English hunting men have during the season a task before them that demands not only a strong seat, fine hands, plenty of pluck, and a good eye for a country, but also a sound knowledge of the galloping and jumping capabilities of their mounts, to say nothing of the necessity of seeing what hounds are doing. Excellence in riding to hounds is therefore judged, not according to conventional ideas as to position and attitude, but from a thoroughly practical point of view; and the seat most prized, is the one which will enable the horse to carry his burden with the least exertion. A rider in jumping competitions requires special skill in collecting his horse, so, as to make him jump "big" and cleverly in a cramped arena in cold 
blood. No just comparison can be made between the difficulty of taking the fences in these shows and those of a "natural" country; for the "made" fences can be studied before starting, are constructed on favourable ground, and are negotiated at a time when the horse's powers are unimpaired by severe exertion. In flat race riding, which demands in the highest degree knowledge of pace and clever generalship, there is but little variety in the conditions of ground. Even in steeplechase riding, the fences are more or less of the "sealed pattern" order, and, like on the flat, the distance and ground are known beforehand. In rough-riding - as I have seen it practised on buck-jumpers by Australians, Cowboys, and Cossacks, and on difficult animals of all kinds in various parts of the world-the game is almost entirely one of sticking on. In Australia and New Zealand, the fences are higher and generally stiffer than anything met with in The Shires; but the variety in obstacles and ground is much less. In pigsticking in India, as I knew it many years ago when I was a subaltern in the "Gunners," and a member of the Nagpore Hunt, there is an almost entire absence of fences; but the ground is generally far more dangerous to ride over than any line of hunting country, especially as full speed is always the order of the day. Consequently, no form of riding requires more trust in the honour of the horse and forbearance from pulling his mouth about, than the chase of the wild boar. In polo, the player needs all the control of military equitation, with the addition of ability in " riding out."

The possession of consummate skill in one form of riding by no means implies competency in other varieties of this art. Some of our best steeplechase jockeys have been very moderate on the flat; and I need hardly say that few flat-race jockeys are good across country. In this 
respect, Fred Webb is a brilliant exception. Poor Fred Archer, though keen and full of pluck, did not perform exceptionally well out hunting when he went to Melton Mowbray. Custance is an instance of a jockey of the highest class being a particularly fine rider to hounds. Even the best steeplechase riders are not always firstflight men out hunting. Few Australian jockeys are good on a buck-jumper. Hunting, chasing, and flat-race riding are by no means sufficient to teach a man how to ride at polo. In all these forms of horsemanship, special practice alone makes perfect.

As a rule, the weak point in the riding of hunting men and jockeys is want of knowledge in the application of hands and legs for keeping a horse under control and for making him obey with promptness and precision every legitimate command of the man on his back. Under the head of "legitimate commands," we may include all that ought to be taught in our military riding schools, as well as the usual details of ordinary horsemanship. It is evident that ability to make a horse rein back, "passage," change the leading leg at the canter or gallop, turn and change from one pace into another with promptness and precision, is useful in every form of riding. Many a man out hunting would have been saved from a nasty kick, and in some cases from a broken leg, when too close behind a tail adorned with a red bow, if he had only known how to rein back; and from being thrown out of a run by losing time when trying to open a gate, if he had been able to have made his animal turn on its forehand. Jockeys frequently lose a good place at the start, from not being able to move to the rear or to one side, without having to turn their horses round. Horses have of course to be taught how to execute these very useful and easily-learned movements, before they can do 
them properly in obedience to the indications of the hands and legs of their riders, who need the requisite instruction quite as much as the animals they bestride. Acquaintance with these simple school "airs" is of more importance in hunting than in race-riding, because the variety of conditions is greater in the former than in the latter.

Whatever may be our private opinion, it is impossible to prove the superiority of one kind of riding over another kind; any more than we can say which is the best sort of fishing, shooting, card game, dinner, wine, fruit, or anything else of which there are several varieties that respectively serve different purposes. All that we can affirm with justice is that each kind of riding has merits which are not possessed by other kinds of riding, and that these merits vary in importance according to the special requirements of individuals. We can, however, take for granted, that the greater number of varieties of riding a man knows, the better horseman he is. This fact has been recognised by all our great generals, from Wellington to Roberts, all of whom have done everything to encourage hunting among their officers. As it is impossible under military conditions to give the rank and file adequate instruction in 'cross country work; ideal horse soldiers are to be found as a great rule only among officers of the Cavalry and "Gunners." In our Colonial cavalry, several of the same type will be found among the men as well as among the officers; for in the Colonies, riding over a "big" country is a common accomplishment of all classes. On the Continent, the vast majority of cavalry officers, though good at school work, know nothing about 'cross country riding, as the term is understood in England, Ireland and Greater Britain. The immense amount of practice in riding which our officers get in India, has greatly contributed to make them the finest horsemen of any army in the world. 


\section{CHAPTER II.}

\section{BEGINNING TO RIDE.}

IT is by no means imperative for a person to begin early in life in order to become a good, or even a finished horseman. Some of the straightest riders I have known, never mounted a horse before they were twenty-one or even older. I must, however, admit that they did not possess that extraordinary strength of seat which I have observed only among those who began to ride when they were boys. I attribute this failure to obtain perfection, to the fact that a high degree of proficiency in the art of balancing the body can be acquired only when a commencement has been made in early youth. Riding is so essentially an affair of nerve and balance, that it is hopeless to become a brilliant performer in the saddle, unless one begins to learn before one knows what fear is, and before one's joints have lost their pliability. Practice, however, can do a great deal, even to putting a man's heart in the right place; for the more familiarised we become with any form of danger, the less do we fear it.

Boys who have the opportunity, usually commence their first lessons in equitation on a donkey or small pony, and by dint of many falls and a little advice, get "shaken into their saddles." I remember when I was a boy of eight or nine, my father's coachman, whom I regarded as the highest authority on riding in the world, repeatedly telling me that I would never be able to ride until I had seventy-seven falls. I unfortunately lost count when I got into the twenties, so 
cannot tell whether he was right or wrong; although I am certain that the "spills" I had made me all the more keen. I believe that a few falls, provided that they are not too severe, do a strong, stout-hearted boy a great deal of good when he is learning to ride; but if the beginner be a man, or a delicate youth, they are apt to destroy his confidence, without which no one can ride well. A bad fall, on the contrary, will in all cases have a bad effect. This fact is well recognised among jockeys, some of whom I have heard remark about poor Fred. Archer, when alluding to his extraordinary pluck, that he retained it because he had not met with a severe accident.

In order to give a grown-up beginner confidence, I would strongly advise that, to commence with, he should be put on a very quiet, easy-paced horse; that he should be allowed to ride with stirrups; and that he should have a comfortable, broad-seated saddle, covered with buckskin, or, if necessary, a buckjumping saddle (Fig. I2I). After a time he might try an ordinary pigskin saddle, and might have a change of horses; but he should hasten slowly. In order to become a fine horseman, it is imperative for a man to practise on a large variety of animals. He should above all things avoid, from the very first, depending on the reins for support; for that trick once learned, will be difficult, if not impossible, to discontinue. It is also incompatible with strength of seat and goodness of hands. A man who "holds on by the reins" will always be liable, when in the saddle, to be pulled on to the horse's neck, in the event of the animal putting down his head to buck, or stretching out his head and neck when making a mistake, as for instance, in jumping. The method of teaching to ride without reins, which I shall presently describe, is admirably calculated to make the pupil independent of their help for "sticking on." He should try to learn to ride by balance, 
and not by grip; for, if a continued effort be demanded of any set of muscles, they will soon lose their power and will be unable to act at, perhaps, the very moment their aid is required to save the rider from an accident. As soon as he feels somewhat at home in the saddle with stirrups, he should try to do without them for short periods of time, which he should gradually lengthen as he improves in his seat, until he can ride in safety and comfort without stirrups. Having acquired the necessary proficiency, there will be no object in his practising further in that way. The respective seats and styles of riding with and without stirrups, differ so much from one another, that a man should thoroughly accustom himself only to the method (that with stirrups) he will habitually employ. The great advantage of practising to ride without stirrups is, that it teaches one to "get well down in the saddle," to lean back, and to ride by balance.

The beginner should never, if he can help it, continue riding after he has become tired; for he will then be unable to maintain a proper seat, and will be apt to acquire a slovenly style.

If a man has to ride in a light saddle, he should practise in one; for however firm he may be in a ten or twelve pounds saddle, he will, as a rule, feel more or less uncomfortable and insecure in a racing or light steeplechase one, unless he is accustomed to it.

A beginner, when he feels insecure in the saddle, has often a strong tendency to steady himself by catching hold of the pommel, or even of the mane. If he requires some adventitious aid, he may be excused for putting a hand back and catching hold of the cantle of the saddle; for by so doing he will be enabled to check the forward movement of his body, which is manifestly the cause of the large majority of falls. If, however, he grasps the pommel or the mane, the fact of his doing so will cause the weight of his body to 
be carried forward. He will then, though probably able to preserve his balance while the horse is going straight on at a uniform pace, be almost certain to roll off, if the animal suddenly slackens its speed, turns sharply, or makes any unexpected movement. His fall in any of these cases will be accelerated by the fact of his holding on in front; but would be more or less checked by his grasping the cantle, which is, after all, but a choice between two evils, and should therefore be avoided if possible. 


\section{CHAPTER III.}

\section{THE HORSE AS A RIDING MACHINE.}

HoRsEs having been fashioned during countless ages by their surroundings, are admirably fitted for a life in the open, but they possess little natural aptitude for civilised requirements. In fact, wild horses which have been uninfluenced by domesticity, are practically of no use to ride or drive; because their legs will not stand work, their tempers are "unkind," they are poor weight carriers, they have bad paces for saddle, or harness, and they are wanting in vigour. These remarks apply to even the semi-wild horses in the Australian bush, and may be extended to Burchell's zebras, which have been unsuccessfully tried for draught in South Africa. I can say from personal experience, that both the mountain and the Burchell zebra are unfit for saddle work. The descendants of wild horses do not become capable of serving our purposes until they have been subjected to careful selection for many generations. Even then, the period during which artificial influences have been at work, is far too short for the production of any great change in conformation. Although wild horses in a natural state of life, often roam many miles during a day, they generally move at a slow pace and with frequent halts, or at least, with several intervals during which they walk. Horses on grass, whether they are wild or tame, have but little inclination to "scour the distant plains," and need corn to stimulate them to take voluntary exercise, as we find with hunters and polo ponies that are 


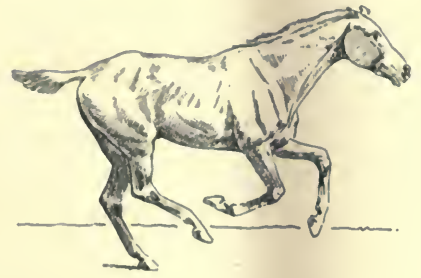

Fig. $\mathbf{I}$.

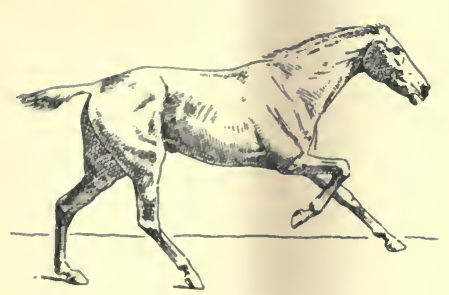

Fig. 3 .

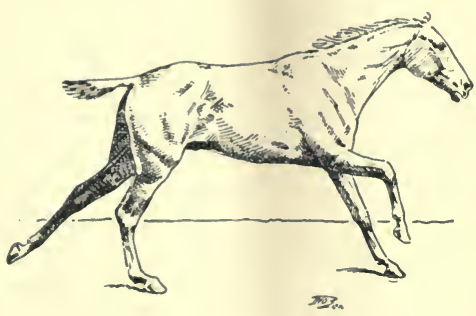

Fig. 5 .

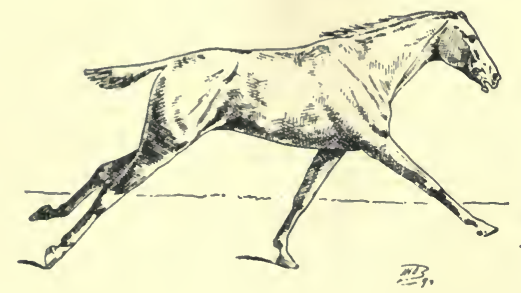

Fig. 7 .

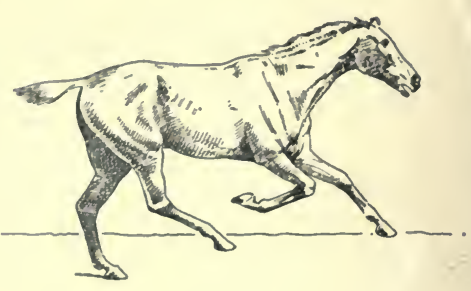

Fig. 2.

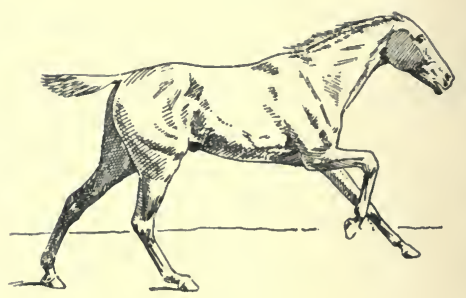

Fig. 4 .

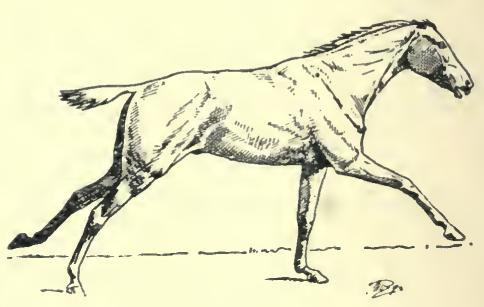

Fig. 6.

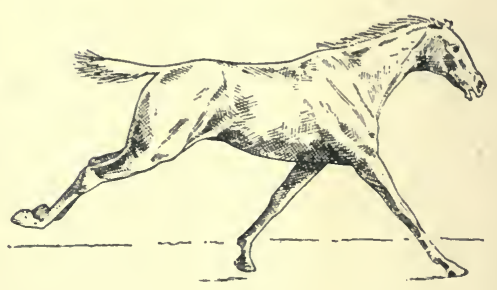

Phases of the Gallop.

Fig. 8. 


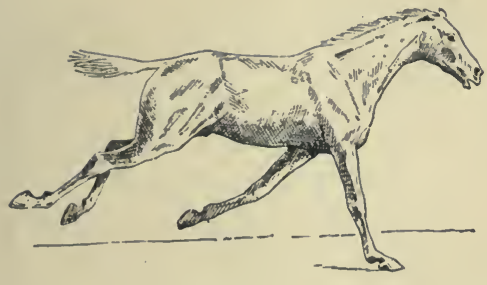

Fig. 9.

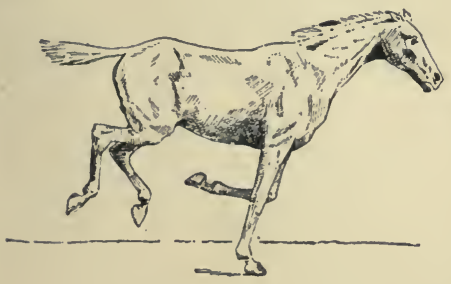

Fig. II.

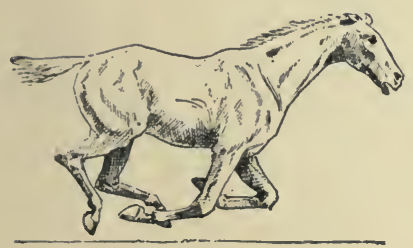

Fig. I3.

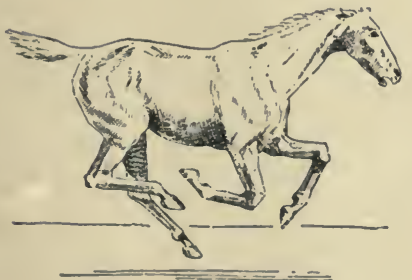

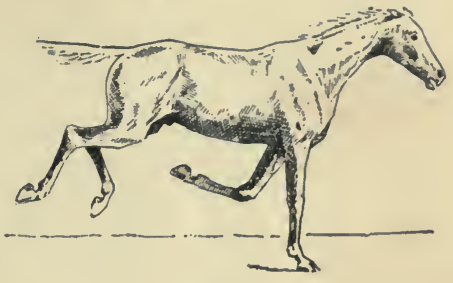

Fig. Io.

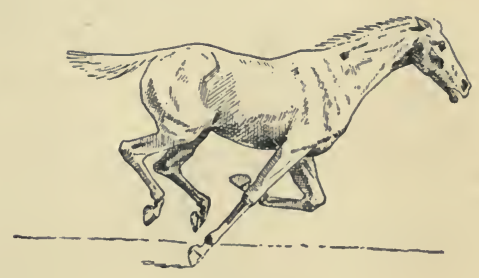

Fig. 12.

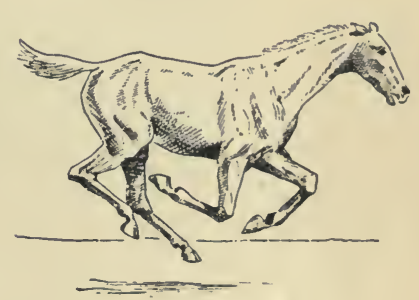

Fig. 14.

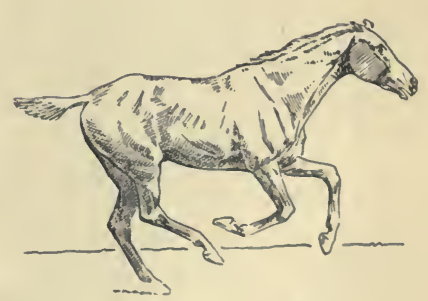

Fig. 16.

Fig. 15 . Phases of the Gallop.

Fig. 16. 
"turned out." Even our best domestic horses have the very serious fault that they are unable to stand continued fast work without incurring a high degree of liability to injury of the limbs, and particularly of the fore legs. Hence, ordinary riders have the double duty of exercising judgment as to the amount of work their mounts can bear with safety, and of performing to the best advantage in the saddle. Jockeys, on the other hand, are as a rule solely concerned in trying to be the first to get to the winning post without paying any consideration to the chance of their horses breaking down.

General Morris of the French army (Essai sur l'extérieur du cheval), showed by experiment that an unmounted horse weighing $850 \mathrm{lbs}$. and standing in an ordinary position, carried about $54 \mathrm{~T} / 2$ per cent. of its entire weight on the fore legs, and about $45 \mathrm{x} / 2$ per cent. on the hind ones; but that when mounted by a ten stone rider, who sat in an ordinary upright attitude, and in a saddle placed in the usual position, the respective percentages were about 56 and 44. It is evident that the lighter the rider, the less would his presence in the saddle alter the natural distribution of weight between the fore and hind legs, other things being equal. As experience teaches us that the fore legs of saddle horses, as a great rule, wear out quicker than their hind legs, we might at first conclude that this inequality, as regards susceptibility to injury, is due to the presence of the rider causing a larger proportion of weight to be carried by the fore legs than is natural. Speed has, however, a far greater influence in this respect, as we may see by the immensely large percentage of flat-race horses that break down in front during training and when running, as compared to hunters which have to accomplish much longer distances and to carry far heavier weights, but at slower speed. I make this remark with due allowance for the fact that race horses are put to work at a much earlier age than hunters. 
THE CANTER.

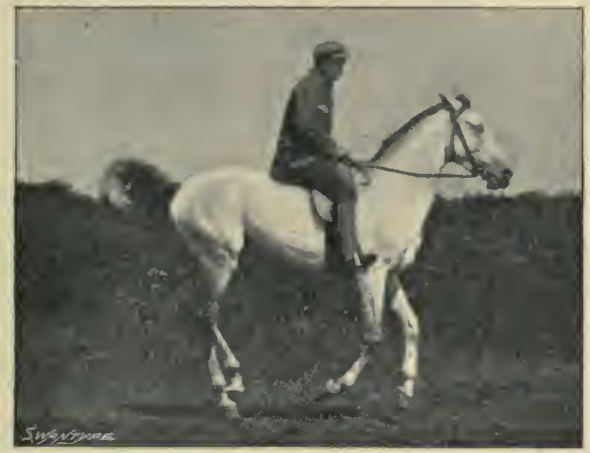

Fig. 17.

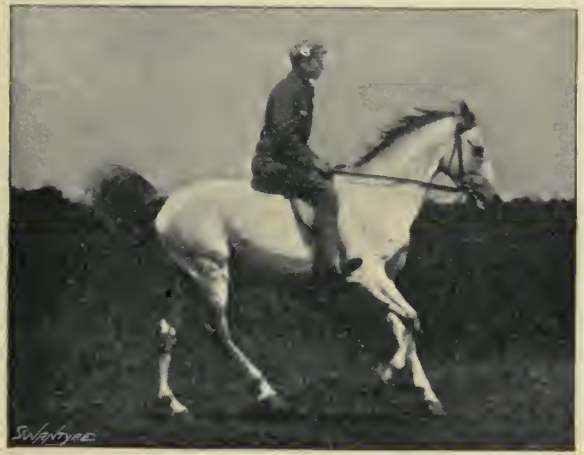

Fig. 18.

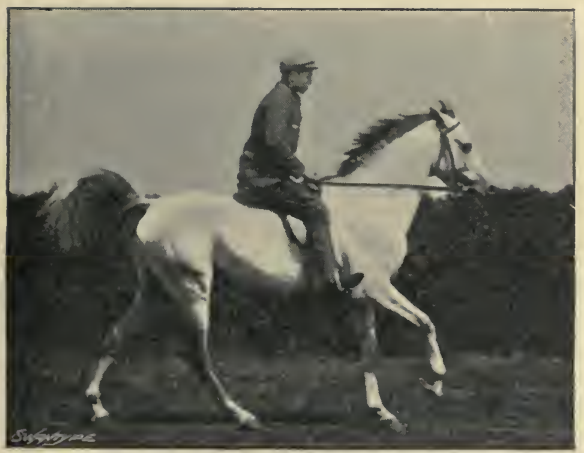

Fig. 19. I hases of the Canter. 
In quadrupeds as well as in bipeds, instability of equilibrium is an essential element of speed; for the more insecure the equilibrium, the quicker can the new base of support be formed. Hence the faster the pace, the more unstable will be the equilibrium. For instance, the centre of gravity is carried farther beyond the base of support in the gallop (Fig. I2), than in the canter (Fig. 24). By Figs. I to I6 we see that the gallop may be divided into the following successive though not very clearly separated periods, namely: (I) support by the hind legs ; (2) propulsion by the hind legs ; (3) support by the fore legs ; (4) elevation of the forehand and to a slight extent propulsion by the fore legs ; (5) suspension. Not only does increased instability of equilibrium add to the quickness of the stride, but it also augments its length, as has been proved by experiment with race-horses ridden at the gallop by lads who, on different occasions, employed respectively the ordinary seat and the "crouching" seat. It is evident that the more a rider leans forward, the more unstable will be the equilibrium and the greater will be the strain thrown on the ligaments of the fore legs during their period of support, and on the back tendons while the fore-hand is being raised. The attainment of increased speed by the rider bringing his weight forward, is accompanied not only by greater danger to soundness, but also by loss of staying power, on account of an unduly large amount of labour being thrown on the muscles which extend (straighten) the fore legs and thus serve to raise the fore-hand. It is evident that the shorter the distance of a race, the more will a jockey have to consider speed; and the longer the journey, the more attention will he have to devote to staying power. In almost all cases when a horse gets tired in a race, he shows by his up-and-down motion (inability to raise the fore-hand to a sufficient height) that the muscles of the forehand are at that time more fatigued than those of the hind 


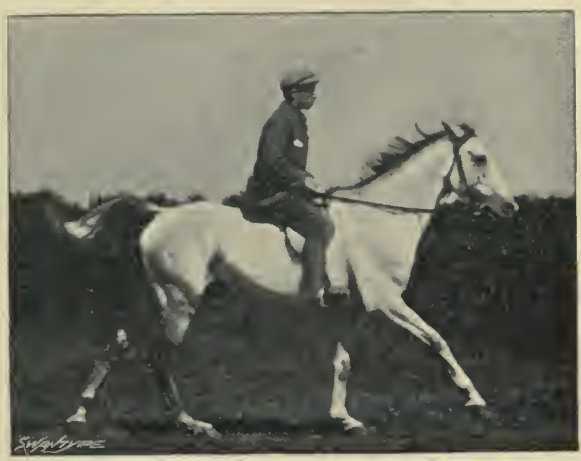

Fig. 20.

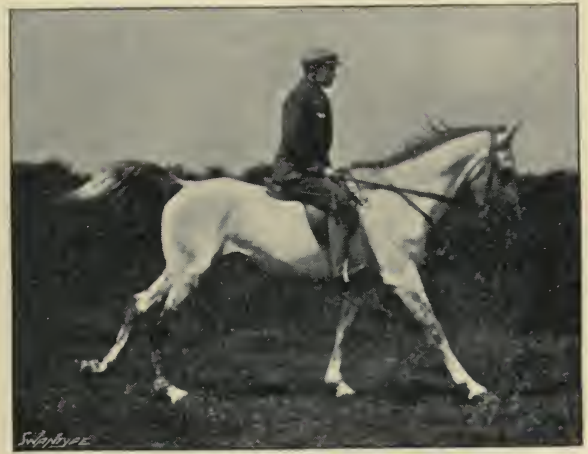

Fig. 2r.

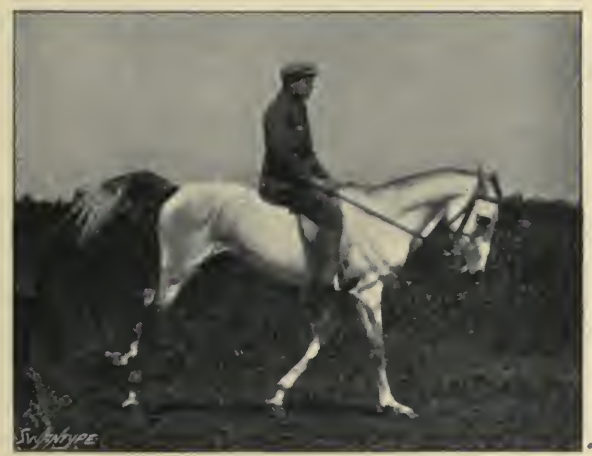

Fig. 22. Phases of the Canter. 
limbs. Consequently, at the end of a long and well contested race, a capable jockey often leans back in the saddle and takes a good hold of the horse's head, by doing which, he relieves the tired fore-hand of a portion of the weight it is trying to support and raise. At first glance it might appear that the presence of a jockey was the chief cause of the muscles of the fore limbs of the racehorse becoming more quickly tired than those of the hind quarters. We find, however, the justly admired "level" style of going only among horses which are the product of many generations of careful selection for saddle purposes. The ordinary harness animal, and still more the cart horse, can gallop only in up-anddown fashion (like a ship pitching at sea), apparently on account of want of ability in the fore limbs (including the shoulders) to raise the fore-hand sufficiently high. In similar positions, thoroughbreds carry a larger proportion of their weight on their fore legs than common animals do, by reason of their necks being longer in proportion to their bodies, and consequently the leverage exerted by their heads and necks being greater. The weight borne by their fore-hands is, however, comparatively small, and the muscles of their shoulders are admirably suited for quick and extended action.

It is instructive to note that first-class sprinters, such as Harry Hutchens was some years ago, and fast skaters, almost always bend very much forward when travelling at high speed.

It is reasonable to infer that if a horse has to go at a speed and cover a distance which will fully try his staying capabilities, he will accomplish his task best, when the respective muscles of the fore-hand and hind quarters are taxed in proportion to their power. Here, the strength of the chain is equal to that of its weakest link.

The foregoing observations undoubtedly point to the fact, 
THE CANTER.

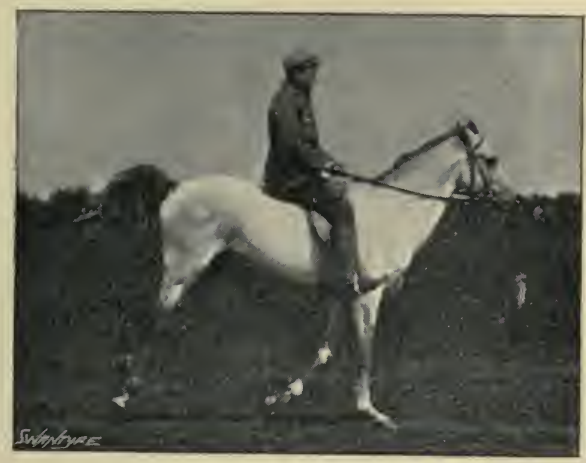

Fig. 23 .

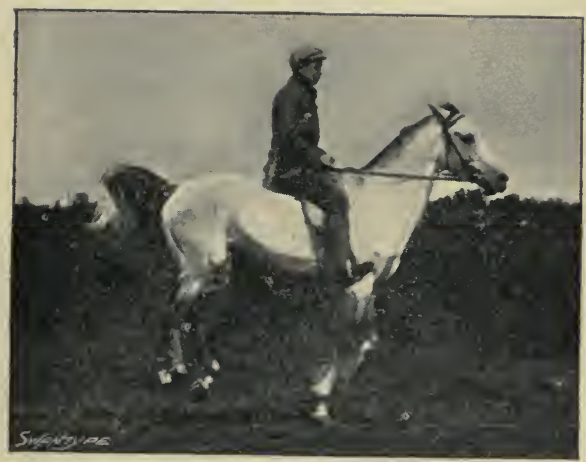

Fig. 24.

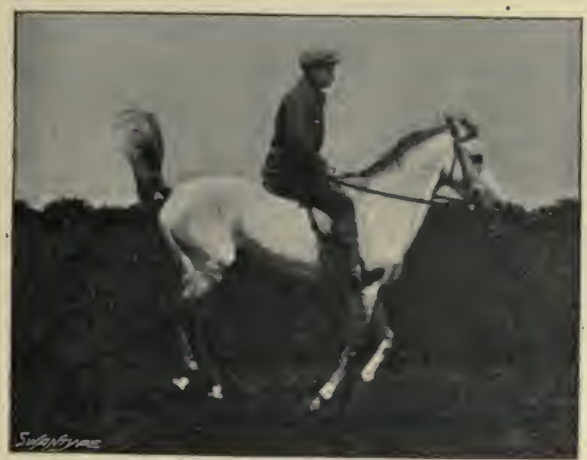

Fig. 25. Phases of the Canter. 
that in ordinary riding, we should endeavour to keep the horse light in front.

A horse's muscles work at such mechanical disadvantage in carrying a weight, that special precautions have to be taken to avoid injury to the surfaces upon which the weight is placed. Bare-backed riding is so uncomfortable to the man and so liable to hurt the horse, that we may accept the necessity of a saddle, which has the great advantage of distributing the weight evenly, and thus rendering it more easy to be carried. The use of a saddle, of course, demands the adoption of precautions for the avoidance of sore backs.

The mouth of a horse lends itself in an admirable manner to the restraining power of man, by reason of the interval (the bars) which exists between the tushes and the back teeth (Fig. 27). Were it not for this peculiarity, we would be unable to use a bit, and would be obliged to depend on a nose-band or similar contrivance for keeping our horses in hand. A not less important circumstance, is the fact that the muscles which bend a horse's head and neck to one side are comparatively weak, and consequently a rider has a considerable amount of power in turning a horse's head to one side.

The position of a horse's head and neck, which in a well trained animal can be regulated to a considerable extent by a good horseman, plays a large part in the amount of control and guidance possessed by a rider. It is evident that the higher the head is carried and consequently drawn back, the more are the fore legs relieved of weight; and the more it is advanced to the front, the greater is the weight placed on them. Raising a horse's head, so as to make him more or less "star-gaze," is bad horsemanship when done with the object of lightening the fore-hand; because it puts his head into a position in which the bit cannot act effectively-an objection that applies equally well to the position of the head when it is brought down towards the knees. If, 
however, we can get the animal to bend his neck and draw in his head without raising or lowering it to any marked extent (say, with the snaffle reins more or less horizontal,

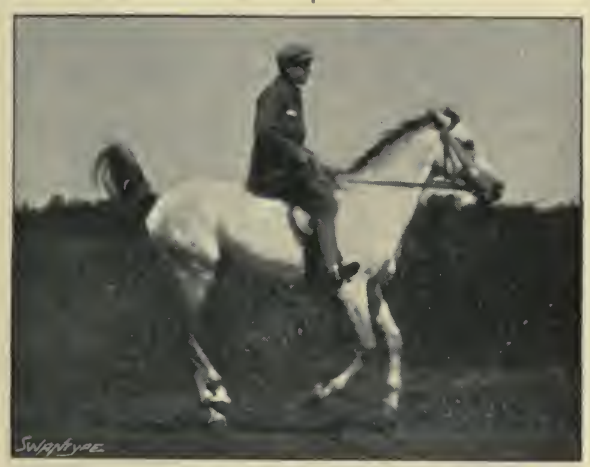

Fig. 26. The Canter.

while the hands are kept down as in Fig. 26), we shall lighten the fore-hand without injuriously interfering with the action of the bridle. The faculty of bending to the rein in this

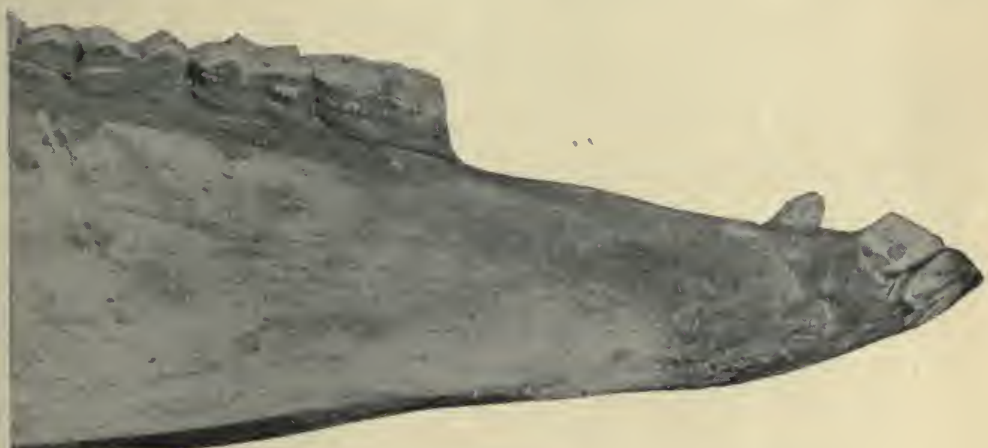

Fig. 27. Side view of Horse's lower 'aw.

manner was evidently possessed by the horse of which Whyte Melville sung : "A better never bent him to the rein."

By bending a horse's neck according to the principle just stated, we are able not only to lighten the fore-hand, 
but can also diminish the animal's speed, as I shall now attempt to show. The shoulder of the horse, on each side of the body, is connected by muscles to the trunk, on which it can be moved backwards and forwards. The chief muscle which draws the fore leg forward, is at one end attached to the humerus (the bone which is between the shoulder blade and the fore-arm), and at the other end to the top of the head. Consequently, a line passing through these two points of attachment will be the direction in which the pull of this muscle works. Therefore, when a horse holds his head in the air, his front action will be necessarily high. I may here explain that all muscles act by contracting, which the muscle that is attached to the humerus and the head does, while keeping one of its attachments fixed and the other movable. Hence, it can draw the fore leg forward, when the position of the head is kept fixed by other muscles of the neck. If the position of the fore leg be fixed, as when the horse is standing still, this muscle when stimulated will draw in the head and bend the neck. Also, the farther the attachments of the respective ends of a muscle are apart, the greater will be the distance through which the pull of the muscle will act. Supposing, therefore, that the muscle we are considering is 39 inches long, and that it can contract to two-thirds of its ordinary length; it can exert a pull on its fore leg of 13 inches in length, when it is on full stretch, by the fact of its attachments being at their maximum distance apart; that is to say, when the neck is held straight and advanced. If, on the contrary, the neck be bent, so that the attachments of the muscle are 30 inches apart, the muscle will have a pull of only 4 (13-9) inches. If the distance between the attachments be 26 inches or less, the muscle will be thrown out of action for the time being. We therefore see that by altering the carriage of a horse's head and neck, we can appreciably shorten his stride. 
By shortening the horse's stride by the reins in the manner just described, we not only lighten the fore-hand, but we also give the animal an easily understandable hint to go slower, which hint he will obey all the more readily if he knows from experience that compliance on his part will be rewarded by cessation of the painful pressure of the bit on his mouth.

Increase of speed implies increased length of pull given by the respective muscles which are concerned in movement; and decrease of speed, diminution in the length of that pull. Hence, at full speed in the gallop or trot, the neck has to be held as straight as possible, so that the muscles of the neck may have the utmost advantage in drawing the fore limbs forward. With decrease of speed, it will be natural for the neck to be more or less bent. I cannot say that the neck is bent proportionately to the diminution in speed; but all good horsemen know from experience that the best way to preserve the regularity of a horse's gallop, is to keep the reins at a fixed length, after ascertaining that the length in question is correct.

We see from the foregoing remarks that the position of a horse's head will affect the stability of the equilibrium of his body (pp. I4 to I6). The advantage to be gained as regards speed, by lowering the head, is limited by the fact that when the head is unduly depressed, the direction of the forward pull given by the muscles of the neck to the fore limbs, will oblige the animal-in order that his feet may clear the ground in front-to bend his knees to an extent which would interfere with his speed; and would also diminish the forward reach of his fore legs. As these principles do not admit of exact application, we must content ourselves by the general statement that a horse as a rule will carry his head lower at full speed than when going slower. 
When a horse turns, the arc of the more or less perfect circle described by his inner leg (left leg, when the turn is made to the left; and right leg, when it is made to the right) will be shorter than that described by his outer leg. Hence, when a horse turns at the halt, walk, or trot, he will be considerably aided by being able to bring his outer fore leg as far forward as possible. When the head is brought round to

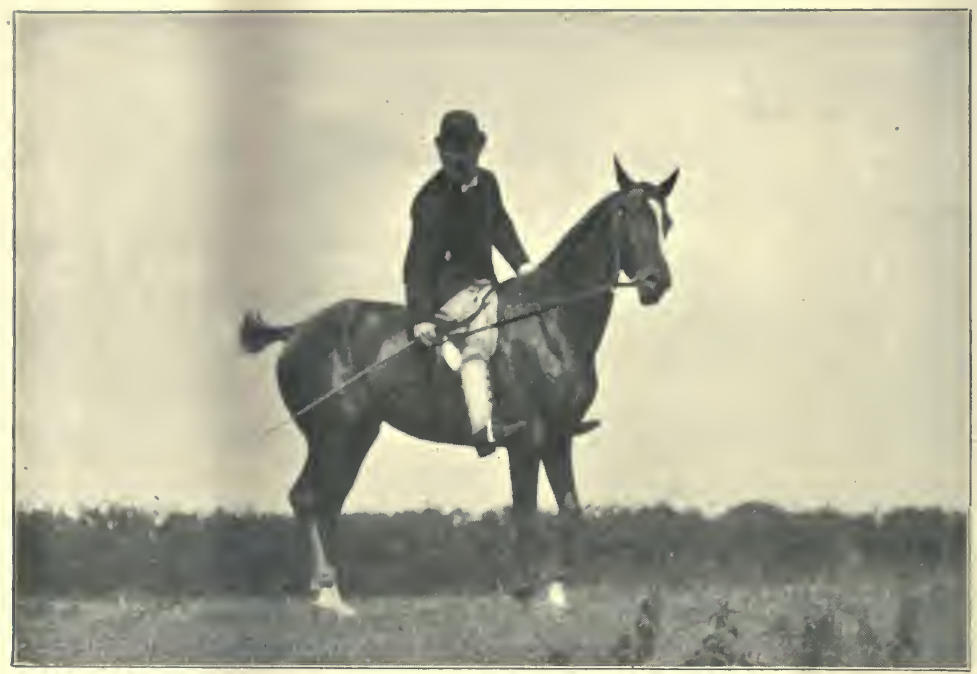

Fig. 28. Turning Horse to the right on his fore-hand.

one side, the points of attachment of the muscle of the outer side of the neck will be further apart than those of the muscle on the inner side of the neck; and consequently the muscle which has the harder work to do in turning at the halt, walk, or trot, will be assisted in its task by the fact of the horse having his head bent to the side to which the turn is being made. Also, when the head is bent to one side, the fore leg of that side will bear more weight than the fore leg of the other side, and consequently it will act all the better as a 
pivot (Fig. 28) for the change of direction. In the canter and gallop this pivot should be the leading fore leg; because this leg bears much more weight (see Figs. I to I6, and Figs. I7 to 24) during each stride than the non-leading fore leg. Therefore, at these paces, a horse should lead with the fore leg of the side to which the turn is being made. Besides, if a horse which was leading with, say, the right fore, attempted to turn to the left (and vice versâ), he would be in great danger of crossing his legs and falling, on account of the leading fore leg going in front of the non-leading one; but it is impossible for the latter to cross the former. As the leading fore leg is advanced more than the non-leading one, the horse when turning at the canter or gallop (contrary to what is the case at the halt, walk and trot), will require to have his head somewhat turned away from the side to which the change of direction is being made. 


\section{CHAPTER IV. \\ BITS AND BRIDLE GEAR.}

Description of a Bridle-Objects of a Bridle-Principles of Bitting-Materials for Bits-Varieties of Bits-Snaffles-Hancock's Mouth-piece Covers-Curbs - Pelhams-Bridles-Methods for connecting the Head-stall and Reins to the Bit-Fronts-Throat-latches - Reins - Nose-bands-Chin-straps-Action of Snaffles-Action of Curbs-Construction of Curbs-Curbchains-Action of Pelhams-Martingales-Bridling a Horse-Adjustment of Bridle-Choice of a Bit.

\section{DESCRIPTION OF A BRIDLE.}

A BRIDLE consists of a bit, head-stall, and reins. The bit is the piece of metal which goes into the animal's mouth; the head-stall or "head" connects the bit to the horse's head; and the reins are fixed to the bit at such a length that the rider can manipulate them.

Some persons incorrectly restrict the term "bit" in all cases to a curb. This particular application of the word is from custom allowable in the expression, "bit and bridoon," in which the bit signifies a curb; and the bridoon, a snaffle.

\section{OBJECTS OF A BRIDLE.}

The three chief objects for which a bridle are used are: (I) to restrain the horse; (2) to direct his movements; and (3) to enable him to carry his rider in the best possible manner.

\section{PRINCIPLES OF BITTING.}

The necessity for the power of restraint and guidance by means of the bridle is self-evident; but the third 
object of a bridle needs some explanation. Were the rider to sit like a "dead weight" with the reins loose; his body being free to move by the hip joints, and having its centre of gravity above the saddle, would be liable to be jerked backwards and forwards by the motion of the horse; and consequently the animal's rate of progression would be materially checked. The skilful rider, on the contrary, by the feeling he has on the reins and by the grip of his legs, will be able to accommodate the weight of his body to the movements of his mount, so as to reduce its retarding influence to a minimum. For this accommodation of weight by means of the reins, it is essential that the horse shall bear on his mouth a fair amount of pressure from the bit, without resenting it, or without altering his pace. It is evident that such indifference to pressure must not be carried to the extent of rendering the animal heedless of legitimate indications which the rider may want to convey to him by the reins and without any undue exertion of muscular power. Besides the accommodation of weight, stability of seat will often demand a certain degree of callousness in the mouth of the horse. Hence, the worse the horseman and the more uneven the ground, the less severe should the bit be.

If an animal is afraid to "go up to his bridle," he will refrain from straightening his head and neck, and consequently the forward reach of his fore legs will become more or less checked; because the muscles of his neck are the agents by which the fore limbs are drawn forward. The result of this constrained carriage of the body will be, that the horse will keep his hind legs too much under him, and will raise his fore legs too high; in fact, he will be "over-collected." Fashionable harness horses which are driven with severe bits they are afraid to "go up to," and whose heads are drawn back by gag bearing-reins, furnish us with an 
excellent instance of this " over-collection." Being "well on their haunches," they bend their knees and lift their fore legs in the most approved manner. The better they stand being "hit and held," the loftier their action, and consequently the higher their price. This style may be suitable for a three or four miles drive in the Park or in Town during the season; but it is not "business" from a horseman's point of view, because it entails a waste of muscular power. We may see a similar needless expenditure of force, in the case of a riding horse which will not face his bit, especially if the man on his back endeavours to keep him up to it by the pressure of the legs or by the spurs. If we desire to ride like "workmen," we should not use a bit our horses will not face. Even the cavalry soldier, who should be able to collect his mount so as to make him circle, turn and passage with the utmost quickness and precision, by a slight indication of hand and leg, requires his horse to go up to the bit.

With respect to driving, I may mention in passing that the high action we see among fashionable carriage horses is altogether false in the majority of cases; because the lofty style is almost entirely confined to the fore legs. The action, in trotting, to be true, should be the same in the hind as in the fore limbs. Nothing looks worse than to see a horse trying to "pick his teeth" with his knees, and at the same time dragging his hind feet behind him.

In order that a horse may freely go up to his bit, its pressure should be applied in a direction opposite to that in which he is proceeding. If the mouth be hurt by the bit, the animal will probably be rendered more or less violent and fretful. Even if the horse be cowed into submission, the control thus procured will be obtained by the sacrifice of a certain amount of working power.

In order that the horse and rider may remain in mutual touch with each other by means of the reins, it is necessary 
that the action of the bit should diminish as little as possible the sensibility of the animal's mouth. Hence we find that when a horse which has a good mouth is properly bitted, there will be an entire absence of rigidity in the muscles of his head and neck, and he will be inclined to "play with his bit."

\section{MATERIALS FOR BITS.}

Bits are made of the following materials :-

I. Hard forged steel, which is by far the best material for a bit, as it is much stronger than the other kinds, although it costs somewhat more to manufacture. For bits, it is tempered so that it will bend rather than break under great strain. Many bits are made of mild steel, and consequently they are little better than those of wrought iron. They are much easier to manufacture than bits made from hard steel.

2. Forged wrought iron, which is fairly reliable; but being comparatively soft, it has a tendency to give way in ordinary wear, in a manner hard forged steel would not do. There is no objection to the snaffles of watering bridles being made of forged wrought iron; but forged steel is the only material that is safe for bits required for serious work. Forged wrought iron bits are forged from iron which has been hammered and rolled into bars that are known in the trade as "best wrought iron bars." An inferior class of bits, which would be properly described as "stamped wrought iron bits," are stamped, not forged, out of wrought iron.

3. Annealed cast iron. Unprincipled dealers not unfrequently try to palm off on unwary purchasers bits of this material, which is a form of cast iron that has been improved in tenacity and appearance by having been cooled slowly after being heated. Many who refrain from the mendacious and not uncommon practice of applying the terms "cast steel " and "forged steel" to such bits, are careful to suppress the adjective "cast," when alluding to their annealed cast 
iron wares ; or they craftily call them "malleable iron," instead of "malleable cast iron." As the leading manufacturers of bits use special trade marks to show the nature of the articles they make, a purchaser will be guaranteed from fraud in this respect, if he has a knowledge of these marks, which unfortunately are generally kept as trade secrets for obvious reasons. Failing this special knowledge, a buyer will have to trust to the honour of his saddler, which he can safely do in the case of several representatives of the trade.

The great objection to all cast bits is that bubbles form in metal during the process of casting, and that neither the presence nor the size of these bubbles can be ascertained by ordinary outward inspection. Consequently, an annealed cast iron bit is not only composed of a weaker material than a forged steel one, but its strength is more or less impaired by the inevitable presence of cavities in its substance. We learn from a leading article in Saddlery and Harness of February, I894, that "the commonest cast iron article, when annealed, can be finished so dexterously, so beautifully, that no expert could tell it from a forged steel one, without testing it by-making it red hot." As explained in a subsequent issue of that journal, the test for distinguishing between forged and cast iron articles is an extremely simple one, and is carried out by making the suspected article red hot and then beating it with a hammer, in which case a cast iron article will crumble, but a forged iron or forged steel one will not break up. This valuable test is in accordance with the fact that cast iron will not weld. A bit of annealed cast iron, and especially one of ordinary cast iron, will be liable to break, if struck sharply with a hammer when cold; but one of forged steel or forged iron will remain intact. In cast iron, whether annealed or not, there are generally sand marks, which an expert would probably detect, although an ordinary observer might not notice 
them. "Steel can be easily distinguished from iron by placing a drop of diluted nitric acid upon it, when a dark stain is produced upon the steel, from the separation of carbon." (Bloxam.)

Annealed cast iron bits are, more difficult to polish, and rust more quickly than forged steel bits. Cheapness is their only recommendation.

4. Nickel and alloys of nickel. The term "nickel," as applied to bits, is a trade name for a composition formed chiefly of nickel, copper and zinc, in varying proportions. These alloys, however much they may be disguised by the fantastic names given to them in the trade, may be always recognised by the claim made for them that they do not rust, which property is their sole advantage. Bits made from them have to be cast, and are consequently unreliable. These alloys are comparatively soft, and are more liable to lose their shape when strain is put on them, than even forged iron. They can be easily cleaned, but they do not look so smart as well-burnished steel. Nickel plated bits wear badly, as the plating is inclined to peel off. Nickel bits suit idle grooms, or places where labour cannot be readily obtained.

\section{VARIETIES OF BITS.}

Bits may be divided into snaffles, curbs, and Pelhams.

\section{SNAFFLES.}

A snaffle is a bit which acts on a horse's mouth by direct pressure and not by leverage. In almost all cases, it has rings for connecting it to the reins.

A bridoon is the term usually applied to the snaffle of a "double bridle," which is a bridle that has a curb and a snaffle. A double bridle is often known as a "bit and bridoon." Saddlers call a single bridle which has a curb bit, 
a " hard and sharp" bridle. A bridoon may be any form of snaffle; but as a rule, it has no cheeks (Fig. 68).

The chief varieties of snaffles are:

1. The smooth single-jointed snaffle, which may have rings

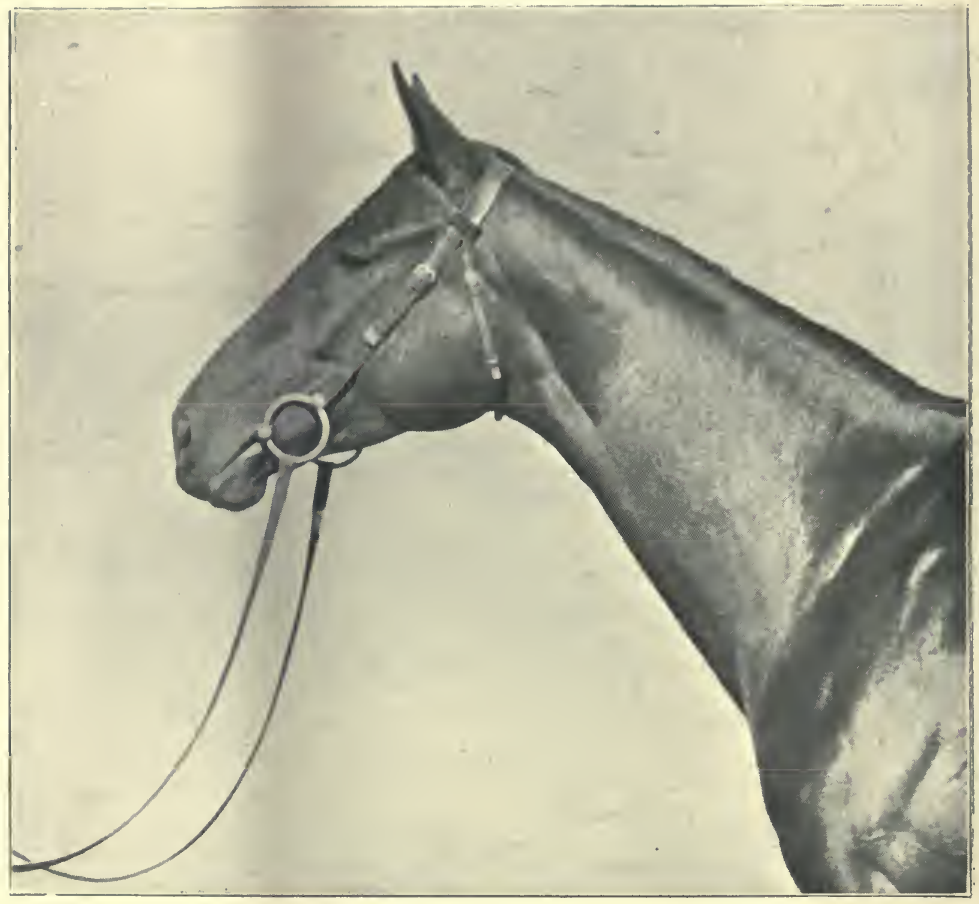

Fig. 29. Racing Snaffle.

without cheeks (Fig. 29), or may have rings and cheeks (Fig. 30).

2. The double-jointed snaffle (Fig. 3I).

3. The unjointed snaffle, the mouth-piece of which as a rule is slightly curved and is then termed a half-moon snaffle (Figs. 32 and 33). This is my favourite snaffle, for reasons I shall give on pages 68 and 69. 


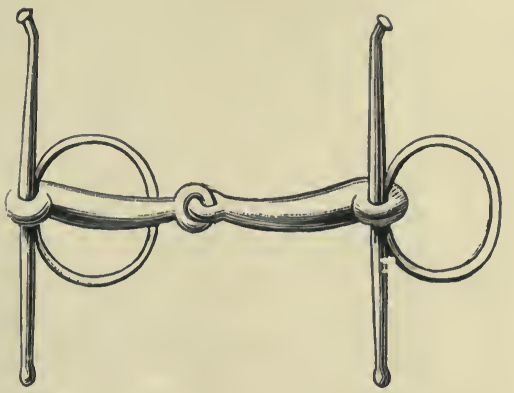

Fig. 30. Ordinary Snaffle with Checks.

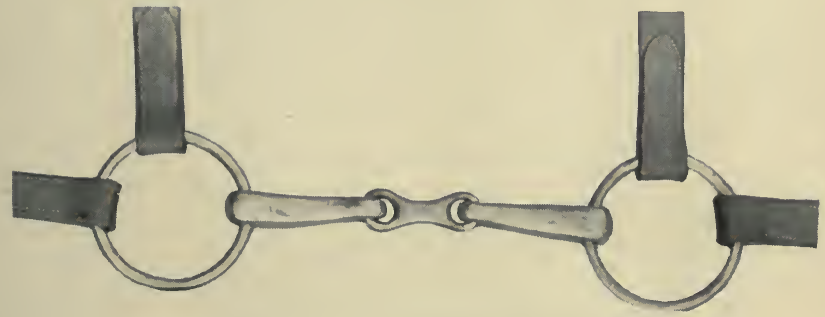

Fig. 3r. Double-jointed Snaffle.

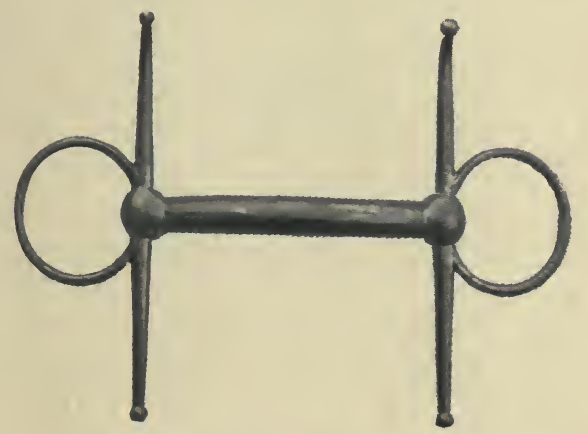

Fig. 32. Elevation of Unjointed Snaffle.

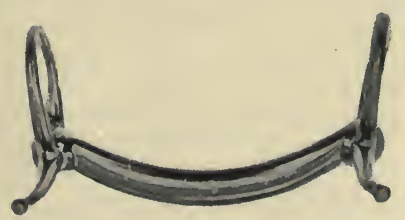

Fig. 33. Plan of Unjointed Snaffle. 
4. The twisted snaffle (Fig. 34). The twist is given: to increase the severity of this bit.

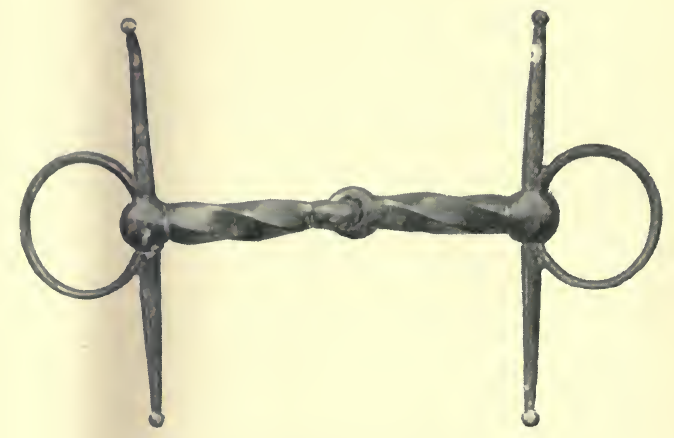

Fig. 34. Twisted Snaffle.

5. The thin racing snaffle (Fig. 35). I cannot understand why this variety was ever invented; for although it may save two or three ounces in weight, it has a great

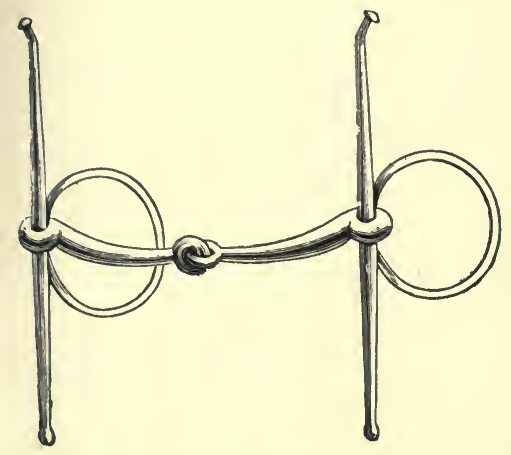

Fig. 35. Thin Racing Snaffle.

tendency to make horses pull, probably because it irritates the animal by reason of the pain it inflicts on the mouth. The racing snaffles of the present day are not nearly so thin as those which were formerly used; and are often of the large ringed type without cheeks (Fig. 29). 
6. The chain snaffle (Fig. 36), in which the mouth-piece consists of a chain of several links. This bit serves well for many horses which require some "holding," and may be made easy or severe to the mouth as the rider chooses. To increase its severity, the chain may be twisted the reverse way, before being put into the animal's mouth. For tender mouthed horses, the chain may be furnished with one of

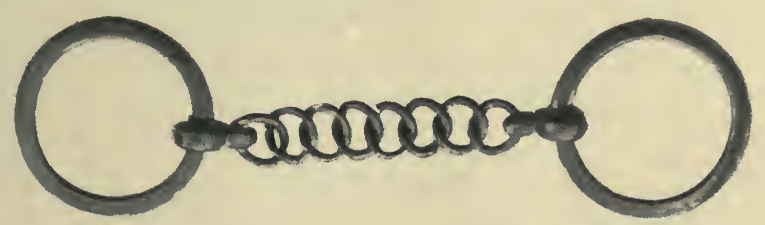

Fig. 36. Chain Snaffle.

Hancock's "curl bit mouth covers" (Fig. 45), or failing that, it may be covered with three or four turns of wash leather sewn on to it. Two chains, one above the other, are sometimes used instead of one.

7. The double-ringed snaffle (Fig. 37) has two rings placed on the mouth-piece-inside those to which the reins are connected-for attachment to the head-stall of the bridle. It is in common use among cabmen, who generally buckle the reins to both rings at each side, and thus convert it into an ordinary snaffle (Fig. 38). For saddle work, the

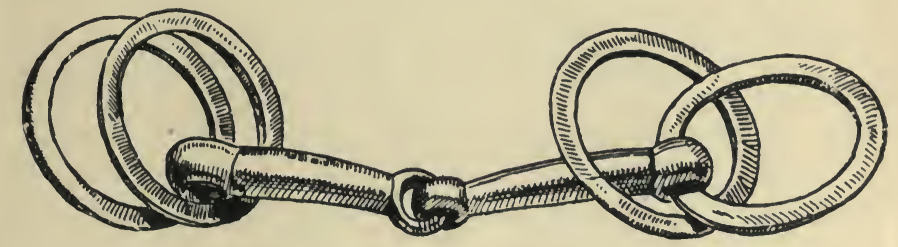

Fig. 37. Double-ringed Snaffle.

rings of the mouth-piece to which the reins are fixed may be provided with cheeks (Fig. 39). It is an excellent snaffle for turning a horse; because the pull of either rein falls directly 


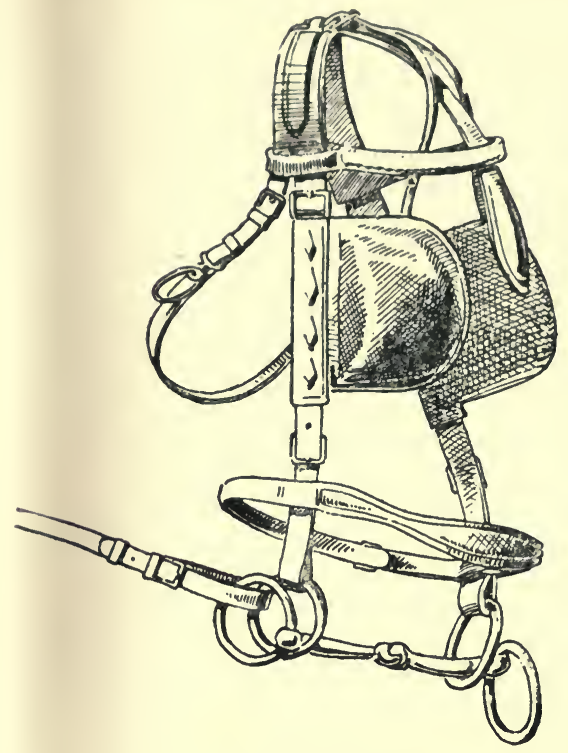

Fig. 38. Doub'e-ringed Snaffle.

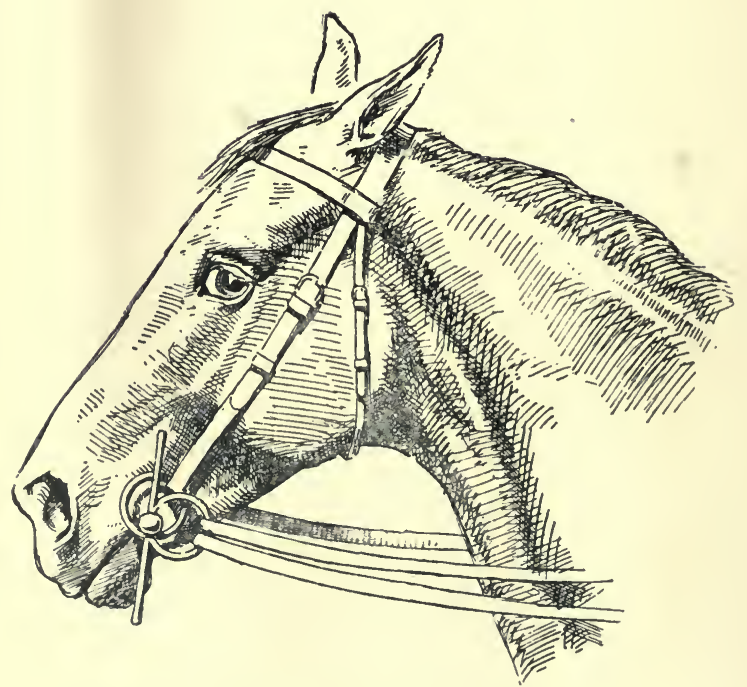

Fig. 39. Double-ringed Snaffle with Checks. 
on the opposite side of the horse's mouth, without being taken to any great extent by the head-stall. The native polo players of Manipur, in which country polo has been the national game for many centuries, all use double-ringed snaffles with their clever ponies.

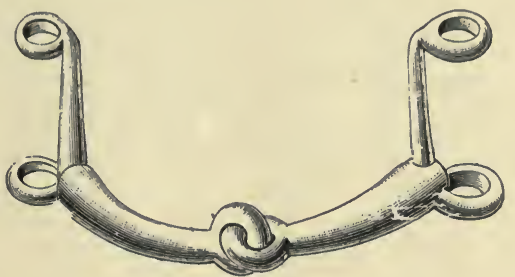

Fig. 40. Bridoon Gag Snaffle.

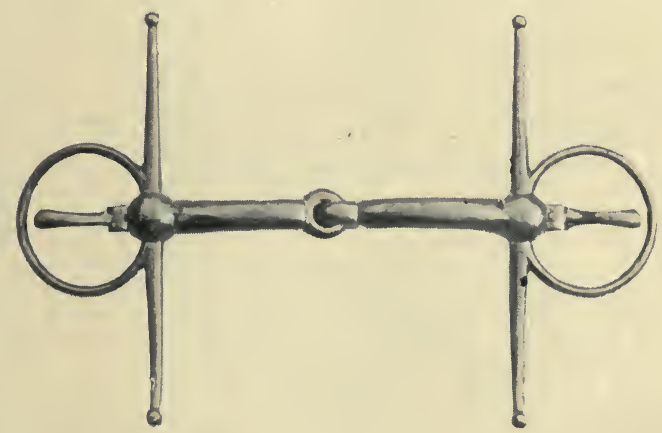

Fig. 41 Elevation of Gag Snaffle.

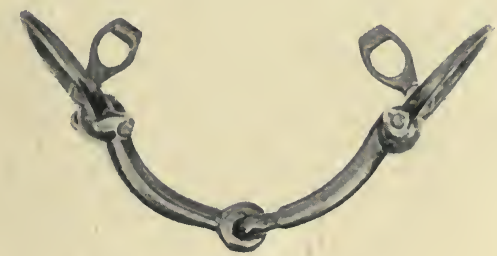

Fig. 42. Plan of Fig. 4r.

This bit should not be employed by riders who have bad hands, because it may inflict great pain if pulled about in the horse's mouth.

8. The gag snaffle is generally used with two reins, one 
being attached in the usual way, while the other is a continuation of a separate strap or "head," the cheek-pieces of which are rounded, and instead of being sewn on or buckled to the rings of the snaffle, pass through holes in projections on each side of the snaffle (Figs. 4O, 4I, and $42)$, or through holes in the rings of the snaffle, and thence to the rider's hands. When the gag reins are pulled, the snaffle is forced against the corners of the horse's mouth, with the result that he has to draw up his

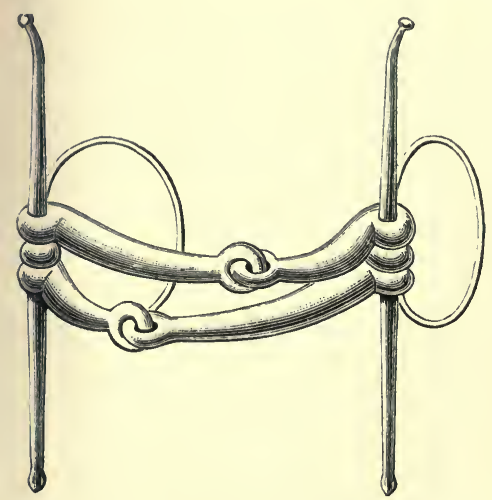

Fig. 43. Double-mouthed Snaffle.

head. This bit is consequently useful with horses that "bore" with their heads down (carry their heads too low), and with buckjumpers. The one shown in Fig. 40 is used as a bridoon to a double bridle.

9. The double-mouthed snaffle (Fig. 43) has two mouthpieces which respectively have joints placed more to one side than to the other, so that, if the joint of the upper mouth-piece be more to the near side than the off, that of the lower one will be more to the off than to the near, and vice versâ. It forms a severe bit, owing to the large amount of side pressure which it exerts on the gums. It should 
not be used with a tight nose-band; because, when a strong hold is taken of the reins, it opens out somewhat in the

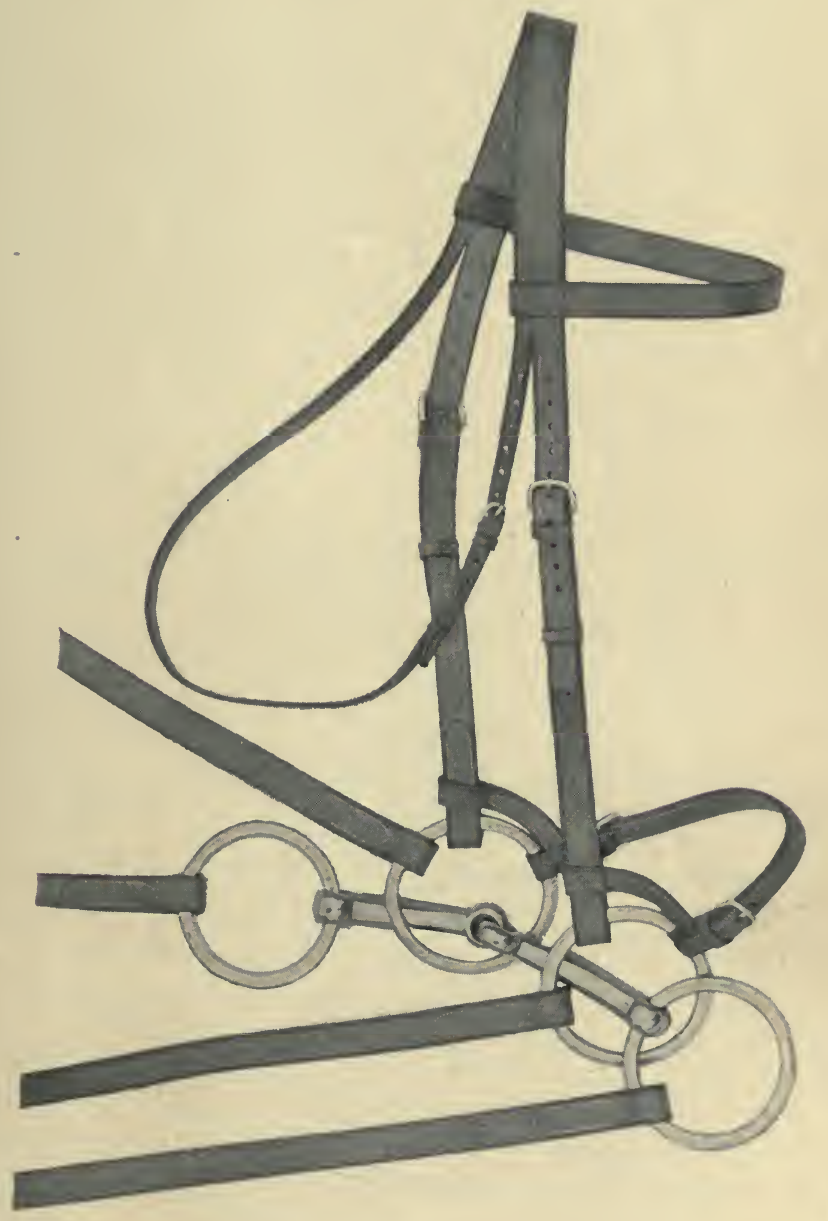

Fig. 44.

form of a $\mathrm{W}$, and it would under such conditions, be apt to hurt the roof of the mouth. Its nut-cracker principle is altogether wrong (pp. 68 and 69). 
IO. A Neamarket snaffle is a snaffle to which a nose-band is attached, with the object of placing, as may be desired, the pressure derived from the reins, on the nose or on the mouth. A useful form of this bridle may be made from a double-ringed snaffle which has attached to its inner rings a nose-band that is kept in position by side straps fixed to the cheek-pieces of the bridle (Fig. 44). When one pair of reins is taken up, its action is that of an ordinary double-ringed snaffle; but when the other is used, all the pressure falls on the bridge of the animal's nose. It will then often prove a valuable check to a hard puller or bolter; probably, more by affording a plain indication of the rider's wishes, than by undue severity.

In another form of Newmarket snaffle, an ordinary snaffle is employed instead of a double-ringed one, and the length of the nose-band is adjusted, so as to divide the pressure between the nose and the mouth, as may be deemed advisable. It forms a nice bit for a horse with a tender mouth. I like the other kind the better of the two; because greater variety of control can be obtained with it.

II. The India-rubber snaffle, which is usually a chain snaffle that has its mouth-piece permanently covered with Indiarubber. The great objection to this form of mouth-piece is that it is impossible by mere inspection to learn the condition of the underlying metal, which is often defective and cannot be kept clean as long as the rubber remains over it. A bit of this kind should not be used without thoroughly testing its strength. From neglect of this precaution, I have known accidents occur, both in my own case and that of others, by these bits breaking during use.

HANCOCK'S PATENT INDIA-RUBBER “CURL BIT MOUTH COVERS."

This (Fig. 45) is an admirable invention, which confers on a snaffle or straight-mouthed curb all the advantages 
and none of the disadvantages of the old form of Indiarubber bits. As these covers can be put on and removed in a few seconds, they allow the metal mouth-piece to be cleaned and examined at any moment. For rendering a bit soft for a light-mouthed horse, this invention is much superior to the contrivance of covering the mouth-piece

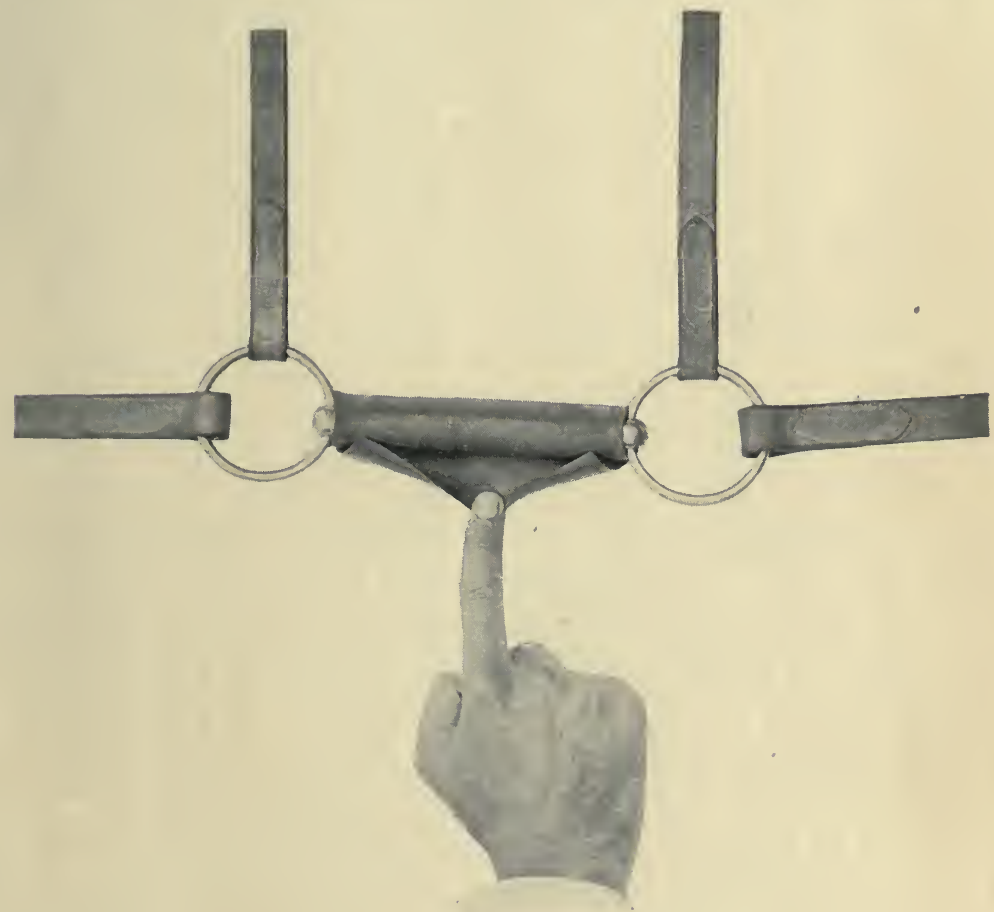

Fig. 45. Hancock's "Curl Bit Mouth Cover."

with a few rolls of wash leather. The increased size and larger bearing surface which these covers give to the mouthpiece, is in many cases a strong point in theirfavour. They can be procured from any saddler.

CURBS.

A curb is a bit which has a special action, owing to its curb- 
chain passing round the lower jaw of the horse. To express the matter scientifically, the curb is a lever of the second order, in which the power is the pull of the reins (4, Fig. 91); the weight, the bars of the mouth, against which the mouthpiece presses (I, Fig. 9I); and the fulcrum the chin-groove (2, Fig. 91), which is the depression at the back of the lower jaw and immediately above the chin, in which the curb-chain should rest.

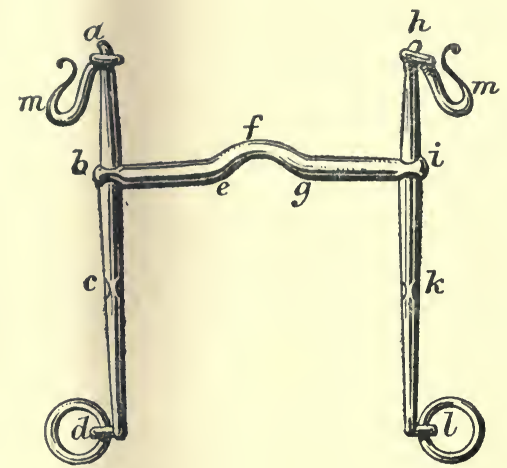

Fig. 46. Ordinary Curb.

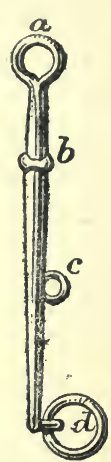

Side View.

The names of the different parts of a curb (Fig. 46) are as follows :-

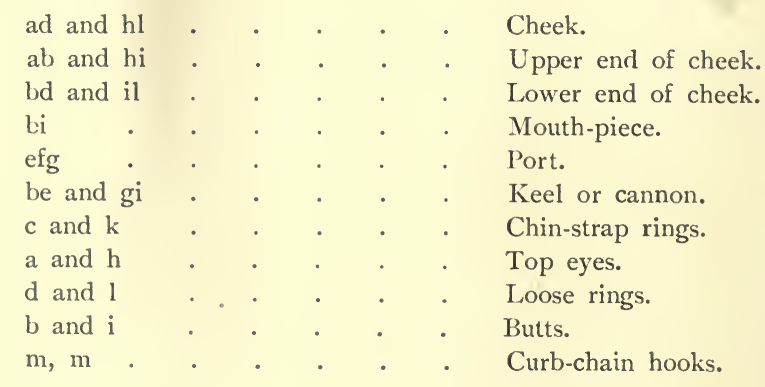

The curb-chain is attached to the top eyes by means of the curb-chain hooks.

The clin-strap or lip-strap (Figs. 47 and 48) passes through 
the "loose ring" in the middle of the curb-chain, and is connected with the chin-strap rings.

The following are varieties of curb bits :-

I. The ordinary curb (Fig. 48).

2. The IVard Union curb (Fig. 49). Of all curbs in common use, this is certainly the best, as I shall try to show further on (p. 83). Fig. 50 shows a Ward Union curb with sliding mouth-piece.

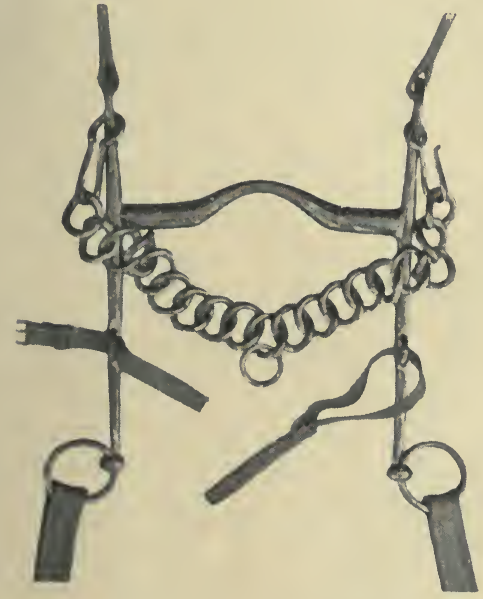

Fig. 47. Chin-strap unbuckled.

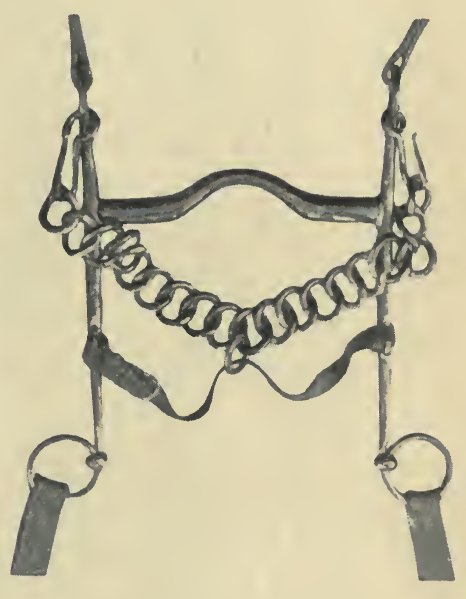

Fig. 48. Chin-strap buckled.

3. The sliding mouth-piece curb (Figs. 50 and 5I), the mouth-piece of which can slide up and down on its cheeks for a short distance.

4. The Ben Morgan bit (Fig. 52) has a mouth-piece which is in the form of the segment of a circle, and which has its convex surface lower in the mouth than the concave one. The chief objection to its use is, that it prompts the horse to get his tongue over it. Ben Morgan, the inventor of this bit, was first whip to Sir Richard Sutton, when he hunted the Quorn country (1847-56). 
5. The Chifney bit (Fig. 53). This form of curb was invented by the celebrated Sam Chifney, who fell into disgrace with the racing public, on account of having been suspected of intentionally losing a race at Newmarket, on the 2oth October, I79I, when riding the then Prince of Wales's horse,

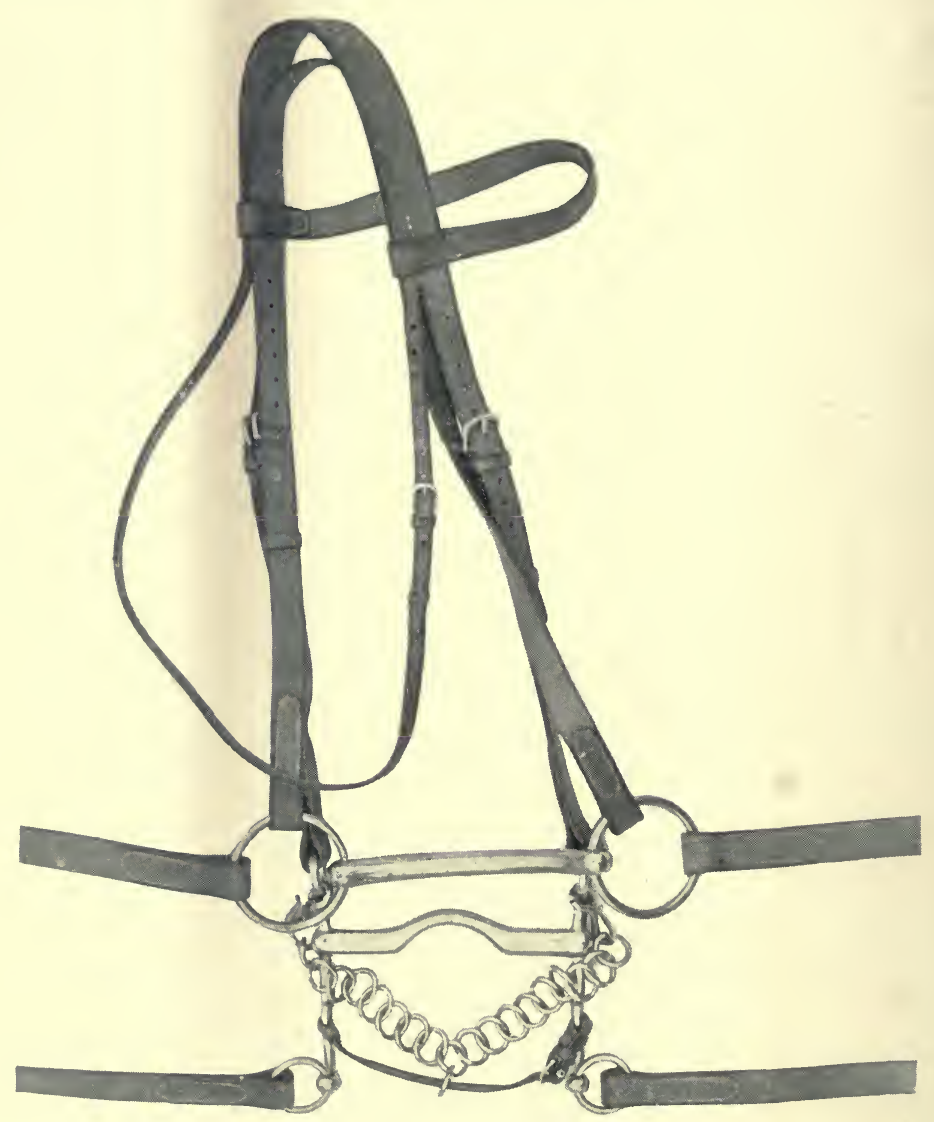

Fig. 4c. Ward Union Curb Bridle with Half-moon Snaffle.

Escape. Its head-stall is attached to short arms that revolve on the mouth-piece, independently of the cheeks of the bit to which the curb-chain is hooked. 
6. The gridiron bit (Fig. 54) has been specially devised to prevent horses which have that trick, from getting their tongue c'jer the mouth-piece. The "gridiron," which is meant to lie on the tongue, revolves on the mouth-piece, and has

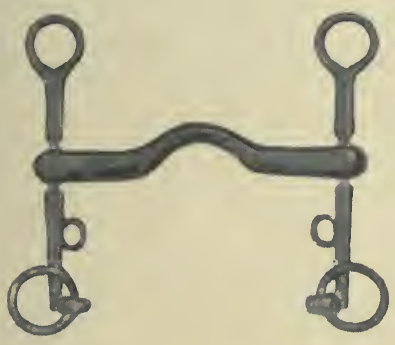

Fig. 50. Ward Union Curb with Sliding Mouth-piece.

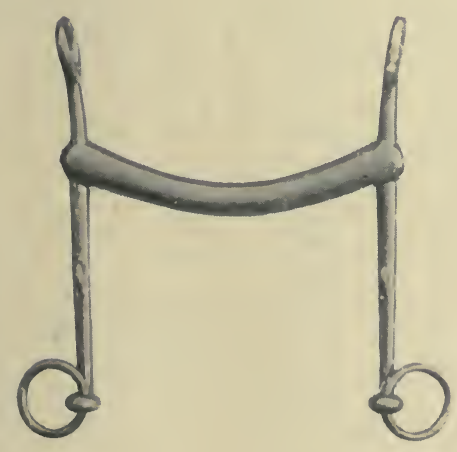

Fig. 52. Ben Morgan Bit.

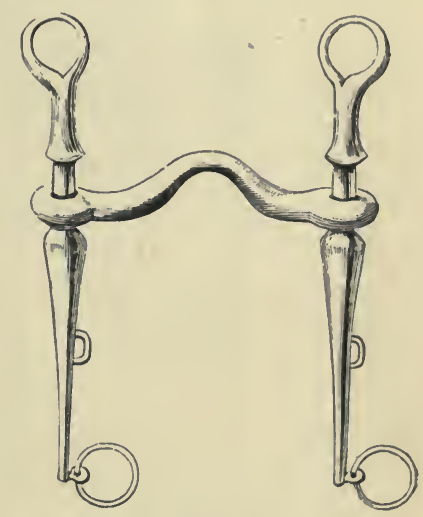

Fig. 5r. Curb with Sliding Mouth-piece.

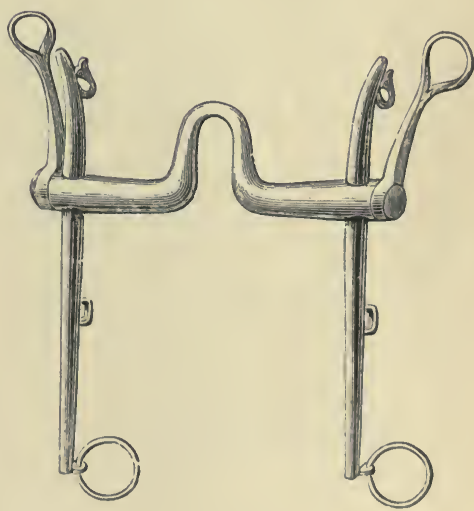

Fig. 53. The Chifney Bit.

a catch that prevents it from going further than just above the port. It appears to serve the purpose for which it was invented. 
7. Lord Thurlow's bit (Fig. 55) has the top eyes of the checks made oval-shaped to the rear.
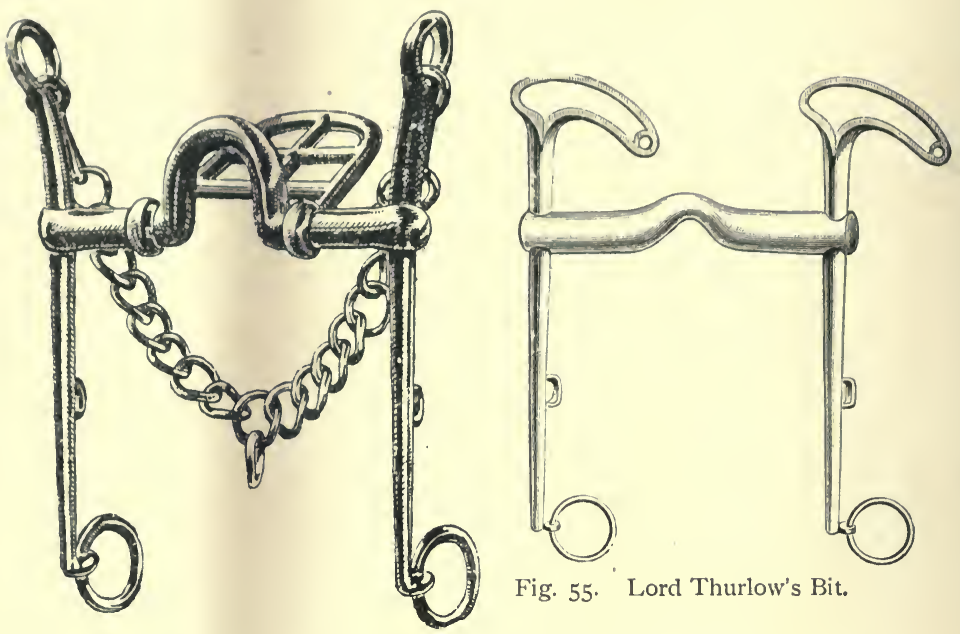

Fig. 55. Lord Thurlow's Bit.

Fig. 54. The Gridiron Bit.

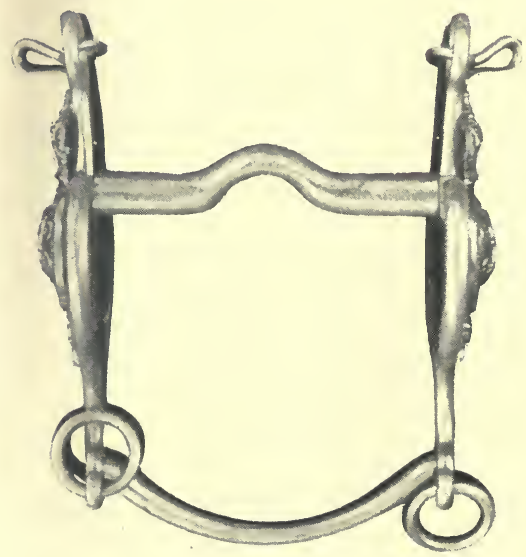

Fig. 56. The Military Bit ; one ring is turned up to show that the rings are movable.

8. The military bit (Fig. 56). In this curb, the lower ends of the cheeks are connected together by a bar, so as to 
prevent the horse getting one of the cheeks over the rein of a companion alongside him.

9. The Segundo bit (Figs. 57 and 58), has a peculiarly

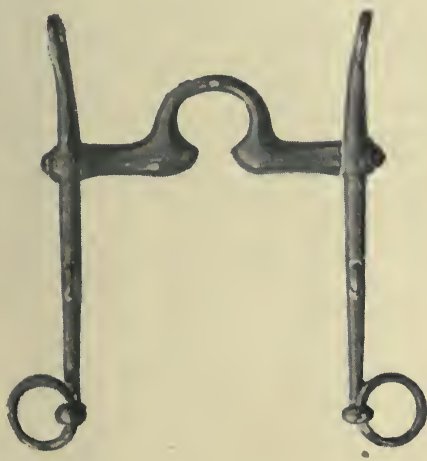

Fig. 57. Segundo Bit.

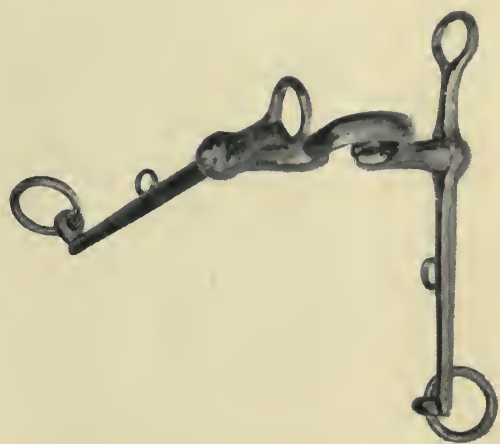

Fig. 58. Segundo Bit with lower end of off cheek drawn back, to show that the cheeks and port are movable.

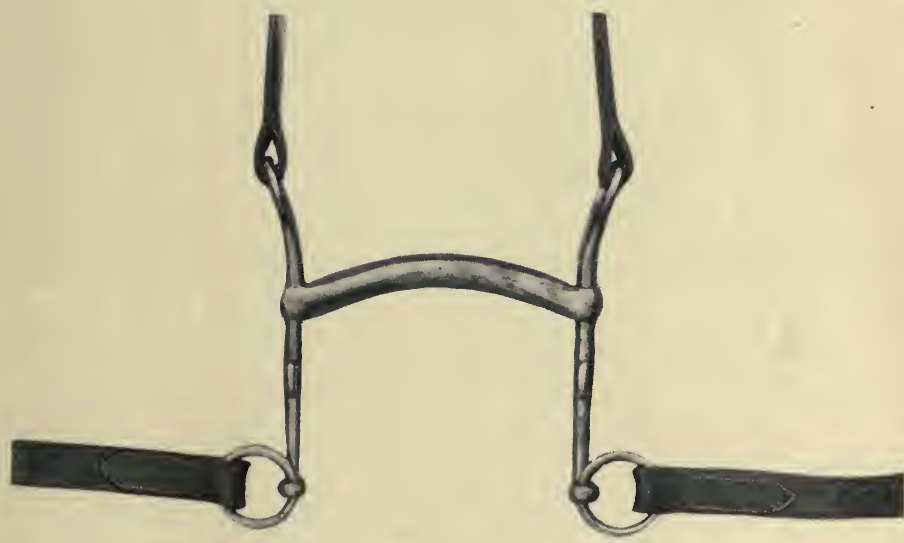

Fig. 59. Curb with Arched Mouth-piece.

shaped movable port, and its cheeks can revolve to a certain extent on the mouth-piece.

10. Curb with straight mouth-piece.

I I. Curb with arched mouth-piece (Fig. 59). 
12. The Mamluke bit (Figs. 60 and 6I), which is used principally by the Turks, is worthy of mention only as a curiosity of barbarism. Its chief peculiarity lies in the fact that in it, the curb-chain is replaced by a large metal ring which is attached to and revolves on the top of the port.

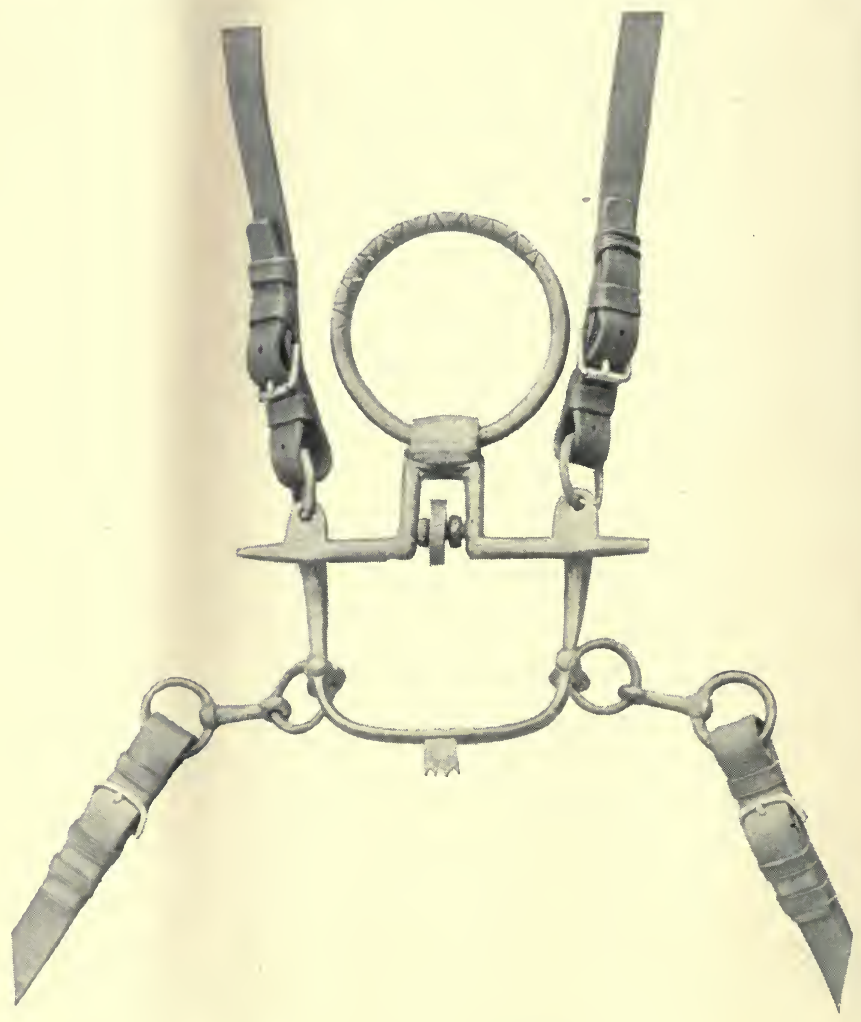

Fig. 6o. Mamluke Bit.

This bit is therefore all in one piece. The one which is shown in Figs. 60 and $6 \mathrm{I}$, and which $\mathrm{I}$ got in Southern Russia, has a small revolving wheel placed at the base of the port, to keep the mouth "lively." It is not improbable that the application of the principle of the 
revolving wheel might not be attended with good results in some cases; but the presence of the iron ring and the great height of the port (about 3 inches in the bit from which I have taken these photographs), render this bit

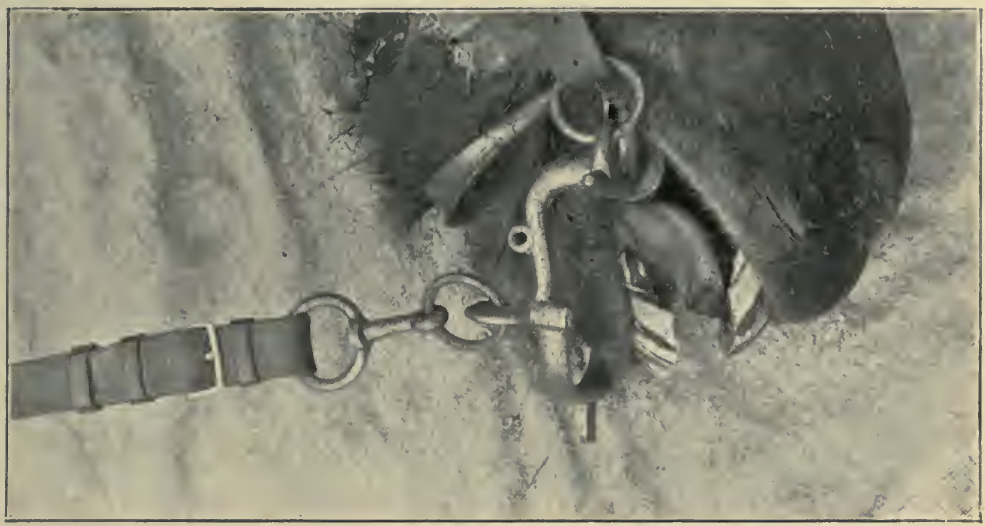

Fig. 6r. Mamluke Bit.

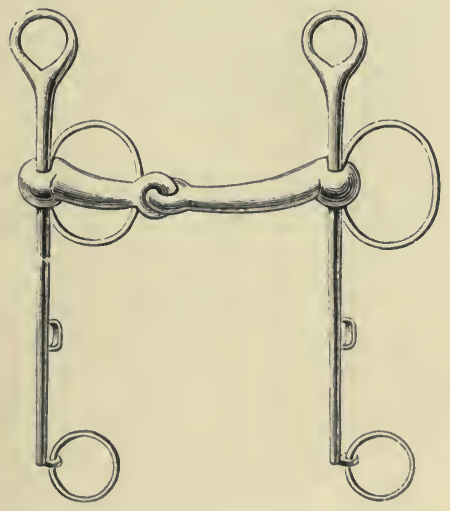

Fig. 6:. Jointed Pelham.

entirely unsuitable for use. The undue height of the port causes the metal ring to have an excessive tendency to mount up on the branches of the lower jaw. The rings to which the reins are fixed, are attached to the bit by swivels. 
PELHAMS.

A Pelham (Figs. 62 and 63) is a bit which is designed to act either as a curb or a snaffle. The snaffle rings in Figs. 63 and 64 work on swivels, which is an old arrangement,

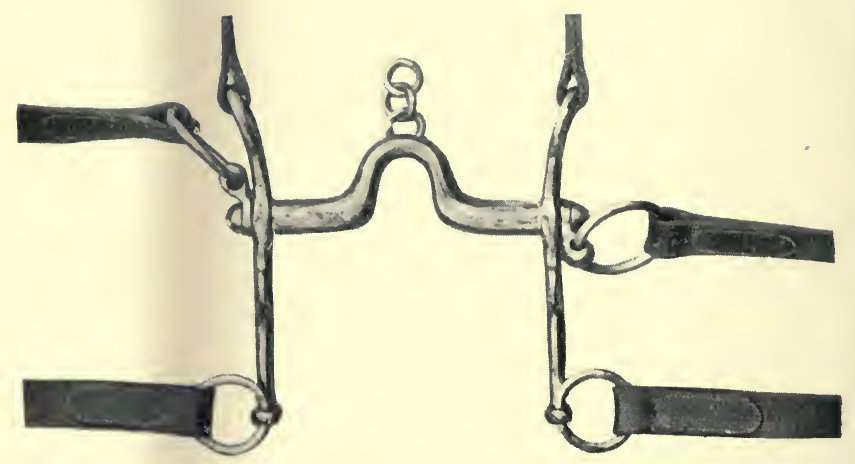

Fig. 63. Pelham with Movable Mouth-piece, and Short Chain or Port.

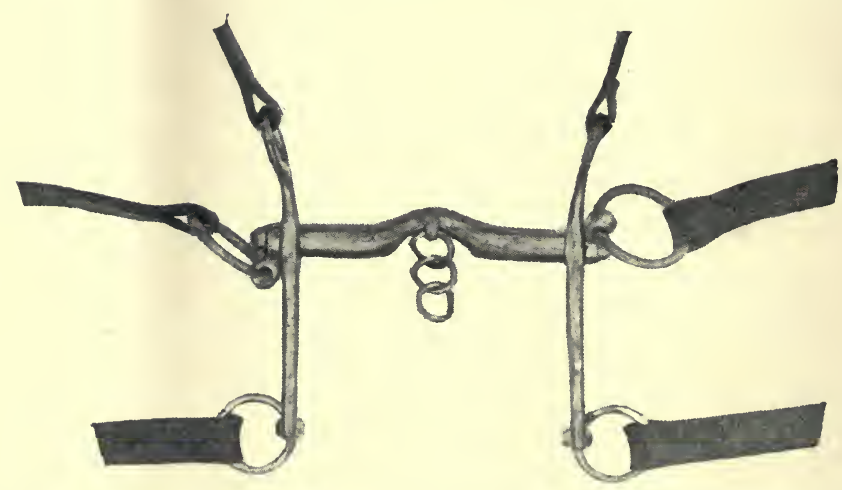

Fig. 64. Pelham (same as that shown in Fig. 63) with Movable Mouth-piece having Port inclined forward.

as we may see in the ancient Mamluke bit depicted in Fig. 60.

In the Hanoverian Pelham (Figs. $\sigma_{5}$ and 66 ), there is a joint at each side of the port, so that the mouth-piece consists 
of three segments which are capable of moving on each other. Also there are rollers on the mouth-piece.

\section{BRIDLES}

Are divided into single bridles and double bridles. A single bridle, which may have a snaffle (Fig. 29) or curb, consists of a head-stall, a bit, and one or two pairs of reins; and a double bridle (Fig. 49), of two bits, two head-stalls, and

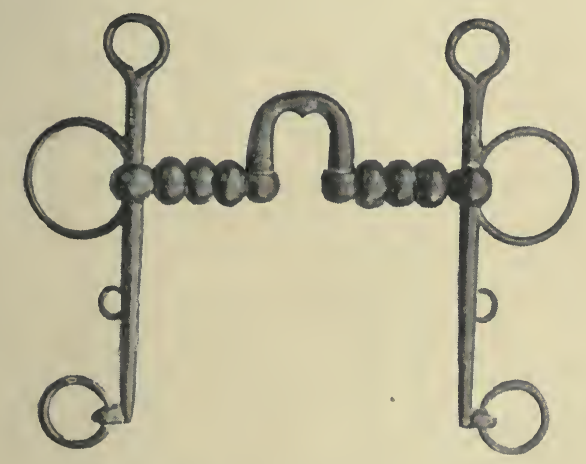

Fig. 65. Hanoverian Pelham.

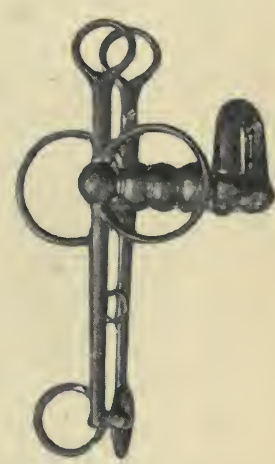

Fig. 66. Side view of Hanoverian

Pelham folded up.

two pairs of reins. The term "double bridle," without qualification, is always understood to mean a bridle which has a curb and snaffle; though it might be applied with propriety to any bridle which has two bits; for instance, a gag snaffle and an ordinary snaffle. If we accept the idea that a double bridle has two "heads," though only one front, we must regard the Pelham as a single bridle.

The leather of a bridle should be mellow and pliable, but not spongy. The pressure which the leather work of bridles and stirrups undergoes in careful manufacture, improves its appearance and makes it thinner. Inferior leather may often be recognised by its thickness and porous character. 


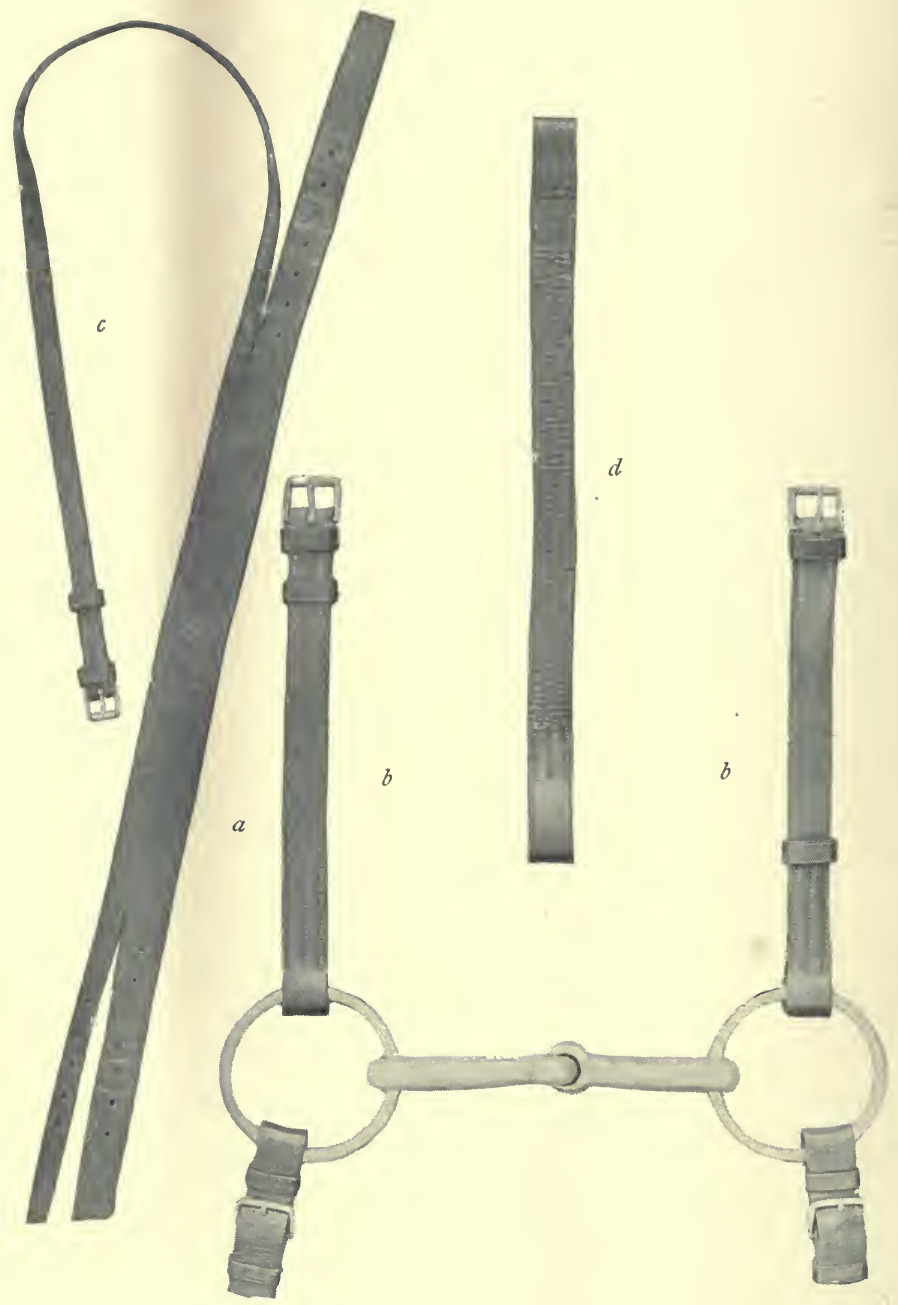

Fig. 67. "Head" of a Single Bridle: $a$, Crown-piece; $b, b$, Cheek-pieces ; $c$, Throat-latch; $d$, Front or Brow-band. 
The names of the different leather parts of a bridle (Fig. 67) are as follows :-

The crown-piece passes over the horse's poll.

The cheek-pieces connect the crown-piece with the bit.

The throat-latch (usually pronounced "throat-lash") passes under the animal's throat, and serves to prevent the bridle from slipping over his head.

The front, forehead-band or brow-band, goes across the horse's forehead, and furnishes at each end, a loop for the crown-piece to pass through. "Front" is the trade term for this strap.

The head-stall or head, which is the trade term, is the name given to the foregoing leather work in a collected form.

The reins are connected to the bit or bits.

Billets are the ends of reins or cheek-pieces which enter the buckles that attach such reins or cheek-pieces to the bit. There would naturally be no billets in bridles that had the reins and cheek-pieces sewn on to the bit.

Loops or keepers serve to retain the ends of the billets, when buckles are employed.

A nose-band (p. 60), is the strap that goes over the horse's nose.

A bridoon head (Fig. 68), is the head-stall of the snaffle of a double bridle, and consists of two straps connected by a buckle.

\section{METHODS FOR CONNECTING THE HEAD-STALL AND REINS TO THE BIT.}

Fashion decrees that the head-stall and reins must be sewn on to the bit, which is undoubtedly the neatest plan; although it is inconvenient to the groom when he wants to clean the bridle, and it does not admit of the bit being readily changed. These are valid objections to a horseowner who, like many in India and the Colonies, is obliged to consider practical requirements rather than appearance, 
and who may not have a saddler's shop at hand. For instance, if he wanted to use a bit that had no head-stall, he would be obliged to get a new head-stall for it, or to detach

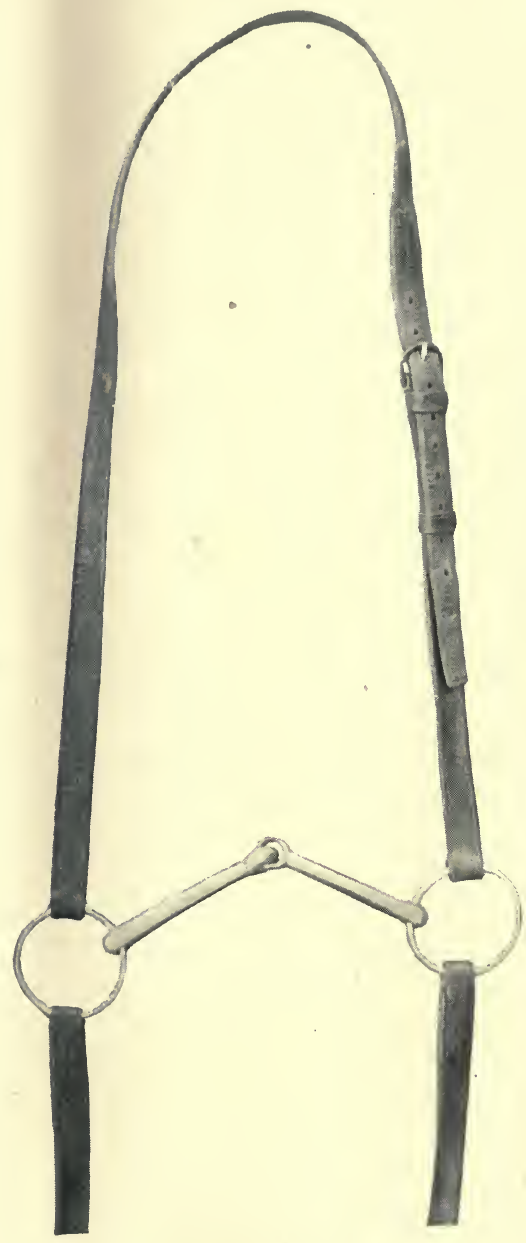

Fig. 68. Bridoon Head.

another bit from its head-stall, so that he might have this head-stall sewn on to the bit he wished to employ. When a 
head-stall and reins are sewn on to a bit, the sewing, as in Fig. 64, should be kept sufficiently away from the steel to facilitate cleaning, and to allow the attached straps to work freely on their respective rings. I prefer the sewing to be oval (Fig. 63), rather than in straight lines (Fig. 49).

While retaining the convenience of buckles, the neat appearance of the sewing may to a certain extent be secured

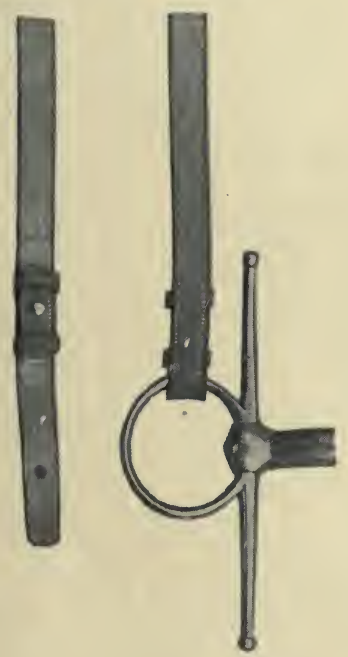

Fig. 69. Stud Billets.

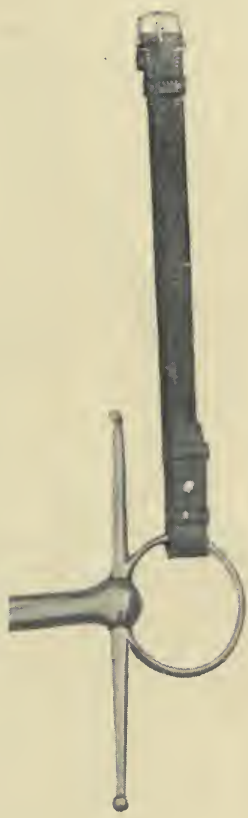

Fig. 7o. Spring Hook.

by means of stud billets (Fig. 69). I like spring hooks (Fig. 70) to connect the bit to the head-stall, because they are even more handy than buckles for removing or replacing the bit ; they allow the rings of the bit to work very freely on them; they look neat; and they are fairly secure; but I do not think that they are reliable enough for reins. They are certainly more apt to give way than stud billets, under strong tenison. 
Double buckles are handier than single ones; because they do away with the necessity of having loops for the billets.

\section{FRONTS}

Are always made of plain leather for hunting use. The front of a racing bridle might appropriately show the owner's colours.

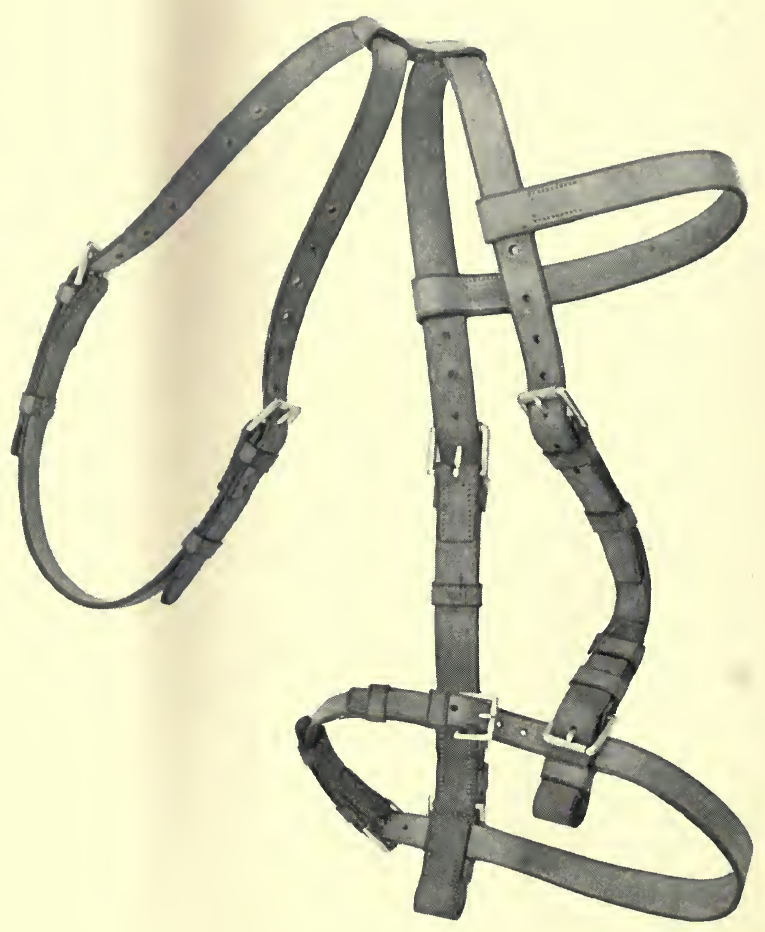

Fig. 71. "Head" of Bridle for rough work.

\section{THROAT-LATCHES.}

As a rule, the throat-latch is a part of the crown-piece (Fig. 67), which in that case is liable to become damaged by a rent in its substance, if, when one happens to be holding the 
throat-latch, the horse makes a sudden movement to escape. Therefore, for work with unsteady animals, as in breakirig, the arrangement for a throat-latch, shown in Fig. 7 I, is specially applicable.

Mr. Langham-Reed points out to me that a valid objection to the throat-latch being a part of the crown-piece is that, in such a case, the width of the crown-piece has to be inconveniently broad, so as to give sufficient strength to the strap. If we examine the part of the horse's poll over which the crownpiece passes, we shall find on that place a slight depression which is about an inch broad. If the crown-piece is not more than that width, it will remain in this depression as long as the bridle is on the animal's head. But if it is broader, it will have a tendency to work forward on the cartilage at the base of the ears, and consequently to irritate those parts. The base of the trumpet-shaped concha (shell) of the ears is much more developed in some horses than in others. Mr. Langham-Reed therefore uses an arrangement by which the throat-latch is connected to the brow-band, and is entirely separate from the crown-piece (Fig. 72).

\section{REINS.}

I like reins to be fairly broad, say, 7/8th inch, and comparatively thin, as already indicated (p. 49). With a double bridle, I prefer to have both reins of equal width, instead of having the curb reins narrower than the snaffle reins, as is sometimes the practice. The snaffle reins have almost always a buckle in the centre, so as to allow a running martingale to be used. As that kind of gear is rarely employed with a curb, the curb reins as a great rule are unprovided with a buckle at the centre. With an ordinary double bridle, the presence of the buckle will help one to distinguish the snaffle reins from those of the curb. When a running martingale is sometimes used on one pair of reins and sometimes on the other, both 
reins should of course be furnished with buckles. I find that when the reins are of equal width, they feel more pleasant in the hands than when they are of different sizes. If the reins are held according to a uniform method, there will not be

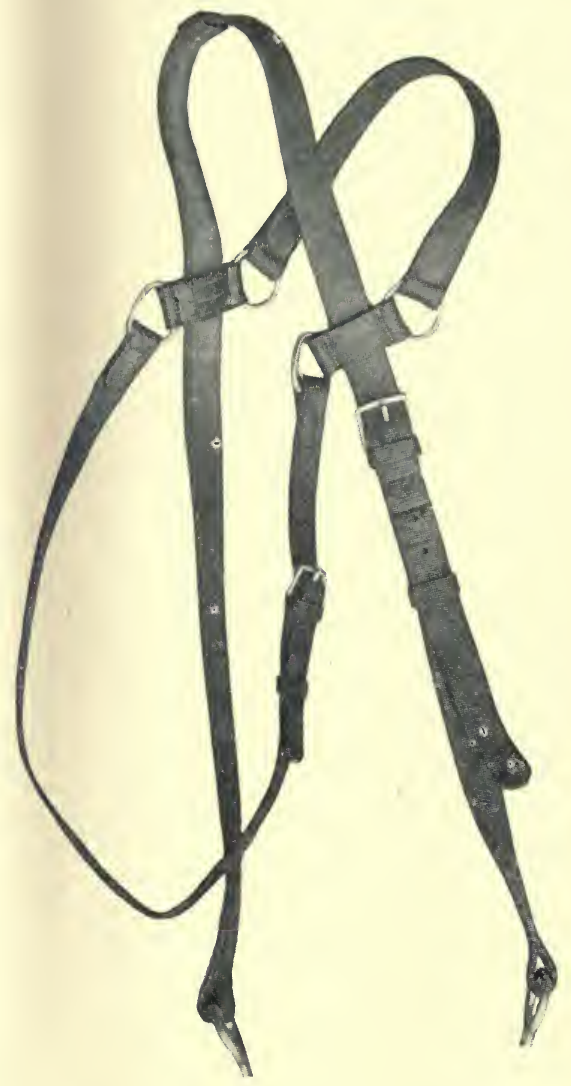

Fig. 72. Mr. Langham-Reed's Head-Stall.

the slightest possibility of the rider becoming confused as to their respective identity.

The only advantage, apart from appearance, of having the reins sewn instead of buckled on to the bit, is that it dispenses with the necessity of having stops on the reins which pass 
through the rings of a running martingale. Stops are pieces of leather which are placed on reins that are buckled to the bit and used with a martingale, so as to prevent the rings of the martingale from catching on the buckles (Fig. 73), as they might do, were the stops absent (Fig. 74). Stops are

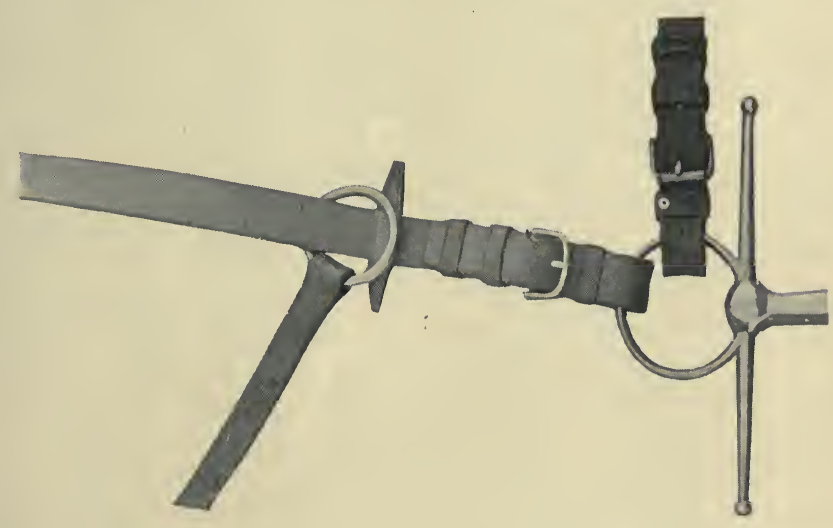

Fig. 73. Stop to prevent Ring of Martingale catching on Buckle of Rein.

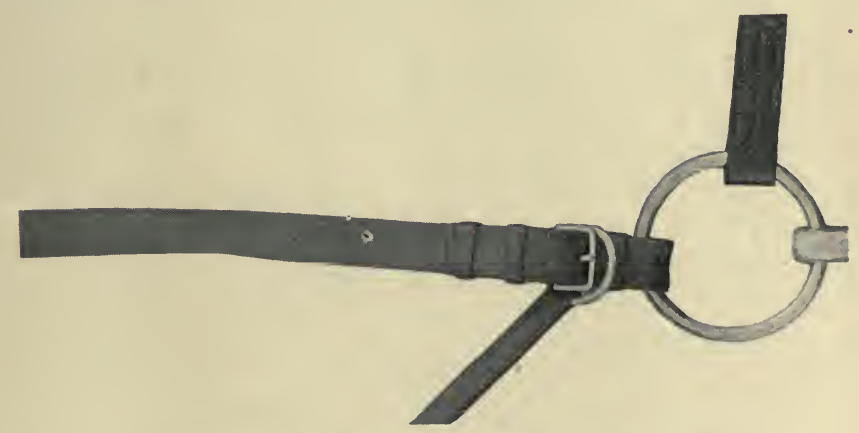

Fig. 74. Ring of Martingale caught on Buckle of Rein.

generally made by sewing together two pieces of leather of the required shape, and leaving between them a space through which the rein is passed. A neater plan is to cut the stop out of an extra thick piece of leather, and then make in its centre a cut of the necessary size for the rein, parallel to its surface. 
By this means no sewing will be required. Stops may be improvised by drawing the billets of the buckles of the reins, and bending them back (Fig. 75). If the loose rings of a

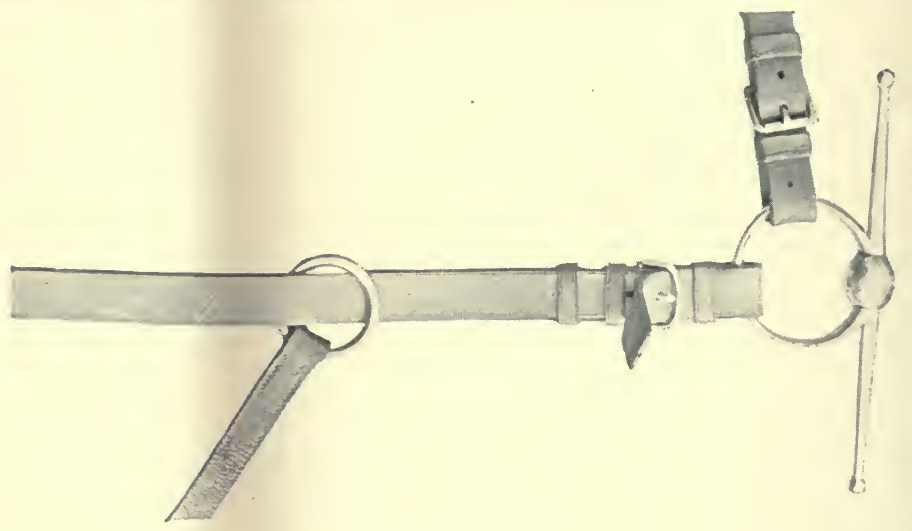

Fig. 75. Stop on Rein.

curb are small (which they should not be, see page 82), and a running martingale is placed on the curb reins, the rings of the martingale will be apt to catch on the loose rings of the bit, if these loose rings occupy the usual vertical position;

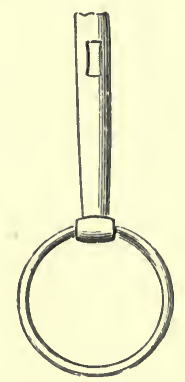

Fig. 76. Loose Ring of Curb attached horizontally.

but will not do so if the loose rings, as recommended by $\mathrm{Mr}$. John Hubert Moore, are attached horizontally (Fig. 76). The great danger of the rings of a martingale catching on the 
buckles of the reins, or on the loose rings of a curb, is that, in such a case, the horse, not knowing that his head has become suddenly tied down, will in all probability severely hurt his

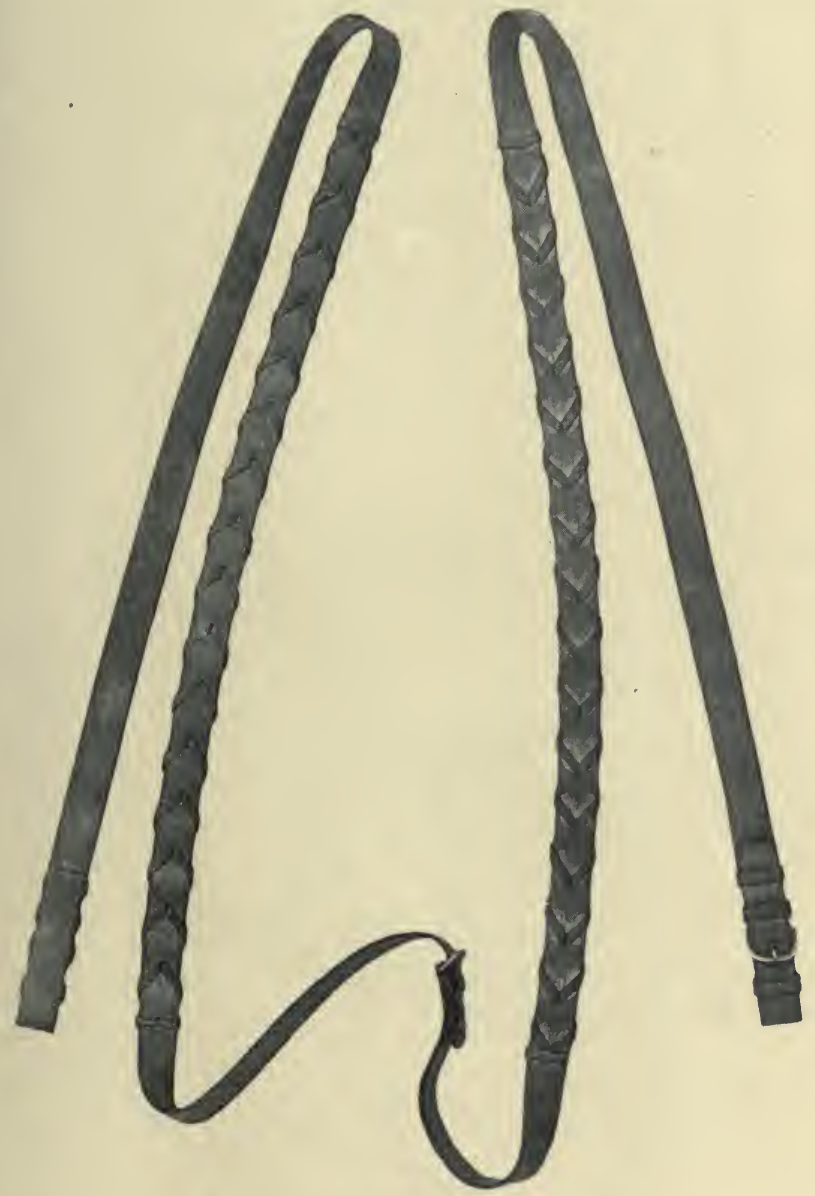

Fig. 77. Reins laced to prevent hands slipping.

mouth the moment he raises or extends his head. This accident is particularly likely to occur when the animal is galloping over rough ground or jumping; because at such 
times he will keep altering the position of his head a good deal, and the consequences of such an accident will then be far more serious than if the movement was slower or more uniform in character. This catching of the rings of a martingale is very dangerous in the case of a rearer, especially when he is held back and is desirous of going on; for the sudden shock on his mouth will be liable to make him rear and throw himself back, in the endeavour to free himself from the painful restraint.

A good contrivance to remedy the inconvenience of the reins slipping through the hands when riding a puller, especi-

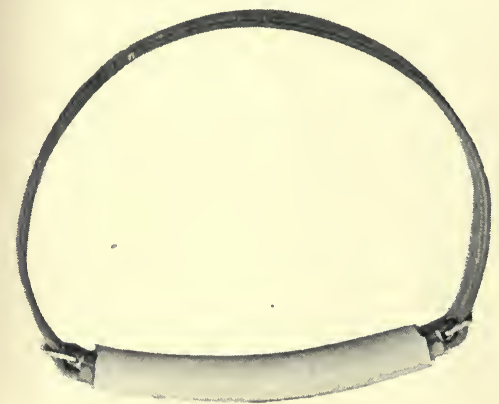

Fig. 78. Ordinary Nose-band with rubber tube.

ally in wet weather, is that of making a series of holes, about an inch-and-a-half apart, in the centre of the reins where the hands come, and passing through the holes, on each side, a narrow leather strap in the manner shown in Fig. 77. Buckingham's rubber covers for reins give a secure grip to the hands.

\section{NOSE-BANDS.}

The following are the usual varieties of nose-bands :

I. The ordinary nose-band (Fig. 78), which consists of a strap that passes over the horse's nose, under his lower jaw, and through loops on the inside of the lower ends of the 
cheek-pieces of the head-stall. In a double bridle it will pass through loops on the cheek-pieces of the bridoon, and not through those of the curb, the action of which it would check if it were attached to that bit.

2. The cavasson nose-band (Fig. 79) has, as a rule, a separate head, which is similar in make to the bridoon head

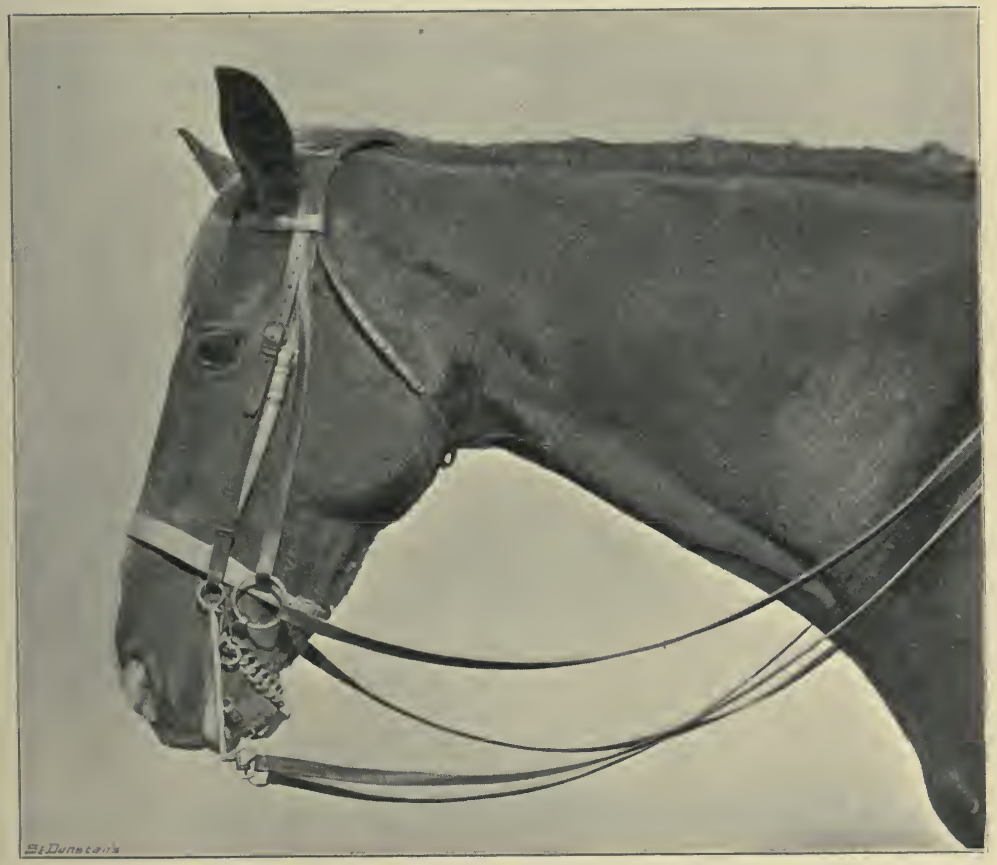

Fig. 79. Cavasson Nose-band.

of a double bridle (Fig. 68); or it may have cheek-pieces which fasten on to the buckles to which the crown-piece of the bridle is attached. In either form it can be raised or lowered as may be required, which is an advantage not possessed by the ordinary nose-band. The cavasson nose-band which has a separate head, is the most fashionable form of this gear, and is certainly neat-looking and useful. 
3. The double nose-band (Fig. 80), or Gillard's nose-band, as it is often called, after the famous Belvoir huntsman (Fig. 8I) who invented it, has the special recommendation that it can be placed lower down, and consequently in a more

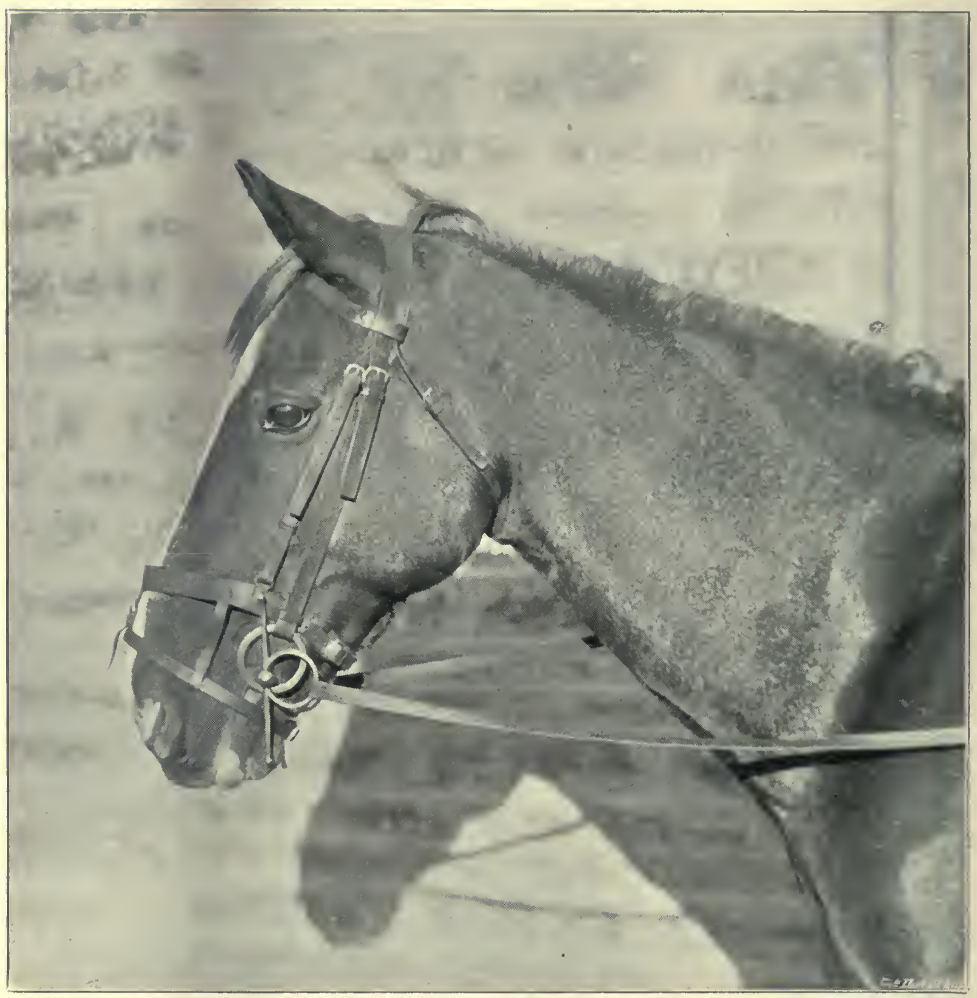

Fig. 8o. Gillard's Nose-band.

effective position, than the other kinds of nose-bands, all of which are above the bit.

4. The Bucephalus nose-band (Fig. 82) passes over the nose and under the lower jaw. Its ends overlap, and are connected with the top eyes of the curb by spring hooks. It can therefore be tightened or loosened by, respectively, taking 


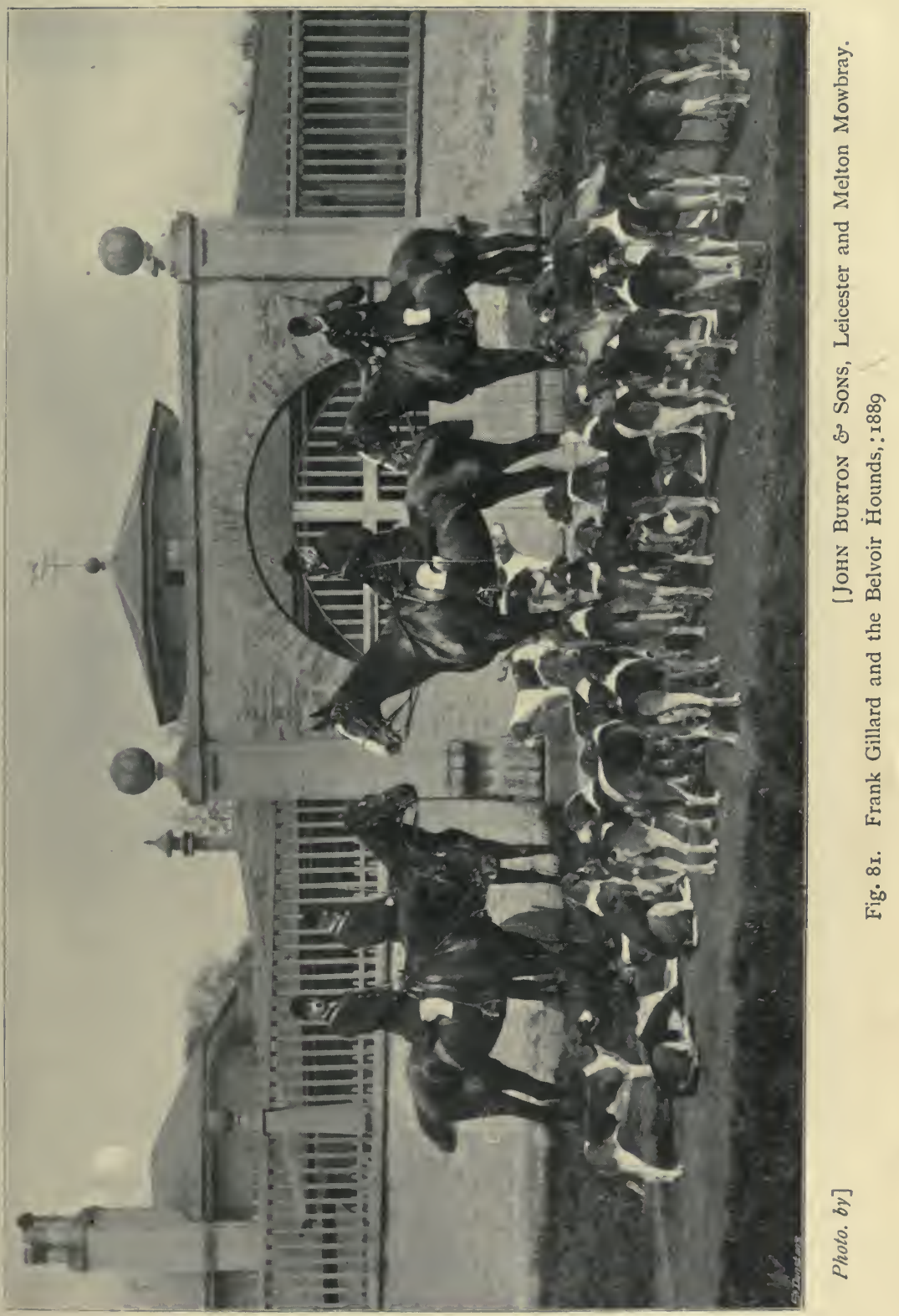



a pull at the reins, or slackening them. The presence of a curb-chain naturally checks its action. Although it has been found to afford effective control with some hard pullers, it has gone almost entirely out of fashion.

The chief useful office of a nose-band is to draw the lower

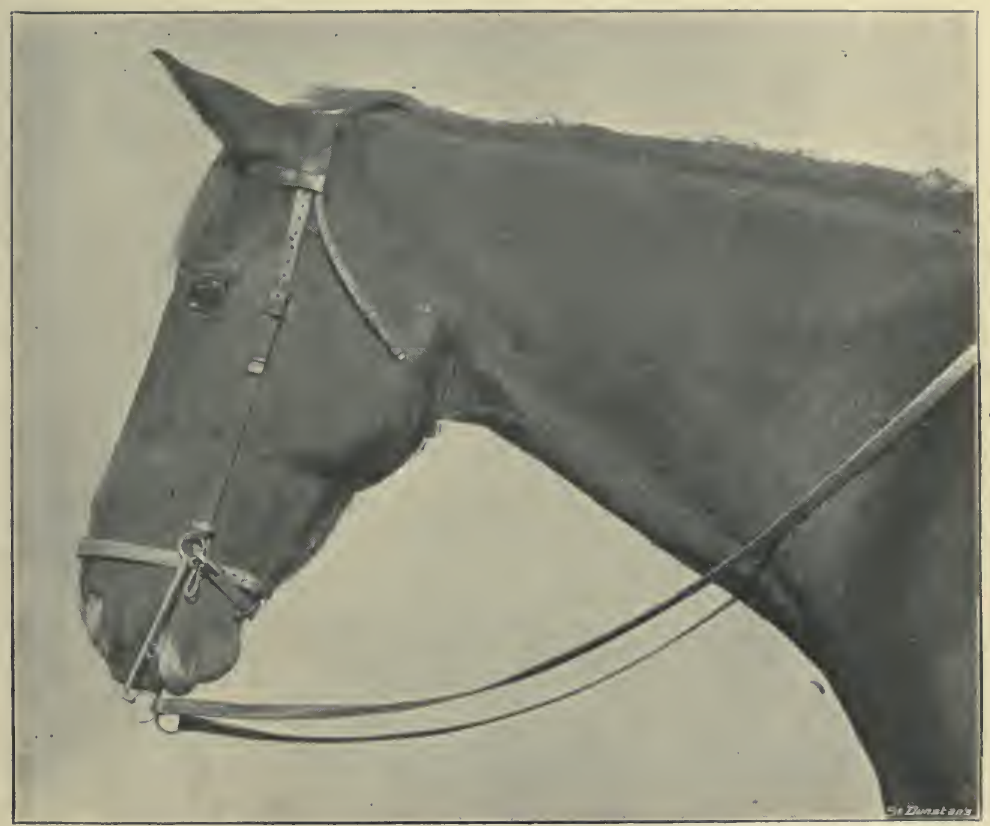

Fig. 82. Bucephalus Nose-band.

jaw up to the upper jaw, so as to deprive the horse of the power of yielding only with the lower jaw, and thus to compel him to bring down his head and bend his neck more than he would do without a nose-band. Also, with a curb, it prevents him from shifting the bit about in his mouth; and when he is being turned, it increases the power of the rider in pulling his head round, because it fixes his upper and lower jaws together, and consequently deprives him of the side play of 
the lower jaw, on which a curb bears. Major Dwyer states that it prevents the horse from catching the bit with his back teeth. With a snaffle, when the animal is turned to the right or to the left, it allows the horns of the snaffle, on the side from which the horse is being turned, to act effectively against the side of his upper and lower jaws. It may be used to "take off" from the plainness of an animal's head. From the foregoing observations we may see that a nose-band, properly put. on, will considerably increase the power of either curb or snaffle; provided, of course, that its presence does not irritate the horse.

It is evident that the lower a nose-band is placed, short of interfering with the action of the animal's nostrils, the more effectively will it carry out its object. In this respect, Gillard's nose-band is the most useful form of this kind of bridle gear.

To protect the horse from any painful pressure of the noseband on the sharp edges of the lower jaw, Mr. Langham-Reed uses an India-rubber tube (a one-inch hose pipe tube will do) to cover the rear portion of the nose-band (Fig. 78).

\section{CHIN-STRAPS.}

The object of a chin-strap is to prevent the curb-chain from shifting upwards on to the sharp edges of the branches of the lower jaw, and to keep the cheeks of the bit from swinging forward and becoming reversed (Fig. 83), as they might do, were it absent, in the event of the horse throwing up his head. When the cheeks are thus reversed, the rider will have but little control over his mount. If, however, when the animal brings down his head again, the rider at the same time slackens the reins, the cheeks of the bit will fall back into their usual position. The chin-strap also helps to prevent a tricky horse from catching the cheek of the bit with his lower lip, or with his teeth. Chin-straps are generally made of leather and provided with a buckle which is placed close tc 


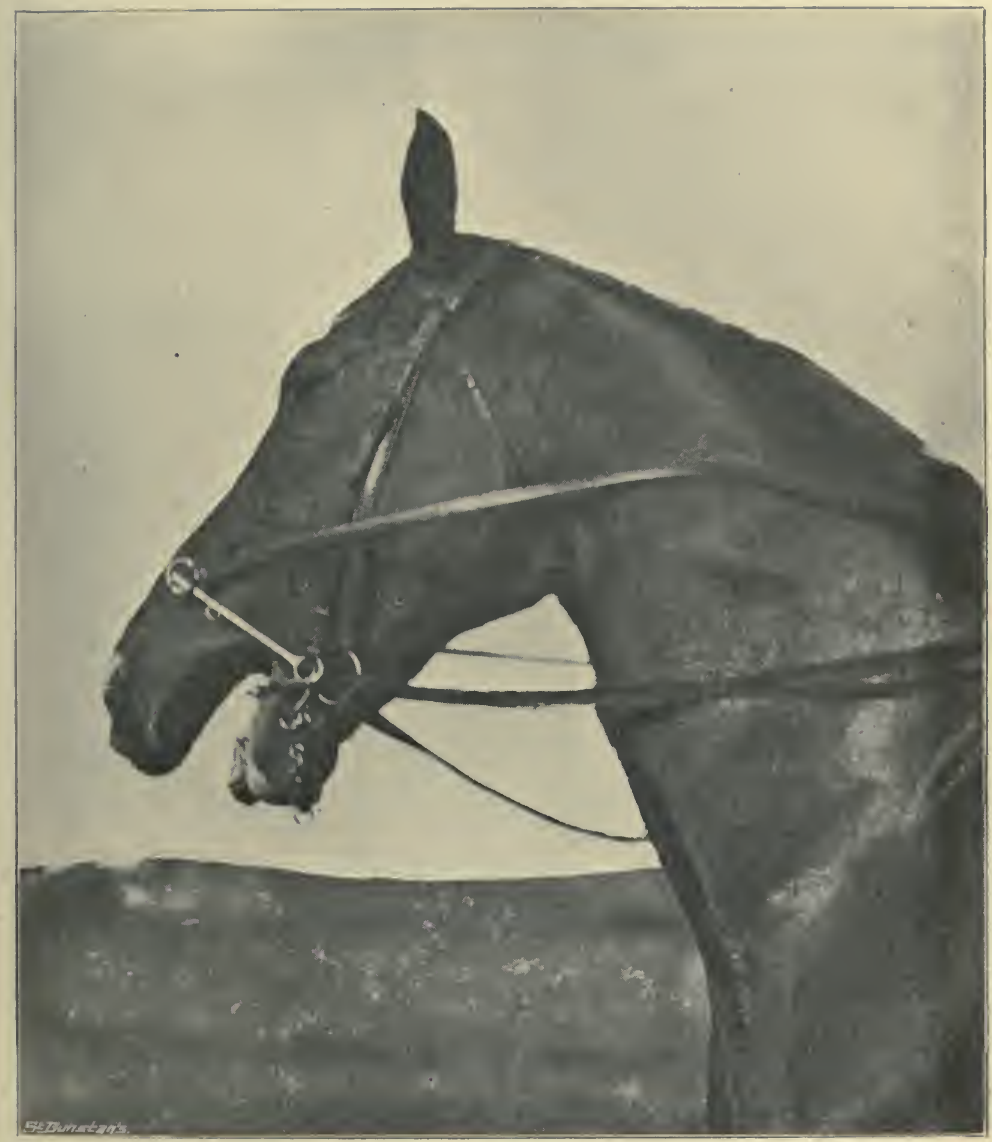

Fig. 83. Curb reversed.

one end (Figs. 47 and 48). A simpler and neater plan, which was shown me by Mr. Langham-Reed, is that of a

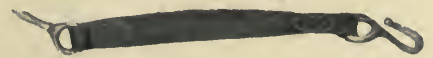

Fig. 84. Chin-strap with Hooks at each end.

strap with hooks at each end (Fig. 84). Instead of a strap, a light steel chain with hooks at each end may be used. An 
objection to this chain arrangement is that the noise it produces, while the horse is being ridden, may prompt the animal to throw his head about. Its cleaning will of course add to the work of the groom.

\section{ACTION OF SNAFFLES.}

The legitimate action of a snaffle is to restrain the horse by pressure on the bars of the mouth (p. I8) and on the tongue.

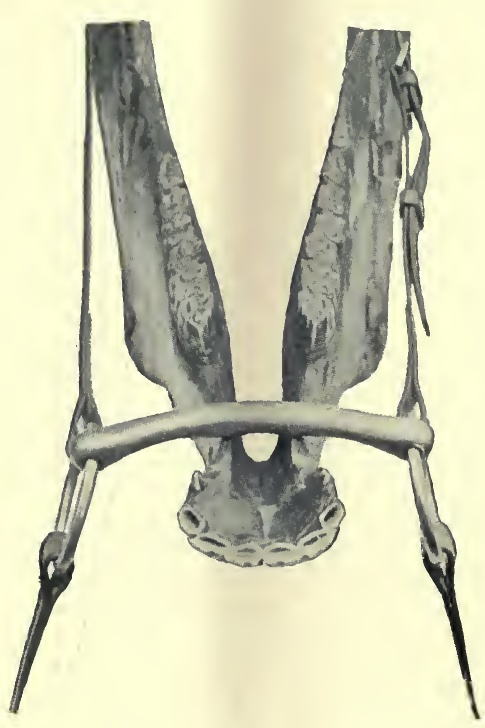

Fig. 85. Action of Unjointed Snaffle on Horse's Mouth.

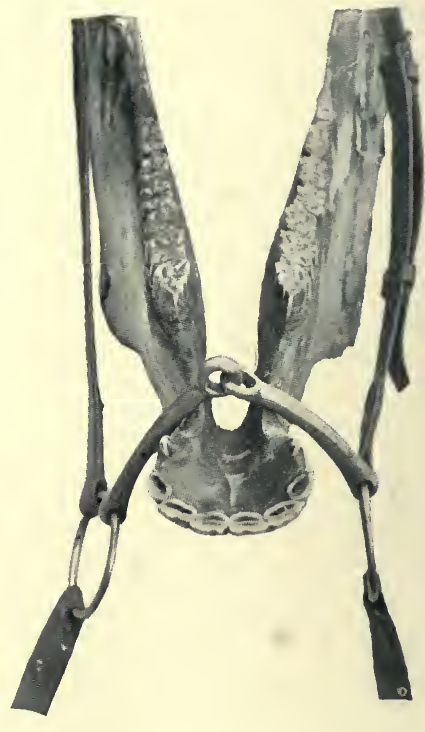

Fig. 86. Nutcracker action of Jointed Snaffle on Horse's Mouth.

In turning the horse to one side or the other; the indication is given by the cheek-piece pressing against the side of the mouth, and also by the head-stall of the bridle pressing against the animal's cheek. It is evident that the restraining indications afforded by the snaffle, will be most direct and most simple when they are applied in the same direction as the pull of the reins. Consequently, the unjointed snaffle is truer in its action than the jointed 


\section{ACTION OF SNAFFLES.}

snaffle, which needlessly irritates the horse by the side pressure it inflicts on the lower jaw (Figs. 85 and 86). In fact, its action to some extent is similar to that of a pair of nutcrackers. The action of the double-jointed snaffla (Fig. 3I) is manifestly less objectionable than that of the single-jointed one. We learn by experience that a horse will

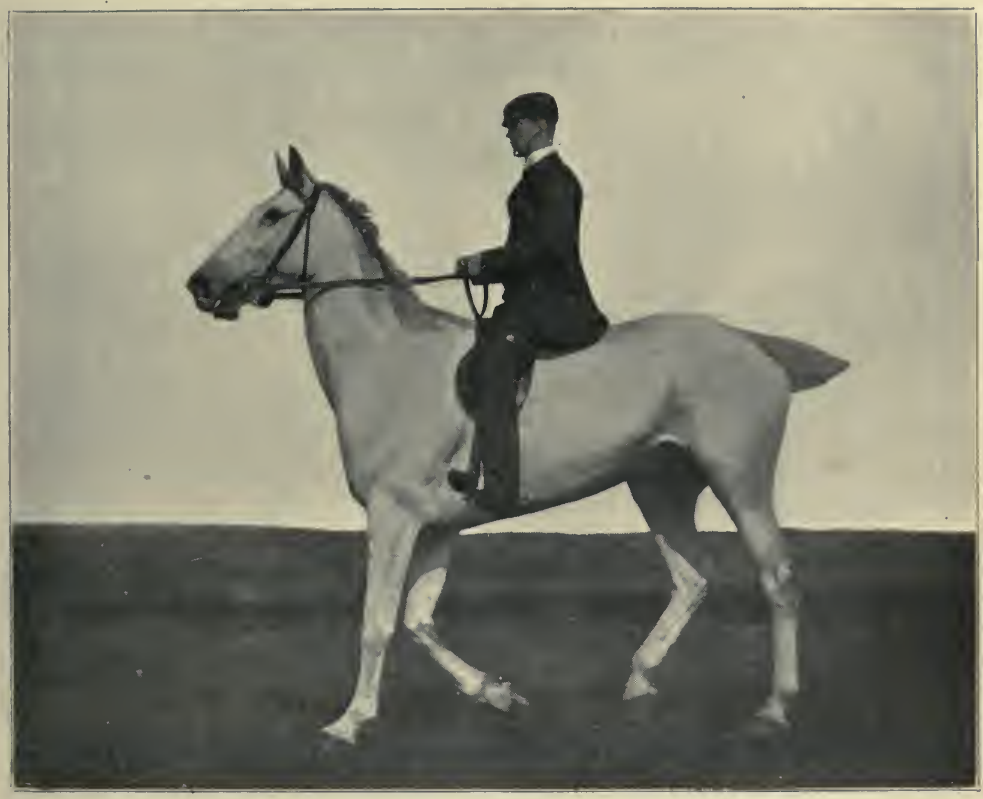

Fig. 87. Groom on Leicestershire Hunter.

obey the pressure of a snaffle more readily and more kindly when it is painless, than when it hurts his mouth. Hence we find that a horse goes best in a large smooth unjointed snaffle, the good effect of which is often increased by covering it with India-rubber. As a rule, a thin jointed snaffle, especially if it be twisted or otherwise rendered more severe, will prompt him to pull, or will make him afraid to go up to his bit. 
Another objection to a jointed snaffle is that a horse can get his tongue over it more easily than over an unjointed one.

When a horse carries his head in a more or less perpendicular manner, the bars and tongue offer the chief resistance; but when he extends his head, or when the rider raises his hands too high, the pressure is likely to fall on the corners of the mouth (Figs. 87 and 88), and possibly on the back teeth in some cases. I cannot say with certainty that a horse ever "takes the bit between his teeth," to use a common ex-

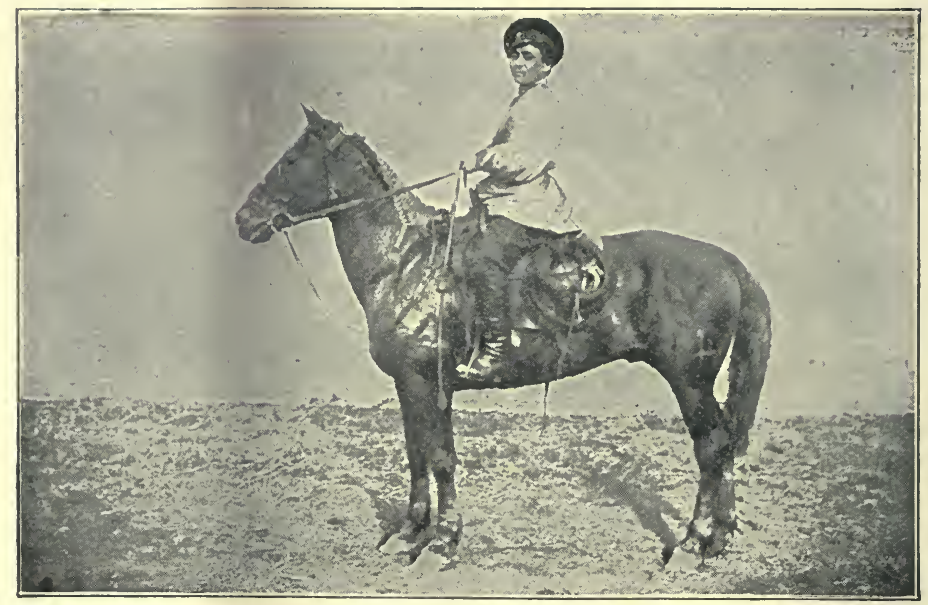

Fig. 88. Kalmuck on Russian Remount.

pression; although it is probable that he may at times bear against the snaffle with the front part of his back teeth.

The bars are the most sensitive part on which the snaffle acts. To save them from pain inflicted by the bit, horses, especially if they are inclined to puil, will throw up their heads or poke out their noses, so as to get the pressure on to the corners of their mouths. It is evident that the effect of a snaffle is at a minimum when a rider holds his hands high, and when the horse keeps his head raised and his muzzle advanced. 
Apart from the disadvantage of the bars of the mouth being relieved from pressure when the horse unduly elevates his head, we have the further important objection that the internal surfaces of the animal's cheeks, immediately behind the corners of the mouth, are apt to get forced by the snaffle -especially if it be a jointed one-against the sharp edges of the back teeth (Fig. 27), and consequently to become more or less lacerated. The pain thus inflicted is often the cause of horses becoming violent when ridden, and of pulling, in order to escape from the torture they are enduring. Liability to such injury is naturally increased, when, as sometimes happens, the edges of the back teeth are abnormally sharp. In such cases, the remedy often suggested is to file down the edges of the front molars. A more rational means of prevention would be the use of a standing martingale, arranged so as to make it impossible for the horse to raise his head high enough to get the mouth-piece off the bars of the mouth. Besides, filing the molars is apt to injuriously interfere with the correct adjustment of the grinding surfaces of these teeth, and should not be attempted, except by an experienced veterinary surgeon.

Laceration of the internal surface of the cheeks of a horse is specially liable to occur in turning the animal, by pulling the inward rein and at the same time loosening the outward one, in which case the mouth-piece will be more or less drawn through the mouth. Under these circumstances, if the snaffle has no cheeks, the outward ring, while the turn is being made, will press the inside of the cheek against the molars, with the probable result of pain and tearing of the mucous membrane. To guard against this untoward accident, it is well to have a snaffle with cheeks, the outward one of which will bear on both jaws, when the horse is being turned, and will not force the horse's cheek against the teeth, as a ring would do. This useful action of the cheek of a snaffle will be greatly aided 
by the use of a nose-band, in the event of the horse opening his mouth as a "defence"; and will be almost entirely nullified, by connecting the upper ends of the cheeks to the head-stall (Fig. 89), as is sometimes done. In turning a horse with a double-ringed snaffle provided with cheeks (Fig. 39), the pressure of the outward cheek will cause the ring against which it presses to lie flat on the cheek of the

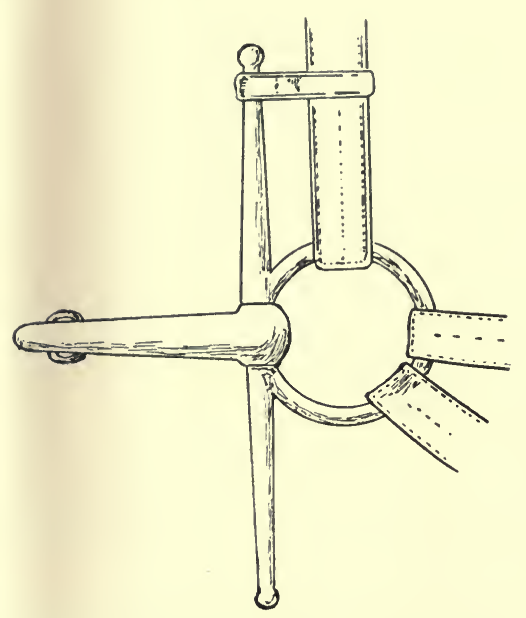

Fig. 89. Cheek of Snaffle connected to Cheek-piece of Bridle.

horse, and consequently the risk of injury to the animal's mouth is reduced to a minimum.

The cheeks of a snaffle are usually solidly connected to their respective rings; the united ring and cheek on each side being free to revolve on the mouth-piece. This arrangement has the disadvantage of rendering the lips liable to get pinched between the cheeks of the snaffle and the mouthpiece, especially when the snaffle has been in wear for some time. To remedy this defect, it is well to have the cheeks and the mouth-piece made of the same piece of steel, and to have the rings work in projections outside the cheeks (Fig. 90). 
There is some truth in the old saying, that if a horse cannot be held in a snaffle no other bit will hold him. At the same time, I must say that I have never taken in hand a hard puller

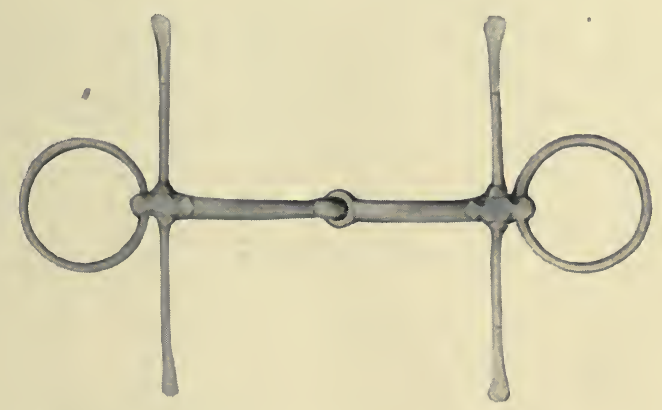

Fig. 9o. Snaffle with Cheeks solidly connected to Mouth-piece.

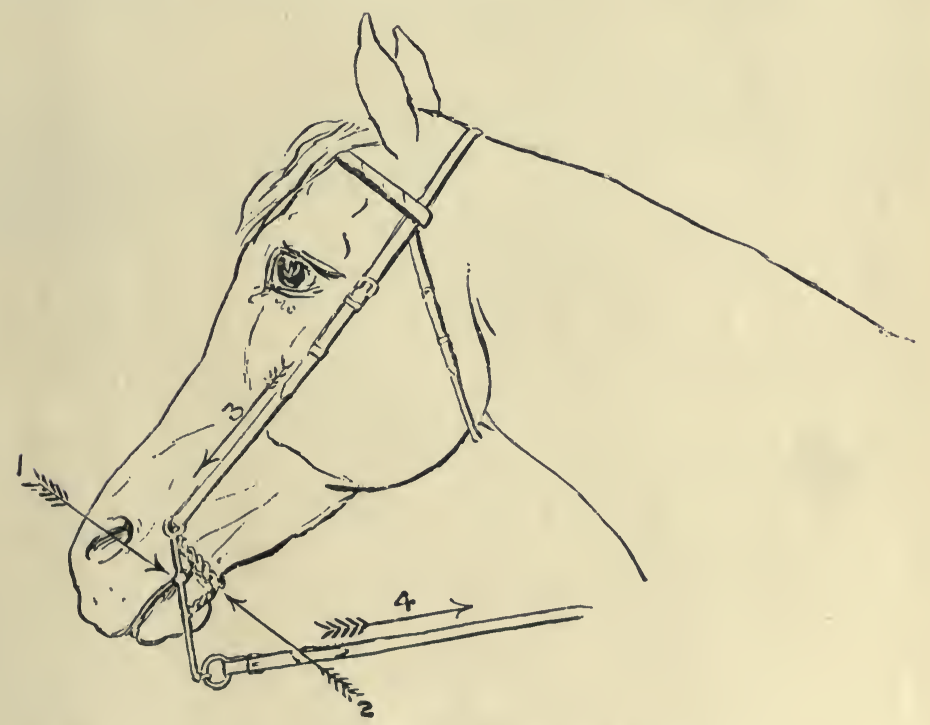

Fig. 9r. Action of the Curb as a Lever.

which I have not been able to get under better control with a curb, properly put on, than with a snaffle. The disrepute under which, for holding a puller, a curb sometimes falls, is 
due in almost all cases, to its having been put on wrongly, or to its faulty construction. Respecting these points, see pages IO3 to IO6, and 77 to 84 .

\section{ACTION OF CURBS.}

When the reins of a curb are drawn tightly, the following pressures are exerted in the manner shown by arrow-heads in Fig. 9I.

I. On the bars of the lower jaw and on the tongue by the mouth-piece.

2. On the chin-groove, which is the smooth and rounded

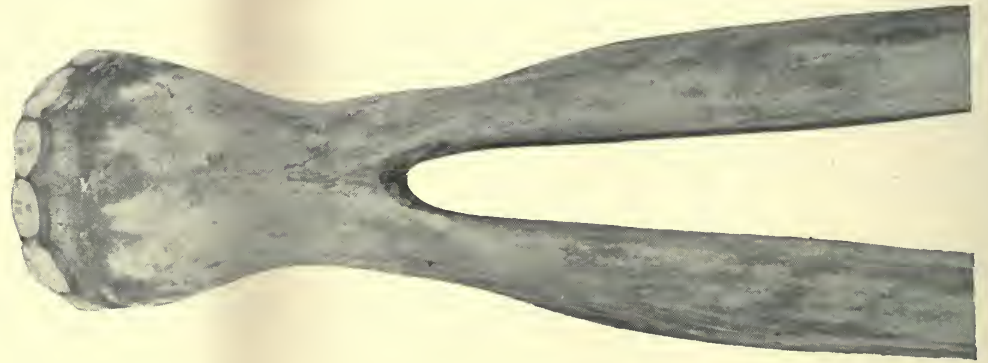

Fig. 92. View of under-surface of Lower Jaw.

portion of bone on the under surface of the lower jaw, and immediately in front of the bifurcation of the branches of that jaw (Fig. 92).

3. On the poll of the horse's head, over which the crownpiece of the headstall passes.

4. The pull of the reins.

From the remarks already made about the principles of bitting, and the action of snaffles, we may conclude that the pressure of the mouth-piece is the only legitimate one for restraining a horse.

The pressure of the curb-chain on the chin-groove should be rendered as little irksome to the animal as possible; because 
any pain it may inflict on him will be in the direction in which he is going, and on that account it can restrain him only by making him afraid to go up to his bit. It will also have the tendency to cause him to throw up his head in the endeavour to save his jaw from injury. That curb-chains hurt horses in the manner described, is patent to anyone who has seen how fretful and unmanageable curbs render many high-spirited animals that will go quietly in a plain snaffle. We may frequently find that the part of the lower jaw against which the curb-chain bears, is galled and bruised. Not uncommonly, in old-standing cases, a bony deposit is formed on the seat of pressure, as a result of continued inflammation. Even if we succeed in getting a horse under control by inflicting pain on him with the curb-chain, we shall render him unsafe and more or less disagreeable to ride, by making him afraid to go up to his bit. The habits of throwing up the head and "keeping behind the bridle," so seriously interfere with the comfort and safety of the rider, and with the usefulness of the animal, that it behoves every owner to avoid, by attending to the proper bitting of his horses, the possibility of their contracting these vices.

The downward pull on the head-stall caused by the ordinary curb is objectionable; because it tends to make the horse carry his head too low down, in which case he will not be able to freely extend his fore legs to the front. By a strange misconception, Continental school riders consider that the legitimate action of a curb is to lower a horse's head, and that of the snaffle to raise it. Consequently, many of them ride with the curb reins in one hand, and the snaffle in the other, so as to make the animal carry his head in a correct position! A horse which has been properly broken, if rightly bitted and well ridden, will not, however, require any compromise in this matter; but will carry himself in good style, either in a curb or in a snaffle, used singly. 
Any alteration in the position of a well broken and correctly bitted horse's head, while he is being ridden, should be effected by a corresponding alteration in the position of the rider's hands, and not by a change of reins; because such a change could not always be made with precision and without danger, as when crossing a difficult country, for instance.

In practice, we find that the employment of a curb has a tendency to make a horse gallop "round" : in other words, to make him bend his knees too much; because when his head is brought down by the action of the curb, the direction of the neck muscles, which draw the fore limbs forward, will not be inclined sufficiently upwards to enable the feet to clear the ground without undue bending of the knees. Although this effect of the curb on the action of the horse may be disregarded when perfect control, rather than speed, is demanded; it has served to practically banish curbs from racing stables.

If we examine the under surface of the lower jaw, we shall find that the bone of the chin-groove (p. 74) is smooth and rounded; and that immediately above it, the edges of the branches of the lower jaw are sharp and sensitive. Hence we may accept the direction of Major Dwyer (Seat and Saddles) that the curb-chain should lie in the chin-groove, without its being given any tendency to mount upwards.

As the bars are more sensitive than the tongue, the port has been devised to take pressure off the latter and put it on the former, in order to increase the severity of the bit. By inclining the port forward (p. 8o), the tongue wili be still more relieved of pressure.

When a curb is used without a curb-chain (Fig. 93), the fulcrum of the lever is supplied by the head-stall, and the weight is the corners of the mouth, against which the mouthpiece presses. Hence, the removal of the curb-chain sometimes acts well with a horse that carries his head too low. 
CONSTRUCTION OF CURBS.

1. Length of upper end of cheeks. - The longer are the upper ends of the cheeks of a curb, the greater will be the downward pull on the head-stall, and the stronger will be the tendency of the curb-chain to mount up on the sharp

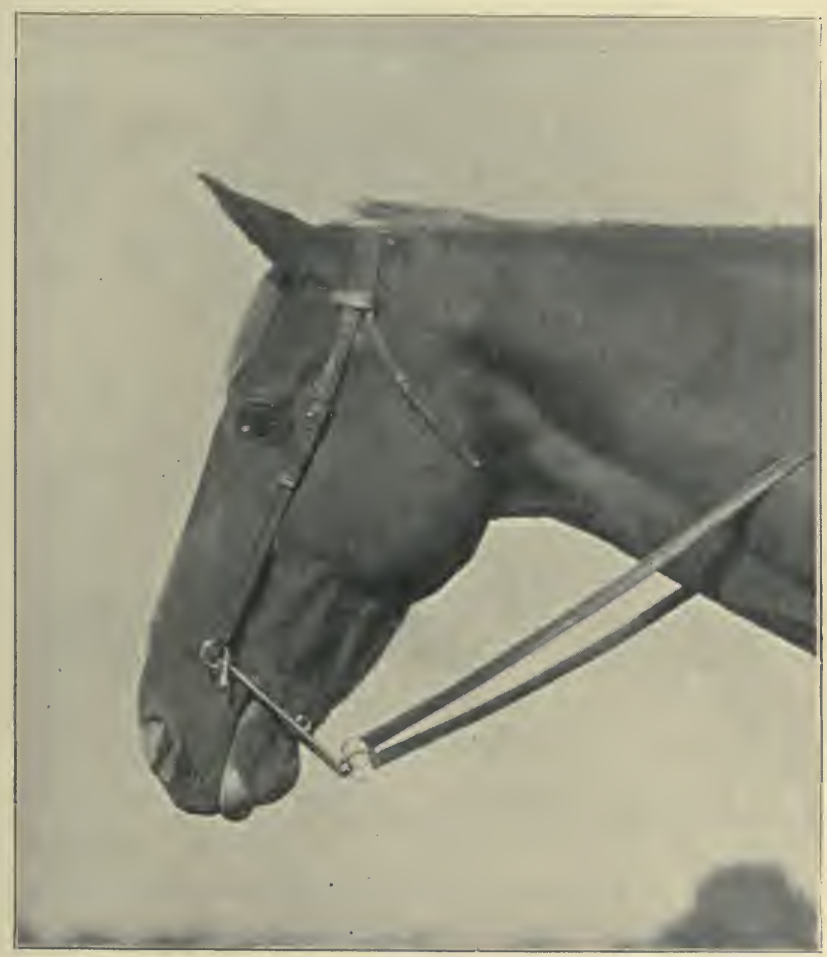

Fig. 93. Action of a Curb which has no Curb-chain.

and sensitive edges of the branches of the lower jaw. If, however, the upper ends of the cheeks be too short, they will allow the cheeks of the bit to come more or less into a straight line with the reins, when the reins are drawn tightly, supposing that the curb-chain is somewhat loose. 
Consequently, such a short length of the upper ends of the cheeks would do away with any mechanical advantage to be derived from the employment of a curb. I have found that for ordinary horses it is advisable to fix this length, measuring from the lower surface of the mouth-piece to the top eye, at from $I 3 / 8$ to $I \frac{1}{2}$ inch (Fig. 94). The measurement is usually taken from the centre of the mouth-piece, which is a plan that does not allow for the thickness of the mouth-piece; for it

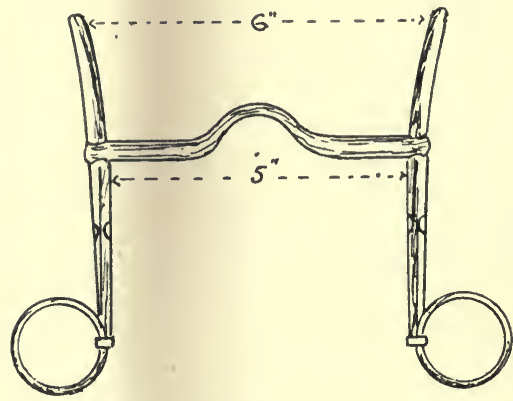

Fig. 94. Properly constructed Curb for ordinary Hunter.

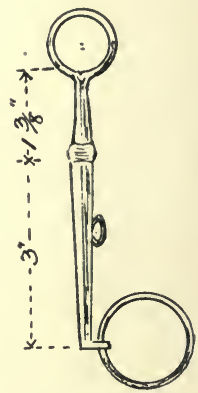

Side View.

is evident, that the thicker the mouth-piece, the longer does the upper end of the cheek practically become.

2. Length of lower end of cheeks.-Having fixed the length of the upper end of the cheek, we may, in order to obtain increased power, lengthen the lower end of the cheek to, say, 3 inches. An important danger of having a curb with long cheeks for hunting, is that, if the horse comes down, he will be liable to hurt his mouth severely by the ends of the cheeks catching on the ground, in the event of the animal's muzzle striking the ground, and especially if it slides forward on that surface. The pain thus inflicted might easily give rise to disordered movements on the part of the horse which would cause a serious accident to one or both of these companions in danger. When a horse falls and is not prevented by his rider 
from saving himself in his own way, he will, as a rule, try to utilise his head as a kind of fifth leg. Hence we not unfrequently find, after a horse has stumbled and come down on a hard road, that his knees have escaped injury by the fact of his head taking the blow. The same thing probably occurs during a fall when jumping; although the protective action of the head may not be so clearly demonstrated. The cheeks in Fig. I16 are too long.

3. Width of mouth-piece.-The width of the mouth-piece of a curb should, as a rule, closely correspond to that of the horse's mouth, while allowing sufficient play to prevent any chance of the cheeks of the bit pinching the lips. If the mouth-piece be unduly wide, the animal may acquire the habit of boring to one side, by finding that he can shift the port over to one side of his mouth, and thus relieve the opposite gum from pressure, by interposing his tongue between it and the mouth-piece. This rule as to the width of the mouth-piece does not always hold good; for some horses which bore and pull badly, will go best in a bit, the mouth-piece of which is broad enough to allow the rider to pull it from one side to the other in the animal's mouth, as occasion may require. The proper width of a mouth-piece for an ordinary hunter will be about 5 inches. We may take the width to vary from $4 \frac{1}{2}$ to $5 \frac{1}{4}$ inches according to the size of the animal.

4. Construction of port.- The height of the port may be increased or reduced, according as we wish the tongue to take more or less of the pressure of the mouth-piece. The great objection generally urged against the use of a high port, is its liability to hurt the horse by pressing against his palate. We, however, find from experiment, that to be capable of inflicting this form of irritation, even when the front teeth are brought close together and the animal is only a small pony, the port must be at least $2 \mathrm{I} / 4$ inches high (measuring from the lower surface of the mouth-piece); and, of course, 
this length would have to be increased in proportion to the extent the animal opened his mouth. It is therefore reasonable to conclude that when the use of a high port irritates a horse's mouth, it does so, in the large majority of cases, on account of the bars having to bear too much pressure, and not by reason of the port touching the palate. I can here lay down no exact rule for guidance, beyond saying that I have never found any benefit, in the holding of a puller, from the use of a port higher than an ordinary Melton port: for instance, that in Fig. 48. We have already seen that pressure on the palate by means of the port is a form of punishment which is opposed to the principles of good bitting.

The width of the base of the port may be taken at one-third the width of the mouth-piece. In making this estimate, I am guided merely by the teaching of experience.

Under ordinary conditions, the port lies more or less flat on the tongue of the horse, when the reins are slack; and when the reins are taken up, the port and the cheeks of the bit are at an angle of about $45^{\circ}$ to the direction of the tongue and bars of the mouth, as in Fig. 95. Hence, when the reins are slack, the port is in the best position for the horse to get his tongue over it, which is a troublesome trick (p. 27I); and when the reins are moderately tight, the action of the port in freeing the tongue from pressure, is only about half that which it would be, if the port was at right angles to the direction of the tongue. In order to remedy these two faults, Mr. Langham-Reed places the port at an angle of $45^{\circ}$ (Fig. 96), which is a contrivance as effective as it is ingenious. The mouth-piece of Fig. 96 is fixed; but that of the Pelham in Figs. 63 and 64 , is capable of revolving forward through an angle of $45^{\circ}$. I like the fixed mouth-piece better than the movable one; especially as the former is free from the fault possessed by the latter, of being apt to pinch the animal's lips, when it becomes loose, as it might do in time. Mr. 
Langham-Reed sometimes uses three links of a curb chain attached to the upper and front part of the port (Figs. $\sigma_{3}$ and 64 ) to keep the horse's mouth "lively."

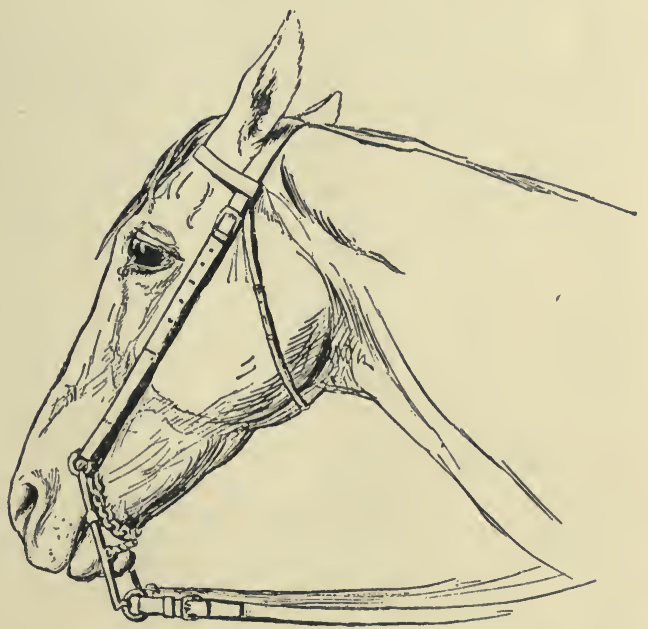

Fig. 95. Angle made by the Cheeks of a Curb, when the Reins are taken up.

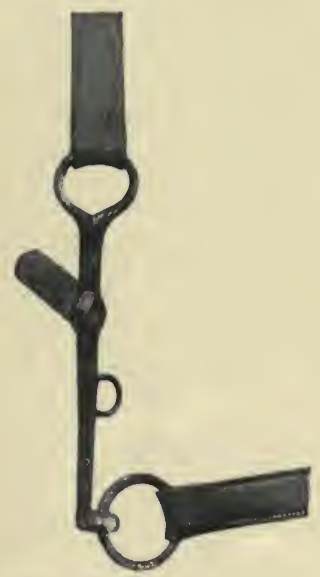

Fig. 96. Side view of Curb which has its Port inclined forward at an angle of $45^{\circ}$. 
5. Thickness of mouth-piece.-With the object of having the mouth-piece comfortable to the animal's mouth, I do not think that it ought to be less than two-thirds of an inch in thickness, which is about two inches in circumference.

6. Outward inclination of upper ends of cheeks.-I like Mr. Langham-Reed's idea of giving an outward inclination to the upper ends of the cheeks, so as to accommodate themselves to the shape of the horse's upper jaw. He makes the distance between the tops of the upper ends of the cheeks, one inch more than the width of the mouth-piece.

7. Size of loose rings. - The loose rings of a curb should be sufficiently large (say, not less than $\mathrm{I} 3 / 8$ inch in diameter) to prevent the rings of a running martingale catching on them, in the event of such a martingale being used on the curb reins.

8. Prevention of top eyes of curb exerting a downward pull on the head stall.-We have already (p. 77) seen the part played by the length of the upper end of the cheek in this connection. We may further obviate the objectionable pull in question by making the top eyes of such a shape, as in Lord Thurlow's bit (Fig. 55), that they will be able to revolve forward without causing any strain to be put on the head-stall. The Chifney bit (Fig. 53) effects this object in a still more perfect form; because its curb-chain alone resists the forward revolution of the upper ends of the cheeks. With it, the whole of the pressure on the mouth is taken by the bars, tongue and chin-groove, and none by the animal's poll.

The downward pull on the head-stall may be removed to a certain extent by having the top eyes of the curb made larger than usual, as in Fig. 96; and by connecting them to the cheek-pieces of the head-stall by means of spring hooks.

A Chifney bit is often objected to, on account of its undue severity, especially when its reins are in the hands of an indifferent rider. If in such cases, the horse that was over- 
bitted in a Chifney, goes all right in, say, a Ward Union curb, we may put the blame as a rule, not on the principle of the Chifney, but on the excessive length of the lower ends of its cheeks, which, speaking generally, should not be longer than three inches. Particular care should be taken that the curbchain does not hurt the animal's jaw ; because more strain is thrown on the curb-chain by a Chifney bit than by any other kind of curb.

Agreeably to the foregoing principles, I have drawn Fig. 94, to show a properly constructed curb for a horse with an ordinary-sized mouth. The measurements are given in inches. The Ward Union bit fulfils the correct conditions so nearly, that an intending purchaser will generally find that it will meet his requirements.

9. Devices to keep the mouth "lively" include the sliding mouth-piece (Figs. 50 and $5 \mathrm{I}$ ), the mouth-piece which revolves through an angle of $45^{\circ}$ (Figs. 63 and 64), a mouth-piece with three or four links of chain hung from the port (Figs. 63 and 64 ), and one with rollers, like a Hanoverian Pelham. My experience is that these devices are of no practical use, except perhaps for hacking.

The curb which has a sliding mouth-piece is not right in principle; because if it is placed so low as to be in correct position (p. 103), when the reins are drawn tightly, the mouthpiece will knock against the tushes when the reins are kept. slack. A horse will often play with this mouth-piece when the curb reins are loose, in which case its presence may aid in keeping the mouth "lively." But when the curb reins are taken up, the mouth-piece will act in the same way as that of any other curb, and will have no up and down play. This bit, nevertheless, suits some horses better than an ordinary curb; seemingly because the upper ends of the cheeks are usually shorter, and consequently more correct in length, than those of the other, the upper ends of the cheeks of which- 
measured from the lower part of the mouth-piece to the top eyes-are generally about $2 \frac{1}{4}$ inches long, instead of being at least three-quarters of an inch shorter. The sliding mouth-piece has the serious objection that it is liable to pinch the horse's lips.

\section{CURB-CHAINS.}

Keeping in view the principle that the curb-chain should on no account hurt the horse, we should select one which will lie flat and smooth, in preference to one with small

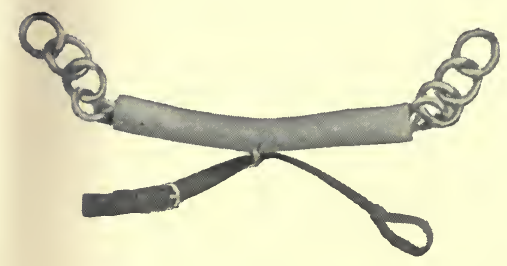

Fig. 97. Curb Chain covered with India-rubber Tube.

and thin links. The chain may be covered with wash leather, or, as Mr. Langham-Reed wisely suggests, by a tube of India rubber (Fig. 97). A neater form of protection is afforded by a leather strap placed between the curb-chain and the horse's jaw ; or instead of a curb-chain, a flat piece of bridle leather, furnished with a few links at each end may be used. "It is very clear that the narrower the chain is made, the more likely is it to cause pain, which is just what we want to avoid, and we should therefore endeavour to make it as broad as possible. The vulgar notion of a sharp curb is, as the reader perceives, a monstrous absurdity" (Dwyer). The width of an inch is ample for a curb-chain. If it is much wider than this, it would be apt to hurt the sharp edges of the lower jaw.

The usual length of a curb-chain (about IO $1 / 2$ inches, when 
twisted, so as to make it lie flat) is at least two inches too long for an ordinary horse; and consequently, when the chain is in use, there is at each side a superfluous length of chain, the removal of which would greatly add to the neat appear-

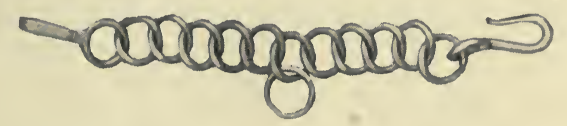

Fig. 98. Curb Chain with Hooks.

ance of the bridle. As broken horses which are ridden in a curb bridle, require, in the vast majority of cases, only one respective length of curb-chain, it is, as a great rule, advisable

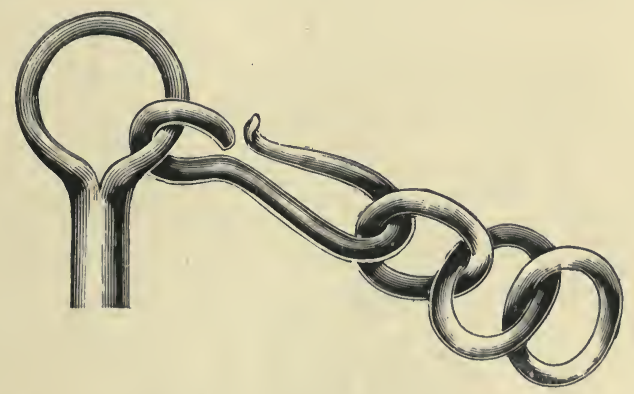

Fig. 99. Ordinary Curb Hook.

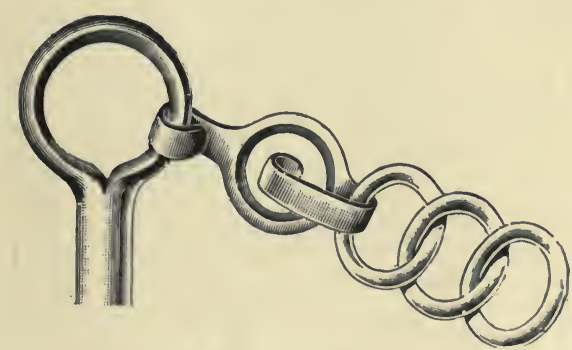

Fig. 100. Patent "Circle Curb Hook."

that when such an animal has a bridle reserved for his own particular use, the curb-chain should be of the exact length required, and without any extra links. It will then look better than a long curb-chain, and in putting it on, there will 
be no uncertainty or loss of time incurred in its correct adjustment. Besides, there will be no impediment in the way of shortening it if the necessity for doing so occurs. In hardly any case, will it be requisite to make it longer than its usual correct length. Even if that rare eventuality comes to pass, the curb-chain can be taken off altogether. Instead of having curb-chain hooks on a curb bit, as is generally the custom, Mr. Langham-Reed has them on the curb-chain of a fixed length (Fig. 98). The patent "circle curb hook" (Fig. IOO), is a useful arrangement for making the curb-chain lie flat against the horse's lower jaw.

\section{ACTION OF PELHAMS.}

When a Pelham has an unjointed mouth-piece, its action is that of an ordinary curb or snaffle, according to the particular reins which are used. When both reins are taken up, its action is usually very faulty; because its snaffle reins will then, as a rule, draw the mouth-piece so high up in the mouth, that the curb-chain will come on the sharp edges of the branches of the lower jaw, and a downward pull will be transmitted to the head-stall. Hence the user of a Pelham should not tighten both the curb and snaffle reins at the same time.

As a rule, Pelhams are wrongly constructed; because the upper ends of the cheeks are nearly always much too long. When the rider takes up the curb reins of a Pelham which has a jointed mouth-piece, its cheeks press against the sides of the mouth, on account of the presence of the joint, and the width of the mouth-piece, instead of corresponding to that of the horse's mouth, varies with each touch of the rider's hands on the reins.

Pelhams when used as curbs, have generally a strong tendency to make horses carry their heads too low, apparently by reason of the downward pull they exert on the head-stall 
of the bridle. This tendency seems to be particularly well. marked in Pelhams which have a jointed mouth-piece.

A Hanoverian Pelham is in some repute for making a horse lift up his feet and bend his knees in fashionable style; probably because it has, as a rule, an irritating effect on his mouth. The gain of action in front will generally be accom-

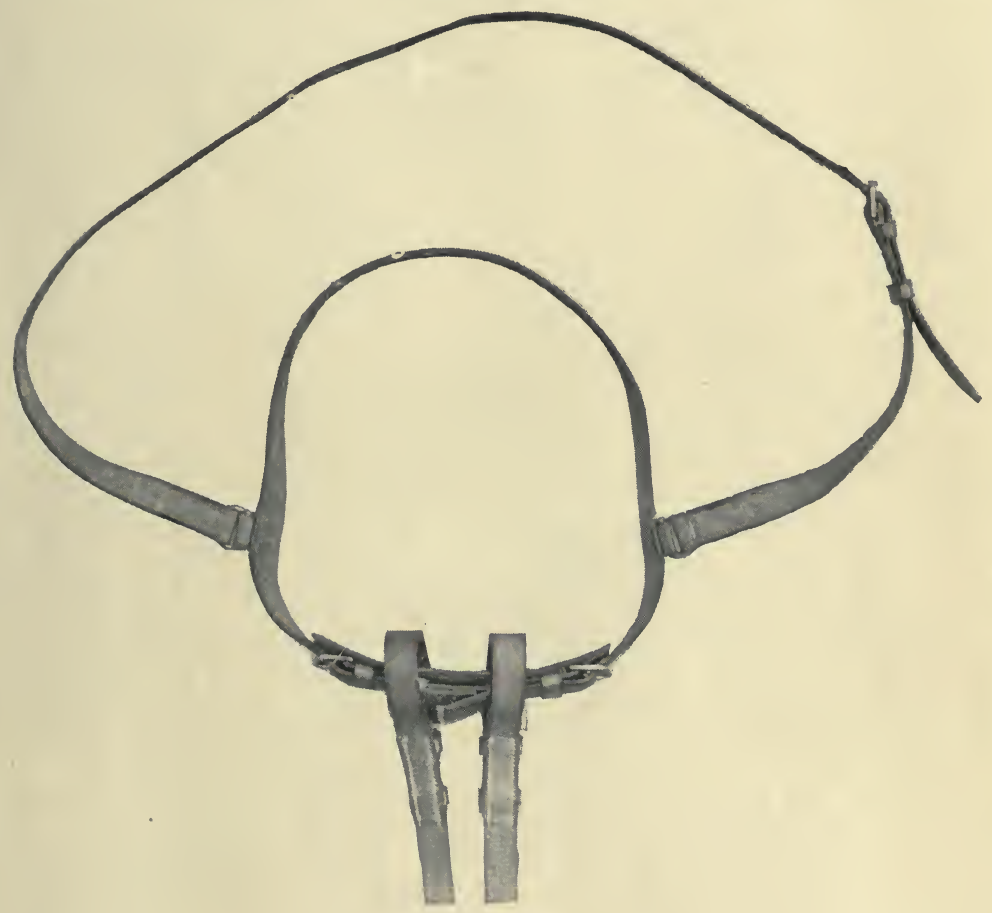

Fig. Ior. Standing Martingale buckled to Cavasson Nose-band.

panied by a corresponding loss of action behind. When used by a rider with very fine hands, it often suits hardmouthed horses, but only of course while they are being hacked or being ridden in a school. In such cases, its value is apparently due to its possession of rollers and joints, the presence of which may tend to keep the mouth "lively." 


\section{MARTINGALES.}

A martingale is a strap which is attached at one end to the girth, girths, surcingle, or breast-plate; and at the other

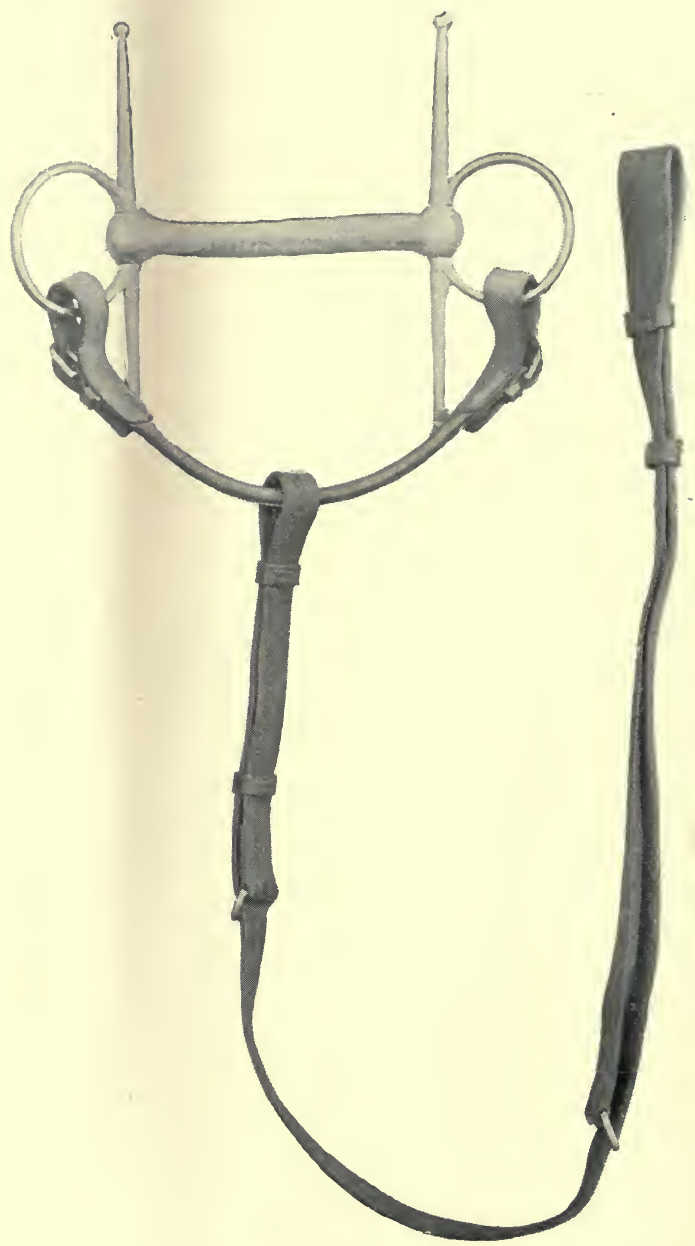

Fig. 102. Standing Martingale attached to rings of the Snaffle.

end is connected to the reins by rings, or is fixed to the noseband or rings of the snaffle. 
The following varieties of martingales are employed :

I. The standing martingale or fixed martingale, which is fixed either to the nose-band, or to the rings of the snaffle. In the former case, the martingale is generally attached as in Fig. IOI. In the latter case, we have the three following kinds of arrangements : (a) a long strap and a short cross-piece

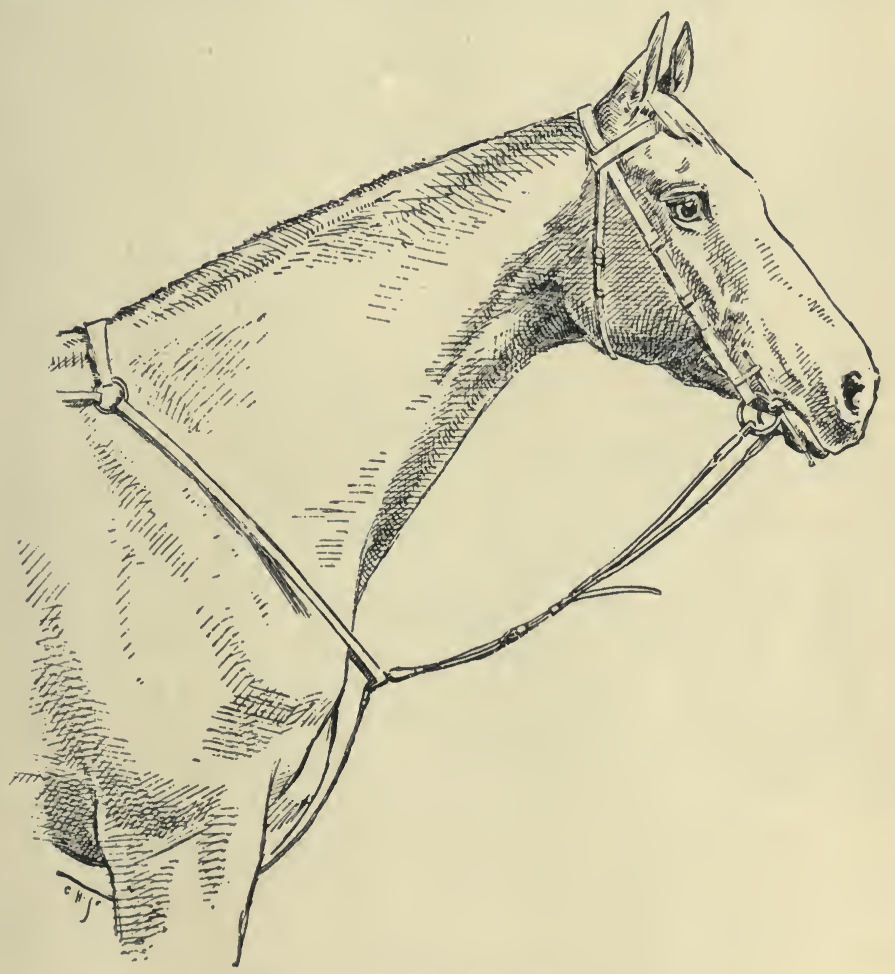

Fig. 103. Cheshire Martingale.

(Fig. IO2); (b) a long strap which is divided at the bridle end into two branches (Fig. II2); and (c) the Cheshire martingale (Fig. IO3), which consists of two branches that are connected with the breast-plate near their junction. The Cheshire martingale appears to be the outcome of an attempt to unite a standing martingale and a breast-plate into one 
article of gear. This combination conforms to the sound principle that the simpler the gear, the better it looks on a horse.

The chief objects of a standing martingale are to prevent a horse from raising his head too high, and from stretching it out too far. Consequently it may be usefully employed with animals that rear, star-gaze, throw their heads up and down, pull and are difficult to turn. We find that the higher a horse holds his head, the less power we have to alter the direction in which he is going; hence the standing martingale, by preventing him from getting his head up, will help us in keeping him straight, as for instance, if he tries to run out at a fence. Bringing in the head of a hard puller by means of a standing martingale, aids in control, by the fact of the martingale taking more or less of the pull which would otherwise fall on the rider's hands.

In almost all cases when a horse raises his head in defence against the snaffle, he does so with the object of transferring the pressure of the mouth-piece from the bars of the mouth to the less sensitive corners of the mouth. With a curb, the attempt is usually made in order to escape from the painful pressure of the curb-chain.

The presence of a standing martingale which is fixed to the rings of the snaffle, not only prevents a horse from holding his head too high, but it also proves to him that he will hurt his mouth against the mouth-piece of the snaffle if he tries to raise his head beyond the limit allowed him by the martingale, and that he will relieve his mouth of painful pressure, the moment he bends his neck and lowers his head. Consequently, the action of the standing martingale which is connected to the snaffle, is instructive as well as preventive; because it shows the horse that he gets punished for disobeying our wishes, and is rewarded for carrying them out. I have always found in hunting, chasing, flat-racing, 
hacking, school riding and breaking, that a standing martingale fixed to the snaffle, acts much better than one which is attached to the nose-band; the reason evidently being that the horse is able to bear on the latter without pain, but not on the former. Hence, in the use of the standing martingale which is connected with the nose-band, the instructive effect of punishment is lost. Polo players, as a rule, prefer to have the

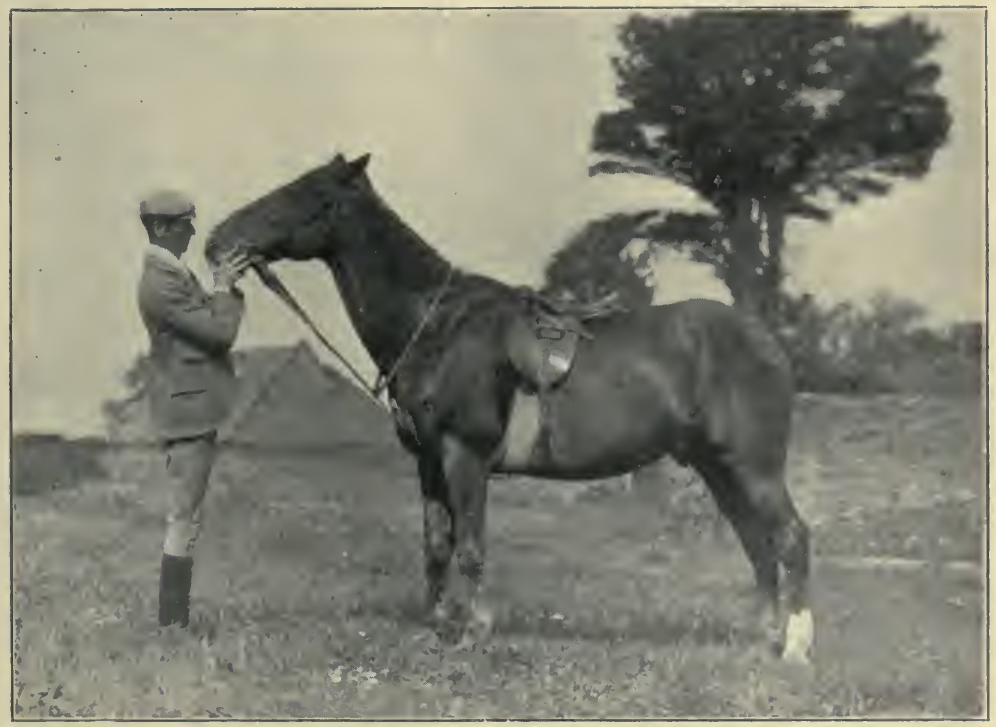

Fig. I04. Maximum length of Standing Martingale.

standing martingale on the nose-band; because, as they say, the pony's mouth is apt to get too much pulled about, if it is on the snaffle. Probably this is a valid objection against the use of this martingale on the snaffle in a game at which the animal gets many inadvertent jobs in the mouth. As I am not a polo player, I shall limit the following remarks on standing martingales to those which are fixed to the snaffle. Owing to the severity and sharp action of a 
curb, it is unadvisable to attach a standing martingale to that bit.

In the adjustment of the standing martingale, the maximum length is evidently that which is just sufficient to prevent the animal from shifting the mouth-piece from the bars to the corners of the mouth (Fig. I04). The minimum length for merely keeping down the head, would, of course, be that which would be requisite to bring the head down to the highest natural position, say, that in Fig. 105. It is manifest that these lengths can be obtained only approximatively, and that they would in many cases require correction after trial. To check pulling and running out, the martingale could be further shortened as might be needed. For riding over a country, I would not use this martingale shorter than the minimum just given.

We now come to the important question:-Is it safe to ride a horse in a standing martingale, if he has not been accustomed to it? My answer to this very practical query is that it would be unwise to do so, if he was a rearer, or if he was to be ridden over fences; but that the standing martingale would be a useful aid in all other cases. To avoid every chance of accident, it would of course be advisable to give an unaccustomed animal some instruction with this martingale before testing it too highly. The best and quickest way to impart this lesson is according to the "long rein" method described in Illustrated Horse-breaking. Or, while riding the horse, we may gradually accustom him to this martingale by beginning with it quite loose, and shortening it a hole at a time with suitably long intervals. When a horse has become used to it, but is too artful to renounce his defence when he finds that his head is free from its restraint, it is certainly safer, even when crossing a country, to employ this martingale, in order to make him look where he is going, than to allow him to stare straight up into the 
sky, to "run out" when he chooses, or to take his rider at any pace he likes.

Mr. John Hubert Moore, who is one of the best " makers" of steeple-chase horses Ireland has ever known, is a warm advocate of the standing martingale for 'cross country purposes. That once well-known chaser, Scots Grey, gained

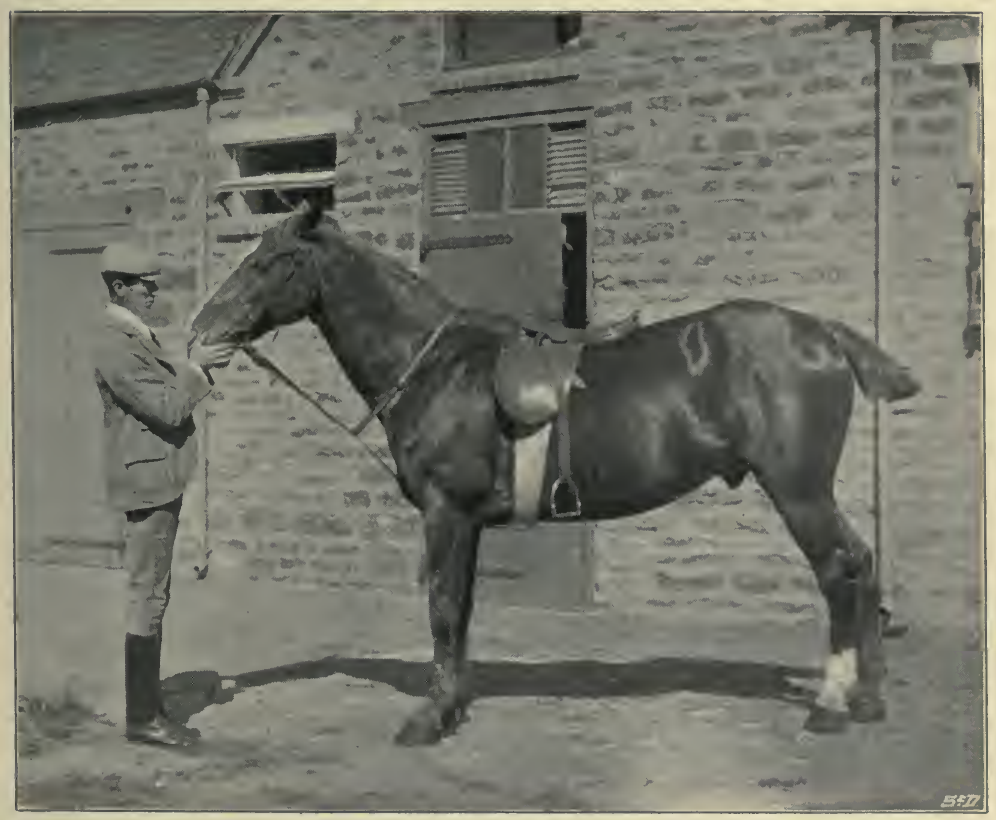

Fig. I05. Minimum length of Standing Martingale.

his principal victories when ridden in this martingale, without which it would have been impossible to have kept him straight.

Acting on the principle that in all ordinary kinds of riding, and especially when crossing a country, we should hamper an animal's movements as little as practicable by gear, I would advise that this martingale should be employed only with 
horses which could not be ridden in comfort and safety without it.

We may improvise a standing martingale by buckling the rings of a running martingale to those of the snaffle, by means of the billets of the reins (Fig. I06).

2. The running martingale (Fig. IO7) has at one end a loop,

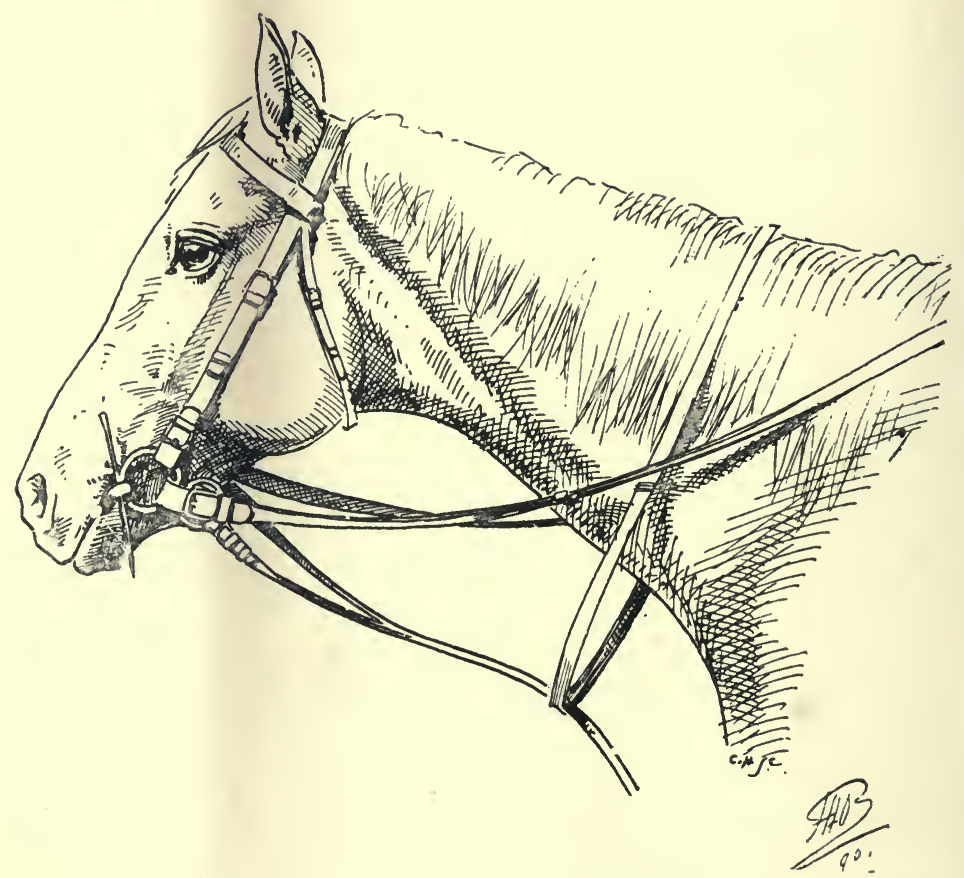

Fig I06. Improvising a Standing Martingale by means of a running one.

through which the girth, girths, or surcingle passes. At the other end, the martingale is split into two branches that are provided at their respective extremities with rings through which the reins pass. It has a neck-strap that prevents the portion of the martingale which is between the horse's fore legs, from hanging too low down. The useful peculiarity.in Lord Lonsdale's martingale (Fig. IO7) is a shoulder near the 
bifurcation of its branches, to prevent the neck strap going too far forward. In training stables, running martingales for

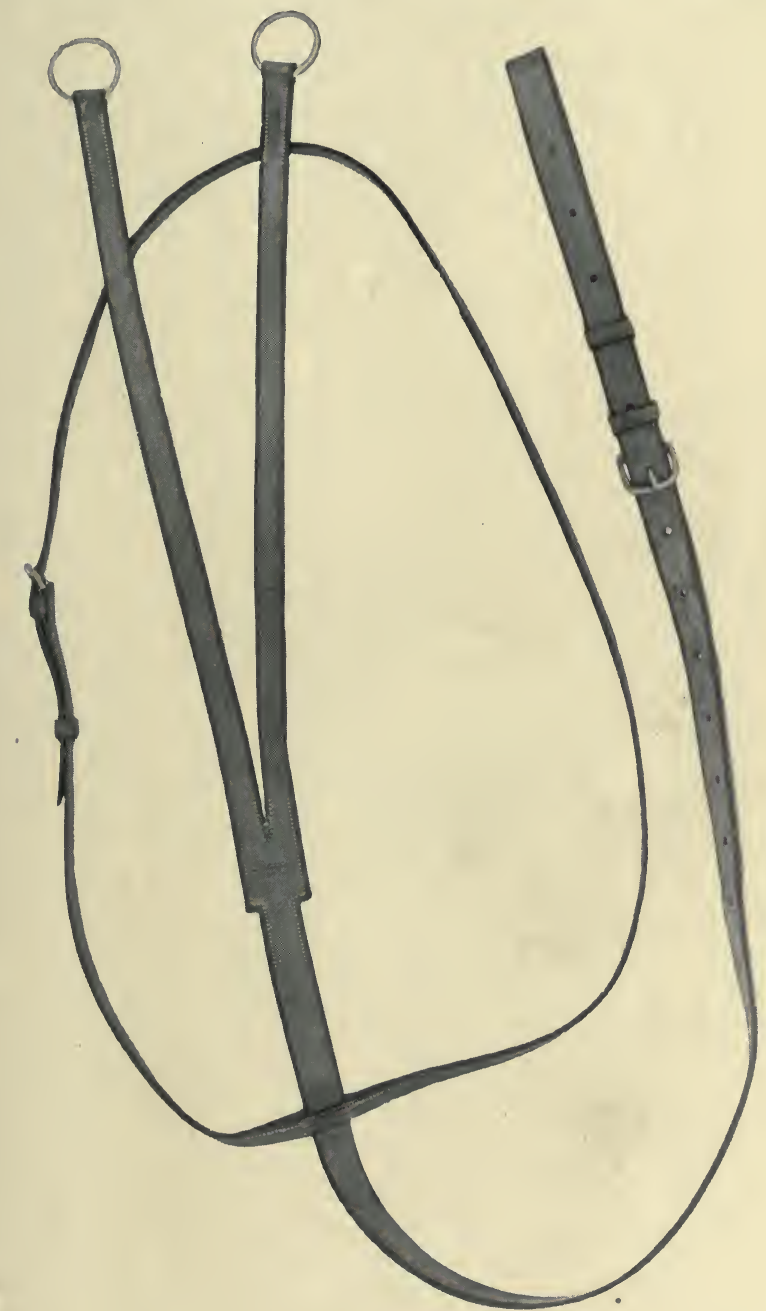

Fig. 107. Lord Lonsdale's registered Running Martingale.

yearlings are frequently furnished with a triangular piece of leather which connects the branches of the martingale together 
(Fig. I08), so that the young one cannot catch his head in them. These martingales are called "web martingales."

The reason for the running martingale being split into two branches, is to allow freedom in the separate action of the reins. If the rings of the martingale were close together, and

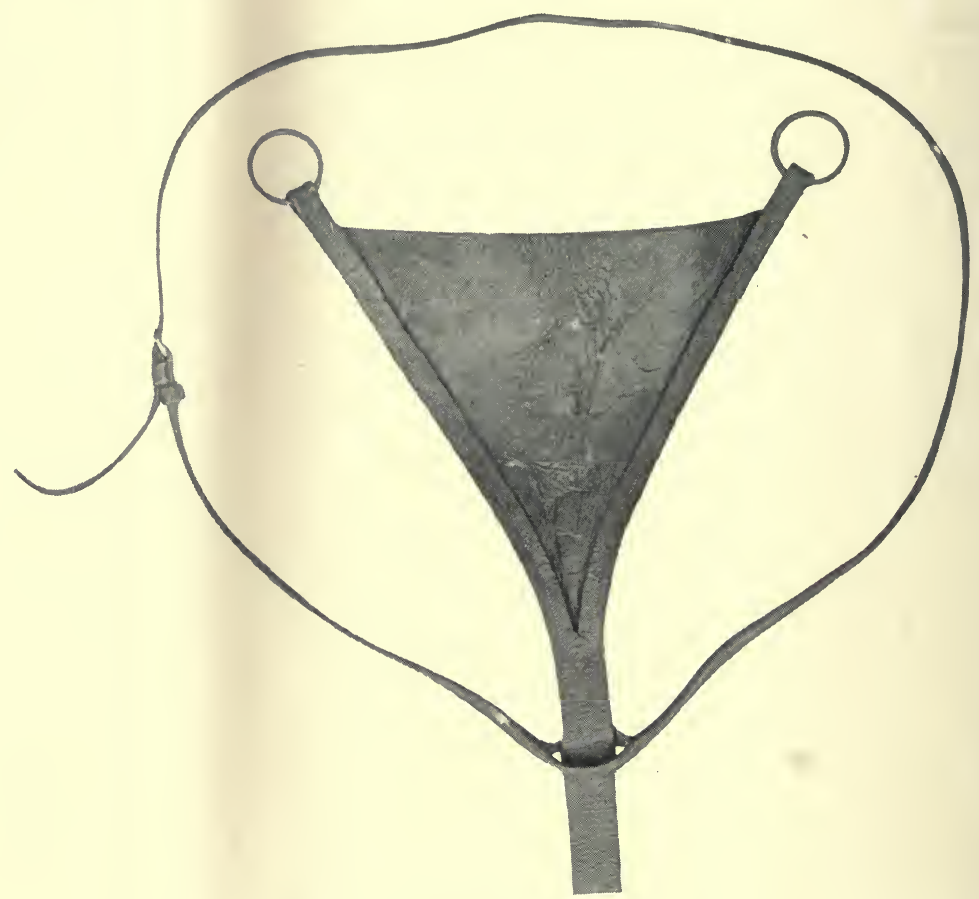

Fig. 108. A “Web Martingale."

the right rein was pulled to turn the horse to the right, the left rein would have to be slackened off (as in Fig. I I I), in order that the pull of the right rein might be effective. By the branched arrangement, the pull of one rein does not affect the direction of the pull of the other rein.

Uses of the running martingale. It is a common idea that the chief use of a running martingale is to prevent a horse 
from raising his head too high. We find, however, that when our best flat race and steeple-chase jockeys and other good horsemen ride with this martingale, they almost invariably employ it so long, that it has little or no effect in keeping the head down. When, as I have already described, a horse is prevented from raising his head too high by a standing martingale attached to the rings of the snaffle, he is punished by the tension of the martingale being transmitted to the mouth-piece of the snaffle, if he tries to get his head in the air; but the moment he brings his head down and bends his neck, cessation of the painful pressure will reward him for his obedience. This automatic means of dispensing punishment and reward is so accurate in its working, that a horse soon learns the lesson set before him. But with a running martingale, the rider, in order to reward the horse for bringing his head into proper position, would have to slacken out the reins with a promptness that would be seldom attainable, and with an entire disregard of control over the animal. In fact, with a running martingale adjusted so as to prevent the horse from getting his head too high, the reins would have to perform the dual office of keeping down the head, and of regulating the speed, which duties could seldom be successfully combined. With a standing martingale, however, the rider can safely relinquish the adjustment of the height of the animal's head to the martingale, and accordingly he is not forced to check the horse's speed, when he wants to get his head down. Some good horsemen, on finding out that the running martingale did not perform its supposed office efficiently, have discarded it altogether, and thenceforth have trusted to their hands to act as their martingale. In this, they were right not to use a running martingale to keep a horse's head down; but they were wrong in thinking that keeping the head down was the only, or even the principal, use of this article of gear. If we closely examine its action, we shall 
find that the great value of this martingale is to aid the rider in turning a horse by keeping his neck straight, when cantering or galloping, which object is greatly facilitated by the opposite rein exerting a strong pressure on the neck.

In regulating the length of the running martingale, we should carefully guard against making it so short that it would interfere with the horse's mouth, when he is not carrying his head unnaturally high; for such interference could have no good result, and would probably impede the animal's move-

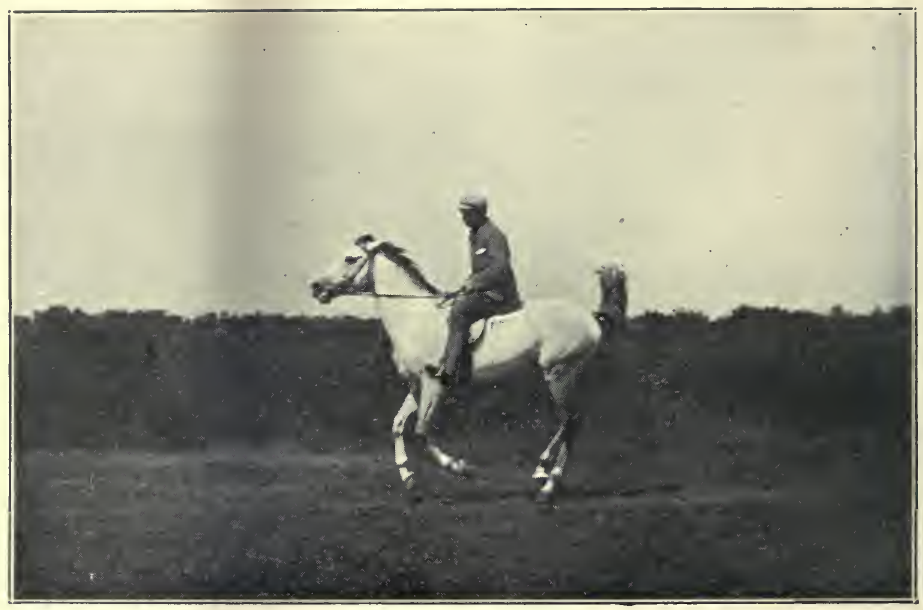

Fig. Io9 Natural Position of Head in Canter.

ments. Although it is impossible to determine with mathematical accuracy the proper length of this martingale, we may from experience fix a minimum length which will answer practical requirements. Assuming, therefore, that the height of the head when it is carried in a natural manner at fast paces, is not greater, or only slightly greater, than that which would bring the reins horizontal when they are held on a line with the withers, as in Fig. I09, we may take the length of the martingale which would be suitable to that position of 
the reins, as the minimum in question. At the period of the gallop in which the horse is depicted in Fig. I09, the animal's head is held higher than at the other periods of that pace ; because, at that moment, the fore-hand is raised off the ground, and the hind legs are brought under the body. In practice we find that the martingale should not be shorter

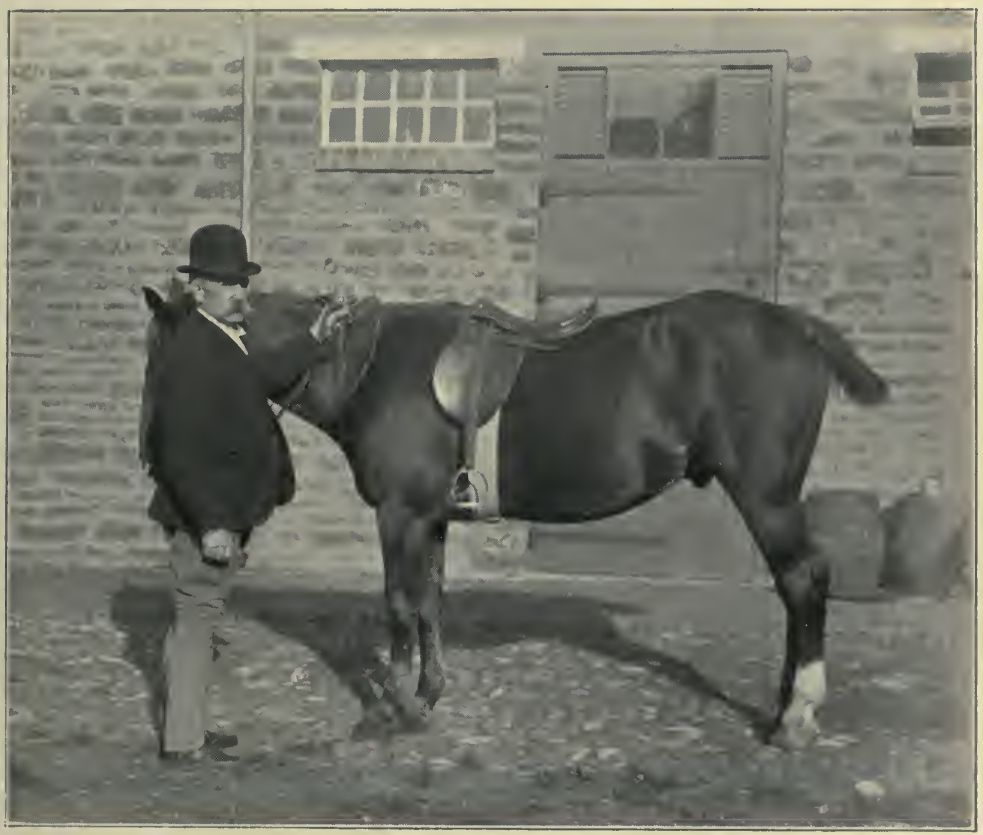

Fig. I10. Measuring minimum length of Running Martingale.

than a length which will allow it, when drawn up, to reach as high as the top of the withers (Fig. I IO). Lengthening it out another three or four inches will generally be an improvement. The use of a running martingale shorter than the minimum I have just laid down, more or less irritates the horse; because, even when he holds his head in correct position, he cannot escape from its disagreeable pressure. The employment of a 
short running martingale for 'cross country work is a very dangerous experiment; for if the rider does not leave the reins loose, when the animal attempts to jump, the horse will

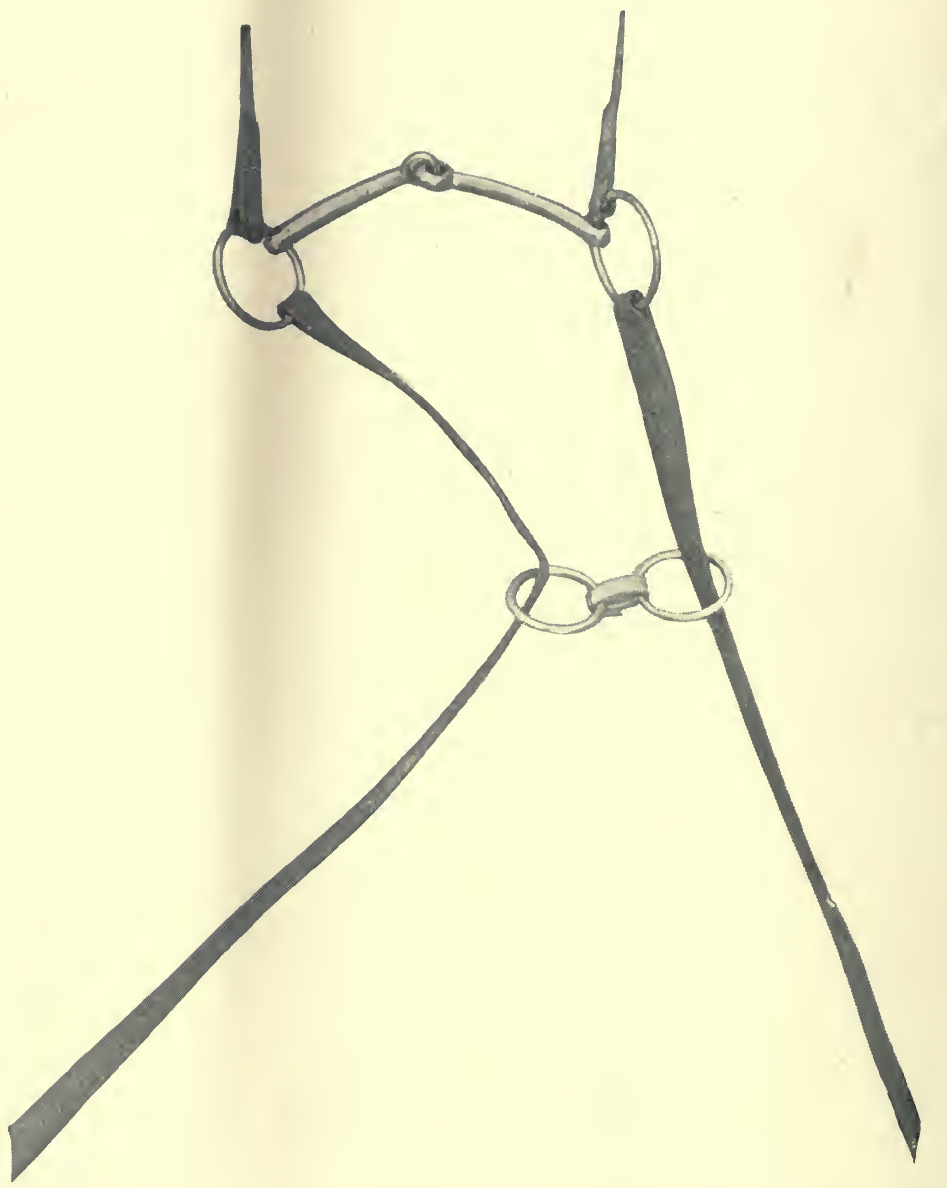

Fig. III. Irish Martingale, or "Spectacles."

be almost certain to hurt his mouth, and consequently he will become afraid to face his bit, or will be rendered unmanageable from pain; the results of either eventuality being highly dangerous to both man and beast. 
A running martingale is useful for preventing the reins from getting over the horse's head, in the event of a fall, or when the animal throws his head about.

3. The "Irish martingale" is formed by passing the reins through a single ring or through two rings connected together by a strap (Fig. III). This not very efficient substitute for a running martingale may be useful for keeping the reins down, in the case of a fall, or with a horse which has the habit of throwing his head about. It has the great disadvantage of hindering the rider in turning his horse ; because the direction of the pull of the inner rein will not be in a straight line, unless the outer rein is let go altogether, which would be a proceeding entirely opposed to good horsemanship. This martingale is very rarely used, no doubt on account of its faulty action.

We may improvise a running martingale by means of a branched standing martingale and two rings of suitable size (Fig. II2).

\section{BRIDLING A HORSE.}

A groom in putting on a bridle, usually takes the cheekpieces of the bridle in the left hand; places the reins over the neck; passes the right hand under the animal's jaw and over its nose, so as to obtain control ; and transfers the cheekpieces of the bridle from the left into the right hand (Fig. I I3). The left hand puts the bit into the mouth, catches the crownpiece of the bridle, and draws it over the ears. The right hand quits the nose, and helps to buckle the throat-latch. This method is well suited for short men or lads; but I think the best way for comparatively tall persons is to take the crown-piece of the bridle in the left hand, while the right holds the reins at their centre in the palm of the hand. The reins are passed over the head and placed on the neck. The right hand, which may be steadied by its holding the fore- 
lock or by the fore-arm resting on the upper part of the neck (Fig. II4), takes the crown-piece and holds it in front

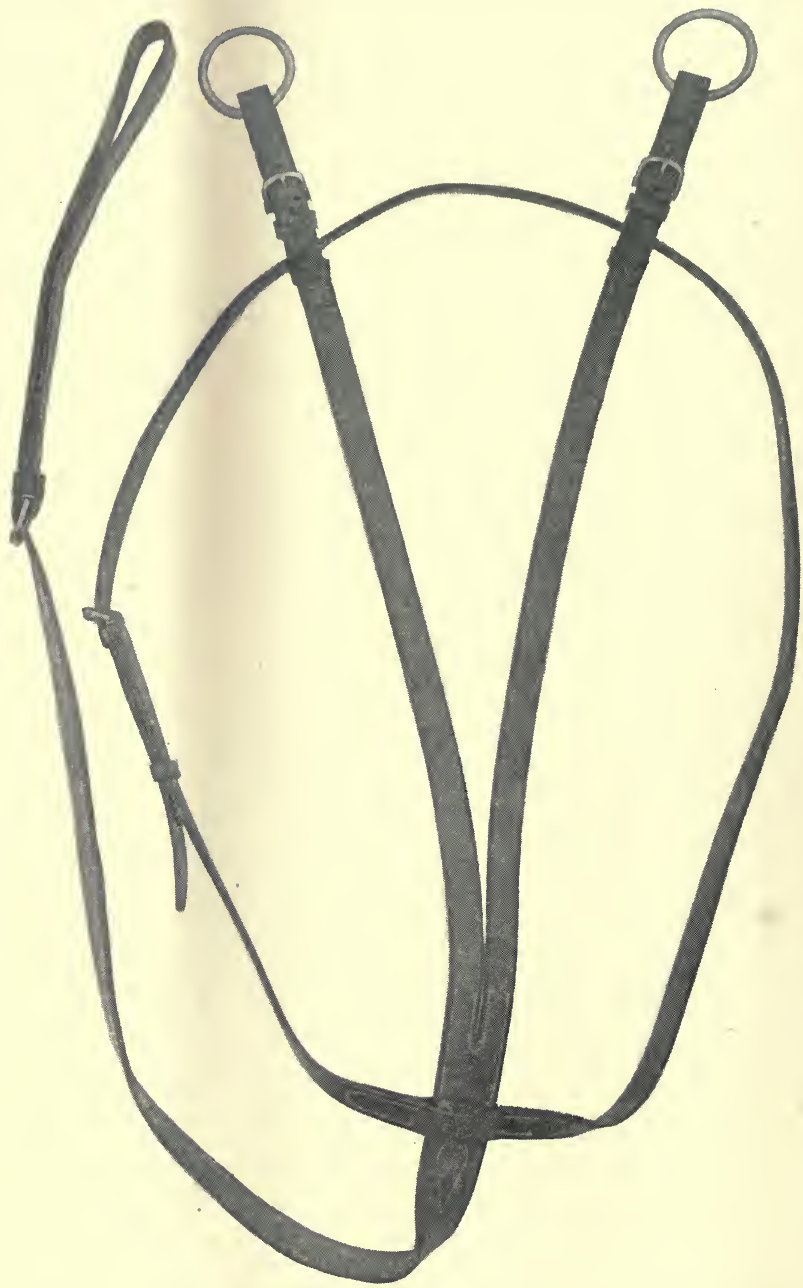

Fig. 112. Running Martingale improvised by means of a Branched Standing Martingale and two rings.

of the face, while the left hand places the bit in the mouth. The crown-piece is put over the ears, the 
throat-latch is buckled, and the curb-chain taken up, if a curb is used.

Before putting on a double bridle, the bridoon should be placed over the mouth-piece of the curb.

\section{ADJUSTMENT OF BRIDLE.}

The snaffle should be put low enough in the mouth to avoid wrinkling its corners.

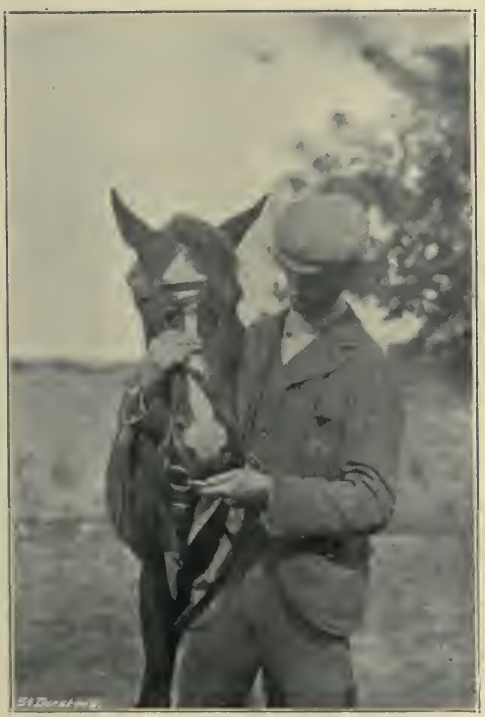

Fig. Ir3. Bridling a Horse.

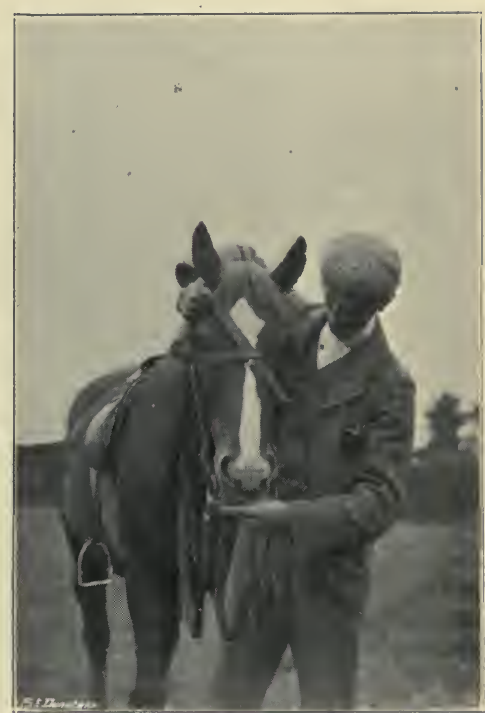

Fig. Ir4. Bridling a Horse.

The mouth-piece of the curb, as directed by Colonel Greenwood in his excellent book, Hints on Horsemanship, should be placed so that it may be just clear of the tushes of the horse or gelding, or about one inch above the corner nippers of the mare; in fact, as low as possible without involving the danger of the curb-chain slipping over the animal's chin. When the curb is in this position, the curb-chain will have little tendency to work up on to the sharp edges of. 
the lower jaw ; and the downward pull on the head-stall will be got rid of as much as the nature of the bit will allow. Also, we may see from Fig. I 5 that the lower the mouthpiece is placed, the broader will be the bearing surfaces of the lower jaw (from the back teeth to the tushes); and consequently, the less liable will the pressure of the mouth-piece be to hurt the horse. I am aware that when placed as I have described, the curb, when its reins are slack, will appear to unaccustomed eyes to be placed too low down. But when the reins are drawn tight, the veriest novice will appreciate the correctness of this adjustment. By adopting this method

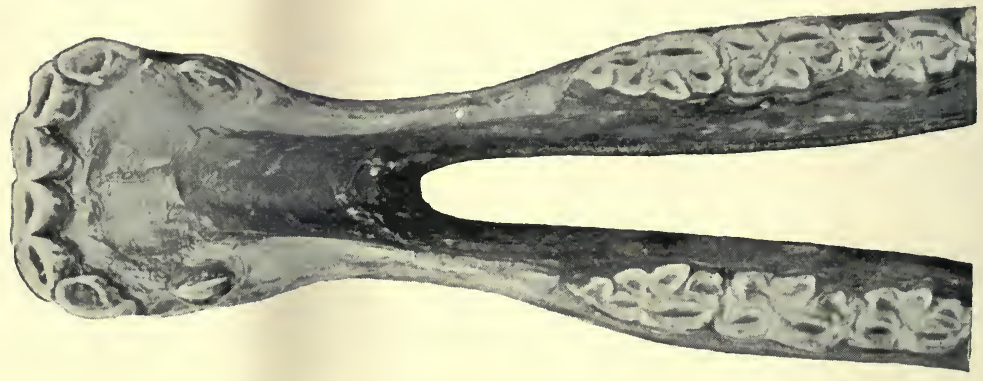

Fig. II5. View of upper surface ot the bones of the lower jaw which form the bearing surfaces of the mouth-piece of the bit.

of arranging the curb, I have succeeded in scores of cases, as if by magic, in obtaining ready control over horses which had previously been all but unmanageable with even the severest curb in their mouths. I am deeply indebted to Colonel Greenwood for this very "straight tip." In the Cavalry, the mouthpiece of the curb is placed an inch higher than what Colonel Greenwood advises.

The curb-chain should pass outside the snaffle (Fig. II6), and should lie flat in the chin-groove, with a certain amount of play, say, up to about $45^{\circ}$ (as in Fig. 95) with the direction of the cheek-pieces of the head-stall. If too much play be given, the inechanical advantage of the curb will of 
course be more or less nullified. If the curb-chain is unnecessarily long, the last links on both sides should be first of all attached to their respective curb-chain hooks, and then the slack portion should be taken up in equal lengths on both hooks, so that the ring through which the

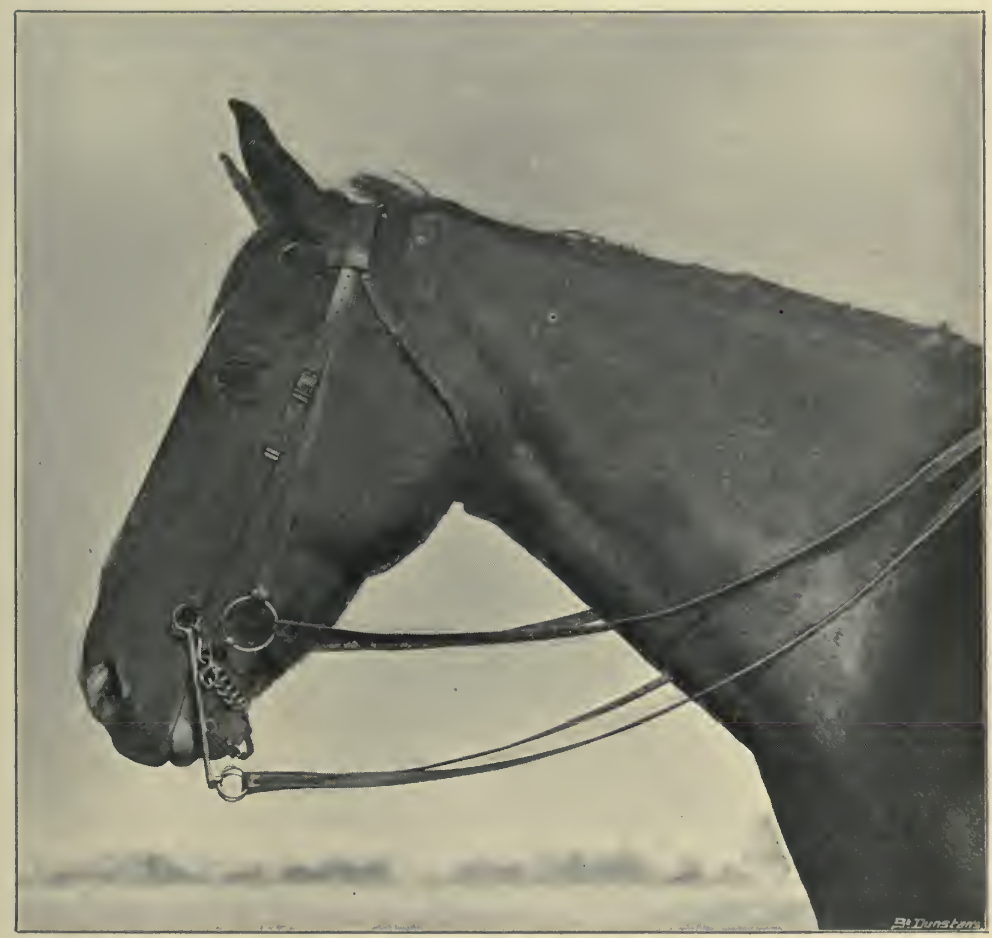

Fig. 116. Correct position of Bit and Bridoon.

chin-strap passes, may be equally distant from each of them (in other words, that it may lie in the middle line of the chingroove), and that the shape of the curb-chain may be the same on both sides of that part of the jaw against which it presses. As Colonel Alderson points out in his interesting book, Pink and Scarlet, care should be taken in hooking up 
the curb-chain, to make the link which goes on the curb-hook, lie flat (Fig. 99) against the animal's jaw, so that it may not hurt the lip.

The throat-latch should be put on loosely, but not so loose as dealers generally have it. If buckled tightly, it will not only incommode the horse's breathing, but will also, as pointed out by "Harry Hieover," spoil the look of the animal's head.

If a nose-band is employed merely for show, it should be moderately loose, as it will then look best; but if for use, it should be drawn tighter. It may then be placed high enough so as not to press against the horse's nostrils, and sufficiently low to close the mouth, for which object it is more effective when low down than when high up; because in the former position, its pressure acts to greater mechanical advantage against the muscles which separate the jaws than in the latter position. As a horse breathes through his nostrils, the fact of his mouth being kept closed does not affect his respiration. The presence of a tight nose-band may make a horse pull from irritation.

The adjustment of martingales has already been described.

\section{CHOICE OF A BIT.}

The fashion which dictates the use of the double bridle for hunting in Leicestershire, is well founded; for that head-gear allows the utmost variety of legitimate feeling on the horse's mouth. Leicestershire men affect the double bridle so much that very few of them would buy a horse shown to them only in a snaffle, no matter how steadily and well he might perform in it. With a double bridle we may ride on the snaffle as much as we like, and keep the curb for emergencies; although, from not knowing how to hold the reins properly, men frequently get into the habit of always riding on both reins, 
and then they blame the double bridle for being too severe. In such a case, if the rider desires to preserve appearances by retaining the double bridle, he can diminish its severity by slackening out the curb-chain, or by even removing it. "When my friends have come to me concerning their unmanageable horse, I invariably find the poor animal has been overbitted, or wrongly bitted, and recommend the easiest kind of bit, which, in nine cases out of ten, succeeds" (Latchford). The usual faults in the construction and adjustment of curbs, are that the upper ends of the cheeks are too long, and that the mouth-piece is placed too high in the mouth. The former fault can be obviated by the use of a properly made curb; and the latter, by intelligent attention to the bitting before mounting.

The curb is especially useful for a horse that "sprawls about" and requires a good deal of collecting when going through heavy ground or over ridge and furrow, or when the animal is tired; for, from the peculiar action of the curb, he will, with it, far more readily bend his neck, and consequently arch his loins and get his hind quarters under him, than he would do with a snaffle. Hence, a curb is indispensable with many horses for crossing an English hunting country in good style. We must also remember that out hunting, and with large fields, like what we see with the Quorn and Pytchley, the ability to obtain instant control over one's mount, even in the midst of exciting surroundings, is essential for the safety of oneself, one's horse, and one's companions, and for avoiding interference with sport.

When riding in an open and comparatively hard and level country, such as we may find in many places abroad, a snaffle may do as well as a double bridle. I have known some horses whose mouths had evidently been spoiled by injudicious, if not cruel treatment, that would go quietly only in a snaffle. The difficulty often experienced in collecting a horse which is 
ridden in a snaffle and which has not his head kept down by a standing martingale, generally arises, as far as I can judge, from the animal poking his head out or carrying it in the air, and thus getting the pressure of the mouth-piece on the corners of the mouth, in which case, the indication given by the pull of the reins, will be to slacken speed, rather than to bend the neck. As I have already indicated, a thick, smooth, unjointed snaffle, with cheeks solidly connected to the mouth - piece (Fig. II7), is the best of its kind for all ordinary work.

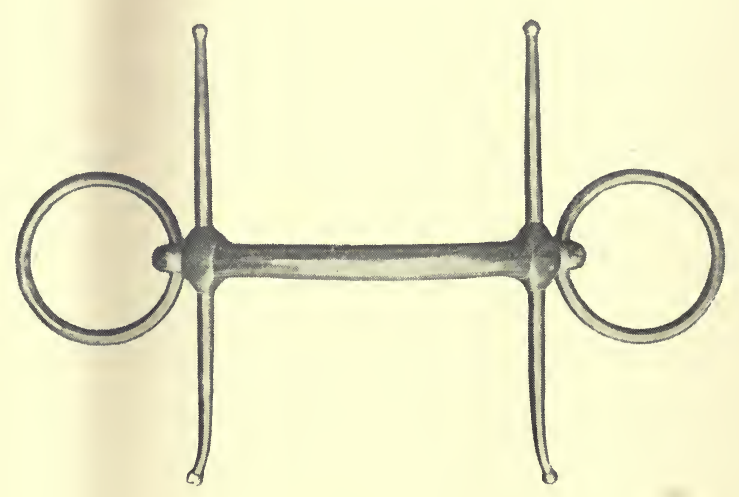

Fig. 117. Half-moon snaffle with cheeks solidly connected to the mouth-piece. 


\section{CHAPTER V.}

\section{SADDLERY.}

Varieties of Saddles-Description of a Saddle-Weight-bearing surfaces of a horse's back and loins-Saddle trees-Webs of a saddle- "Bellies" on the seat of a saddle-"Back" and gullet lining-Covering of saddlesPanels-Self-fitting military saddle-Nolan's saddle-Australian buck-jumping saddle-Measuring a horse for a saddle-Stirrup leathers-Stirrup ironsSafety bars and safety stirrups-Girths-Saddle cloths-Breast plates-Cruppers-Surcingles-Position of a saddle on a horse-Saddling a horse.

\section{VARIETIES OF SADDLES.}

THE chief kinds of saddles are: hunting (Fig. I I8), military

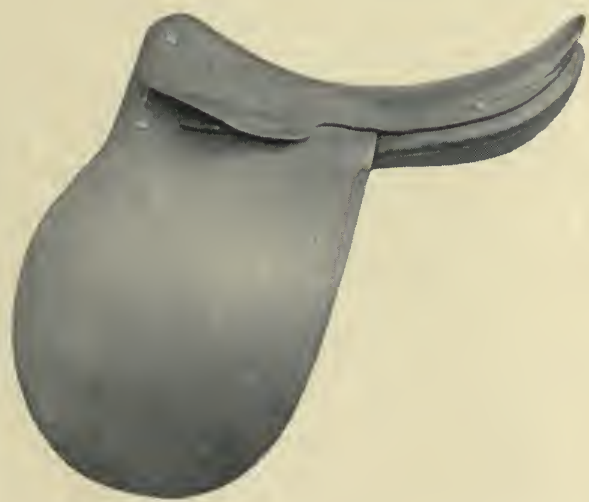

Fig. I18. Hunting Saddle with a nearly Straight Head.

(Fig. I 19), racing (Fig. I20), steeplechasing, and buck-jumping (Fig. I 2 I) saddles.

\section{DESCRIPTION OF A SADDLE.}

A saddle consists of a wooden framework or tree, which is. 
strengthened with steel or iron; webs stretched over this framework; a covering of leather; and a peculiarly shaped cushion or panel, which serves to protect the animal's back from injurious pressure by the tree. As accessories to the

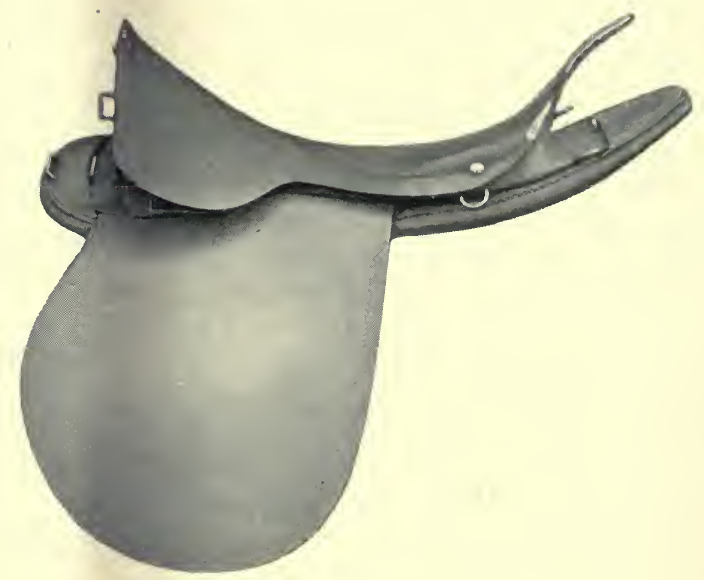

Fig. I r9. Military Saddle.

saddle, we have one or two girths, which are attached to the saddle, and which keep it in position on the horse's back;

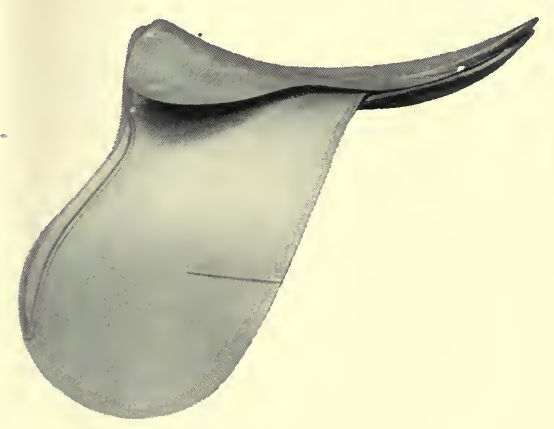

Fig. 120. Racing Saddle.

stirrup leathers, which may be of leather or webbing, and which are connected to the saddle by the spring bars that are fixed to the bars of the tree; stirrup irons, which hang 
from the leathers; a breast-plate, which is attached to the saddle, and which helps, if necessary, to prevent it from working backwards; a surcingle, which goes round the saddle and

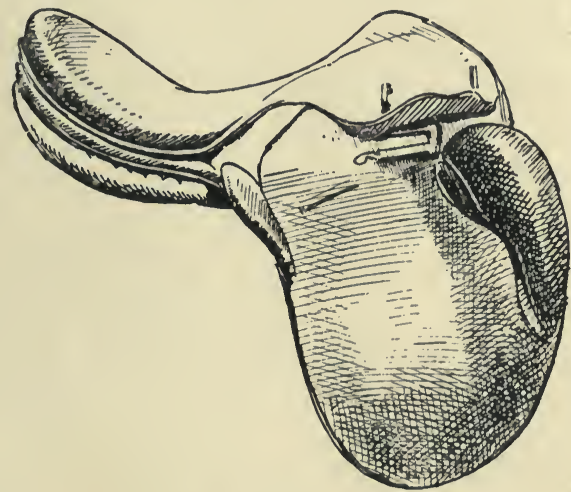

Fig. I2r. Buckjumping Saddle.

the horse, and which aids the girth or girths in keeping the saddle in its place; and, on rare occasions, a crupper,

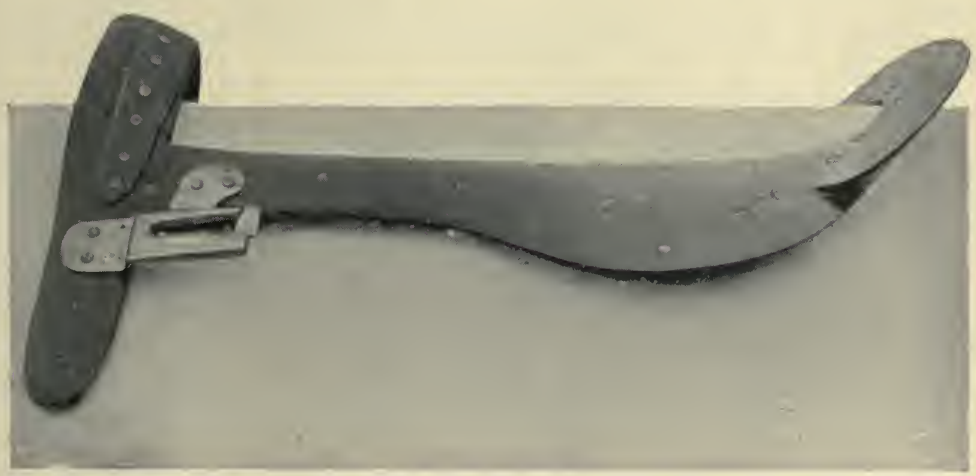

Fig. I22. Tree of Hunting Saddle.

which is intended to prevent the saddle from shifting forward.

The tree (Figs. 122 and 123) consists of two bars, a 
pommel (called a "head" by saddlers) or front part, and a cantle or rear part. The bars are connected in front by the pommel, and in rear by the cantle. The broad rear portions of the bars over which the pelvis of the rider rests, are termed the bellies of the tree. The gullet is the channel which runs down the centre of the under surface of a

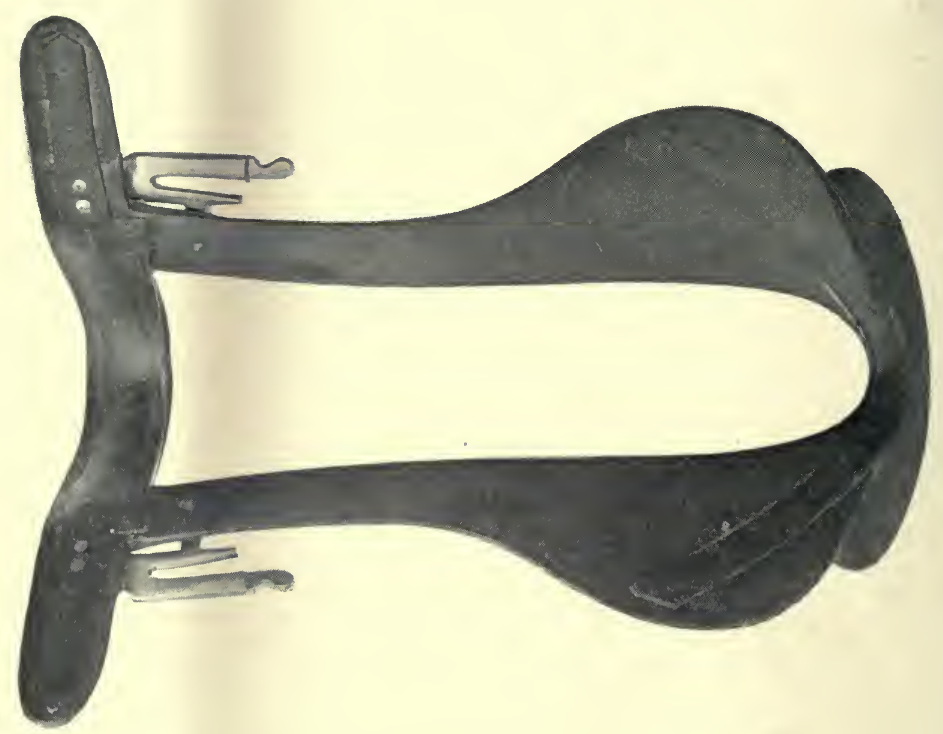

Fig. 123. View of under surface of Saddle Tree, Fig. I22.

saddle, from pommel to cantle. The gullet plate is the metal (preferably, steel) arch under the pommel, and the points of the tree are the wooden continuations of the gullet plate.

In order to strengthen the tree, steel plates, called "bar plates" in the trade, are often rivetted to its under surface (Fig. I24). The cantle plate, which is the nearly semi-circular plate at the cantle, is a necessity in all saddles. The cantle plate, shown in Fig. I26, gives solid attachment to a ring for a crupper. 
The seat is that portion of a saddle which the rider sits. upon, and which is covered with leather. The twist or waist is the narrowest part of the seat, and is about midway between the pommel and the cantle. The flaps of the saddle are the leather side-pieces against which the knees of the rider rest. Knee-rolls or knee-pads are placed on the flaps to help in preventing the knees of the rider going unduly forward. They are either built up between the two thick-

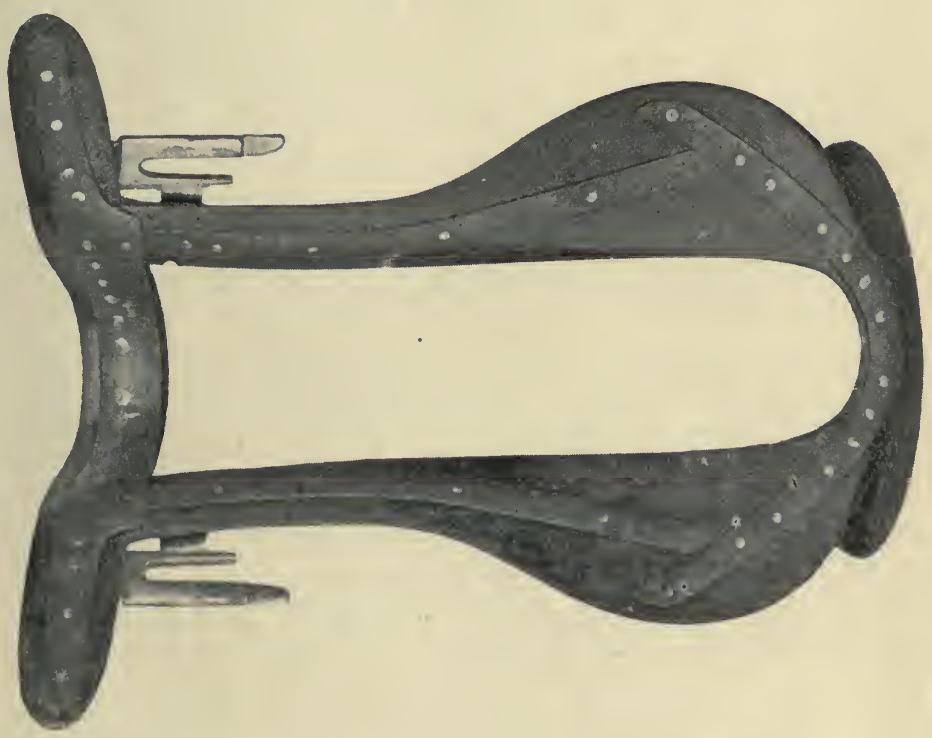

Fig. 124. View of under surface of Saddle Tree, with Bar Plates.

nesses of leather which compose the flaps used for this purpose, or are separately sewn on to their respective flaps, which in that case are of a single thickness. The skirts are the leather surfaces that cover the bars on which the stirrup leathers are suspended. The sweat flaps are the pieces of leather which are placed under the girth straps on each side to prevent sweat working through, and also to prevent the buckles of the girths from hurting the horse. The point pockets are the 
small recesses in which the ends of the points of the tree rest. $D s$ are small semicircular metal rings which are attached by chapes (short straps) to the front and back of the saddle for strapping on a coat, shoe-case, etc. Staples are somewhat similar in size and shape to Ds, but are firmly fixed to the front of the tree, and are used to afford attachment for the breast-plate.

\section{IVEIGHT-BEARING SURFACES OF A HORSE'S BACK}

AND LOINS.

If we examine a horse's skeleton, we shall find that his spinal column is composed of a large number of short bones called vertebra. There are seven vertebræ of the neck, eighteen of the back, six of the loins, five of the croup, and from thirteen to twenty of the tail. In the middle of each vertebra there is a more or less upright bony projection (spine), which is only thinly protected from injury by skin and ligaments. At the withers, these projections or spines attain their greatest length. On each side there are eighteen ribs attached, above, to the eighteen vertebræ of the back, and below, to the breast-bone; thus forming a strong case or barrel, which is capable of offering considerable resistance to pressure applied to its upper surface. The last few ribs have a decided slope to the rear; in fact, in a wellribbed-up horse, the end of the last rib would come within three or four inches of the point of the hip. The vertebræ of the loins have long side projections of bone (transverse processes) but no ribs. Consequently the loins are not as well fitted to bear weight as the back. The space on each side of the back and loins is occupied by a large mass of muscle. The rearmost portion of the shoulder-blade lies immediately below the withers, and is covered by a lump of muscle which is known to saddlers as the "saddle muscle." During movement, the top of the shoulder-blade rotates back- 
wards when the fore leg of the same side is advanced, and rotates forwards when it is drawn back. Bone, as we all know, is very sensitive to pressure, and soon becomes inflamed if subjected to its influence for any considerable time. Hence, the saddle should be kept clear of the withers, the shoulder-blade, and the middle line of the back and loins. Muscle and skin are much less sensitive to pressure than bone, and consequently we find that the muscles on each side of the back and loins are capable of bearing with comparative impunity the pressure of the saddle, provided that it is evenly distributed by a soft medium, such as a well-stuffed panel, and that it is not continued too long. Pressure on or close to the rearmost point of the shoulderblade, would not only be liable to set up inflammation, but would also injuriously interfere with the movements of the fore legs.

Although the loins, owing to the fact of their being unprovided with ribs, are much less able to bear weight than the back; we find that they suffer no injury from taking a share of the pressure of a saddle containing a rider, provided, of course, that ordinary precautions are observed. No doubt this ability on the part of the loins to bear pressure is due in a great measure to the fact of the back ribs sloping to the rear, and thereby taking a portion of the weight which would otherwise fall on the transverse processes of the vertebræ of the loins. This comparative immunity possessed by the muscles of the loins to bear pressure, is well illustrated by the use of a properly made and properly stuffed side-saddle, the bearing surface of which always extends, in a backward direction, beyond the last vertebra of the back. For practical purposes we might assume the length of the weightbearing surfaces of the back and loins to be about 22 or 23 inches. Their width will, however, vary a good deal according to the shape of the particular animal. We may approxi- 
mately regard the weight-bearing surfaces of the back and loins as the parts pressed upon, when a properly fitted hunting saddle-tree is placed on a horse. We find from experience that with a full-sized animal, a space of not less than $3 \mathrm{r} / 2$ inches in width, down the centre of the back, should be left free from pressure. We may therefore take this as a minimum width between the bars of a saddle-tree intended for hard work.

\section{SADDLE TREES.}

The trade of saddle-tree making is entirely separate from that of the saddler, whose business is to construct saddles from materials furnished to him by the tree maker, tanner, saddlers' ironmonger, hair and wool merchant, and other tradesmen.

In the selection or ordering of a tree, the following are the chief points which have to be considered:-

I. The tree must be sufficiently long:-As the reduction in the length of a saddle will be accompanied by a saving of only a pound or two, no useful end under ordinary conditions will be gained by having a saddle much shorter than a length which will correspond to that of the weight-bearing surface of the back. Any marked diminution in the legitimate length of a saddle is objectionable, on account of its curtailing the surface over which the weight of the rider should be distributed, and also by its tendency to give horses sore backs. I have pointed out in Veterinary Notes for Horse Owners that "the use of too short a saddle is not an uncommon cause of sore back, just behind the cantle, upon which spot an undue proportion of the weight is liable to be thrown in such cases. With a saddle of this kind, if a horse is made to go fast or jump, the skin immediately behind the cantle being pressed downwards and backwards, will become forcibly wrinkled at each stride the animal takes; 
the usual result being that inflammation is set up, and a tumour appears. A repetition or two of this process increases the evil; pus is formed; and the horse may be laid up for a month or more with an abscess, which is called a 'sitfast' when it occurs in the position mentioned, and when it assumes a chronic form; it being either a sac of soft matter, or an unhealthy sore with a hard margin of skin round it. I have seen so many cases of these injuries having been produced by the saddles in question, even after the stuffing had been altered several times, that I am confident I am right in saying that saddle galls behind the cantle are more often caused by the shortness of the tree, than by the cantle touching the back. We should bear in mind that the correct length of the tree depends principally on the length of the thighs of the horseman. The tendency to such an injury is naturally increased by the unworkmanlike practice some riders affect of sitting far back in the saddle, and of sticking their toes out in front of the horse's shoulders; the consequence being that the weight is thrown on the cantle at each stride, instead of on the centre of the saddle."

An average length for the tree of a hunting saddle with a "straight head" (Figs. 122 and I20) would be about $181 / 2$ inches, measured down the centre from pommel to cantle. This length is about an inch longer than that of the bars, which is unaffected by the shape of the head.

2. The tree should be sufficiently wide, not only to distribute the weight, but also to afford comfort to the rider. Hence we find that the width of a tree measured across the broadest part of the seat, will vary from about IOI $/ 2$ to I4 inches. It is evident that the broader a man is "in the beam," the wider must the bellies of the tree be.

3. The weight bearing surfaces of the under part of the tree should accurately correspond with those of the back, with respect to shape. Not only should the top of the 
withers (like other parts of the spinal column) be free from pressure; but no pressure should be put near that part by any portion of the gullet plate at any point higher than the bars of the tree, neglect of which precaution is not unfrequently the cause of inflamed withers, The necessity for accurate fitting of the bars is self evident. We now come to a subject of compromise between comfort for the rider, and comfort for the horse.

We all know that the smaller a saddle is in the twist, the better will be the grip, on account of the greater facility

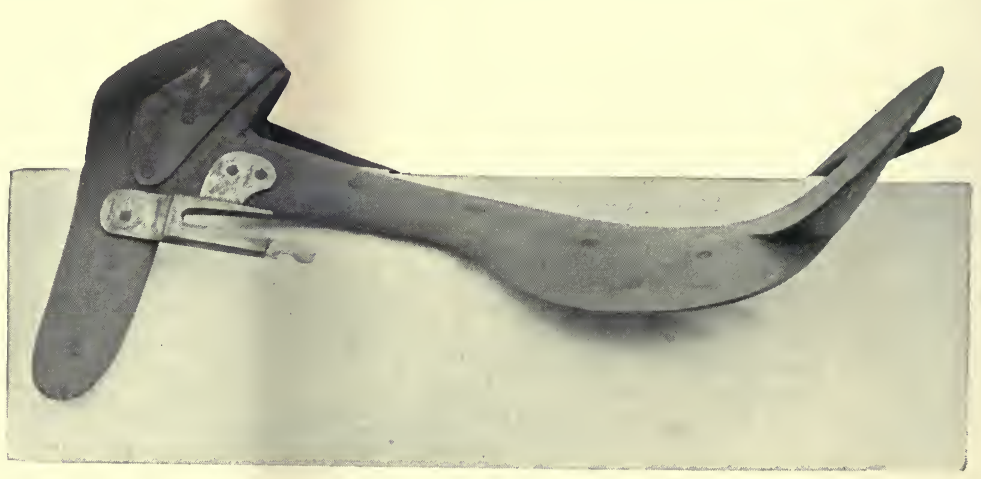

Fig. 125. Saddle Tree with narrow twist and a good deal of dip in seat.

the rider will have in getting down into the saddle and closing his thighs. At the same time, we must remember that a narrow twist can be obtained only by dangerously reducing the distance which the bars are placed apart from each other, so that they may not exert painful pressure on the back-bone, or on the sensitive structures close to it. It is evident that the necessity for taking precautions against such injurious pressure is proportionate to the length of time the rider will be on the animal's back; the weight the horse will have to carry; and the amount of shifting and concussion produced by the weight on the 
saddle. Hence, however suitable a saddle with a narrow twist (Figs. I 25 and I 26), may be for steeple-chasing, roughriding, or hacking, it is out of place in the hunting field. Figs. I 22, I 23, I 25 and 126 will show the difference between the two kinds of saddles.

A heavy-weight rider will require a heavier saddle than a lighter man, not because he needs a saddle with a larger

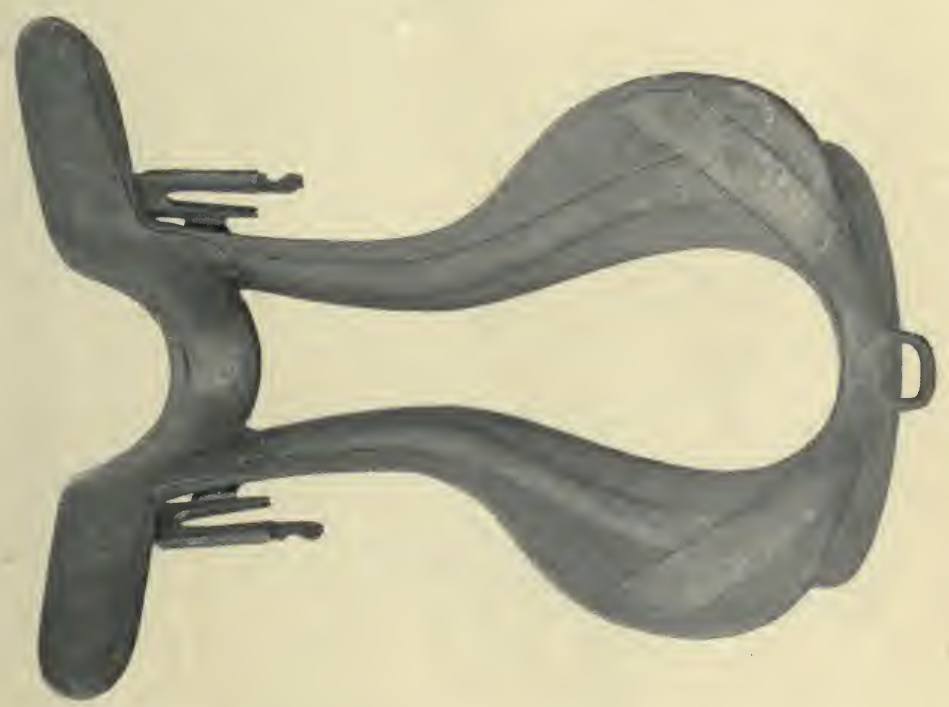

Fig. 126. View of under surface of Saddle Tree, Fig. I25.

weight-bearing surface, but because his saddle should have greater strength in the material of its tree, so that it may not bend or "give" under the weight, and thus cause it to be unequally distributed on the weight-bearing surfaces of the back. We should bear in mind that these surfaces are but little subject to change of shape during movement, and consequently the tree should be rigid in proportion to the weight it has to carry. Any "spring" which the saddle may have, apart from the panel, should be derived almost entirely from the webs (p. 122). In steeple-chasing and flat race riding, 
we have frequent cases of saddles opening out at the gullet plate and breaking at the bars and points of the trees from excessive pressure and shock. A weight of one pound in the saddle for every stone the rider weighs, is a fair allowance. We may take Io lbs. as a minimum weight for a hunting saddle, complete with girths, leathers; and irons; and 14 lbs. as an ordinary weight. If the gullet plate of a hunting saddle,

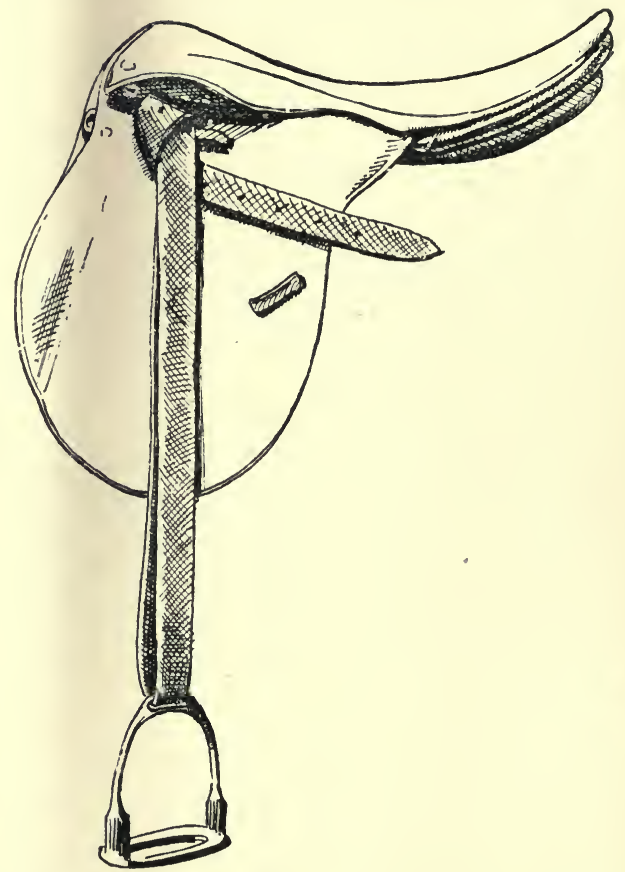

Fig. 127. Hunting Saddle with half Cut back Head and Knee-rolls.

under fair usage, opens out (thereby causing the points of the tree to become separated from the sides of the horse, and the arch of the pommel to come down upon or to approach the withers), we may rest assured that the saddle is at fault. But with racing saddles, which are made within very narrow limits of weight, it is almost impossible to have the gullet plate strong enough to preserve its original form under severe 
work, for a prolonged period. It not unfrequently happens that a very light saddle (say, one between 2 and $3 \mathrm{lbs}$. weight) lasts for only one steeple chase. A saddle is practically useless after it has opened out at the gullet; for the original form cannot be restored, so as to stand work, without the saddle being taken to pieces.

Many prefer a saddle with a cut-back head (Fig. 125) to one with a straight head (Fig. I22). The idea of the

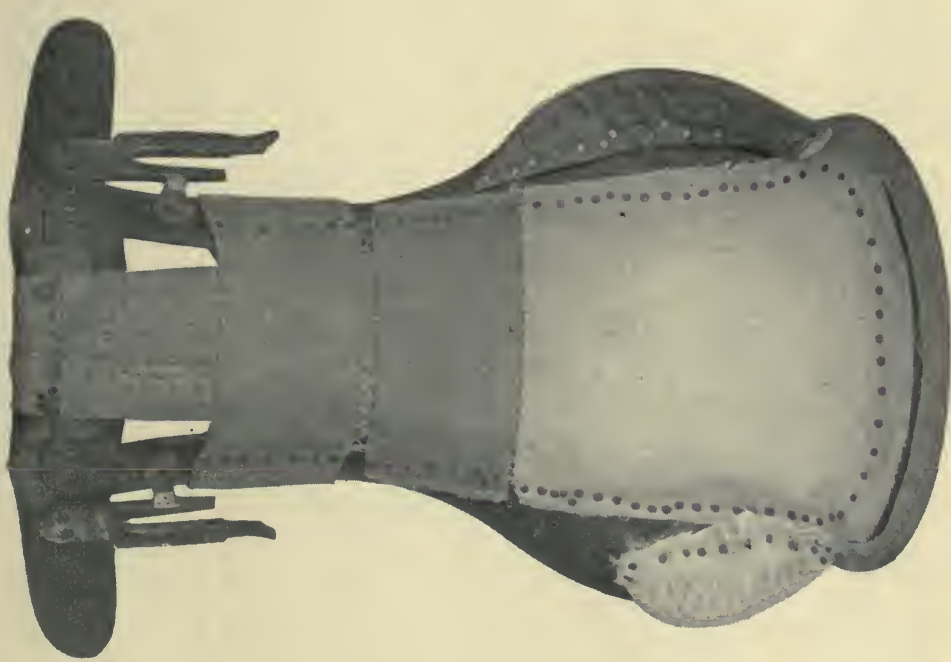

Fig. 128. Upper surface of Tree, with Webs.

former looking better than the latter is entirely a matter of taste. The cut-back head probably gives the horse the appearance of having more sloping shoulders than he would have with a saddle of the other shape; but such an impression is, to my thinking, marred by the suggestion of weakness; for the straight-cut head acts to greater mechanical advantage, and consequently does not require such a heavy tree as the other form. The fact that the head is closer to the rider's fork in a cut-back saddle than in one with 
a straight head, may make the former slightly more dangerous to ride in than the latter. It appears to me that the straight head affords the better fit of the two. The saddle shown in Fig. I27, has, what is called by saddlers, a half cut-back head; and that in Fig. I I8, a quarter cut-back head.

\section{WEBS OF A SADDLE.}

The webs of a saddle consist of strong hempen bands which

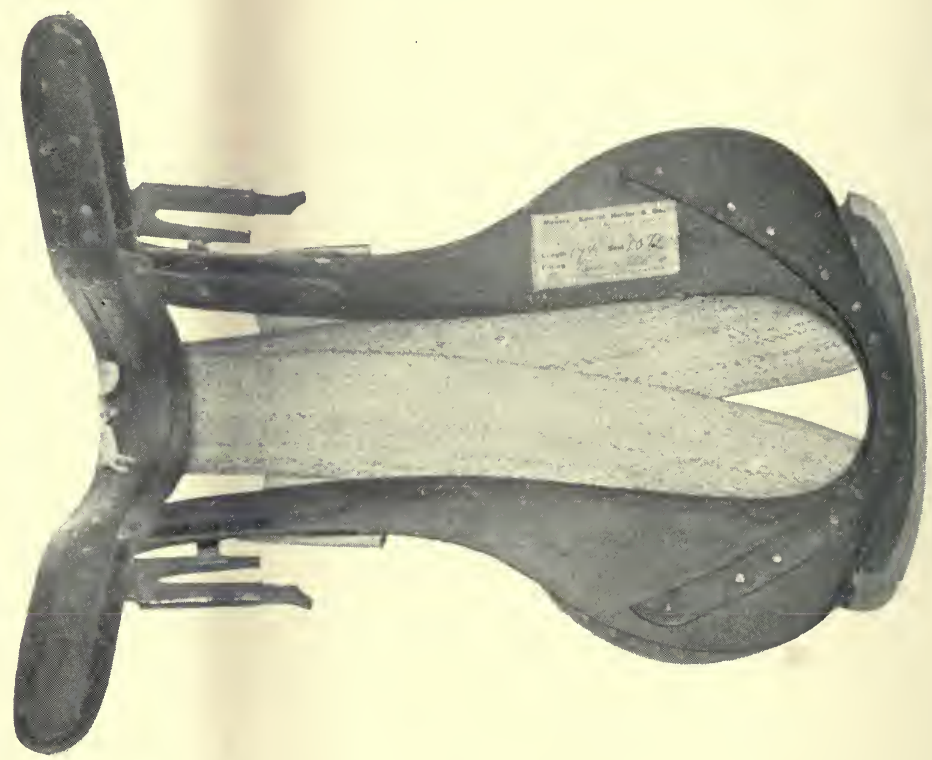

Fig. 129. Under surface of 'Tree, with Webs.

are about three inches broad, and are carefully stretched under severe tension before they are put on, so that they may not afterwards "give." In the tree shown in Figs. I 28 and I29, two webs extend from head to cantle, to both of which parts they are securely nailed. In Fig. I28, we see that two cross webs are placed near the twist of the tree, and that a piece of canvas fills up the open space between the bellies of the tree.

The object of the webs is to afford the rider a comfortable 
seat with a nice spring in it, and to keep that portion of the horse's back which lies between the bars, free from pressure. If the webs are not sufficiently strained, they will, instead of carrying the rider's weight, allow his thighs to disagreeably bear on the bars. If, on the other hand, the webs are too tightly strained, the tree may become bent, with the result that it will present a convex, instead of a more or less level surface to the back. When a saddle is thus "cast" - to use the trade expression - the bearing surface which it offers to the animal's back, will become proportionately diminished in extent, and consequently it will be more or less liable to give a horse a sore back; although it may afford the rider a very comfortable seat. In this respect, the convenience of a horse is, as a rule, of much more importance to the animal's proprietor, than his own sitting at ease; because its neglect may put the animal out of work for a long time. We may see that for comfort in a saddle, it is necessary for the cantle to be of a certain height above the centre of the back, so that the webs may give the seat sufficient flexibility, without their being strained too tightly.

\section{“BELlies" ON THE SEAT OF A SADDLE.}

In order to afford the rider a fairly level surface for his "seat," "bellies" (Fig. I28) are placed on the sides of the upper surface of the tree. They project about $3 / 8$ inch beyond the tree, and consequently add about $3 / 4$ inch to the width of the seat. They are built up with hair or wool, and are covered with either leather or serge; the latter for choice. Care should be taken that they do not come too far forward (as on the off-side of Fig. I28); because their position in this case would prevent the rider's thighs getting properly down into the saddle. The correct position is shown on the near-side of that illustration. 


\section{“BACK" AND GULLET LINING.}

In order to obviate, in well-made saddles, the undesirable alternative of having to nail the panel to the tree, leather, which is called the "back," is nailed round the upper surface of the tree, so that it projects a little beyond the tree, and thus furnishes a kind of welt to which the panel can be sewn. The old and very objectionable method of driving nails through the panel into the tree was a frequent cause

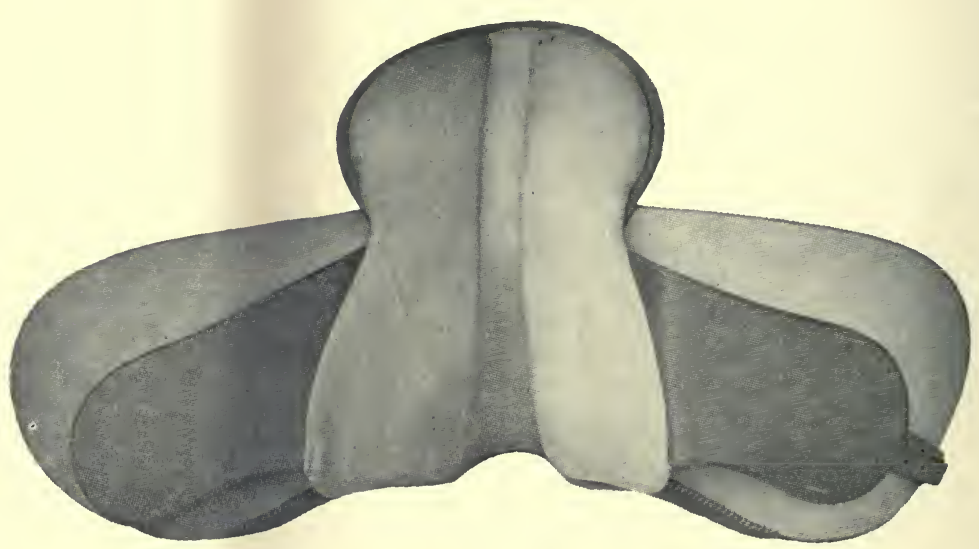

Fig. 130. Saddle with Short Panel and open Gullet.

of sore backs, on account of the nails hurting that part. One nail, placed in the centre line and just under the cantle, must be retained. When a saddle has an "open gullet," as in Fig. I30, this open space down the centre of the saddle, between the bars, on the under surface of the tree, is filled up by a piece of leather (usually basil) nailed to the bars.

COVERING OF SADDLES.

The seats and skirts of good hunting saddles are of pigskin, which is too thin to be used alone for the flaps of these saddles. Plain flaps are almost always made of a single 
thickness of cow-hide which is stamped to resemble pig-skin; and flaps with knee rolls are covered with pig-skin, because cow-hide is not pliable enough to take the shape of the rolls. If pig-skin is employed for the flaps of a hunting saddle, it will require to have underneath it another thickness of leather to which it has to be sewn, in order to give the flap sufficient rigidity. A single thickness of leather for the flaps is certainly the neater arrangement of the two. In well turned out racing saddles, the flaps will generally be of thin cowhide, split to the required thickness; and the knee rolls of pig-skin. Much care is taken in the selection of suitable pigskin for high class saddles; the skins which have fine, regular grain, and sufficient strength being most in request. Imitation pig-skin is never used for the seats of the best saddles. It can be easily detected by the fact that it is deficient of the holes in which the bristles of the pig take their origin in the real hide.

For increasing the grip of the rider, the entire saddle or only its flaps may be covered with doe-skin, which is strong and durable, and answers its purpose well. It is however, expensive, and is more suitable for use in hot climates than in a damp one like England. Imitation doe-skin, made of sheepskin, does not look very unlike its original; but it wears badly. Cow-hide, turned inside out, gives a grip equal to doe-skin; but flaps made of it soon show the wear of the stirrup leathers working backwards and forwards on them.

For comfort in riding, flaps should be cut well forward as in Fig. II8, so as to allow the thighs to be kept at a good slope. Dealers as a rule, like the opposite shape, so as to improve the appearance of the shoulders of their horses, which is a matter of much more importance to them, than comfort in riding.

The question as to the advisability of having flaps with knee-rolls or plain flaps is one which has given rise to much 
discussion. It is evident that the only valid argument which can be advanced in favour of the former as compared to the latter, is that of superiority of grip. Many advocates of plain flaps assert that they can stick on quite as well without kneerolls as with them; but such a statement is merely an expression of opinion, which cannot be accepted as a proof. Some go even so far as to say that knee-rolls on a saddle are a source of danger; because, if a rider in such a saddle, while trying to "remain," happens to become displaced so far forward as to get his knees in front of the rolls, he would have great difficulty in getting them back into position. The reply to this is of course, that had he been shot forward with similar force when in a plain-flap saddle, he would have come off. Instead of imagining supposititious cases and considering individual opinions, we are far more likely to arrive at a true solution of the question by enquiring into the nature of the saddles used by men, who, as a business, ride extremely difficult horses; for instance, Australian rough-riders. These high priests of the art of sticking-on, habitually employ saddles which have enormously large knee-rolls. My friend, Steve Margarett, an Englishman who made a great reputation in the Colonies for his skill in riding buck-jumpers, was one of the few men in Australia capable of doing so in an English hunting saddle, a feat which he and all the other rough-riders regarded as being particularly difficult. Also, the use of kneerolls in steeplechase saddles, even by the finest horsemen, is a point in their favour for the purpose under discussion. On the other hand, although an ordinary plain-flap hunting saddle may not afford sufficient "gum" for the riding of buckjumpers by men who have not practically studied that art, it is amply sufficient for every useful requirement of good riders in the hunting field. If the owner wishes to obtain extra security from falling out of such a saddle, he may have some stuffing put into the panel just in front of the spot where the 
knees come. He should get the flaps, which should in this case be thin, made pliable with a little kidney fat or saddle dressing after they have been damped with water, and he will then find that after he has ridden a few times in the saddle thus prepared, there will be a comfortable recess formed in each flap for the knees. Knee-rolls have been objected to on the ground that their employment is apt to cause sprains of the leg and back, especially on landing over a drop-jump; but such occurrences are so rare that they may be disregarded. Apart from the fact that plain-flap saddles are more fashionable, I like them for hunting and all ordinary work better than those with knee-rolls; because they last longer, are somewhat cheaper, show off a horse's fore-hand better, and give all the grip needed by a man who can ride. If a man has any doubt about his ability to remain, he should of course cast aside all sentimental ideas as to the appearance of himself or of his horse, and choose the saddle in which he feels most secure. As a great rule, an indifferent rider will perform better in a saddle with knee-rolls, than in a plain-flap one; because he will almost always turn out his toes under provocation, and by doing so, he will remove his knees from the flaps of the saddle, in which case, the knee-rolls would be of far more help to him than the recesses in the plain flaps. In a light racing or chasing saddle, no recesses would be formed, and consequently knee-rolls are of service.

\section{PANELS.}

The legitimate object of a panel is to prevent the bars of the saddle from hurting the horse's back by reason of their hardness. In all cases the presence of the panel has the disadvantage that it removes, to a greater or less extent, the seat of the rider from the back of the animal, and thus diminishes the close connection which should exist between the two. Hence, the fitting of the saddle should be accom- 
plished chiefly by the bars accurately conforming to the shape of the weight-bearing surface of the back, and not by an inordinate amount of stuffing in the panel. It is evident that if the bars do not fit the back, a proportionately large quantity of stuffing will be needed to afford an even bearing.

There are two kinds of panels, namely, the ordinary panel,
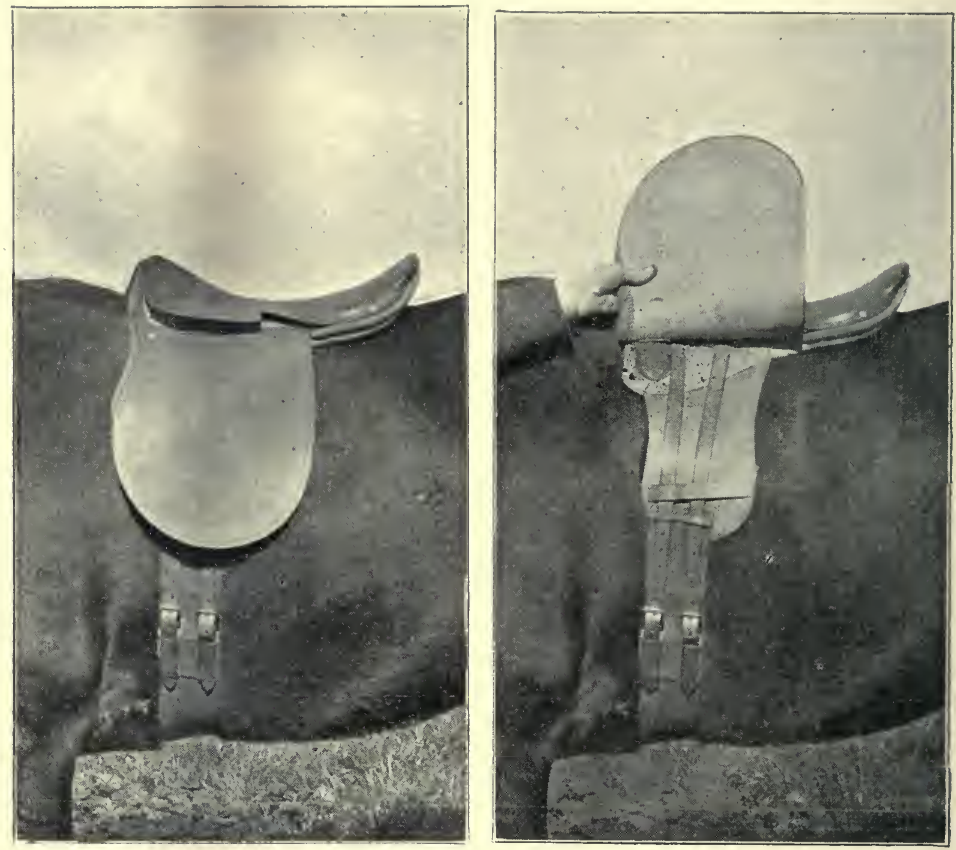

Fig. 131.

Lord Lonsdale's System of Girthing.

Fig. 132.

and the short (or half) panel. The former extends down nearly as low as the bottom of the flaps. The latter (Figs. I 3 I and I32) stops short a little below the points of the trees, and slopes upwards and backwards towards the seat.

The advantages of the short panel are that it is the lighter of the two, owing to less material being required in its construction, and that it allows the rider's legs to get 
closer to the horse's sides than they would do with a full-sized panel. Its disadvantage is that with it, the sweat flap is the only protection which the animal's ribs have against possibly painful pressure by means of the buckles of the girths; but this drawback can be easily obviated by increasing the thickness of the sweat flap. To remove these girths out of the undesirable position which they usually occupy underneath the flaps, Lord Lonsdale has introduced the method of employing a short broad girth and particularly long girth straps (Figs. I 3 I and I32), so that the buckles will come below the swell of the animal's chest, and consequently will not interfere with the rider's legs, which they are always more or less liable to do, when high up. The only objection to Lord Lonsdale's plan is that the appearance of the buckles below the flaps of the saddle, is apt to be unsightly to unaccustomed eyes. The fact that the buckles in this method of girthing are free from the pressure of the legs, appears to entirely obviate any chance there might be of their hurting the horse by pressing against his sides, especially when, as with Lord Lonsdale's arrangement, there is a thick broad leather strap between the buckles and the horse's skin.

The "open gullet," or "open channel," (Fig. I30), should be used with all saddles, because it helps to keep the centre line of the back cool.

The chief materials employed for stuffing panels are: curled horse hair, "flock" of various qualities, and felt. Curled horse hair fulfils every requirement of softness, elasticity and freedom from caking, but it cannot be so easily "regulated" (worked with a seat awl to get it level) in a serge-lined panel as flock, on account of the greater difficulty there is of separating its fibres from each other. It is the best stuffing for leather covered panels, which will be presently considered, and which do not admit of being regulated by 
the awl. Some saddlers consider that if a serge-covered panel is stuffed with horse hair, the ends of the hairs are apt to work through the serge and irritate the horse's back. "Best flock" is made from white all-wool serge cuttings, old government powder bags, and the waste of Whitney blankets. Inferior flock consists of shoddy that generally contains a large percentage of cotton and other vegetable fibres, which are less elastic than hair or wool, especially when exposed to the action of damp. A very fine kind of flock is composed of curled hair, which is about half the thickness of horse hair.

Instances are not unfrequent of horses getting sore backs from incompetent or dishonest saddlers re-stuffing good saddles with inferior flock, which quickly becomes caked, and thus causes unequal pressure.

The possession of a high degree of softness by the panel necessitates the panel being comparatively thick, and is imperative only when the saddle has to be kept on the horse's back for several hours. Also, the thicker the panel, the less close will be the rider's grip. Therefore, although curled horse hair or the best flock is necessary for the stuffing of a saddle required for hunting, campaigning or similar work; felt will do for polo and steeple-chasing, at which sports the saddle bears weight for a much shorter time. It is manifest that the harder the condition and the less jumping there is, the less liable will the back be to suffer.

Generally, the covering of panels is serge, leather or linen. Serge is used for both kinds of panels; and leather, as a rule, only for short ones.

For convenience of discussion under this heading, we may divide panels into absorbent panels and leather covered panels. The chief advantages of the latter are that they remain dry, and require for their preservation only the application of a little grease from time to time. If they are 
stuffed with curled hair, they will keep their shape and elasticity for a long period. Their disadvantages are, that, to be re-stuffed, they require to be taken out of the saddle, and that they are not as comfortable to a horse's back, when he is sweating, as serge-covered panels, which quickly take up any excess of perspiration. The fact that liability to sore back is increased by clipping the hair off that portion of the back which is covered by the saddle, shows that it is an advantage to have an absorbent material between the skin and the panel. The presence of unabsorbed sweat between the back and the panel will naturally make the skin of the part soft and liable to injury, especially during severe and prolonged work.

The advantage which a serge-covered panel derives from its power of absorption, is more or less counterbalanced by the subsequent trouble of drying it, and by the increased weight and loss of elasticity due to the presence of mineral matter being left in the stuffing by the absorption and subsequent evaporation of sweat. It is evident that unless such a panel is carefully dried, after it has been made wet, it will soon become spoiled. Beating the panel with a stick, after it has been well dried, will remove some of the deposited mineral matter, but by no means all of it.

By far the hardest part of an ordinary serge-covered panel to dry, and to keep clean and soft, is its flaps, namely, the portions which are absent in a short panel. Hence, the short panel is the best shape for panels covered with serge-in fact, for all panels.

Slight alterations in the stuffing of a serge-covered panel are easily made by passing the seat awl through the serge; and extensive ones, by making a cut or two in the serge, generally in the middle of the panel, and adding or removing stuffing, the position of which can be altered by means of the seat awl and seat iron. The cuts are afterwards closed 
by stitches. As the edges of a cut in the leather-covering of a panel cannot be easily brought together, without leaving a ridge which might hurt the back, this method of altering the stuffing is not practised with leather-covered panels. In their case, the stuffing can be supplemented by taking out the panel, nailing strips of felt to the under surface of the tree, as may be required, and replacing it.

The respective merits and disadvantages of serge and leather as a lining for saddles, greatly depend, as we have seen, on the particular circumstances of each case. I think serge is

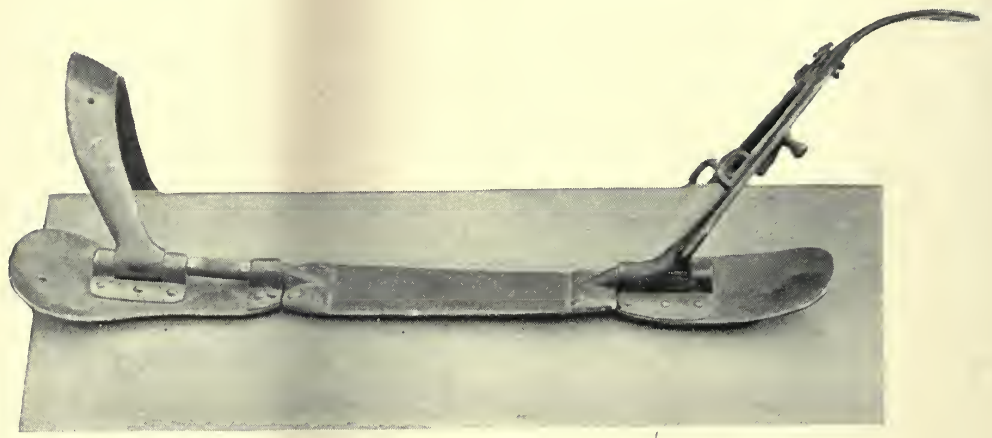

Fig. 133. Side View of Austrian Officer's Jointed Saddle Tree.

the better of the two for a hunting saddle, when the services of a good saddler can be obtained to re-stuff the saddle from time to time, as for instance, before each hunting season.

On account of its smoothness and consequent freedom from friction, linen often acts well as a lining, when the horse's coat has become a good deal worn under the saddle, which is much more apt to take place with side saddles, than with cross saddles. Owing to the closeness of its texture, it does not readily admit of stuffing being regulated.

The facility offered by the open texture of serge for regulating the stuffing, combined with its high power of absorption, is its great recommendation as a lining for saddles. 
SELF-FITTING MILITARY SADDLE.

The Austrian Officers' Jointed Saddle Tree (Figs. I 33, I 34,

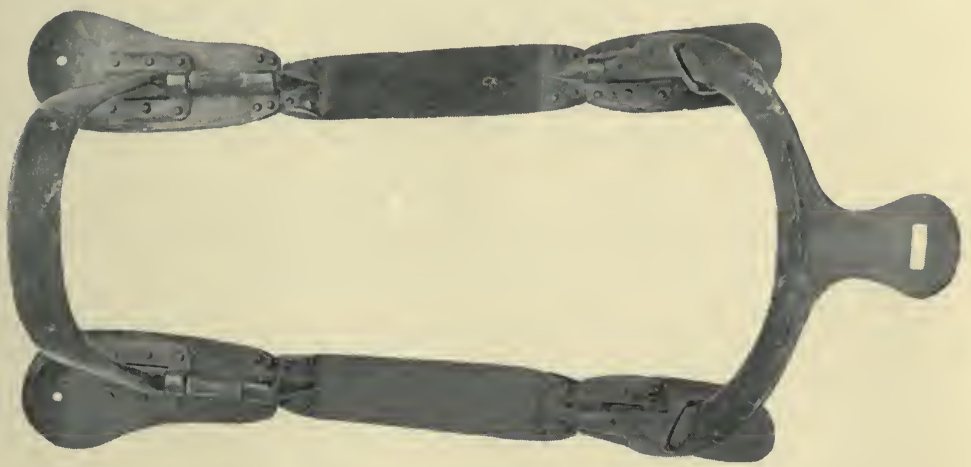

Fig. 134. Plan of Austrian Officer's Jointed Saddle Tree on a Broad-backed Horse.

and I35), is useful for military saddles, because it is to a certain extent self-fitting. It is composed entirely of steel, and the bars are made to revolve on rods which are

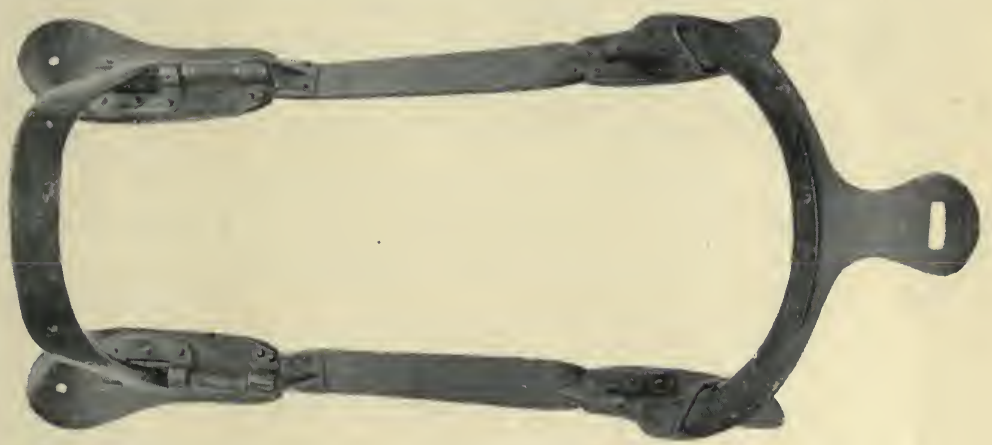

Fig. 135. Plan of Austrian Officer's Jointed Saddle Tree on a Narrow-backed Horse.

placed horizontally in a longitudinal direction. Consequently, the bars assume the slope of the back of the horse upon which they rest, as we may see by comparing Figs. I 34 
and 135 with each other. The fact of the bars being flexible, facilitates the automatic adjustment of the rider's weight. This tree is known in England as the Keith-Fraser saddletree, because the late general of that name introduced it into this country, and made some improvements in it. Its great weight (about $8 \mathrm{lbs}$.), is an objection to its use.

\section{NOLAN'S SADDLE.}

In this saddle, the panel, flaps, girth straps and sweat flaps

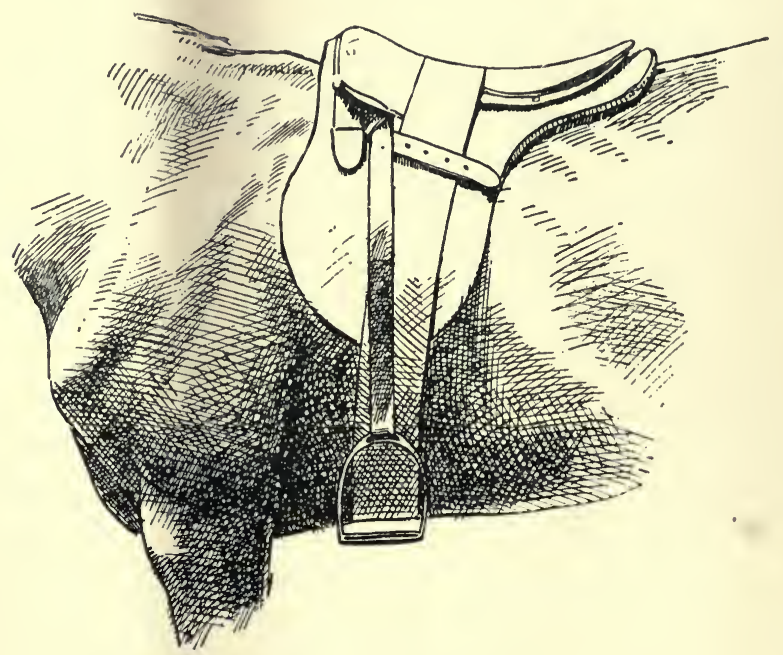

Fig. 136. Nolan's Saddle.

are removed. This stripped tree may be placed on a thick felt saddle-cloth (Fig I36), in which pockets are made for the reception of the points of the tree. A broad surcingle does duty for the girths. This saddle gives a close and secure seat. It was invented by the late Captain Nolan, of Crimean fame, who suggested that it should be used on service, over a blanket, which, after the saddle had been taken off, could be utilised to cover the horse. 


\section{AUSTRALIAN BUCK-JUMPING SADDLE.}

This saddle (Fig. I2I) has a particularly deep dip in the seat, a narrow twist, and has very large knee-rolls, which are about six inches high, and which curve backwards so as to catch the thigh just above the knee (Fig. I37). It is sometimes provided with a "monkey strap," which is used to hold

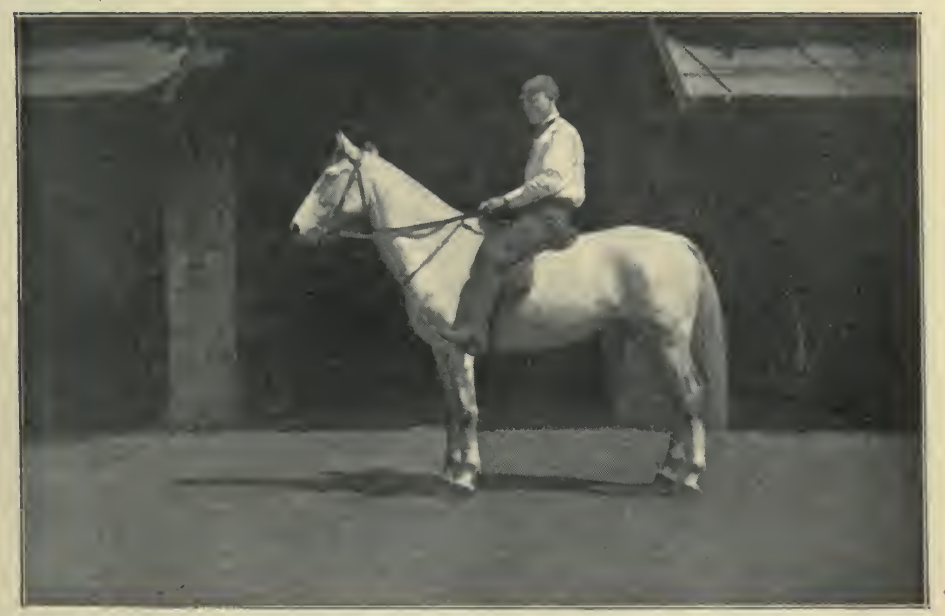

Fig. 137. Rough Rider in Buck-jumping Saddle.

on by; and which was I believe invented by the famous Darcy Highland, of wild-bull-riding renown.

\section{MEASURING A HORSE FOR A SADDLE.}

In order to make a saddle which will correctly fit a particular horse, the following measurements are required :- I. A transverse section of the withers and back at the place where the gullet plate and points of the tree will come. 2. Transverse section of the back underneath the cantle. 3. Contour of the longitudinal portion of the back immediately below the position which the bar of the tree, on each side, will occupy. 
The transverse section at the withers can be taken by the instruments shown in Figs. I38 and 140. The former is made somewhat on the principle of the head gauge used by hatters, and consists of a folding-up case, in which thin pieces of wood can move freely up and down, and can be clamped by screws at the ends of the branches, when the desired position has been obtained. In the latter, screws work in an arched

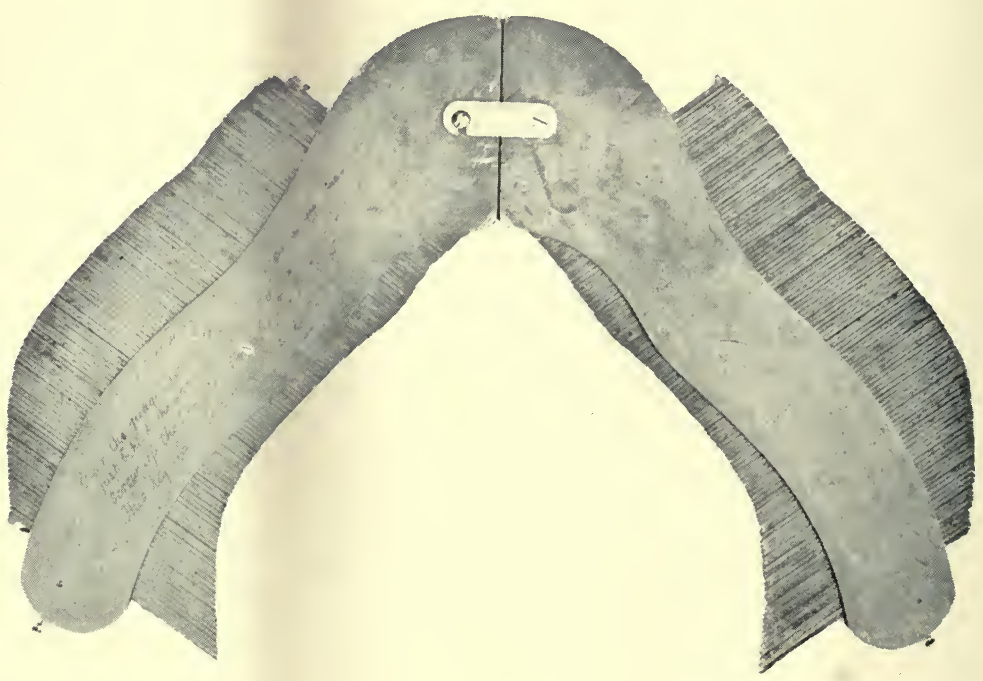

Fig. 138. Messrs. Champion and Wilton's Gauge for the Withers.

piece of metal, and press against a leather strap, which is drawn tightly over the withers by means of a girth, before the measurement is taken. With either instrument, the actual lines of the withers and back should be taken, without making any allowance for the space which will exist between the upper part of the gullet plate and the withers. Care should be taken to hold the gauge, whichever one is employed, in a vertical position and at right angles to the direction of the animal. When the correct measurement 
has been made, the gauge is laid on paper, and a tracing taken.

If no special instruments are available, we can take both the front and rear measurements, by moulding a strip of lead of suitable length, width, and thickness, over the parts in question. In order to avoid any error which might arise from the ends of the strip of lead opening out or closing, after removal from the back, it is advisable, while the ends are in position, to measure the distance they are apart by means

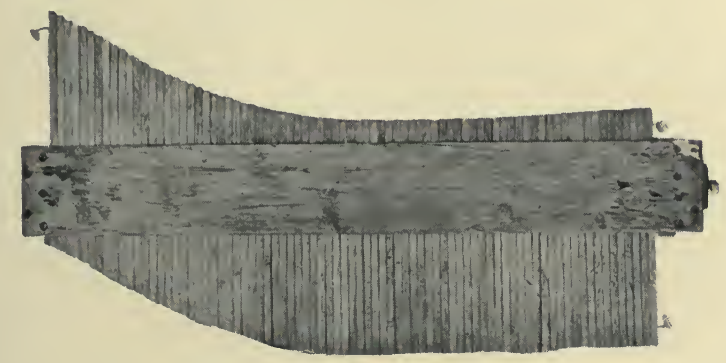

Fig. 139. Messrs. Champion and Wilton's Gauge for thé Back.

of a pair of calipers. The measurement is then transferred to paper, in the manner described.

The gauge depicted in Fig. I39, which works on the same principle as that shown in Fig. 138, is suitable for taking the longitudinal contour of the back, and also the transverse section of the back, where the cantle comes.

\section{STIRRUP LEATHERS}

For hunting and ordinary use should be made of particularly strong, pliable and well-dressed leather. Web leathers made preferably of pipe (circular) webbing are often used in racing and chasing for the purpose of lightness; but they have the great disadvantage of twisting round when the horse is in movement and the foot is out of the iron, and 
thus rendering it difficult to pick up the stirrúp. It is evident that web leathers would look extremely out of place in the hunting field. With light leathers, the part through which the holes are punched should be strengthened, as is always done with webs, by an extra thickness of leather; because, when a fracture takes place, it almost always

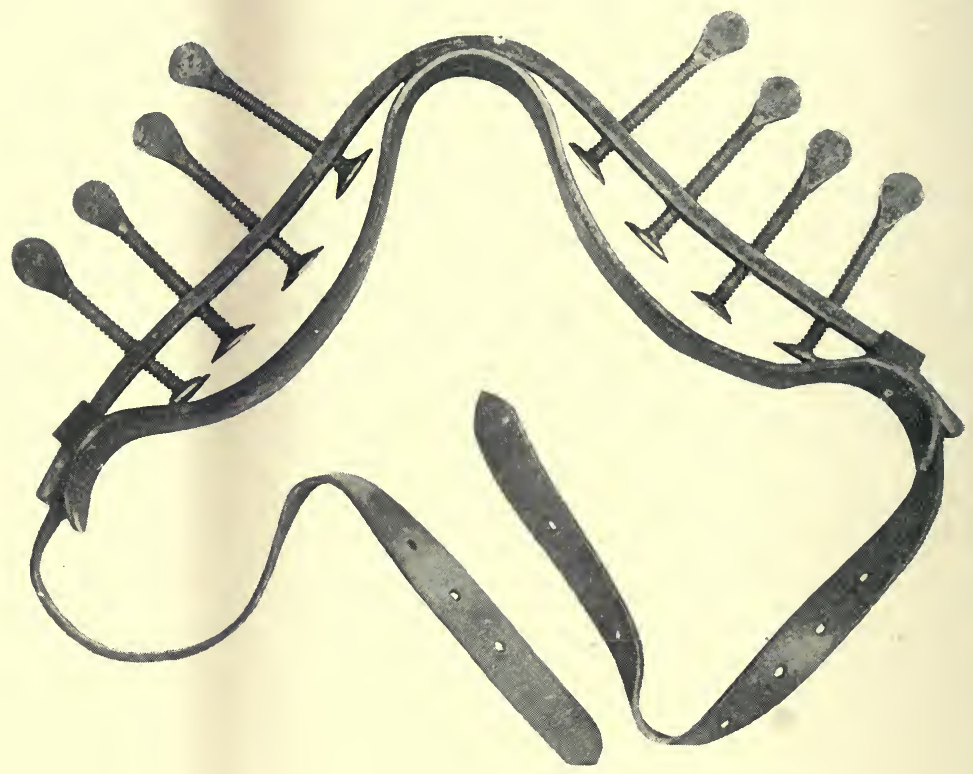

Fig. I40. Mr. T. U. Clarke's Gauge for the Withers.

occurs at the hole through which the tongue of the buckle passes.

The short tongue of the buckle of a stirrup leather and the open space below it (Fig. I4I) are relics of former days, when it was the custom to pass the end of the leather (Fig. 142) through that open space (Fig. I43). As this arrangement made an uncomfortable lump under the skirt of the saddle, and as it increased the difficulty of 
altering the length of the leather, it has now been generally given up in favour of the plan shown in Fig. 127. Recognising the fact that the unnecessary shortness of the tongue of the old-fashioned buckle made its manipulation somewhat awkward, especially when mounted, Mr. Langham-Reed has wisely applied the principle of an ordinary girth-buckle (Fig. I49) to stirrup leathers (Fig. I44). Every horseman should adopt this sound improvement.

\section{STIRRUP IRONS.}

The fashionable stirrup iron for hunting is the "open-

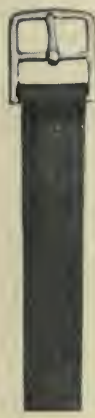

Fig. I4I.

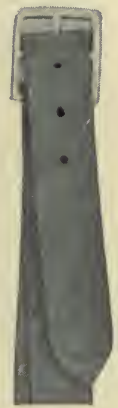

Fig. I42.

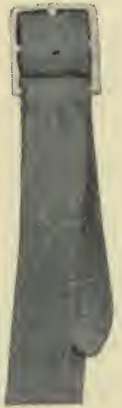

Fig. I43.

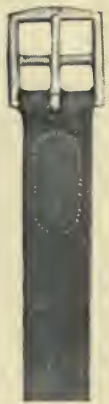

Fig. 144.

Stirrup Leather Buckles.

bottom Persian-side iron," to use the trade expression. There is very little difference between the Persian-side iron (Fig. 145) and the "spade-side iron" (Fig. I46), both of which look better than the "round-leg iron" (Fig. I47). Irons with "open bottoms" (Fig. I27), give a better hold to the feet than solid ones, and the economy of weight, if that is a point to be considered, is obtained at a part which can best spare the loss of material. Stirrup irons should be made of hard forged steel (p. 27).

Some saddlers use the term "Prussian-side," and others 
"Persian-side" for the side iron shown in Fig. I45. I adopt the expression employed by the trade journal, Harness and Saddlery.

Moderately large and fairly heavy irons, say $1 \frac{1}{2} \mathrm{lbs}$. the pair, are most comfortable and certainly look best in the hunting field and for ordinary work. Light irons are always more difficult than heavy ones to pick up in the event of the horseman losing them. When they are small, besides the danger of getting hung up (dragged), the rider may find it

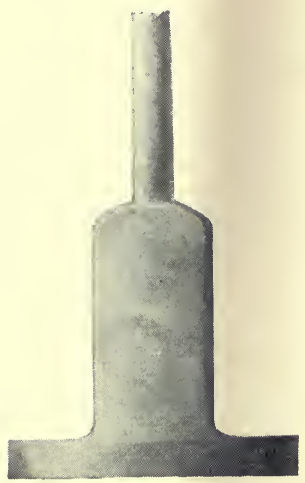

Fig. 145 .

Persian Side Iron.

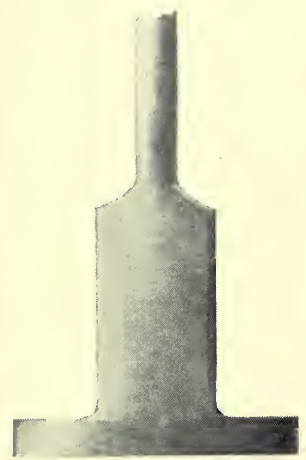

Fig. 146. Spade Side Iron.

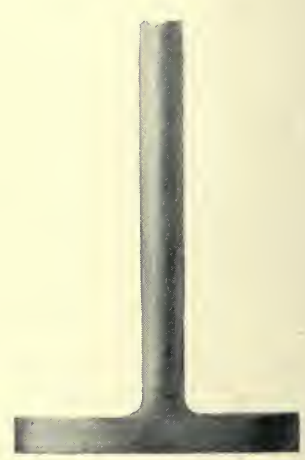

Fig. 147. Round Leg Iron.

awkward to get his feet into them, if he has any clay adhering to the soles of his boots, which often happens in the field, when a man has to dismount or to walk previous to mounting.

I feel convinced that when a man gets dragged, the accident nearly always arises from the stirrup being too small. I have known only one case of a rider's foot getting caught by its going through the iron. This solitary instance in my experience happened during a fall, when both horse and rider came down. One of the best proofs we 
can obtain of the comparative safety of large irons, is afforded by the fact that it is an extremely rare occurrence for a cavalry soldier to get dragged, although military saddles are unprovided with spring bars. Their irons, are, however, very large. It seems impossible that a sufficiently big iron could retain the foot, unless its upper part catches high up on the instep. To prevent this occurring, the heels of all properly constructed riding boots are made long, so as to prevent the irons working too far back on the foot. Most of

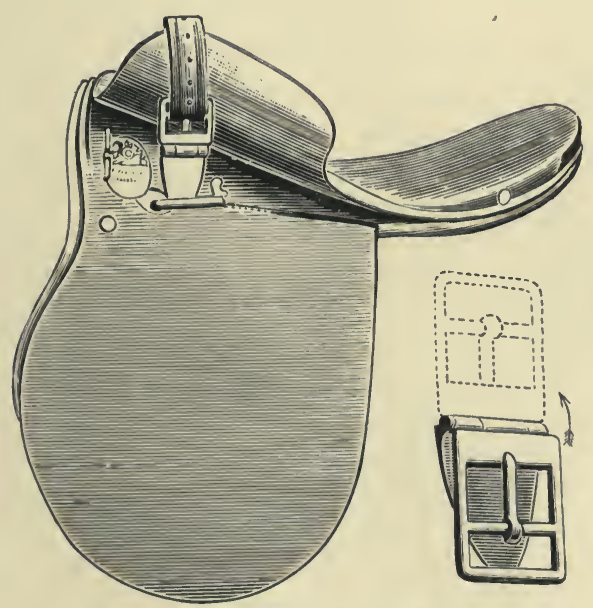

Fig. I48. Weston's Patent Safety Bar and Buckle.

us have doubtless found when riding with ordinary shortheeled boots, and with our feet well home, that the irons sometimes catch on the insteps in this manner. A boot with smooth uppers, like those of the hunting and Wellington type, and thin soles, are naturally least liable to get caught.

" Hunting stirrups vary considerably in size and weight, roughly speaking as follows: $-4 \frac{1}{4}$ in. $\times 4 \frac{1}{2}$ in., 20 to $24 \mathrm{czs}$. per pair ; $43 / 8$ in. $\times 45 / 8$ in., 22 to 26 ozs. per pair; $4 \frac{1}{2}$ in. $\times 4 \frac{3}{4}$ in., 24 to 28 ozs. per pair; $4 \frac{5}{8}$ in. $\times 43 / 4$ in., 26 to 
30 ozs. per pair ; $43 / 4$ in. $\times 47 / 8$ in., 28 to 32 ozs. per pair" (Harness and Saddlery).

\section{SAFETY BARS AND SAFETY STIRRUPS.}

Safety stirrups for men look so unsightly that they may be considered to be quite obsolete. One of the best safety bars is Weston's Patent Safety Bar and Buckle (Fig. I48). I never use any of these contrivances; for I consider that I obtain all necessary safety by keeping the locks of the spring bars open (Fig. I 2 I).

\section{GIRTHS.}

Girths, while fulfilling their duty of efficiently keeping the saddle on a horse's back, should be as little liable as possible to hurt the surface on which they press. Hence, they should be broad, soft, and constructed so that their tendency to retain sweat between them and the horse's skin may be reduced as far as practicable. They can best fulfil the last-mentioned important condition when they are absorbent and open in texture. It is evident that sweat retained between the girth and the skin will have the effect of the moisture of a poultice in rendering the part soft and unusually liable to injury from pressure or friction.

As a material for girths, wool is superior to cotton or leather, because it is softer, more absorbent, and does not become so hard on drying after having become wet. The only drawback to ordinary woollen girths is that they are not sufficiently ventilated, an objection which has been overcome in specially constructed woollen girths that are sold by many good saddlers.

The plan of giving ventilation by slitting up a broad leather girth into several narrow straps, or by using a number of cords of cotton or of plaited or twisted raw hide often acts well; but its adoption may give rise to 
girth-galls, if care is not taken to smooth out, when girthing up, any wrinkles there may be in the skin underneath the girth. It is evidently more difficult for the pressure to be evenly distributed by these cords, than by a broad girth which consists of one piece.

Great care should be taken to keep girths clean and soft, and to oil them from time to time, if they be of leather.

I prefer a broad girth attached at each side by two buckles, to two narrow girths. The Fitzwilliam girth, which consists of a broad girth with a narrow one over it, is

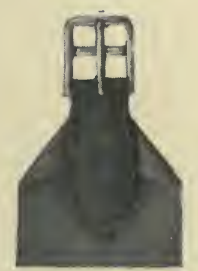

Fig. 149. Girth Buckle with Cross Bar.

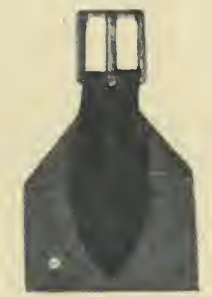

Fig. I50. Girth Buckle without Cross Bar.

handy with a martingale or breast-plate, through the loop of which the narrow girth can be passed.

A girth buckle has a bar placed across its under surface, so that the point of the tongue may lie flush with the buckle (Fig. I49), and that it may not be liable to be pulled through, as it would be, if it had not the centre bar to support it (Fig. I50). If the centre bar be absent, the point of the tongue of the buckle, on account of its being necessarily raised, will stick into the flap of the saddle and will soon wear it out, and it will also be liable to tear the girth strap when the horse is being ungirthed. Without the centre bar, the girth has to be pulled tighter when girthing up, than with it. 


\section{SADDLE-CLOTHS}

Are generally made of felt, and their primary object is to prevent the panel from soaking up sweat and becoming thereby soiled and more or less spoiled. The term mumdah, which is applied to felt saddle-cloths, is derived from a Hindustani word that signifies "felt." A saddle-cloth should be as thin as efficiency in serving its purpose will allow it to be, so that it may give as little "play" as possible to the saddle. Although in all possible cases, the fitting of the saddle should be limited to the adjustment of the shape of the tree and to regulating the amount of stuffing in the panel; the use of a thick numdah with an improperly shaped or deficiently stuffed saddle, is often a valuable make-shift when necessity gives no other choice. The use of an ordinary saddle-cloth is accompanied by the slight disadvantage, that the middle line of the back which is covered by the saddle, is, by the fact of the numdah resting on it, deprived of the benefit of air circulating along it. An attempt to remedy this objection is sometimes made by cutting a longitudinal piece out of the centre of the saddle-cloth. Here, the cure is worse than the complaint; because injurious pressure will be exerted by the edges of the aperture thus made, especially if the edges be bound with tape, to preserve them from fraying out.

Saddle-cloths made of one thickness of leather, admirably answer the purpose of saving the panel from injury; but for hunting and other long continued work, they have the objection of retaining perspiration, instead of soaking it up, as felt ones would do. It is a good plan, before using a new leather saddle-cloth, to rub into it a little cod-liver oil, which will keep it soft for a long time. 
BREAST-PLATES.

There is only one form of breast-plate (Fig. IO3). It is attached at one end to the girth or girths, and at the other end to the staples of the saddle. Its use is to prevent the saddle shifting backwards, as it might do if the girths were slack, especially if the animal was one of the "herringgutted" sort. Even with a well-shaped horse, a breast-plate often comes in useful on a long day and in a hilly country. It is much employed out hunting.

\section{CRU PPERS.}

The object of a crupper is to prevent the saddle going forward, which it would be naturally inclined to do in proportion to the comparative size of the animal's body behind the girths. The continued infusion of thorough-bred blood among our 'cross-country horses has gradually rendered the use of cruppers obsolete in the hunting field. They are still employed now and then by farmers, and a good deal in the Colonies, where the local buck-jumpers often need some forcible check to prevent them from getting the saddle on their neck, when, by suddenly raising their head, they not unfrequently succeed in breaking the girths and unseating the rider. In pageants, a crupper is sometimes employed as an attachment for a false tail.

\section{SURCINGLES}

Are rarely used by hunting men, as they savour too much of the training stable and race-course. They are employed in the Army and a good deal in the Colonies.

\section{POSITION OF A SADDLE ON A HORSE.}

From the remarks made on pages I I 4 and I I 5 , we see that the saddle must not be put so far forward on the horse's back, 
as to interfere with the play of the shoulder-blade. Taking the length of the weight-bearing surfaces of the back and loins at 22 or 23 inches, and that of the panel of an ordinary hunting saddle at about i 8 inches, we have a limit of 4 or 5 inches for regulating the position of the saddle. In this task we should be guided by the object we have in view. If we desire the attainment of the highest possible speed, we should, agreeably to the remarks made on pages I4 and I6, place the saddle as far forward as we can without interfering with the play of the shoulder-blade. If we require the animal for hunting or other ordinary work, we may place the saddle further back (say, 3 inches), so as to save the fore legs from undue strain. I have often found that this precaution acts well with animals which are heavy in front, and with those which are somewhat infirm on their fore legs. All horsemen know that a hunter requires to be light in front, especially when landing over fences. Although it is impossible to determine with mathematical accuracy the best position for the saddle to occupy, whether with a view of saving the fore legs from injury or for obtaining a high rate of speed, a knowledge of the principles to be observed cannot fail to be useful as a guide to practice. Instead of adopting for all horses a uniform position for the saddle, it is well to try how each animal goes with the saddle in different positions, always remembering to keep it clear of the play of the shoulders, and then to adopt the one which suits the horse best. A man of experience will readily tell when the position of the saddle which is between his legs, is in harmony with the movements of the animal he is riding.

\section{SADDLING A HORSE.}

The saddle should be placed on the withers and drawn back (so as not to rumple the hair which is under it) into a 

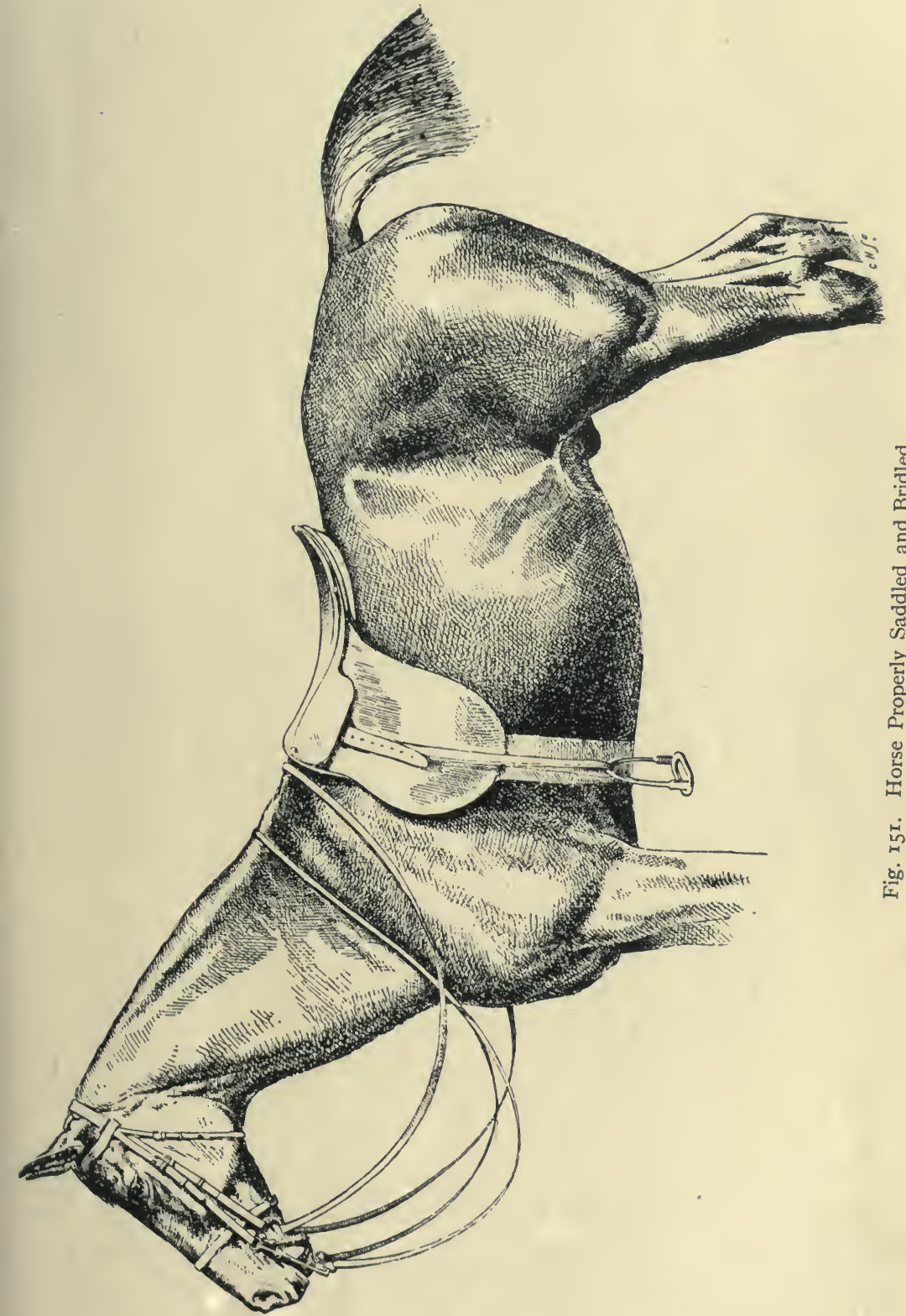

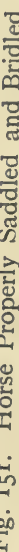


position clear of the shoulder-blades, and as much further back (see preceeding section) as may be deemed advisable. With the object of giving a horse the appearance of having lengthy shoulders, sellers sometimes put the saddle too far back for the comfort of the animal.

If a saddle-cloth be used, the groom, before girthing up, should bring the front part of the cloth well up into the arch of the gullet with his fore finger or thumb, so as to prevent it from becoming pressed down on the withers by the saddle.

With two girths, the front one is taken up first, and then the hind one. We should avoid tight girthing, and should try to hit off the happy medium between the girths being so loose as to allow of the possibility of the saddle slipping either backwards or forwards, or so tight that they would interfere with the horse's breathing. To prevent the girths slipping, they should be placed well back from the animal's elbows (Fig. I5I) when girthing up. In order to obtain uniform pressure, it is well to do about half of the tightening on one side and the remainder on the other side. If the groom, as is the usual stable custom, takes up the girths only from the near side, he should at first do little more than to take up the slack of the girths, and should then run his fingers between them and the skin, from the near side to the off, so as to smooth out any wrinkles. Finally, he tightens the girths to the required extent.

Some horses swell themselves out on being saddled and consequently need to be walked about for a short time, after which the girths will have to be taken up afresh, before the rider can mount without incurring the risk of the saddle shifting its position.

For safety's sake, the spring bars of a saddle should be kept always open, or at least well oiled, if closed while being used. When they are open, there is not the slightest chance of the stirrup leathers coming out, as long as the rider 
remains in the saddle, unless he puts his weight on the stirrups, and happens to perform in a very hilly country, or to scramble up a steep bank.

The following is a useful plan for causing a stirrup iron to remain at right angles to the side of a horse, in case the rider's foot comes out, so that he may readily pick up the iron again: Twist the leather in the direction the hands of a clock proceed, if on the near side, and vice vers $\hat{a}$, until-it is shortened to about two-thirds of its original length; pull

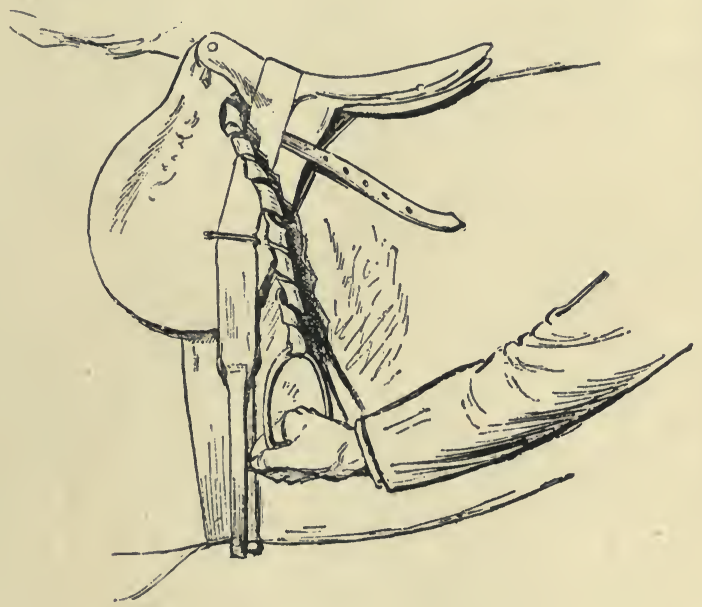

Fig. 152. Twisting Stirrup Leather.

it hard down (Fig. I52); and let it go. On regaining its usual position, the leather will be found to have received a twist which will keep the iron at about right angles to the horse's side (Fig. 15I). An unskilful rider who loses a stirrup, often finds great difficulty in catching it again with his foot if it happens to lie parallel to the horse's side, and he will naturally feel "all abroad," if his horse plays up, or if he is trying to negotiate a jump, unless he has the support of both stirrups. It goes without saying, that when the 
leathers are twisted as I have described, the irons will be in the best position for the feet to take them. It also strikes me that in the event of a fall, the feet would come out of the irons more readily when thus placed, than they would do if the leathers had not been twisted.

When a girth is too long to be used in the ordinary way, it may be shortened by taking a fold of the webbing near

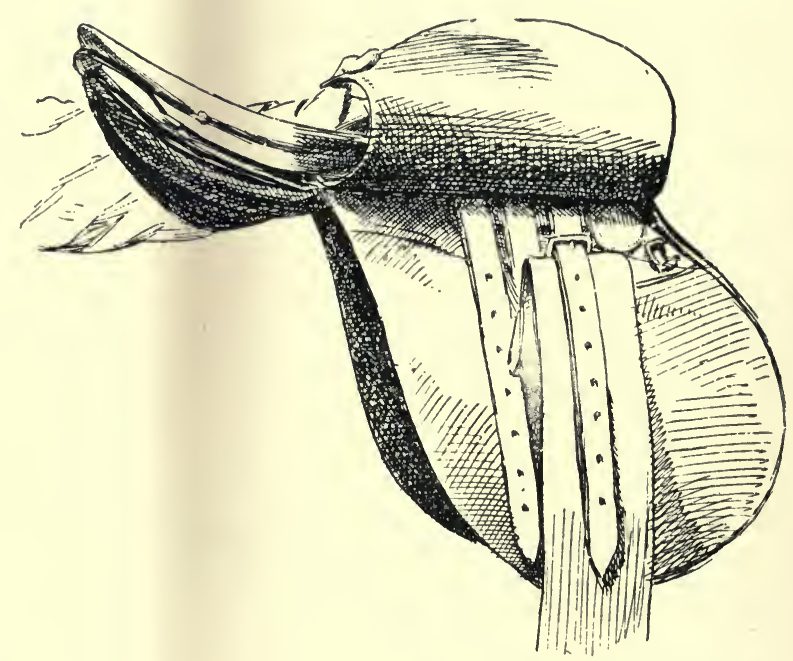

Fig. 153. Shortening a Girth.

one end, passing the tongue of the buckle through it, and attaching the buckle to one of the girth straps (Fig. I 53). This should be only a temporary measure, as it is apt to tear the webbing.

A rider may tighten his girths without dismounting, by bringing, say, his right leg in front of the saddle-flap, and then shortening the girths with the right hand (Fig. I 54).

A ready way of using a stirrup leather, the sewing of which has become undone, is to make a hole in the part where the stitching was, and to pass the tongue of the buckle 


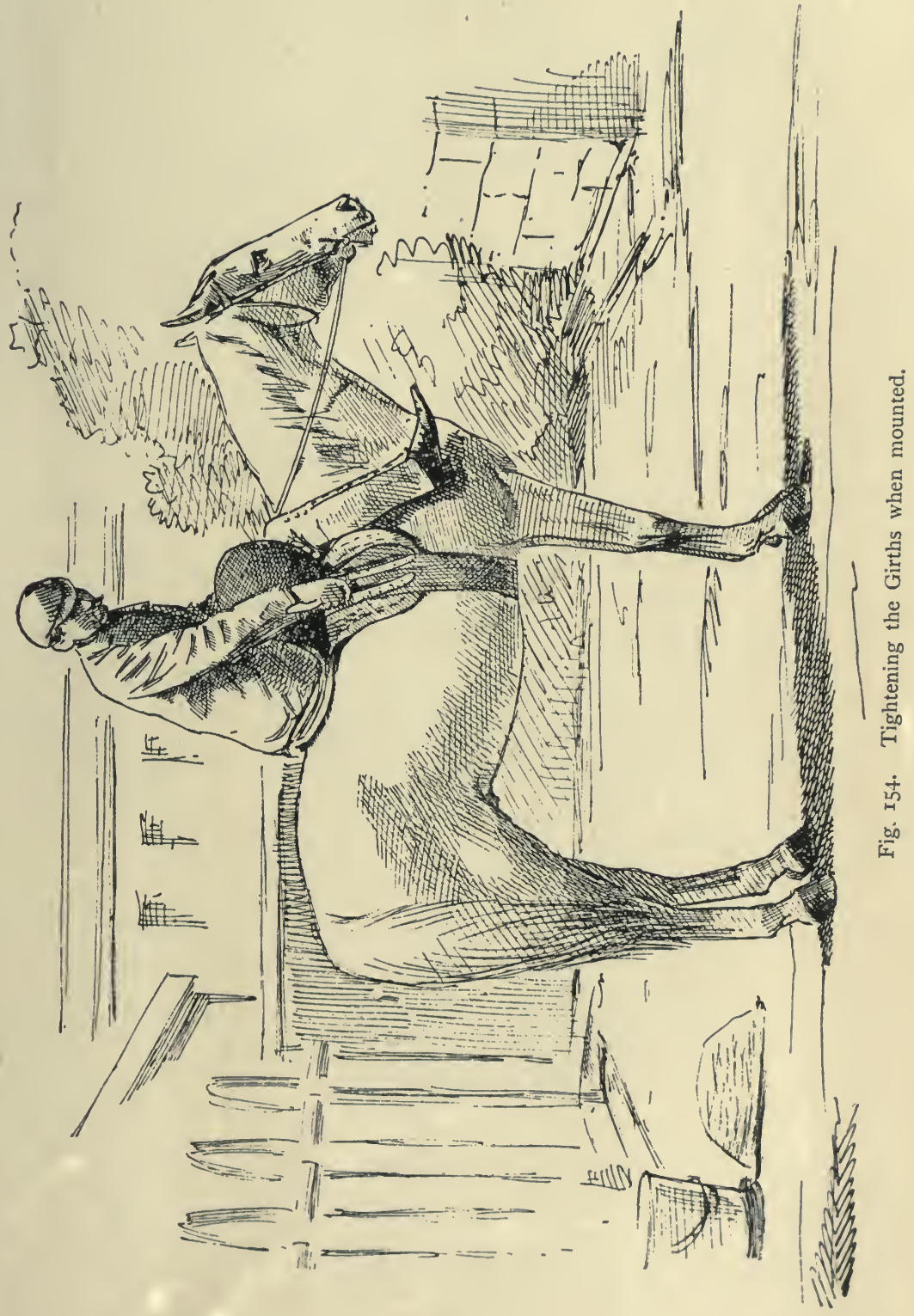


through this hole, and also through one of the punched holes at the required length (Fig. 155).

When a saddle is on a horse without a rider, the irons

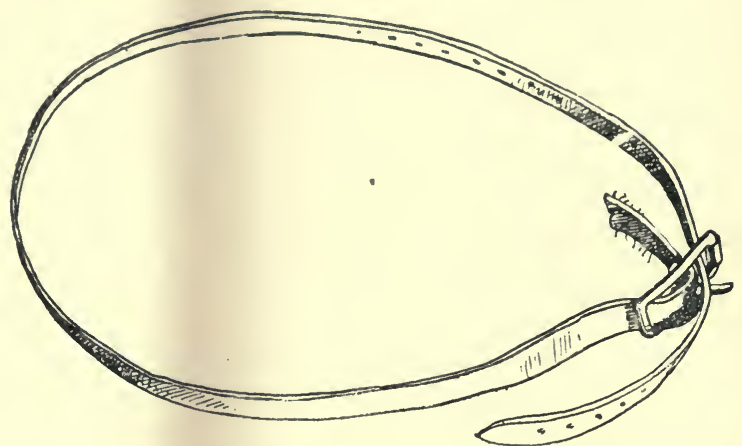

Fig. 155. Using a Leather, the Sewing of which has become undone.

should be thrown across the saddle-the right to the near, and the left to the off side-or they should be drawn up on the leathers as shown in Fig. I56. If the irons be allowed to hang down by the horse's sides, he will be apt to get one of

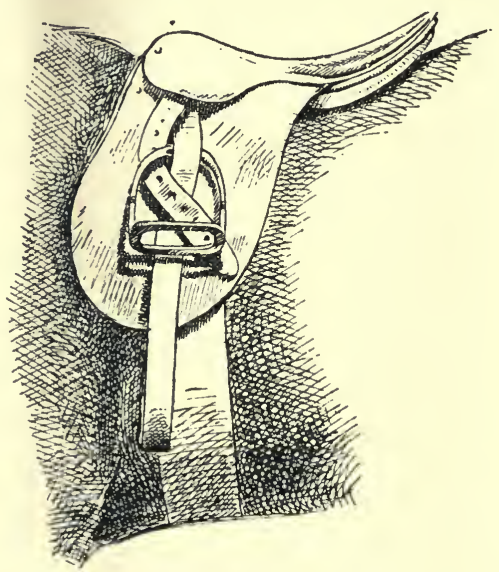

Fig. 156. Drawing up Iron on Leather.

his hind feet, or his lower jaw, caught in them in the event of his kicking at flies, etc., or of turning round to bite at his side. I have seen several cases of such accidents. 


\section{CHAPTER VI.}

\section{HOW TO HOLD THE REINS.}

General Remark-Principles to be observed in holding the Reins-Holding Single Reins in both Hands-Holding Single Reins in one Hand-Holding Double Reins in both Hands-Holding Double Reins in one Hand-Shortening the Reins when held in one Hand-Shortening the Reins when held in both Hands-Changing the Reins from two Hands into one Hand-Changing the Reins from one Hand into two Hands-Respective merits of one-handed and two-handed Riding-Military Method of holding the Reins-Tying up one Rein.

\section{GENERAL REMARK.}

The methods which I shall describe in this chapter for holding the reins, are those I have found by experience to be the best for their respective purposes, and are based chiefly on the practice of jockeys and hunting men. Except in the Army, there is no standard routine for manipulating the reins.

\section{PRINCIPLES TO BE OBSERVED IN HOLDING THE REINS.}

The following are the usual principles to be observed in holding the reins :

I. A secure grip of the reins should be maintained with as little stiffness as possible; because stiffness implies continued muscular contraction and consequent defective manipulation from fatigue.

2. When both hands are used, we should hold the reins so that we can freely move our hands, either separately or together, in any required direction.

3. When both hands are used, the manner of holding the reins by one hand should be the same as that by the other, so 
that the feeling of the hands on the reins may be the same on both sides.

4. When a horse which has an even mouth is going in a straight direction, the action of one rein should be the same as that of the other rein.

5. As a horse is much more powerful than we are, we

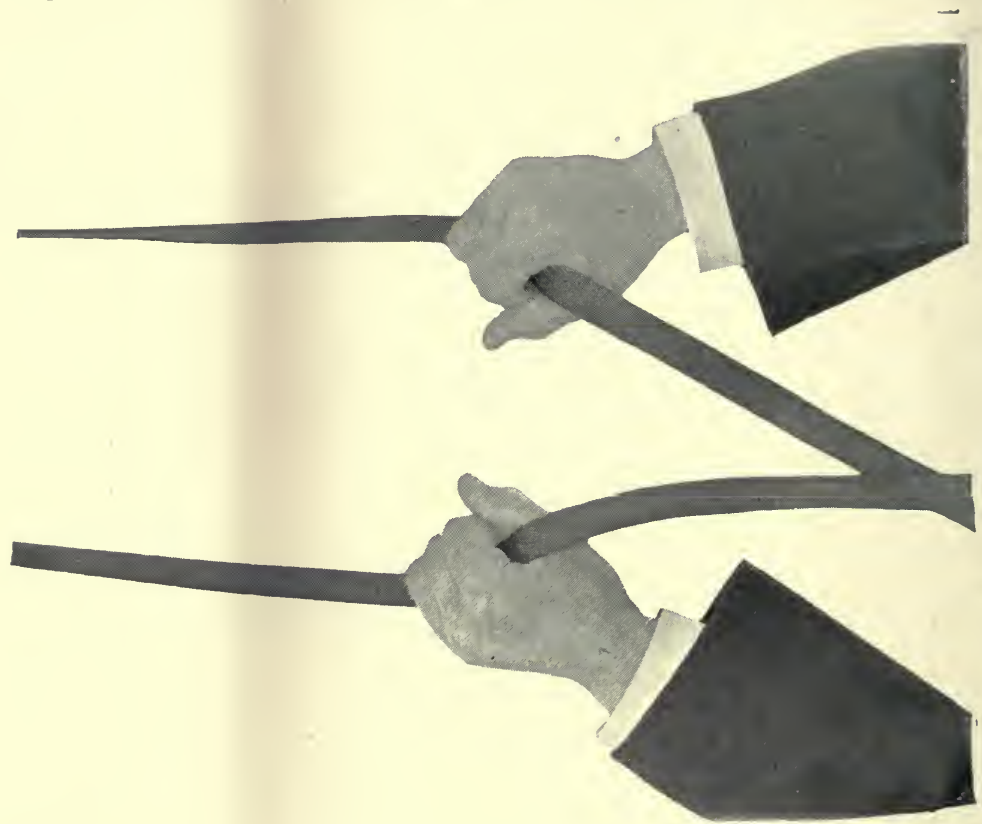

Fig. 157. A rein in each hand.

should apply our strength to as great mechanical advantage as practicable.

HOLDING SINGLE REINS IN BOTH HANDS.

Pass the near rein between the little finger and the third finger of the left hand, bring it out between the fore finger and thumb, and take up the off rein in the same manner in the right hand (Fig. I 57). The reins thus held in the usual 
horse-breakers' style, will be in the best position for general use. If we wish to obtain a firmer grip on the reins, we may pass the slack of the off rein into the left hand, and the slack of the near rein into the right hand (Fig. I58). This crossreined method of holding the reins, which is the one generally adopted by jockeys, gives a firmer grip on the reins than the plan shown in Fig. I57, on account of the friction between the opposing surfaces of leather; but it does not allow the

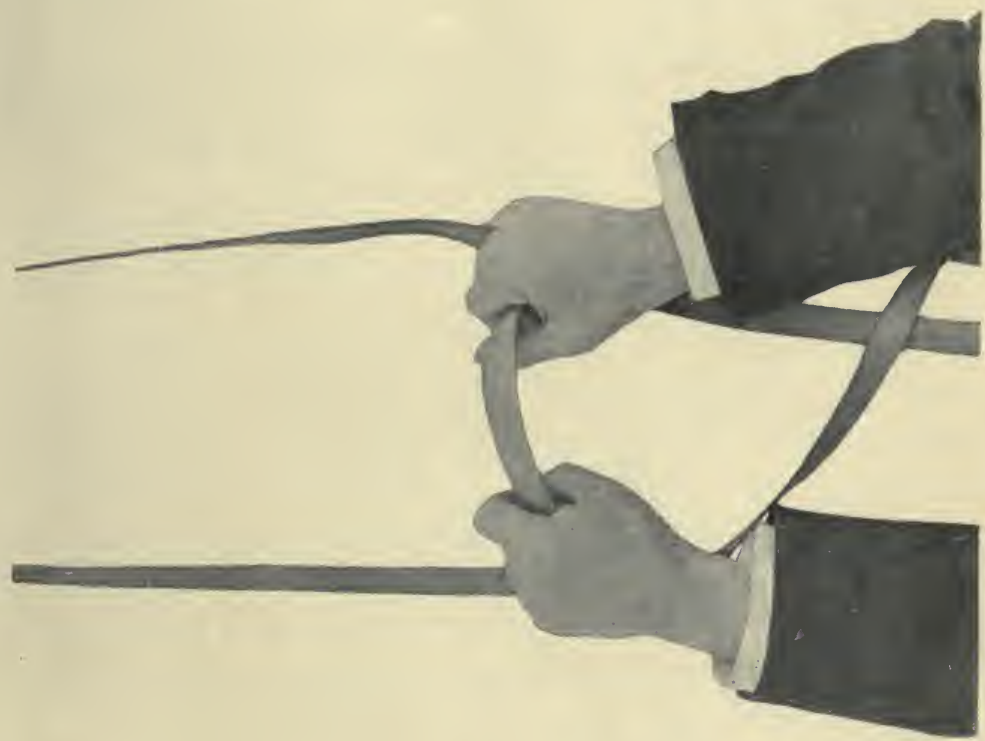

Fig. 158. Single reins crossed in both hands.

rider to freely separate his hands, as he might desire to do when trying to pull a horse round, as for instance, in the event of the animal attempting to run out at a fence. This objection would naturally have much less weight on a racecourse, than in the hunting field.

HOLDING SINGLE REINS IN ONE HAND.

With the reins held as in Figs. 157 or 158 , we pass the off 
rein into the left hand between its fore finger and thumb and across the portion of the near rein that is in the palm of the left hand (Fig. I 59). On leaving go the off rein with the

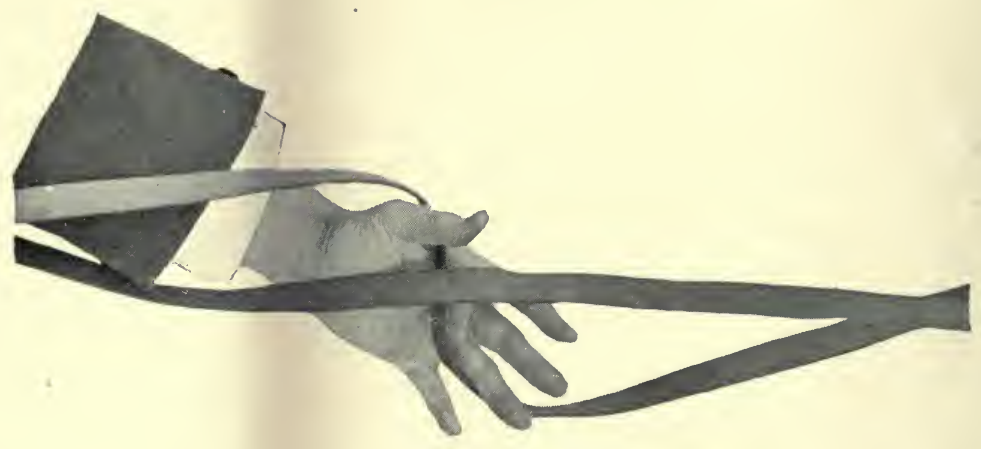

Fig. I59. Single reins crossed in one hand.

right hand, we close the fingers of the left hand, rotate the left hand inwards, and let it fall from the wrist in an easy manner (Fig. I60). In taking up the reins, without having

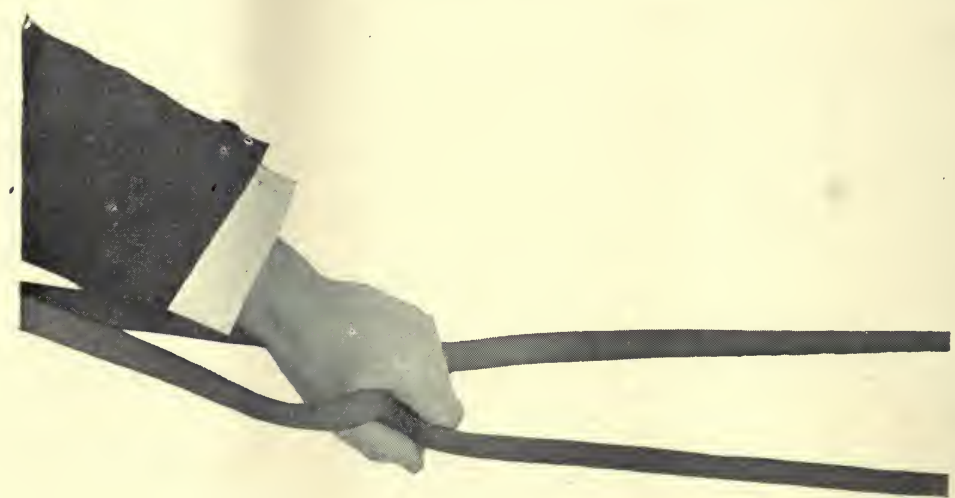

Fig. 160. Single reins crossed in one hand.

them previously in both hands, we take hold of the near rein, so that it passes between the little finger and the third finger and between the fore finger and thumb of the left hand, and 
then pass the off rein into it in the manner just described. With the reins held in one hand (say, the left), we should not hold the knuckles in a vertical position; for by doing so, the off rein will come up higher on the horse's neck than the near rein. On the contrary, the knuckles should be carried more or less horizontally, as they would be when the hand is
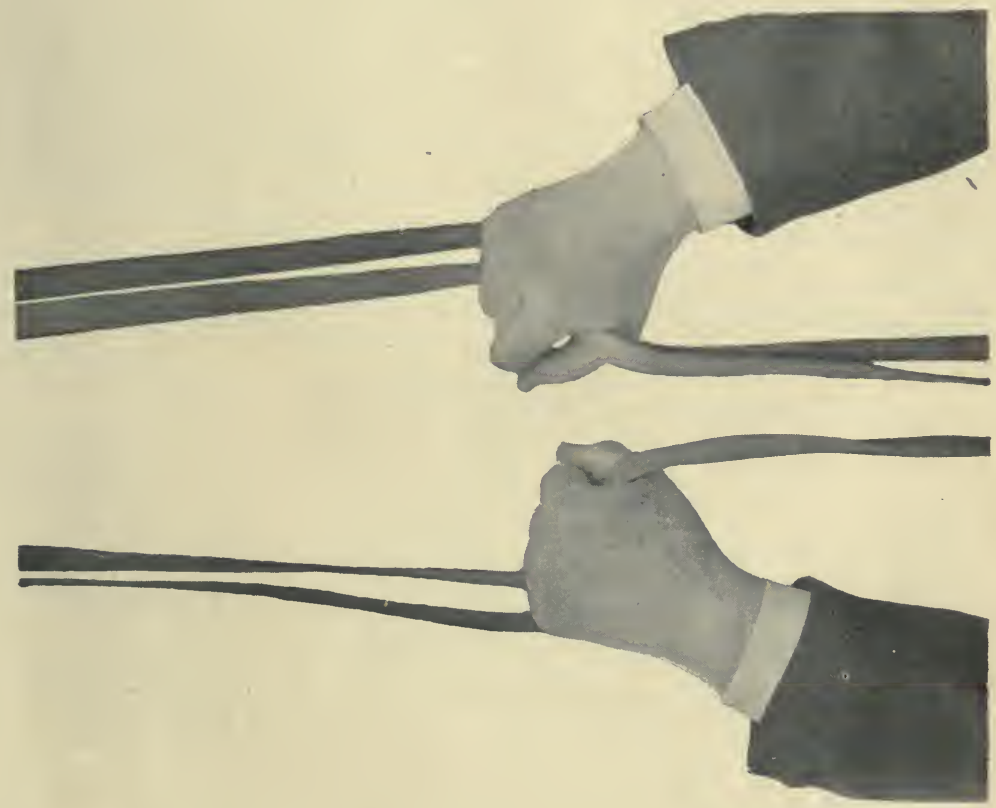

Fig. 161. Double reins held separately in two hands.

allowed to fall without stiffness from the wrist. Whether the reins are held in one hand or in two, we should avoid "rounding the wrists," not only on account of the consequent stiffness imparted to these joints, but also because that action tends to cause the elbows to be carried outwards, and thus diminishes the force which the arms are capable of exerting on the reins. 
HOLDING DOUBLE REINS IN BOTH HANDS.

We may hold double reins in both hands in the same way as we hold single reins, except that the little fingers (Fig. I6I) separate the reins on each respective side. The question as to which rein should be on the outside, may I think be decided by the amount of control which is required to be obtained over

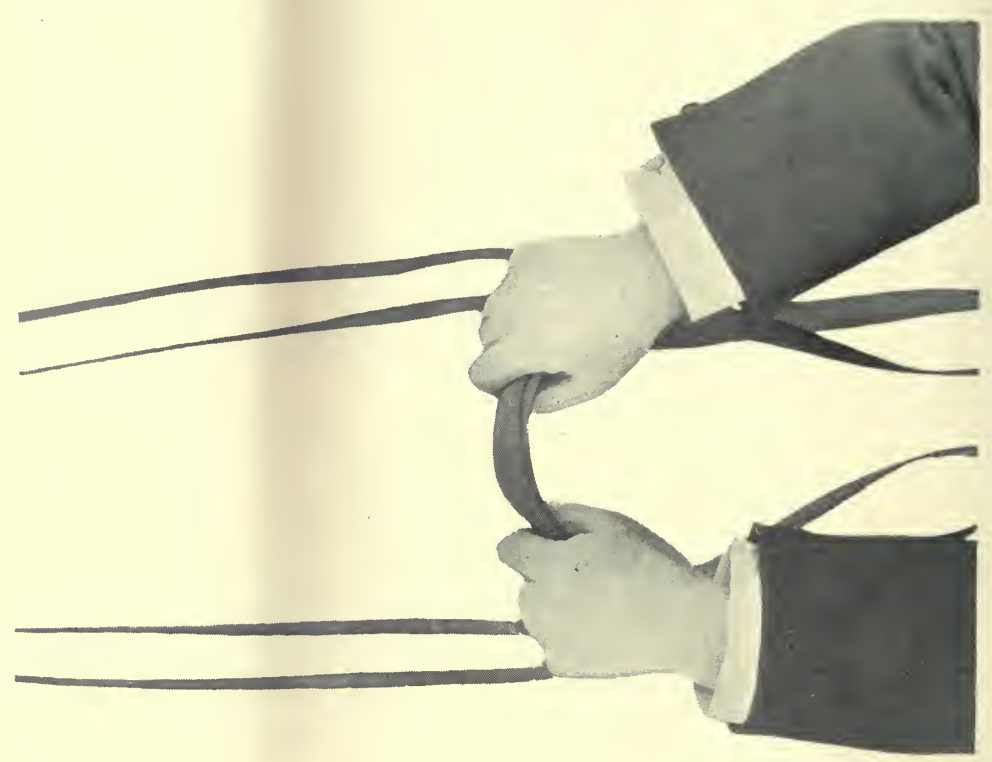

Fig. 162. Double reins crossed in both hands with the little fingers between them.

the horse ; because, by the rotation of the hand, we can work the outward rein more effectually than the inward one. Hence, if we want to employ the curb more than the snaffle, we should keep the rein of the former outside that of the latter, and if need be we may lengthen out the snaffle reins so as to take all bearing off them. Also, if we wish to remind the animal every now and then that we have a curb ready to check his waywardness, we may have the curb reins on the 
outside, and at such a length that little or no pressure is put on them when the hands are carried in the ordinary way, although these reins can be drawn tightly, if the hands are rotated inwards and the little fingers closed on the palms of the hands. If we desire to have an equal bearing on both the curb and snaffle reins, it is immaterial which of them we have on the outside, or we may use them as one rein passing

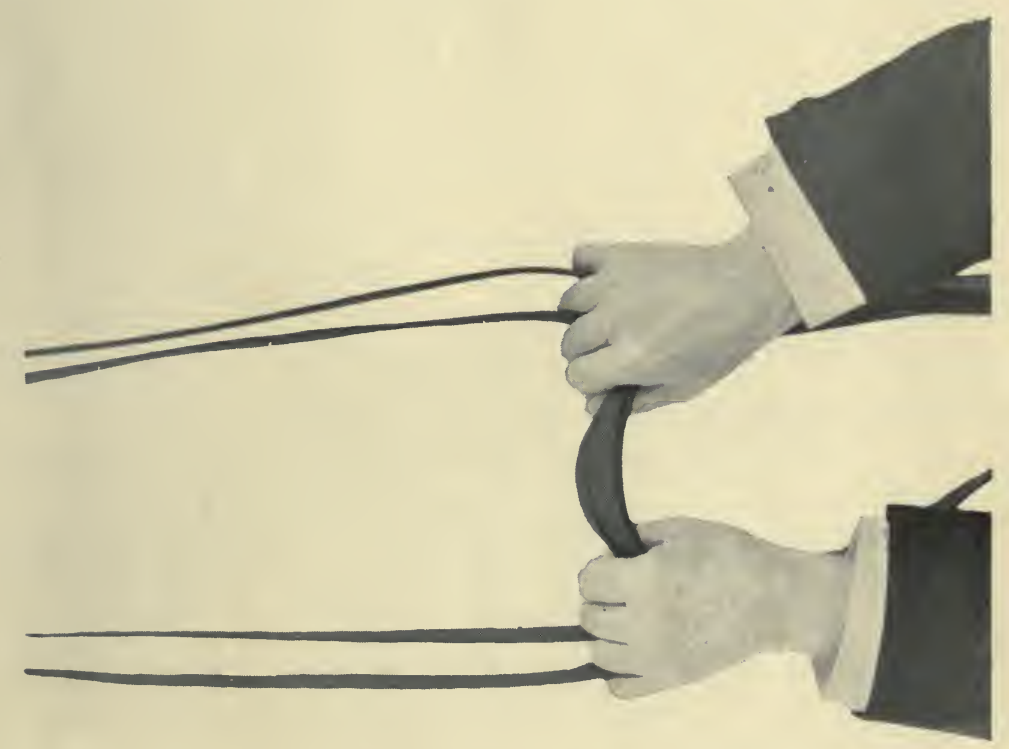

Fig. 163. Double reins crossed in both hands with the ring (third) fingers between them.

between the little finger and ring finger. If the snaffle is to be the predominant rein, it will of course be on the outside, and the curb reins more or less slack.

When holding double reins as in Fig. I6I, if we wish to obtain a better grip of the reins, we may "cross" the reins as we did with the single reins (Fig. I 58), and will then hold the reins as in Fig. I62. Instead of holding the respective little fingers between the two reins on each side, as in Figs. I6I and 
I62, we may keep the ring (third) fingers between them, as in Fig. I63. This plan does not give such a strong hold on the reins as that of having the little fingers between the reins; but it is the one generally adopted by jockeys, because it leaves the little finger free to keep hold of the whip.

\section{HOLDING DOUBLE REINS IN ONE HAND.}

The fore finger of, say, the left hand separates the two off reins; the third finger or the little finger (Fig. I64) divides

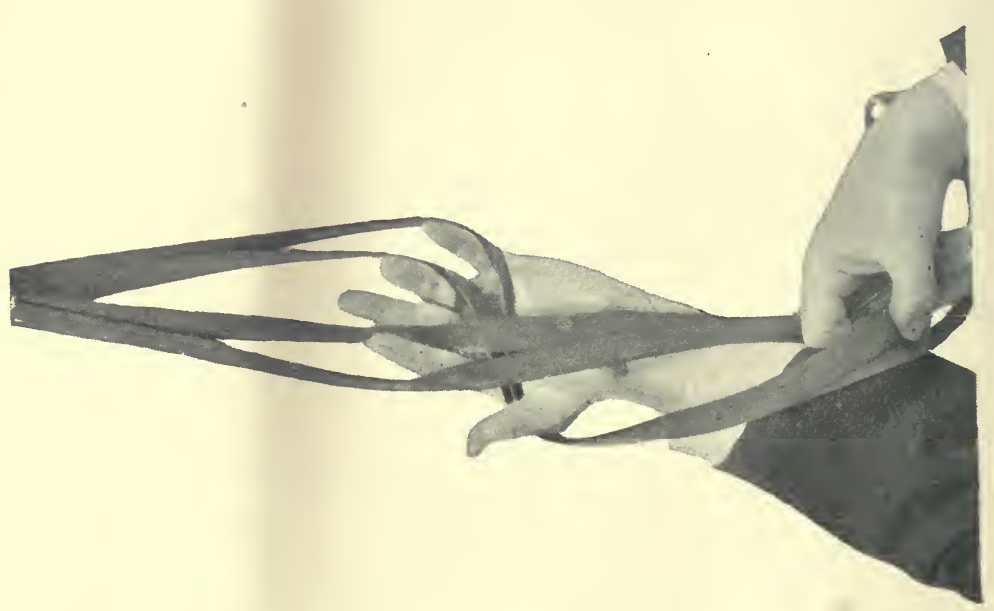

Fig. 164. Holding double reins crossed in one hand.

the two near ones; and the reins are crossed in the palm of the hand as with single reins. It is convenient (as we have seen with double reins) to have the reins on which we want to have the stronger pull, on the outside. If the rider wishes to use only one rein, he may hold it crossed in his hand, and may hook up the other on the middle finger, and let it loose (Fig. I65), or draw it up to a greater or less extent.

SHORTENING THE REINS WHEN HELD IN ONE HAND.

If the reins are held for instance in the right hand, take 
them in the left hand, slip the right forward as in Fig. 166, and having got the required length, close the fingers of the right hand on the reins and let go the left. Or take the slack of the reins in the left hand and draw them through the right, until they become short enough. Double reins are shortened in the same manner, except that the reins on each side are kept apart by the appropriate fingers of the respective hands.

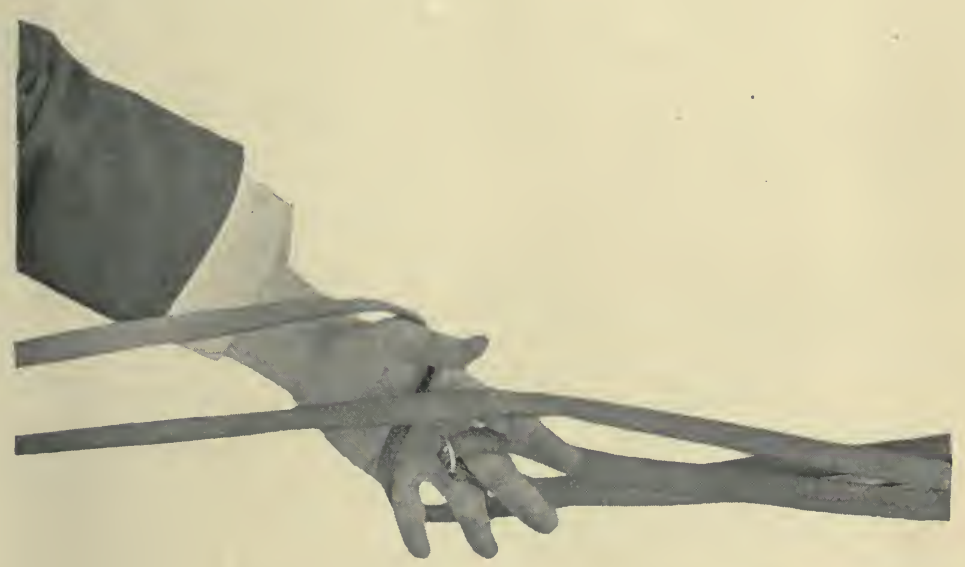

Fig. 165. Double reins in left hand: one crossed, the other hooked up on middle finger.

SHORTENING THE REINS WHEN HELD IN BOTH HANDS.

Supposing that single reins are held as in Fig. 157 , and thàt we want to shorten them, for instance with the right hand, we pass the off rein "crossed" over the near rein into the left hand, and placing the off rein between the little finger and the ring finger of the right hand, we slide the right hand forward on the off rein until we obtain the required length. We then take the near rein between the fore finger and thumb of the right hand (Fig. I66); close the fingers of that hand; let go the reins with the right hand; and take up the reins at their shortened distance with the left hand, 
so that the reins are held as before, namely, as in Fig. I 57. Double reins held as in Fig. I6I, are shortened in the same. way, except that the reins on each side are kept apart. If, to start with, the reins are held as in Fig. I62, or Fig. I63, instead of passing the off rein into the left hand, we let go the slack of the near rein with the right hand; slide the right hand forward on the off rein while carrying it a little outwards and in a somewhat circular manner; and take up the

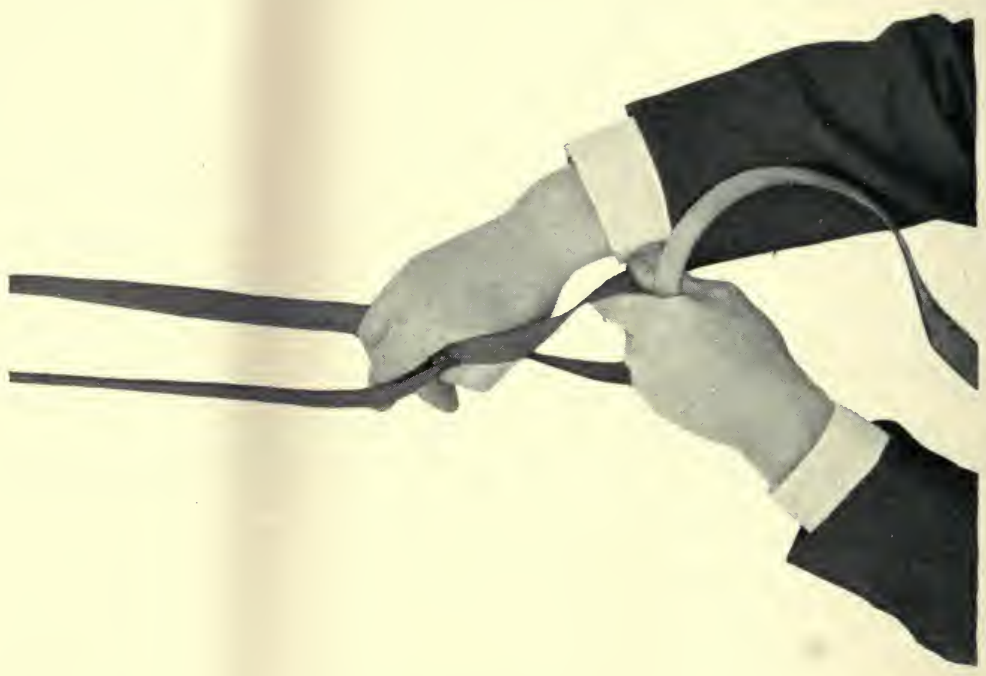

Fig. 166. Shortening single reins.

near rein crossed over the off rein with the right hand. The left hand now takes up its side of the reins, and the reins are held as before, namely, as in Fig. I62, or Fig. I63. The circular movement given to the right hand while it is being carried forward; is necessary in order to maintain an even feeling on both reins; because the portion of the off rein which is between the horse's mouth and the left hand is longer than the same portion of the near rein.

When the horse is not pulling hard, and when the reins are 
held as in Fig. I58, or Fig. I63, we may, in order to shorten them, simply draw the hands apart, while the hold of the first, second and third fingers of the hands on their respective reins is loosened, and that of the little fingers is tightened on the free part of the reins, which action will naturally cause the hands to slide forward on the reins. When the proper length has been obtained, the first, second and third fingers of each hand should close on their respective reins. The hands should then be brought together into their original position; the slack of the near rein being allowed to slip through the right hand, and the slack of the off rein through the left. This method is specially applicable to our purpose when we are obliged to shorten the reins, and desire at the same time to interfere as little as possible with the horse's mouth.

CHANGING THE REINS FROM TWO HANDS INTO ONE HAND.

As the reins have to be held a little shorter in one hand than in two, we may change them by shortening them with the hand in which we wish to hold them. Thus, to change into the right hand, reins which are held as in Fig. I 58 , we may take hold of them as in Fig. I66; close the fingers of the right hand; and let go the left hand. Or we may pass the rein or reins held by one hand into the other hand without any previous shortening. Double reins may be shifted into one hand in the same manner.

\section{CHANGING THE REINS FROM ONE HAND INTO TWO} HANDS.

Supposing that the left hand holds both reins, either single or double crossed, we may take up the off reins with the right hand, so as to hold them in the manner shown respectively by Figs. I 57 and I 58, and by Figs. I6I, I62, and 163 . 


\section{RESPECTIVE MERITS OF ONE-HANDED AND TWO- HANDED RIDING.}

Sensible people ride with one hand only when they are obliged to do so ; because, even with the quietest animal, both hands may be needed at any moment for control or guidance. Besides, an even feeling on the reins when they are held in one hand, can be maintained only by keeping the hand in the median line of the horse's body, which is naturally a more or less irksome task for the rider. Any continued deviation of the hand from this central line will give a one-sided feeling to the mouth. The three great objections to one-handed riding, as far as control is concerned, are : that by its adoption, the available strength of the rider is reduced by nearly one-half; that the rider has to rely almost entirely on reversed indications for turning the animal to the right or to the left; and that, while keeping an even feeling on the reins, he is unable to draw his hand further back than the front of his body, which fact naturally obliges him to hold his reins shorter than he need do if he had both hands on them. Cavalry men and polo players have of course to ride with one hand; for the other hand will be occupied by, respectively, a weapon and a polo stick. In pigsticking in India, the right hand will have to be free to use the spear. The Boers in South Africa habitually ride with one hand; because, when on horseback, they are accustomed to carry in the right hand a rifle, which they rest on the right thigh.

\section{MILITARY METHOD OF HOLDING THE REINS.}

According to The Cavalry Regulations, the reins are held in the left hand; are divided by the little finger; and are brought up through the hand between the fore finger and thumb (Fig. 167). Thus, the hold on the reins is chiefly maintained by the lateral pressure of the fingers and by the 
downward pressure of the thumb on them. As the muscles which draw the fingers laterally together (the adductor muscles of the fingers) are far weaker than the muscles which cause the hand to become clenched (the flexor muscles of the fingers); it follows that the military method of holding the reins is much less secure and a good deal more tiring than the "crossed" one-handed plan (Fig. I60), which also has the advantage of utilising the friction between the opposing surfaces of leather. Besides, with only the little finger separating the reins, one rein can be made shorter than the other rein, only by about three quarters of an inch, so that the direct lateral indication of the rein is practically nil. The only good

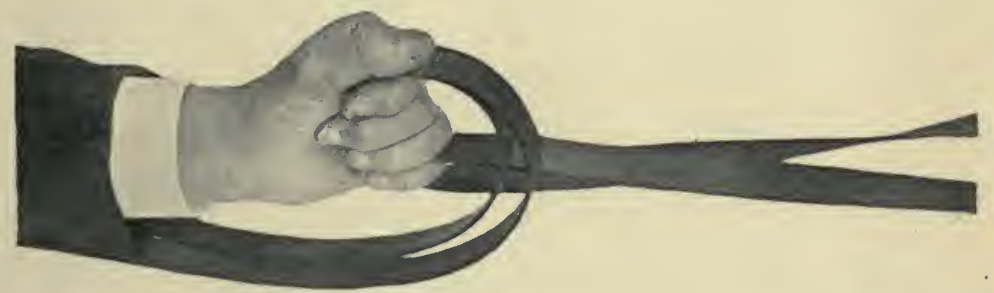

Fig. 167. Reins held in one hand in military fashion.

point about our military method of holding the reins, as far as I can see, is that it enables the rider to readily shorten the reins with the fore finger and thumb of the right hand, the other fingers of which are supposed to be occupied with the sabre or lance.

This method is unsuitable to two-handed riding; for when the horseman uses both hands, he is obliged to lengthen out the off rein, in order to get an even feeling on both reins, as in Fig. I68. If he has now to quit the reins with the right hand, as for instance when he is about to use the whip, he cannot take up the reins in the left hand in the same prompt and secure manner as he could by the crossed method. It is evident that any "fumbling" with the reins when they 
are being changed from one hand to another, might be sufficient for a jockey to lose a race, or for a hunting man to fail to prevent a refusal at a fence. It frequently happens that the rider who adopts this "school" system of holding the reins in both hands, neglects in the hurry of the moment to shorten the off rein at all, and consequently pulls his horse round to

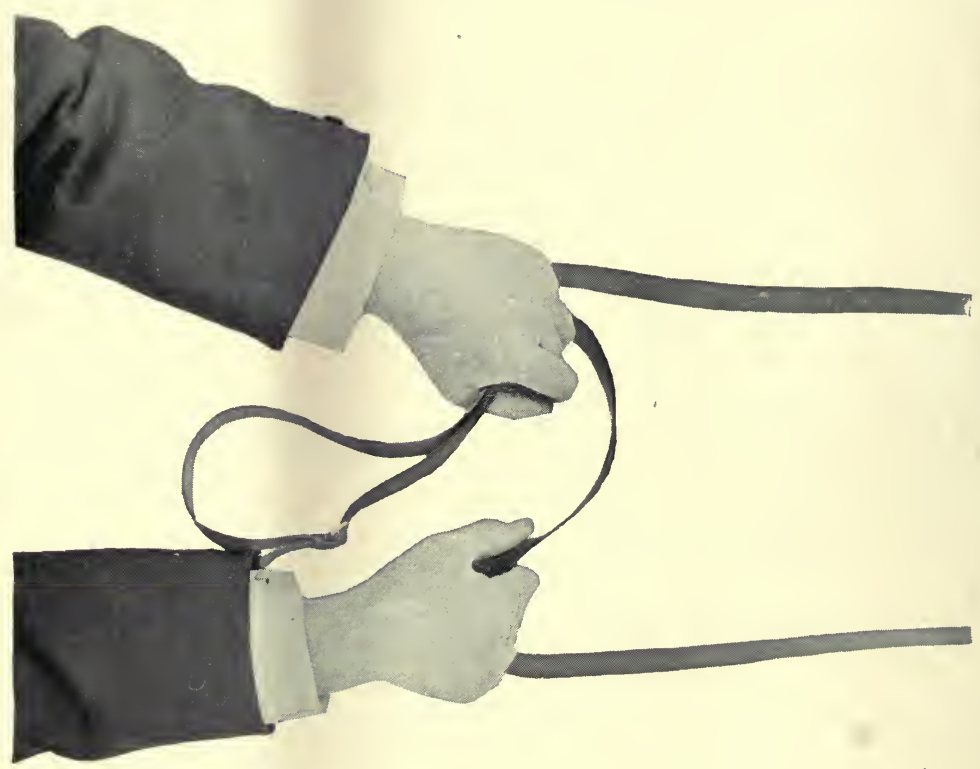

Fig. I68. Off rein taken up by right hand from position shown in Fig. I67.

the left, by reason of the near rein being shorter than the off. Another objection to it is that one hand has a different hold on the reins to that which the other hand has. When the reins are held as in Figs. I 57 or I 58 , both hands have exactly the same hold, and the off can be passed into the left or the near into the right in an instant.

On this subject, Colonel Greenwood, in his excellent book, Hints on Horsemanship, pertinently remarks: "Even our finest two-handed English riders (who in my opinion are the 
finest riders in the world), when they use the right hand on the right rein, continue to hold both reins with the left hand, and then slip the right rein a little through the left hand in order to place both hands even. This is a most vicious habit. When they quit the right rein to use the whip, or to throw the arm back at a fence (another most vicious habit), by their system of holding and handling the reins they have not the power to place the lengthened rein short in the left hand. Alas, poor horse! he is then pulled to the left by the

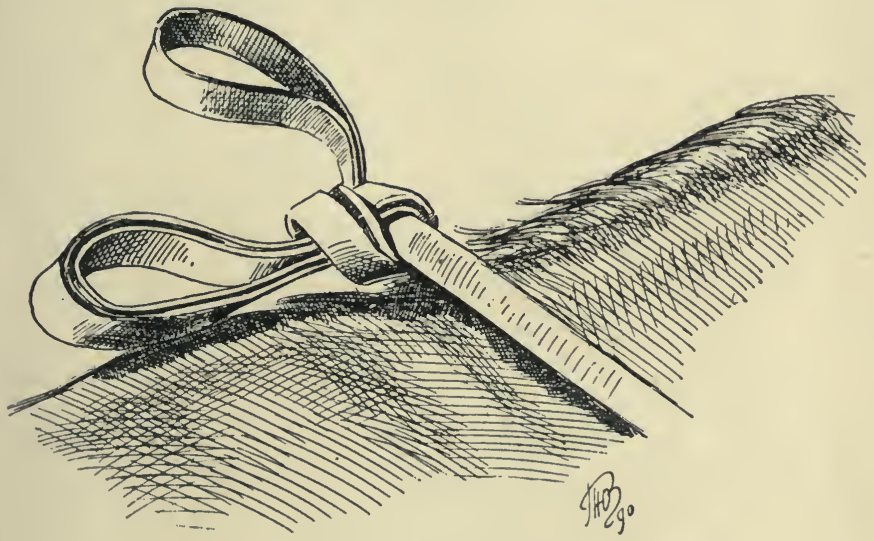

Fig. 169. Tying up a rein.

left rein, driven to the left by the whip on the right, and then abused for answering the natural indication which he has been trained habitually to obey."

TYING UP A REIN.

With double reins, if the rider wishes to use only one, he may put a slip-knot (Fig. I69) on the other, at the desired length, so that he may have it ready to take up at any moment. It should be put well forward on the neck, so that the horse in extending his head, may not be liable to bear suddenly on the bit to which the reins with the slip-knot are attached. "The reins should never be tied in hunting or 
in sivimming a horse, since, by catching across the neck, they act like a bearing rein, and oblige the horse to carry his head up and his nose in. In hunting this would bring his hind legs on his fences, and oblige him to leap from the top of his banks and to land all fours, instead of extending himself and letting himself down gently. In swimming, it obliges him to keep his whole head and neck out of water. I very nearly drowned a horse in this way in the Serpentine" (Colonel Greenwood). 


\section{CHAPTER VII.}

\section{MOUNTING AND DISMOUNTING.}

Before Mounting-Mounting with Stirrups-Mcunting with Stirrups in Military Style-Mounting without Stirrups-Getting a Leg Up-Mounting during Movement-Dismounting when Halted-Dismounting with Stirrups in Military Style.

\section{BEFORE MOUNTING}

IT is desirable for the rider, unless he has saddled and bridled the horse himself, to see that these operations have been carried out correctly; and that the stirrups are of the proper length.

After a little practice, the rider will be able to get the approximate length of his stirrups before mounting, by measuring them with his arm. This will be about the distance of the tips of the fingers to the arm-pit, when the arm is held straight (Fig. I70). The shape of the horse or saddle may cause this length to vary a hole or two, one way or the other.

\section{MOUNTING WITH STIRRUPS.}

I. As a rule, if the man and horse be of proportionate height, it is best for the former to stand a little to the left front of the near shoulder of the latter, take up the reins with the left hand, and lay hold of the mane with it, about half way up the neck. He takes the stirrup in the right hand, at the part where the leather goes through the eye of the iron, places the left foot in the stirrup, and puts the right hand well over on the off side of the cantle (Fig. I7r), so that he may not disarrange the position of the saddle when mount- 


\section{i7O MOUNTING AND DISMOUNTING.}

ing. By standing at the left front of the shoulder, the man will be in the best position to get into the saddle, if, when he puts his left foot in the stirrup, the horse moves forward. $\mathrm{He}$ will also be out of the way of danger, in case the animal hits out with his near fore, or cow-kicks with his near hind. $\mathrm{By}$ placing the left hand well up on the crest, the rider ensures for himself a short hold of the reins, in the event of the horse

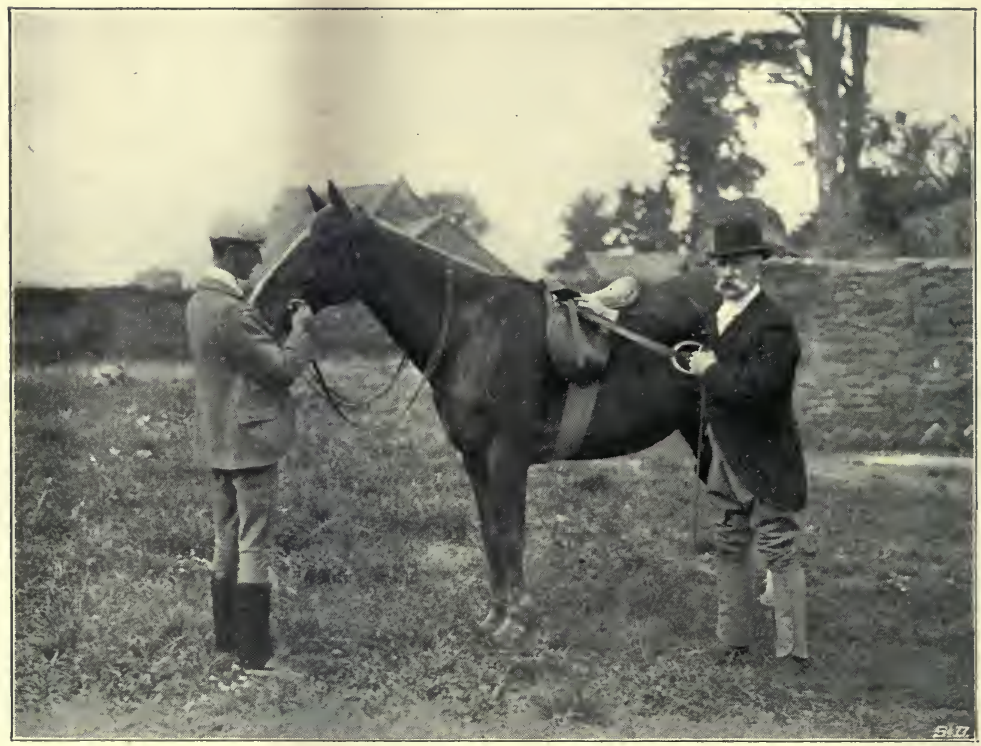

Fig. I70. Measuring length of stirrup leathers.

wanting to start off the moment he feels weight on his back. Besides, by having his hands well separated, the rider is able to balance himself better when mounting, in the event of the horse moving, than he could do if his left hand was on or close to the pommel. If he is below middle height, he may have to stand close to the horse's flank, so as to reach the stirrup with his left foot. In this position, however, he will run the risk of being cow-kicked if the horse be vicious. If 


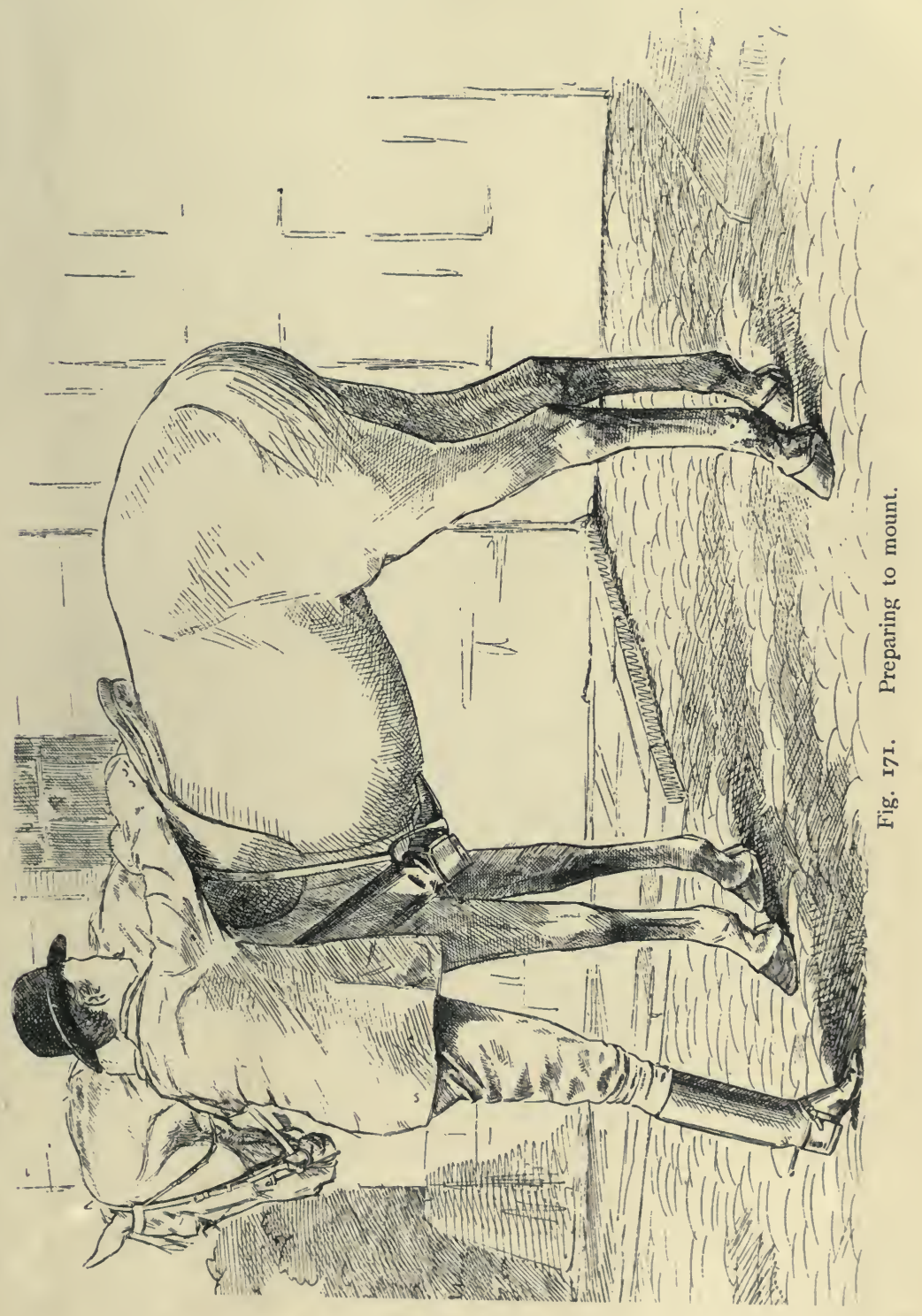


he is of very short stature, he may not be able to reach the cantle, in which case he will probably be obliged to steady himself by catching hold of the flap of the saddle. If tall enough, he should spring smartly up into an erect position, with his foot in the stirrup, his left hand on the mane, and his right hand on the off side of the cantle. He should then swing his right leg over, with the knee nearly if not quite straight, and at the same moment he should let go the cantle. The act of mounting, from the time the right foot quits the ground, till the rider "drops" lightly into the saddle, should be done in one easy and graceful motion, or with only a very slight pause before swinging the right leg over. The left hand now quits the mane, and the right foot takes the stirrup. If the horse is fidgety, the rider may have to steady the off stirrup with his right hand, while the foot is being put into the iron.

It looks very slovenly for a man in the act of mounting, to throw his right leg over with a bent knee, or to "climb" into the saddle in a laboured manner. When preparing to mount, it is a bad practice to try to put the left foot in the stirrup, without holding the iron with the right hand at the same time, so as to avoid touching the horse with the toe, which would be likely to make him unsteady to mount. In fact, merely poking the toe at him, has sometimes that effect. For the same reason, we should avoid touching the horse with the right foot when taking up the off stirrup.

If the animal is difficult to mount, the rider when trying to get on his back, may find it helpful to shorten the near rein (Fig. I72), so as to prevent him from getting away. The horse will then be forced, unless he be very headstrong, to go round and round the man, instead of moving forward. If, on the contrary, the off rein be shortened, the man will lose control as soon as the animal begins to revolve, for he will then be on the outside, instead of the inside of the circum- 
ference of the circle described by the horse. When the rider has his left foot in the stirrup, his left hand well up on the crest and holding the mane, and his right hand on the cantle; he should be able to get into the saddle if he is at all active, or rest himself, foot in stirrup, even if the horse moves forward, or begins to "dance about."

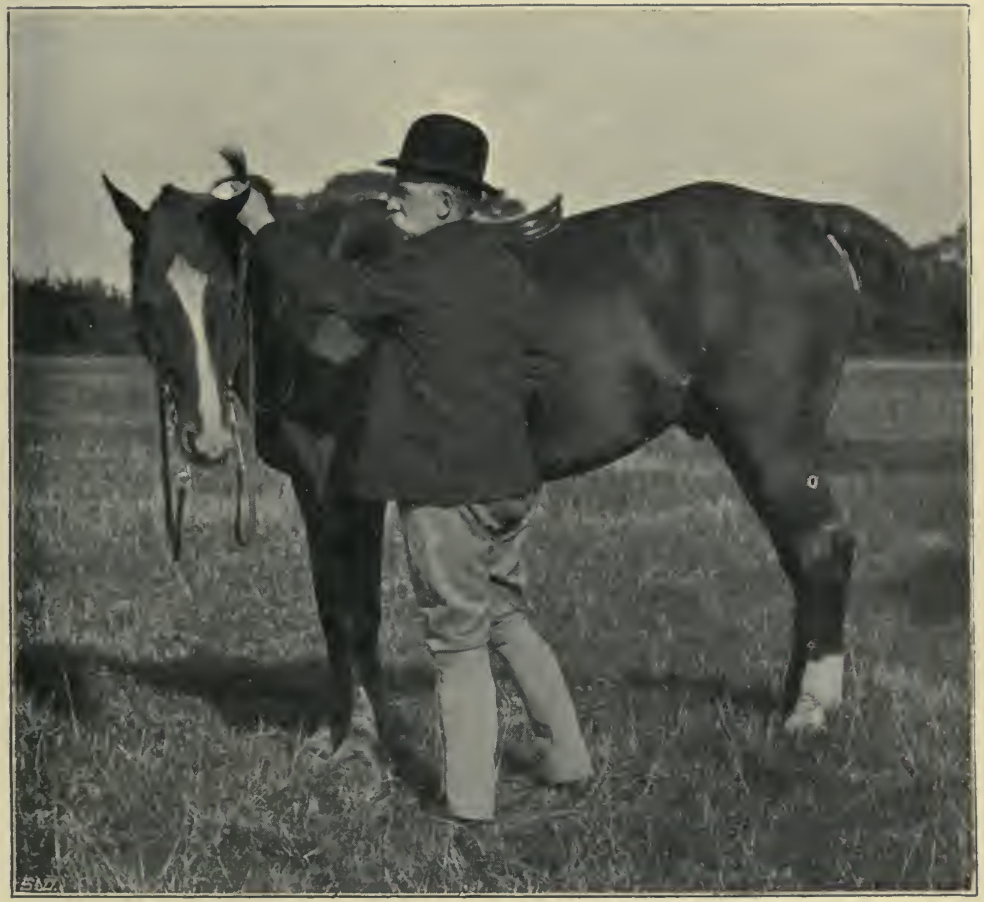

Fig. 172. Bringing horse's head round to near side when mounting.

2. Australian rough-riders, when preparing to mount a difficult horse, as a rule bring the animal's head round, by taking (as already described) a short grip of the near rein, which they hold in the left hand, along with a handful of the mane. They then put the left foot in the near stirrup with the aid of the right hand, taking care not to touch the animal's 
side with the foot; they place the right hand on the pommel; and after a tentative effort or two, they glide into the saddle almost before the horse is aware of the intention. Placing the right hand on the pommel when mounting, is less liable to disarrange the position of the saddle, and consequently to make the animal fidgety (which is specially to be avoided when trying to mount an unbroken animal), than putting it on the cantle, as is usually done. It has, however, the disadvantage of rendering the mounting more difficult for a man who is not very active, than the method of placing the hand on the cantle. These rough-riders, to prevent the horse from seeing what they are doing, frequently before mounting, cover the animal's near eye with a soft hat, cap, or other suitable object, which they insert on the near side, between the cheek piece of the bridle and the side of the horse's head (Fig. I73), and remove it as soon as they are in the saddle. They also, sometimes use a surcingle placed over the pommel in order to prevent the saddle moving forward, in the event of the animal bucking. I do not know which to admire most, the cleverness with which these men mount fractious brutes, or the skill with which they "remain."

With horses which have acquired the unpleasant trick of trying to move on, or of " playing up," the moment the rider, after having placed his left foot in the stirrup, attempts to mount; the plan of placing the right hand on the off side of the cantle gives the rider a much firmer support, supposing that he has only the left foot in the stirrup and has not brought his right leg over, than the method of placing the right hand on the pommel when mounting. Hence it is to be preferred in all cases, except in that of horses which are unaccustomed to a saddle. Experience teaches us that among horses which have been ridden several times, very few of them will be irritated by the right hand being placed in mounting, on the cantle, especially on its off 
side. But, as we all know, there are a great number of horses that are ridden every day and are more or less difficult to mount, on account of the disagreeable trick in question, which is much more disconcerting to the man who is in the act of mounting, when his hand is on the pommel, than when it is on

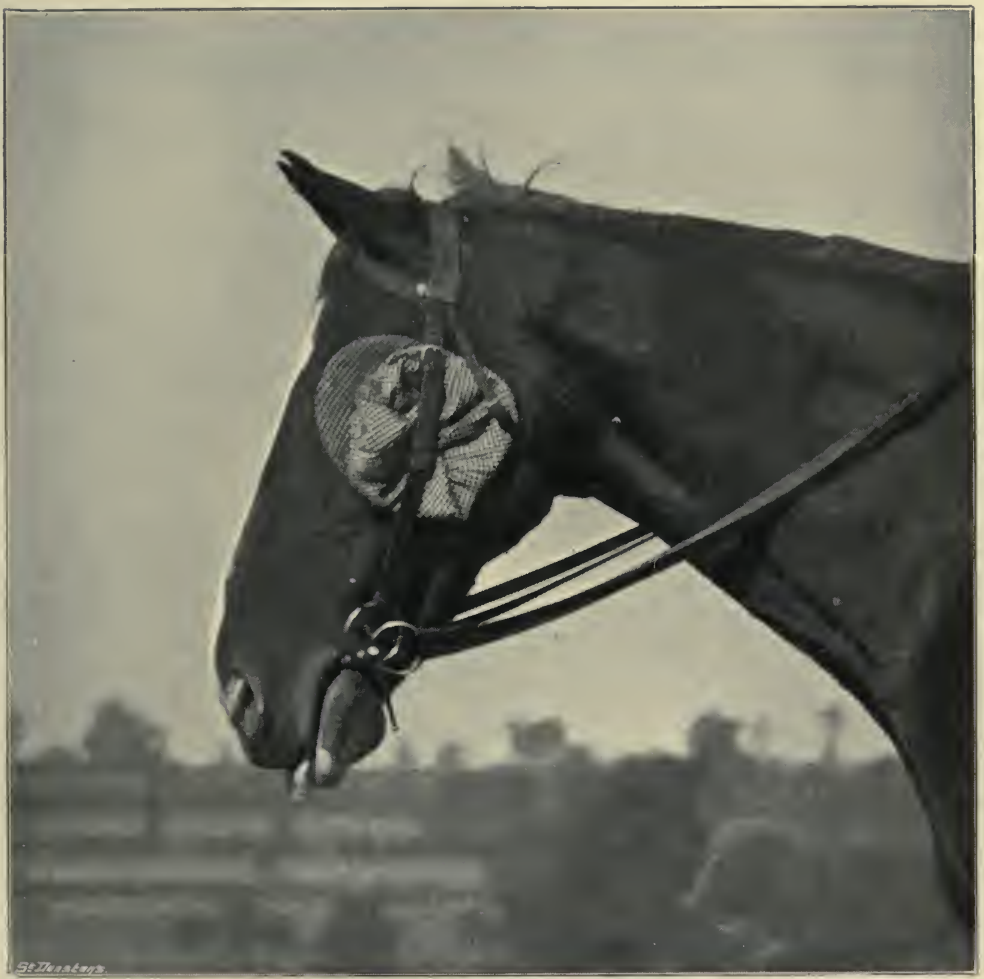

Fig. 173. Covering a horse's near eye with cap.

the cantle. Consequently, however suitable the former plan may be for animals that are being mounted for the first few times, the latter is the better for general use.

3. When attempting to mount fidgety horses or ponies which have hogged manes, we may in the first instance catch 
the animal by the left ear (in Colonial style), or by the crownpiece of the bridle with the left hand, and then shorten the reins (Fig. I 74).

\section{MOUNTING WITH STIRRUPS IN MILITARY STYLE.}

The action of mounting by this method is divided into "preparing to mount" and "mounting." The motions may be briefly described as follows :

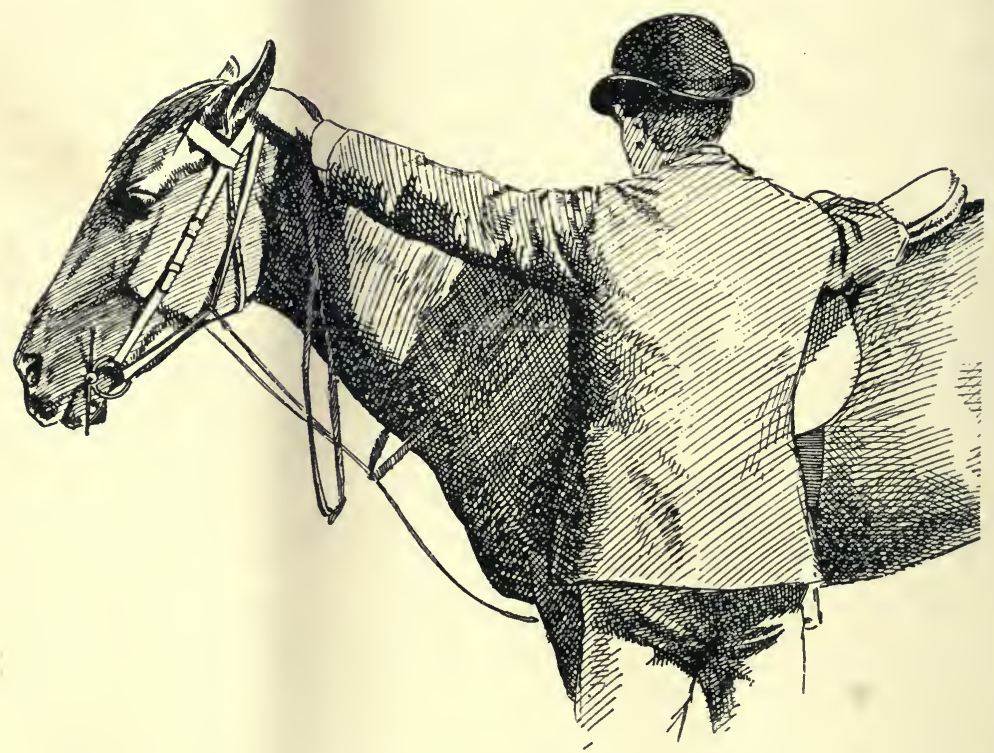

Fig. I74. Preparing to mount hogged maned pony.

Preparing to Mount.-I. Stand facing the horse with the right foot opposite the:stirrup, and the heels about six inches apart. Place the left hand on the crest of the horse, about twelve inches from the pommel. 2. With the right hand draw the reins through the left hand, so as to obtain a light and equal feeling of both reins on the horse's mouth. 3. With the right hand throw the slack of the reins to the off side, twist a lock of the mane round the left thumb, and take hold of the 
left stirrup. 4. Place the left foot in the stirrup, the left knee against the flap of the saddle, and the right hand on the cantle. Draw the left heel back, so as to avoid touching the horse's side with the toe (Fig. I75).

Mounting.-I. By a spring of the right foot, raise the body

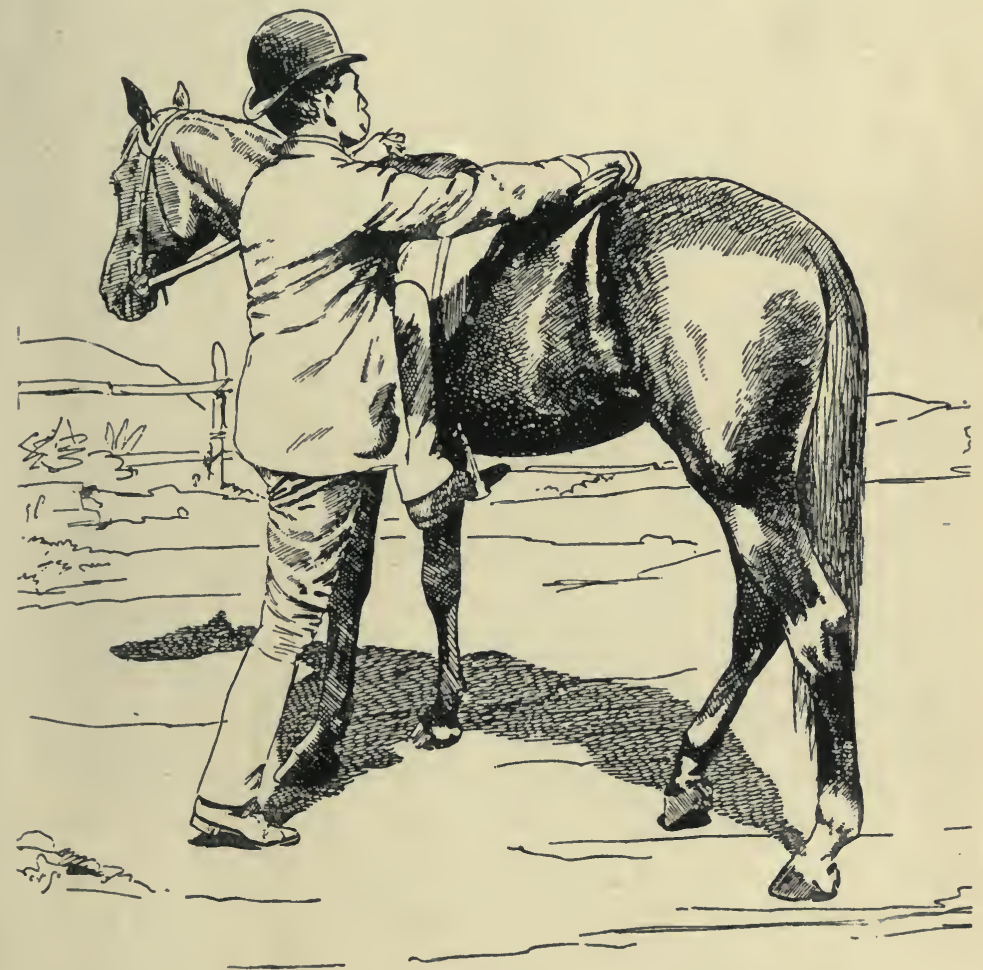

Fig. 175. Preparing to mount in military fashion.

erect in the stirrup. Bring both heels together and draw them a little back. Keep the knees firm against the saddle, and the body partially supported by the right hand. 2. Swing the right leg over the cantle, which the right hand quits just in time to get out of the way of the right leg, and goes to the pommel so as to support the body, which falls gently into the 
saddle. 3. The left hand quits the mane, and the right the pommel. The reins are taken up at a proper length and the right foot is placed in the off stirrup.

\section{MOUNTING WITHOUT STIRRUPS.}

If a man be active and of a height proportionate to that of the horse, he may mount in this manner by taking the reins and mane, about half way up the neck, in the left hand, placing the right hand on the pommel, and then vaulting

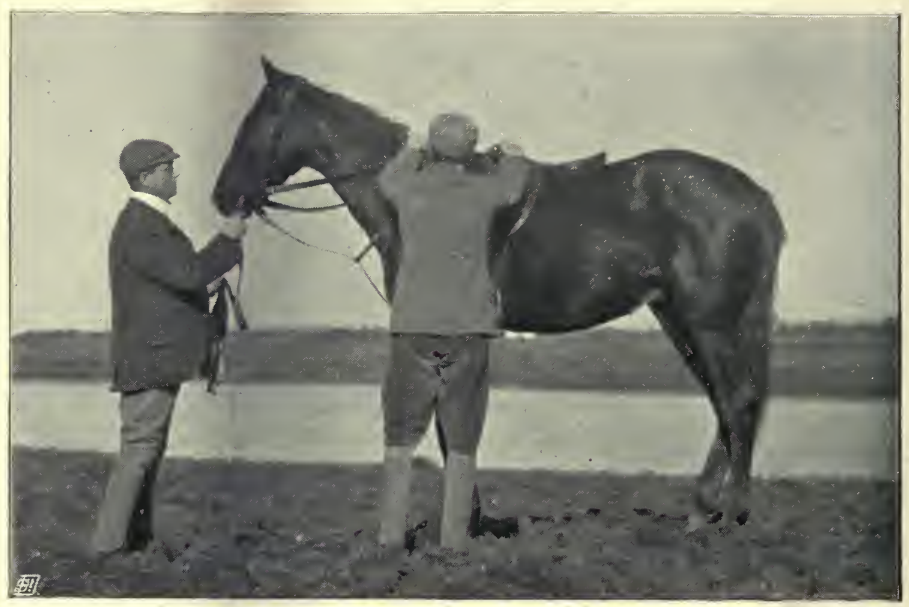

Fig I75. Riding lad preparing to mount.

lightly into the saddle. Mounting without stirrups according to the Cavalry Regulations, by placing the left hand on the pommel and the right on the cantle, and then supporting the weight of the body on both hands, before throwing the right leg over, may do well enough with a steady school horse, but it is a dangerous and unworkmanlike proceeding with any animal which is not a mere machine; for if the horse moves after the would-be rider has made his spring and before he is safely in the saddle, he will run the risk of getting a fall, or of having to let go the horse. But, with the left hand on the 
mane and the right hand on the pommel, even if he fails to mount, the horse cannot very well break away.

Lads in training stables usually mount by placing the right hand on the pommel of the saddle and taking hold of the mane about a third of the way up the crest, while standing by the side of the horse's near shoulder (Fig. I76). They then spring up, so as to rest the weight on the animal's withers, and bring the right hand to the off side of the saddle (Fig. 177). Nothing now remains but to throw the right leg over the

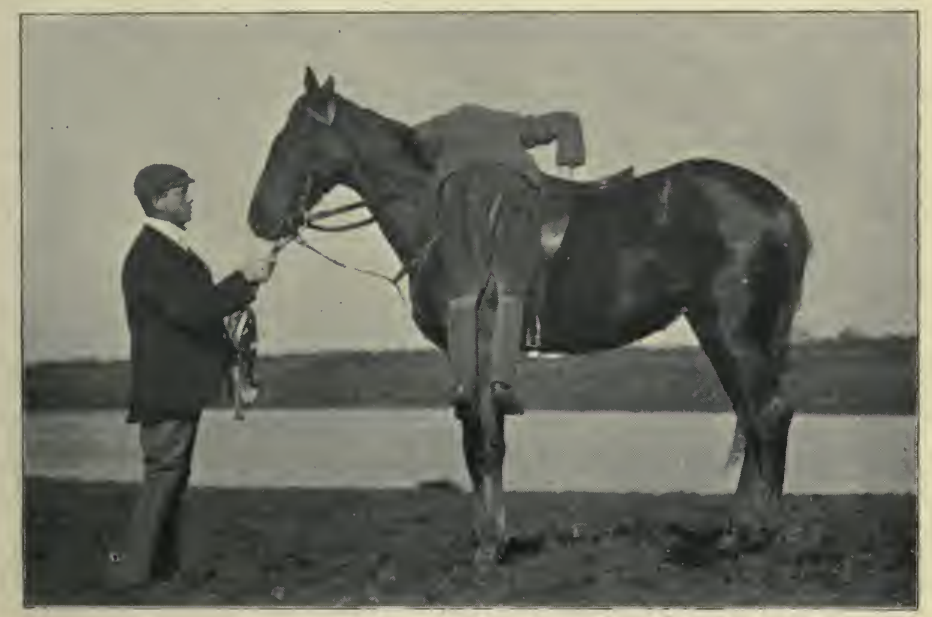

Fig. 177. Riding lad bearing his weight on horse neck when mounting. saddle, and to pick up the stirrups. If a lad is active, though short, he can mount while the horse is walking on, as well as while he is standing, and without the animal being held.

\section{GETTING A LEG-UP.}

- A man should always get a leg-up, especially if he be at all heavy, with a light saddle, say, one not over four pounds weight; because mounting in the ordinary way would be apt to damage it. With a racing saddle, the jockey should take the reins in his left hand, which he should place on the mane 
if he can reach it. If tall enough, he should place the flat of his right hand on the centre of the saddle, and not on the cantle, lest by bearing his weight on the cantle, he might hurt the tree. He should then raise his left foot off the ground, and the man who is going to give him a leg up, should take hold of his left leg, just above the foot, with his right hand (Fig. I78), or, if the rider is comparatively heavy, he may

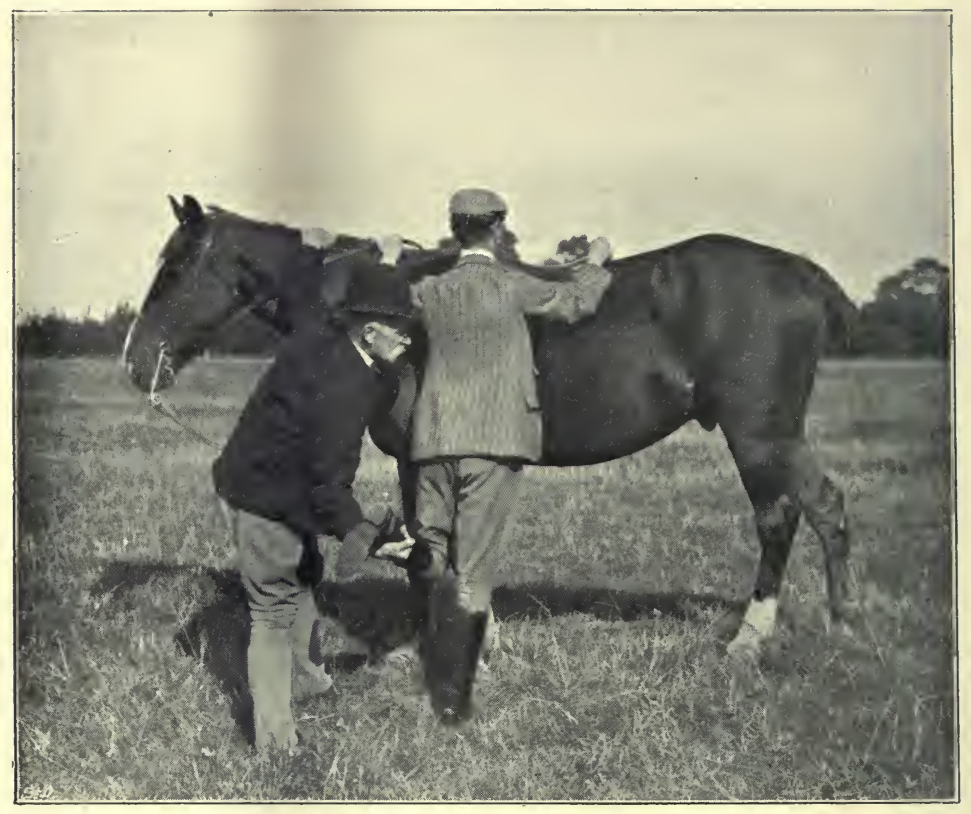

Fig. 178. Getting a leg-up.

place his fore-arm underneath the rider's left leg, close to the foot, steadying himself the while with his left hand on the horse's mane, and should raise him up without giving any jerk, which might cause him to come heavily down on the saddle, or might cant him over to the other side. The jockey being raised to the proper height, brings his right leg over the saddle while steadying himself with his left hand on the 
mane, and with the flat of his right hand on the centre of the saddle. He then sinks carefully down in the seat and takes the stirrups. If the saddle be a very light one, the jockey when getting into it, should bear the weight of his body on his thighs, and should not plump suddenly down in the saddle lest he might injure the tree. The same method of mounting may be adopted with an ordinary saddle, though the precautions I have described against breaking it need not be observed.

\section{MOUNTING DURING MOVEMENT.}

As directed by Colonel Greenwood, the rider should hold the reins and mane in his left hand and the pommel with his right, and then spring into the saddle, after taking a few steps along with the horse. This is much easier to do when the horse is in movement than when he is standing still, and is a very useful feat to learn. Being able to mount in this manner may, after a fall, save a man from being thrown out during a run, or from losing a steeplechase.

The best way to learn to mount in this manner, is on a horse lunged by another man, or on an animal in a small circular track, like that of a circus. At first it is well to have a steady horse that has been taught to do a slow, wellcollected canter, which is the easiest pace for mounting in this manner. A pair of side reins, shortened as may be necessary, will help to collect the horse without entailing trouble on the rider, who will generally have quite enough to do in looking after himself. If the horse is not very quiet, it is better to lunge him with the "long reins" than with a single lunging rein and a caveson; for far more control can be obtained by the former than by the latter.

DISMOUNTING WHEN HALTED.

I. The readiest way is to take the reins in the left hand, draw them through it, and grasp the mane about half way 
up the neck, catch the pommel with the right hand, take the feet out of the stirrups; and spring lightly down, landing about on a line with the point of the horse's shoulder. If the active horseman wishes to remount while the animal is moving on, he has only to take two or three steps forward without shifting the position of his hands, to enable him to spring back into the saddle. The following method is, however, the usual way. It is best for men who are not quick on their legs, and is somewhat similar to the one laid down for the cavalry soldier.

2. Place the left hand with the reins in it on the mane about half way up the neck, and put the right hand on the front of the right flap of the saddle (Fig. I79). Take the right foot out of the stirrup, swing the leg with a straight knee over the cantle, place the right hand on the pommel, or on the off side of the cantle, whichever comes the easier, alight on the ground, with the right foot to the left front of the animal's near shoulder (Fig. I80), and remove the left foot from the stirrup. The right hand is placed on the front of the off flap, in preference to placing it on the pommel, both for safety's sake, in the event of the horse making any violent or unexpected movement, and to avoid the risk of causing the saddle to shift its position. I have taken for granted that the rider is at least of average height. It looks very awkward for a man when dismounting, to bring his right leg with a bent knee, over the saddle, and to get off "all of a heap." When dismounting, as well as when mounting, the body should be kept erect, and the different movements should be performed with smartness and precision, but without any appearance of stiffness or exaggerated gesture. We may take for granted that every motion of the horseman ought to be characterised by grace.

An inexpert rider, especially if his horse is fractious, will be much assisted in dismounting by the groom standing in 
front of the animal and holding its head by the snaffle reins, one in each hand, and three or four inches from the rings on each side. The horse's mouth should be held somewhat higher than its withers, both for appearance sake and for

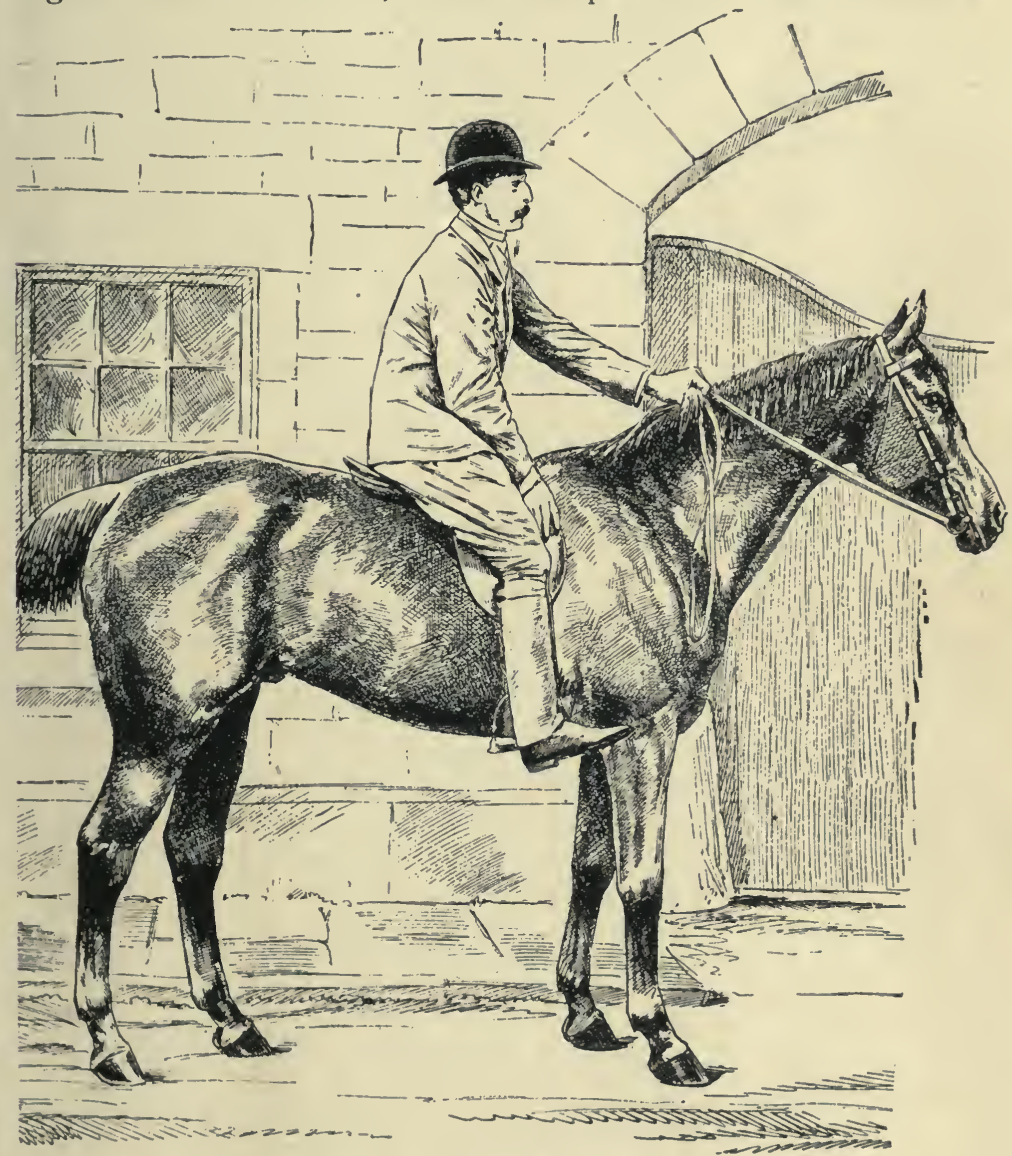

Fig. 179. Preparing to dismount.

obtaining increased control. If there be no snaffle, the groom should hold the cheek-pieces of the headstall of the bit, and not the curb reins; for if these reins are grasped and the horse happens to throw his head about impatiently, 
he will be liable to receive a painful shock from either mouth-piece or curb-chain, or from both, and consequently to rear or to make some other effort to escape from the control of the man who is holding him.

I wish to draw special attention to the necessity of every riding horse being taught to stand quietly to be mounted without being held by a groom or other assistant; because any horse which requires this to be done, is dangerous to mount when held by an inexperienced person, who might from ignorance cause a serious accident from holding the animal in a wrong way, letting him go too soon, or hanging on to his head too long. Under ordinary conditions, it would be impracticable to have a capable man always at hand for this particular duty.

\section{DISMOUNTING WITH STIRRUPS IN MILITARY STYLE.}

The action of dismounting is here divided into "preparing to dismount" and "dismounting."

Preparing to dismount.- I. The right hand takes hold of the reins behind the left, and the right foot quits the stirrup. 2. The left hand slides forward on the reins, until it is about twelve inches in front of the pommel. 3. The right hand throws the slack of the reins to the off side, takes a lock of the mane, brings it through the left and twists it round the left thumb, and the fingers of the left hand close on it. The right hand is then placed on the pommel or off holster, and the body is kept erect.

Dismounting.-While supporting the body with the right hand and left foot, the right leg is brought gently (without touching the horse's hind quarters or the saddle) to the near side, heels together. 2. The body is gently lowered until the right toe touches the ground. 3. The left foot quits the stirrup and is placed in a line with the horse's fore feet; the position of the hands remaining unaltered. 4. Both 


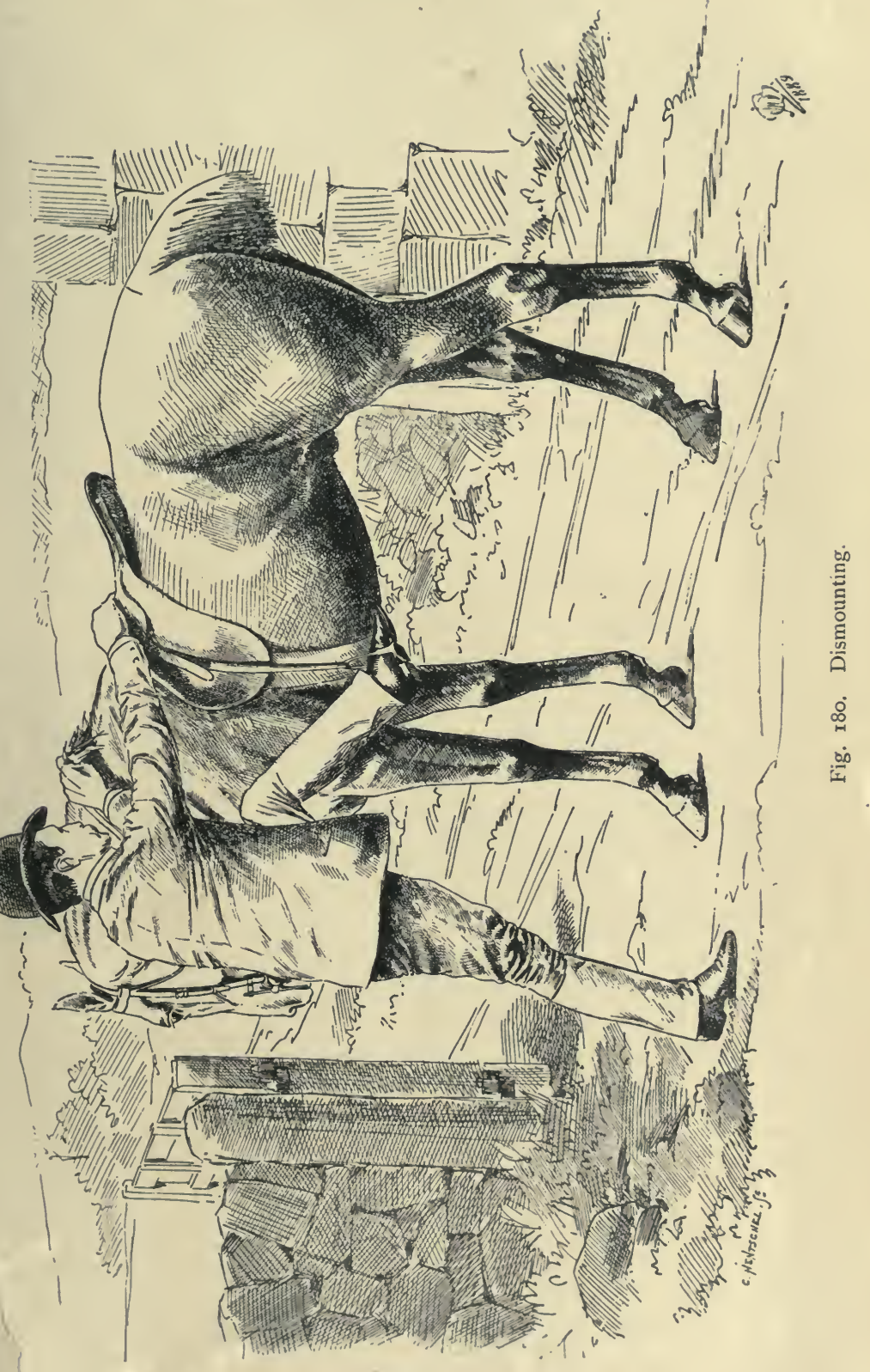


hands quit their hold, and the man turns to the left on the left heel and brings the body square to the front. During the turn, the right hand lays hold of the rein near the ring of the bit, and raises the horse's head as high as the man's shoulder.

\section{DISMOUNTING DURING MOVEMENT.}

Dismount by the first method, which is described on pages I8I and I82, taking care, if the horse is going fast, to support the weight for a moment on the hands and to throw the feet forward. This can be done at any pace by an active man or boy. 


\section{CHAPTER VIII.}

\section{THE SEAT.}

Classification of Seats-Differences of Seat in various kinds of Riding--The Hunting Seat-The Military Seat.

\section{CLASSIFICATION OF SEATS.}

Speaking generally, we may class the seats appropriate to different kinds of riding, under the respective headings of the hunting seat, the flat race seat, and the military seat. The hunting seat may be taken as the representative one for work with hounds, "between the flags," hacking, and rough-riding ; and the military seat for military riding and school equitation. The seat for polo may be looked upon as a combination of the hunting and military seats. The old English seat for flat race riding is nearly the same as that for hunting, and the "crouching seat" will be noticed further on.

\section{I)IFFERENCES OF SEAT IN VARIOUS KINDS OF RIDING.}

In the Army, the necessity for uniformity of appearance and regularity of movement, render routine and horse control of paramount importance. Besides, in it the men are more of a size and more nearly of the same age than in civilian life. Hence, every mounted soldier has to assume as nearly as possible one particular kind of seat (that laid down in the Cavalry drill book), irrespective of individual differences in conformation, and has to keep his feet drawn back, so that he may be ready at any moment to apply 
one or both legs as an "aid." Having only one hand on the reins, he has to rely more on the legs to guide his horse than a hunting man would have to do. As the assumption of the initiative is never allowed to the high school horse, and but seldom to the trooper, both have to be kept far more in hand by reins and legs than an ordinary riding horse, whose cleverness and intelligence will often extricate his rider out of a difficulty. In polo, the demands for control over the horse are nearly similar to those in military riding; hence there is little difference in the seat for either of these two purposes, except that at polo, as in hunting, uniformity of appearance is not a matter for consideration. As our Cavalry have to perform over rough ground in the open, as well as on parade and in the school, it would be desirable if they were taught to vary their seat according to circumstances; but as this is not practicable, our military authorities have wisely introduced a seat which is a compromise between the academic school seat and the hunting seat.

In hunting and race riding, the great object is to enable the horse to do his work with the least possible fatigue to himself. Consequently, the rider should not only interfere with him as little as practicable, but should also conform to the animal's movements, which he could not do if he were obliged to maintain a rigidly uniform kind of seat, to say nothing about the resulting fatigue to himself. There is no difference in the seat for hunting and for steeplechasing, in both of which, men usually ride a hole or two shorter than when hacking; because they have greater necessity to be able to lean back at times. Also, it is less fatiguing to ride with stirrups which are a trifle short than with those that are slightly long. The respective seats adopted by the generality of Australian rough riders, American cow-boys and Cossacks, for instancé, are those which are specially suitable to their saddles. As regards hunting, we should not forget 
that although utility is the first consideration; fine horsemanship is usually accompanied by the possession of an easy, graceful' seat.

\section{THE HUNTING SEAT.}

The best position for a man to assume in the saddle when riding across country or for ordinary purposes, varies so much in individual cases, owing to differences in conformation, that no good purpose would be served by trying to lay down rigid rules as to the seat. All that can be usefully done in this respect is to discuss principles which can be applied according to circumstances.

A man should ride by the combined aid of balance and grip of the legs, the latter being exerted only just enough to assist the former in retaining the body in proper position. In this manner, any disturbing sway of the body will be prevented, and the muscles of the legs of the rider will remain untired, and consequently capable of gripping the saddle in a moment with the tenacity of a vice, in the event of the animal making any untoward movement. If grip predominates over balance, not only will the muscles of the legs become fatigued, but the attitude will be characterised by stiffness, which we all know is incompatible with good horsemanship.

Almost all the precautions of seat as far as grip is concerned, should be taken with the view of preventing the rider from being thrown forward on sudden provocation (Fig. I8I). The fact of the hands having hold of the reins ensures the rider from falling over the horse's tail, in the event of the animal starting forward from the halt or moving to the rear, which, from his conformation, he is unable to do very quickly. As any pull on the reins given by the horse is transmitted through the arms to the shoulder joints, and as these joints are at a comparatively long distance from the centre of 
gravity of the rider's body; the power which he obtains from the reins in preventing his body from going in a backward direction, acts to great mechanical advantage. In endeavouring to save himself from being moved unduly forward out of the saddle, it is necessary for the rider to have a fairly broad base of support, and to have the means of preventing his centre of gravity from being carried beyond it. The base of support in question is formed by the thighs and lower

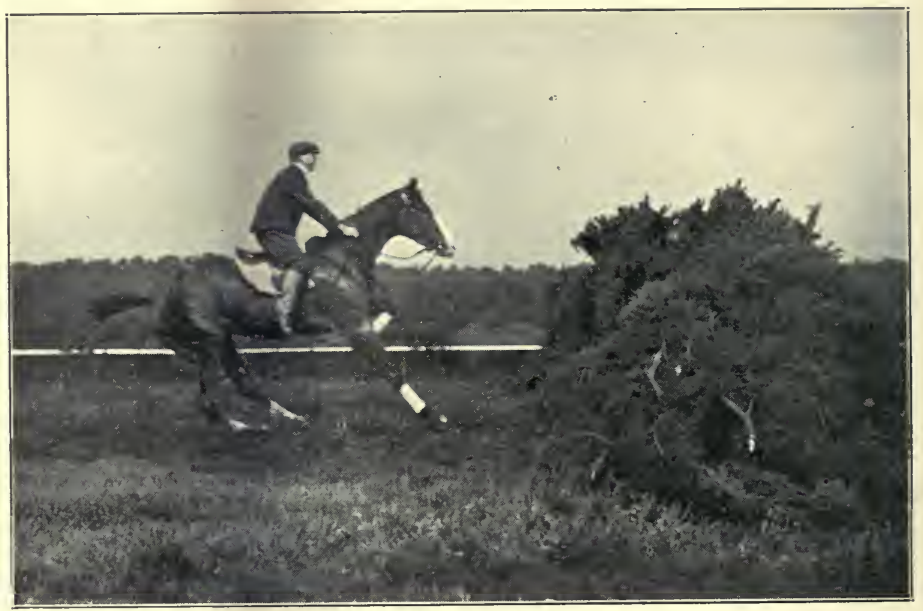

Fig. 181. Stopping short.

bones of the pelvis. Hence the thighs should be kept in a sloped position, and not perpendicular. The degree of their slope must however be compatible with ability on the part of the rider to apply the lower portion of his legs to the animal's sides, so that he may be able to direct, control, and stimulate the movements of the horse, as I shall try to explain later on. In this compromise, the length and shape of the rider's legs will naturally have to be considered. Thus, a short-legged man will have to ride with comparatively longer stirrups than a long-legged individual. 
In order to obtain all the adherence that is possible from friction between the thighs and saddle, the rider should get down into the saddle as much as he can. In fact, one of the great advantages of practising riding bare-backed, or on a saddle without stirrups, is that it forces the rider into the saddle. As the ribs of a horse swell out behind the girths, the rider who gets well down into the saddle will sit forward in it. We may often hear people say that a man ought to sit well back when going over fence ; but the fact is, that in such a case he should sit forward and lean back.

Both for security of seat and for ability to accommodate himself to the movements of his mount, the rider should be able to bring his weight back with the utmost facility; but of course without having to alter the position of his thighs and knees, because that has been adopted with the object of obtaining the best possible grip. If we examine the mechanism by which the rider can adjust the position of his centre of gravity, we shall find that the upper part of the body can freely revolve on the lower edge of the pelvis as a pivot (its connection with the legs being maintained by the hip joints); and that a much smaller amount of backward and forward rotation can be obtained by the working of the joints of the spinal column (those of the loins, back and neck). Hence it is well for the rider to sit with his rump well under him, and the pelvis sloped a little to the rear (Fig. I82), in the natural and unconstrained position a man would sit on a chair or stool. The more the rider gets into the saddle, the greater will be the backward slope of the pelvis, and consequently the stronger the seat. If, on the contrary, he sticks his rump out behind him (Fig. 183) -instead of sitting on it as he ought to do-he will naturally decrease his stability by bringing his centre of gravity forward. Any attempt to correct the position of the centre of gravity by hollowing out the back (Fig. I83), can be made 
only by continued muscular contraction, and would therefore be objectionable.

As the movements of the horse at each stride, especially in the canter and gallop, tend to cause the rider's body to be

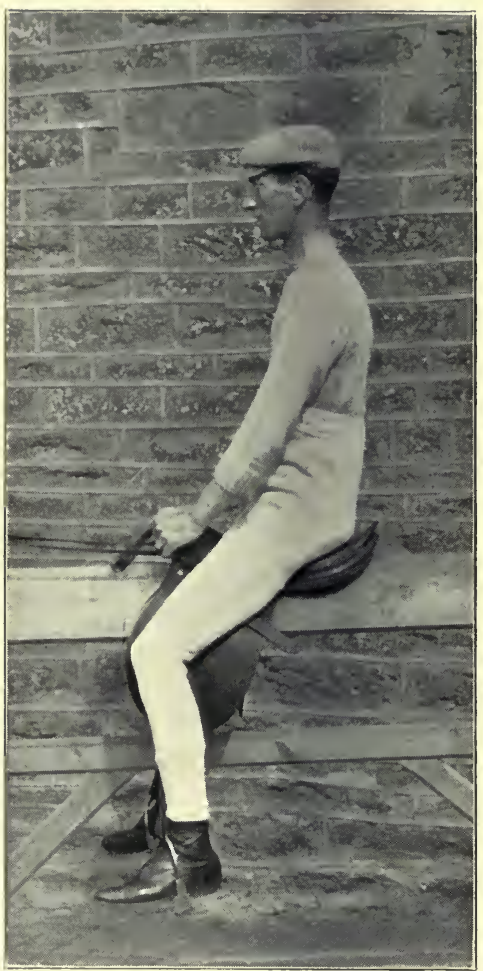

Fig. 182. Sitting easily.

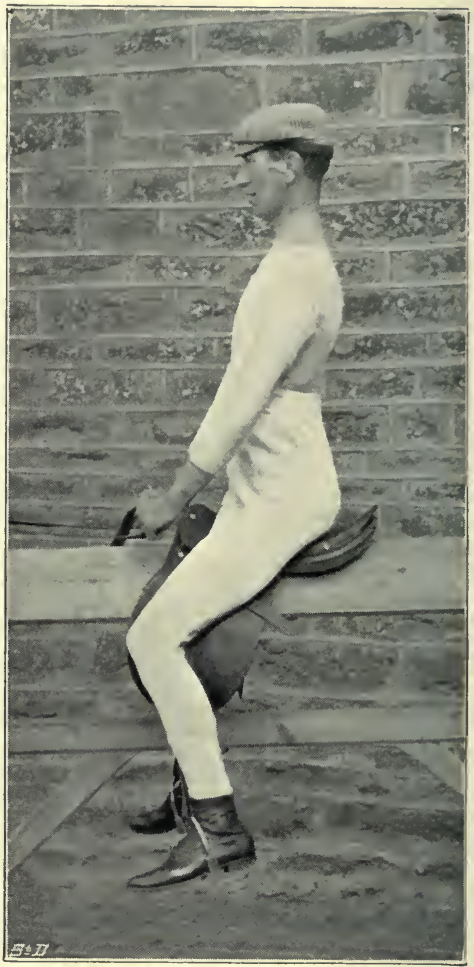

Fig. 183. Back hollowed out.

jerked alternately backwards and forwards in a manner that would more or less interfere with the regularity and effective action of the animal's paces; the rider should as much as possible counteract this disturbing action by conforming to the horse's movements, which he can best do by the working of the joints of the hips, aided to a slight extent by those of 
the spinal column, and by maintaining a steady position of the base of support, formed by the thighs and knees. If he carries his feet unduly forward with the knees more or less straight, as is often done with the unconscious object of obtaining an increased bearing on the stirrups, the rider will be liable to be bumped up and down in the saddle at each stride, by reason of the necessarily inelastic nature of the stirrup leathers. Here, the reaction to the downward pressure on the stirrup irons will be transmitted upwards through the legs, with the result of communicating more or less motion to the body. The same thing occurs, though to a greater extent, when a sudden check is given to the speed at which the horse is moving, as for instance, when he lands over a fence in a sticky manner, or "props" after a buck-jump. If on the contrary, the rider keeps his thighs sloped and his legs, from the knee down, in a more or less vertical position, the play of the knee joints will tend to obviate any jerk that may be communicated to the legs by the stirrups, and will greatly save the horse from inconvenience, and the rider from falling off, or at least from bumping up and down.

Apart from the disadvantages of riding with a straight leg which we have just considered, we have the anatomical fact that by straightening the leg, the inner surface of the knee and thigh is rendered rounder than when the knee is bent. For grip we naturally require a flat and not a round bearing surface.

We often see some of our best performers sticking out their feet a good deal to the front; but only when they are "taking things easily." No fine horseman sticks his feet out in front when he "jambs" himself into the saddle and rides "all he knows."

It is evident that the more weight is put on the stirrups, the less there will be on the seat of the saddle. Hence, when a 
rider wants to sit down in the saddle, he should put as little weight as he can on the stirrups.

The grip of the knees acts to greater advantage than that of any part of the thighs, because the bones of the knee stand out prominently from the thigh bone, and the pressure falls more nearly at right angles to the surfaces to which it is applied than it would do higher up the sides of the horse. The more the knees are turned in, the more is the pressure taken by the bony prominences of these joints; and the more they are turned out, the more does it fall on the soft tissues which are at the back of the thighs and knees. It is evident that in getting down into the saddle, the hollow and not the back of the thighs should be applied to the sides of the animal.

As the grip of the knees in all ordinary cases will be applied above the "swell" of the horse's barrel, it will be found that security of seat will be enhanced by also obtaining a certain amount of grip from the calves of the legs, which, as a rule, can be applied below the swell of the barrel. In utilising this pressure from the calves of the legs, care should be taken that the grip of the knees is in no way interfered with. We may observe that, with ordinary shaped legs, the more the rider turns his toes in, the greater will be the preponderance of the pressure from the knees, over that from the calves, and vice versâ. Bad riders who affect plain-flap saddles often afford a good illustration of this fact; for, failing to obtain sufficient knee-hold on the slippery flaps, they instinctively turn out their toes and bring their heels close to the horse, in order to get what grip they can with the calves of their legs, and, presumably, having short stirrups, so as to obtain all possible purchase on them, they show a good deal of "daylight" between the knee and the flap on each side, when viewed from behind or from the front (Fig. I84). The rider who wishes to possess a strong seat should 
therefore keep his feet in a position which will give him a maximum amount of combined grip with the knees and with the calves.
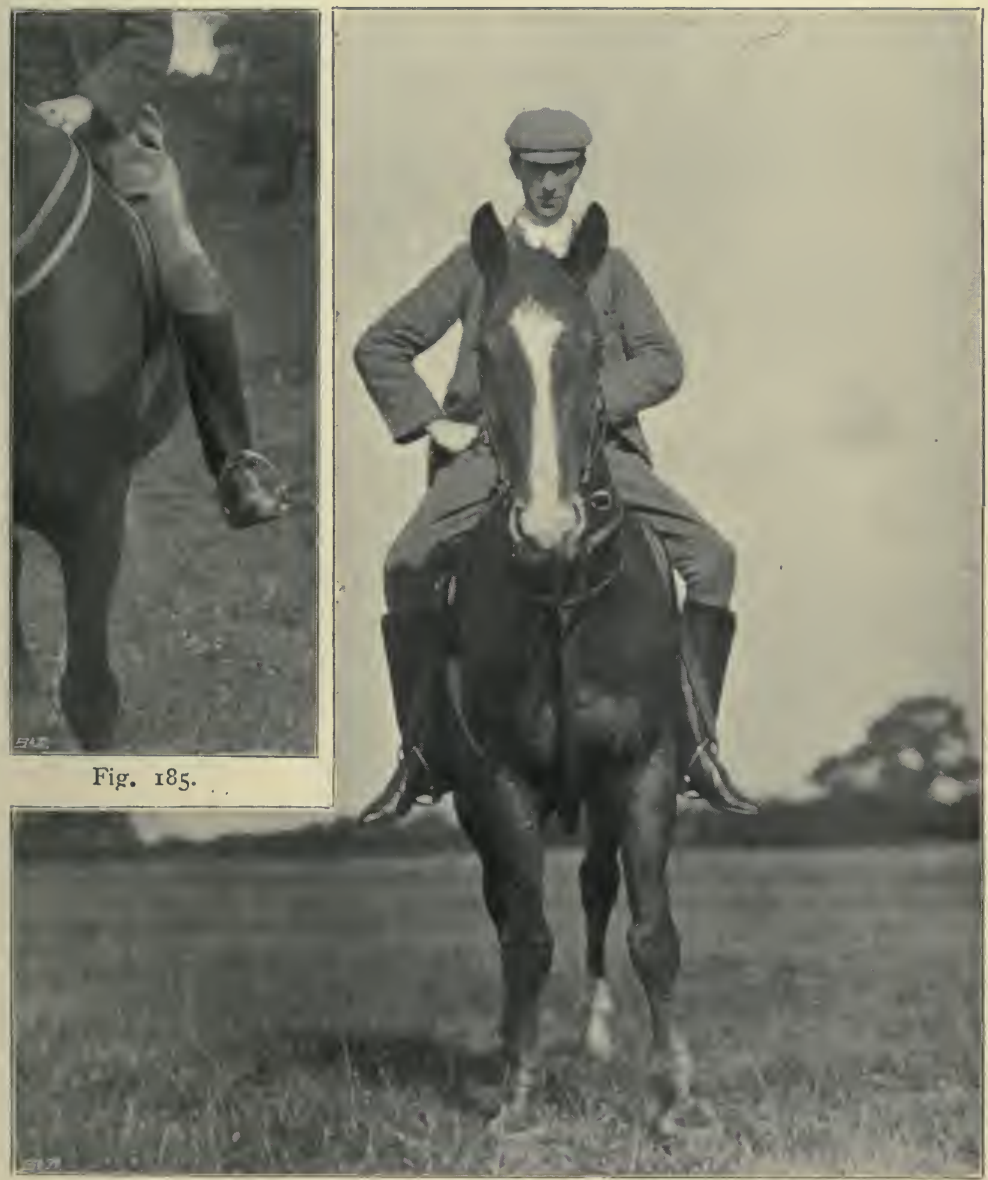

Fig. 184. Daylight showing between knees and saddle.

The best position for the legs greatly depends on their length and shape. It is evident that, in any case, the legs from the knees to the ankles should not be directed inwards, 
as in Fig. I84. I venture to think that the outward direction of the leg in Fig. I 85 may be taken as a maximum. I may point out that the rider in this illustration had particularly long legs. As a man with long flat thighs will be able to get a better grip with the knees than a short round-thighed rider, the former will be more independent of a grip with the calves than the latter, and consequently will be able to keep his feet farther away from the horse. In any case, a rider who wears spurs will do well to keep his feet parallel to the horse's sides (the toes turned neither in nor out); because, in this position, he will not be so liable to involuntarily touch his horse with them as he would be were his toes turned out, in the event of the animal jumping or "playing-up." I would not advise that the toes should be turned in and the heels turned out, as in military riding; because the effort needed to keep the feet in that position would be too fatiguing to be maintained for a period sufficiently long for practical requirements. The usual tendency even of good horsemen is to turn the toes too much out; hence the learner will do well to cultivate the habit of keeping his feet parallel to the horse's sides.

The feet should be put "home in the stirrups" (Fig. I86), so as to avoid any chance of their coming out of the irons. For military and school equitation, the plan of riding with the feet only as far as the ball in the irons, allows the play of the ankles to ease to some extent the bumping up and down motion which the rider unavoidably has, when he does not rise in the trot; and enables the heels to be kept close to the sides more easily than could be done with the feet home. The latter is an advantage only for circus purposes, and, as we have just seen, is entirely opposed to the principles of useful horsemanship. The former has nothing to recommend it from this point of view; because, although bumping up and down in the saddle at a trot may conduce to uniformity 
of seat on parade, it is unnecessarily fatiguing to both horse and rider, and should consequently be eschewed by all practical horsemen who have the liberty to think for themselves. As the position of the knees against the flaps of the saddle should remain as nearly fixed as possible, there should be little or no play of the ankle joints when rising at the trot; such movement being confined to the joints of the knees and hips. Instead of the knees being allowed to move up and down on the flaps of the saddle-as they would do if the ankle joints were kept in play-they should remain in the one fixed position in which they can grip the saddle to the best advantage at any moment. Indifferent horsemen can generally be recognised even at slow paces, by the way they allow their knees to slip about on the flaps of the saddle.

A rider as a rule should avoid putting his weight on the stirrups; for by doing so, he will lessen the power which the knees have of gripping the saddle ; and by necessarily keeping his legs more or less straight, motion which will have a disturbing effect on his seat and on the movements of his mount, will be imparted to his body through the stirrups. The stirrups are, however, a useful aid for holding a puller, and for preventing the muscles of the legs from becoming fatigued.

The heeis should be somewhat depressed, so as to increase the grip of the calves of the legs. If the toes are pointed in a downward direction, the muscles of the calves will thereby be rendered flaccid. Supposing that the feet are kept more or less parallel to the horse's sides, we shall find that the closer the feet are brought to the animal's ribs, the more will the grip of the knees be loosened; but that it will be increased by pressing on the stirrup irons with the inner edge of the boots, the effect of which pressure will tend to carry the feet a little outwards (Fig. 185).

The feet, except when touching the horse, should be kept 
steady, and should not be allowed to work backwards and forwards ; because they should be ready at any moment to be applied with precision to the animal's sides. The shoulders should be kept square to the front and "down"; and the head and body more or less erect, but without any hollowing of the back or other approach to stiffness in the attitude. The rider will then be in the best position to conform to the movements of his mount, and to see where he and his horse are going, and will be in a comparatively difficult one from which to be dislodged. The muscles of the hands, arms and shoulders, should be free from all stiffness, except when the animal is pulling hard, and the elbows should work close to the sides. The act of sticking out the elbows is not only ungraceful, but it also causes the arms to work at a mechanical disadvantage, and obliges the rider to "round" his shoulders, the doing of which will interfere with the free play of the body.

A rider should pay particular attention to the distribution of his weight, with the object of favouring the movements of the horse, in attempting to do which, the body should be free to bend forward, to the rear, or to either side; although the position of the thighs and knees should remain unchanged. As a great rule, too large a proportion of the rider's weight is put on the animal's fore-hand; consequently, the rider should generally lean somewhat back, especially when going through heavy ground, down hill, over fences, or across ridge and furrow.

As the head and neck of the animal act in concert with the movements of the hind limbs; an intelligent rider will soon learn from the "feel" of the reins when he is going fast, to move with the horse, so that his weight may be carried smoothly. The fact that this act of conforming to the movements of the animal is mechanically advantageous, is amply proved by the injurious effect "dead weight" has on a horse's 
staying power. For instance, suppose that two horses of equal merits were to be ridden against each other in a long race by two capable and equally good jockeys, and that although they were to carry the same weight, one being lighter than the other, had to put up, say, two stone of lead, it is abso-

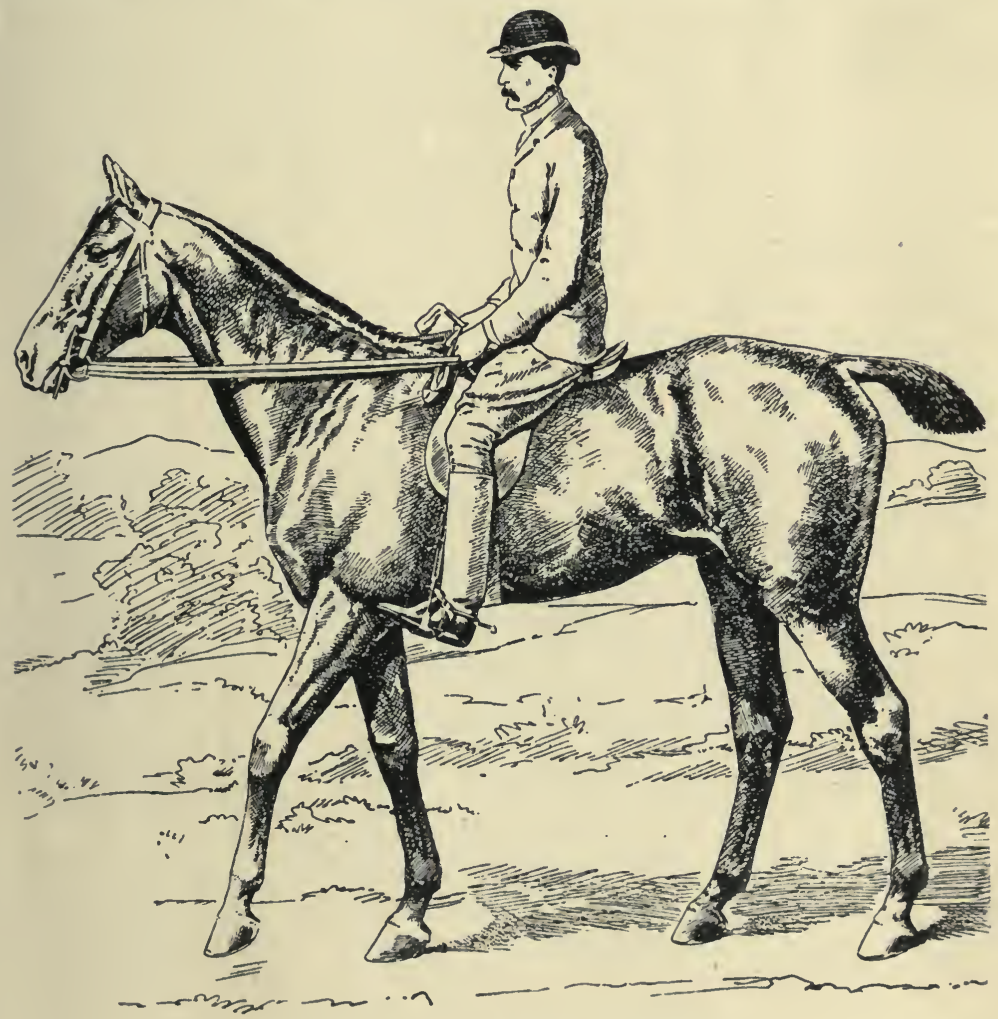

Fig. 186. Hunting seat at the walk.

lutely certain, if both were to ride the race in the same way, that the jockey who had to put up dead weight would lose.

It is manifest that the best seat for ordinary riding is a combination of convenience for the rider and of mechanical advantage for the animal which has to carry the weight. The 
former condition can of course be readily determined and may be assumed as that in which the body and head is held more or less erect in an easy manner. But the latter, owing to the varying nature of the special circumstances in each case, does not admit of exact definition. On referring to Chapter III., we see that the forward motion of the horse consists essentially of propulsion by the hind legs, and raising of the weight by the fore legs, which act in the gallop more or less like the spokes of a wheel without a tire. Although the production of instability of equilibrium (pp. I4 and I6) favours speed,

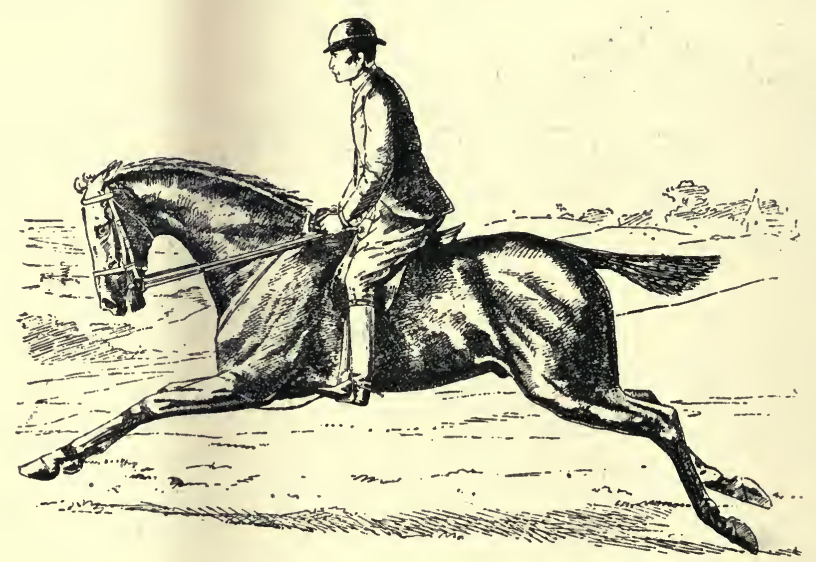

Fig. 187. Hunting seat at the gallop.

it militates against the staying power of the horse and against the soundness of his fore legs by surcharging his fore-hand.

The seat of the rider should conform to the pace and speed at which the horse is travelling, and should consequently be varied according to circumstances. Mr. Oswald Brown has endeavoured to indicate these differences in Figs. 186 and I87.

The length of the stirrups with the seat described, will enable the rider to clear the pommel of the saddle easily when 
he stands up in them (Fig. I88), and as a rule will bring the lower part (the "tread") of the stirrup irons a little below the ankle joints, when the feet are taken out of the stirrups and allowed to hang down. In short, the length of the stirrups should be that which will assist the horseman in assuming a

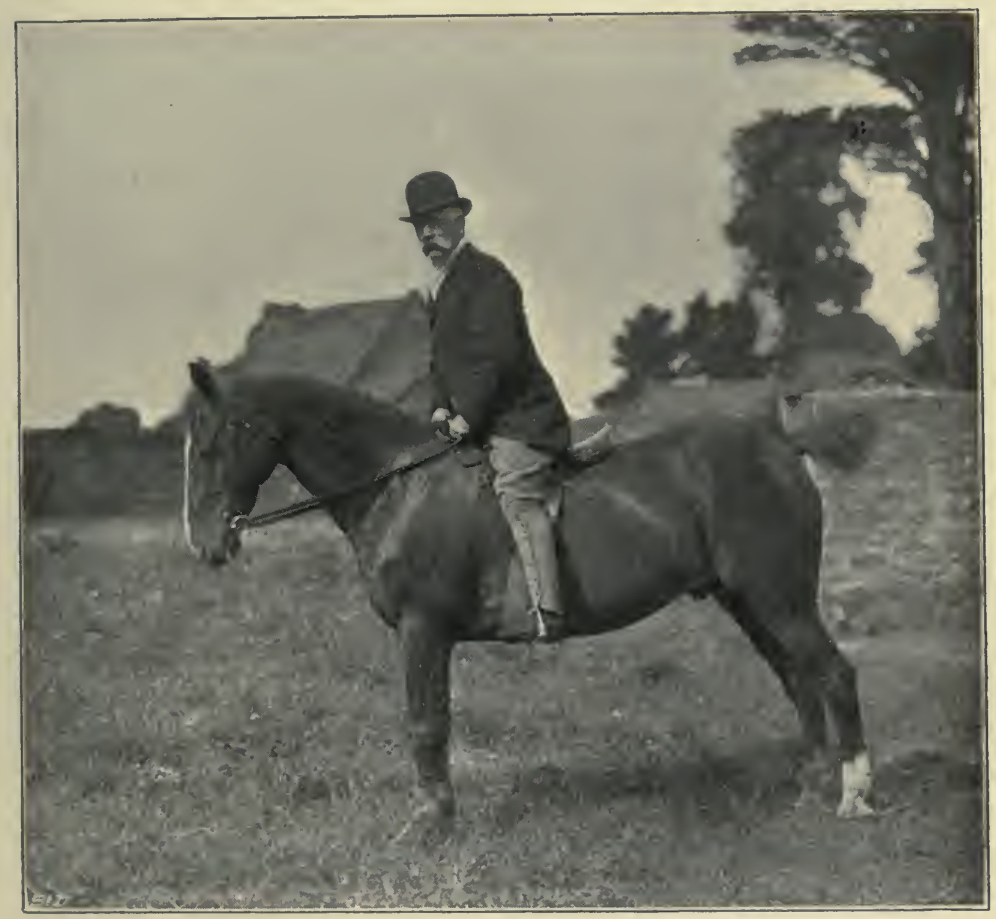

Fig.:188. Clearing the pommel to see if the stirrups are the right length.

good seat, and cannot be determined by any fixed; measurement. If the rider finds that when he is riding a puller at a gallop, he can get his knees well into the flaps of the saddle, draw his feet back, and in this manner exert his strength to the best advantage, he may rest assured that his stirrups are of the right length. 
THE MILITARY SEAT.

The position without stirrups is described as follows in Cavalry Drill: "Each man should have his body balanced in the middle of the horse's back, head erect and square to the front, shoulders well thrown back, chest advanced, small of the back slightly bent forward . . . . . The thigh should be stretched down from the hip, the flat of the thigh close to the horse's side, the knees a little bent, and the legs hanging down from the knee and near the horse's sides. The heels should be well stretched down, and the toes raised from the insteps, and as near the horse's sides as the heels. A plummet line from the front point of the shoulder should fall one inch behind the heel.

"While following these instructions, the man must, however, sit easily on his horse, without having his muscles unnaturally braced, and without stiffness. In order to get his toes and heels into a proper position, he should be taught to turn the flat part of the thigh from the hip towards the horse's side, and not merely to twist the foot inwards from the ankle or knee.

"This is the position halted, or at the walk; at the trot the body must be inclined a little backward, the whole figure pliant, and accompanying the movements of the horse. The elbows and lower limbs must be kept steady.

"The position with stirrups is nearly the same as without stirrups, the knee being a little more bent.

"A plummet line falling from the point of the knee should drop directly on the ball of the foot. The foot should be kept in its place by the play of the ankle and instep, the stirrup being under the ball of the foot. The lower edge of the bar is, as a general rule, to be from two and a half to three and a half fingers' breadths above the upper edge of the heel of the boot, when the man is sitting in the proper position. The 
Instructor must remember, however, that, though he should follow the general rules in fitting the stirrups, a great deal depends on whether the rider has a thin flat thigh or the reverse; a man with a thick thigh requires slightly shorter stirrups, otherwise, when the horse is in motion and the muscles are brought into play, he will not have a proper hold of the stirrup." 


\section{CHAPTER IX.}

\section{RIDING WITHOUT REINS.}

A PERSON who begins in the ordinary way to learn to ride, is hampered by the fact that he has simultaneously to attempt two tasks, one of which (managing the horse) cannot be performed until he attains proficiency in the other (sticking on). Besides, until his seat becomes secure, he will necessarily pull his horse's mouth about, and will consequently spoil it to a greater or less extent. If he commences his lessons in the open and does not want to risk an accident, he will have at first to be led about by a man either on foot or horseback, unless the animal is of an angelic disposition. Control over a horse is much easier obtained in a manège than outside, but the use of a riding school is seldom procurable, and even in it one must know how to apply the control before one can take advantage of it. With a beginner, there is the difficulty of getting him to alter his animal's paces, in the manner required, unless his mentor is mounted and is leading him, which is an awkward arrangement that requires the services of two horses. All these inconveniences can be easily overcome by the adoption of the long reins method, which I have been the first to apply to the teaching of riding. Its great advantage is that it gives the teacher as much control over the horse as an expert rider would have, and the pupil, recognising this fact and feeling that he is relieved from an embarrassing and more or less dangerous task, can devote his entire attention to learning 
how to obtain security of seat. After he has acquired that art, the object of the long reins system is fulfilled, and he is then well qualified to engage in the second and final part of his studies, namely, in that of guidance and control. The only drawback to this method is that it requires the teacher to be an expert in this kind of driving, which is by no means as easy to do properly as it looks.

Before putting the long reins method into practice, it is advisable to give the horse some instruction in it, so that he

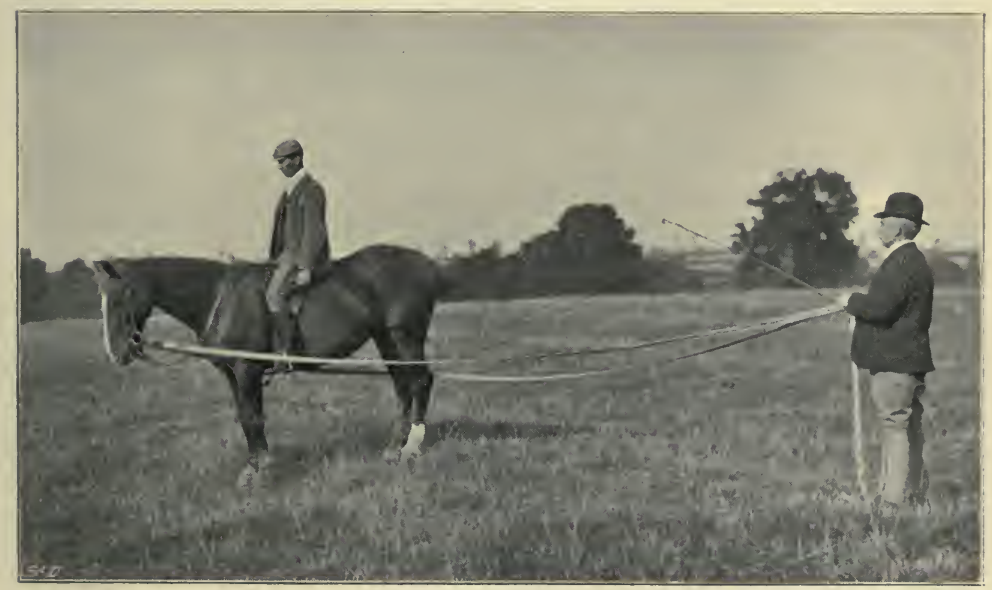

Fig. 189. Riding without reins.

may carry his rider steadily and intelligently. The required gear is a snaffle bridle, long reins, and a standing martingale. The best reins for this purpose are those of $1 \mathrm{I} / 2$ inch "circular" webbing, and each about eight yards long. It is almost always necessary to use a standing martingale of proper length, in order to prevent the horse getting his head up too high, in which case the outward rein would be apt to go over the animal's croup and inconvenience the rider. The reins should not be connected together, so that, if 
required, one may be let go, and the other kept tight, as might be necessary with a fractious horse. The horse is driven round in a circle; being led by the inward rein, and supported by the outward one, which passes round his hind quarters (Fig. 189). One great point to be observed in this system of driving, is that the respective lengths of the reins should be so regulated, that the horse will circle with an even feeling on both of them, and without any tendency to pull the driver after him. When the animal goes steadily, the driver should hold the reins in one hand, and the whip in the other. When he wants to turn the horse to the right-about, from the position shown in Fig. I89, he should change the whip to the left hand; take a long step forward with the right foot; slide the right hand forward on the right rein; and having got the proper length, should take a steady pull at the right rein, while letting the left one slip through the left hand, until the turn is made. Before turning to the left-about, the reins should be changed into the right hand.

After the pupil has learned to sit easily at the walk, trot and canter, he should get practice in turning, which at first should be done slowly and with due warning. To give him confidence, he should in the beginning be allowed to hold the neck strap of the standing martingale, which strap should be lengthened out as may be required. By degrees, he should dispense with its aid.

With the long reins, practice can be given over fences, as well as on the flat. For jumping, the precaution should be taken that the inner end of the obstacle should be free from the presence of an upright post or other object which might catch in the reins.

The subject of training horses with the long reins is dealt with at considerable length in Illustrated Horse-Breaking. 


\section{CHAPTER X.}

\section{HANDS AND LEGS (AIDS).}

The Aids-Respective Duties of the Aids-Order in which the Aids should be Applied-Combined Action of the Aids-The Legs- Whips and SticksWeight of the Body-Voice-Position of the Hands-Length of ReinsManagement of the Reins-Good Hands-Riding with Slack Reins.

\section{THE AIDS.}

THE terms "hands" and "mouth" are misleading when applied to riding, because they wrongly imply that a horse has to be controlled and guided solely by the reins; that is to say, by only one end of his body, instead, as he ought to be, by both ends. The controlling and guiding powers which a good horseman usually employs, and which we may term the "aids," are the hands, legs (and spurs), whip (or stick), weight of the body, and voice. I am of course aware that in manège parlance the word, "aids," is restricted to the action of the reins (hands) and legs in riding. But as the other means which I have mentioned, for conveying the wishes of the rider to the horse, act in a more or less similar manner, and as they are valuable adjuncts to the reins and legs, I feel that I am justified in including them in this definition.

\section{RESPECTIVE DUTIES OF THE AIDS.}

The uses of the reins are to restrain the forward movement of the horse by exerting pressure on the mouth in a direction opposite to that in which he is proceeding, or in which he is placed; to turn the head of the animal to the right or to 
the left; to turn the animal to the right or to the left without bending his neck; to bend the head and neck in a vertical direction; to raise the head; to lower the head; or to combine, when practicable, two or more of these actions, as is done when the head is drawn to one side, and lowered by the action of one rein, and when the movements of the horse are checked at the same time by the pressure of both reins.

The duties of the legs (feet and spurs) are to stimulate the horse to go forward; to make him bring his hind legs more under his body than he would otherwise do; and to turn his hind quarters to one side, or to check their revolution in an opposite direction, by the pressure of the drawn back foot or spur.

The duties of the whip or stick are similar to those of the legs in stimulating the horse to go forward, and in controlling or directing the lateral movements of his hind quarters.

The weight of the body by being carried back, forward, or to one side, acts as an indication of the wishes of the rider, and as a mechanical assistance to the horse, by effecting a helpful alteration in the disposition of the weight he bears.

The voice can act as a stimulant to the horse to increase his speed; as a caution to him to go slower, or to keep quiet; and as a command to him to halt.

\section{ORDER IN WHICH THE AIDS SHOULD BE APPLIED.}

The chief point we have here to consider is that a suitable indication of the reins should always precede the application of a stimulus by the spurs, heels, whip or stick, in order that the horse may not get out of hand from excitement or from eagerness to obey. This principle applied to driving is recognised by every good whip. The stimulus of the voice, usually conveyed by the familiar click of the tongue, 
is generally of such a mild character that precautions as to its employment will rarely be necessary.

\section{COMBINED ACTION OF THE AIDS.}

As a horse has two pairs of legs at different ends of his body, the aids which we can legitimately employ singly, are those which produce a general effect. Those that produce only a local effect, should not be used except in a combined form; it being immaterial whether the combination consists of two or more aids or of an aid and an impulse derived from the horse. For instance, if when mounted on a horse at the halt, we wish to turn him, say, to the right, we should do so by hand and leg, or by hand and whip or stick; because merely pulling the right rein would be an indication for him only to turn his head to the right and not his body also. It is true, that habit will generally make him obey the signal given by the reins according to the wishes of his rider; but, being guided only by his head, he will make the turn more or less uncollectedly. Again, let us suppose that we were galloping through heavy ground on a sluggish horse and wanted to "collect" him (make him light in front, i.e., make him get his hind legs under him), it would be useless merely to pull at the reins, because the effect of that would be to stop him. If, however, we combine the action of the reins with that of the spurs, we shall diminish the forward reach of the fore legs by holding him in with the reins, and shall increase that of the hind ones, by touching him with the spurs; the result being that more or less weight will be transferred from the fore hand to the hind legs. If, on the contrary, we were riding a free-going horse, there would probably be no need to use the spurs or heels as an aid, to assist the action of the reins in "pulling him together"; because his own impetuosity would make him keep his hind legs in 
active movement, even when the forward reach of the fore ones was somewhat checked by the reins.

\section{THE LEGS.}

The only part of the legs which is effective as an aid, is that which is below the knees; because, as we know from experience, the pressure of the knees or thighs produces no well-defined indication. The strongest leg indication is that by the spur; the next strongest, that by the heel; and the mildest, that given by the side of the drawn-back foot or by the calf of the leg. As a general stimulant (a stimulant to both hind and fore limbs) for the horse to go on, both spurs or both heels should be simultaneously applied as nearly as possible to the part of the animal's sides that is mid-way between the action of the two pairs of limbs, with the object of dividing the stimulation equally between them. Hence, when capable jockeys use spurs, they apply them close behind the girth. To use the spurs as a hint to the horse to go on, when the feet are in proper position, as in Fig. I87, the toes should be turned out, and the feet should be brought to the sides without the heels being raised or drawn back; for either of these actions would more or less tear the skin, instead of merely pricking it at one spot. Bad riders, on account of allowing their legs to swing backwards and forwards, often involuntarily spur a horse about the shoulders; and men who never ought to have been given a mount, have been known to spur a horse on the stifles. Spurs used by inferior horsemen should be very short in the neck.

When the spur or heel (on one or both sides) is applied well to the rear of the girths by the drawn-back foot, it acts as a signal to the animal to bring forward the hind leg of that side (or both hind legs, as the case may be). Consequently, if a galloping or cantering horse which is 
leading, say, with the off fore, as in Figs. 17 to 26 , gets spurred only with the drawn-back right foot, or more severely spurred with it than with the left foot, during his off hind support (Fig. I9), he will be liable to change his leg, on account of receiving a stimulus to bring forward his off hind out of its turn. The same thing is apt to occur from a similar stimulation on the near side, when the near hind is on the ground, or when both hind legs are being brought forward.

These remarks still further strengthen the conclusion arrived at in the preceding paragraph, that the only place to spur a horse, so as to make him increase his speed, is close behind the girths. As a great rule, the use of the spurs should be restricted to this form of their application, and the lateral movements of the hind quarters should be regulated only by the pressure of the side of the drawn-back foot; because under such conditions, the horse is much less liable to mistake an indication of the spur, than when the spur is employed for both purposes. At the halt, as when turning the horse on his fore-hand, or at riding school work, this rule need not always be observed, especially with blunt spurs, which are amply sufficient for a free goer under all circumstances.

\section{WHIPS AND STICKS.}

In order that the whip may act efficiently as a stimulant to the horse to go forward, it should be sufficiently long and pliable to touch the animal on both sides of his body, so that its action may not be one-sided. In fact, when a jockey strikes a horse with his whip, the near side of the animal is usually more severely punished than the off side, on account of the whip wrapping itself round the lower part of the chest, and the knot formed by the junction of its lash with the shaft, striking the near side. Here, the part 
of the body upon which pain is inflicted, should evidently be the same as that stimulated by the spurs, namely, the portion of the sides close behind the girths. I am at present considering only extreme forward stimulation; because all ordinary and comparatively painless forward stimulation is much better obtained by the legs than by either whip or stick, the action of which in this case is one-sided, and is more or less distracting to the attention of the horse, by the flourishing of the whip or stick in the air.

To obtain the best result in the regulation of the lateral movements of the hind quarters, the whip or stick should be held point down and the hand on the rein, so that its effect may be aided by the action of the rein. For the purpose in question, the whip or stick should not be less than 37 or 38 inches long. Its action will then be much more effective than that of the drawn-back foot, because it can be applied farther back.

The ordinary varieties of riding whips are: the hunting whip, the cutting whip, and the crook-handled cutting whip.

The hunting whip or hunting crop has a handle set at right angles to the crop; a loop or keeper for the attachment of the thong; and a lash at the end of the thong. The crop is generally about two feet three inches long; although an addition of nine inches to this length would make it much more useful for obtaining command over a horse's hind quarters; keeping a closing gate in check; or reaching very low latches. I see nothing out of place in the use of a crop of this sensible length when hunting. Stiff cane is probably the best material for a crop, although whalebone covered with gut is greatly in vogue, probably because it is expensive. The handle is usually of horn and notched on the upper surface, so that it might not slip when applied in opening or shutting a gate. With the same object, a small stud is generally put on 
the upper side of the inner end of the handle. On rare occasions the handle has the form of a hammer, which is an arrangement that appears out of date, because it suggests acts of demolition that would not generally be tolerated by the present race of farmers. Also, it makes the whip unnecessarily heavy to carry. A hunting whip, besides being

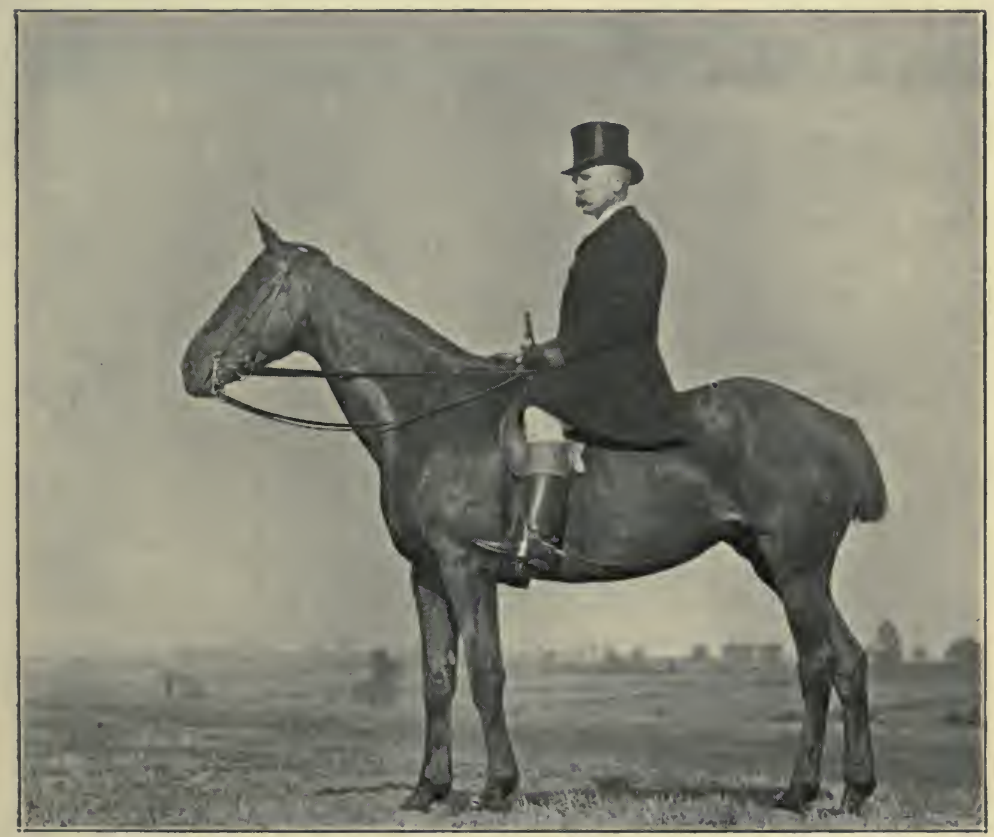

Fig. 190. Out hunting.

the correct kind of whip with which to follow the hounds, is the only one that is thoroughly efficient in opening gates, which in the Shires is often an indispensable procedure for maintaining one's place even in the first flight. According to hunting etiquette, the crop should always be accompanied by its thong, which is a certain encumbrance when handling the reins, and which an ordinary member of a 
fashionable hunt could rarely use with propriety for its legitimate purpose of bringing up straggling hounds and other work that would come within the province of the whippers-in and huntsman. Such aid might at times be appropriately rendered at that undress function, cub-hunting, and with small provincial packs that are not well supplied with hunt servants. In ordinary cases, the only use of the thong is for the end of it to be wrapped round the rider's hand, when he is opening a gate, so that he may not drop the whip by accident.

The way sanctioned by custom for carrying a lunting crop, is that of holding it with the loop up (Fig. 190). When the rider does not want to use the thong, he coils the slack of it round the palm of the right hand, beginning at the lash, and then grasps the crop. If he wants to be ready to crack the whip, he may hold the lash in the right hand; or may leave the thong hanging down. In cracking a hunting whip on horseback, the rider should make his upward and downward cuts in a vertical plane, parallel to and a little away from the side of the animal, so that he may not accidentally hit him.

There are two principal varieties of the cutting whip: one, the usual old-fashioned pattern, which tapers gradually off from the butt, and which has a leather-covered handle placed between two mounts that are, as a rule, silver plated. The other, which has a projecting butt specially made to prevent the whip slipping out of the hand of the rider, and which on that account is particularly well suited for race riding. A cutting whip should of course be well balanced, so that it may be light in the hand. Almost all good horsemen who use a cutting whip, like it to be fairly stiff. This is a practical point that I must leave to the judgment of the rider; as I cannot give any exact directions on the subject. 
A crook-handled cutting whip is a cutting whip with a handle like that of a hunting crop. Although at first glance it appears from a riding point of view to combine the advantages of both kinds of whips, its shaft as a rule is too pliable to allow it to be very efficient in opening gates.

The presence of a cutting whip with hounds is generally viewed with disapproval; because it savours too much of horse-breaking and rough riding. The practice of these arts is certainly out of place in the hunting field, as it is apt to cause danger and inconvenience to others.

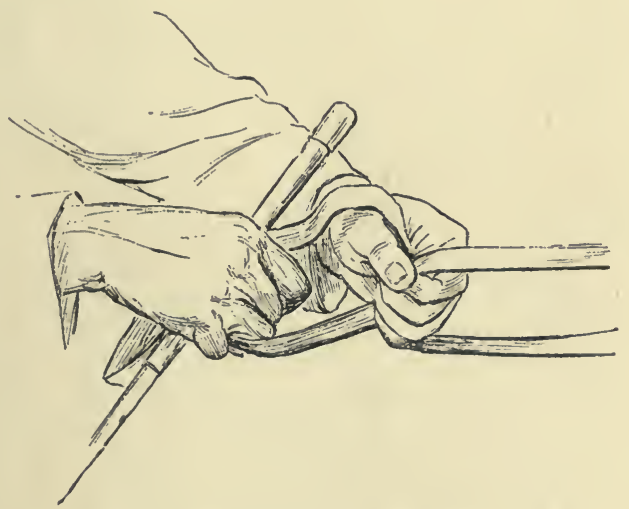

Fig. 19r. Shortening the reins before using the whip with the right hand.

A cutting whip is usually carried by the rider with the lash down; for if the point of the whip be kept up, the horse will probably watch it, expecting a cut at any moment, and his attention will consequently be distracted from his work. When the rider, like a jockey towards the end of a race, is waiting to use it as a stimulant to the horse to go on, and does not know which hand he may be called upon to use, he had best hold the whip six or seven inches from the butt end, so that he may be ready, if necessary, to change it into the other hand without delay. In order to use the whip 
with the right hand for the purpose in question, supposing that both hands are on the reins, as in Fig. I 58, the rider should let go the slack of the off rein out of the left hand and should slide that hand forward on the near rein, and grasp the off rein in the full of the left hand, as shown in Fig. 191. As explained on page 162, the left hand should go forward in a somewhat circular direction, and not straight

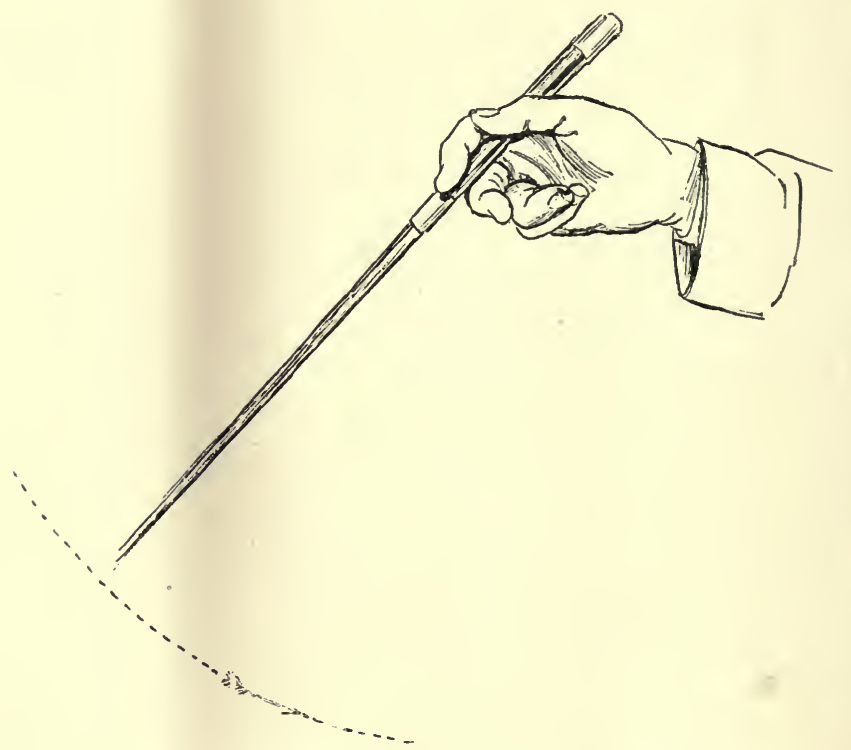

Fig. 192. Swinging the whip forward, before bringing it up.

to the front, so that an even feeling on both reins may be preserved the whole time. It is necessary to shorten the reins in this way; for when the reins are held in one hand, they should naturally be shorter than when they are held in both hands. If the reins are held as in Fig. 157 , the near rein should be passed into the right hand, and the left hand should slide forward on the near rein and take up both reins in the manner just described. Both reins being now grasped 
in the left hand, the right hand (which holds the whip) should let them go, and should swing: the whip slightly forward, so as to bring it between the first and second fingers (Fig. I92). The whip is now quickly swung to the rear and brought into the position shown in Fig. I93; the hand is raised not higher than the rider's right ear by the bending of the elbow; the first finger slips round the handle of the whip; and the cuts,

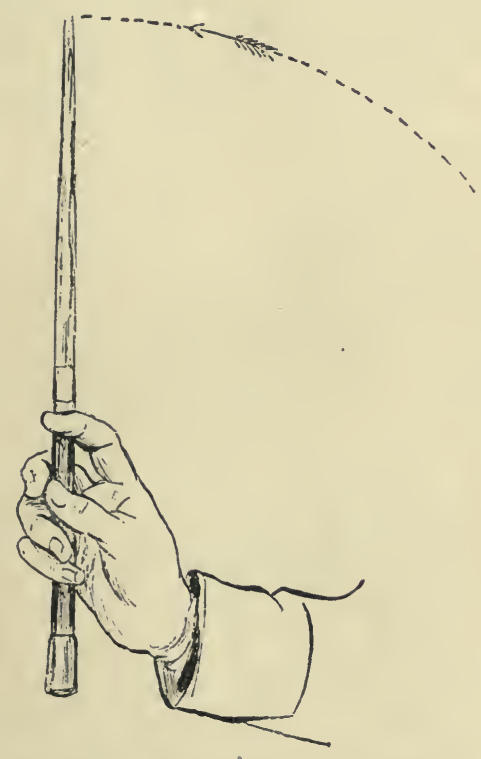

Fig. 193. Bringing the whip up before using it.

which should rarely exceed two or three, should be given straight down, close behind the rider's boot, without any backward swing.

Although the explanation of changing the reins into the left hand and picking up the whip has occupied some space, these actions can be performed, after a little practice, with the utmost rapidity. In race riding, the moment for using the 
whip is such a critical one, that it is essential a well practised method should be adopted, so that the jockey may run no chance of making a fatal muddle with the reins. Such mistakes, which would be hardly excusable in an amateur, are not unfrequently committed by professionals who fancy themselves not a little. We often see jockeys "let go the reins" the moment they use the whip. It strikes me, that the reason they fall into this unpardonable error, is that they do not slide the bridle hand forward to shorten the reins before the whip hand quits them, as ought to be done. When there is little time to act and none to think, the mere knowledge of the

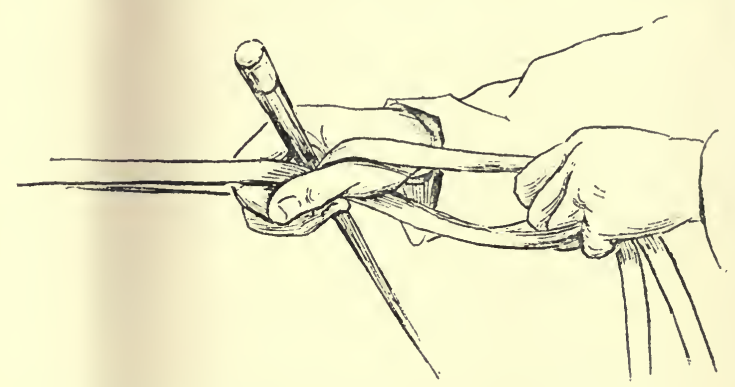

Fig. 194. Shortening the reins before using the whip with the left hand.

proper method of doing a thing cannot be utilised. An action, however, which has been sufficiently often repeated to have become automatic, will be instinctively performed without the necessity of reflection, on the senses receiving the required stimulus.

When the whip has to be changed from one hand into another hand, say, from the right into the left the former should shorten the reins (Fig. 194) in the manner before described for the left hand; the left hand should now quit the reins, seize the whip (Fig. I95), and draw it through the right hand.

The stick that is specially dedicated to riding, particularly in 
Ireland, is the "ash plant," which should be a sapling cut during winter and seasoned by being hung up in a chimney, or stuck into a heap of stable manure. The best saplings are those that grow from the portion of an ash tree which remains in the ground after the trunk has been cut and removed. The commercial ash plant is usually as brittle as a clay pipe, and therefore cannot be relied upon. The stick I like best for riding, and even for walking, is the Neilgherry cane; because it is practically unbreakable, is smooth, heavy

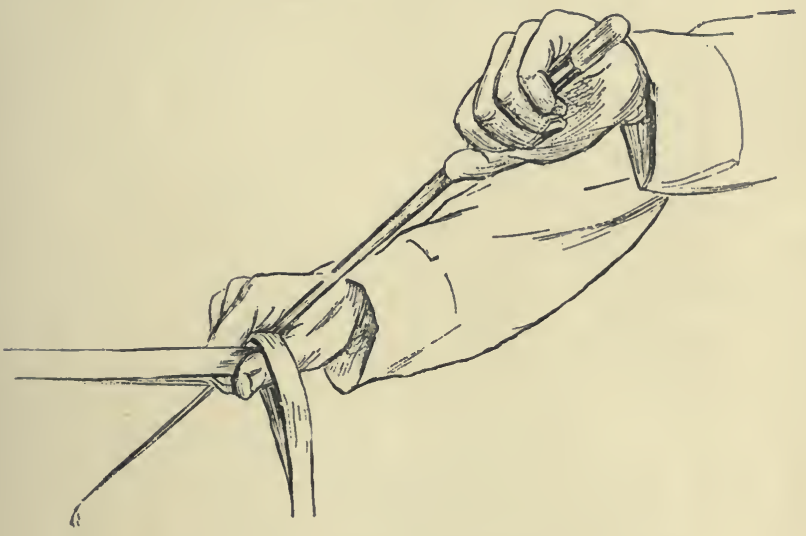

Fig. I95. Drawing the whip through the right hand.

for its size, stiff, and looks well. It is neatly finished off by its root-butt. A cane with knobs on it would mark a horse, and is therefore unsuited for riding.

\section{WEIGHT OF THE BODI.}

All changes in the position of the weight of the body, as an indication and help to the horse, should be effected as far as possible only by the play of the joints of the hips and those of the body, so that the position of the legs may not be altered; for if that were done, the security of the seat would be more or less imperilled. Hence, in bending the body to one side, as for instance in turning, the grip of the knees on 
the flaps of the saddle should be increased, so as to avoid placing much more weight on one stirrup than on the other stirrup, which might have the effect of disarranging the position of the saddle. In such cases, it is almost impossible during rapid movement to help putting a little more weight on one stirrup than on the other.

VOICE.

"The horse's keen perception of sound makes the human voice a powerful means of controlling and guiding him by association of ideas. As he readily recognises change of tone, but not of words, we should reserve a particular tone for each of our different orders, the number of which should be kept as small as possible, so that ambiguity may be avoided. Also it is, of course, well to have only one unvarying word or expression for each order .... We should carefully refrain from wearying the attention of the animal by needlessly speaking to him. In fact, we should reserve the use of our voice for occasions on which it is needed to produce a definite effect"-(Illustrated Horse-Breaking).

\section{POSITION OF THE HANDS.}

A horse at the trot, canter or gallop, usually carries his head at an angle of about $45^{\circ}$ to the ground, in which position the higher the snaffle reins are held above the withers, the greater will be the tendency of the mouth-piece to slip off the bars of the mouth and come on to the corners of the mouth, in which case the snaffle will act improperly. Hence, in two-handed riding, we may safely accept the old rule of holding the snaffle reins with one hand on each side of the withers, or as little above the withers as practicable. If the horse gets his head too low down, we should naturally raise the hands, in order to place it in correct position, which can be determined only from the 
manner the animal carries himself. However high the horse holds his head, we cannot conveniently bring our hands lower down than three or four inches below the withers. Any attempt in this direction will rarely be of use; because it will generally result in irritating the horse to resistance. The better plan, when practicable, would be to slacken out the reins for a few moments, in which case the horse, finding his head free, will generally bring it down of his own accord into proper position. For purposes of control and guidance, it is best as a rule to hold the hands eight or nine inches apart. When only one hand is employed, it should work as nearly as possible directly over the withers, so that an even feeling may be kept on both sides of the mouth. Whether one or both hands are used, it or they should be allowed to fall loosely from the wrists, with the line of the knuckles at an angle of about $45^{\circ}$ with the ground. As the muscles of the neck draw the fore limbs forward, we shall, by keeping the hands "down," generally aid in preventing the animal from going too high in front, and thereby shortening his stride.

As the tendency of the curb is to make a horse carry his head too low, the hands, when manipulating that bit, need not as a rule be held so low down as with a snaffle.

\section{LENGTH OF THE REINS.}

Speaking generally, the reins should be held at as great a length as is compatible with control, so that, if the animal makes any disconcerting movement, he will not be liable to pull the rider on to his neck, or to hurt his mouth by undue tension on the reins. This rule is recognised by all good horsemen as being of special application to 'cross country riding. As already explained, the reins can be held at a greater length in two hands than in one. As power to control and ability to guide are essential conditions of good horsemanship, they should in no way be sacrificed by holding the 
reins too long, which, owing to considerations of personal safety, is one of the last faults an indifferent rider is likely to commit.

\section{MANAGEMENT OF THE REINS.}

The following are important points connected with this subject :

I. As the reins are the means by which a rider keeps in touch with the fore-hand of the horse, they should not be used in a way that will make the animal afraid to go freely up to the bit, or to resent the pressure on his mouth. If he "keeps behind his bridle," the desirable connection cannot take place; and if he resents the pressure, he will become more or less unmanageable and dangerous. Consequently, the bitting and the handling of the reins should in no way be painful. Therefore, when the rider takes a pull at the reins, he should do so, to employ the apt expression of $\mathrm{Mr}$. J. H. Moore, as if he were trying to draw the cork out of a bottle without spilling a drop of the contents. If he finds that the metaphorical cork resists his pull, he may increase the tension, but should on no account transmit any jerky movement to the reins.

2. When the rider wants to communicate his wishes to the horse by the agency of the reins (or by any other aid), he should do so in the clearest possible manner, in order that there may be no chance of the animal misunderstanding his meaning. Even the kindest tempered horse can be quickly converted into a vicious brute by being given orders he does not comprehend, and by being punished (by reins, whip, spurs or stick) for not obeying them. Therefore, when we wish to make a horse turn, we should (supposing that both hands are on the reins) carry the hand of the side to which the turn is to be made, well away from the shoulder (Fig. 198), so that the pull may act laterally, and consequently in an effective manner, which it would not do if its direction was from front to rear. 
3. The steadier the bit remains in the mouth, the more accurately will the horse under ordinary conditions obey its indications, and the less inclined will he be to resent its presence between his lips. Hence we should as a rule keep our hands steady, without any irritating sawing or "niggling" at the reins. If, however, the animal bears too much on the bit as a defence against our attempted control, we may draw the bit through the mouth, so as to prevent him from thwarting our wishes. Even in turning the horse, we should be careful not to shift the bit in his mouth, to avoil doing which, we should preserve a uniform tension of the reins on both sides of the bit, although the pull of the reins will not be in the same direction. Here we shall be greatly aided by bringing the opposite hand across the body, so as to apply its rein to the neck; for not only will the friction between the rein and the skin help to keep the bit in position, but the pressure of the rein on the neck will be an additional indication for the horse to turn.

4. In order that the rider may be able to use his hands with precision, no disconcerting movements should be communicated to his arms by his body, which can be kept steady in the best manner by a firm grip of the knees on the flaps of the saddle, and by keeping the feet from going too far forward. In fact, correct manipulation of the reins is impossible without a good seat.

5. The amount of hold which a horse takes of his bridle should not be much in excess of that which is necessary for the rider to keep in touch with him; because the more the animal bears on the bit, the more weight will he put on his forehand. I have previously alluded to the general advisability of keeping a horse light in front. These remarks of course refer to ordinary riding, and not to the crouching seat of race riding.

6. If we wish the animal we are riding to maintain a steady 
and level style of going, we should keep the reins at a fixed length, and should not "give and take" to him, which action on our part would be liable to interfere with the regularity of his movements, and to prevent us from having an even feeling on his mouth, by prompting him to keep continually changing the position of his head. In race-riding and in the riding of training gallops, the principle of keeping the hands steady is well recognised.

7. If a horse is heavy in front and is not very impetuous, we can as a rule lighten his fore-hand by holding him in with the reins, and at the same time sending him up to the bit with the legs (p. 209).

8. If a horse keeps a dead and heavy pull on the reins, and is too free a goer to stand being touched with the spurs or heels, we should try to prevent him from advancing his head beyond a certain point; but the moment he yields by bending his neck and loosening his lower jaw, we should reward his obedience by "giving" to him; but not till then. By thus making a horse understand that he will save his mouth by bending his neck, we shall often succeed in getting a hard puller in hand. I may explain to inexperienced riders that the change of stiffness to pliability of neck and jaw is the usual way in which a puller intimates to his rider that he is willing to obey.

9. When a horse pulls so hard that we are not able to get his head in by force, we may accomplish our object by giving to him with such quickness that he will think that he has overcome our resistance and will cease stiffening his neck against us, and will consequently carry his head in an unconstrained position. As soon as we find him doing this, we should take a pull at him, and if he makes another snatch at the reins, we should again give to him; and so on, until at last he will probably think that he has gained the victory, and will therefore cease hostilities. As a parallel case I may cite 
the means by which we may circumvent a horse which has the not uncommon trick in the stable of continually hanging back against his head-collar chain. If we tie up the chain short with a piece of twine when the animal is in his stall, we shall find as a rule that when he throws his weight on the head-collar and consequently breaks the twine, he will imagine himself free, and will cease pulling against the chain, which still binds him. Here I think we have got the explanation of the fact that there are some men who are able to hold pullers, although they are not particularly strong. They act according to the sound though somewhat ambiguously expressed adage, that "if you don't pull against a horse, the horse won't pull against you."

Io. Bumping up and down in the saddle is often due to the rider maintaining too short a hold of the reins, which causes him to be pulled forward at each stride.

I I. Reversed indications of the reins cannot be so easily understood by a horse as direct ones; they are lessieffective ; and are more liable to be irritating. Consequently their employment is apt to spoil the animal's temper, both by exciting him to resistance and by imparting to him the dangerous knowledge of his own power. I particularly wish to caution those of my readers who have not had much experience among horses, to avoid jerking the reins, as a signal for the horse to go on ; because the practice of this reversed indication is liable to teach him to jib and rear, and will in all cases more or less spoil his mouth. Its pernicious action in these respects needs no explanation. This false indication is habitually employed by the vast majority of persons who drive horses in this country.

I2. Knowing the danger (to the animal's temper among other things) of a horse disobeying our orders, whether wilfully or on account of his not understanding them, we should as a rule prefer strong and direct indications to weak and reversed ones. When the reins are held according to the military method in 
one hand with the little finger separating them (Fig. I67), it is almost impossible for the rider to turn the horse by a direct pull of the reins; because he can shorten either rein only to an extent equal to the thickness of his little finger, say, threequarters of an inch, which would evidently be insufficient to make a horse turn his head. Hence, the pressure on the opposite side of the neck has to be used as an indication for turning. Thus, if the cavalryman wants his horse to go to the right, he presses the near rein on the near side of the neck, by carrying his bridle hand more or less to the right, and vice versâ. His horse, if well trained, will obey in an admirable manner and even in the excitement of "action," this feeble signal, combined, as it should be, with an indication from the leg. A free-going horse, bitted and trained for ordinary riding, would almost to a certainty fail to answer such a signal, if he were excited, as for instance by the music of the hounds; partly because he had not been specially educated for that kind of work, and also because he is not afraid to go boldly up to his bit. It is evident that a horse would be useless in the ranks, if he were to go up to his bridle in the free manner desirable in a hunter or chaser.

The impossibility of turning a horse only by a direct pull of the reins when they are held in one hand in military style, can be easily demonstrated by trying to do so, when driving a horse in single harness, in which case the terret rings will prevent any pressure on the opposite side of the neck. When the reins are held as in Fig. I60, it will of course be much easier to turn the animal with one hand than when the reins are separated only by the little finger. The readiness with which horses can be made to understand indications of the reins, is proved by the fact that young horses in many breeding districts when wearing a halter and ridden bare-back, can be guided in any direction by the single rope held by their rider, who uses a direct pull on the mouth to turn them to one 
side, and a pressure on the neck to turn them to the other side.

The rein which presses on the neck during the turn in onehanded riding, has two distinct actions ; for while pressing on the neck, it also inclines the horse's head more or less away from the side to which the turn is being made by its pull on the opposite side of the mouth. This action of the rein on the mouth is permissible only at the canter and gallop (pages 22 and 23).

I3. The arms (including the hands) should work independently of the body, and each arm should work independently of the other arm, although at times their action may be similar. Each hand has its own special work to do, and consequently the reins should not be held like an oar with which a man steers a boat.

\section{“GOOD HANDS."}

We may see that the idea of "good hands" being the sole means for collecting, restraining, and guiding a horse, is wrong; because the hands are only one of several means (aids) by which this object is attained. The possession of a strong seat is indispensable for the correct application of the aids, which cannot be used with precision, if the rider hangs on by the reins or rolls about in the saddle.

\section{RIDING WITH SLACK REINS.}

When a rider has to trust entirely to the honour of his mount to bear him safely out of difficulty, he ought as a rule to ride more or less with loose reins, so that he may not bring both to grief by undue interference with the animal's mouth.

Stock-driving in the Colonies and pig-sticking in India furnish us with instances of the necessity at times of riding with the reins slack, which is a method that is practised at the 
expense of the staying power of the horse, by making him too heavy in front. When a stockman on a trained stock horse, attempts to bring in stray and half-wild cattle, his mount, acting with intelligence almost equal to that of a shepherd's dog, gallops down the marked-out beast, turns as it turns, with the quickness of a coursed hare, and accomplishes his part of the driving-in with but the slightest indication of his rider's wishes. While this exciting chase is going on, the man restricts himself to the use of his long stock-whip on the beast as may be required, sits still, lets the reins slack, and watches the object of his pursuit and not the horse, so that he may be prepared for any twist, turn, or sudden stop made by the latter, whose movements he is well aware, will correspond to similar ones made by the former. It would be almost impossible for him, if he kept his eyes on the horse, to tell what the animal was going to do under such circumstances. Out pig-sticking over the black cotton soil in the Central Provinces of India, which has numberless holes and fissures on its surface, and across ground covered with large loose stones, such as at Paunchgawn near Nagpore, and over the low hills close to Allahabad, a rider cannot avoid a fall, if he goes straight, unless he is on an experienced pig-sticker and allows perfect freedom to its head. If he does this, the clever animal will pick its way, almost at racing pace, over holes and stones without making a mistake. Here also, the rider has to watch the pursued one, so as to be prepared for every "jink." It is evident that when a horse has to gallop over ground such as I have described, or after cattle out stock-driving, no rider who keeps a tight hold of the reins could possibly avoid interfering with his horse's mouth, and consequently bringing them both to grief; for the animal, when picking its way, would have to lengthen or shorten its stride, turn or stop, quicker than its rider could foresee. The old school of hunting men in Ireland used to ride with slack reins. The hounds ran slow, and the 
men preferred to watch the hunting, than to devote their attention to jealous riding; so they left the horses to do their work without assistance. A high degree of sagacity was developed in them by trusting to their honour, and making them use their intelligence, without expecting assistance from their riders at every turn. Hence arose that peculiar cleverness possessed by the old Irish hunter, such as Signal, Fencer, Whisky, and Mickey Free, who were famous in Muskerry many years ago.

We frequently meet with instances of extraordinary clever horses being very impetuous, some of whom will brook no interference with their mouths. On one of this sort, a meddlesome rider is certain to be brought to speedy grief. Horses which are accustomed to tight reins, on the contrary, often cannot keep on their legs over obstacles or over bad ground, without their riders having a good hold of them by the head.

If a rider is accustomed to give his horse plenty of rein, the intelligent animal will soon learn to look out for himself, will check his speed and get his hind legs under him before "taking off"; for horses dislike falling nearly as much as their riders do. It is manifest that when a horse has to "collect" himself, and has to gallop without assistance from the bridle, that he does so by the expenditure of a large amount of force, which would be saved were he ridden up to his bit. Besides, he will jump "stickily" at his fences, and will be slow at getting away from them. 


\section{CHAP'TER XI.}

\section{GUIDANCE AND CONTROL.}

To Start into the Walk from the Halt-Riding at the Walk-Collecting a Horse-To Trot-To Canter-To Gallop-To Pull Up-To Change from One Pace into Another-To Turn a Horse at the Halt-To Turn a Horse during Movement-To Passage-Swerving-To Rein Back-Going Up or Down Hill-Swimming a Horse-Picking up Objects from the Ground when on Horseback.

I HAVE taken for granted that readers of this chapter have studied Chapters III. and X., in which, to save repetition, I have explained several points that I shall again allude to in this one.

The instructions in this chapter are given on the supposition that both hands are on the reins.

\section{TO START INTO THE WALK FROM THE HALT.}

The rider should feel the reins and apply the legs so as to send the horse up to the bridle and make him go on. He may also give the animal a signal with the voice to start.

\section{RIDING AT THE IVALK.}

When a horse walks at ease, he does not require to lift his feet off the ground so high as at faster paces; consequently he brings his head lower down, which action facilitates his forward movement by increasing the instability of his equilibrium. As the suspensory ligament of the head and neck (which ligament extends from the withers to the poll) is elastic, the more the head is brought down, the longer will 
the neck become. Hence, when a horse is walking at ease, the reins will have to be held longer than at any other pace; and they should be allowed to remain nearly slack; because at each step in this walk, a horse moves his head from side to side in order to aid in the adjustment of his weight, which he cannot do, if the reins are kept tight and at a fixed length.

\section{COLLECTING A HORSE.}

To collect a horse at the halt or at any pace, we should feel the reins and apply the legs, so as to send him up to the bridle, get his hind legs under him, and lighten his fore-hand. With the object of economising a horse's powers by keeping him light in front, we should usually have him collected when going fast. Some of the exceptions to this rule are pointed out in the remarks made on "Riding with Slack Reins," page 227. When a horse moves naturally at the trot (Figs. 196 and 197), canter (Figs. I7 to 26), or gallop (Figs. I to I6), his head will be at an angle of about $45^{\circ}$ to the ground; but the greater the collection, the more nearly will the head assume a perpendicular position. In all cases, a position of the head which will bring the muzzle closer to the breast than would be necessary to make the line of the face perpendicular with the ground, will interfere with the action of the shoulders and will at the same time make the animal heavy in front. Consequently, the rider should try to avoid allowing his mount to get his head into this position.

\section{TO TROT.}

Whether the rider wishes to start from the halt into the trot, or to change into it from some other pace, he should keep his hands low, take a tolerably firm hold of the reins, lean a little forward, and by slightly rising in the stirrups, indicate his wishes to the animal. When trotting in ordinary fashion, the 
rider's body alternately assumes two different positions: one, that of sitting down in the saddle when one particular fore leg (Fig. I96) is in support; and the other, that of standing in the stirrups when the other fore leg bears weight (Fig I97). As a great rule, men always rise and sit down on the same respective fore legs, of the horse they are riding at a trot. I see from an inspection of Figs. I96 and I97, that I sit down when the off fore is on the ground, and stand up, when the near fore is in support. It is quite immaterial whether this

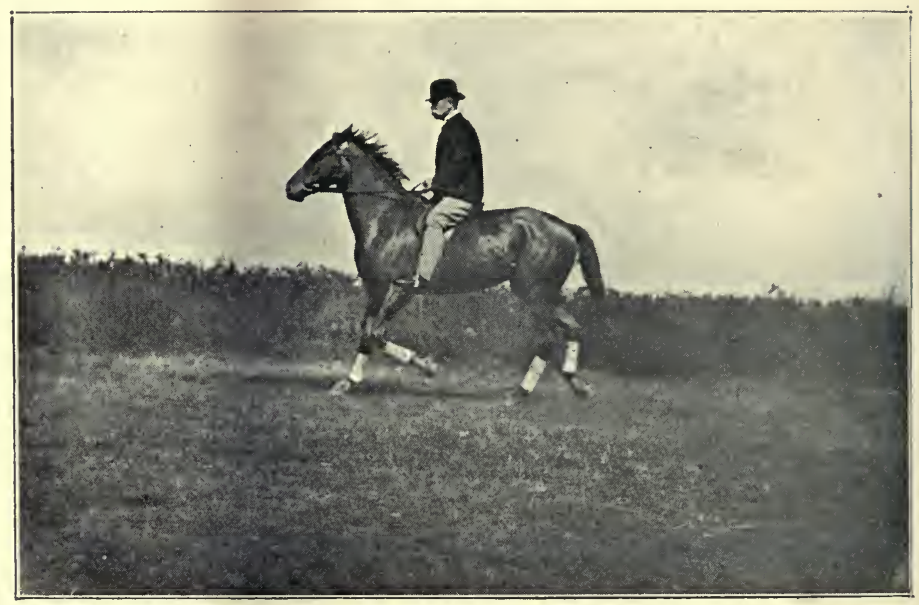

Fig. 196. Sitting down at the trot.

order of sitting down and rising is observed, or the reverse. It is advisable, however, to acquire the not very difficult knack of being readily able to change the order of rising and sitting down; because the latter action places more weight on its respective fore leg than the former does. The correctness of the statement that riding a horse in the ordinary manner at the trot, puts more weight on one particular fore leg than on the other fore leg, is amply proved by the fact that a sound horse ridden in this way will not trot quite "level." Although an 
experienced man would not be apt to mistake for unsoundness such irregularity of gait; no careful veterinary surgeon would test a horse for lameness when mounted, by having him ridden at a trot by a man who went up and down in the saddle. In such a case, the rider should of course bump in the saddle in military style, so as not to favour one leg more than the other. Although the trot is a diagonal pace of two time (near fore and off hind, and off fore and near hind), more weight falls on the fore legs than on their respective hind fellows.

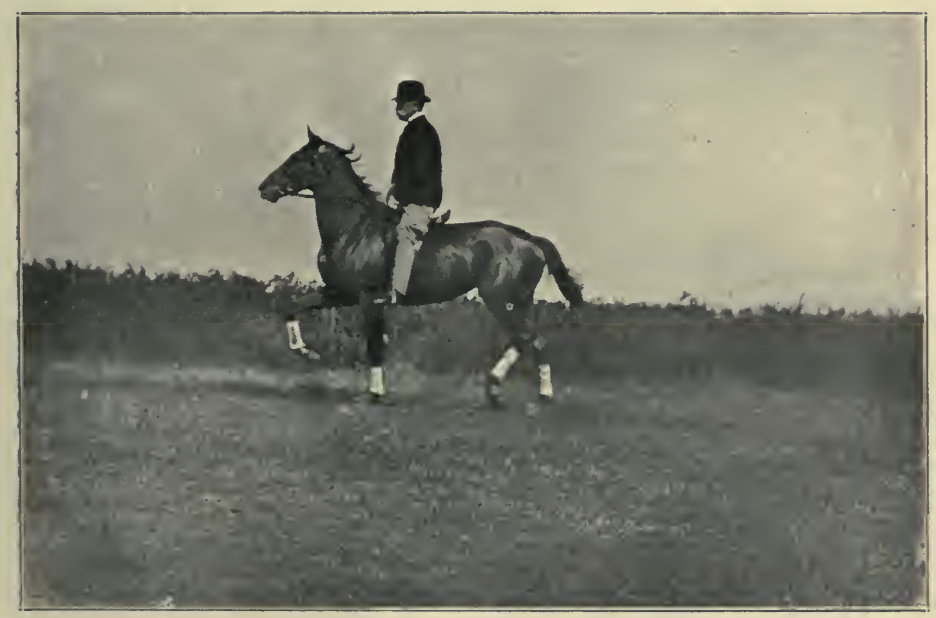

Fig. 197. Rising at the trot.

As a rule, the body should be slightly bent forward when sitting down at the trot (Fig. I96), so as to be ready for the rise; and should be held upright when standing in the stirrups (Fig. 197). If the horse pulls hard, the rider may lean a little back, so as to use his strength to more advantage. The majority of fast trotters are hard pullers; though some of them will slacken speed the moment the rider lets the reins loose. The knack (an easy one) of rising in the stirrups can be learned only by practice. One should endeavour to time 
the rise and fall of the body accurately with the movements of the horse's fore legs. The up-and-down motion of the rider should be only just sufficient to relieve the action of the horse, for if exaggerated, it will unnecessarily fatigue him; and it should be performed in an easy and graceful manner. The non-military rider should always rise in his stirrups at the trot; because it is fatiguing both to the horse and himself, as well as un-English, to bump up and down.

\section{TO CANTER.}

The canter is a pace of more or less regular three time, in which the footfalls are, when the off fore is leading: (I) near hind (Fig. I7); (2) near fore and off hind (Fig. I9); and (3), off fore (Fig. 2I). After the off fore quits the ground, there may or may not be a period of suspension (Fig. 25), which will be terminated by the near hind again coming down. When the near fore leads, the order will be reversed. When cantering a horse in a circle to the left or turning him to the left, which is much the same thing, the near fore should lead; and when he is going to the right, the off fore. In a canter on a circle to the right (which will be in the same direction as the hands of a watch proceed) or in a turn to the right, the left leg or rein, as already stated, is said to be the outward leg or rein; and the right leg or rein, the inward leg or rein; and vice versâ.

When a horse is ridden at a canter on a circle or is being turned, the tendency of his hind quarters is to be carried outwards, because the preponderance of weight is on his forehand. As experience teaches us that in such circumstances a horse will keep best in hand and safest on his legs, when the hind feet follow in the track of the fore ones, we may usefully employ the drawn-back outward foot for keeping the hind quarters in correct position. We may extend this valuable indication to making a horse strike off into 
the canter with whichever fore leg we wish him to lead; or change his leading fore leg. The drawn-back outward foot of the rider will also act as a hint to the animal to bring his outward hind leg under him and thus to strike off into the canter with the proper fore leg leading. Owing to the fact that the leading fore leg has to raise the fore-hand off the ground at each stride, a good deal of weight will have to be taken off the fore-hand in starting into the canter from the halt, or in changing into the canter from the walk or trot. Therefore, to make a horse strike off or change into the canter with, say, the off fore leading, we should turn the horse's head slightly to the left, feel both reins with the hands somewhat raised, sit down in the saddle, lean a little back and to the right, and apply the drawn-back left foot. To do this with the near fore leading, the moment of application of the leg as an aid should of course be reversed. In all these indications, the change in the position of the weight of the rider's body will be an effective signal and useful mechanical help to the horse.

Riding men are generally content with their horse going off into the canter, even if he takes the preliminary steps in a more or less disordered manner, and leads with whichever fore leg he likes best. If, however, they wish to make a horse start off at that pace from the halt or change into it from the walk or trot, with precision and with the desired fore leg leading, they must have the animal previously trained to do this, and must possess the knowledge and skill to apply the aids in a correct manner. Although the requisite knowledge can be supplied by a book, the not less necessary skill can be acquired only by practice. Practical instruction of a competent nature will combine these two conditions in the best possible manner.

Supposing, therefore, that the horse understands his work, and that we wish him to change from the trot into the canter 
with the off fore leading, we should apply the aids as already described; but in using the left leg, we should touch the animal with the spur or heel, at the moment the near fore comes down on the ground; because, at that instant (Fig. 197), the near hind is in the act of being brought forward, and a touch of the spur or foot will tend to quicken its advance, so that it may come down before the off fore, and immediately after the near fore and off hind are raised. The near hind will then be in the position shown in Fig. I7, and the other legs will be off the ground and in the correct order of movement for the canter. To change from the trot into the canter with the near fore leading, the reversed aids should be employed. The same respective aids should be used to change from the walk into the canter, although this will be a more difficult feat than changing from the trot; because in the former case, three of the legs of the horse will have to be raised off the ground, instead of only two in the latter case; and the animal has less forward impulse. Consequently, he will usually require to be more sharply collected. Getting the horse to strike off from the halt into the canter, demands a preparation as well as a stimulus and an adjustment of weight. For instance, to make him do this with the off fore leading, we should, by touching him with the drawn back spur or heel of the right foot, cause him to advance the off hind more under him than the near hind; and having thus prepared him, should make him strike off in the way I have already described. The object of the preparation in this case is to take weight off the near hind leg, so that it may be more easily and more quickly brought forward in response to the touch of the left leg of the rider. In order to assist the horse in understanding the signal to strike off with the off fore leading, we may place him in a direction slightly oblique to that in which he is going to proceed, and with his off shoulder more advanced than his near 
shoulder. The inverse aids to those described will be required to make the animal strike off from the halt into the canter with the near fore leading. He will require much special instruction (see Illustrated Horse-Breaking) before he can be made to correctly perform this movement, which is evidently much more difficult than changing from the walk into the canter.

Although it is immaterial from a mere riding point of view, with which fore leg a horse leads when he is going at a canter to the front ; many (absurdly, I venture to think,) consider it fashionable for him to do so only with the off fore. This is quite right when a horse is ridden by a delicate lady who wants to be carried as smoothly as possible; but it is absolutely immaterial, as far as comfort goes, to a rider in a man's saddle. The dictates of fashion can in no way excuse the bad horsemanship of, under ordinary circumstances, turning a horse to the left, or circling him to the left at a canter with the off fore leading. A horse is said to be cantering false or galloping false, when, at either of these respective paces, he turns or goes on a circle to the left with the off fore leading; or to the right, with the near fore leading. School riders sometimes purposely make their horses canter false, in order to show that their animals will obey the aids, even when they are applied reversely. This air de manège is of course never meant for ordinary application. Riding men who study the welfare of their horses, should bear in mind that more strain and concussion fall on the leading fore leg than on the nonleading one.

The rider of a cantering or galloping horse can easily tell with which fore leg the animal is leading; because the motion of the canter causes the rider's leg which is on the same side as the horse's leading fore leg, to be carried more forward than the rider's other leg. If from inexperience he has any doubt on this subject, he can easily settle the 
question by leaning slightly forward, and observing which of the fore legs is more extended to the front than the other. This will be the leading fore leg, as we may see from Figs. 17 to 26.

It is generally supposed that when a horse is cantering in a straight direction, that the track of his hind feet should be the same as that of his fore ones; but I am unacquainted with any scientific reason for this assumption, which appears to me to be incorrect, seeing that the leading shoulder is more advanced than the non-leading shoulder. If, however, the rider wishes the horse to keep his body straight in the canter, he can do so by his legs, and then the horse will be going in a constrained and unnatural manner.

\section{TO GALLOP.}

The typical gallop is a pace of four time; the order of the foot-falls, when the off fore leads, being (I) near hind, (2) off hind, (3) near fore, and (4) off fore. The canter and gallop merge imperceptibly into each other. In the canter, the rider will generally feel most comfortable when he sits well down in the saddle and leans somewhat back. But in the gallop, and especially when the animal is going very fast, he will fee! as a rule that he conforms most accurately to the movements of the horse when he bends a little forward, takes a good hold of the reins, and keeps the weight off the seat of the saddle by the grip of the knees (Fig. I 87). In this position he will not put much weight on the stirrups.

TO PULL UP.

A horse should as a rule be pulled up gradually, so that the suspensory ligaments of the fore legs may not be strained. In order that a horse may be able to stop himself effectually, he should be in a position to make full use of both fore and hind legs for this purpose. Hence, he should be bent 
both before and behind; that is to say, his neck should be bent and his hind legs should be well under him. Therefore, the reins should be felt ; the hands lowered; the drawn-back feet applied; the upper part of the body brought back, so as

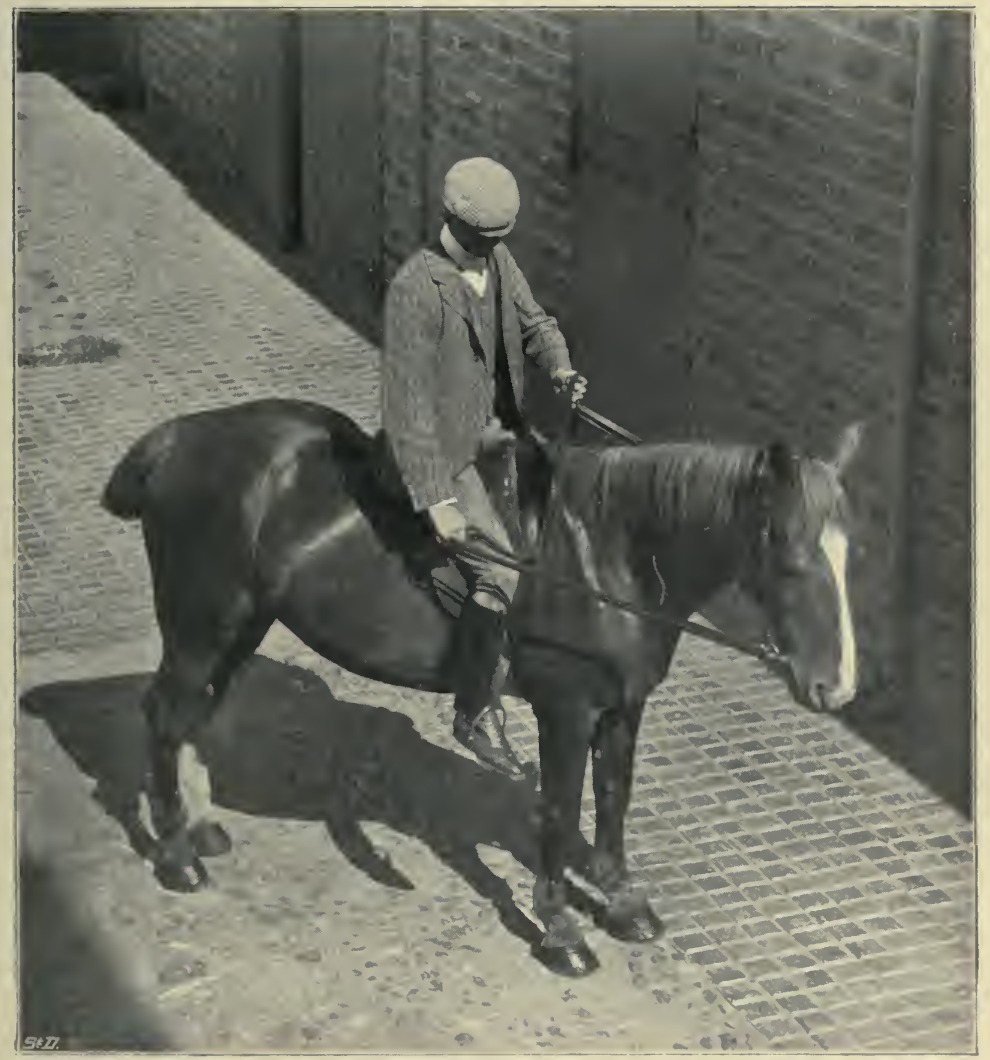

Fig. I98. Turning a horse with outward hand raised.

to relieve the fore hand; and the knees should firmly grip the flaps of the saddle, so that the body may not slide forward. It is well to teach a horse to pull up in obedience to a vocal signal, so that he may perform this action in a manner most easy to himself. 
TO CHANGE FROM ONE PACE INTO ANOTIIER.

Changing from the canter into the gallop, and from the gallop into the canter is merely a question of respectively increasing and diminishing speed. On page 23I I have considered the change into the trot from other paces, and on page 236 the respective changes from the trot and walk into the canter. The other changes need no special mention.

\section{TO TURN A HORSE AT THE IIALT.}

Turning at the halt may be divided into turning on the fore-hand, centre, and hind quarters. To turn the horse on his fore-hand at the halt, say, to the right, we should depress the right hand and keep it well away from the shoulder (Fig. 198), so as to give the indication of pulling the head round as clearly as possible. As the flexibility of the neck increases in proportion to its distance from the withers, the left hand should be carried somewhat to the right and raised (Fig. 199), so as to aid in preserving the bend of the neck. We should lean a little forward in the saddle to lighten the hind quarters, and a little to the right so as to help in fixing the off fore; and should bring the hind quarters round by the application of the drawn-back right foot, or whip (Fig. 28), in the event of the animal not being well trained. The pivot in this turn is the inward fore leg. In the turn on the centre, the fore and hind feet describe arcs of the same circle.

Io turn a horse on his hind quarters at the halt is a somewhat difficult school movement, which does not come within the province of ordinary riding.

TO TURN A HORSE DURING MOVEMENT.

To explain the principles which should guide us in turning a horse at the canter or gallop I cannot do better 
than give the following extract from Illustrated HorseBreaking:- " The body of a quadruped being supported at two ends by limbs, it follows that when a horse turns of his own accord, the point round which the revolution takes

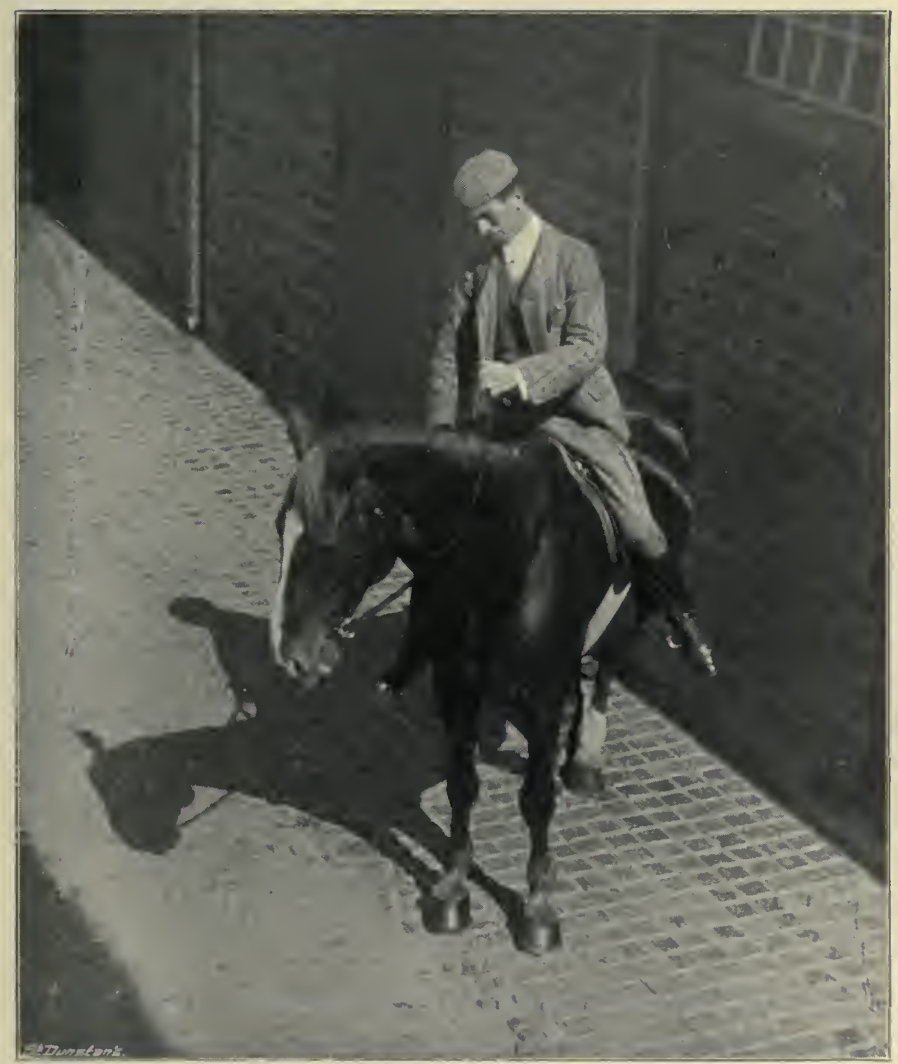

Fig. 199. Turning a horse with outward hand raised.

place will approach the heavier end according to the difference of weight on the two ends. As the weight on a horse's forehand, which at the halt is only slightly more than that on the hind-quarters, increases during movement in propor- 
tion to the speed, the tendency to turn on the fore-hand, when a turn is being made, will similarly increase. If the weight were equally distributed between both ends of the horse, his balance during a turn would be preserved in the best possible manner, and the track of the hind feet would coincide with that of the fore feet. In proportion, however, as the weight on the fore-hand exceeds that on the hindquarters (or in proportion to the speed), the greater will be the liability of the animal to fall or to have his balance unduly disturbed when turning, by his hinder end describing a larger arc than the fore part of his body; or, in other words, by the track of the hind feet going outside that of the fore feet. To correct this tendency, we should, when about to turn the horse during rapid movement, slacken speed, lean back in the saddle and hold the horse's head up, so as to bring the weight back; draw back and apply the outward leg (the left if the turn is being made to the right, and vice versâ) to the animal's side, and lean inwards, so as to oppose the centrifugal force." In order to give, as clearly as possible, the indication to turn, we should carry the inward hand well away from the side of the horse ; and to prevent the head being brought round (p. 23) and the mouth-piece being pulled through the mouth, we should keep the outward hand low (Figs. 200 and 201), and its position fixed.

The aids are applied for turning a horse at the walk and trot, in a manner similar to that at the halt.

It is evident that at the walk or trot; a mounted horse will turn best when he receives the signal to do so, at the moment that the outward fore leg comes on the ground; for in response to the signal he can then check the forward reach of the inward fore leg, and can also carry it to a greater or less distance to that side, in which case it will be in a favourable position to act as a pivot for the fore-hand. 
If, on the contrary, the horse begins the turn while the inward fore leg is on the ground, he will cross his legs and place himself in an awkward if not a dangerous position. As, luckily for us, horses take no pleasure in falling down, they will rarely make a mistake in turning this way. At the canter or gallop, there is a considerable amount of danger

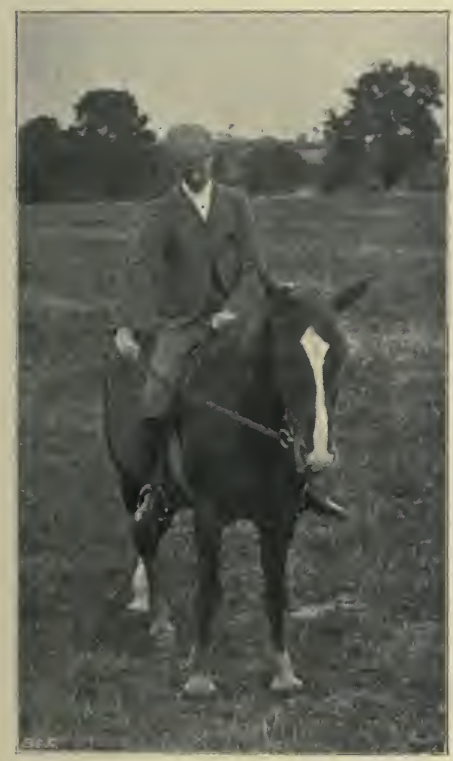

Fig. 200.

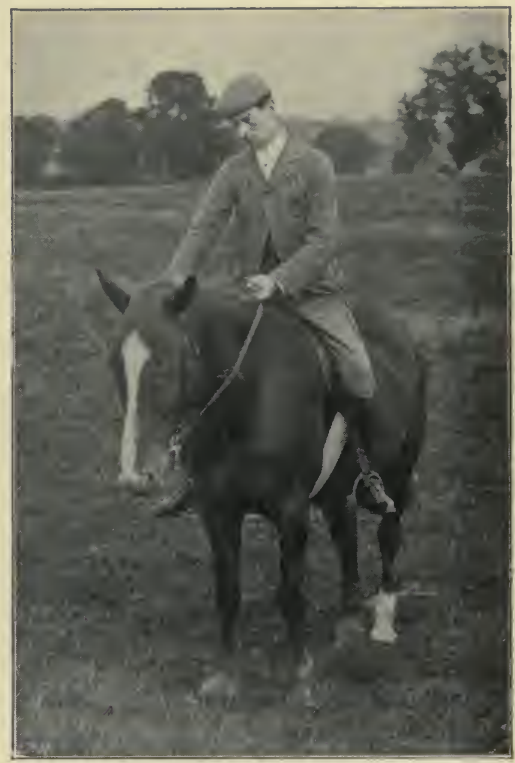

Fig. 201.

Turning a horse with the outward hand kept low.

in trying to turn an ill-broken horse to the side opposite to that of his leading fore leg; for he would then be liable to cross his legs and come down; but a well-taught animal under similar conditions would change the leading leg of his own accord, and would thus obviate all risk of making a mistake. Some horses are naturally so clever that they will do this without any previous instruction. 
TO PASSAGE.

Although the passage (to employ a riding school term) is generally regarded as a manège movement; it is of such general utility when done at a walk, that I shall here describe its execution at that pace.

The passage is a side movement, in which the track of the hind legs is apart from and parallel to that of the fore ones. It can best be done when the horse is collected at the walk; for if he is uncollected, he may fail to raise his outward feet (the near if going to the right and vice versâ) high enough to clear the inward ones. A man can easily close (take ground) to the right or to the left, while facing to the front ; because he is capable of moving his legs freely to one side, without-changing the position of his body; but a horse possesses this power of lateral leg-movement to such a very slight extent, that he is practically unable to close to the right or to the left without altering the position of his body. Therefore his body has to be inclined towards the direction of the closing movement. If the angle thus made is more than $45^{\circ}$ the animal will as a rule have difficulty in executing the movement. An angle of from $30^{\circ}$ to $35^{\circ}$ will generally be found to meet all requirements. It is evident that if a rider wanted to close a little to the right or to the left, as might often occur at a check in a crowded hunting field or at the starting post in a race, he might fail to do so, if he did not know how, or was unable, to make his horse passage. To execute the passage, the horse is placed obliquely to the direction in which he has to proceed, and his head is turned towards that direction, in order to give more freedom of movement to the outward fore leg (the left when going to the right, and vice versâ), and to place more weight on the inward legs than on the outward ones, to aid which object the rider should lean a little towards 
the inward side, and will therefore place more weight on the inward stirrup than on the outward stirrup. The reins will also be used to prevent the animal going forward. In the passage at a walk to the right (Figs. 202 and 203), the rider should give the impulsion with his drawn-back left foot at the moment the animal places his near fore on the ground (Fig. 102); because at that instant the off hind is on the point of coming down, and the near hind can then

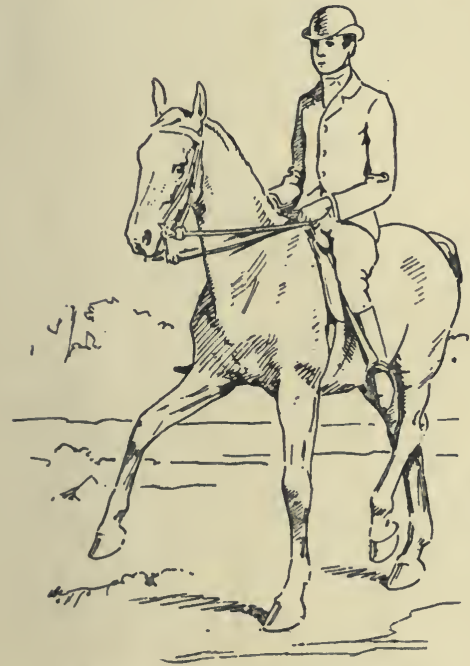

Fig. 203. Passage to the right.

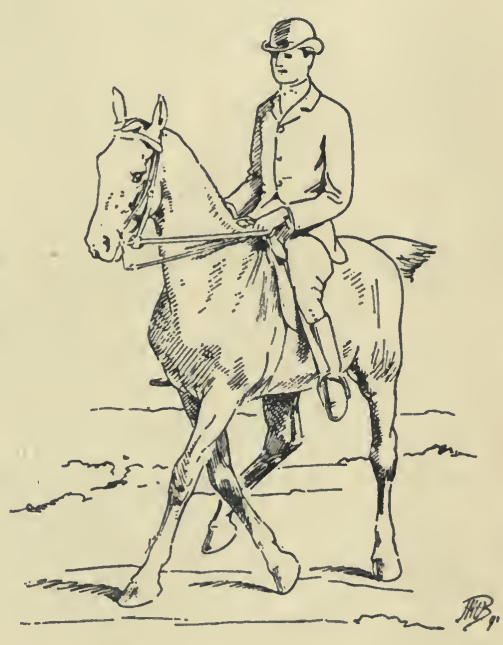

Fig. 202. Passage to the right.

be picked up and brought in front of the off hind. It is much better for the rider to take the time of giving this indication from a fore leg, which he can closely observe, than from a hind one, the movements of which are hidden from his view. The pressure of the left leg, to be effective, should be reserved as a signal for the near hind, and consequently should not be continuous. The near fore leg will cross the off fore leg (Fig. 202), because the head is bent to the right; more weight is placed on the off fore than on the 
near fore; and the pressure of the left leg serves as a stimulus to the horse to go forward; but as he is restrained from doing so by the reins, he can answer this stimulus only by moving to the right, to facilitate which action on his part, the aids are applied in the special manner described. The inverse aids are employed for the passage to the left. After the horse has finished the passage, he should be placed in his original direction by bringing his head and neck straight by means of the reins, and by making him turn on his fore-hand to the required extent by the drawn-back inward foot, aided by the weight of the rider's body being brought forward and inclined towards the outward shoulder.

\section{SWERVING.}

It often happens even with the steadiest of horses, that when proceeding forward, the animal, from some cause or the other, suddenly swerves off to one side, say, to the right. In this case, if the rider wants to keep on in the original direction, he should feel both reins and turn the horse's head to the left in the manner already described, and should at the same time apply the drawn-back left foot, with a touch of the spur, whip or stick, if necessary, so as to make the animal bring his hind quarters round into the original direction. The aids will of course be reversed for a swerve to the right. Badly broken horses when thus swerving will often, in partial compliance with the pull of the reins, bring the head round, without also altering, as they ought to do, the position of the body. A cut of the whip, with the point down, and the whip hand on the reins, will generally be the best means for bringing their hind quarters round.

The whip or stick should of course be held in the hand opposite to the side to which the horse usually swerves, which he will generally do to the left side, owing to the fact of his being more often handled, led, lunged, fed, mounted and 
otherwise manipulated on that side than on the off side. Of all silly things, the rider should avoid striking a horse on any part of his fore-hand with the object of straightening him, because that would be an attempt to turn the heavy end of the animal round the lighter end.

\section{TO REIN BACK.}

Even on the race-course, it is well for a jockey to be able at times to rein his horse back at the start, instead of having to go round and come up again, in doing which he might easily lose a good position. Also, among a crowd of horses in the hunting field, when waiting for one's turn to go through a gate or at the only practicable part of a fence, especially when close behind a tail adorned with a red bow, a like command over one's horse is to be appreciated. I may explain that there are two forms of the rein back: one, in which the preponderance of weight is placed on the hind legs; the other, in which it is put on the fore-hand. We see the former when the carter tries to make his draught animal push back a heavy load by raising the horse's head and forcing him to throw all his weight into the breeching. In the latter, which is alone applicable to saddle work, the horse increases the proportion of weight on his fore-hand by lowering his head, and consequently gives freedom and lightness to his hind legs in the backward movement. If it be right for a horse to be light in front when going forward, it is surely correct for him to be light behind when reining back. Experience tells us that the best way for a saddle horse to rein back is in diagonal two time (that of the trot), namely, near fore and off hind, and off fore and near hind. It is reasonable to assume that we should begin the rein back with the diagonal which is more advanced than the other diagonal, and that the fore foot of the former will, as a rule, 
be in advance of that of the latter at the halt, supposing that the horse is not standing with both fore feet equally advanced. Therefore, if, say, the near fore is more advanced than the off fore, we should (I) turn the animal's head to the near side, and bring the body forward and to the near side, in order to diminish the weight borne by the off hind; (2) draw back the right foot so as to prompt the horse to lift up the off hind; and (3) feel both reins, with the object of making him take a step to the rear with the off hind, the backward movement of which will be accompanied or quickly followed by that of the near fore. In the execution of this step, the hind quarters should be kept straight by the application of the drawn back right foot, and the hands should be held low in order to maintain the preponderance of weight on the forehand. To obtain the next step, the head is turned to the opposite side and the reversed aids are applied.

Before starting in this rein back, we can easily tell which is the more advanced fore leg of the two by the fact that its shoulder will be farther to the front than the other shoulder.

If both fore feet be equally advanced, we can begin with either of the two diagonals. In all cases, the rein back should consist of a continued series of steps executed with ease and precision. To obtain this desirable end, the horse should go freely up to his bit; because if he has any tendency to keep behind his bit-from defective training, faulty manipulation of the reins, or wrong bitting - there will be proportionate risk of the rein back becoming replaced by the disordered and dangerous run back, with possible rearing and falling over.

\section{GOING UP OR DOWN HILL.}

If the ascent be steep, the rider can catch hold of the mane with one hand, lean well forward, leave the reins loose, grip the saddle tightly with the knees, and avoid putting weight on the stirrups, which might cause the saddle to shift 
backwards, and the leathers to come out of the spring bars. The horse may be allowed to take a zigzag course. When going down a steep hill, the rider should keep a good hold of the horse's head, so as to make him get his hind quarters under him, grip tightly with the knees, draw the feet back,

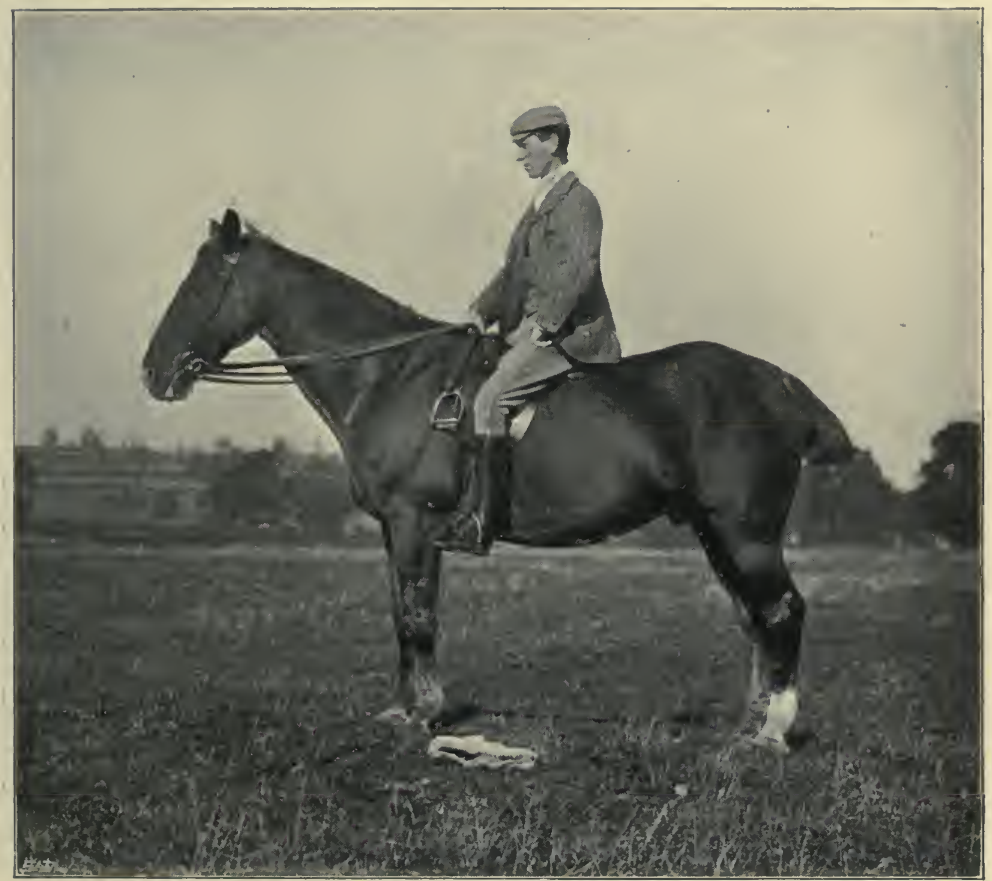

Fig. 204. Preparing to pick up an object off the ground.

lean as far back as possible, and let the horse go straight down, but not obliquely. If the animal happens to slip when proceeding in the former manner, he will in all probability merely let himself down on his hind quarters; but if in the latter, he may fall on his side and roll over.

SIVIMMING A HORSE.

The rider should take the feet out of the stirrups, leave 
the reins slack, and lay hold of the mane. Or he may get off the saddle and hold on by the pommel or by the mane with one hand, while he tries with the other hand to guide the horse, when necessary, by feeling the reins lightly on one side, or slightly splashing him with water on the other side. Or he may hold on by the tail.

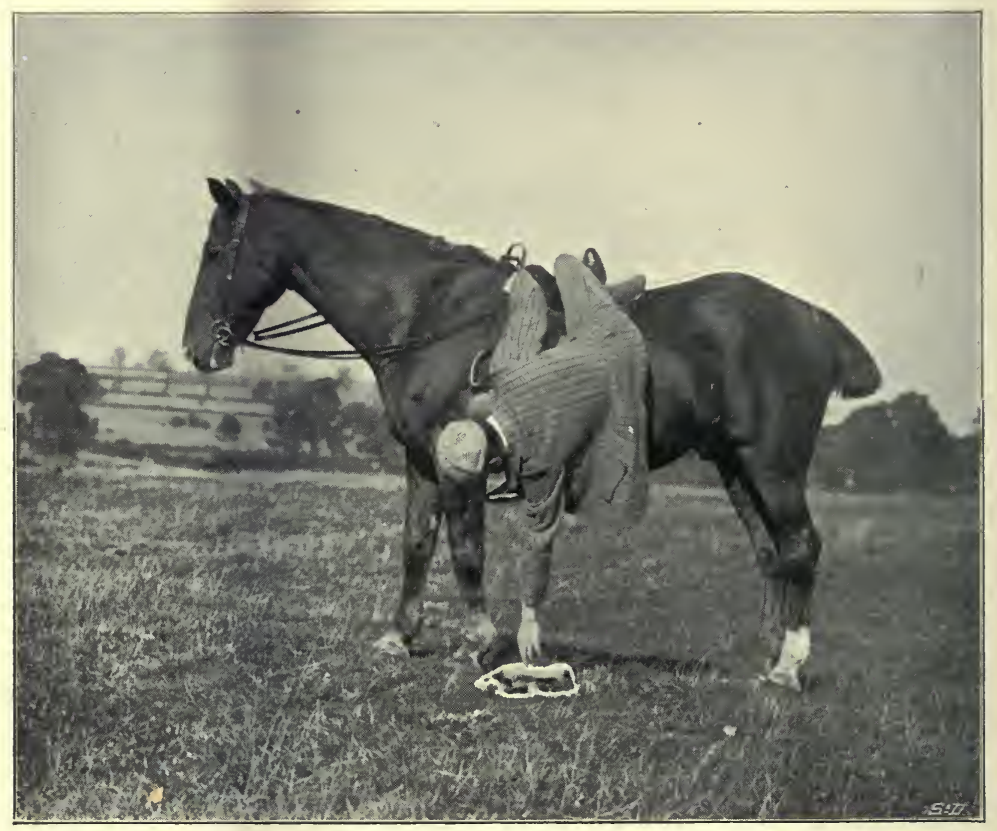

Fig. 205. Picking up an object off the ground.

\section{PICKING UP OBJECTS FROM THE GROUND WHEN ON HORSEBACK.}

If, when on horseback, we wish to pick up without dismounting, an object such as a whip or pocket-handkerchief, say, with the left hand, we may do so, by catching a good hold of the mane with the right hand; taking the right foot out of the stirrup; bending over to the near side, so as 
to catch the off side of the cantle with the right heel; and by the aid thus afforded, pick up the object. It is almost needless to say that the horse employed should be particularly steady.

Another and easier method which is specially applicable to a horse or pony that has had its mane clipped off, is to take with the right hand a back-handed hold of the right stirrup leather (Fig. 204), after having removed the right foot out of its iron, and then to reach down and pick up the object with the left hand (Fig. 205). The body can easily be drawn back into the saddle by means of the grip the right hand has on the off stirrup leather. To perform this feat with safety, it is necessary to have the horse tightly girthed up. With both these methods, the reins should in the first instance be passed into the right hand and drawn up to the required length. 


\section{CHAPTER XII.}

\section{RIDING AND BRIDLING HORSES WITH VICES.}

General Remarks-Boring-Buck-jumping-Throwing Up the Head-Throwing Down the Head-Difficult to Mount-Kicking-Rearing-Jibbing-Pulling and Running Away-Shouldering-Getting the Tongue over the Bit-Shying and Unsteadiness-Stumbling.

GENERAL REMARKS.

As I have described in Illustrated Horse-Breaking what I have found to be the best methods for "making" and breaking horses, and for curing them of various faults of mouth and temper; I shall in this chapter confine my observations to the procedure a rider ought to adopt if he finds his mount to be fractious, and has got no time to break him.

The ability to make a difficult horse conform to the wishes of his rider, who of course ought to be a good horseman, is mainly dependent on the fact of his possessing nerve, patience, firmness and knowledge. It often happens that a man who in his youth could have done almost anything he pleased with horses, begins to lose his wonderful power as soon as his nerve commences to "go." A hesitating manner in going up to a horse, a trembling about the knees, or a nervous clutching at the reins when mounted, betrays the rider's secret, often before he is conscious of it himself, to the observant animal, who is only too ready to change the position of servant for that of master. Although our horses should never be allowed to successfully oppose their will to ours, we should try to obtain from them friendly 
obedience, rather than sullen submission; for a horse's courage and intelligence are as needful to us as his strength and speed.

\section{BORING.}

Some horses carry their heads too low down, generally from the effect of the continued use of a curb or Pelham (p. 86); while others bore to one side, sometimes to such an extent as to constitute bolting off the course, or out of the line the rider wishes to take, from having been spoiled by incompetent performers. With the former, the unjointed or gag snaffle may be tried; or as a substitute for the gag snaffle, we may take up the cheekpieces of the head-stall, so that the bearing of the mouth-piece on the corners of the mouth may make the horse hold his head up. The latter, however, require for comfortable riding something more than mechanical devices to cure them of their unpleasant trick. All of us who have ridden much are aware that the large majority of horses have what is called a hard and a soft side to their mouths, the former being generally the right; the latter, the left. This is evidently owing, as I have already said, to horses being led, handled, etc., much more on the near side than on the off; and to the fact that most riders use the left hand more than the right on the reins. As many riders sit "anyhow" on a horse, with one leg advanced or drawn back more than the other, it would be strange if riding horses were to escape all bias in their gait.

I am inclined to think that many horses learn to bore, from their mouths becoming insensible from the continued pressure of the curb. Hence I would advise that a horse should not be ridden for a long time on the curb, the action of which, with a double bridle, should be frequently relieved by that of the snaffle. I have also a strong suspicion that the nutcracker action of the ordinary jointed snaffle teaches a horse to 
bore. Whether that be the case or not, I always find that horses do not go as well in it, as in an unjointed snaffle.

So-called stiffness of neck and hardness of mouth have nothing to do with the physical condition of these parts, but are merely terms to express the horse's inability to understand or unwillingness to obey the aids.

When riding a horse which bores to one side, the rider,

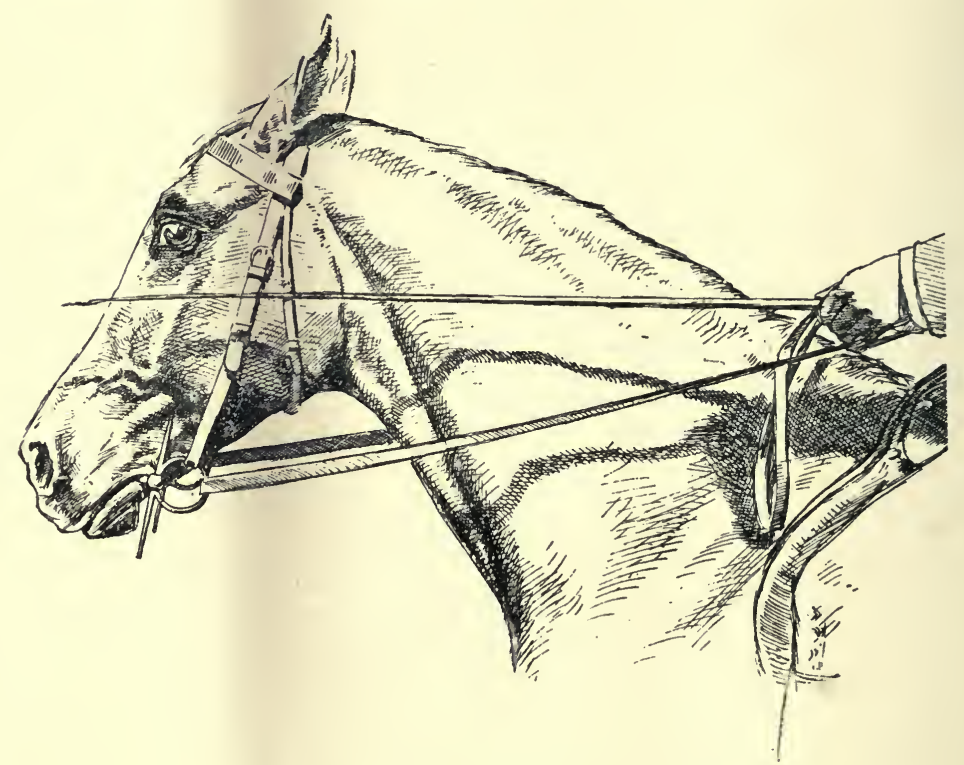

Fig. 206. " "Showing" a horse the whip.

by holding one hand lower than the other, and by playing with the rein of the side opposite to which the animal bores, may keep his neck straight. At the same time he should not forget to make the horse, by means of his legs, and if need be by his spurs, carry his hind quarters properly. From time to time a touch of the whip on the hind-quarters, will be still more effective. I have found that the plan of straightening a horse by the application of a cutting whip or stick 
on his hind-quarters, to be far more effective, than by "showing" him the whip (Fig. 206), in the usual way. We should bear in mind that the faulty action of the hind quarters have nearly as much influence in the production of boring as that of the head and neck. It is evident that if a horse has his hind legs well under him and properly placed, he cannot be heavy in front. A standing martingale fixed to the rings of the snaffle will often give the rider a good deal of power over a horse that bores to one side. With such an animal, we may pass a strap through the ring of the snaffle on the opposite side to which he bores, and through the loop formed by the throat-latch, and tighten the strap as may be required. This arrangement will often make him go with an even feeling on both reins.

\section{BUCK-JUMPING}

Appears to be an instinct formed in horses when they were preyed upon by carnivorous animals which made their attacks by jumping on the backs of their quarry. I am inclined to think that buck-jumping is a vice common among all wild and semi-wild horses; for I have seen it among such animals that were bred in Australia, New Zealand, North and South America, South Africa, and on the Russian steppes. I have never known English, East Indian or Arab horses buck, and find that this vice is becoming comparatively rare among Australasian horses which are reared under civilized conditions. Forty years ago, almost every "green" Australian horse bucked. The buck-jumper, with the quickness of thought, throws his head between his fore legs. At the same moment he arches his back, bounds in the air with his head and shoulders down and his croup up, and with his fore legs thrust straight out to the front, and his hind legs gathered under him. The difficulty in sitting him consists chiefly in the fact that the suddenness of the downward movement of his 
head is very apt to cause the rider to be pulled more or less forward on to his neck, by means of the reins, and that the shock of the impact of the fore legs with the ground and the violent cant of the loins, will in such a case generally complete the disconnection. The regular buck-jumper will buck forwards, to one side, or even backwards, until he dislodges his rider. Or, not content with this, he may go on until he breaks the girths, gets through the saddle, or tires himself out. When he succeeds in breaking the girths, he usually does so by getting the saddle on to his neck during his convulsive movements, and then, when he throws up his head, something must go. No matter how strong a seat a man may have, he will be almost certain to part company with his mount, if in the first instance he makes the mistake of hanging on by the reins. I can say from experience that when a horse bucks, the rider suddenly becomes aware that there is nothing in front of the pommel of the saddle except a sheer precipice, and feels himself jerked forward without having anything to hold on to. In the Colonies, a horse is said to "pig-jump," when he bucks only forward; but if he supplements that movement with the still more disconcerting action of bucking to one side or backwards, he can fairly claim the distinction of being able to buck-jump.

Some buck-jumpers are perfectly quiet to mount; but the moment they feel the rider's weight in the saddle, they will try all they know to get him off. Others will not buck unless they are very fresh, or under some unusual excitement. An Australian steeplechase mare with which I won some races, always bucked with me (but never at other times), if I happened, when riding her, to take a paper of any sort in my hand. The instant she heard the crackling sound it made, down went her head, and if I did not come off, I generally had a very near escape. I believe I am correct in saying, that as a rule there is no vice which a horse, if 
mastered a few times, forgets so readily as buck-jumping. Many Australians can sit these horses to perfection, though men who have not learned during their youth to do so in the: Colonies, very rarely acquire the knack. . In fact I have never known a man whose riding experiences were limited to horses bred in the United Kingdom and similar countries, to be able to sit a bad colonial buck-jumper. Although I had a good deal to do with animals of this class, when I lived in India, I made no voluntary attempt to cultivate this art.

If the rider finds that his horse is going to "put his back up," he may pull him sharply round, and get his head up before the animal can buck; but he should be very careful to keep a light hold on the reins, lest the horse by a sudden downward dash of the head may pull him on to his neck, in which case the animal will be almost certain to gain the first fall, if, to use a Colonial expression, he "goes to market." Herein lies the cause why so few of even our best riders whose experience has been confined to English and Irish horses, can sit a buck-jumper; because, having been brought up to the idea that they should always keep a "nice hold of the horse's head," they cannot on a sudden emergency relinquish the long accustomed habit, and are accordingly put down. It is of course essential that the rider should lean well back, and it is always well for him to watch the animal's ears, so that he may accommodate his seat to the erratic movements of his mount.

If a man has to ride a buck-jumper, he will have a much better chance of "remaining" in a small enclosure than in the open; for in the former, the animal will not be able to get up much pace. In the latter, the rider is impaled on the horns of a dilemma; for if he keeps a good hold of the reins, he will probably get pulled over the animal's neck; but if he lets the reins loose, the horse will generally go off at a smart pace, and will then buck and halt with an amount 
of momentum that will be almost impossible to resist, even if the sudden shock be not followed by several others of the same kind. The heavier the ground, the more difficult will it be for a horse to buck, and the easier will be the falling. Mounting a horse in water up to his girths and then letting him "rip," is an old and safe plan for taking the buck out of an animal.

For evident reasons, the saddle for a buck-jumper should be furnished with a crupper and breast-plate. A gag snaffle will of course be the best general bit with which to ride an animal of this kind. Or, having put on a snaffle with double reins, we may unbuckle one pair at the centre, cross them over the withers, and attach them respectively to the "Ds" on each side (the near rein going to the off " $\mathrm{D}$," and the off to the near), so that the horse may not be able to get his head down. He should then be ridden with the other reins. This method, which I have often tried with success, is of course more suited for breaking than for ordinary riding.

Before mounting a horse which is inclined to buck, it is advisable after having saddled him, to lunge him and turn him sharply several times with the long reins (p. 205) for a few minutes, so as to remove from his back the cold feeling of the saddle, and to make him obedient to the reins. The arching of the back when a buck-jumper is first saddled, may be taken as a very useful danger signal. We may justly feel safer in mounting him when his back has gone down, than when it is up. If one has to ride a buck-jumper, it is well for the first few minutes to have an assistant to hold him by a leading rein, so as to check the horse to some extent in his plunges and to prevent him breaking away.

Mr. John Stevens, from whom I bought some winners, when he used to ship horses from New Zealand to India, tells me that the Maories have a capital plan of riding buck-jumpers 
bare-back, by passing a rope a couple of times round the animal and then tying it, or by using a strong surcingle inside which they get their knees. The more a horse thus

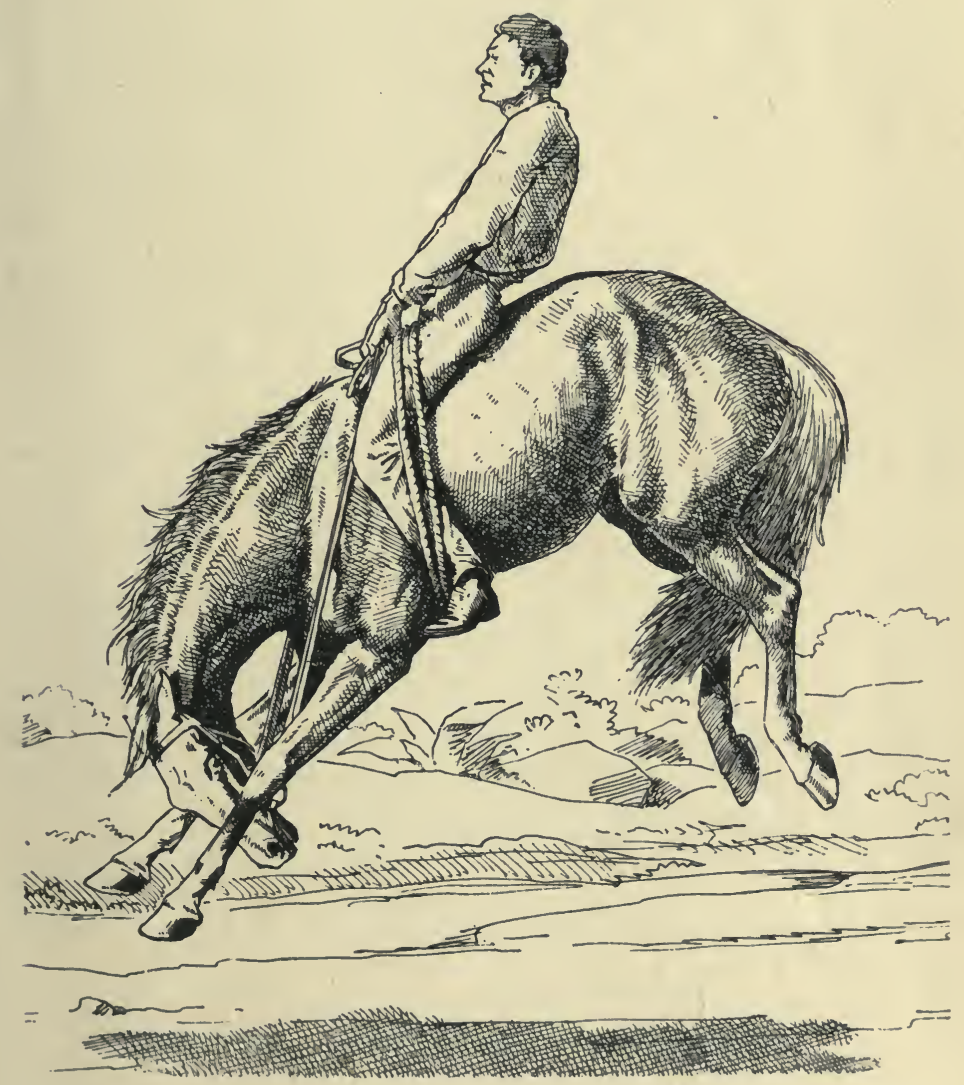

Fig. 207. Maori method of riding a buck-jumper.

equipped bucks, the firmer are the rider's legs jammed between the surcingle or rope and the animal's sides (Fig. 207). If the horse throws himself down or falls, the rider can easily get free, as his feet are outside the rope or surcingle, as the case may be. 


\section{THROWING UP THE HEAD.}

If a curb bit is used, we should be careful that the curb chain cannot hurt the sharp edges of the branches of the lower jaw (p. 77), and we should see that the mouth-piece is law down in the mouth (p. 103); or we may try a thick unjointed snaffle (Fig. II7). The most effective plan of all, is to use a standing martingale attached to the rings of the snaffle (p. 90).

\section{THROWING THE HEAD DOWN.}

This vice is by no means so common as the one alluded to in the preceding paragraph. Though equally unpleasant to the rider, it is not so dangerous, because it does not prevent the horse seeing where he is going. It is put into practice by the animal suddenly throwing his head down as near as he can to the ground from time to time; his object apparently being to annoy the rider by pulling the reins through his hands. An effective way for stopping this trick, which, according to my experience, is generally practised at the walk, is to hold a stick and the reins crossed in both hands, and to rest the stick and the reins on the pommel (Fig. 208). When the reins are thus held, it will be impossible for the horse to pull them through the hands. In fact, the horse after having made a few fruitless attempts, will generally cease from annoying his rider in this manner.

\section{DIFFICULT TO MOUNT.}

It will be best as a rule to take a short grip of the near rein, as described on page 172 , and make the horse go round and round several times, so as to show him that he cannot break away; and then mount. It is generally easier, and almost always far safer, to mount by oneself, than to have the horse held by an assistant, especially if that individual 
is inclined to hang on too long, or to attach himself to the curb reins. I have described in Illustrated Horse-Breaking an easy and effective means for combating this vice.

\section{KICKING.}

The first thing to do, if practicable, is to see that the saddle or girths do not pinch the horse. If we are on his

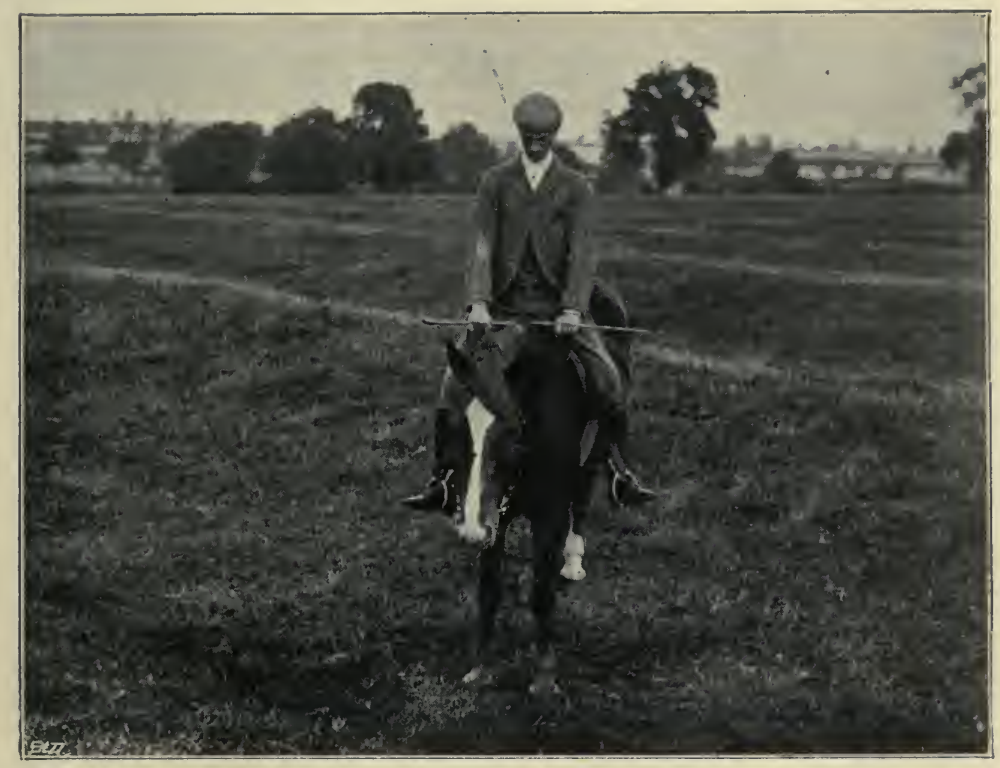

Fig. 208. Plan for preventing a horse throwing his head down.

back at a time that he is indulging in this vice, we should keep his head raised, speak to him, "shake him up" by pulling the bit through his mouth from side to side, so as to lighten his fore-hand, and if necessary, cut him about the shoulders with the whip or cane for the same object.

\section{REARING.}

My experience among rearers in many countries is that pain inflicted by the bit (whether by a severe bit or by 
rough handling) is the great cause of this vice. Hence we find that in countries like England, where curbs are in general use on ordinary riding horses, rearing is much more common than in countries like Australia, where the snaffle is chiefly employed. Also in England, there is a far larger percentage of rearers among hunters, which are almost always ridden in double bridles, than among racehorses, which hardly ever go out in any other bit than a snaffle. Furthermore, I have invariably found both in my own case and in that of others whose performances I have witnessed, that a touch of the curb is the best means to make a horse which is that way inclined, "stand up straight on end." I would therefore advise that a curb should not be employed when riding a rearer. I may state in passing, that many men who in obedience to the dictates of fashion, use a double bridle on every kind of horse, are unable from want of skill and coolness to discriminate between the curb reins and the snaffle reins on a sudden emergency, or even under ordinary conditions of riding. If such men have to ride a horse that has a tendency to rear, they ought to use only a snaffle bridle (with an unjointed mouth-piece for choice), or if they are unwilling to commit such a supposed solecism, they should dismount the moment the animal shows any inclination to "get up." The first thing therefore to do with a rearer is to see if the bitting is in fault, and to rectify it, if such be the case. With a double bridle, it will generally be advisable to take off the curb-chain, the presence of which might irritate the animal. In any case, the use of a curb is out of the question.

The two most important points about rearing are that all rearers are too light in front, and that a horse cannot rear unless his hind legs are fixed on the ground. We should accordingly put all the weight we can on the forehand, and should try to keep the horse's hind feet moving. 
With these objects in view we should, when a horse rears, bend forward as much as possible; lower the left hand for choice, as horses usually turn more readily to that side than to the right; and try to turn the animal to the left with the snaffle rein, while leaving the off rein slack, so as to avoid exerting any pressure in a backward direction on the horse's mouth. If the horse gets very straight up, it may be dangerous to feel his mouth at all with the reins, and we may have to content ourselves with catching hold of the mane or even clutching the horse round the neck, ready to slip off to one side in case he comes over. When in this position, we should grip tightly with the knees, so as not to put weight on the stirrups, which in such a case might come out of the spring bars and thus cause us to part company with our mount. While the horse is playing up, it is generally safest to keep the feet away from his sides.

If we have a few minutes to spare, we can generally bring the animal under control, by getting off; taking the near reins close to the bit in the left hand, and making the horse circle round by touching him smartly on the hocks and gaskins with a whip or cane. When he answers this indication on the right side in a lively manner, we should teach him to do so, on the other side. If we then mount him and hold the rein and whip or stick as in Fig. 28, or in the left hand, and give him another turning lesson, we shall generally find that the practical application of this instruction will act as an effective defence against the horse's trick of getting up on his hind legs. The turning lesson is simply a rough and ready way of teaching the turn on the forehand (p. 240).

Hitting a rearer between the ears with a stick or bottle full of water, as is sometimes recommended, is a barbarous practice which is apt to make him break his knees, may 
injure his poll, is certain to make him "shy" of being touched about the head, and will have no curative effect.

The standing martingale attached to the rings of the snaffle (pp. 90 to 94) acts as a valuable preventive against rearing, by bringing the head down and thus putting weight on the fore-hand, and by punishing the mouth when the horse tries to get up. I would not, however, advise that a rearer should be ridden for the first time in this martingale; because, on feeling the unaccustomed restraint when attempting to rear, he might throw himself backwards, as I have known horses do. Lunging and turning the horse sharply several times with the long reins for about a quarter of an hour, will generally be sufficient to give him all the preliminary instruction he will require with the standing martingale.

Major W. M. Sherston told me that a capital plan for stopping a horse from rearing, is to hit him a blow over the eye with the flat of the hand the moment he "gets up." He said that one or two applications are enough for the animal's life. Although I have never tried this plan, I can fully believe in its good effects, especially as it makes the horse bring down his head and shy off to one side, which are actions that are opposed to the attainment of an upright position. It has the disadvantage of being apt to make him shy of being handled about the head.

\section{JIBBING.}

The vice of restiveness, or that of obstinately refusing to go on, is called "jibbing," or being "nappy." Ignorant people often apply the word "restive" to a horse that is unsteady; in fact, one which will not remain standing in the same place. As passive resistance is more difficult to overcome than active opposition, the exhibition of this vice will try a rider's temper and baffle his powers of persuasion and coercion, more than the whole list of equine tricks put 
together; except, perhaps, the unpleasant habit some animals have of prancing, dancing about, and refusing to walk quietly when mounted. We should here bear in mind that rearing is often a form of jibbing; that in all cases these two vices are closely allied to each other; and that the horse when practising either of them, is too light in front. If the rider tries in the usual way to urge on a restive animal, the horse will probably back, kick, shoulder his man up against the first convenient object, bite him if he can get in reach, rear straight on end, or even throw himself down and roll. A friend of mine who was a brilliant 'cross country rider, was once riding a horse of this description. They got on all right together until they came to a small watercourse, at which the horse stopped and refused to proceed. My friend, who was holding the reins loosely in his right hand, shook them on the animal's neck as a hint to go on. In an instant the brute whipped his head round, seized the rider's wrist with his teeth, and dragged him off his back. The poor fellow battled with the horse for several minutes, and dealt him blow after blow about the muzzle and face with his left hand; but the horse kept shaking him like a terrier would a rat, until at last when he let go, my friend's wrist was a mass of pulp, and had of course to be amputated. I am glad to add that this terrible accident did not shake the iron nerves of the sufferer, Mr. Bertie Short, and that he subsequently won many steeplechases in India, though he had to wear a hook. He used to ride with double reins sewn together at intervals, so as to form loops, each about four or five inches long. He was thus able to shorten or lengthen his hold, or to take both reins in his right, and use the whip in his left hand.

In first tackling the offender, supposing that he is not also a rearer, we may sometimes succeed in bringing him to reason by a few cuts of a whip or stick across his hind 
legs, while pulling him from side to side; but above all things we should avoid hitting him about the shoulders or neck, because that would be the plainest possible hint to him to rear, even if he had not had the idea of rearing in his mind, by making him still lighter in front. If our coercive efforts do not promptly have a good effect, we should at once cease them, lest they might irritate the animal to still further resistance; and then we cannot do better than follow the routine described for overcoming rearing. In turning the animal round to one side and then to the other, we should gradually increase the size of the circles, until at last we can get the horse to go in any direction we wish. We should on no account attempt to rein him back, lest the movement to the rear might prompt him to get up on end. Also, the employment of spurs will generally be worse than useless. As I have explained in Illustrated Horse-Breaking the rationale of all this work, I need not go over the same ground here.

When the horse shows that he has "given in" by going forward, we should not display our bad horsemanship and vile temper by flogging, spurring or jobbing the animal in the mouth; for no horse has sufficient intelligence to connect any of these forms of cruelty with his previous act of disobedience. On the contrary; his most natural conclusion would be, that they were meant as a punishment for his going forward. The frequency with which such punishment produces a fresh exhibition of jibbing, proves the correctness of this statement.

Most of us no doubt have read Dick Christian's story as told by the Druid, of Mr. Marriott of Welby, who bought a restive horse whose former owner could do nothing with him. "Mr. Marriott takes him home; and the very first time he rides him, he stops dead at a gate. A man came up and Mr. Marriott shouts to him: 'Here's a shilling for you, my 
man ; go to my house and bring me the Leicester newspaper.' Blame me, but he sat on his back six hours reading the newspaper, the horse wanted to come back and tried it on several times, but he would not let him. Now and then he tries quietly to get him up to the gate, and about tea time he does it. He then rode him through, making much of him; he was such a patient, clever man; he'd have sat on him for a week, and have his victuals and his umbrella sent him, rather than be beat; that evening he rode him to Kettleby, Grimstone, Ashfordby, and so home, and opened all the gates on the road. He gave him no trouble no more; you see as time and good judgment brings all things to pass." The part of Mr. Marriott's performance which I specially admire is his "making much of him" after the horse had given in. Although few of us when going out for a ride could spare six hours to sit on a motionless horse, the infliction of that long halt on the rebel was thoroughly sound in principle; because it made the horse connect the idea of distressing tedium with that of his vice. The principle of making a horse go round and round to one side and then to the other, when put into practice, has a somewhat similar, though stronger and very much quicker effect.

\section{PULLING AND RUNNING AWAY.}

If a horse cannot be promptly got in hand, the rider should use the reins in the manner described on pages 224 and 225 , and 253 to 255 . If the animal gets his head up, the rider should drop his hands and wait until he lowers it before taking a pull. In order that the muscles may work to better advantage, the rider should hold the reins rather short, and they may be knotted in order to give a firmer hold. If the horse carries his head low, the rider may saw the bit (pull it through the mouth from side to side) to make him bring it up. When a horse pulls hard, the rider should sit down, 
should grip the flaps of the saddle as tightly as he can with his knees, and should draw back his feet (pp. 192 and 193); for at such a time it is all important for him to be able to manipulate the reins with precision, which he could not do if his body was moving about. As a horse is far stronger than we are, we have to depend much more on skill than on strength for holding a hard puller. Hence our chief object in this case should be to secure accuracy in the manipulation of the reins.

Many bad riders when on a puller thrust their feet forward, hump their shoulders, stick their elbows out, and jam their fists against their waistcoat; and others keep their arms straight. and throw their whole weight on the stirrups. It is evident that both these styles should be avoided.

As a rule, the most desperate puller will not break away from control unless his rider has the temerity to give him his head. All may go on well until something startles the animal, who is generally on the look out for an excuse to play up. If, when he bounds forward, the rider becomes shifted in his seat, or slackens the reins, the horse will get his head free, and then the odds are against the man on his back. The rider of such an animal should watch his every movement, so as to be ready to catch him by the head in a moment, and to prevent him from making the second or third forward bound which he requires to do before he can bolt. Such a horse can often be held at a gallop as long as the rider does not allow him to get his head into some particular position; generally stuck out and held up. He should of course use every means to prevent him from doing this. If he fails to hold the animal, he should, if practicable, circle him round and round to whichever side he finds that the horse will turn more readily, which will generally be the left, until he can get him in hand.

There are some horses that will run away when galloping, 
if their riders attempt to " catch them by the head"; but will not do so if they ride with very light hands, using the play of the wrists rather than the pull of the arms, and speak soothingly to them from time to time. We may observe that many racehorses when doing their training gallops will take a strong feeling of the reins as a signal to go all the faster; but they will slacken speed and pull up, the moment their heads are "let go" at the conclusion of their spin.

However much satisfaction a man with his own spurs on a borrowed horse may have in allowing him to run away, and even in urging him to go on when he begins to show signs of having had enough; no horseman worthy of the name would wilfully incur the risk of breaking an animal down, rather than exhaust every effort in trying what fine hands and patience can effect. I believe horses have been known to run away (I don't mean breaking away for a few hundred yards) with some of our best riders; although I have never seen an animal which was properly bitted do so with a really good and strong horseman who was at the time in fair training. We may take for granted that in all ordinary cases, when a horse runs away, he is wrongly bitted, or the rider has bad hands, is weak, or is out of condition. I am sorry that I am unable to supply my readers with any patent method for stopping a runaway, or for remaining in the saddle on a difficult horse or when going over a fence. I can only indicate the best means for attaining these desirable ends.

As regards the bitting of a puller, I would advise that with a double bridle the curb should be put low down in the mouth (p. I03). I may here refer to what I said on page 73 , respecting the superiority of a properly-made and a correctly put-on curb to a snaffle for holding a puller. In all cases an unjointed snaffle (Fig. II7) is much the best form of that bit. With a double bridle we 
have a choice between the two. We should bear in mind that the action of a curb is peculiarly liable to produce insensibility of the mouth, on account of its pressure being distributed almost completely round the lower jaw, while that of the snaffle falls only on the upper surface of the jaw. Even the jointed snaffle and the chain snaffle leave the under surface of the jaw free from pressure, and consequently interfere comparatively little with the circulation and nervous supply of the part. Hence we should avoid riding even the worst puller continuously on the curb, the action of which we should alternate from time to time with that of the snaffle, so as to preserve the sensibility of the jaw. It is evident that the sensibility of the mouth is the means by which we are enabled to remain in touch with the fore-hand of the horse. I would here recommend the alternate, not the combined, employment of the curb and snaffle.

A nose-band (Fig. 80) placed low enough to close the animal's mouth without pressing on his nostrils, is often very useful, by preventing him from giving to the pull of the reins only with the lower jaw. A standing martingale attached to the rings of the snaffle will greatly add to the power of the rider in all cases, except when the horse gets his chin into his chest. A Chifney bit (Fig. 53) may also be tried. Blackwell's nose-net has been recommended. Its good effect as a rule soon wears off, and its appearance is certainly very unsightly on a saddle horse.

\section{SHOULDERING}

Is a form of jibbing, in which the animal tries to press the rider's legs against some convenient object. The rider should pull the horse's head towards the wall, tree, or other rubbing post, and should proceed in the manner just described for combating jibbing. 
GETTING THE TONGUE OVER THE BIT

Is a very troublesome trick; because it generally lessens. the rider's power of control over his mount, and often prompts the animal to pull. With a curb, the gridiron bit (Fig. 54), is a perfect preventive against this vice. As

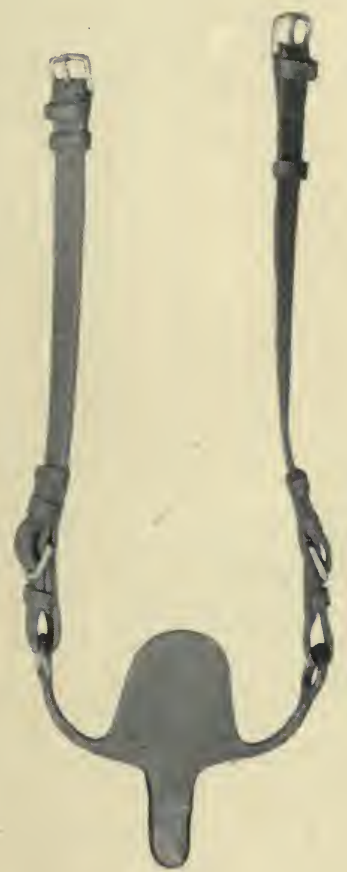

Fig. 209. Plate to prevent horse getting his tongue over the bit.

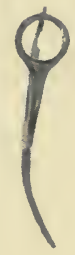

Fig. 2ro. Side view of plate shown in Fig. 209.

already stated, a horse is less liable to want to put his tongue over a Langham-Reed port (Fig. 96), than over one which has an ordinary port.

The usual plan adopted, in order to stop a horse getting his tongue over the mouth-piece, is to shorten the cheek-pieces 
of the bridle so as to bring the bit higher up in the mouth. Here, an unjointed snaffle would be more effective than a juinted one. This preventive measure is often unsuccessful; and even when it answers its purpose, it has the serious objection of interfering with the proper adjustment of the

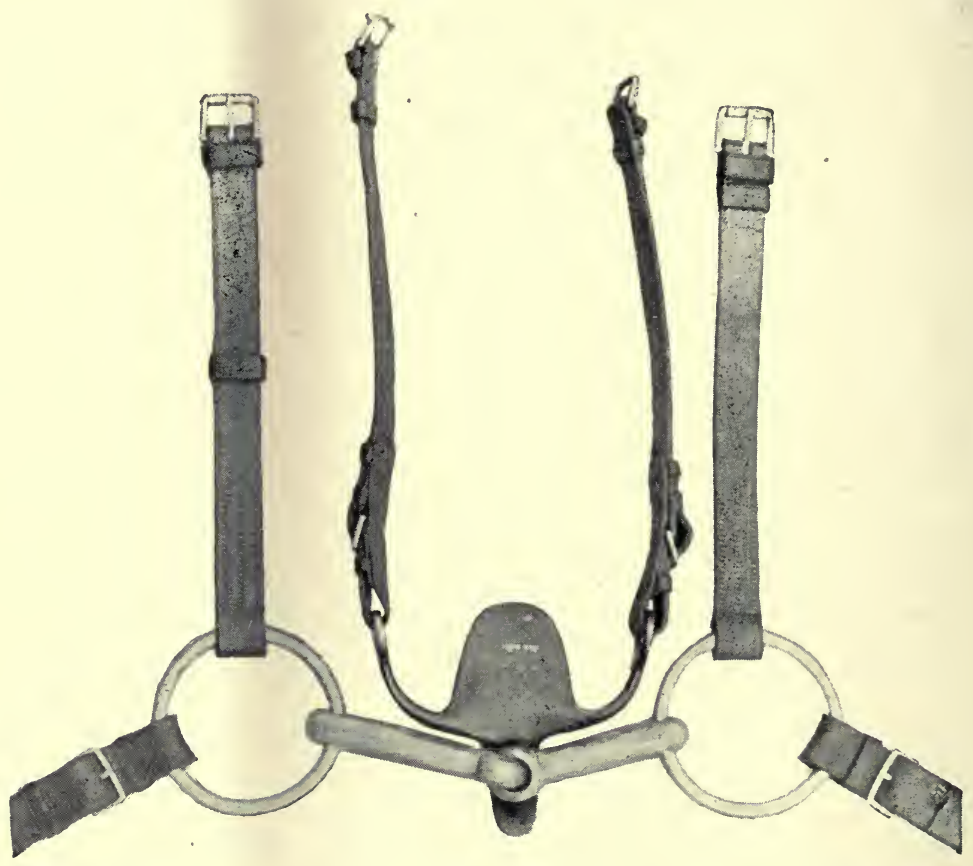

Fig. 211. Position of Snaffle on Tongue Plate in Horse's Mouth.

bit. While I was at the Russian Remount Depôts, in I 898-99, I found that many of their cavalry animals had the vice in question, and was often asked how to prevent it; but could suggest no remedy, except those just given. On my return to this country, Mr. Clarke, the Rugby saddler, showed me the following American invention, which appears to be thoroughly effective in making it impossible for a horse to 
get his tongue over the bit. This excellent arrangement consists of a steel plate (Fig. 209), which is placed in the mouth like an ordinary bit, except that it has no reins. The upper portion of it is flat and broad; the lower part, narrow and slightly curved (Fig. 210). The bit, when put into the mouth (Fig. 2II), rests on the lower end of the plate, and the upper end will then prevent the animal from getting his tongue over the mouth-piece.

\section{SHYING AND UNSTEADINESS.}

A horseman ought to be above minding small eccentricities of manner in his mount, and should take in good part a playful shy or kick, a slight rear or a light-hearted bound or two, although he should never tolerate direct opposition to his wishes. When horses are "fresh," especially when they have just come out of a warm stable into the cold morning air, they will dance about, and lark on little or no provocation; but on their return home after a hard day's work, they may be sedate enough for any old gentleman. I have always found that punishment by whip, spurs, or jobbing the animal in the mouth with the reins, has a bad effect, as a correction of shying and unsteadiness; although we may with benefit remind the animal by a steady hold of the reins, a firm pressure of the legs, and a chiding word or two, that his duty is to be obedient and well-conducted. It is only reasonable, as "Harry Hieover" remarks, to turn the horse's head away from the object at which he shies, so that it may no longer affect him.

In the vast majority of cases, the faults we are considering are the results of unskilful riding on previous occasions. A generous, high-spirited horse may start at a bird flying across the road, or at hearing the report of a gun, as any nervous person might do, or prick his ears on seeing some unusual object. It sometimes happens that the man on his back there- 
upon jerks the reins, digs the spurs into his sides, hits him with the whip, and calls out, "Do you think I stole you?" or some other expression which he has the authority of his groom for considering to be en règle. An animal thus treated will naturally-for a horse has a marvellously retentive memory-associate in his mind the idea of punishment with any object or occurrence that will remind him of the previous unpleasantness. Or a timid rider, when expecting some sight or noise which he may think will alarm his mount, may try in anticipation to strengthen the courage of them both by clutching at the reins and saying "Steady lad," "Whoa-ho boy," or some other soothing expression. By acting thus, he will make the horse believe that something very dreadful is going to happen, and will cause him to be thoroughly on the qui vive against danger. When he has been worked up into this state by his rider, he will of course be only too ready to express his fear in a form which will probably be very disagreeable to the man on his back. I recollect one morning when I was in the Bengal Staff Corps, that finding I could not ride my charger, as there was something wrong with him, I thought it would be fun to go to parade on a very good-looking selling plater I owned. He did not quite like the look of the sepoys at first, but calmed down very soon. The order was given to fire a feu de joie, which I may tell my non-military readers, tries a horse's steadiness as much as any noise I have ever heard. I saw the other officers drawing up their reins and going through their usual "Whoaho boy" performance. As I knew that my lately enlisted mount had never heard a feu de joie, I tried the experiment of sitting still and leaving the reins slack. At the word of command, the rattle of musketry came down the front rank, and then up the rear rank, causing all the old chargers to whisk round and to try to "jump out of their skins ;" but neither the plater nor I took the slightest notice of the row. 
So surprised was I at his tranquillity that I thought he was deaf, until I had to go out to "take up a point;" for after cantering a few yards, I spoke to him, and he went up to his bridle in a moment; thus showing that he paid far more attention to an indication from $\mathrm{me}$, than to one from outside.

Shying is sometimes due to defective sight caused by cataract and shortsightedness, which is frequently present with that prominent appearance of the eyes called among horsemen "buck eyes." It may also be a silly trick practised even by the best tempered horses. We can recognise this form by the fact that the animal will go on with his game of, say, shying at every heap of stones he sees by the side of a road, only when he is fresh, but not when he is tired. A well-bred mare I once owned was a very bad shyer when ridden by grown-up persons out hacking or going to a meet, but would never shy after seeing the hounds or when ridden by a child.

Habitually prancing and dancing about is a very disagreeable variety of unsteadiness that is in almost all cases a vice, manifested by impatience of control. Its worst forms are generally associated with the habit the animal has of "blowing his nose." This kind of snorting, exhibited without adequate cause, is a certain sign of an unruly temper, as I have found, particularly in my breaking experiences with wild and vicious horses.

\section{STUMBLING.}

The usual causes of stumbling, which may act singly or in a combined form, are failure to raise the feet high enough, undue depression of the toe when the foot is being brought forward, and excessive weight on the fore-hand. When a horse stumbles from the first two causes, but not from the third, the accident will not as a rule be enough to upset the equilibrium of the body, and a not very nervous rider may 
well disregard it, unless the animal is intended for show, rather than for use. Many horses which have low and good galloping action, trip or "toe" when walking. The animal which stumbles from being heavy in front is dangerous to ride ; because if he catches the ground with the toe of an advancing fore foot, a fall will be the probable result, from the centre of gravity being too far beyond the base of support. If the animal be also infirm in front, he will have but a remote chance of recovering himself in the event of a bad trip. All that the rider can do to prevent such a catastrophe is to lean well to the rear and ride the horse up to his bridle, so as to get the weight back. In doing this, a properly adjusted curb will be more efficacious than a snaffle. When a horse stumbles, I think it is best for the rider to leave the animal's mouth alone as much as he can; because anything he may do with the reins to prevent the horse coming down, will more or less interfere with the efforts made by the animal to save himself. These efforts, being instinctive, are no doubt the best for the purpose. The fact that a horse which falls from a stumble on a road, often cuts the fore part of his head and at the same time does not injure his knees, shows that it is most unwise to pull the reins when an animal stumbles; because a snatch at the reins would be very likely to prevent him getting his head down and thus saving his knees. In such cases, the injury to the head is usually trifling, and is generally inflicted on one of the orbital arches, which are the prominent bony arches that protect the eyes.

A rider should on no account punish a horse for stumbling; because that would have the effect of only making him start and prance about, after the mistake had occurred, and would not make him go more collectedly in future. Besides, the habit of dancing about after a stumble is particularly disagreeable to the rider, and it betrays to all spectators the unpleasant fact that the animal had previously erred in the 
same manner. As a horse never stumbles intentionally, punishing him for this accident is cruelty of a reprehensible kind. Much may be done to prevent stumbling by attention to shoeing. "Knuckling over behind," which is a stumble with one of the hind feet, can generally be stopped by lowering the foot, if it be too long, and reducing it under the toe, so as to get the slope of the hoof at an angle of from $55^{\circ}$ to $60^{\circ}$. The slope of the fore feet should be about $50^{\circ}$. Weakness, the awkwardness common among young horses, and bad shoeing often induce stumbling. 


\section{CHAPTER XIII.}

\section{RIDING OVER A COUNTRY.}

Jumping-Riding Refusers.

\section{JUMPING.}

THE best way to learn how to ride over fences is to get on a quiet, clever, and rather sluggish pony or cob, and " potter" about on him in the country over easy places. Of course this practice cannot often be got, except out hunting, on one's own land, or on that of a friendly farmer whose permission has been previously obtained. A gap through which the animal can walk or climb over, will be a formidable enough obstacle to begin with, and the novice should " hasten slowly" before attempting anything of the three foot six or four foot cutand-laid hedges or posts and rails order, which may be looked upon as a final test of this preliminary course of education. A lead by a judicious mentor will be a great assistance to the beginner, who will thus not only learn to stick on, but will also acquire the equally valuable knowledge of what fences his animal can safely negotiate. This information cannot be obtained by practice over artificial fences (like those in a riding school), which accomplishes its object in teaching a man to "remain," when the horse takes off on one particular kind of ground; but is of little use to meet the varied exigences of practical work in the field. As no two horses jump alike, the oftener the tyro gets a change of mount, the greater ought to be his progress. 
In considering the art of riding over fences, we should draw a sharp line of demarcation between steeplechasing and ordinary riding over a rough or enclosed country, because the respective styles of riding are essentially different. In riding over natural fences (as out hunting) or over broken ground (as in pig-sticking or chasing wild deer), a horse must depend mainly on his own judgment ; for circumstances requiring decision will often come far too rapidly for the rider to maintain the initiative, which he can do fairly well when riding over steeplechase jumps, the nature and position of which are known to him beforehand. When the safety of man and beast has to be entrusted to the honour of the horse, it is manifest that he should be given a free. hand within reasonable limits, and consequently his mouth should be interfered with as little as practicable, supposing of course that he is worthy of confidence. If he cannot be relied on, he will require the necessary schooling, which is a branch of horsemanship we are not at present considering. In steeplechase riding and when trying to cross a flying country with the utmost speed, we should keep a steady hold of the horse's head, so as to get some of the weight off his fore-hand, which bears most of the strain, especially when going fast. But out hunting and when crossing broken ground, safety as a rule will be of more consequence than speed. Besides, when a man follows hounds, he cannot enjoy himself if he has to concentrate all his thoughts on riding.

One great point about riding over a country, is that one should never put a horse at a fence, unless one is determined to get to the other side; because indecision in this respect will quickly turn the stoutest hearted animal into a refuser. If a young horse is hunted by a capable man, he will soon learn that the presence of a fence in front of him imposes no obligation on him to jump it, unless his rider gives him the signal, on the receipt of which he will know what he has got to do. 
In steeplechasing, on the contrary, the horse should have the necessity impressed on him of clearing with quickness and precision every obstacle at which he is turned. The value of a hunter chiefly depends on his being able to understand his rider's wishes. Need I say how necessary it is for the man on his back to have pluck and decision of character?

As it is essential for safety, when crossing a country, that a horse should take his fences in a steady, business-like, manner, the rider ought to try to avoid betraying any unusual eagerness or anxiety, beyond showing by a firm pressure of the legs, and a good hold of the animal's head, that he means to go straight, when approaching an obstacle. He should eschew the vicious habit of shifting about in his seat, and of working with the reins, or " niggling" at the horse's mouth, as we sometimes call it in Ireland. We should bear in mind that the art of riding well over a country consists chiefly in making as little as possible of the jumps, and that the fact of the rider treating fences and level ground with equal indifference, will inspire his horse with confidence to take things in the same spirit. On a strange horse or on one of which we have any doubt, we might restrain his pace a bit, or send him along with an encouraging word. But we should never, unless on a peculiar horse or in a peculiar country, pull him up, when we come to a fence, in order that he may take it according to any arbitrary ideas of our own; and we should not frighten him by whip, spurs, or voice, to show the spectators how brave we are, or to harden our hearts. In order to be one with a horse, we should endeavour to get him to take his fences in the same manner as we would do ourselves, were we on foot, and were we possessed of the requisite activity. As horses are very prone to take liberties-perhaps because, as Whyte Melville says, they don't like jumping-the rider should show his mount that he means business. If, however, when going up to a fence, the horseman sees proper cause for pulling up, 
or turning his animal off it, he should do so with the clearest "indications" of leg and rein, so that the horse may not make the mistake of thinking that he is allowed to refuse. I have ridden some horses who were passionately fond of jumping, and who would have taken a lot of stopping to have made them turn away from a fence at which they were put. Such desirable animals are unfortunately rare exceptions, probably, more from the fault of riders, than from that of Nature.

Riding in a flying country is somewhat like steeplechasing, in which the possession of the powers for galloping, staying, and jumping makes the perfect horse. As every rider who steers his own horse has a right to study his own convenience as to the pace at which his animal should go at his fences, I have nothing to remark on this subject beyond saying, that if a horse which is going fast, requires to be steadied at a jump, the pull ought not to be taken nearer, as a rule, than about forty yards away from it, and that the horse ought to be allowed for that distance to make his own pace up to it; always supposing that the rider has a steady feeling on the animal's mouth. As the mouths and manners of horses greatly vary, it would be useless for me to lay down rules about steadying them, or riding them at fences, except in general terms. As a rule, clever jumpers fence best when the rider lets them have their head, and allows them to make their effort without either rousing or restraining them. Many horses, however, are so shifty and uncertain that they need all the assistance they can get. Those of us who have gone in for athletics, must have sometimes felt, when running up to a jump, that the steps we were taking would not give us the proper take-off, and that it was necessary for us, in order to obtain it, to lengthen or shorten our stride. We may experience the same feeling when riding a horse up to a fence, and if we have had sufficient practice and are possessed of the 
requisite "nerve," we may be able to make him extend or collect himself, so that he may take off correctly. This interference should be attempted only by a man who is a sufficiently fine horseman not to make a mistake, which is a dangerous affair at this critical moment. Usually, the best way to make a horse jump "big," is to pull him together, on nearing a fence, and make him bring his hindquarters under him, by the pressure of the legs and, if need be, a touch of the whip.

When a horse is going at a fence, the rider should have

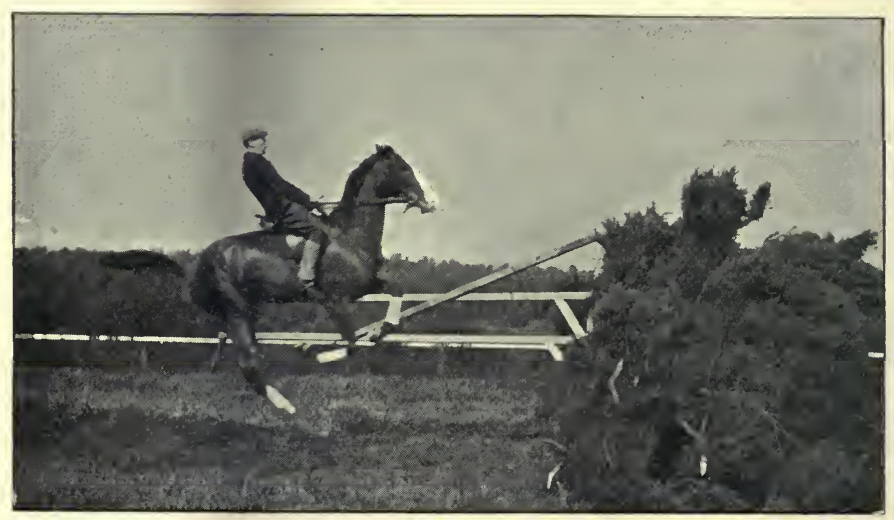

Fig. 212. Taking oft.

both hands on the reins, so as to prevent a refusal, or to "pull the horse together," if required. As a horse, when taking off, has to raise his forehand off the ground (Fig. 212), and as the ordinary seat of a rider puts an unduly large proportion of weight on the forehand, the rider should try to rectify the faulty distribution of weight, by leaning back, which he should do only by the play of the hips, and without any shifting of the seat from what it was at the canter or gallop. On this subject, my friend Mr. E. M. Owen, the well-known G.R., remarks: "The body should :go with the horse, and 
there should be no settling down into the saddle to disconcert the last few strides, which the animal should always have to himself. How can he be expected to properly collect himself and control his limbs, when a rider is what is called, 'getting back'? We see many falls from that cause. If riders would only allow the horse to do that for them, instead of bustling the animals, there would be far fewer 'clumsy brutes' about

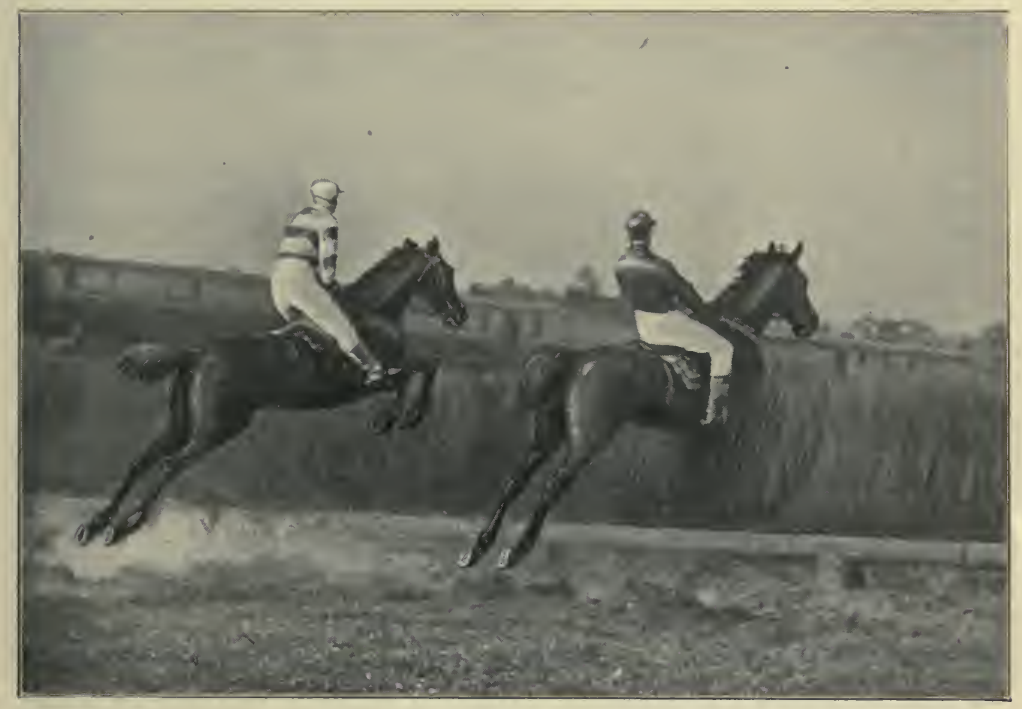

Fig. 2r3. Dollery on Cloister and Mawson on Horizon.

than there are, and all because men won't sit still, and allow the horse when he rises to put them back naturally. If this be done, the body will gradually go into its proper place, as the horse descends, and consequently the weight will be distributed evenly. Give the horse plenty of head-room and the body will go with him. As an example, get on a rocking horse, hold on tight to its head, and see how it will act."

Fig. 2 I 3 furnishes us with a valuable object-lesson. In it we see Dollery leaning well back and having his feet drawn 
back a little. We all know that Dollery is one of the finest 'cross-country riders that ever lived. Poor Mawson, though full of pluck and good judgment, had not a very strong seat. Both jockeys in Fig. $2 \mathrm{I} 3$ are riding with the reins at a proper length.

The rider should avoid the trick of raising one hand; for it is not only ungraceful, but it also deprives him of the assistance of that hand at the very moment it may be most

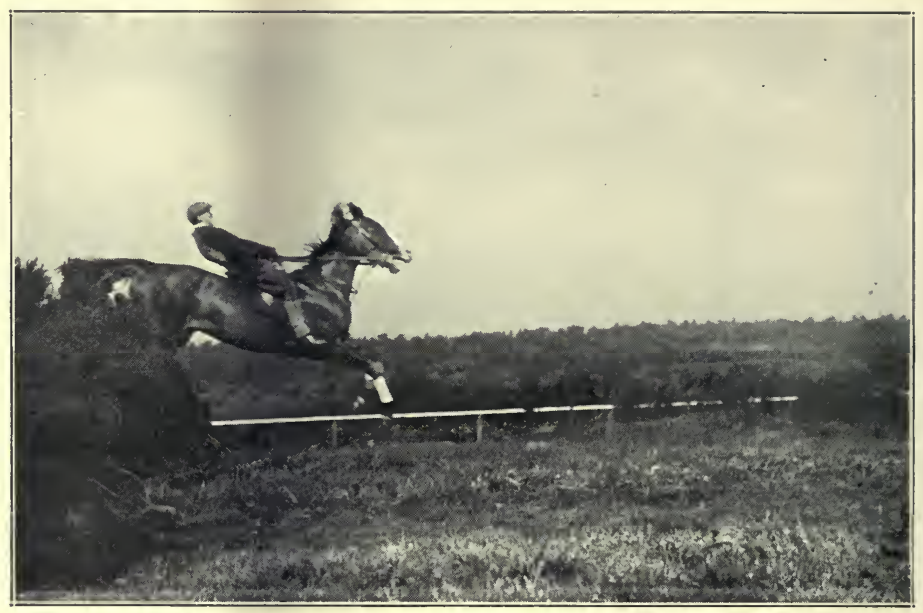

Fig. 2I4. Leaning well back.

required. The tell-tale trick of catching the cantle of the saddle, unless, perhaps, over a deep drop jump, is reprehensible on the same account, and is also dangerous in the event of the horse happening to fall; because the rider might not get clear if the animal were to roll over. The tendency of an inexpert or inexperienced rider, when coming up to a fence is almost always to bend his body forward, and to thrust out his feet in front. If the feet be held forward when the horse lands on the other side, the resulting jerk of the feet on the stirrup irons-as the knees will then be neces- 
sarily straight-will re-act in the direction of the legs, and as this will be behind the centre of gravity, the jerk on the irons will have a strong tendency to tilt the rider over. Although a weak-seated rider is sometimes "jumped out of the saddle" by a "flippant" fencer; bad riders, in the large majority of falls, tumble off at the moment of landing. I cannot see how a man can lean too far back when landing over a fence. Besides obtaining safety for himself, he will reduce very considerably the jar on the horse's fore legs, by leaning back

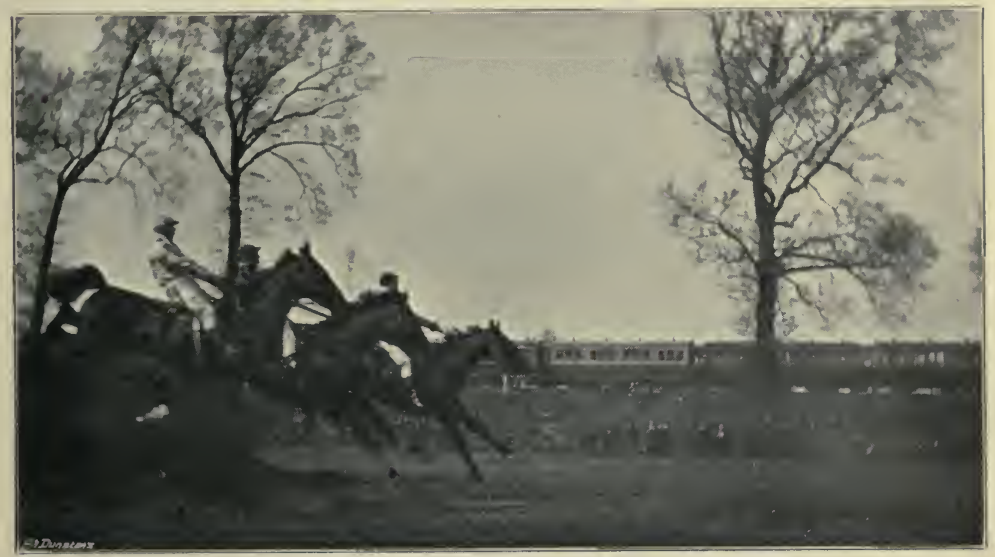

Fig. 215. Clearing the water-jump at Sandown Park.

(Figs. 214 and 215). In all cases, when going at a fence, a man should ride with a long rein (Fig. 2I6) (not with a short one, as in Fig. 217), so that he may not run the risk of interfering with the horse's mouth when he lands, or of being pulled over the animal's neck. The hands, one on each rein and well separated, should be held little, if anything, beyond the pommel.

From nervousness, or from an insane idea of "lifting" a horse, some riders contract the bad habit of jerking up their hands just as the horse is making his spring. By doing this, 
the rider prompts the horse to throw up his head, and thus not only checks the action of the animal's hind quarters, at the very moment their assistance is most needed, but also prevents him from seeing where he is going to put his feet on landing; and consequently he performs the very. action which

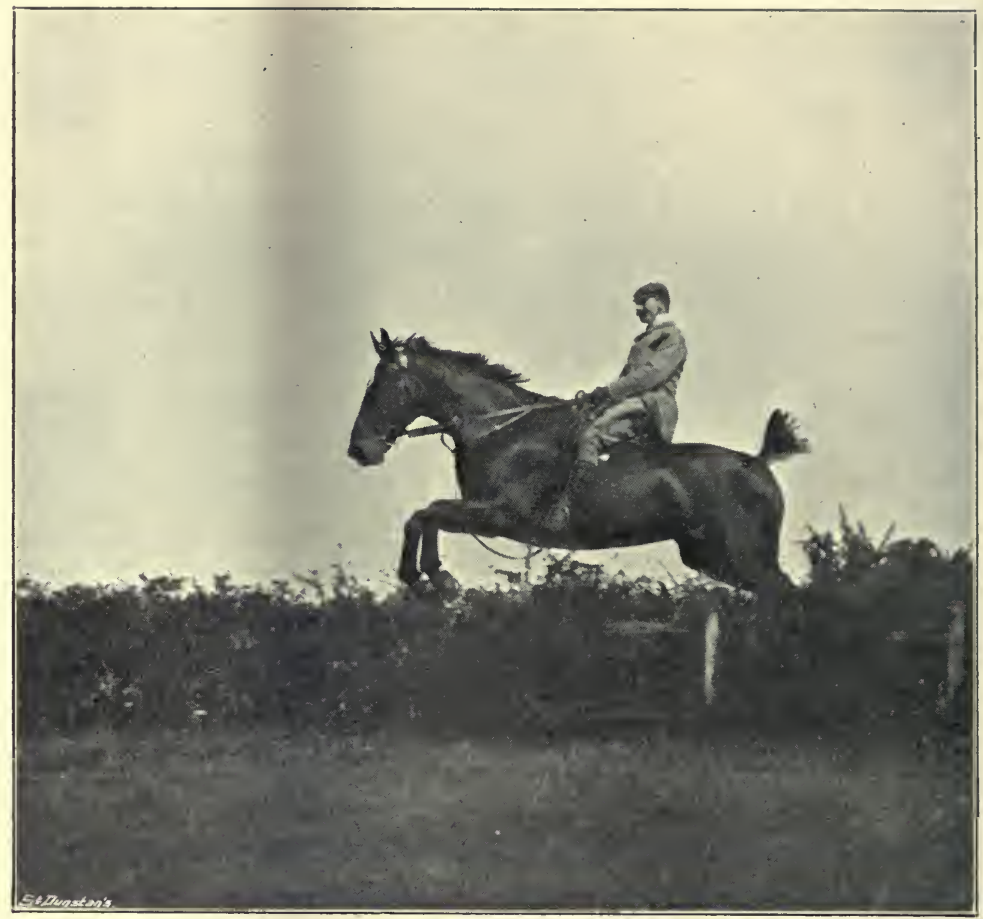

Fig. 216. Hands down and reins a good length.

is best calculated to make the animal fall. On the contrary, he should keep his hands low down, so that the horse may be able to bend his neck, and carry his head in the best position for conforming to the action of his hind quarters, and to see where he can put his feet.

As the proportion of weight on the forehand increases 


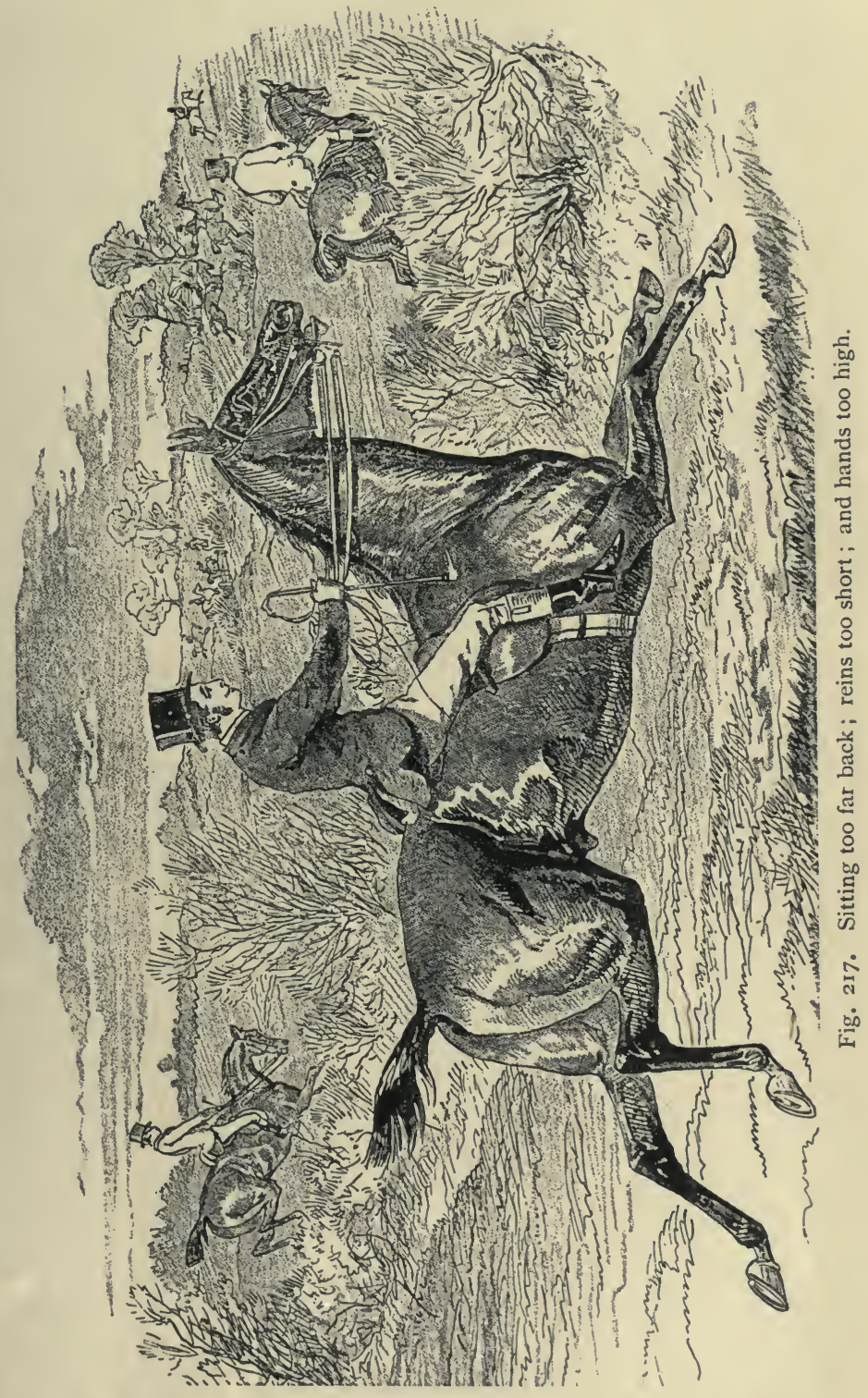


according to the speed, the faster a horse goes up to a fence, the more difficulty will he have in raising his forehand, so as to obtain the proper "angle of projection." On the other hand, when a horse is going fast, the impetus which the speed at which he is going gives him, will be a useful addition to the effort he makes when trying to clear width. Hence the truth of the old axiom that a man should ride slowly at timber, i.e. any high obstacle; and fast at water, i.e. any broad place. As a horse when jumping a high obstacle has not only to project his body upwards, but has also to project it forwards; so that his hind quarters may clear the fence on the other side, he will require to go moderately fast, even when leaping posts and rails. When I write about going slow at height, I mean that it should be done at a steady canter. At steeplechasing, a good deal has to be left to the honour of the horse, while the jockey does his part by sitting still, and keeping a nice hold of the animal's head. In such cases, we shall generally see that an accomplished chaser will steady himself, when coming to a high fence.

If a horse happens to fall, and the rider has the good luck to maintain his seat, he should leave the reins perfectly loose, so as not to interfere with the animal's efforts to get up. If he be unseated, he should try to roll clear, while keeping hold of the reins as long as he can. In a fall, if one brings one's chin as close as possible to one's breast, the neck will be less liable to be broken, than if the head is held straight or carried back. A fisherman, after hooking and landing a salmon, kills him by bending his head back. Practice undoubtedly enables us to acquire, to some extent, the art of falling softly; but it is not a sufficiently exact science to be fully discussed in a book.

\section{RIDING REFUSERS.}

Horses generally refuse an obstacle, because they are afraid 
of falling; are sulky; have got into the habit of "running out," by being allowed to do so, or by being "pulled off" their fences by timid riders; are afraid to face their bit; or because they fear to hurt themselves when taking off or landing.

When a horse refuses on account of being afraid to propel himself, the mischief generally lies in the hocks; but when his dislike to jumping arises from his dread of painful concussion on landing, the cause will most frequently be splints, fever in the feet, corns, navicular disease, or injured ligament or tendon. It is not very uncommon to find slight cases of laminitis or navicular disease among good hunters, and even among successful steeplechase horses. I have known two or three cases of horses which had been bold fencers, becoming refusers from having over-reached on their back tendons. It is evident that the harder the ground, the more will any form of unsoundness in front injuriously affect a horse's jumping capacities. I remember a sad case of a good steeplechase rider being killed by his horse falling on him over a small fence; simply because the landing was hard, and the animal had bad corns. Hunting men, for their own safety, and for avoiding the risk of spoiling a valuable horse, should be particularly careful not to make the disastrous mistake of attributing to bad temper a refusal which was really caused by physical infirmity; for if they follow up such a blunder by undeserved punishment, they will in all probability ruin their horse by converting him into a refuser, and may also bring themselves and him to grief by forcing him to make an attempt which he is incapable of properly accomplishing. As hunters have to be shod rather short in front, so as to prevent them from pulling off their fore shoes when landing over a fence, they are peculiarly liable to corns, which in them are not an unfrequent cause of refusing.

When riding a somewhat faint-hearted or "reluctant " horse, 
we may sit well down in the saddle, and catch a good hold of his head, with the reins well separated, and both hands on them. An encouraging word and a firm pressure of the legs, with a touch of the spurs if required, may stimulate the animal's courage. But, on the other hand, many clever horses will decline the invitation, if the man in the saddle even "feels" the reins or brushes their sides with his boots. One of the worst falls I ever had, was when riding a steeplechase on a very uncertain tempered horse, whose owner, a steeplechase jockey, had failed a few days before to make him jump. We had only a small field opposed to us, and as I did not "move" on him, we agreed all right for a while. At the end of the first half of the journey I was leading by several lengths, and thought the race was as good as won, until we arrived at the eighth or ninth fence, which was a $4 \mathrm{ft}$. 6 in. wall that could not be "chanced." I suppose that the fact of my not liking the look of the barrier made me bustle my mount; for I touched him with the spurs, just as he was going to make his effort, as I felt he was taking off very far away from the wall, and that he would require an unusually strong impulse to clear it. The moment I made this mistake, I felt him try to stop; but his intention was formed too late, so all he could do was to breast the masonry. In another instant he was stretched on his back on the landing side, the saddle smashed, and I crumpled up.

If we know that the horse we are riding is inclined to refuse to a particular side, which will be the left in the large majority of cases, it is advisable to carry the whip, crop, or stick, point down, in the opposite hand, so as to have command over the horse's hind quarters, in straightening him, when required; and the drawn back leg of the same side should also be used for this purpose. "Showing" a horse the whip on the side to which he is going, or to which one expects him, to refuse (Fig. 206), is, as I have already 
said, far less effective in keeping him straight, than using it on his hind quarters on the opposite side. The not uncommon fool's trick of hitting a horse on the right shoulder, when he refuses to the left, and vice versâ, is of course a direct incentive to do wrong.

Some men will make any horse refuse, however clever and willing the animal may be. I have known individuals of this class get up to ride over a country, even in steeplechases, without the slightest intention of crossing a single fence. It is common enough out hunting, even in the Shires, to see people, actuated by the contemptible ambition of "showing off," riding at fences, and deliberately pulling their animal off, before it is too late. They then hold forth about the wonders they would have done, had not "that brute of a horse" spoiled their fun. There are others, however, with the best intentions, who are unable to induce their mount to jump. In nine cases out of ten, the fault lies in the rider not being able "to throw his heart over"; for something more than mere passive permission is needed to get most horses to leap kindly, especially those which have had poor horsemen on their backs. Incompetent riders who mean going straight, often fail, on account of not pressing the animal up to his bridle with their legs, and from using the reins in a wrong manner. For instance, if he goes too slow at his fences, instead of pulling him together and sending him up to his bit, they slacken the reins and let him run out, without attempting to steady him with the pressure of their legs, as they ought to do. If the horse is a free mover, they take a dead pull on his mouth and never think of closing their legs to his sides, which is the one indication above all others, by which the animal understands that his rider means jumping.

The habit of riding with only one hand on the reins, or with an unequal feeling on the reins, when both hands are employed, is a frequent means by which horses are taught to 
refuse. When a man habitually rides only with, for instance, his left hand on the reins, he can hardly help carrying this hand more or less to the left, instead of keeping it in an exact line with the withers, and will thereby give the horse a constant indication to turn to the left. When keeping to the road, a horse will naturally ignore this false indication to a greater or less extent; but its influence on his mind will be certain to make itself felt, when crossing a country, especially as horses are almost invariably handled and led on the near side.

We may frequently see the rider of a horse which happens to refuse a fence, take him again and again at it, while vigorously plying whip and spurs. The rule in such cases is that each time the animal baulks, he does so with a stronger determination than ever not to jump the obstacle. Horses have such retentive memories, and such obstinate wills, when their tempers are fully roused, that a lesson or two of this sort often ruins a horse for life. I recall an instance of a steeplechase rider trying a good jumper he was to ride in two or three days' time, over the course which was to be "flagged out" for them. After negotiating a few fences cleverly, the animal, whether from jumping in "cold blood," or from some reason of his own, baulked at a small bank with a ditch in front of it. The rider lost his temper, probably on account of the presence of a few friends who had come to admire, and used whip and spurs when bringing the horse round, but he would have nothing to say to the fence, although his rider cut him almost to "ribbons." When the race came off, the horse of course refused at the very same place, and would go no farther. I cannot too strongly impress on my readers that a man should never be drawn into a pitched battle with his mount, unless he is all but certain of victory. It is no matter how strong and good a rider a man may be, he cannot, when on a horse's back, force him to jump a fence which he has. 
made up his mind to refuse. Many men have the wrong idea that if a horse baulks with them, they are bound to "have it out" with him; as if the refusal were a personal challenge on the part of the horse, and that if they did not punish him severely for the supposed insult, their reputation for bravery would suffer. The contest is such a one-sided affair that no one but a cowardly bully or ignorant fool would engage in it. Were the horse free to kick and bite the man, who is at liberty to flog and spur the animal, there might be some merit in the: rider's exhibition of cruelty. The moment we find that punishment does not succeed, we should resort to some other means (see Illustrated Horse-Breaking) to accomplish our object; for the more we punish, the worse will the effect of the horse's victory be on him.

However senseless it may be for a man to fight his own horse for the unworthy object of gratifying resentment and "showing off," the action is trebly unjustifiable when the horse belongs to someone else, especially when the culprit is a hired servant. We pay our jockeys to ride races, and our grooms to look after and exercise our hunters in the best possible manner, but not to afford them an opportunity of displaying their bravery at the expense of our four-legged property.

Few things are more apt to disgust a horse with jumping than the practice of "larking" him several times in succession over the same obstacle. Instead of using whip and spurs on a horse that determinedly refuses a fairly easy fence, it is much better to keep him at the obstacle, work nis mouth about, back him and weary him, so that at last he will be glad to take the fence, and thus escape the pulling-about he is receiving. The moment he has cleared the jump we should "make much" of him, and, if practicable, take him straight back to his stable, in order to show him that although he 
will be punished for disobedience, he will be rewarded for compliance with our wishes.

When following the hounds, we should not persevere at a fence which our horse refuses, unless there is no other way over; for the hunting field is not a place for breaking in horses, and the temporary disagreement may be forgotten in the successful negotiation of subsequent obstacles. 


\section{CHAPTER XIV.}

\section{HUNTING PRELIMINARIES.}

Iunting as a Sport-Choice of a Country-The Hunting Season-Getting a Stable Together-Hunting Men and Farmers-Hunting Men and Shooting Men-Joining a Hunt-Hounds-Blood-Foxes-Hunting Things-Hunting Mufti-Riding Gear-Bandages and Boots - Some Hunting Expressions.

\section{IIUNTING AS A SPORT.}

FROM a riding man's point of view, hunting, as we know it in Great Britain and Ireland, is the best of all sports; chiefly on account of its variety, its high standard of excellence, its interesting and exciting nature, its health-giving effects on horse and rider, its easy participation, and the fact that a man can take as much or as little of it as he likes, and can enjoy the sport in his own way. The enclosed nature of a hunting country, its varied character, and the differences in its fences, render fox-hunting, as a test of horsemanship, far superior to flat racing, steeplechasing, polo, pig-sticking, show-jumping, or hunting in other countries. In the days when steeplechases were run over a natural country, the fences were similar to those met with when following the hounds; but they are now more or less of a uniform pattern. As far as my experience goes, the next best riding sport to fox-hunting is pig-sticking, which unfortunately cannot be enjoyed in this country, and which has the drawbacks of langerous ground and absence of fences. In riding on the flat and between the flags, the limits of weight are too narrow for the generality of men, and the duration of the contest is 
very short. We must remember that riding forms only a part of the enjoyment to be derived from any form of hunting with hounds.

With respect to fox, stag and drag, Captain King-King remarks to me "that although comparisons are odious, it cannot be denied that a good fox-hunt in a good country is the finest form of hunting; but there are few red-letter days in a season, and in the participation of a perfect run there is a large element of luck. Hunting the wild stag, as done by the Devon and Somerset or Sir John Amory's staghounds, is without doubt the most scientific form of the chase. A man of ordinary intelligence may be an earth-stopper, but a good harbourer must be a born genius, like a huntsman or a poet. The drawbacks to wild-deer hunting are that the country is a rough one, and that the danger of changing deer, or, still worse, of the deer running to herd, is ever present. Happily an old stag is so full of dodges that, like other over-clever folk, he sometimes defeats his own ends by an excess of talent. In hind-hunting, we may sometimes find ourselves running thirty or forty hinds and calves at a moment's notice! Also, one hind is very much like another; but no two stags are exactly similar in appearance as regards heads. A slight difference in colour is not uncommon, and will be of help in distinguishing one animal from another. The chase of the carted deer has the advantage that it is only about two to one against having a gallop. The failure occurs when the deer runs the road or won't run at all, in which cases stag-hunting is a humiliating affair. The majority of deer will run well if they are properly managed, and herein lies the science of stag-hunting from the cart. Also, this sport can be carried on in countries where fox-hunting is impossible, from plethora of pheasants, want of coverts, etc."

Major "Jack" Hanwell, who was Master of the Royal Artillery Draghounds, Woolwich, and who was killed in 
South Africa, wrote as follows about drag-hunting in Baily's Hunting Directory for 1899-1900:- "Drag-hunting is of course only excusable in a country where there is no animal suitable to hunt, or where the country is so cut up by wire, market gardens, railroads, canals and other impossible obstacles, that any but a selected line is out of the question. To those who live in such a country, the Drag affords a legitimate excuse for a gallop over fences. Those who hunt to ride, rather than ride to hunt, find that it has many very great advantages.

"The pace is always good, the line generally straight, every fence is jumpable, and there is seldom a check before it is wanted. Of course, the knowledge that it is not the 'real thing' spoils it as a sport ; the pleasant anxiety in finding and the skill and difficulties of hunting are wanting, but the pace and jumping commend the Drag to the hard-riding division, and make it a grand school for the young beginner.

"I remember a discussion on this subject by some keen hunting men, certain of whom were disposed to run it down. These latter were silenced when a well-known old sportsman, who had hunted all his life, and been master of hounds for many years, summed up the debate as follows:- 'You are quite right to hunt a drag if you have got nothing else. Always hunt, even if you have to lay the line yourself.'" Major Hanwell's article contains a full and lucid description of this sport.

\section{CHOICE OF A COUNTRY.}

As hunting cannot be fully enjoyed unless one understands it, a man who is new to the game will do well to begin with harriers; for he will see more of their work, all of which is done in the open, than he would do that of foxhounds, who are a good deal in coverts and woodlands. The mere rider extracts from a day's hunting about the same proportion of 
pleasure that a deaf man would obtain from a well got-up play. A season or two with harriers and provincial foxhounds, preferably in that land of sportsmen, Devonshire, will give a beginner an admirable course of preliminary drill. He might then try the Midlands. Even Leicestershire has a drawback, namely, that it takes time to learn. Hence we find that no matter how fine a horseman and how well mounted a stranger may be, he has no chance of giving the lead to Meltonians of the best sort, until he has made a careful study of the lie of the land. It is impossible to imagine a more delightful country to cross than that which is hunted by the Quorn, Cottesmore and Belvoir ; but it has to be jumped. Besides, there are so many bridle-paths and the gates open so easily, that a man who can harden his heart only now and then, will be able to see more good sport, even at a distance, than he would probably do elsewhere, supposing that he knows something about hunting. Without that knowledge or without the ambition to acquire it, he had better select some district in the provinces where the obstacles are not very formidable, and the foxes, like the dingle breed, are not too enterprising. Melton Mowbray is an ideal centre to hunt from, because the respective countries of three of the best packs touch that famous market town; there is practically no wire; and the sport cannot be surpassed. Oakham is more rural, though less central, and the meets in its vicinity are not so large. Market Harborough is at the junction of Mr. Fernie's, the Pytchley and Woodland Pytchley countries, and was formerly Melton's great rival as a hunting centre, but most of the best meets are a long way off.

The good service of trains which exists all over the Midlands greatly helps hunting people in getting about. Besides, special trains frequently run from the chief hunting centres to outside meets.

Furnished houses at from $£ \mathrm{I} 50$ upwards for the season 
can be obtained with more or less difficulty, and $£ 250$ would be a fair amount for the hiring of a good hunting box at Melton. A man with economical ideas could live comfortably in an hotel on a pound a day, and could have his hunters put up at 27 or 28 shillings a week, in loose boxes and with the best of forage and bedding; but would have to provide his own grooms. Outside Melton, one ought to be able to hire loose boxes at five shillings a week each.

\section{THE IIUNTING SEASON.}

In Leicestershire, hunting begins with the first meet of the Quorn at Kirby Gate, on the first Monday in November with the meet usually at Gartree Hill (Fig. 218); and the last meet is generally that of the Belvoir in the first week of April. Although a man may add to the duration of his happiness by cub-hunting, which usually begins about the middle of September, or earlier if the ground is not too hard; Leicestershire farmers do not welcome strangers before the regular season. Also, cub-hunting in the Shires is poor fun for outsiders, because hounds as a rule are not allowed to go over the open until the latter end of October. It has, however, the merit of teaching a stranger the geography of the country, and the position of the coverts, which knowledge will be useful to him later on. If a man can spare time for only half a season, he will generally do well to take his sport before Christmas; for although the fences will be blind, foxes will be plentiful, and there will be less likelihood of hunting being stopped by frost than later on. Naturally, the fallen leaves and broken twigs which have accumulated in the ditches during autumn, will require snow and thaws to clear them out. An open February is the ideal month, but if it is mild, the vixen question will arise all the earlier in March. Towards the end of the season, the pleasures of the chase are more or less alloyed by the 
knowledge that vixens heavy with young, or suckling their cubs, may be furnishers of blood. Of course hounds, when possible, are stopped off a heavy vixen, or one which has laid up her cubs.

Captain King-King gives me the following notes :-

"The season for hunting wild stag and buck is from early in August to the middle of October; the former being about the time their heads become 'clean' (devoid of velvet); and the latter the beginning of their rutting season, during which they lose condition, and do not regain it until the spring grass appears. If they are fed, they will recover their strength much quicker than if left to Nature. They are at their best during summer, which is the only part of the year that is suitable for hunting in wild rough districts, such as forests and moors. Wild stag are occasionally hunted in spring. The rutting season is naturally the cause of their being unprofitable animals to hunt in winter. The New Forest used to hunt bucks in spring, and occasionally in winter. Although bucks are a little later than stags, the same rules apply to them. After the wild stag and buck season has closed, there is a short interval before the commencement of hind hunting, which comparatively poor sport goes on through the winter, and ceases when hinds are palpably in calf.

" The roe ruts in summer, and is in condition all the winter. Unlike the British deer, he sheds his horns in the autumn or early winter, and consequently is our only wild male deer that can be profitably hunted during the 'hunting season.' Unfortunately he is a short-running, dodging brute, which sticks to coverts, and is not much better than a hare.

"With carted deer, hinds and haviers (unsexed deer) will have to be used until about the middle of December. When stags are cut as calves, they do not get horns, and are called 'polled haviers.' 'They then have lost so much the appearance of their sex, that few people can tell them from big 


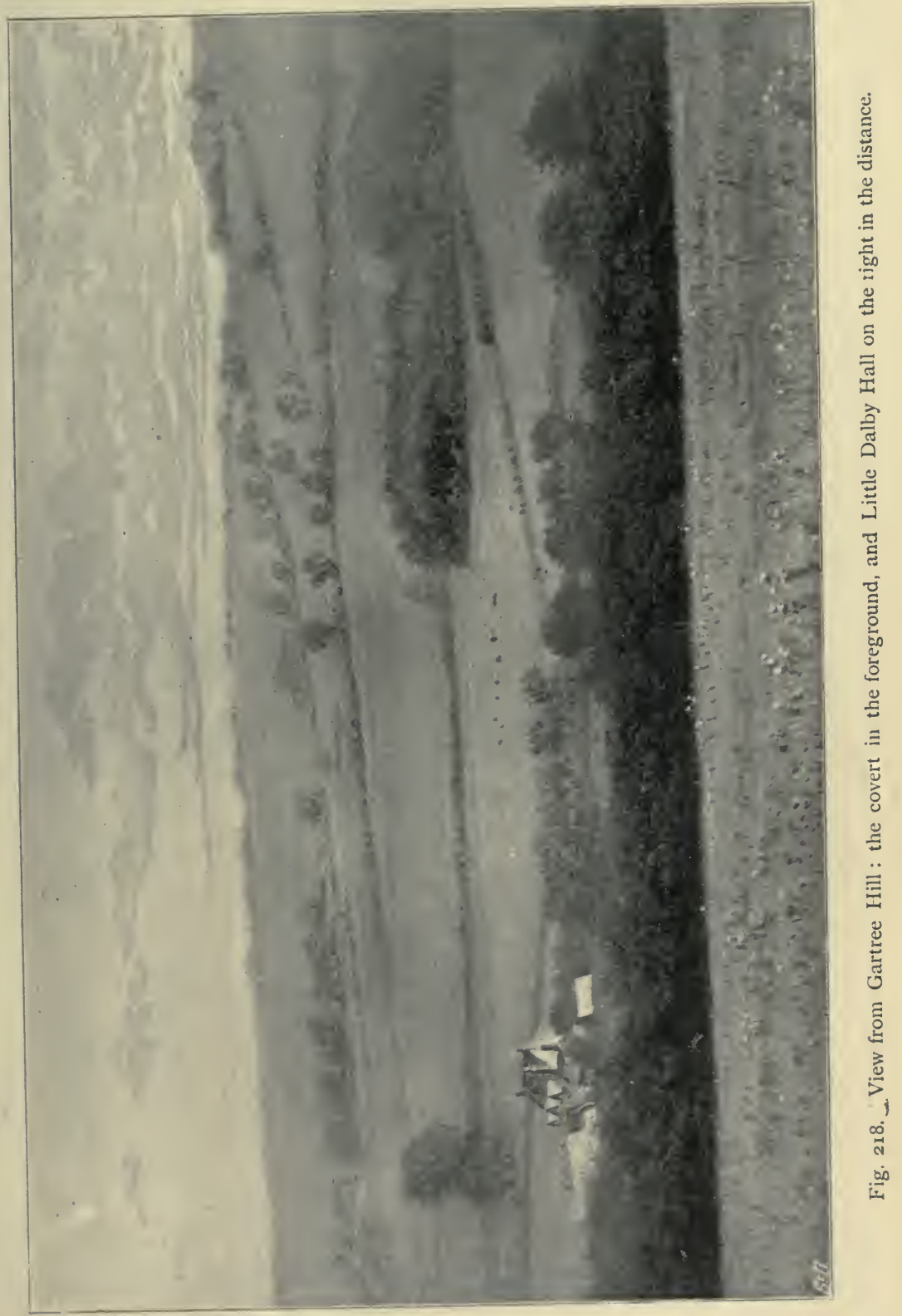


, 
hinds. If they are cut later, they get one set of horns, which are never shed, and which always remain in velvet. Tha term 'havier' or 'heaver' appears to be derived from the Scotch and North Country word 'aver' (French avoir), which originally meant 'property' and now signifies 'work-horse.' Possibly it came in that way to mean 'gelding.'

"Harriers generally begin hunting as soon as the country is rideable, and leave off about the middle or towards the end of March. Some packs wind up with stag."

\section{GETTING A STABLE TOGETHER.}

The first question here is : to buy or to hire? For convenience, there is nothing like hiring, which, as a rule, can be done in the Shires at about $£ 20$ a month each horse; the owner having to take all fair risks of disease and accident. A heavy weight who wants to go straight, would of course have to pay more, say $£ 25$ a month. The hirer has to pay the stable bills, which may be put at 25 shillings a horse; supposing that one man looks after three horses, which is quite as much as he can do properly. The expense of a stud groom and second horseman will of course be extra. The rate of hiring is much lower in many provincial districts, and so is the quality of the animals. It is as a rule best to hire from a dealer who has a large choice of animals, so that if any particular hireling does not suit or goes wrong, the customer can get him changed. Even when a hireling is fit to hunt, which is not always the case, he generally has a store of unpleasant surprises which he has learnt from previous riders. Considering the rarity of good horsemen, and the ease with which an animal's mouth and temper can be spoiled by a bad rider, we may safely conclude that a thoroughly confidential hireling is very seldom found, and that, when he is encountered, he usually leaves public for private service. 
The less ambitious a man is, the more likely is a hireling to suit him.

In purchasing, the personal equation has to be studied. Some folk, myself among the number, like to buy a horse when he is young and unspoiled, and teach him what is good for him ; but in such a case we should, previous to bringing him into the hunting field, make him obedient to hand and leg, intelligent when opening gates, and clever over fences; for manners and ability to jump are the first essentials in a hunter. Even then, he will need at least a complete season for acquiring experience, without which no horse can be a safe conveyance across a country. A man who would knowingly take a kicker, with or without a red bow on his tail, among other horses, could not be a gentleman; for he would be devoid of consideration for others. The sin, which unfortunately is not an indictable crime, of riding kickers, is the cause, during every season, of serious accidents to riders, horses and hounds. Putting a danger signal on the animal's tail is no palliation of the offence ; because it is often impossible to get out of the way of such a labelled beast in a crowd at the covert side, or when going through a narrow passage, for instance. It is infinitely better to stop at home than to hunt at the risk of others. If a man rides a kicker, the least he can do is to keep as far away from other people as he can. Some, luckily not many, selfish creatures put a red bow on their horse's tail or place the flat of their hand, with the palm to the rear, behind their back in a crowd, in order to get more room than is their due, even when they are riding a perfectly quiet animal!

My experience leads me to think that in the large majority of cases, when a horse kicks at hounds, he does so because he is unused to them, and is consequently afraid of them; and when a horse kicks at another horse, he does so out of revenge for having been kicked himself on a previous occasion. In the former case, the kick is an effort to remove an obnoxious 
object out of the animal's vicinity; in the latter, it is an attempt to inflict injury. The necessity of accustoming horses to hounds, or at least to dogs, before taking them into the hunting field, is obvious. With this object it is well to keep a foxhound in the stable-yard, and take him out with the hunters when they go to exercise. We may cure a horse of kicking hounds; but I have never known a horse cured of kicking other horses.

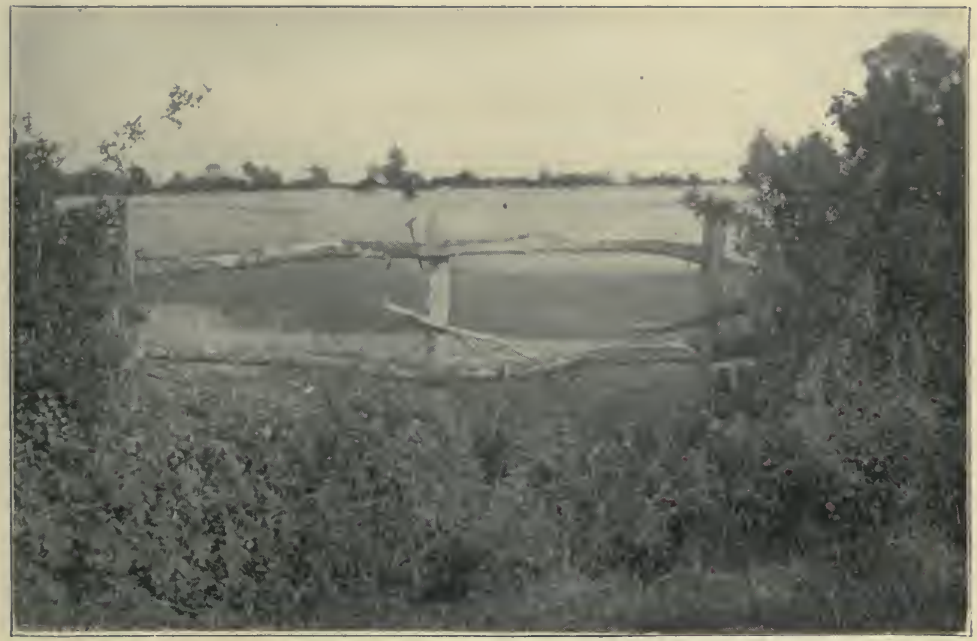

Fig. 219. Wire.

One cannot expect to buy a "made" and well-conditioned hunter under six years old. An Irish four-year-old often knows as much as an English six-year-old; but he has not had the "hard" feeding which is necessary to qualify him for the first flight in the Shires; and, besides, he will as a rule know little or nothing about jumping hedges and posts and rails. Irish horses are sometimes hunted when they are only three. One great advantage of experience, and consequently of age, in a hunter, is freedom from impetuousness ; 
for the more a horse sees of hunting, the steadier he becomes; provided, of course, that he is ridden by a capable man. As a rule, dealers are the best persons to purchase from; for they keep the required article, and one can often arrange with them to get a trial, say, for a month, for a certain sum, in the event of the animal not proving suitable. There is not much chance of purchasing at an auction what one requires, except at the end of the season. One may buy a promising youngster from a farmer; but very seldom a "made" hunter. As I have discussed the subjects of conformation, breaking, and soundness in, respectively, Points of the Horse, Illustrated HorseBreaking, and Veterinary Notes for Horse-Owners, I need not refer to them here.

The number of horses a man will require, will greatly depend on the number of days a week he intends to hunt, and on the length of time he wishes to stop out on each occasion. The old computation of three days a fortnight may be taken as a fair average, which allows for illness and accident. In Leicestershire, which is well supplied with bridle-paths and gates that will open, a second horse is required to relieve the first one at "the change of horses," which is generally made at about half-past one or two. When Lord Lonsdale hunted the Quorn, he had an excellent rule, that second horsemen were not to jump fences, but were to stick to the roads and bridle-paths. By it, horseflesh as well as farmers' crops and fences were spared as far as practicable. If a man in Leicestershire takes out only one horse, the animal, in the large majority of cases, will have had quite enough work by two o'clock; and no sportsman would care to hunt on a tired horse. When using a second horse, one should take particular care that the second horseman saves him as much as possible. A second horse is not required in countries devoid of facilities for crossing them without jumping, or out stag-hunting; because a stag in most cases runs to a "point," in which case, the second horse would 
have to do as much or nearly as much work as the first horse ; and a second deer from the cart is utilised only when the first one has done practically nothing. If the first deer had run a sharp ring, a second horse would be useful; but this happens too seldom to be worth providing for.

\section{HUNTING MEN AND FARMERS.}

Hunting is.a sport which exists only by the good-will of farmers, who usually obtain an adequate, though generally indirect, return for permission to ride over their fields. In parts (more in Ireland than in England) where the breeding of hunters is an important agricultural industry, farmers are of course alive to the advantage of hunting as a market for their young half-breds. In the chief hunting districts of England, the soil is often unsuitable for the breeding of "nag" horses, on account of its poverty in lime, and consequently few English farmers either breed hunters or ride them. In no walk of life do we find enthusiasm for a sport among men who do not take part in it. On the other hand, the large majority of English farmers are Conservatives, and have a great respect for their social superiors. Mr. Richard Ord tells us in his Foxhunter's Vade Mecum that at least $£ 7,500,000$ is spent every year on hunting in the United Kingdom. In Midland fields, numbering from 200 to 400 , there are many hunting people who migrate for the season into the country and spend in it a large amount of money, a good deal of which finds its way into the pockets of farmers in exchange for supplies for house, stable, and servants' food. A comparison between the state of trade in Melton Mowbray during the season, with what it is out of the season, will amply prove this fact. Besides, in hunting countries, oats and hay fetch at least Io per cent. more than in non-hunting districts. Farmers, like other human beings, do not readily shape their conduct according to general principles. Hence, the thought that 
hunting confers substantial benefits on agriculture, is not always accepted by farmers as sufficient compensation for damages inflicted on their property, such as broken fences, damaged crops, poultry and lambs killed by foxes, abortions among cows and ewes which have been frightened by hounds and horsemen, and stock being let loose over the country by hunting people neglecting to shut gates after them. Also, in all classes of life, we meet with men who like to obtain a benefit without paying anything in return. Thus we find men who want to hunt without contributing even to the covert fund, and we may be certain that such free lances will show less care in avoiding damage to fences and fields than those who act on the principle of give and take. On the other hand, there are farmers (not many, I feel sure), who are glad to profit by the presence of hunting visitors in their district, but do nothing in return, beyond putting up red flags.

Compensation for poultry killed by foxes is a frequent cause of offence; not as a rule because of its insufficiency, but because of the want of method in its distribution. In some countries, the poultry fund of a hunt acts as a benevolent institution for certain petty farmers, who are consequently incited to levy blackmail for the retention of their good-will. To avoid this disastrous result of ill-advised generosity, it is best, I think, for a M. F. H. to have local damage fund agents (say, in every village), who would personally inquire into and settle claims. It is evident that if people are careless enough to leave poultry out at night, they ought not to expect others to take the risk. When thieves in hunting districts break into fowl houses, they not uncommonly pluck the birds and scatter the feathers about, in order to make it appear that foxes were the marauders. It is an instructive fact that the more a country is split up into small farms, the more wire (Fig. 219) will be found in it.

In fox hunts there is a damage fund-which is generally 
known as the covert or poultry fund-for covert rents, repairs and damages. In most subscription packs, a yearly balancesheet of this fund is furnished to each subscriber.

Hunting men and farmers hold very different views respecting the killing of lambs by foxes. As this diversity of opinion often gives rise to friction between men who ought to be the best of friends, I have tried, while living in the country, to learn all I could about the subject. Mr. Scarth Dixon tells us that " a hungry fox will certainly take a weakly, new-dropped lamb, and I believe that in mountainous districts, such as obtain in some parts of Cumberland, the small lambs of the

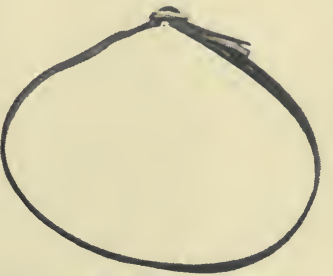

Fig. 220. Garter straps.

native breed are not safe until they are several days old. But in the lowlands, or even in the hills where game is plentiful, and where the sheep are of larger size, it is rare indeed that a fox will attack a lamb. If those gentlemen who think that the foxes are going off with their choice lambs would keep a sharp look-out, they would find in the majority of instances that the culprit was a dog, and in all probability one belonging to themselves."

Farmers who have had experience both in Wales and in the Midlands, inform me that ordinary English ewes do not protect their lambs from foxes by any means as well as IVelsh ewes, and lambs are therefore more liable to be carried off in the Midlands than in Wales. The higher protective 
ability of Welsh ewes appears to be due to the fact that they are wilder, and consequently more resourceful than their English sisters. Besides, the ewes of some Welsh breeds are furnished with horns. Experienced farmers, in whose testimony I have the fullest confidence, consider that lambs are not safe from foxes until they are at least a month old. It is true that evil-minded dogs will kill lambs, but such animals will rarely be content with one or even two lambs, if they have the chance of slaying more, and will also worry grown-up lambs and sheep, and will thus betray themselves. A fox may kill a lamb because he is hungry, or a vixen to obtain food for her cubs; but will not, like a dog kill out of pure love of mischief. Besides, when a dog takes to this criminal habit, he will soon make his vice known by his uncontrolled indulgence in it. Sheep dogs are much more inclined than other breeds to fall into the evil habit of worrying sheep ; because they are trained to follow; head, and drive sheep, and are often taught to bite the hind legs of these animals by mischievous boys who take a delight in this minor form of sheep-worrying. Unfortunately, it is generally the case, that the best and keenest sheep dogs are those which are most liable to contract this vice. Some shepherds make a practice of giving dead lambs as food to their dogs, which consequently become apt to help themselves when this supply runs short. Leaving dead lambs in a field, as is often done, is of course an encouragement to foxes and dogs to kill live ones. If a dead lamb has to be left in the open, the precaution of removing the skin should always be taken.

Respecting the curing of the vice, in dogs, of killing lambs or poultry, Mr. Head, mine host of the Harborough Hotel, Melton Mowbray, informs me that during his long career as a large farmer in Kent, he met with several cases of the successful reformation of such animals, by catching them, if possible red-handed; tying them up very short; and beating 
them unmercifully with their dead victim. They should of course be severely "rated" at the same time. This method of correction accomplished its object so well with a valuable setter which Mr. Head owned, that ever afterwards the sight of a sheep of any age was so appalling to the dog, that if he met one when out for a walk, he would run back to his kennel with all possible speed. I have also heard that tying the dead lamb or fowl to the collar of a dog and allowing it to remain on until it drops off, as a result of putrefaction, is effective. A good old plan with a sheep-worrying $\mathrm{dog}$ is to put him into a room or loose box with a combative ram. If we adopt this expedient, we must not repeat the error committed by a Master in confining his hounds along with a fighting ram, who amused himself by playing a game of nine-pins with the hounds as long as the Master was looking on. Happy in the apparent success of the experiment, he went to luncheon, and on his return was shocked to find that the only things which remained of the ram were a pair of horns, a good deal of wool, and a few bones. Any of these corrective methods would of course be useless with a sheep-worrying sheepdog, unless the animal was to be put to other work.

I am greatly obliged to Mr. Head for having, on my behalf, made enquiries among his farming friends respecting the manner in which foxes devour young lambs. The results of these investigations, and of his own experience, show that a fox as a rule begins breaking it up at the groin, and pulls out and eats the intestines, of which foxes are particularly fond. Mr. Head found that when he placed butchers' offal near coverts for young cubs, Mrs. Vicky always chose the intestines in preference to other parts for the nourishment of her family.

An old and very skilful Midland poacher assures me that foxes and badgers, when they seize a lamb, do so, invariably by the muzzle, and not, like dogs, by the throat. He confirms 
Mr. Head's remark about the liking which a fox shows for the entrails, and states that a dog prefers the flesh of the legs and other parts. He tells me that although a badger will at times kill a lamb, it will not eat it. My friend, who prides himself on the fact that he has never committed the unsportsmanlike action of killing game out of season, informs me that he has often cured dogs of sheep-worrying, by taking the erring animal and a ram into a field, and connecting them together by means of a halter, which is put on the tup's head, while the rope, in the form of a running noose, is passed round the dog's neck. If the dog shows fight or "stands his ground," the ram will in all probability give him a good "doing," and should be aided therein by the whip of the teacher. If he tries to escape, he will be more or less strangled by the rope. A short continuance of this lesson will go a long way towards reformation.

Roaming dogs will often cause abortion among pregnant ewes which they annoy. Hounds and horses passing through a field occupied by ewes or cows heavy in young, will be likely to produce a similar effect. Hence the necessity for Masters to send round notice to farmers in whose district hounds are likely to hunt. Some agriculturists are not content with the price of lambs. A man who had a farm near Gartree Hill, which is on the Melton side of Little Dalby, once sent in a claim for a cart colt of his that got mange, so he said, from mangy foxes which were in that covert!

Farmers often draw a line of tar or raddle (a red pigment used for marking sheep) down the backs and shoulders of lambs, as a means of protecting them from foxes. This precaution is not always effective. I am told that all wild animals, from rats to red deer and foxes, dislike tar. It appears that the smell of sheep dip is the cause of red deer being shy of ground grazed by sheep. They do not greatly mind the presence of cattle. 


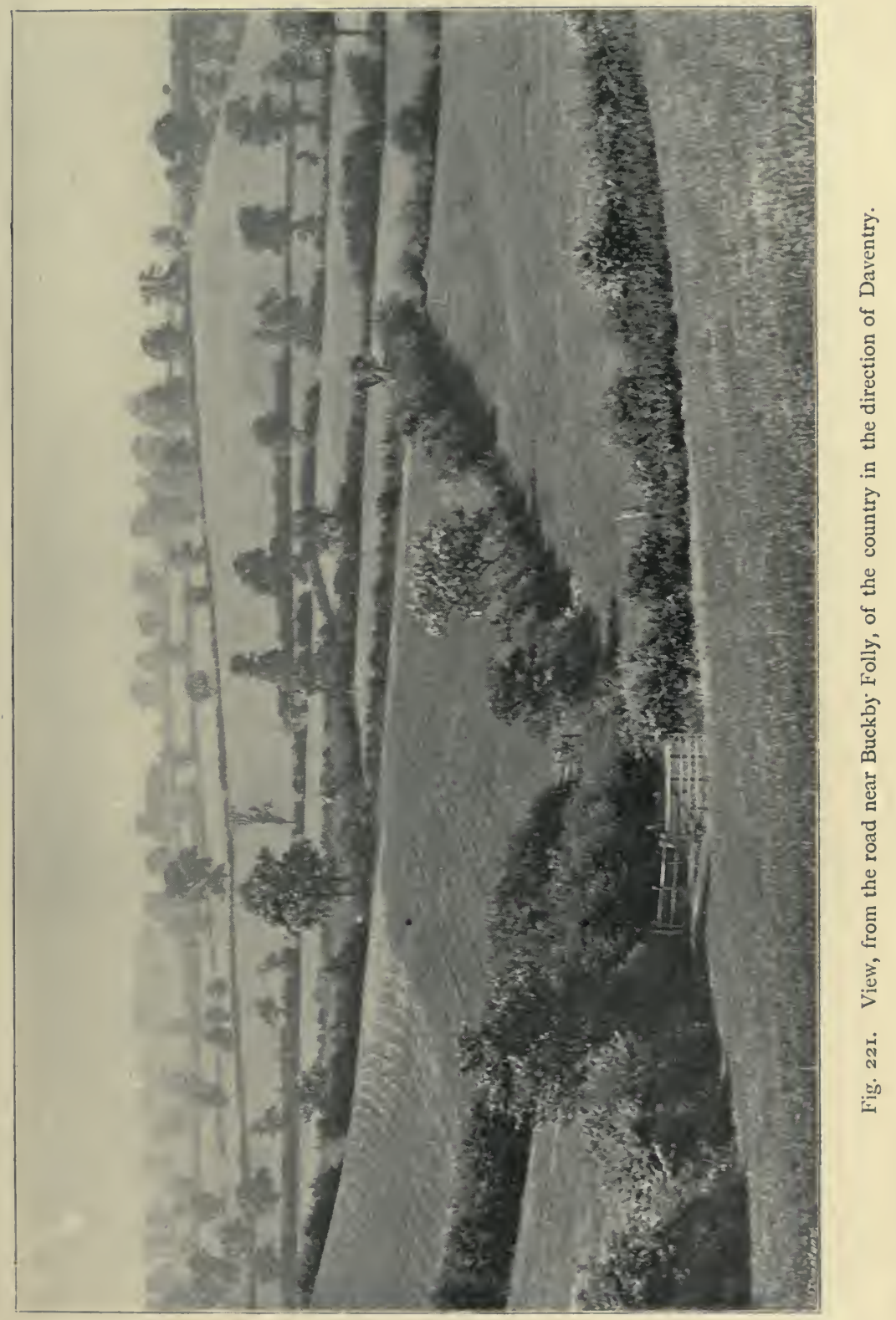



Treating farmers as friends, and giving them social recognition, will do more than money to keep down wire and prevent friction. At the same time, the authorities of a hunt should be prepared to give just compensation for damage. A farmer cannot be expected to take down wire and put up posts and rails at his own expense for the benefit of hunting people. In a certain fashionable country, I have seen great harm to hunting arise, from the M. F. H., with undoubtedly good intentions, paying for the taking down of wire in some cases; the result being that other farmers put up wire for the first time in their lives, so that they also might be squared. Compensation and civility, and no bribery, should be the rule.

The conciliation of farmers by tactful and generous treatment is incumbent not only on the authorities of a hunt, but also on each of its members ; for official effort in this delicate matter will often fail without individual support. Dealing with farmers for stable and house supplies can generally be made a strong bond of union; but, unfortunately, stud grooms in some cases are so exorbitant in their demands for commission, that their masters' custom is not worth having. To allow a farmer a fair profit, a hunting man ought to make his own purchases of forage from him, which is an undertaking that demands special knowledge possessed by few hunting men, who lose half the pleasure to be got out of horses, by leaving all stable details in the hands of their grooms. When Lord Lonsdale hunted the Quorn country, which he did in a prince-like manner, he made a practice of advertising at-his own expense the names, addresses and nature of the stable supplies of all the farmers of his district, so that the members of the Quorn hunt might be able to obtain their hay, corn, straw, etc., direct from the local producer. In those days, almost all the stud grooms continued to patronise the Melton corn dealer, who, besides being a good business 
man, was also a farmer, and was on Lord Lonsdale's list. A better plan than the advertisement one, is the appointment of a resident gentleman to put hunting people in communication with farmers who will supply them with forage. Such a man should of course be absolutely above the suspicion of taking commission on his own account. In considering this question of buying forage, we must remember that many fashionable hunting men require credit, which is an article not usually supplied by agriculturists. Neglect to deal with farmers is certainly one of the most fruitful causes of wire, and is a crime against hunting which a good sportsman would not knowingly commit.

The members of a hunt should not only do their best to get on well with the farmers, but should also try to make themselves popular in their district by subscribing to local institutions, such as agricultural societies, and should be always ready to suitably reward, or at least courteously acknowledge, acts of civility from the labouring classes, as for instance, catching a loose horse, or opening a difficult gate. We must not forget that working men in the country usually do not get more than fourteen shillings a week, and that kindness shown to them has a good effect towards securing the respect of the farmers, with whom they are more or less closely in touch.

It has often been proposed that hunts should pay to farmers a certain sum per acre for land over which the members ride. Such an arrangement would be unworkable, on account of the impossibility of making it equitable. The natural features of a country, its distance from headquarters, its facilities of communication, and the position of coverts, cause ground to be very unequally used, and, consequently, what would be wholly inadequate compensation in one case, would be extravagant liberality in another instance. It is evident that an unequal scale of compensation would 
be productive of more jealousy and unpleasantness, than entire absence of payment for damages.

As an act of conciliation, masters and prominent hunting men sometimes give the services of a stallion to the farmers of the district, usually on the condition that they do not keep up wire during the season. In doing this, they often forget to consider if the soil is suitable for the type of animal they propose to be cultivated. For instance, it would

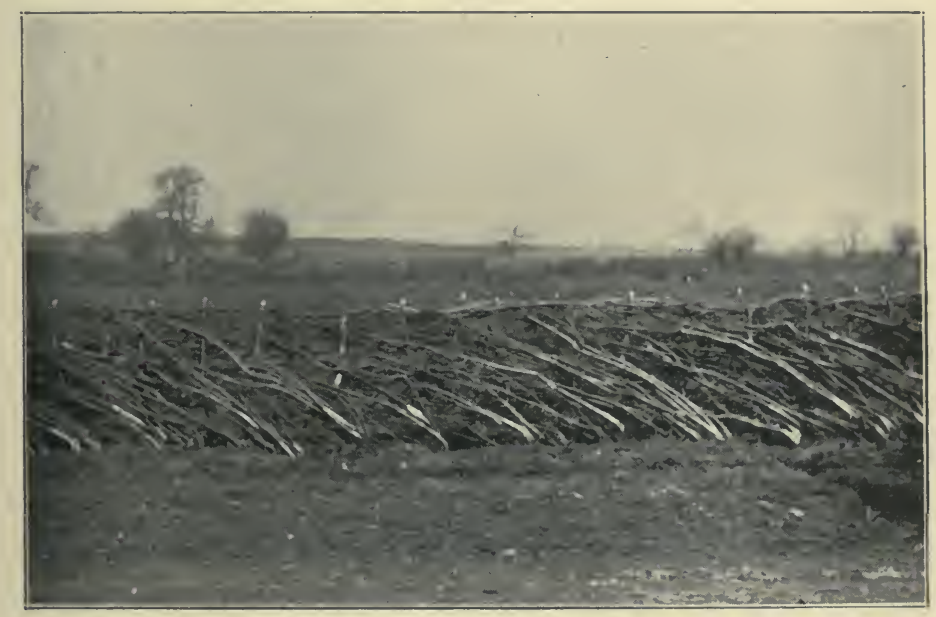

Fig. 222. Hedge newly cut and laid, about 3 ft. 9 in. high.

be hopeless to attempt to breed good hunters in many parts of the Midlands, or Fen country, which is famous for the production of the horse-show type of Shire animal. In such parts, a Shorthorn bull would be more useful to the generality of local farmers, than a thorough-bred sire.

\section{HUNTING MEN AND SHOOTING MEN.}

The great enemies of hunting are preservers of pheasants who desire to make "newspaper bags"; for to accomplish this Cockney ambition, foxes have to be killed. The toll 
taken by foxes, is not sufficiently large to spoil a game preserver's amusement, and should be cheerfully borne by shooting men who understand that the principle of "give and take" should govern every branch of sport. The chief offenders in this respect are shooting tenants, who as a rule take no interest in country affairs, and are entirely in the hands of their servants. In the vast majority of cases their gamekeepers shoot every fox which comes within range, and never let off an old one. When, for shame sake, they spare a litter after killing the vixen, their mercy is of little use; for the cubs, having no one to show them about the country, degenerate into the short running kind, which give no sport. The cubs that are brought up on flesh of various sorts, suffer more or less from indigestion, on account of being deprived of the fur or feathers, which are as necessary a constituent of their food as is hay or straw in that of horses largely fed on corn. From dyspepsia, their coats get a mangy appearance; although of course parasitic mange can be set up only by contagion. Shooting men and gamekeepers should understand that the rearing of cubs without the vixen, cannot be received by hunting men as an act of conciliation. When a so-called sportsman of this kind comes into possession, usually his first act is to request the local M.F.H. not to draw his woods until they have been shot, in some cases more than once. This means that hounds do no cub-hunting in these covers, and probably do not get into them until after Christmas. When many of the woods in a country are occupied in a similar manner, it is evident that for half the season a considerable portion of the hunt territory is unavailable. Consequently, an M.F.H. often has the greatest difficulty in arranging his meets, and in more than one instance a fewer number of hunting days per week has been the result. Very often, when the time at last arrives for the drawing of such coverts, 
few if any foxes of the right sort are to be found; a fact which has indirectly led to the retirement of several keen and hard-working Masters.

When coverts are closed to hounds, deluded foxes naturally seek these supposed abodes of safety, and are then promptly killed by the gamekeepers, who thus get a disproportionately large number of victims. Fox-shooting, which is not practised by farmers, inflicts infinitely more injury on foxhunting than does wire, and the only remedy is for hunting people to rent as many coverts as they can. Luckily, the best part of Leicestershire is comparatively free from pheasants, on account of there being few coverts suitable for them in it; although these birds abound in the Charnwood Forest.

As a rule, landed proprietors having been brought up in close touch with country interests, are more tolerant of the sports of others than the casual tenant. Yet we find even among them rich men who, although they participate in and profess devotion for the chase, take good care that no fox leaves their coverts alive. Some of them keep up wire, and hunt in a strange country. Of such is the kingdom of Satan.

Warburton feelingly sings :-

"I honour that sportsman, whatever his rank, Whose heart heaves a sigh when his gorse is drawn blank.'”

\section{JOINING A HUNT.}

The best course of action which a stranger who wishes to join a hunt, can adopt, is to call on the Secretary, tell him his intentions, and conform to the usages of the hunt in the matter of subscription, etc. He will find the addresses of all the hunt secretaries in Baily's Hunting Directory, from which he can obtain a great deal of information about 
different packs. The following rates of subscription are taken chiefly from that book :-

Blencathra. "The minimum subscription is $2 \mathrm{~s} .6 \mathrm{~d} . "$

Eskdale. "All subscriptions are accepted; these vary from three guineas to one shilling."

East Essex. The minimum subscription is Ios. 6d.

Mid-Devon. The minimum subscription is $£ \mathrm{I}$ Is.

Craven. The minimum subscription is $£ \mathrm{ro}$.

Blackmore Vale. "Strangers are expected to subscribe to the Poultry Fund at least £Io."

Mr. Fernie's and the Pytchley. Minimum subscription is $£ 25$. An increased subscription would be expected from a family with more than one hunting member.

Whaddon Chase. The minimum subscription is $£ 35$.

Grafton. The minimum subscription is " $£ 35$ payable in advance. This does not entitle a non-resident to bring a friend."

Quorn. The minimum subscription in Lord Lonsdale's time was $£ 25$; and $£ 50$ was levied on a man who took a hunting box, even if he had no family; because he would most probably have hunting visitors. Under the present popular mastership of Captain Burns-Hartopp, there is no hard and fast rule as to subscriptions to the Quorn.

Bedale. About $£ 5$ a horse is the usual subscription.

Duke of Beaufort's. "Gentlemen other than land and covert owners are expected to subscribe at the rate of at least $£$ IO per annum for every day per week they hunt.”

The Vale of White Horse Hunt charge men a similar subscription, and ladies $£ 5$.

Bicester and Warden Hill. "Visitors for the hunting season at least £io per horse. Other strangers $£ 35$, unless subscribers of at least $£ 25$ to an adjoining pack, when $£ \mathrm{IO}$ is required." The enlanced subscription for "other strangers" is of course made (and very rightly) to lessen the number 
of chance visitors who would like to make a convenience of the hunt without giving an adequate return. The object for thus penalising them is more to keep down the size of the field, than to get money for the hunt. In olden times, when communication was difficult, this necessity did not exist ; and besides, those who then joined "the glad throng" were almost all residents, and helped the sport in one way or the other. The only people who have an absolute

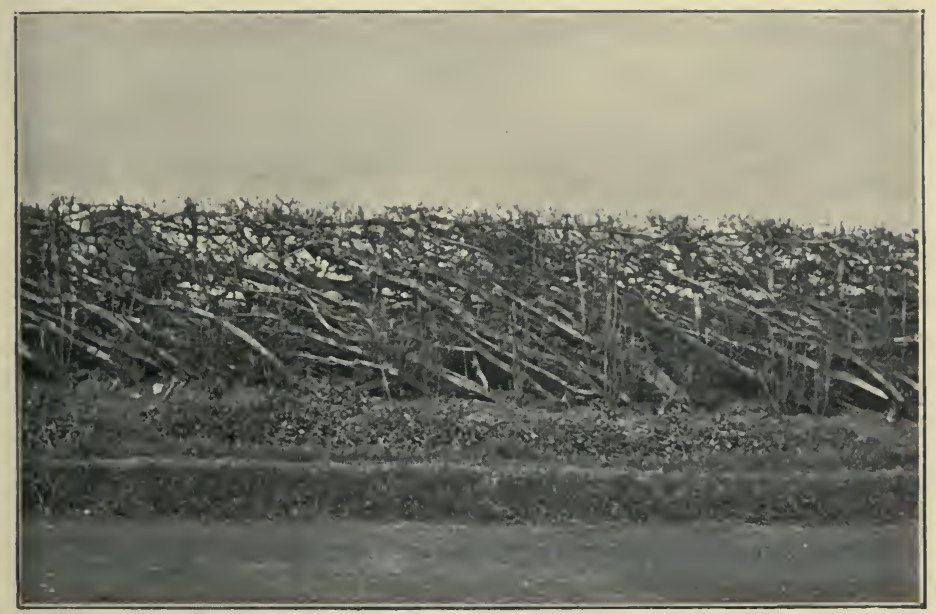

Fig. 223. A second season cut-and-laid hedge, about $4 \mathrm{ft}$. high.

right to join in a hunt, apart from the question of subscribing, are those who own or rent land in that country. If a one or two horse man who lived in the district of a fashionable subscription pack and who was not well off, desired to ask for a reduction, his best course would be to meet the Master or Secretary, and explain matters. He would probably receive the concession of being allowed to subscribe $£$ Io for one horse or $£ \mathrm{I} 5$ for two, and he would be well advised to make the offer of walking a couple of puppies, supposing that he was willing to take the trouble 
to do them justice. His reduced subscription would doubtless be credited to the covert fund. Even with a non-subscription pack, like what the Belvoir was when it was hunted by the Duke of Rutland and his son Lord Edward Manners, a subscription to the covert fund would always be courteously received, and its payment should be regarded as a debt of honour in discharge for the inevitable damage done to crops and fences by one's presence in the field.

In a few English hunts (about one in every twelve), a cap is taken in amounts which vary from a shilling to a pound, and the collection as a rule goes to the general fund, the earth-stopping fund, the huntsman, or hunt servants. Formerly, a cap was often made for the huntsman when a fox was killed, and no doubt was the cause of a good deal of "hark halloa" and "tally ho back." Lord Lonsdale tried the capping system at a guinea a head with the Quorn, and seven guineas were amassed on the first day. Capping consequently disappeared from Leicestershire. In Ireland, on the contrary, capping is practised with success in about fivesixths of all the fox hunts; the usual "field money," as it is called, being half-a-crown, although the South Union demand five shillings.

It is usual at the end of the season to give a present to the hunt servants, who certainly deserve it. A suitable amount for a man of moderate means would be three pounds to the huntsman, and a pound to each whipper-in. Formerly a "tip" of, say, a crown each, was often given to the earthstoppers. Stopping is now generally done by local keepers, who are paid by the hunt or Master. In the spring they are sometimes given a dinner, at which they usually pose as lovers of the fox, and only tolerators of the pheasant. I may mention in passing, that two is the full number of whippers-in, as in Fig. 81. Each of these hunt servants carries a stirrup leather over his right shoulder. The man who 
has a horn-case on his saddle, and is behind Frank Gillard, is the second horseman of the great Belvoir huntsman.

\section{HOUNDS.}

The hounds we have to consider from a riding point of view are as follows :-

I. Fox-hounds. - Their height as a rule varies from 22 to 24 inches; the latter measurement being equivalent to about I6 hands in a hunter. Bitches are generally about one inch smaller than dogs of the same pack. Probably the best height for bitches is 22 inches; and for dogs, 23 inches.

2. Stag-hounds.-The term stag-hounds and that of buckhounds are derived from the game they respectively pursue, and have no significance as regards the variety of hounds, which are generally drafted fox-hounds. In the Queen's, dogs run from 24 to 25 inches. Lord Coventry, the late Master, liked to keep up the size, and certainly had a very smart pack. Baron Rothschild's are much smaller. The Devon and Somerset have hitherto been 25 and 26 inches. Captain King-King wisely points out that it is advisable not to have them over 22 inches for carted deer; because, at that height they could not, bar accidents, kill their quarry, which can beat off, or keep at out-fighting, a whole pack, so long as he remains on his feet. Big hounds can knock him off his legs, but small ones cannot. Both sizes will be able to kill him, if he gets down in a ditch.

Stag-hounds hunt red-deer, both stag and hind; and wild as well as carted. Wild hinds are hunted during winter; and carted stags or hinds, any time which convenience may dictate.

3. Buck-hounds hunt wild fallow deer, both bucks and does. The application of the term "buck-hounds" to the Queen's is wrong, because the quarry of that pack is the carted stag. The New Forest appear to be the only hounds that habitu- 
ally chase fallow deer, which variety of deer is hardly ever kept in confinement for hunting purposes. The New Forest occasionally hunt wild red deer, of which there are very few in that district; because Government, about fifty years ago, ordered all the New Forest deer, red as well as fallow, to be exterminated. A small number of fallow deer survived, and, since then, their increase has been encouraged. The New Forest hunt call their pack deer-hounds.

The hunting of hinds and does is resorted to, only when the males are out of season, namely, after the middle of October. It is said that there are too many hinds on Exmoor, and not too many deer of any kind in the New Forest.

4. Harriers as a rule are pure harriers, dwarf fox-hounds, or cross-breds; and are from $15 \mathrm{x} / 2$ (Colchester) to 24 inches (Stannington) high. A good height would be: bitches, I8 inches; dogs, I9 inches. Although their legitimate quarry is hare, they sometimes hunt fox in Ireland; but should of course be called off, if they got on to one in a fox-hunting country. In bygone times in England, they used occasionally to hunt fox after Christmas, but that form of chase is now strictly reserved for fox-hounds. Most Masters of harriers would consider out-lying red or fallow deer to be fair game. The Ripley and Knap Hill harriers, when Mr. Seymour Dubourg was Master and Huntsman, had some excellent sport with wild roe in the rough country round Sandhurst. That gentleman is now Master and Huntsman of the South Berks, and there is no better sportsman in field or kennel.

5. Drag-hounds are always fox-hounds. The usual drag is the droppings and the bed of a tame fox, flavoured with aniseed, of which only a little should be employed; because it becomes blown about, and hounds are apt to run wild at it. Many hounds hate aniseed and will not run it. A red-herring in a hare-skin with a little aniseed is sometimes used. One of 
the Middlesex packs of drag-hounds in the season of I899I900, ran and took a stag which the Queen's had left out near London.

Deer-hounds should not be confused with either staghounds or buck-hounds. They are merely large rough greyhounds which were formerly employed in Scotland for coursing red deer; a brace of them being slipped, as in coursing hare. When I was in Kimberley, South Africa, in

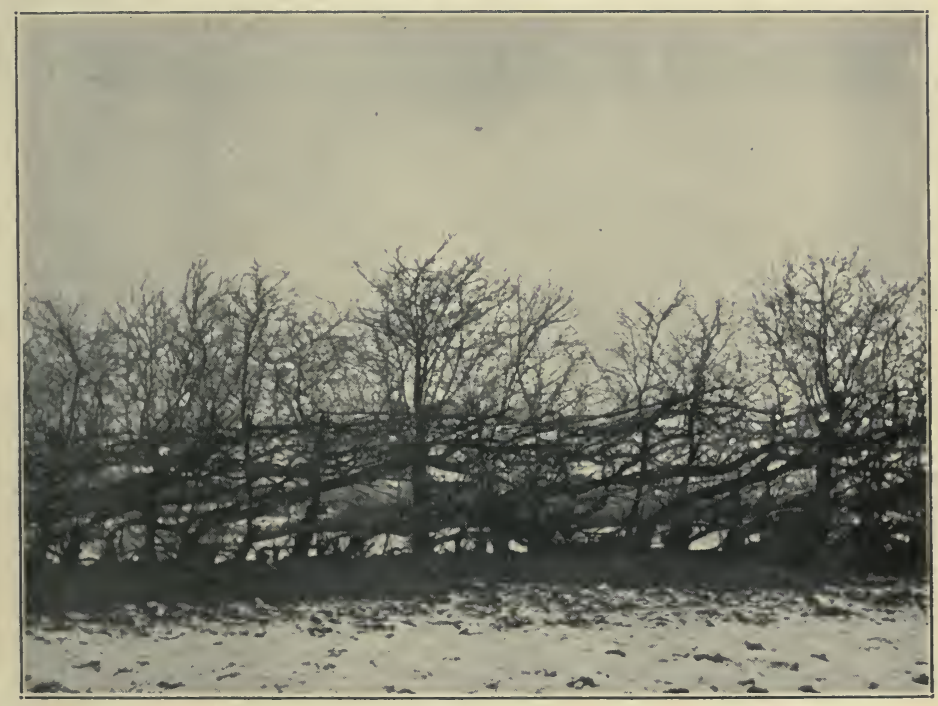

Fig. 224. Old cut-and-laid hedge, about 4 ft. 6 in. high.

I 892, that good sportsman, Mr. Fenn, was Master of a pack which used to collectively course steinbok (Antilope tragulus) over the veldt, and which were followed on horse-back.

As a tendency to riot makes hounds unreliable, they should be kept strictly to their respective quarries. Hares and deer of all kinds, but not badgers, are riot to fox-hounds. Hares, roe and fallow deer are riot to stag-hounds. Rabbits are the chief riot of harriers. 
During the present season of I900-I, there are, according to the Field, 163 packs of fox-hounds in England; 23 in Ireland; and $\mathrm{IO}$ in Scotland. The respective number of harrier packs are: 99, 26, and 3. There are 18 packs of stag-hounds in England, and 4 in Ireland.

In that good book, Unasked Advice, "Impecuniosus" justly remarks that there is "a great deal of nonsense talked about fast and slow hounds. I am no friend of the old Towlers, but surely almost all hounds of the present day are well bred enough to go, with a good scent, fast enough for any horse. It is the keeping on going that stops the horses. Bluecap and Wanton would be no farther from the horses than the slowest old blue mottles, if they had over-run the scent and were casting about to recover it. It is going steadily on that reaches a given point in quick time-not flying for five minutes, and checking for ten."

As a rule, fox-hound puppies should be whelped during the first quarter, and certainly not later than the first half of the year, so that they may have as much time as practicable for their early development, which might be seriously checked by the cold of winter. Autumn puppies are often undersized and delicate.

Puppies go to their walks when they are weaned, say, after they are two months old, provided that the bleak weather of January, February and March is over. They are usually taken back to the kennel during the following March.

Persons who walk puppies should be prepared, for the sake of the good cause of hunting, to bear with patience their extremely mischievous though playful ways. If practicable, it is better to walk two than one, because they do much better in company than singly. Like all other young animals, they require good feeding, plenty of exercise, and abundance of fresh air. As food, they may get new milk; scraps from the table, including green vegetables; a boiled paunch now 
and then, and bones on which to clean and develop their teeth. Confinement makes their legs crooked, and straining at a collar not only ruins their shoulders, but also is very apt to make them choke themselves or break their necks. It is advisable to keep them from coming in contact with or even going near strange dogs, which are liable to give them distemper, in which case they will seldom return to the kennel. Distemper, to which foxhounds are peculiarly

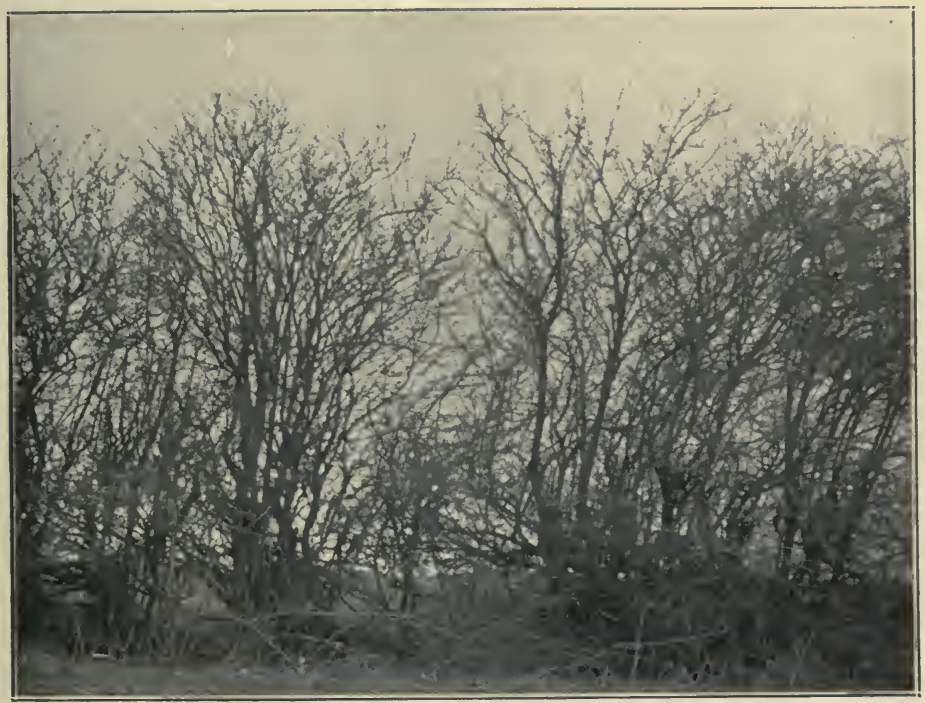

Fig. 225. A practicable Bullfinch.

susceptible, is an extremely infectious disease, and often assumes an incurable type. The chief part of its proper treatment consists in careful nursing and attention to sanitation.

Shortly after the return of the youngsters to kennel, a puppy show is held for the encouragement of those who have walked them. The judges are neighbouring Masters and Huntsmen, and the prizes are almost always silver cups. 
The show, with its luncheon for the exhibitors, is a pleasant and useful function for the promotion of good feeling in the country towards hunting.

\section{BLOOD.}

In the general pursuit of game as a sport, the idea among Englishmen is that the quarry should have a fair chance of escape. Therefore, digging out a fox which has gone to earth and giving him to the hounds to be broken up, may appear at first glance to be unsportsmanlike. On the other hand, we have the fact, that to be keen, hounds require blood. Tom Firr puts the case admirably in the following words: "When a bad, short-running fox goes to ground for instance, if he can be got out and dispatched, so much the better, for he is the sort to blood hounds with. It must be borne in mind that it is necessary to keep hounds well in blood. On the other hand, if a fox makes a point of seven or eight miles, or as many more as you like, and goes to ground, cheer the hounds at the earth to the very echo, rejoice over it as if you had him, but by all means leave him there. He is the sort you want for another day."

On this subject, Captain King-King tells me that "I cannot imagine anyone but an ignorant theorist upholding the idea that blood is needless for hounds. The way to break a hawk from undesirable game is to fly her at it with her legs weighted, and she will soon leave off the pursuit of the unattainable, unlike some human beings. Also, setters and pointers will not remain keen, if the man who shoots over them keeps continually missing. It is true that staghounds very seldom get blood; but they have comparatively speaking no difficulties to daunt and dispirit them. Not for them is the dusty scentless fallow, or the almost impenetrable stick or gorse covert, and they always have a scent. Yet for all that, we often hear of deer being 'left out.' When hounds 
mark a fox to ground, they should be made as much of, as if they had killed him. They will then go home satisfied with knowing where they have left him. If this is not done, the pack will soon leave off troubling themselves to mark any of their foxes to ground and will come away, much in the same fashion that a London pug dog will do, when his hunted cat has disappeared down an area. Sometimes it is imperative in the early stages of hound tuition, to dig out a fox and give

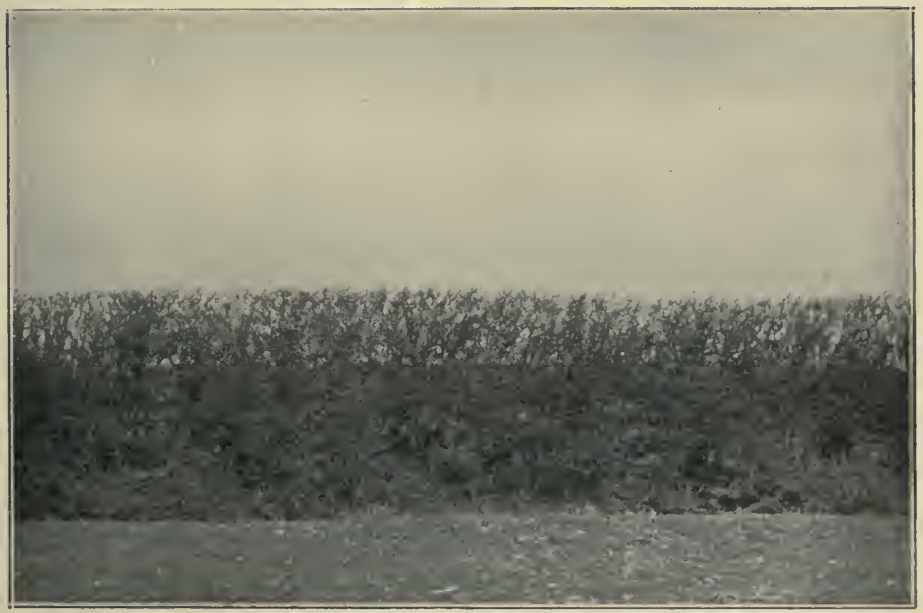

Fig. 226. Topped hedge, $6 \mathrm{ft}$. high.

him to them, in order to teach them to mark. A fox for every three times that a pack goes out is a fair allowance.

"The most useful way in which hounds can get blood is, when it is practicable, to open a drain so far that they can draw the fox themselves, after marking him in. In such a case, he should not be taken from them, and they should be allowed to worry him their own way, which action on their part will leave neither a brush for a lady, nor a pad for a schoolboy. The hound who, after the mîlée, secures the fox's head, should be allowed to keep it and carry it home if he 
chooses, though of course not into the lodging room. He will be a hound to breed from, as he possesses indomitable resolution, which is the first quality of a fox hound. The great advantage of hounds drawing a fox, is that it increases their confidence, and gives them the idea that Reynard's entrenchments are not impregnable, and that they themselves are invincible. They will then almost always mark their fox to ground, if they cannot catch him. I have seen hounds who, from bad management, would not do this, and who consequently accounted for their fox by habitually losing him. I am always sorry for the fox; but, as Jorrocks says, 'It's not that I loves the fox less, but the 'ound more." "

We should remember that too many foxes spoil sport, and are a calamity to farmers and other persons who keep poultry. We consequently find that in several hunts, a day every now and then, and especially during cubbing time, has to be devoted to obtaining blood and bustling foxes about in woods, dingles, and other places where it would be impossible to get a good gallop. If this were not done, the country people would have to keep down the number of foxes by less legitimate means. The best way to make foxes quit big woods at short notice, is for hounds, when they kill, to break up their fox in the thickest part of the covert.

A form of blood-giving which I do not like to see, even if it be necessary, is that of surrounding a covert, when cub-hunting, and attempting to drive back cubs which try to break out and escape. The strict hunting theory is to let all but one cub go; but sometimes he goes too! The fear that a change of law would injuriously affect hunting, has undoubtedly been the cause of the Act against cruelty to animals being confined to those which are kept under domestic conditions. In Ireland, the necessity for blood is more often overlooked in favour of giving a fair chance of escape to the fox, than in England. 
Another form of encouragement is that of blooding a young sportsman at his first kill. The ceremony is performed by the huntsman, who touches the neophyte on the forehead, chin, and each cheek, with the bleeding end of a pad, and then presents him with the pad or brush, as the case may demand. If he gets the brush, he had better put it into his pocket, than attach it to the browband of his pony, who may kick him off or run away, because horses greatly dislike the smell of

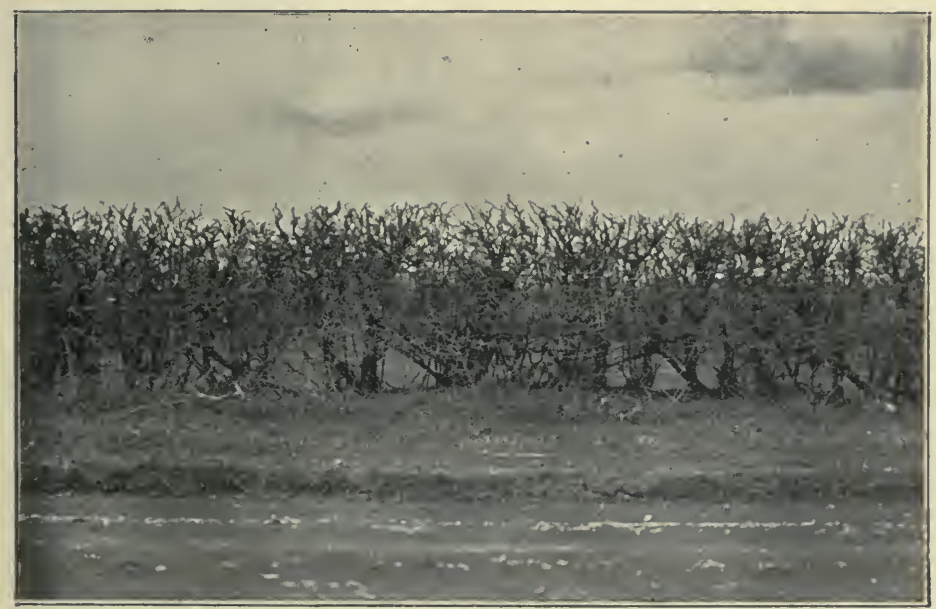

Fig. 227. Hedge, 3 ft. 6 in. high.

blood. In Highland deer forests, a somewhat similar ceremony, which makes one "free of the hill," is observed at the death of one's first stag.

\section{FOXES.}

The usual period of gestation of vixens, like that of bitches, is nine weeks, and the cubs as a rule are dropped about the middle of March ; although, in exceptional cases, particularly during mild winters, they may be whelped as early as Christmas. There is little difference between the appearance 
of vixens and dog foxes, except that the former are usually smaller than the latter, and have smaller and sharper heads. Of course it is comparatively easy to tell a heavy vixen. A nursing mother will be thin and out of condition, and is often so poor in coat and brush, that inexperienced people have been known to mistake her unthrifty state for mange.

Suckling vixens generally go out for food during the night; but dog foxes as a rule like to lie out above ground in the spring, probably to escape the discomfort of the nursery. Hence, after the beginning of March, it is advisable not to stop earths over night, and only " put them to " (lightly close them) on the hunting morning, so as to ensure as far as practicable, the safety of Mrs. Vicky when hounds are drawing or running. If this usually sound precaution of closing earths in the morning be omitted, a dog fox may get into an earth in front of the hounds, in which case no attempt should be made to put in a terrier, who might kill some if not all of the cubs, supposing they were present. If possible, a covert holding a heavy or suckling vixen should not be drawn.

Vixens in most cases run shorter than their male companions; because they do not travel in search of lovers, and consequently they do not know the country so well; but occasionally they give long runs. For instance, the bobtailed fox which was found at Walton Thorns, and was killed outside Old Hills, after passing within a field of Cossington Gorse (an eight mile point and a twelve mile run in 52 minutes), was a vixen that had lost her cubs. Vixens are not so often found as dog foxes; because they generally lie at earth, while the males lie out. Foxes are more or less nocturnal animals, as we may see by an examination of their eyes, the pupils of which contract in a manner somewhat similar to those of a cat, when the nerves of the eyes are stimulated by light. 
The nature of a country has a great deal to say to the merits of its foxes from a hunting point of view. When they live in places which afford them plenty of food and shelter, like the Cheshire dingles (narrow wooded valleys), they adopt a stay-at-home policy, and give no long runs; because they are out of mental and physical condition, and do not know the lie of the land. Even in a good country, turned down foxes do not acquire a knowledge of it, until they have gone through a season of "travelling," which is the term applied to the long excursions which a fox makes to visit a vixen. A travelling fox is the one for a "point," especially when he is a long distance from home. "Turned down" cubs are those which are taken from their home, to a strange place, and left to their own devices to become naturalised subjects.

It appears that nowadays, foxes in the Midlands run shorter than formerly, chiefly no doubt on account of the great increase of railways and spectators on foot, in carriages and on bicycles. Passing trains do not head foxes so much as plate-layers and other workmen on the line.

Captain King-King gives me the following notes on preserving foxes: "The ambition to preserve foxes is a most laudable one in a resident of a hunting country, and can as a rule be easily attained, if a suitable covert is available. The chief conditions which are required in a covert for this purpose are-that it should be in a retired situation, and well away from roads and footpaths, and that it should contain rabbits. If the owner succeeds a shooting man who was no friend to the chase, one of the first things he should do is to get rid of the keeper; for it is as difficult to try to reform a vulpicide keeper, as it is to reclaim a sheep-worrying dog. With a new man he should begin as he means to go on. He can do some shooting, and to give the keeper an interest in the work, he may even rear a few pheasants, hatched under hens from eggs taken from the wild nests. A tarred string round the 
coops, and a cord on it with a few small bells, which will sound when there is a breeze, will generally keep the foxes off the young birds at night. All wild animals dread a metallic sound; hence a deer stalker never has a ferrule on his stick. Supposing that foxes like the new covert, or that the covert is one to which they have been accustomed, the proprietor will probably have a litter of cubs bred in it. He can help the vixen and prevent her from marauding about the neighbouring poultry yards, by shooting for her now and then two or three rabbits, which he may find during his afternoon walk round the covert or coverts. The bunnies should be allowed to remain where they fall and should not be touched, because foxes suspect danger if their food is handled. Before repeating the performance after the first occasion, the place should be left quiet until the dead rabbits are taken away. In a short time, Mrs. Vicky will regard the report of the gun as the sound of her dinner bell, and an observant third person might see her following the gunner at a respectful distance. When the cubs become big, they ought to catch their own prey, or they will be no good for hunting. If it be desired to feed foxes in the season, the best things to give them are dead rats, which can be easily procured, when a neighbouring farmer takes in a stack of grain. Foxes are very fond of them; in fact; Tom Firr thinks that these rodents are their favourite food. It is advisable at first to pour water over the dead rats, as is done with the bait of a trap; but when the foxes begin to take them with confidence, this precaution against putting them off their meal will not be needed. The coverts can be shot a week or two after hounds have drawn them. The shooting will not cause the foxes much alarm; because the vixen will probably be underground, and the dog somewhere out of the way, unless the hounds have caught him. In the summer and autumn, foxes kill many hedgerow-abiding rats, which destroy young game and eggs, and seldom get in the 
way of Pincher, the terrier. The foregoing details comprise all that is required to be done for foxes in natural fox coverts.

"If the coverts have not been previously occupied by foxes, it is by no means certain that these animals can be induced to voluntarily adopt them, even at the expenditure of much trouble and expense. In any case, some foxes must be turned down in them. Although it is easy to make an artificial earth, which will cost about $£ \mathrm{IO}$, the difficulty is to get the foxes to use it. Foxes should never be turned down in the covert one

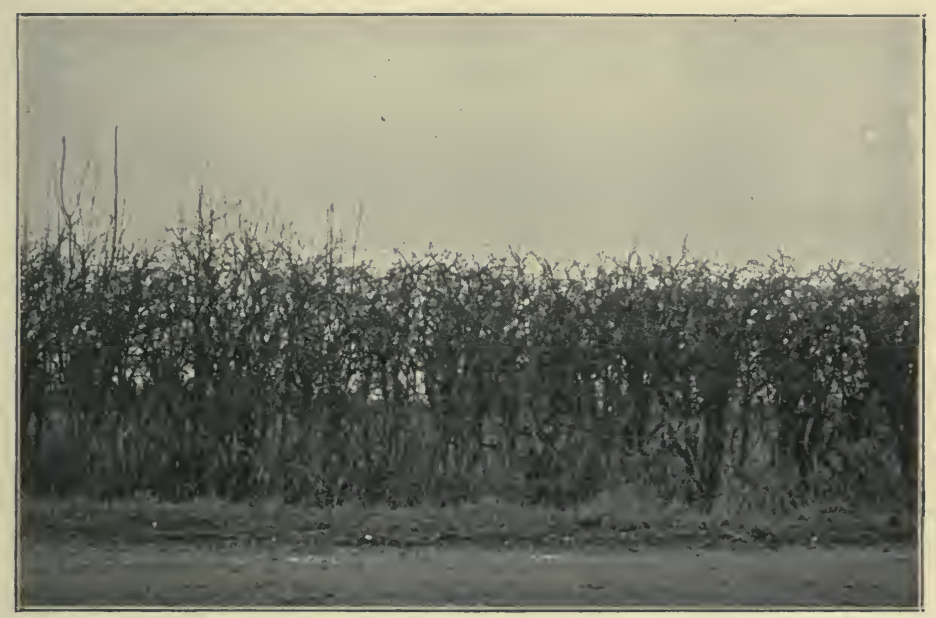

Fig. 228. Hedge, $6 \mathrm{ft}$. high.

wants them to inhabit; because, if this is done, they will promptly disappear, on account of their dislike to stay in a place which is known to their enemies. But if they are turned down two or three fields away from the covert, they will find the shelter for themselves, and will think that they have defeated their foe. It is a good plan to put a vixen into the artificial earth, and surround it by a fence made on the principle of a deer leap. By this means, a fox coming to visit the vixen, can jump in, but cannot escape. One must not, however, keep him long, and must prevent other dog foxes from 
entering the place. The vixen should come into residence early in January, and if there are no wild foxes about, a dog fox should be put along with her in the earth, which should then be enclosed. If the prisoners are blessed with offspring, an opening should be made in the fence, so that the whole family may be able to get out. Whatever the old foxes do, the cubs will never forget that this earth was their first home. They can of course be supplied with dead rats, as before described.

"Tom Firr believes that badgers kill cubs. Although badgers are snappers up of unconsidered trifles, I hardly think that they would go out of their way to add a cub to their menu, which is large and varied. They certainly take poultry and kill game and rabbits. I knew a case of a farmer who had lost a large number of turkeys, and was making out a bill which would have staggered humanity in the person of the M.F.H., when a heavy snowstorm came, and another turkey disappeared; but the tracks in the snow showed that $\mathrm{Mr}$. Brock, not bold Reynard, was the culprit. That badger was promptly dug out, and sent to the Zoo, where he lived at ease for many years. A jealous vixen will sometimes kill another vixen's cubs, and I have known two litters respectively destroyed by the rival dams. The most curious case I ever heard was that of a mangy old dog fox killing a whole litter of cubs, and eating one, if not more of them, in a country overflowing with game of all sorts.

"A terrier should on no account be put into an artificial earth, even as a last chance of a find for that day; because doing so will in all probability make the foxes forsake it.

"The best material for a fox covert is gorse, which requires a good deal of care, and will not grow well everywhere. It is also liable to get killed by frost. One-third of a gorse covert should be burned down regularly, as a covert of this kind becomes hollow at the bottom in time. Although Midland hedges consist chiefly of hawthorn; blackthorn is 
generally found in coverts. Gorse and thorns mixed form a capital covert. The great majority of coverts in the Melton district consist of thorns, as for instance, Clawson Thorns, Hose Gorse (so called in error), Sherbrook's covert, and in nearly all the coverts of the Belvoir country, except the 'heath' coverts, which are of gorse. Cream Gorse, Thrussington Gorse, Barkby Holt Gorse, Scraptoft Gorse, Adam's Gorse, Mundy's Gorse, Grimston Gorse, Lord

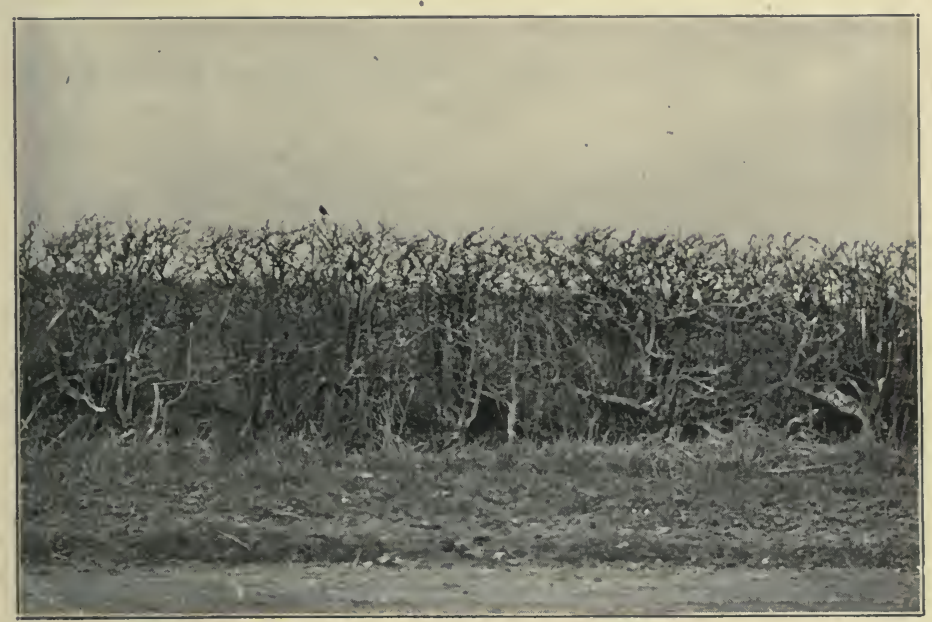

Fig. 229. Thin hedge, $5 \mathrm{ft}$. high.

Morton's Gorse, John O'Gaunt, Thurcaston Gorse, and the Coplow comprise almost all the gorses in the Quorn country on the Melton side. Welby Holt is partly gorse and partly thorns. Grimston Gorse should be called Brudenel's Gorse, because the late Lord Cardigan, then Lord Brudenel, made it. A stick (stakes and faggots) covert is often used as a makeshift while the blackthorn is growing. There is, for example, the Kilworth Sticks near North Kilworth. Sticks in a covert will of course require to be renewed from time to time."

"The Garden and Woodland" editor of The Field, in 
answering a correspondent who asks what is the best way to prevent gorse coverts from getting open at the bottom, replies as follows: "The only way to keep gorse from growing tall and becoming naked at the bottom is to keep it topped when young. You might chop down your covert in sections, leaving the stumps a foot or so in height. If this is done in Spring, say February or March, it will soon break out again. Some old coverts we had to deal with were burned in alternate sections, and the ground chopped over and fresh seed sown."

The fact that a covert is dry and faces to the south will greatly conduce to the comfort of foxes residing in it. George Carter, the famous huntsman of the Fitzwilliam, was a strong advocate of having, when practicable, a ditch guarded by posts and rails round every covert, so as to drain the ground, and give the foxes a feeling of security in their abode. Sand will of course be much drier than clay.

The smaller a covert is, the less likely is it to hold foxes, especially after Christmas.

\section{HUNTING THINGS.}

There are three forms of hunting coats usually worn. In I 865 or I866, General, then Captain, Owen Williams, of the Blues, introduced into modern use the swallow-tail coat, which is similar in shape to the orthodox coat of evening wear. It is, however, kept buttoned in front, and shows a few inches of the hunting waistcoat, which in all cases is particularly long, for purposes of warmth. This coat looks smart, but offers no protection to the legs in case of rain. It and the long-waisted cutaway, which is thoroughly workmanlike, are held in equal favour by Conservative Meltonians, who are apt to regard the single breasted frock coat as provincial. The frock is increasing in favour, at least among wearers of black; probably because it will generally keep the knees dry, during wet 
weather; supposing of course that it is long enough, as it ought to be, to cover the knees. Naturally, it cannot perform this office, when its wearer is riding against a strong head wind.

Previous to the swallow-tail coat, the cutaway was the orthodox pattern; but in the early part of the nineteenth century, "skimpy tails" were the fashion. "Snob" in Alken's illustrations of the "Quarterly Review run," I 826, is depicted in a frock on a bob-tailed horse.

A black hunting coat, like a pink one, may be of the cutaway, swallow tail, or frock pattern.

The material (strong Melton) is the same for both pink and black hunting coats. The cloth, to meet the exigencies of weather and hedges, has to be so thick and hard, that no one but a first class tailor can make out of it a comfortable coat for riding.

The great point about the fitting of a hunting coat, is that it should have plenty of room under the arms, so that it may offer no impediment to the wearer in using his hands on the reins. This indispensable requirement is greatly neglected by tailors, few of whom know anything of horsemanship. The riding men who suffer most from neglect in this matter, are those who are muscular in the arms and shoulders, and who consequently need extra room in the "sigh," as tailors call the part of a coat which covers the armpit on each side. The coat should also be roomy across the chest. For purposes of warmth, the lining of the coat round each wrist as a rule is respectively furnished with a piece of cloth and elastic, so as to prevent cold air from going up the sleeves. Woollen cuffs answer the same purpose equally well, and can be removed or put on as may be required. It is well to have the tails of the coat lined with waterproof, in order to save them from becoming wet and dirty by contact with the horse. A ring for the hat guard should be fixed 
inside the collar, at the back of the neck. "American shoulders" (padded broad shoulders) look so bad that they ought not to be seen in the hunting field.

Pink (scarlet) is the orthodox colour to go hunting in. Consequently, whether a man belongs to a hunt or not, he is as much entitled to wear a red coat when he follows the hounds, as he is to don a pair of top boots. A black hunting coat might be suitable for a man with a small stable, but not for an owner of a large stud of horses, who ought to be a "red-man," as they say in Leicestershire.

The members of several hunts wear special collars. For instance, the Pytchley wear white collars; the Ledbury, brown; the West Somerset, black; and the New Forest, green ones, which are similar to the collars of the Tarporley Hunt Club, and the Caledonian Hunt Club, both of which are clubs within hunts. Formerly, many hunts had distinctive colours; but as far as I can learn, the Duke of Beaufort's and the United are the only ones which now wear hunt livery. The hunt coat of the former is blue, with brass buttons and buff facings, not collar; and that of the latter, green, which is worn by the hunt servants as well as by the members. The officials of some hunts wear a distinctive dress. In the late Duke of Beaufort's time, the hunt servants wore green plush, which the present Duke changed to green cloth, as being the more serviceable, especially during wet weather, when plush absorbs water like a sponge. The Heythrop servants wear a green plush coat and red waistcoat, and those of the Old Berkeley East and West hunt in yellow. The Master of the O.B.H.W. dons yellow; and the Master of the East, scarlet. The Master and servants of the Atherstone wear a white collar.

The practice of wearing during the hunting season a red coat at dinner or ball, instead of a black evening coat, is a matter of local custom and varying fashion. At Melton it 
is usually worn, except on Sundays, when black is substituted ; but at Belvoir, in the late Duke's time, it was worn, even on Sundays. At hunt balls, all the members are supposed to wear it. Some men commit the solecism of appearing in scarlet in the evening, and in black with the hounds. The Master of the Old Berkeley West wears a yellow dress coat in the evening; and the ordinary members, pink with yellow facings. The members of the Hampshire and Monmouthshire wear a dark blue coat in the evening.

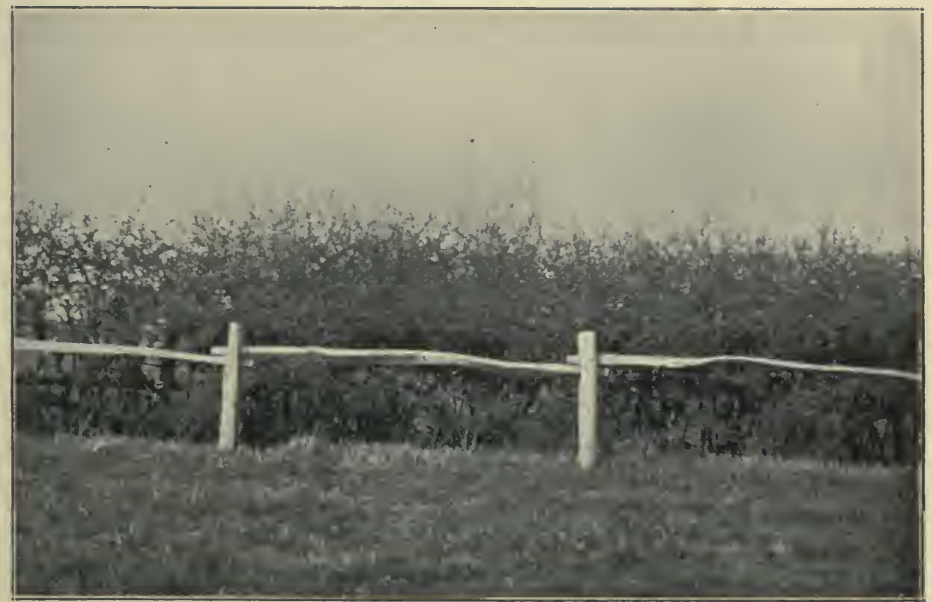

Fig. 230. Single oxer: rail about $3 \mathrm{ft}$. high.

The large majority of hunts have distinctive buttons, which the Meynell gives to each subscriber of $£ 25$; and the Taunton Vale, to any subscriber of seven guineas. With a hunt which does not make a rule of this kind, it is best for a stranger, even though he is a subscriber, not to wear them, until he has been invited to do so by the Master; for the unauthorised wearing of hunt buttons is a fertile cause of unpleasantness. The same remark applies to collars and other forms of special hunt dress. A man who hunts 
a country at his own expense, has of course the right to institute a personal button.

Hunting breeches are made either of white buckskin, white cotton cloth or white cord. Those of the former material look smarter and give a better grip in the saddle than those of the latter; but cost a good deal more, and are very uncomfortable if they happen to get wet. The chief points about breeches are that they should have plenty of length from the knees to the fork, and should be loose about the thighs, so that they may allow perfect freedom of movement to the legs; and should be made in such a manner that when they are drawn on, the openings at the knees shall be in their proper places. If the knees of the breeches require to be twisted round, in order to get them into correct position, they will tend during use, to work back into their old place, and will look untidy, even if they do not feel uncomfortable. In attempting to obviate this fault in construction, breeches are often made uncomfortably tight at the knees. In such cases, even when this constriction is supplemented by the employment of tight garter straps, the buttons generally work round, after the wearer has ridden a few miles. If the breeches are cut properly, they will have no tendency to become shifted. Formerly, the top button of the knees of the breeches was supposed to lie in the small depression which is on the outside of the knee cap and at its lower edge, and which is considered by some sportsmen to have been made for that purpose! At present, the buttons as a rule are brought to the front as much as possible, which arrangement is apt to cause unpleasant pressure of the buttons on the shin bone. The custom is for four buttons to show above the boots, and three above the leggings.

Garter straps (Fig. 220) are put round the legs, to prevent the knees of the breeches working round. They are about a 
third of an inch in width, are provided with plated double buckles, and are made of pipe-clayed leather for white breeches, and of brown leather for rat-catcher. Since about I880, garter straps have gradually superseded knee ties, which

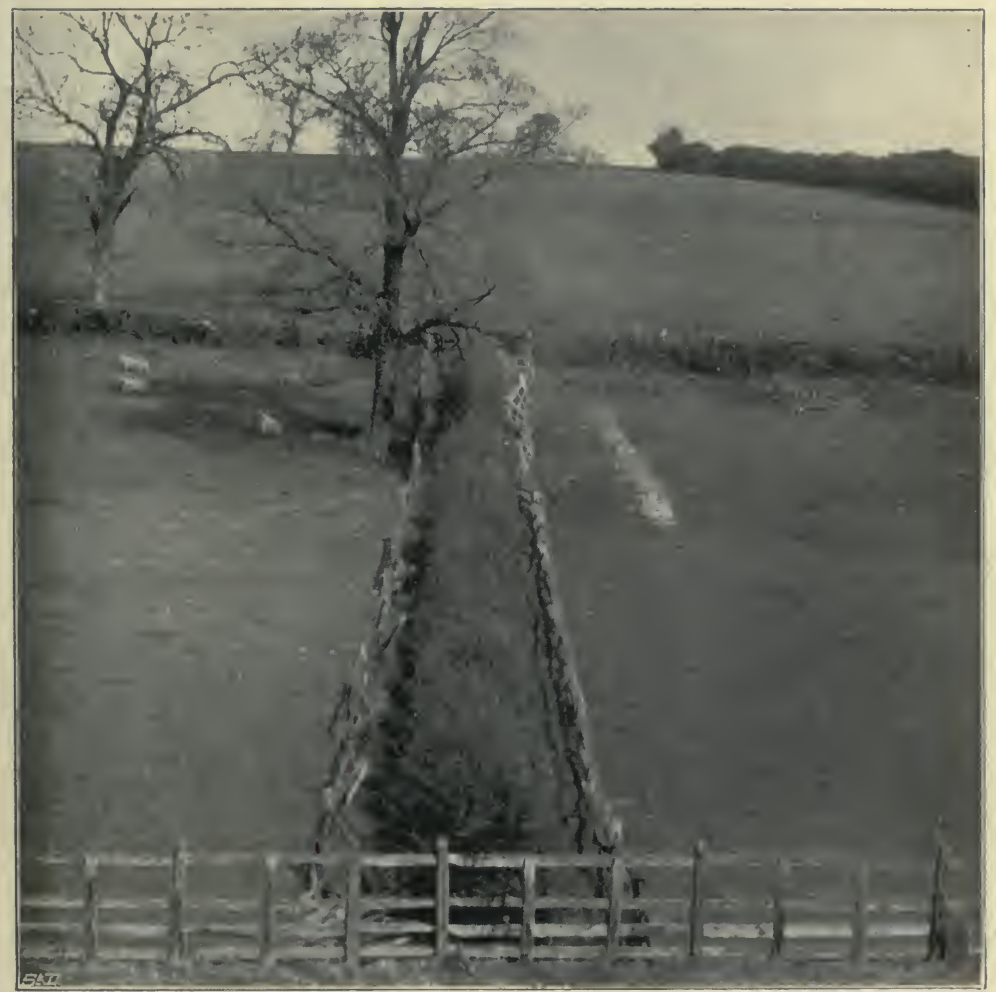

Fig. 23I. Double oxer : rails about $3 \mathrm{ft}$. high ; and about ro ft. apart.

are now worn only by sportsmen of the old school. They consist of white leather ribbons put round the leg and tied in a bow just below the fourth button of the breeches.

A tall hat furnished with a hat guard of black cord, is the correct head-gear for hunting. Many years ago, the stiff velvet cap was largely used, but is now seldom worn 
except by Masters and hunt servants. The fact of the famous Lord Waterford breaking his neck in a fall which he had when wearing a hunting cap in 1859 , was certainly the chief cause of the cap going out of fashion; for the news of that accident spread the apparently reasonable idea that concussion of the head with the ground is better broken by a tall hat, than by a cap. Poor Captain Park Yates, Master of the North Cheshire, was wearing a cap when he was killed by a fall on his head. A hunting hat should be somewhat stronger than an ordinary silk one, and should be large enough to come down over the back of the head, as well as over the forehead, so that it may be able to retain a firm position on the head. For this object and to prevent sweat soaking through the hat, a hunting hat is usually provided with a quilted lining. Many people think that Russian leather makes the best lining for this purpose.

A hunting tie or hunting stock is a combination of collar and tie. The centre of the stock is placed on the front of the neck, the ends are passed in opposite directions round the back of the neck, brought in front, tied in a reef knot, crossed in front of this knot, and finally secured, as a rule, by means of a pin or brooch, of the safety, horse-shoe or fox pattern. A gold safety pin is often used. A brooch pin is naturally safer than an ordinary pin. Nowadays, hunting ties - are nearly always made of white cotton material. Long ago in Ireland, I often saw fogles of blue bird's-eye on a white ground, in the hunting field. They were worn in the Shires until about I 885 .

A hunting waistcoat is usually of some fancy woollen material. It is long in the waist, single breasted, it buttons rather high up, and its pockets, as a rule, are provided with flaps.

Hunting top boots should have long, low heels, so as to prevent the stirrup irons pressing and catching on the 
insteps, and should be easy to the feet. Tight boots being cold boots, are very uncomfortable during a long ride on a winter's day, and besides, they are not agreeable things to walk in, in the event of the rider parting company with his animal, or having to lead it home, in case of an accident. In view of such eventualities, the thin soles which are used with flat race and steeplechase boots, and which give a pleasant feeling of the stirrup irons, are not suitable for hunting boots, which have to be made somewhat stouter.

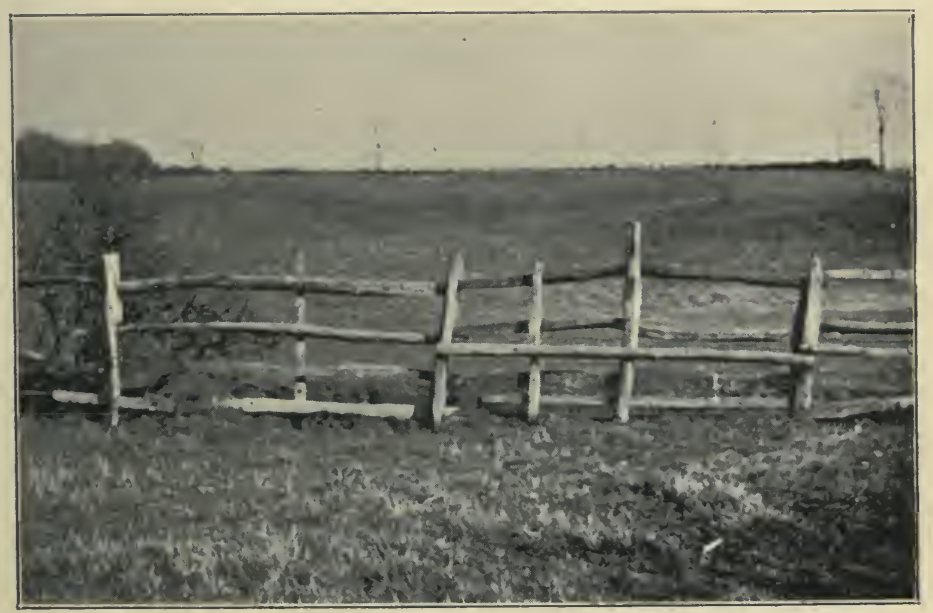

Fig. 232. Posts and rails; about 3 ft. 9 in. high.

Fashion varies from time to time, respecting the depth and colour of tops, which are now about $4 \frac{1}{2}$ inches deep. Formerly, they were much deeper.

Spurs of the hunting pattern are always worn with top boots -although many good horses go better without them-and should be buckled, in a manner which will bring the neck of the spur at about right angles to the leg of the boot. The buckle should of course be on the outside of the boot. If a rider wishes to avoid pricking his horse with his spurs, 
which he may often do involuntarily when landing over a fence, and especially if he gets shifted in his seat, he may have the rowels removed, or use spurs with the ends smooth and rounded. It is a bad plan to use blank rowels -in the form of a shilling for instance; for they are apt to cut a horse's sides more severely than pointed ones. Spurs with short necks, which are less. liable to touch a horse than those with ordinary long ones, are not fashionable; although they are certainly more workmanlike, unless the rider has extremely long legs in comparison to the depth of the horse at the girths.

With regard to gloves, the choice lies between brown leather and white woollen ones. In either case, they should be sufficiently large to give perfect freedom to the hands and fingers. With this object, leather ones should be at least two sizes larger than those worn for dismounted use. Tight gloves not only impede the hands in manipulating the reins, but they also make the hands cold. Thick or thin gloves are a matter of fancy. Personally, I like them thin; because with gloves of this kind, I can feel the reins much better than with thick ones. Woollen gloves are particularly applicable for use in wet weather; for when the reins are damp, they give a far better grip than leather ones, and keep the hands much warmer. Wool is a far worse conductor of heat than leather, and besides, the woollen material of gloves holds within its interstices a large quantity of air, the heat-conductivity of which is only half that of wool. When using leather gloves, it is a convenient plan to carry a pair of woollen ones between the sweat-flap and the girths on the near side, in case of rain.

\section{HUNTING MUFTI (RAT-CATCHER).}

A man should appear in the hunting field, either in correct 
hunting dress or in ordinary riding clothes, which some call "mufti;" but which is usually termed "rat-catcher" by hunting men. A mixture of the two is generally regarded as an exhibition of bad taste which should not be inflicted on our companions of the chase. As a meet is a social function, those who attend it should, as a rule, turn out in as good style as they can, from motives of courtesy, as well as from those of self-respect. Rat-catcher is

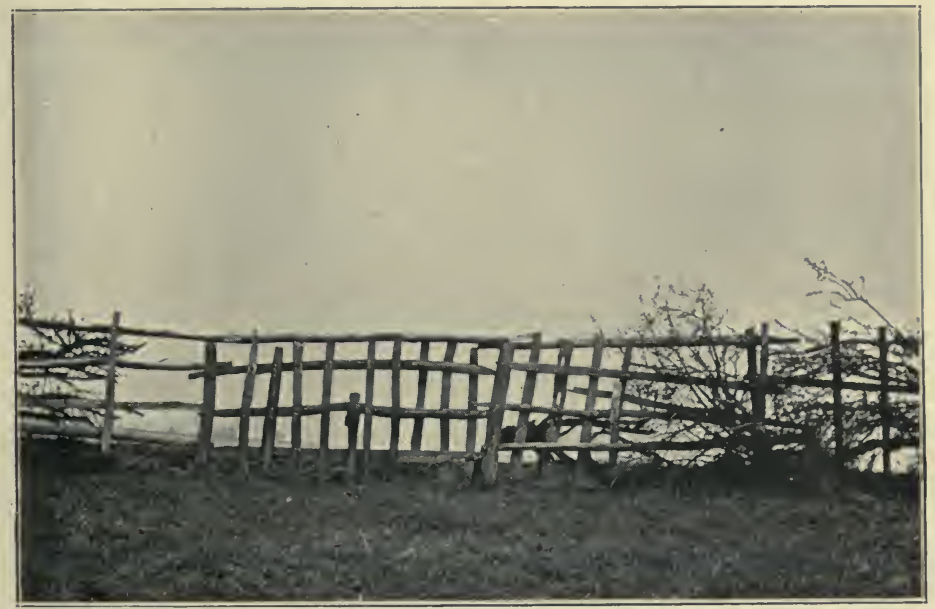

Fig. 233. Posts and rails; about 3 ft. 9 in. high.

occasionally allowable, when one intends to do more looking on than riding, as for instance, when showing hounds to a young horse, and is used out cubbing, and until fixtures are advertised. Correct rat-catcher consists of a coat of the shooting or round shape; bowler hat (stiff felt for choice); tweed or brown cord breeches; and butcher boots, either of brown leather or black leather, or leggings. As a black coat demands a high hat, it should not be worn with a rat-catcher get-up. A hunting tie and a hat-guard are always allowable. Black butcher boots are more generally worn with mufti, than brown leather ones, which are the 
recognised kind of boots for polo. Leggings are as appropriate as boots, except that the latter look much better than the former, when spurs are worn.

\section{RIDING GEAR.}

Hunting custom ordains the use of a plain-flap saddle, double bridle and breast plate, and sanctions that of a noseband (a caveson one for choice), and a leather saddle cloth. A numdah is not considered, smart. Martingales are not very often used. Out hunting, a martingale, and especially a standing one, is not an unmixed blessing, because it is liable to catch in a gate which is being opened, and its presence would then be apt to cause an accident. Fashion requires a hunting whip with thong and lash to be carried. On page 212, I have alluded to hunting whips.

\section{BANDAGES AND BOOTS.}

The danger of a horse over-reaching on his back tendons, when he lands over a fence on soft ground, is so serious, that it might be provided against, although it does not occur very frequently. As a means of its prevention, I greatly prefer specially made boots to bandages; because they afford much better protection, and are not liable, like bandages, to trip up the horse by becoming undone. The boots may be made of black leather, and lined with woollen cloth. They would often save a horse's legs from being cut by wire.

\section{SOME HUNTING EXPRESSIONS.}

In Chapters XIV., XV. and XVI., several hunting expressions are explained in course of description or by the context. A few of those which remain will now be dealt with.

"The Shires" is a term which, though frequently used, has not, as far as I can learn, received an authoritative defini- 
tion. Hunting men of the Midlands apply it as a rule to the districts hunted by the Quorn, Belvoir, Cottesmore, Mr. Fernie's and the Pytchley; and not to particular counties. Thus, although Lord Harrington's hounds hunt in Nottinghamshire, a portion of which county is in the Quorn district, they are regarded as a provincial pack. Again, the Blankney is not in the Shires; although several of the meets of the Belvoir are in Lincolnshire, which furnishes a portion of the Blankney territory; the remainder being in Notts.

"The Provinces" include all districts not in the Shires.

"High Leicestershire" is the high and hilly country from Keythorpe to Owston, Jaunde, Wardley and Allexton.

In England, calling fox-hounds "dogs," except when making a sexual distinction, is regarded as a proof of gross ignorance of hunting. In Ireland, uneducated hunting men are not very particular on this point of hound language. Also, they often make the mistake of using the plural instead of the singular, when speaking of the Meath, Kildare, etc. Incorrect terms are current in all countries. In Leicestershire and in the South of Ireland, a dyke means a ditch, although English dictionaries tell us that it is a stone-wall fence. The word is correctly used in Scotland.

The late Duke of Beaufort wrote against the use of the abreviated form of "whipper-in," and said that a whip is a thing one carries in one's hand, and not a mounted servant. I think this ruling applies only to formal speech or serious writing. In fact, a friend tells me that the last time the late Duke spoke to him, his Grace used the word "whip" while speaking about one of the hunt servants! The employment of this monosyllable in casual conversation is certainly not regarded as a breach of decorum by even the best class of hunting men. Some veterinary surgeons object to the term "vet."; but no lieutenant in the Army would mind being called a "sub." 


\section{CHAPTER XV.}

\section{THE SHIRES AND THEIR FENCES.}

FOR pleasant riding we require light "going," which we obtain best on turf; and for good hunting we need an enclosed country, fairly stiff fences, and a sufficiency of coverts and woods, which should not be too large. Although grass is the ideal material for galloping on, we must not forget that the light plough which almost entirely replaces pasture in Essex, rides light and holds scent admirably. Hounds of the modern type are more apt to run away from horses in an open country, than among fences, which stop hounds more than hunters, supposing that the obstacles are jumpable. Captain King-King reminds me that " in down countries there are no fences, and a fox is viewed away from gorse coverts; but he is soon out of sight. I consider the pace of a fox and that of a hound to be about equal ; the former for choice. I have never known a fox, unless a cripple or heavy vixen, absolutely coursed down; though I have seen plenty which have been found on moorland, get a start of only a few yards. Of course I am not counting foxes which are chopped. It is marvellous how a fox can break view on an open plain, and bring the hounds to their noses. We may see him going on, but they can't. The slightest inequality of ground is enough for him. In I863, I saw an hour and twenty minutes with the Vine, and a kill in the open, with not one fence. All this was over downs. On Exmoor and Dartmoor there are practically no fences, but no countries hold better or keener 
foxhunters." Although fences can be dispensed with in foxhunting, they are an immense advantage from a riding point of view, on account of reducing the pace, providing variety which is always charming, and giving one an opportunity of pounding one's best friends. Besides, any fence that hides a fox will help him. A bad fox runs under cover of the fences; a bold one crosses the middle of the fields for, say, thirty minutes sharp, and then, when hounds run up one fence

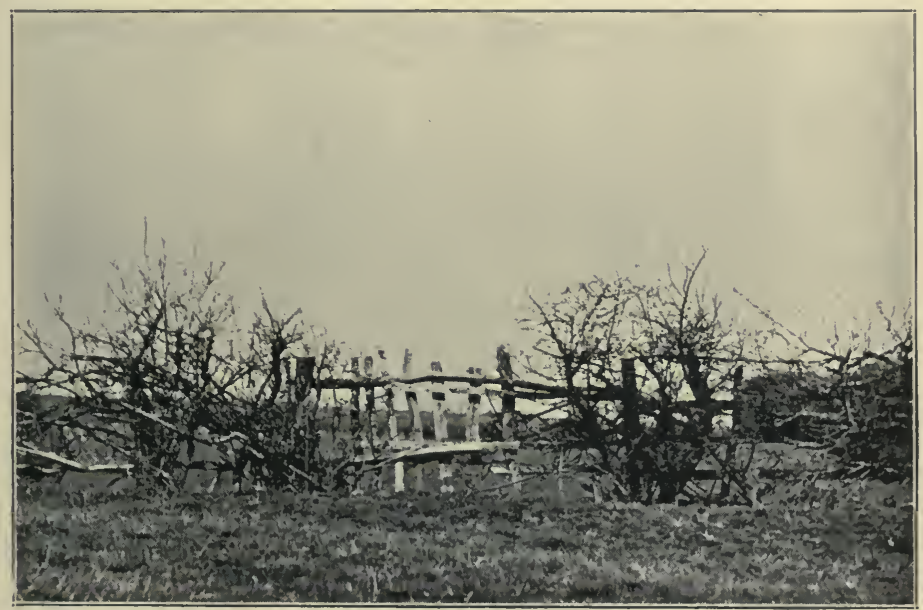

Fig. 234. Posts and rails.

and down another, we may be certain that he is beaten or is looking for a hole. Although foxes may sprint as well as hounds, they do not stay as well. Hence, for good runs it is necessary that hounds should hunt as much as possible by scent and not by view. Hounds when going straight, can always beat horses.

Fences to a great extent are the product of stock farming. On arable ground they are needed chiefly to mark out boundaries, and for this purpose they may be of the flimsiest nature. In a dairy farming country, like Cheshire, they will 
have to be sufficiently stiff to keep in the placid tempered cows, which do not require very formidable means of restraint. For horses and bullocks, which with sheep are the great support of the farmers of the Midlands, far bigger and stiffer obstacles have to be constructed, in order to keep them in bounds. Bullocks become particularly frisky, when they get into condition, and are formented by flies. Also, beasts with horns (Shorthorns, Herefords, and Welsh for instance), take pleasure in destroying fences with these weapons. Polled cattle are seldom seen in the Midlands. Consequently, the fences in the Shires are admirable tests for the respective jumping and riding capabilities of horse and man. Figs. 218 and 22 I give a general idea of the nature of the country in the Midlands.

Woodland foxes as a rule give better runs than gorse covert foxes; probably because the former have more time to mature their plans, and may steal away from a wood; but the latter are always viewed away from a gorse and are holloaed at.

Increase of pasture, improved ideas among farmers as to the advisability of preserving purity of breed in their sheep, and the necessity, in these bad times, of preventing loss of "keep" by trespass, are the chief causes of the fences in the Shires being much more formidable nowadays than formerly.

The presence of ridge-and-furrow (p. 356) proves that the Midlands were once (many years ago) arable land. I learn from Captain King-King that "the late Admiral Meynell told me that in the beginning of his father's mastership of the Quorn (I 753 to I 800), there were practically no fences between Six Hills (about six miles north of the Quorn Kennels) and Nottingham. The chief obstacles must then have been brooks and bottoms. When the thorn fence was first planted, it required a double post and rail to protect it, as the comparatively new fence in Scraptoft big field has now. When the 
fence grew up, it no longer needed the rails, which rotted away in time, and it developed into the bullfinch (bull-fence)."

Whyte-Melville also tells us, "boundary fences of property were few and far between, straggling also, and ill-made-up; the high thorn hedges that now call forth so much bold and so much timid riding, either did not exist, or were of such tender growth as required protection by a low rail on each side, and a sportsman, with flying coat-tails, doubling these obstacles

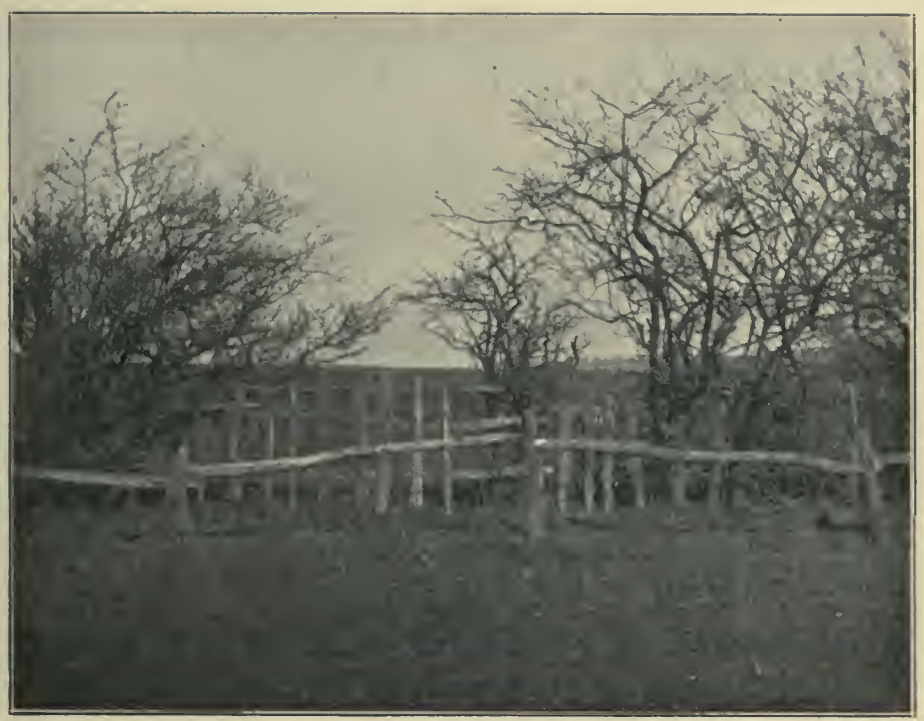

Fig. 235. Double posts and rails: rails about $3 \mathrm{ft}$. $6 \mathrm{in}$. high; and about Io ft. apart.

neatly, at his own pace, forms a favourite object for the artist of the time." The remarkable change in the stiffness of the fences was undoubtedly due to the general adoption of the cut-and-laid fence, which, from its deceptive character and unchanceable nature, is a great stumbling block to Irish hunters for the first few times; for it is an unknown quantity in the Emerald Isle.

The cut-and-laid (Figs. 222, 223 and 224), which is often 
wrongly called a stake-and-bound, is made out of a hawthorn hedge, by lopping off the superfluous branches and twigs; cutting about half through the lower part of the stems (trunks) of the bushes, so as to enable them to be readily bent; arranging them at an angle of about $45^{\circ}$ to the ground, and twisting-in the branches and upper portion of the stems, so as to form an almost impenetrable obstacle of a height, usually, from $3 \mathrm{I} / 2 \mathrm{ft}$. to $5 \mathrm{ft}$. The construction of these fences costs money, and requires skill which is not possessed by every farm labourer. This useful art is more highly cultivated in Leicestershire than in any other county, and is put into practice throughout the Midlands by local authorities for keeping down the height and adding to the strength of the whitethorn hedges by the roadside. In time, the severed branches of a cut-and-laid begin to throw out shoots and leaves, so that the once trim fence sometimes assumes a dilapidated appearance (Fig. 224). As the vast majority of the fences in the Shires are of hawthorn, the cut-and-laid, in more or less perfect repair, is the typical jump of that part of the world.

When a hawthorn hedge, instead of being lowered, trimmed, and twisted upon itself in orthodox cut-and-laid style, is allowed to grow wild, it assumes the type of the bullfinch, which, when practicable, can be crashed through (with an arm over the eyes, and the head lowered), but not jumped, in the ordinary sense of the term.

The increasing care which has been devoted during late years to thorn fences in Leicestershire, has considerably reduced the number of bullifinches in that county. Long ago, thrusters were often described as charging dense bullfinches which, after yielding them a passage, closed again so tightly that the brave men disappeared completely from view. Fig. 225 shows a practicable bullfinch which is quite stiff enough for ordinary people. 
When a thick hedge is merely lowered, parallel to the ground, it is generally called a topped hedge (Fig. 226).

By being lowered and trimmed, hedges present an endless variety of form (Figs. 227, 228 and 229).

The term "oxer" is applied to a hedge (usually young or cut down), which is protected from the assaults of cattle by a guard rail on one (Fig. 230) or both sides. A "single oxer" has generally a ditch on one side, and on the other side a rail,

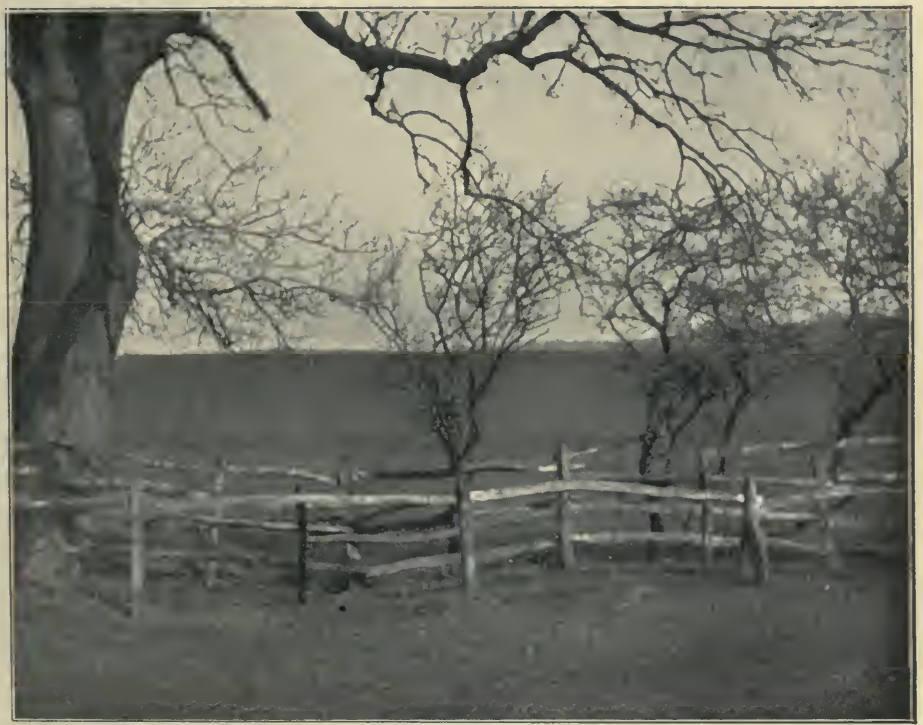

Fig. 236. Double posts and rails.

which is sometimes replaced by a wire, that is supposed to be taken down at the end of October. A "double oxer" (Fig. 23I) requires a horse to jump big and spread himself out, when going freely. Oxers are not often met with, probably on account of the increasing popularity and strength of cut-and-laid hedges ; and because wire is sometimes used to protect hedges, especially in summer.

Posts and rails (Figs. 232, 233 and 234), though less frequent 
than hedges in the Shires, are a very important factor in hunting at headquarters; for they brook no trifling. A double posts and rails (Figs. 235 and 236) takes a good deal of doing. Sometimes it may be jumped as an in-and-out (generally obliquely), provided one's horse is very temperate. A bold hunter who can "throw a big lep" would probably prefer to do it " in once." High railway posts and rails (Fig. 237) have been jumped; but not often.

Stone walls (Fig. 238) are seldom met with in the Shires.

A steady and clever horse is required for the safe negociation of a Midland wooden stile (Fig. 239).

In Leicestershire, where almost all the gates (Fig. 240), readily open, the rule is to go through them, not over them.

As the hunting parts of the Midlands are chiefly of clay, which absorbs water slowly, and as the surface of the ground is generally of an undulating character, most of the rain which falls on the grass fields, quickly finds its way to fences at a lower level, in which effort it is aided by the frequently occurring ridge-and-furrow; and consequently the large majority of hedges in the Shires have a ditch (Fig. 24I) either on the taking off or landing side, according to the direction the horse is going. This addition to the obstacles makes it necessary for a good Leicestershire hunter to be able to "spread himself out" over a fence; for if he cannot do so, he will be certain before he has gone far, to drop his hind feet into the ditch or against the rail on the other side of some leap or the other. As typical Leicestershire hunters of high class, I may point to the grey horses in the Frontispiece and Fig. 87.

Ridge-and-furrow (Figs. 208 and 242), was an old-time method of draining arable clay land, by which system drains were made, say, from 8 to I 2 yards apart, and the earth was heaped up towards a ridge between them by "ploughing 
against the hill." Ridge-and-furrow ploughing was applied not only to hilly land, but also to level ground which was more or less water-logged, so as to drain the ridges. Although this kind of drainage has gone out of use in the Midlands many years ago, when plough gave way to pasture, ridge-and-furrow still remains strongly in evidence, especially in Leicestershire. The difference between the top of the ridges and the bottom of their respective furrows, varies from

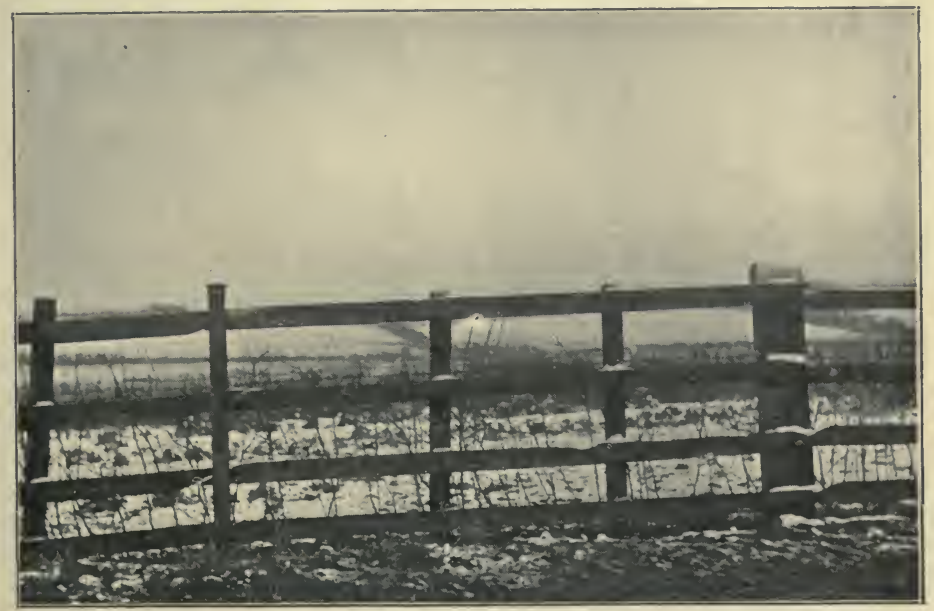

Fig. 237. Railway posts and rails; about 5 ft. 4 in. high.

about eighteen inches to three feet six. It appears that in the time of the Commonwealth, Leicestershire was all plough.

There is a great difference in the ability of horses to cross ridge-and-furrow. Some, usually the short legged, compact sort, quickly learn to glide over it with the facility of a fox; and others insist on jumping each furrow, instead, as they ought to do, taking the furrows in their stride, which they should regulate for this purpose. Galloping across ridgeand-furrow greatly tries the forelegs and shoulders of horses that are heavy in front. 
In Leicestershire there is a fair sprinkling of brooks, the most notable being the Whissendine, Twyford, Scalford, Smite, Marefield, Manton, Norton, Staunton and South Croxton brooks ; and there are innumerable "bottoms," which are narrow brooks with a fence on one side. When the fence is on the taking-off side, the jumping of a bottom demands, more than any other fence, that a horse should take his rider's word that there is something on the other side.

The Midland fences, as we have seen, are essentially hedges, timber, and water; and there is an almost entire absence of banks and walls, which are respectively the chief obstacles in several provincial counties. 


\section{H A P T E R X VI.}

\section{WITH HOUNDS.}

THE distance which we can hunt from home varies according to our means of communication. With the railway, all things are possible in this respect. If we have to ride to a meet on a horse we intend to steer in the wake of foxhounds, we may accept ten miles as an ordinary maximum length for this preliminary journey, which might in exceptional cases be extended to another four miles, provided that the road was level and good, and that the rider took his horse quietly, and arrived early enough at the meet to get off his horse's back for a quarter of an hour or twenty minutes. Even at ten miles from home, our animal would probably have to travel on a good day from 35 to 40 miles, which would be quite far enough, considering the variety of country he would have to traverse. If our horse is to be led to the meet, and we can drive out or ride on a covert hack, a couple of miles may be added to the limit in question. With staghounds, Captain King-King thinks that 16 miles is not too far, if we give ourselves plenty of time. With the stag, we know when we'll begin. In all cases of road work, when riding to a meet, or returning from hunting, we should do as little cantering or galloping as practicable, and should take advantage of every soft bit of "going" we can find on the side, and thus save our mount from the "'ammer, 'ammer on the 'ard 'igh road," which is a prolific cause of round joints, splints, hot feet and other forms of unsoundness.

The orthodox "hounds' pace," when taking hounds to the 
meet and home, is six miles an hour. As a rule, the slower a huntsman is in chase, the faster he goes from covert to covert. Hunters without hounds usually travel at a steady pace of about seven miles an hour.

Many men like to drive to a meet, instead of riding, so that they may arrive at it without even a speck of dust on their clothes, for the furtherance of which object they will generally wear a large handkerchief or piece of silk or cotton cloth, as an apron over their legs while they are in the trap, in order to prevent any of the pipeclay or dressing of the breeches from soiling the coat. No amount of "clean dirt" which has been acquired with hounds will count.

Although the custom may be old-fashioned, a stranger commits no solecism in taking off his hat to the Master, as a respectful salutation to the Commanding Officer of the field day.

Masters have so much to try their tempers, and need such implicit obedience in order to carry out their work properly, that the etiquette of the hunting field ordains that any member to whom the Master may address strong "language" must receive it without reply. If he wishes to show that he resents the rebuke or abuse, as the case may be, he may go home and not come out again with that particular pack, by doing which he might commit the folly of metaphorically cutting off his nose to spite his face, especially if he had paid his subscription. The knowledge that his censure must be received in silence, ought to make a Master trebly careful not to unnecessarily wound the feelings of those under his command. His position is more autocratic than that of a colonel at the head of a regiment; for a Master is practically at the top end of the chain of hunting responsibility, and in hardly any case would brook a reproof from his committee, even supposing the pack was a subscription one. If a member of the field will not obey the Master, the rebel or the hounds 
must go home. It is evident that a Master, to be good at his work, requires not only infinite tact, but also the rare gift of being able to command men.

When hunting in England, a stranger will do well never to speak to any member of the field, except when spoken to. If he be well dressed, well mounted, and well behaved, the natives will soon find out all about him; and, if he be eligible, according to their ideas, will receive him into their sporting circle.

In going from the meet to the covert at which the first draw

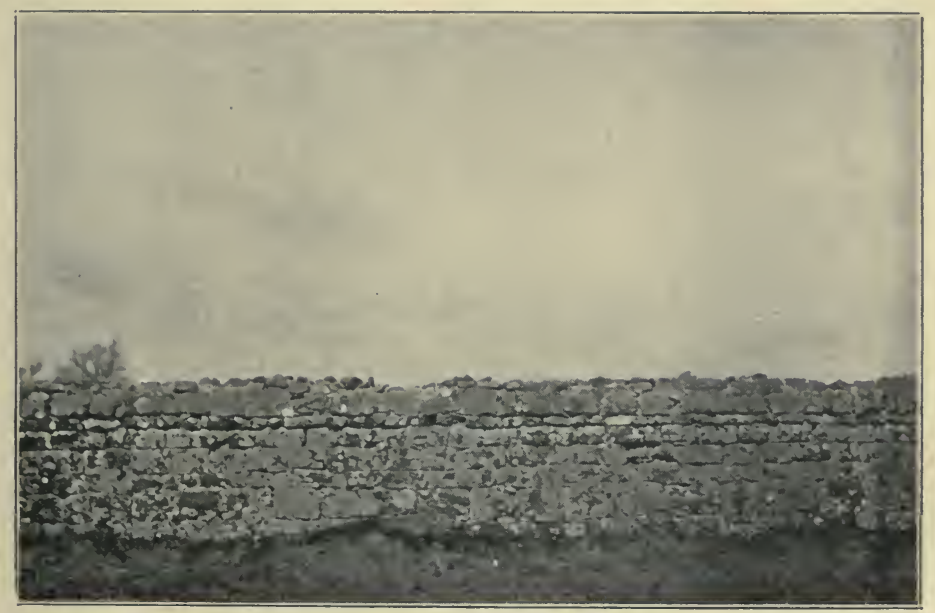

Fig. 238. Stone wall ; 4 ft. 6 in. high.

is to take place, and in riding from covert to covert, we should take care not to press on hounds or horses.

Success in drawing a covert occupied by a good fox, greatly depends on the field being prevented from thwarting the labours of the huntsman and hounds. Hence, in all well organised hunts, the Master selects, as far as practicable, a position, generally to windward of the covert, for the field to occupy, while the covert is being drawn, and the field is not 
supposed to go away before the hounds. The huntsman's duty is to attend to his pack, and he should never depart without an unmistakable "Forrard away" blow of his horn, which is the signal to start, unless the Master exercises his authority by requesting the field to "give them half a minute, Gentlemen." After that, it is a case of catch them who can. This parade business with the field can be best performed at the first covert; for the field is then more in hand than subsequently. In getting the battalion to take close column, the Commanding Officer of a large hunt would do well, if possible, to follow Lord Lonsdale's example when he hunted the Quorn, in having four or five hunt servants specially told off to keep the field in bounds; but few Masters have such a large staff as the late Master of the Quorn had. After the first run, the field will probably be more scattered, in which case they should more than ever remember the necessity of keeping motionless and silent, so that they may not prevent the fox from breaking, or make him turn back, in the event of his leaving the covert. No practice is better calculated to spoil sport than the detestable one of starting a field by a holloa, which any blunderer, whether on foot or on horseback, might use. After the huntsman has sounded the joyfully expected notes, a few holloas to let all the field know that the pack is away, and to cheer the hounds, may be useful. In most cases, the whipper-in who views the fox away, holloas; but sometimes he can mutely signal to the huntsman.

The danger of giving a holloa at the wrong time is so great, that it is best to abstain from this form of vocal exercise, which the Master of a well organised hunt might not improbably resent as an impertinence. The fact remains, that the higher the class of a hunt is, the fewer unofficial holloas are to be heard in it. It is a popular idea that if one sees a fox going away unnoticed, either breaking covert or when the hounds 
are at fault, one's duty is to call out two or three times, "tally ho!", so as to attract the attention of the huntsman; and to shout "tally ho back!", if Reynard leaves the covert, changes his mind and returns to it. Here, the holloa may be given when the fox is too far off, in which case the hounds might not be able to take up the line properly. If the holloa is given too close, it may have the effect of sending the fox back into the covert, and spoiling what might have otherwise been a good run. Besides, there is often more than one fox

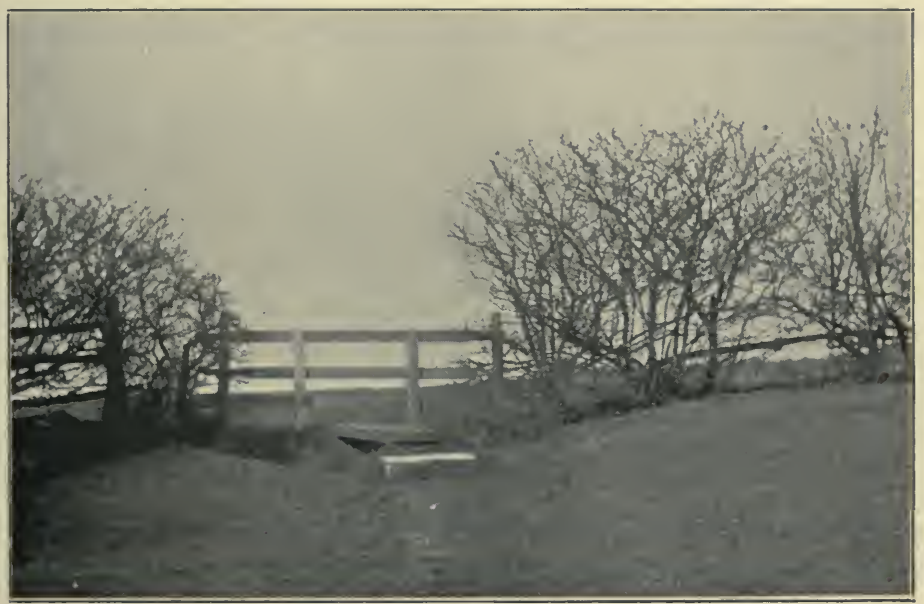

Fig. 239. Midland stile.

in a covert, and the viewed one may not be the fox which the huntsman wants to pursue. Further, the viewed fox may be going in the wrong direction, for instance, away from the kennels, at the end of a long day, and especially when the hounds are far from home. If, on viewing a fox, we have good reason to think that a judicious holloa would be helpful to the huntsman, we might, if practicable, ride up to him, or to one of the whippers-in and tell him what we saw, or hold up our hat. 
A friend tells me that a certain Irish hunt used to put on their card of fixtures," "Gentlemen are requested not to call to the hounds"! In the Midlands with a proper staff, no fox goes away unnoticed. If we holloa "Tally ho back," we shall get the credit of having headed the fox. Some people have a special aptitude for this performance.

In starting for a run, we should be careful not to interfere with the Master or any of the hunt servants, and to make way for them on every occasion. A man who knows the country and the ways of foxes, will generally be able to form a good idea of the direction in which the fox is going, and can accordingly ride with great economy of horse-power and fences. Hence we often find that old hunting men, even when they are badly mounted and have lost their liking for big leps, will see more of a run and be nearer the death, than many of the hard riding brigade who steer horses which are fit to win over a country. A man who would attempt to go absolutely straight in the Shires, would encounter many obstacles which no horse could get over without a bad accident; but even in fences which are thus fortified, there is generally a weak place or two which can be negotiated without danger, but which is not always apparent to uninstructed eyes. Besides, as I have already indicated, it is essential, in order to cross a country well, that a man should be able to judge at a glance, if his horse is able to clear any particular place. I think I may safely say that Tom Firr, Frank Gillard and Gillson knew every fence in respectively, the Quorn, Belvoir. and Cottesmore countries. This marvellous gift of knowing a country is not possessed by all brilliant performers, some of whom never know where they are. Captain King-King tells me that on one occasion when the fox went to ground, Captain "Doggie" Smith, who in his time was the best man over Leicestershire, jumped into a field in front of the house in which he was staying, and asked where he was! The 
lady-novelist idea of men riding habitually in a bee line over Leicestershire, Northamptonshire or Warwickshire, is absurd, a good proof of which is afforded by the fact that the jumping of an ordinary five barred gate in these districts is an extremely rare occurrence. There are of course many hunters which could accomplish such a feat, if they were fresh; but no sensible man would fatigue his animal in this manner, when he could far more easily open the gate. The necessity of a Leicestershire hunter being steady at opening gates, is a

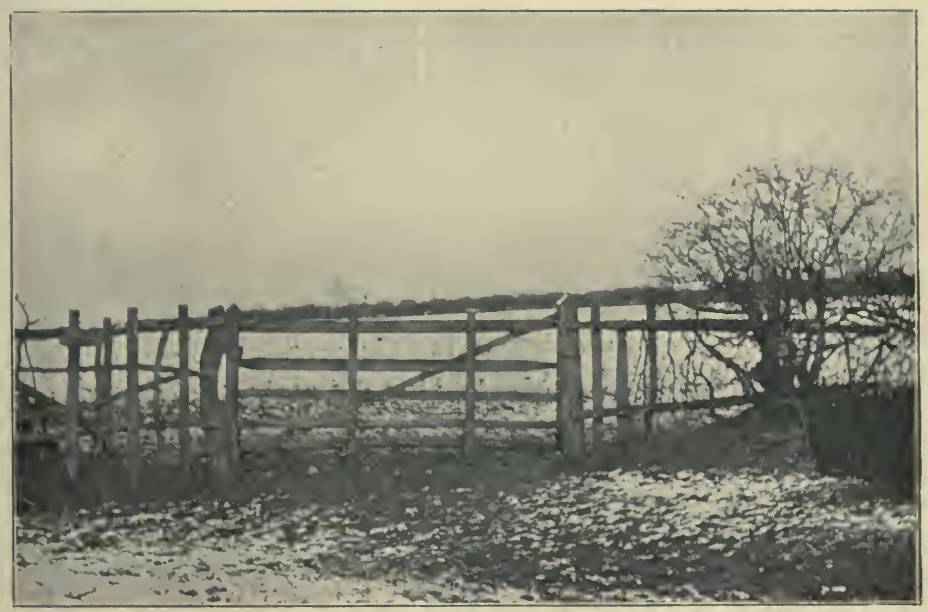

Fig. 240. Gate.

valid reason for not trying him over them. The true principles of hunting enact that a man should save his horse as far as practicable, without undue loss of position. Riding straight is necessary in steeplechasing, where the length of the course is known beforehand, and the sport is a riding contest; but in hunting we never know how long the run is going to last ; there may be another run ; and the journey home remains to be accomplished. To keep his place in the first flight, a man must not only know the country, and if possible its fences, 
but must also be a fine judge of pace and ground, so that he may go through a run with the least expenditure of his horse's strength and wind. In doing all this, he should carefully avoid riding over winter wheat, clover, roots, and other crops.

We may divide hunting men, according to the way they ride after hounds, into four classes, namely: the first flight, who take their own initiative, and who comprise about onetwelfth of a Leicestershire field; the second flight, who, if they are wise, will use their brethren in front as a line of skirmishers to show them the weak places in the enerny's fortifications; the men who almost entirely dispense with fences as short cuts, but who, by riding to points and utilising bridle paths and gates, generally manage to see a large portion of the fun; and the Macadamisers, who stick to the roads. Among these varieties of horsemen, the second flight men are the most likely to accept advice, which certainly should not take the form of recommending a novice to select a pilot out of the front rank; for if he gives him plenty of room, he will probably lose him, and if he keeps close to him, he will be likely to jump on him, in the event of the man in front coming down. Besides, the galloping capabilities of their horses may be very unequal, and the strain of keeping our man always in view will not be pleasant. In a country which is fairly free from woodland, the best plan is to keep a look-out as far as practicable in front of us, so that we may see, if possible, what hounds are doing, and may thereby be able to cut off corners. In this way, we may be able to obtain the great advantage of seeing how to get out of a field, before jumping into it.

Nothing betrays the ignorance of a rider more surely or with greater publicity than the fact of his riding his horse to a standstill, or until the unfortunate animal falls down from exhaustion; for any person with even a slight knowledge of horses will be able to tell when his animal has had enough. 
I need not dilate on the enormity of enjoying sport on a suffering horse. Whyte-Melville tells us that "there is a right way and a wrong of traversing every acre of ground that lies between them. On the grass, we must avoid crossing high ridge-and-furrow in a direct line; rather let us take it obliquely, or, if the field be not too large, go all the way round by the head-land. For an unaccustomed horse there is nothing

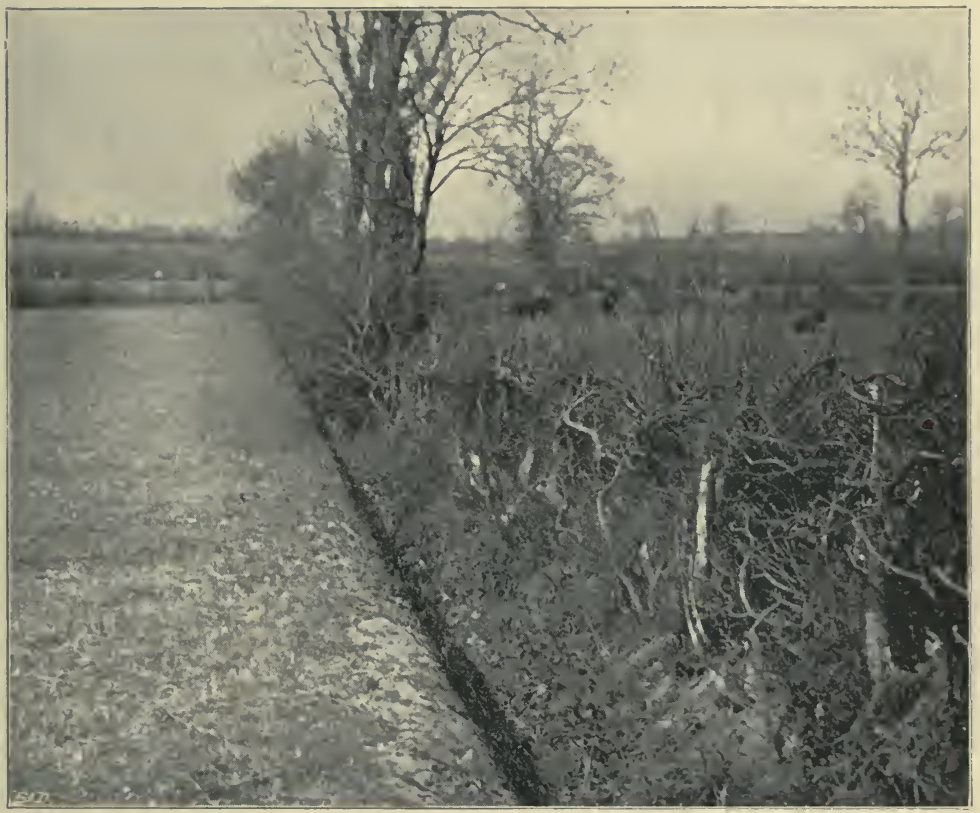

Fig, 24r. Hedge with ditch on one side.

so trying as these up-and-down efforts, that resemble the lurches of a boat in a heavy sea. A very true-shaped animal will learn to glide smoothly over them after a season or two, but these inequalities of surface must always be a tax on wind and muscular powers at best." My experience is that a clever and well-broken horse, even if he is only a fouryear-old, will learn to galiop over ridge-and-furrow properly, 
in a few lessons. I have certainly found that going out of the way to avoid crossing ridge-and-furrow more or less at right angles, entails too much loss of ground to be usually adopted. An unaccustomed horse may often be saved from a shaking by changing the canter or gallop into a trot. Following the head-land is generally advisable, when the centre of the field is heavy; and always, when it is under cultivation.

During the intervals between spells of active movement, a rider, especially if he is a heavy weight, will greatly economise the staying powers of his mount, by getting off him, as often as he can do, without incurring the risk of being left behind. He will also be greatly aided in the same object, by letting the horse drink a few go-downs of water at any convenient stream or other suitable watering place, when the animal is thirsty, and especially when he is hot. I have fully discussed in Stable Management and Exercise, the rationale of this procedure, which is opposed to English practice.

As a gate in the Shires will generally slam-to, if it is held open and then let go; we should, when passing through one, and especially when the hounds are running, be most careful not to let go the gate, if some one else, at a reasonable distance off, is coming up. Neglect of this act of civility is regarded as a gross breach of hunting etiquette. If there is a third party coming up, the new comer will have to hold the gate for him, and so on. If a man opens a gate by himself or is the last person to go through it, he should be careful to perform the important duty of shutting it; because omission to do so is liable to entail the disastrous result of letting stock loose over the country, and consequently of exciting farmers to oppose hunting. Pulling up during a run and getting off to help a person who has had a bad fall, or catching a loose horse for a "field officer," are acts of generosity which are beyond the limits of conventional politeness. 
In the Shires, there is so often only one practicable place in stiff fences which form a boundary of large fields, that a person who attempts the comparatively easy spot and fails, is supposed to give way to the next comer who is desirous of trying his luck. The fact of there being other loop-holes of deliverance would of course modify matters. In some provincial countries, in which the fences are not as big as those of

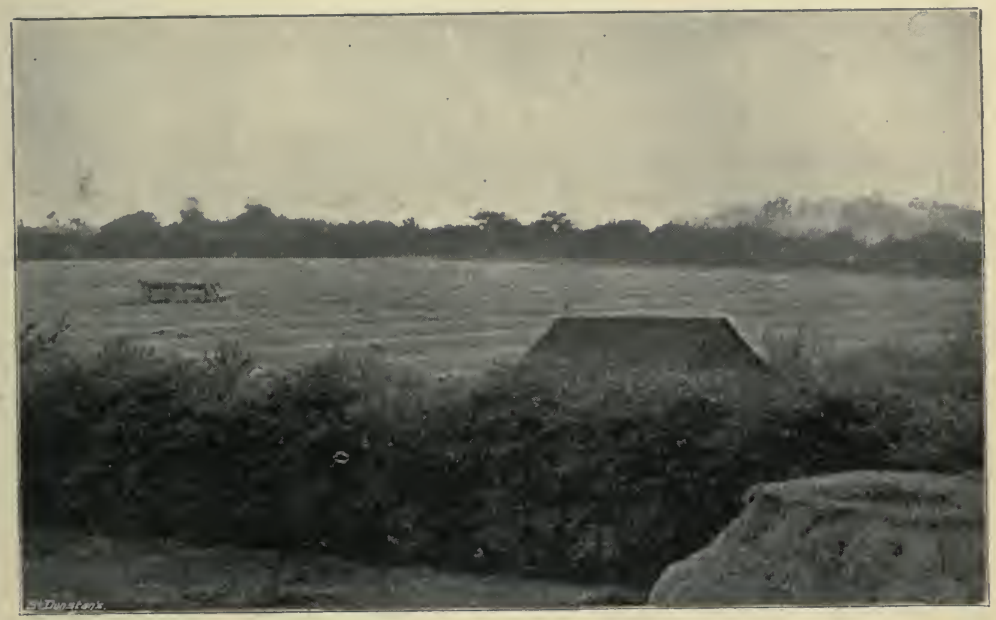

Fig. $2+2$. Ridge and furrow.

Leicestershire, anyone who can secure a position in front of an easy place, is supposed to have taken a lease of it.

The practice of pulling down fences and cutting wire on other people's land without lawful permission, is an unjustifiable offence against property which no honourable man would commit, unless he was determined to subsequently give full reparation and apology. Yet there are men who commit such acts, say nothing about them, and leave the opprobium they excite to fall on the Master.

Larking over jumps is another practice which is a source of great offence to farmers, and gives rise to many a sneer 
by hunting onlookers, who naturally view with disfavour this form of "showing off." During a run, and when trying to regain our place with the field after having been thrown out, are the only times that jumping is permissible. In order to still further aroid doing wanton injury, we should resist the enticing temptation of having a gallop in a field when going by a bridle path, as for instance, from covert to covert.

Although the crime of over-riding hounds or otherwise interfering with them may be easily committed by any misguided individual when the pack is running slow, the boldest and best mounted thruster will have little chance of being guilty of it in a "big" country, with fast hounds which have been given a good start after a flying fox with a scent. Similarly, the classic advice that during a run, one should ride to one side of the pack, instead of close behind it, which would of course make the hounds think more of their own safety than of the fox, is not of frequent application in the Shires. In those parts, one seldom has the opportunity of steering one's course by the direction of the wind; for keeping hounds in view will generally be difficult enough, without having to attend to the fact that foxes, other things being equal, prefer going down wind to travelling up wind. I am inclined to think that in Leicestershire, the position of coverts has a far greater influence on their route, than the particular quarter from which the breeze blows. A fox will not run up wind for longer than fifteen minutes at the outside, and it is then either "Who whoop to ground," or, if the refuge or drain is stopped or inaccessible, he will turn down wind and the pace will usually slacken. Few pursuers seem to think that hounds can become blown as well as horses. A ringing fox consults the ground he is running over, and not the wind, and does not mean to go far in any direction.

Captain King-King remarks that "the length and duration of a run, the colour and size of a fox when viewed, and the 
shortest way home, are things on which fox hunters never agree. It is generally admitted that the usual speed of foxhounds in a fast run, is about eight miles an hour from point to point. The quickest thing I ever saw was when the Ludlow hounds did a 6 miles point in 27 minutes, and beat the horses $1 / 2$ mile. Of course this run was nearly straight. No two opinions are alike in a discussion about the ground run over. Few men know the country they hunt in, and still fewer pay any heed to the direction in which they are going. The next fence is good enough for them to think of. A stag goes much straighter than a fox. In the season of I898-9 we ran a 15 miles point in South Bucks with the Queen's in I hour and 25 minutes, which was very fast.

"Owing to the drier condition of the ground as a result of increased draining, scent does not lie so well in Leicestershire as formerly, and its foxes by no means run such good points now as they did 20 years ago. Belvoir foxes on the Melton side are not generally straight runners; although I have known many good things with them : for instance, a run of ro miles from Coston Gorse and killed at the Wheat Hills near Little Dalby, and another of the same length, from Melton Spinney to Cossington Gorse. The flying thing of the season in the Melton District is almost always with the Belvoir. It is no good asking the Master or Huntsman what is the distance the hounds ran; because they will give too full measure.

"There is no rule about giving the brush, which may be offered to any deserving party, as for instance, a lady who has gone well, a distinguished stranger, or a promising boy. Some, myself among the number, prefer the head as a memento."

Baily's Hunting Directory gives an account of the Greatwood run (Badminton, I87I) which lasted three hours and a half, and was over a distance of twenty-eight miles as hounds ran, with a point of fourteen miles. 


\section{CHAPTER XVII.}

\section{RACE RIDING.}

General Remarks-The Jockey's Seat-Handling the Reins-Starting-Judging Pace-Different Ways of Riding a Race-Waiting-Using a Pace-makerMaking the Running-Waiting in Front-Keeping with One's Horses-General Remarks on Race Riding-Peculiarities of Horses-The Seat when FinishingTactics of Finishing-Riding Rogues-Riding Pullers-Orders-Use of the Spurs-Use of the Whip-Effect of Punishment on Horses.

\section{GENERAL REMARKS.}

IF a horse were a mere machine, a jockey's business would be the delightfully simple one of regulating his speed, so that he might gallop over the appointed course in the shortest possible space of time. Horses, however, will not bear being treated in this mechanical manner; for they have individual peculiarities and infirmities, which have to be studied by the rider who strives to be the first to catch the judge's eye. As riding, then, is not an exact science to which cut-and-dried rules can be applied ; I must content myself, in this chapter, with noting down a few hints and practical remarks which I trust will be useful to novices.

THE JOCKEY'S SEAT.

The correct seat of a jockey, so far from being a "sealed pattern" attitude, has to conform to varying conditions of horse, ground, and distance, which a capable jockey will be able to recognise, and will be ready to fulfil, as occasion may demand. Thus, from the way the animal is going and from the nature of the ground-according as it is up-hill 
down-hill, or level-he will know how he can adapt the position of his weight to the best advantage, by bringing it forward, by leaning back, or by keeping it evenly divided between the fore and hind quarters of the horse.

In Chapter III. I have discussed the subject of a jockey bringing his weight forward, as much as possible, in order to increase the speed of his mount. When he finds (as he will often do towards the end of a long race) that his horse, instead of going level, puts too much weight on his forehand, he should of course try to relieve the tired muscles of that part by bringing his weight back, and by taking a good hold of his horse's head. The necessity, in ordinary cases, of leaning well forward when going up a hill, and of leaning back when going down a descent, is evident. Through heavy ground, which is very rarely met with on flat racecourses, the weight of the jockey's body should be kept farther back than on ordinary turf; because the heavier the ground, the greater difficulty will the muscles of the fore limbs experience in raising the forehand at each stride.

For convenience of description we may consider the jockey's seat under three varieties, namely, (I) the ordinary or hunting seat, in which a man sits down in the saddle; (2) standing in the stirrups ; and (3) the "crouching seat." We have seen that any of these seats may be used, according as circumstances demand.

Standing in the stirrups is an old-fashioned term which I use in default of a better. This seat is assumed in order to enable the rider to conform to the movements of the horse in the best manner, while carrying the weight more forward than could be done when sitting down. In it, the body should be slightly bent forward, and should be free from stiffness. The seat should be somewhat raised from the saddle-not stuck out over the cantle-without any up-and-down motion. 
The knees should be very little bent, in fact only sufficient to give their joints some "play." The heels should be a trifle depressed, and the feet should be kept parallel to the sides of the horse, and should be placed well "home" in the stirrups. The legs and feet should be kept perfectly steady. The head should be held well up, the eyes looking straight between the horse's ears, the shoulders down, and not rounded, and the hands on each side of the withers, with a good steady hold on the reins, so that the horse may go well up to his bridle. The fingers, wrists, elbows and shoulders should be kept as loose and pliable as possible. As Tom Cannon kindly pointed out to me, the position should be such that the points of the shoulder, knee and toe should be very nearly in the same vertical line, and the whole attitude should be characterised by grace and ease. The balance of the body should be preserved by the grip of the legs, a light pressure of the feet on the stirrups, and the hold the rider has on the reins, while the knee-joints act as a spring to "give and take" to the motion of the horse, so that the weight may be carried smoothly forward at each. stride, and that there may not be the slightest jolting, or upand-down movement. By riding in this manner, the horse's muscles which are used in galloping, will act to the greatest advantage. The balance should be true and well maintained, so that in the event of a stumble, swerve, or any unexpected movement, the horseman may be ready to throw his shoulders back, grip the saddle with his knees, and "catch the horse by the head" in a moment.

I am well aware that many good English and Australian jockeys do not ride exactly as I have described; for instance, several turn their toes out and depress them. We should, however, remember that if a man who has a bad style rides well, he does so, either in spite of his faulty method, or would ride all the better were it improved, or because some physical peculiarity necessitates his adopting a style of his own. 
The harder a horse pulls, the tighter should the grip of the knees become. If the rider, when trying to hold his horse, presses on the stirrups without gripping with the knees, the stirrups and feet will move forward, and the rider's seat will be carried over the cantle, an attitude which will throw the weight back towards the loins, and will cause the body to bump up and down, on account of the arms being necessarily rigid. But, as the saddle cannot shift like the stirrups, a firm grip of the legs will enable the hands, arms and body to conform to the movements of the animal's head and neck, as he moves forward at each stride. The more the horse pulls, the closer should the elbows be brought to the sides; and to gain more power, the knuckles may be turned down and the palms of the hands up.

It would at present be premature to say whether or not the old English racing seat which I have described and its necessary length of stirrups, will be entirely discarded in flat race riding for the "crouching seat" and its short stirrups. In any case, "standing in the stirrups," will continue to be the usual seat for steeplechasing and other fast cross country. work, which require the rider not only to be able to bring his weight forward, but also to get well down in the saddle ; lean back; and use his legs to stimulate, collect, and guide his horse. On this subject, Fig. 213 preaches an eloquent and convincing sermon.

The so-called American "crouching seat" is merely a return to the style practised in the early part of the nineteenth century by many English jockeys, and especially by the famous Jem Robinson, who won the Derby six times during the years 1817-1836; and the Two Thousand, nine times. Fred Archer used to get very far forward on his horse's neck, when he was sending him along as fast as the animal could travel. George Fordham also "humped his back" a good deal. In this connection I may quote the utterance of an 
experienced Newmarket trainer, who, when the owner asked him to whom he should give a mount in a race for a good stake: "Oh, sir, put up Archer. He packs himself up so, that I believe he rides seven pounds lighter than his real weight." The owner did, and Archer won. Up to the arrival of Sloan, all our modern jockeys rode with their stirrup leathers at the usual length. To obtain full benefit from this seat in bringing the weight forward, the jockey has to shorten his stirrups, so that his knees will be about on a level with the withers of his mount (Fig. 243), by doing which he will necessarily deprive himself of the valuable assistance he can obtain from his legs in guiding, collecting and stimulating his horse, as I have tried to explain in Chapters X. and XI. The manner in which many of the crouching jockeys bump up and down in their saddles is a travesty of good horsemanship. The action of bending forward and lowering the head which is greatly practised by jockeys, naturally decreases the resistance of the body to the wind, which is an important factor in race riding except when there is a strong wind on the back of the horseman. We may gain a fair idea of the resistance of the air, by putting our head out of a railway train which is going, say, 36 miles an hour, which would be about equal to the speed at which a fairly good racehorse could cover a mile. A capable jockey will be able to tell by the way his horse is going, how he ought to distribute his weight, and prevent his body from offering an undue impediment to the wind. The saddle cannot be brought much more forward than its ordinary position.

\section{HANDLING THE REINS.}

The reins should be held crossed (as described in Chapter VI.) in both hands, and the whip should be kept, lash down, in the right or left hand, as the case may require. "Almost all jockeys put a knot (Fig. 244) a few inches from the end of 
their reins, in order to prevent the slack of the rein from flying about; the knot being made so that the buckle points down. The fashion for the last twenty-five years, or longer,

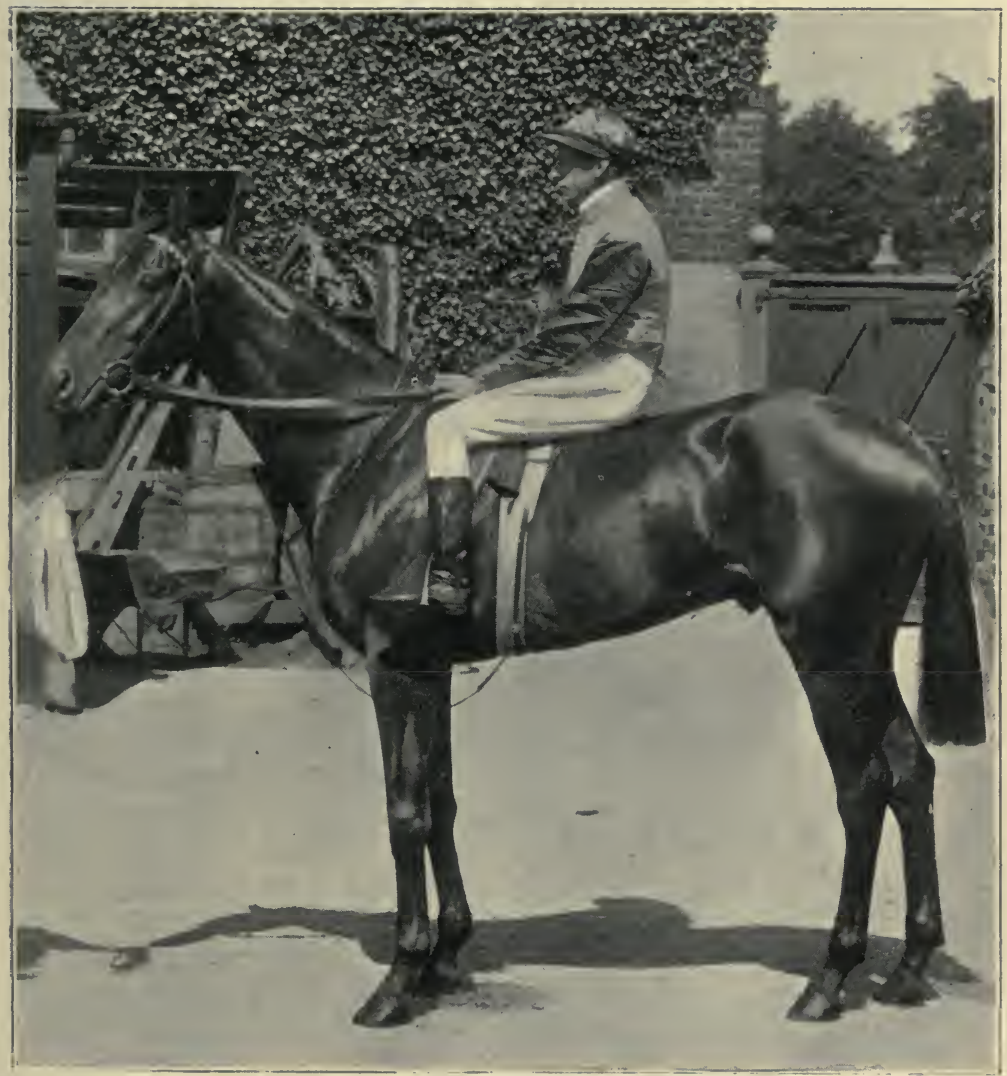

Photo. by」

[Clarence Hailey, Newmarket.

Fig. 243. J. H. Martin on Joe Chamberlain.

is to use a single rein on a snaffle, even with a martingale, in preference to double reins. John Osborne, who was second to none as a great jockey, and Edwin Martin, who won the Cambridgeshire on Bathilde, give me their opinion 
which is well worth having, that a jockey has much more command over a horse with two reins than with one.

A jockey should keep his hands "down," so that the horse may be able to carry his head and neck in the best possible manner for favouring the movement of his limbs and loins. I have nothing to add to the remarks I have made in Chapter $\mathrm{X}$. on the management of the reins.

\section{STARTING.}

Whether the orders are to wait, or to make the running, a jockey should employ every legitimate means to "get off" as quickly as he can; for whatever distance is lost at the start, must be made up when the horses are galloping, at which time the effort to regain the lost lengths may be equivalent to throwing away an advantage of as many pounds. We should remember that the faster horses are going, the greater is the effort required to make up lost ground. Although a horse may, when his field is going comparatively slow, decrease a gap of five or six lengths, with but a trifling expenditure of force; the task of making up such a distance in, say, half a mile, when they are racing against each other, may try his powers to the utmost. When walking up to the starter or facing the "gate," the jockey should sit down in the saddle with his seat well under him, so that he may not be jerked back on to the cantle, or pulled over the pommel of the saddle, in the event of the horse suddenly springing forward, or swinging his head down and stretching out his neck, as impetuous ones will sometimes do. He should keep his legs close to the horse's sides, so as to be able to press him up to the bridle, if required; should ride with sufficiently long reins to avoid the possibility of checking the horse when he is getting into his stride; and should be "off" with the drop of the flag. When coming up into line, he should keep his horse on the move as much as practicable; for an animal that is bending 
and prancing within reasonable limits, will generally gain a much better start than another which walks sluggishly into position. Besides, in order for a horse to quickly settle down into his stride, it is necessary for him to be well in hand at the moment of starting. The idea which was held by many English jockeys, that, no matter how good a start a man got, he ought to steady the horse, so as to "get him on his feet," arose most probably from their inability to collect a horse by their legs as well as by their hands.

Lads learn the tricks of starting - such as stopping a little

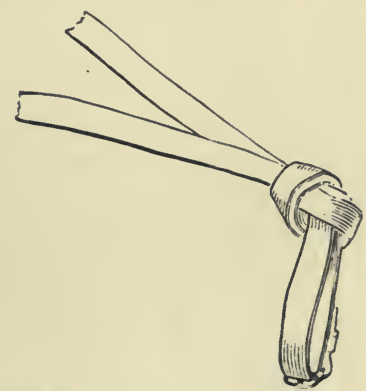

Fig. 244. Knot on end of rein.

behind and then coming into line at a canter, while the others are walking, on the chance of the starter letting them goquite soon enough, without it being necessary for me to allude to such practices, beyond saying that they do not "pay" with a starter who will not stand any nonsense.

In many cases the efforts of a jockey at the post are understood and assisted by his horse. For instance, the once celebrated Nutbush, who was well-nigh invincible at five furlongs, would never start, no matter what her jockey did, until the starter dropped his flag. Then she went into her bridle in an instant, and was nearly always clear of her field in the first hundred yards, thus adding an immense advantage to her magnificent turn of speed. 
The saying that a man will generally beat a boy when it comes to racing, is equally true when applied to starting.

"At the start, boys (for I allude to them-the light weights of the present day) are generally left at the post or get badly off, and ride their horses to a standstill before half the distance has been gone over in the vain hope of gaining their lost ground" (William Day). It often happens that in a big handicap, after two or three false starts, the light weights are "all over the place," and their horses are fretful and out of hand. When they return with difficulty to the starter, they are unable to get them quickly "on their legs," and they let them "go all abroad," with the certainty of running them to a standstill before they can take a pull; while one of the top weights, who on public form appears to have several pounds the worst of the handicap, gets off well in front with his horse cool and collected, and is not caught by the lightlypenalised ones, until their bad start, or misapplied efforts, have deprived them of the greater part of the advantage which they appeared to have on paper. After that, when it comes to a finish, what chance can a tired boy have against a strong, resolute man?

\section{JUDGING PACE.}

A jockey should not only have a firm seat, good hands, be thoroughly well up in all the tactics of race riding, and have courage and dash to carry them out as opportunity may offer ; but should also know at what pace his horse is going in comparison to that of the other runners, should be able to regulate his speed so that he may have the best possible chance of "getting home" successfully, and if required, should be able to select the exact spot from which he ought to make his effort at the finish. Constant practice and natural aptitude are necessary to enable one to acquire this valuable art. 
The rude awakening from their dream of self-satisfied superiority which English jockeys have lately had, is as good a proof of the fallacy of applying routine methods to a contest, as the results of certain battles fought in South Africa. Until Sloan made his presence felt, our jockeys as a rule copied each other, instead of studying horses, and became saturated with the idea that perfection in riding was to steady their horses after starting, to come with a rush at the finish, and win by a head on the post. Hence, inability to judge pace was the weak spot which American jockeys found in the armour of their English confrères, the vast majority of whom obtained no instruction in judging pace, except when riding races, in which case the casual lesson often comes too late. Old-time heat races were an admirable means of teaching jockeys this art; for the manner in which a horse went in a previous heat, would give his jockey valuable information as to the rate of speed he should adopt in the succeeding one. In training racehorses in England, the directions as to speed are generally of the vaguest description, and usually consist of the "steady canter" type, which might mean anything from a riding school "tit-up," to a gallop of nearly full speed. The fact that the distances of these gallops are seldom if ever marked out, introduces an element of uncertainty which renders an English training ground all but useless as a school for instruction in pace.

In India, where I trained many winners, training gallops are almost always given on round courses which are as nearly as possible level, and which have each quarter of a mile marked out by posts that can be seen from a distance. The trainer usually times each gallop, and, by means of a split centre seconds watch, can tell the time for each quarter of a mile, and can thus point out to his riding lads any faults they may commit in judging the rate of speed, either for the whole gallop or for its component parts. From practice of this 
kind, these lads, if capable, soon acquire the ability of riding a gallop of, say, a mile, to within a very few seconds of the time they set themselves to cover it. I have invariably found in the many cases which have come under my observation, that this practice greatly improves the pace judging ability of English jockeys who go out to India. In Training and Horse Management in India, I have given the following approximate time scale of speed for a horse which could do a mile in I minute 48 seconds, with the weight he is accustomed to carry in his training gallops :-

\begin{tabular}{|c|c|c|c|c|c|}
\hline Quarter speed & . & • & - & $3 \mathrm{~min}$. & $\cdot 50$ \\
\hline Half speed & - & ${ }^{\circ}$ & $\cdot$ & 2, & 45 \\
\hline Three-quarter speed & - & $\bullet$ & $\cdot$ & 2, & 5 \\
\hline Full speed & . & . & • & I , , & 48 \\
\hline
\end{tabular}

For a horse which could cover a mile in I min. $42 \mathrm{sec}$, the respective times would be : 3 min. $37 \mathrm{sec}$; 2 min. $36 \mathrm{sec}$; I min. 58 sec.; and I min. 42 .

Although the undulating character of ground in England and the frequent variations in the nature of its "going," are difficulties to be overcome in the introduction of the Indian method into this country, the system has such important advantages that it is well worth a trial. Although the "clock" is used in much the same way for training in Australia, New Zealand and America, I refer to its employment particularly in India, because I had many years' practical experience of it in that country.

\section{THE DIFFERENT WAYS OF RIDING A RACE}

May be summed up as follows:- I. Waiting; 2. Using a pace-maker; 3 . Making the running; 4 . Waiting in front; 5 . Keeping with one's horses, and then, if one can, coming away at the finish and winning. As it is impossible to foretell how a race will be run, or what changes may occur while the horses are running; a jockey should be ready to vary his 
tactics, according to circumstances, with the utmost promptness. When we consider that the time for action often allows only two or three seconds during which to calculate the various chances and to resolve what to do, we shall cease to wonder that this jockey instinct, or intuitive power of grasping the situation, combined with quickness and courage to act, is as rare a mental faculty as genius in any other walk of life. Possibly, a dozen men in England who can ride 8 st. 7 lb. possess it; probably, not as many.

\section{WAITING.}

As a rule, in all fairly long races, a jockey should wait; for by doing so, the horse will not incur the risk of being run to a standstill, and the rider, seeing how the other horses are going, can form a good judgment as to the advisability of remaining, for the present, where he is, or of going to the front. If he injudiciously forces the pace from the start, he will probably not find out his mistake until the race has been lost.

A capital jockey who had not the reputation of always riding to win, once told me that he learned to appreciate the advantages of waiting, from observing the manner in which horses that made the running "came back" to him, when he was on animals which had no chance, and of which he did not make very much "use."

If the orders be to wait, they should not be carried out, as is sometimes done, by losing the start, or by pulling the horse out of his stride, in order to get him behind at all hazards. A jockey with waiting orders should, on the contrary, get away as well as possible, and should settle down as soon as he can into a steady, uniform pace, a trifle slower than that of those who are "making play," and should wait until they "come back" to him or until he arrives at the spot from which he sees that it is time to make an attempt to recover 
lost ground. He should, then, gradually draw up to the front, so as to be able to make his effort at the proper time, judging from the way the horses he most fears are going, and by the distance they are from him.

If a jockey is left more or less behind at the start, by getting off badly or by his horse being a slow starter, he should ride with extreme patience; for trying to make up ground too quickly will mean certain defeat, in the case of a strong opposition. The most memorable instance of an admirably ridden waiting race of this kind was the St. Leger of 1863 , in which Lord Clifden, who was a very slow starter, was left thirty yards at the post, and before the leaders had gone a quarter of a mile, he was about I 50 yards behind them. Osborne let this great horse settle into his stride without moving on him, and began to come up to his field at the Red House. He got into a good place on entering the straight, and won, to the astonishment and admiration of everyone who saw him.

It is a very general idea that light weights should make the running, or at least have it made for them; and that heavy weights should wait. I am convinced, however, that if a light weight is possessed of a fair turn of speed, it is sound policy for his jockey to wait with him-always supposing that the race is not a short one, and that it is not run at too slow a pace-because, when it comes to racing at the finish, the light weight being comparatively untired, ought then to have the best possible chance of getting home. Even a moderate plater, if started fresh for the last few hundred yards of a long race, would beat the best and fastest stayer in the kingdom. Weight tires a horse quite as readily as pace will do. In fact, a horse should:be ridden more with regard to the distance he can compass, than to the weight he has to carry.

It is usually thought that weight "tells" on a horse in a race only after a certain distance has been run. I am inclined 
to think that this idea is erroneous, and that every pound of extra weight on a horse's back diminishes the rate of speed at which he can travel, even during the early portion of the journey, when he is quite untired.

\section{USING A PACE-MAKER.}

Modern experience in cycling has shown that a man on a machine can do far better time with a good pace-maker than without one. As I have no experience in the art of pedalling, I cannot advance any authoritative reasons for this statement, which is universally accepted as an incontestable fact. It is probable that the progress of the man, who in all these cases keeps close behind his pace-maker or pace-makers, is materially aided by the current of air which follows the man or men in front, owing to the comparative vacuum that they leave behind them at each moment of their progression. In any case, they considerably lessen the resistance which the cyclist would otherwise experience from the wind, especially if it was a head one. Mr. William Day writes as follows in his valuable book, The Racehorse in Training:- "I may here mention an interesting fact, which is the cause, undoubtedly, of unsatisfactory performances in long-distance races. It is the waiting too long for, or more strictly speaking, perhaps, it should be called the lying back too far from, the horse that is detailed to do the work. As a rule, the distance between the two is some eight or ten lengths. It should never exceed two or three lengths; for if you concede more you are virtually making, not a fast, but a waiting race of it."

Horses generally go better and settle down in their gallop sooner with a lead than without one. This is specially true with young ones, which are apt to sprawl about, and go on with all sorts of "calfish" tricks when they are in front; at least during the first part of a race. Some horses, however, 
will never run kindly except when they are making their own running.

The Miner was a horse that would not make his own running, though he was one of the stoutest horses of his day. If he had had a pace-maker in the St. Leger, history might have been written differently, though the admirers of the famous Malton chestnut will not hear of such a thing. Undoubtedly, it was the strong pace set by Blair Athol and Ely in the Great Yorkshire Stakes, in which Chaloner and Custance tried the cutting-down game, that enabled the Miner to win at York, and called him into prominent notice for the great Doncaster event.

It is essential that the jockey on the pace-maker should judge the pace accurately. If he does not make it strong enough, and if there is no other horse to set the lead, the jockey in whose interest the pace-maker was supposed to act, should as a rule make his own running. Thus, in the St. Leger of I873, when Merry Sunshine failed to make the pace fast enough for Marie Stuart and Doncaster, these stable companions of his took up the running near the Red House, and finished first and second. In this race, Mr. Merry's colours were in the van from the fall of the flag

\section{MAKING THE RUNNING.}

Experience tells.us that a jockey should never make his own running, except when he is on a horse that frets or goes unkindly when there is anything in front of him, or when he cannot get any other rider to make the pace fast enough, as did Pratt on Sornette in the Grand Prix of I870. When A pology beat one of the best fields that ever went to the post for the Ascot Cup, she took up the running a mile and a half from home; and when Persimmon won, he had his head in front at the old mile post. When Saunterer, in the race for the Goodwood Cup, beat Fisherman, who was both stout and 
fast, Osborne waited with him for the first mile, and then as he was pulling very hard, he let him go to the front, and was never headed. Saunterer was a very fine stayer and a very hard puller. If Osborne, who generally rode him, could get him to settle down in his gallop, he used always to wait with him at least for a portion of the journey; but if he found that the horse was irritated by being kept back, he used to let him go to the front and wait there, which is a policy all fine jockeys adopt in similar circumstances.

If a jockey who has received orders to make use of his horse and not to wait, finds that the pace is made quite strong enough, he will, if he be a good judge, utilise the leader or leaders as pace-makers, and will be ready, when they are beaten, to go to the front, by which time he ought to know the exact state of affairs. If he be incapable in this case of acting up to the spirit, rather than the letter, of his orders, he will probably run his horse to a standstill, from being unable to "let well alone." Anyhow, he should endeavour to judge the pace so that the horse will have enough left in him to make his effort at the finish, in the event of his being collared. When it is probable that there is a good stayer or two in the field, and especially without a pace-maker, it is seldom wise to give orders to make the running, unless the horse is a good stayer and is rather deficient in speed. One of this sort, even when carrying a heavy weight, would, as far as my experience goes, be best suited by the pace being made strong all through.

A jockey should of course never commit the generally fatal mistake of "making every post a winning post," as appears to have been done with more horses than I would" care to particularise.

When the ground is heavy, it may be good policy for a light weight to make the running, as weight tells far more through "dirt," than when horses can hear their feet rattle. 


\section{WAITING IN FRONT.}

Many horses, like what Saunterer was, are such hard pullers, that in a slow run race they cannot be kept behind, without more being "taken out" of them than the extra pace would do, were they allowed to go freely. If a horse of this kind is not a fine stayer, his jockey should wait in front with him; in other words, he should merely keep in front without forcing the running on his own account, and should simply conform to the pace of those immediately behind him, until the moment arrives for him to make his effort. An impetuous horse should never be kept back to an extent which will cause him to "fight in his gallop." Instead of doing that, his jockey should allow him to go at a speed just beyond that at which he would expend his strength in the air. A fast pace will steady, as well as hold, most horses.

\section{KEEPING WITH ONE'S HORSES.}

The easiest of all tactics to pursue is to keep with one's horses until the finish, and then to come away if one can.

\section{GENERAL REMARKS ON RACE RIDING.}

A jockey should generally avoid keeping alongside any of the other horses, especially when he is on an impetuous. animal; for galloping stride for stride is liable to excite a horse, and to throw him out of the even, steady stroke he ought to preserve. On the contrary, he should, if not wanting to force the running, keep behind, or a little to one side, of some horse in front, and wait till he gives way to. take his place, or until the time comes for "getting through." It has often happened that the best horse in a race has. lost it from some of the other jockeys racing directly alongside him, from time to time, in order to make him pull and tire himself out. In acting thus, a jockey, of course, inten- 
tionally sacrifices his own chance in order to secure the defeat of an opponent. If a man finds that this "little game is being tried on " him, he should get in the track of one of the leaders, if there be any in front, so that his horse, seeing another directly before him, may not pull over much or break away; or he might drop a little back.

During a race, a jockey should not try to pass any horse which is going as well and as strong as his own. As a rule, he ought to wait, or, as jockeys call it, "suffer," until the other begins to give way, when he may then draw up and take his place. I cannot too forcibly express the necessity of patience.

When a jockey finds that his horse can go no faster than he is galloping at the time being, he should almost invariably take a pull at him, if only for half-a-dozen strides, in order to give him a chance of "coming again," which he could not do were he not eased off for a moment. Exceptions to this would be, when the jockey is close to the winning-post, has the lead, and finds he can keep it; and when his horse is one of the jady kind which will not stand their mouths being touched.

If a jockey, who has waiting orders, finds that all the others are acting as if they had similar instructions, he should try to avoid "getting the slip" from any of them. This manœuvre is carried out, when they are going slow, by a rider catching his horse by the head and sending him, it may be, five or six lengths in advance of his field, before the other jockeys are aware of his intention. Having gained this start he should continue to go strong, and either make play all through, or let the others gradually catch him, while they are all going fast, so that he may have a bit in hand when it comes to a finish. These lengths, gained thus with but trifling exertion, when the pace was bad, may be worth a good deal of weight before the winning-post is passed. It is evident that it is no use 
giving one's field the slip, if one is not prepared to take advantage of it by going ahead at a strong pace.

It sometimes happens that the riders of the two best horses wait too long on each other, and thus allow their field a start which cannot be recovered in time. Or they may make the mistake of riding against each other, without thinking of the remainder of the field.

As a rule, in a match, if one's opponent be on a "cur," one should try to jump off with the lead, and cut out the running at once, whatever sort of a horse one may be on, provided he be but "game"; for nothing makes a rogue shut up so soon as being collared.

Inexperienced riders are often deluded into waiting when they ought to go on, by a jockey pretending to flog, when in reality he is but whipping his boot. This dodge is, of course, only "tried on " by the rider of the speedier horse of the two, in the hope of inducing the man on the stayer to slacken speed, from the idea that he has the race in hand, and that there is no use in hurrying. If a man perceives his opponent pursuing these tactics, he should of course keep on at his own pace or increase his speed, supposing that there is no other horse formidable in the race.

There are numberless instances of races won and lost by what some might call strategy-but which others, less charitable, might stigmatise by another name. A case in point occurred many years ago in the Liverpool Cup. The rider of the leading horse-the subsequent winner-suffered from the infirmity of deafness. The rider of the horse immediately behind the leader, seeing that he had nothing else to beat, holloaed at the top of his voice: "Pull out of my way-you are beaten!" So great was the reputation of the formidable jockey behind him, that had our deaf friend heard him, there is no manner of doubt but that he would have "pulled out of the way." Fortunately he did not hear, and won very 
easily. This is the only case, which I can quote, of the advantage of having defective hearing - at least, at racing.

I remember, however, a case that occurred abroad, in which rascality was frustrated by the fact of a would-be tempter having an impediment in his speech. A jockey who stammerred very badly, had backed the horse he was riding, for a great deal of money. At the distance post he found himself collared by an outsider, who came up full of running. Knowing his man, he stuttered out to his unexpected opponent: " I-I-I w-w-will g-g-g-"; but, in the excitement of the moment, he could not complete his sentence. Brimful of mortification at his loss, he afterwards reproached his friend for not having listened to him, and said that he would have given him a hundred pounds to have pulled. "Then why the deuce didn't you say so? " was all the consolation he got from his brother rogue.

If a jockey be behind two horses-the leading one close to the inside of the course, while the other is a little away from it, but in rear of the leader-he should never attempt to get through on the inside, unless he knows what sort of men he has to deal with, and that there is a good chance of their giving way to him; for all that the second jockey will have to do, in order to shut him in, will be to close up on the leader. He will then be obliged to slacken speed, so as to let the second horse pass him, before he can get round on the outside. If the two leaders act in concert, they may slacken speed at the same time as he does, and keep him hemmed in until all chance of winning be passed. Many who ought to have known better, have been caught in this trap. As this manœuvre is accomplished without any crossing or jostling, it does not come under the head of foul riding.

It is, generally, dangerous to try to get through on the inside; for many men will refuse to give way, or to pull out, 
and it is anything but pleasant to be shoved up against a post, or against the railings.

Many jockeys labour under the misconception that, if they are leading, the inside of the course belongs to them, even when they are not occupying it, and that they are consequently entitled to cross an opponent who attempts to come up on the inside. Such a cross would be foul riding, according to the Rules of Racing.

Above all things a jockey should not "lie off" an absurdly long distance behind his field; and when carrying a heavy burden, he should never allow a dangerous light weight to get too far in front.

A jockey ought to pay due attention to the nature of the ground over which he has to go, and to any peculiarities possessed by his mount. It is almost unnecessary, especially now that the course has been changed, to quote here the historical sheep-track on the Cambridgeshire Hill at Newmarket. Lord Poulett had cause to remember how his wellplanned coup with $\mathrm{Nu}$ was upset by the jady Gardevisure, who owed her success entirely to her pilot having secured this much-coveted place. If a part of the course be heavy or hilly, the jockey might ease his horse a little; and he might rattle him along down-hill, or where the ground was sound, always supposing that his legs and feet can stand it.

Fordham's winning the Derby on Sir Bevys in 1879, furnishes a good illustration of the advantage of paying attention to the state of the ground in a race. The "going" on that day was very heavy and "holding." The great jockey, instead of coming sharp round the rails, took a clear sweep of his horses at the corner, and although he lost some distance by doing so, he got on the upper ground which was firm and sound, and thus managed to win.

Particularly on a large open course like that at Newmarket, and especially before riding a long race, a jockey should 
study the various landmarks; so that he may know at any moment how far he has got to go. I could mention more than one instance of the Cesarewitch having been apparently lost through a jockey not knowing how far away he was from the winning-post.

Jockeys are often unjustly criticised for the manner in which they ride races, especially when they are on horses that, like Mr. Bragg's Grand Flaneur, will make only one supreme effort. John Osborne, who rode some of his finest races on this famous horse, was once found fault with for having waited too long with him; the fact being that if he had taken the opening which was given him, he would certainly have been beaten, and consequently Osborne had to wait for another opening, or "come round," which he had not enough weight in hand to do. All sorts of harsh things were said about Lester Reiff for the way in which he rode Good Luck in the Cambridgeshire of 1900, and yet when Kempton Cannon had the mount on that horse for the Liverpool Cup of the same year, he performed in a similarly disappointing manner.

Instead of waiting on the inside of a circular course for an opening, it is often good policy for a jockey who is riding a horse full of running to bring his animal past his opponents on the outside, in which case he will almost always have a clear road. In the Great Metropolitan Handicap of I9co, M. Cannon was disappointed more than once with King's Messenger. Finding that he could not get through his horses, he gradually worked round them, made his effort on the outside of the course, and won in masterly fashion.

Jockeys are frequently blamed for the shortcomings of their horses. At the Liverpool July meeting of I884, General Owen Williams' Black Diamond was ridden in the All-aged Plate by Archer, and Mr. Wadlow's Frolic by Osborne. At the distance, Frolic looked like winning; but he died away, and Archer won easily on Black Diamond. Osborne, whose 
quiet style did not please the self-appointed critics, came in for a good deal of censure, and it was freely stated that Archer had out-ridden him. After the race, Black Diamond was sold to Mr. John Martin, who on the following day asked Osborne to ride the filly, and Osborne consented, as Wadlow had said nothing to him about riding Frolic. Archer happened to have the mount on Frolic, who was accordingly made favourite at 75 to 40 on him. The result of the race was similar to that of the previous day, and Archer's severe finish got Frolic only a little nearer the winner. Even Osborne, who always took his victories gravely, had a smile on his face as he returned to scale. "I thought I had won at the distance," said Archer to him in the weighing room. "So did I yesterday," replied the Northern jockey.

Fashionable jockeys are particularly liable to become recipients of indiscriminating praise. A follower of that good jockey Sloan, when discussing the Liverpaol November meeting of 1898 with a fine judge of racing, could hardly find words sufficiently laudatory of the way in which the American had ridden Nouveau Riche in the Liverpool Stakes, and was specially warm in his admiration of Sloan for not having lost any ground. The man whom he addressed reminded him that Sam Loates rode an equally fine race on the same horse a couple of days later for the Grosvenor Cup, and that he won still more easily, although he was carrying $4 \mathrm{lb}$. more. At the same meeting it was said that Weatherall caught Sloan napping in the race for the Feather Plate, when Philopena beat Samandal by a neck. This was not the case ; because Sloan as usual made the best of his way and got on the inside; but his horse failed to stay.

\section{PECULIARITIES OF HORSES.}

Horses with short, upright pasterns cannot go down a hill freely - the running of Vauban, the Two Thousand winner, 
in the Derby, was a good example of this fact-and they do not act well on hard ground. Animals with sloping pasterns generally like to " hear their feet rattle," and seldom get their legs jarred when going down an incline. The fact of a horse having heavy, straight shoulders greatly interferes with his ability to gallop with advantage down a hill.

'The best kind of horse for going down a hill, is a light moving, quick striding animal who has flat, oblique shoulders, sloping pasterns and sound legs and feet; but a long striding horse, especially if he be a bit straight in front, is seldom at home except on the flat. On this subject, the Sporting Times remarks: "We incline to the opinion that on the Derby course Iroquois would always beat Peregrine, just as Bend Or beat Robert the Devil. Very big horses, like very big men, do not climb hills well, and coming down shakes them all to pieces. It is the light springy sort who are the best at the game, and of such is Iroquois."

Horses with rather high action and good hocks are the best to climb a hill. The possession of large broad feet is useful on a heavy course, from the mechanical advantage they have over small hoofs. A compact, quick-striding horse, like what Freeman was, is well adapted for a cramped course, like the Roodee at Chester; but a big long-striding animal-Lord Clifden, for instance-requires a straight level course, like that at Doncaster, on which to display his powers. The length and height of a horse does not matter so much, provided he has quick hind action and gets his hocks well under him. Knight of the Garter, who was one of this sort, though a very big horse, squandered his field in the Chester Cup of I 869, with 9 st. I lb. up. Also Asteroid, who was built on a large scale, won in 1863 , carrying 9 st. 4 lb., beating eleven others. Unsound horses generally act best on a soft course, especially those with any tendency to laminitis or navicular disease. Old horses which are somewhat stiff on their legs, 
should have a steady preliminary canter to warm them up before starting. Certain horses appear to have a special liking for certain courses and varieties of ground. Game, honest horses are often several pounds better, when facing a hill, than one with a suspicion of " softness," though they might be as nearly equal as possible on the flat.

As a rule, lazy horses which require riding to make them extend themselves, are far better stayers than the impetuous sort. We may often observe the fact of a horse being "trained to the hour," by his becoming a trifle dainty in his feeding, and lacking, when taken at a walk, some of his accustomed fire. Admiral Rous, speaking generally, remarked: "Large horses like big men, run fast and seldom stay a distance, but they can carry weight."

Horses vary as much in their respective powers of carrying weight as they do in staying a distance. For instance, certain speedy animals are effectively stopped if they have anything more than 7 st. $7 \mathrm{lb}$. on their backs, and others can perform creditably only in welter races. Brown Brandy, who was a small but very stout horse, won a lot of races with fairly heavy weights up; but showed comparatively poor form in light weight races.

\section{THE SEAT WHEN FINISHING.}

Here, also, no hard and fast rules are admissible. If a jockey who is leaning well forward, finds that his horse is going level, he would be foolish to sacrifice the increase of speed which his forward position gives him, by leaning back. But if he feels that his horse, instead of going true, is labouring in his stride from the fact of too much weight being on his fore-hand, he should sit down in the centre of his saddle with his seat as much under him as possible; supposing that his stirrups are fairly long. He should catch a good hold of the horse's head 
so as to collect him at each stride; should lean slightly back; grip the flaps of the saddle tightly with his knees, and draw his feet well back so that the weight at each stroke of the horse's hind legs may not come with a jerk on the stirrups, which would cause it by re-action to be thrown to the rear, and would thus increase the work the horse has to do. The hands and arms should yield to the extension of the horse's neck at each stride, without, however, slackening the reins in the slightest. The rider should avoid the unsightly trick of working his hands in a circle round and round; and should carry them in the direction the horse is going, without any side motion. The hands should be brought within four or five inches of each other, and should be kept low, say-not more than two or three inches above the withers.

The rider having assumed this position, should conform to the movements of the horse, so that the weight may impede the animal as little as possible. The seat and thighs of the rider should appear as if they were glued to the saddle, and there ought not to be the slightest approach to any bumping up and down. Whether the jockey can, or cannot, relieve the horse of weight, by giving a forward impulse to his body when the hind legs are on the ground, is a question which does not concern us here, nor is it one of practical application. We know that "dead weight," over which the muscles of the jockey cannot exercise any influence, is particularly disadvantageous at a finish, however well placed it may be. We are also aware that if a man be tired or weak, however "still" he may sit, his horse will not be able to gallop by any means as fast as he would do were the rider fresh and strong. These facts seem to indicate that the jockey can afford his horse a certain amount of mechanical assistance which cannot be derived from the reins, which, though they may serve to "collect" him, or to retard his speed, are powerless to give 
him any onward impulse. As the legs of the rider are the only other parts which connect him to the horse, the "lift"if there be one-must proceed from them, and may be the result of the weight being, more or less, taken off the horse's back at each instant, as his hind feet make their stroke. Colonel Greenwood, in his excellent book, Hints on Horsemanship, considers that such mechanical assistance can be given.

A man requires a good deal of practice to finish well; but, if he does it badly, he is certain to impede the horse's movements by rolling about in the saddle. Hence, if he be not expert in the art, he had better sit still. He should catch a good hold of his horse's head, and shculd assume the position which he finds to be the easiest one for the horse and for himself. As the action of finishing is very fatiguing to the jockey, he does not, as a rule, "sit down" before he comes to the distance post.

\section{TACTICS OF FINISHING.}

At a finish it is generally best to be on the side farthest away from the judge. When two horses are coming up the straight, on perfectly even terms, the farthest-off one will, of necessity, appear to the spectator to be ahead of the other. It is, therefore, very difficult for the judge, in a close finish to efface entirely from his mind an impression of, say, ten or twelve seconds' duration. It has happened that when the actual winner has finished close under the judge's box, that he was not even placed by that official. If the jockey cannot use his whip in his left hand, he might keep on the whip hand of his most dangerous opponent, who might, if he was on his near side, close in, either intentionally or - by his horse swerving, and would thus prevent him from using the whip with the right hand. If the horse has a tendency to swerve 
under punishment, to the outside of the course, it may be just as well to have something on the near side, so as to keep him straight.

Before sitting down to finish, it is generally advisable, especially if the race has been run at a strong pace, to take a pull at one's horse for a few strides, so as to enable him to catch his wind, and to collect himself before he makes his effort.

Care should be taken not to suddenly begin to finish on a long-striding horse, who should, on the contrary, be prepared for his effort, so that he may not be thrown out of his stride. A quick, short-striding animal will dash into full speed in an instant.

It is a dangerous and often a fatal mistake for a jockey to ease his horse, or to cease riding him, when leading and close to the winning-post; for by so doing, he may make him "stop," and may then be unable to get him into his stride again, in time to "stall off a rush" from one of the others. Even the great George Fordham was once caught rapping in this way, when riding for his then constant employer, Mr. Ten Broeck. Neither of the two ever forgot how Sam Rogers swooped down on Fordham, who was riding Amy. She had, to all intents and purposes, won her race, when the Demon took a pull, thinking that the other one was beaten, and then he could not set her going again in time. It is probable that the Derby of IS80, when Archer, on Bend Or, caught Rossiter on Robert the Devil, was another case in point.

At a finish, if one finds that the leader has the race easy, one might get directly behind him, on the chance of his slackening speed to look round, or to gaze at his boots, or at the stand, and then one may, with a rush on the side away from which the other's head is turned, manage to beat him on the post, before he can set his horse going again. 
Many an important event has been lost from over-confidence of the rider of the leading horse, who, when winning easily, has tried to make a race of it for "the gallery," or has been cajoled into slackening his speed by one of the other jockeys, and has then been unable to make an effort in time when required to do so.

Above all things, a jockey should not mistake the winning post for some other landmark, as did almost all the jockeys, except S. Loates on Pax, in the race for the Hare Park Handicap, during the Newmarket July Meeting of 1900. Loates, who was nearly last, seeing his opponents in front pull up, kept Pax going, took the lead, and was never caught.

As a last piece of advice, I would recommend the tyro never to be too anxious "to get home," and never " to draw it too fine."

\section{RIDING ROGUES.}

As the generality of rogues will run kindly enough, until they are pressed or hustled, a jockey when riding one of this sort should, as a rule, make the running, or at least. keep with the leaders, and, if he finds that he is winning easily at the finish, he should, on no account, take a pull, or allow any of the others, if he can help it, to close up on him; for many rogues will either not try a yard, or win by "the length of a street." The jockey should sit still, ride as quietly as possible, and should do all he can to persuade the jady one that he is running away. It often happens that the more the rider pulls, the faster will the "rogue" go. The jockey should allow him to make his own running and effort, while. interfering with him as little as possible. Horses learn so. quickly what a race means, that I believe better results than we often get would be obtained, were we to trust more to theirjudgment than we do, as to how they should be ridden in. their races. 
Rogues run very much better in a match or in a small field than they do in a crowd.

"Of this indisputable truth," remarks Captain Jones, "I have had ample proof. It has always been a matter of surprise to me, that trainers do not teach young horses their lessons in scenes and under circumstances resembling, as much as possible, those under which they have subsequently to fight their battles, and, oftentimes, to carry their master's fortunes. I am led to this reflection by an old reminiscence of a horse of my own, which I had bought as a two-year-old. He was as well bred as Eclipse, and of real racing shape and make. He had run but once as a two-year-old. I bought him in October for a good round sum, by the advice of a friend of ripe and rare judgment. He wintered well. Wanting to try him alongside another horse early in the year, I put four of them together, and galloped them a mile in their clothing far away from sight or sound. To my delighted amazement, the young one seemed to hold the old horse (one of some pretensions) the whole distance, and was only beaten half a length. If this form were correct, there was nothing beyond my reach for that year, not even the Derby; as the horses were carrying boys of the same weight, while my old horse, which had won good races before this (and, I may add, since), would have made small work of three-year-olds at even weight. I believed I had a treasure, but to make assurance doubly sure, I determined to try them regularly, with jockeys in boots and breeches, and as close an imitation of the real thing as I could devise. Alas for the result! The young horse was beaten two hundred yards! He could not be got to gallop in public, although he was a perfect kill-devil at exercise.

"I gave him another chance in a good class race with an 8 st. Io lb. man on his back. The brute led his field to the 
distance, and looked like coming in alone. Directly the shouting commenced, and he could see the crowd, he shut up like a clasp-knife, and was shortly after relegated to the cab-rank, in which I hope he will long live to expiate the sin of the unfulfilled promise of his youth."

If a jady horse manages to run a dead heat in a race for which there are several starters, the chances are in favour of his winning the deciding heat, supposing that he has not had much punishment. I was greatly impressed with this fact on seeing the running of The Ghost, in the Clewer Welter, at the Windsor July Meeting for 1877 . This arrant thief, who was a non-stayer, ran a dead heat, Custance up, in the race in question, with Mr. Gretton's Dovedale, steered by Cannon. I knew the mare could stay a bit, so backed her in the deciding heat, and lost my money; for The Ghost won cleverly. Although the second journey was all against him, he ran quite a different horse to what he did the first time of asking.

Nothing is more calculated to make a horse a rogue than running him a severe race when he is out of condition.

\section{RIDING PULLERS.}

Although a curb is objectionable from its tendency to make a horse go "round" and high ; still, if a jockey cannot hold a horse in any kind of snaffle, it is better for him to use a curb, taking care to put it low down in his mouth, than to take the chance of his running himself to a standstill, or to be obliged to saw his mouth or pull his head about, so as to keep him in his place. Speaking to and humouring a horse a little will often make him stop pulling. We should drop the hands when a horse gets his head up, and should take a pull the moment he lowers it. If possible, a large smooth unjointed snaffle (Fig. I I7) should 
be used. We might try the effect of a standing martingale fixed to the rings of a snaffle (page 90). We may take for granted, especially as the pace will hold most of them, that it is the fault of the jockey if a horse runs away in a race.

As the majority of hard, determined pullers are done running when they stop pulling, being then left without the power of making an effort; a jockey ought to be particularly careful to "keep a bit in hand" with a horse of this sort.

That hard pullers often fail to stay is frequently the fault of their riders. I quite agree with Hiram Woodruff, the celebrated American trainer, when he remarks that "it is often said that a horse cannot pull hard and last; and this is contrary to the facts that I am about to mention. Trustee lasted; and he was a hard puller. Captain McGowan lasted; and he was the hardest-pulling horse in America, I suppose. Dexter pulls a pound or two, I can assure you; and he has shown his capacity to go on. The truth is, that the pulling horses last well enough, but the riders do not last so long. It is just so with the runners."

\section{ORDERS.}

As a rule, it is not advisable to give orders, if the jockey knows his work, though he should be briefly told the horse's good and bad qualities from a racing point of view, if he be unacquainted with them. It is always injudicious to lay down precise directions, such as to keep a certain number of lengths behind the leading horse, who may be sent from the start to cut out the running for another, at a pace which might cause himself to collapse long before the distance post is reached. Or to wait on some particular horse-a proceeding which has been the cause of many a mistake; for the dreaded one 
may turn out a rank duffer which is unable to go fast, so that the jockey, by waiting on him, may have, in the meantime, allowed the others to get so far ahead that he will not be able to catch them before it is too late; or he may run himself to a standstill in endeavouring to keep the lead all through. If a jockey be capable of carrying out minute instructions, he will certainly be clever enough to accomplish the far easier and more profitable task of acting up to the spirit of broad general directions. As a rule, it is much better to ride a race so as to suit the capabilities of one's own horse (with which one ought to be fully acquainted), than to devote one's entire attention to the weak points of the supposed dangerous horse or horses, which must naturally be problematical. For this reason, I would never hamper a jockey's judgment by laying out the programme cut and dry; but would simply tell him my horse's peculiarities, and what kind of running would most likely bring him home. For instance, with a fast horse in a one-and-a-half-mile race, instead of telling an inexperienced rider to wait so many lengths behind, I might say, "Get off well, if you can; settle down into a steady pace, and if you are all going fast, don't mind about the others getting a bit ahead. When you have gone about half the journey, gradually begin to creep up, so as to get at the distance post within a couple of lengths of the horses which are going strongest in front of you ; take a pull for a few strides if you find your horse at all distressed, and make your effort the moment you think you can get home." If the animal then gets beaten, the probability is that the winner was the better horse of the two at the weights and distance run-a fact which owners of defeated horses often overlook.

If I remember rightly, it was that very successful turf operator, Mr. F. Swindells, who replied to a jockey that asked him how he was to ride his horse: "Nay, lad, that is thy 
business to know how the horse should be ridden; I cannot teach thee."

\section{USE OF THE SPURS.}

Spurs ought to be put on for a race, unless the horse runs unkindly when they are used, or the jockey is such a bad rider that he cannot spur properly at a finish, or cannot help touching his horse with them. After taking one's spurs off to ride a rogue, it may be just as well, in the preliminary canter, to touch him a couple of times with one's heels in order to show him that he need not fear punishment from them. Some horses, on the contrary, will not extend themselves unless the rider has spurs.

As a rule, a horse should not be touched with the spurs until the finish, when three or four digs will be quite enough to make any ordinary animal exert himself to the utmost. An inexperienced rider ought to endeavour to make his horse go fast at a finish by catching a good hold of his head and "riding him out," and not by spurring or flogging him.

On one occasion, Hayhoe, who was training the late Baron Rothschild's two-year-old filly, Tomato, told Edwin Martin to ride her a gallop with spurs, and to touch her with them, just to show her what they were like. The jockey did so, and the filly finished her work in a satisfactory manner. A few days after, Martin got on Tomato with spurs, to ride her a trial, but she refused to move a step, and began to shiver and buck-jump as if something was wrong. Martin dismounted, and took off the saddle, thinking it might be pinching her, or that a thorn or thistle might have got into the panel. As the gear was found to be all right, Martin remounted, but with the same result. At last, at Hayhoe's suggestion, the spurs were taken off. The moment that was done, the filly walked away as quiet as a lamb, thereby giving them to know, as plain as words could have told, what her ideas on spurring were. 
During her future career she never had spurs used with her, and always ran kindly and gamely.

Many sensible trainers do not allow spurs to be used with their mares when running.

\section{USE OF THE IWHIP.}

When hands and spurs fail to make a horse go fast enough to win his race, we may use the whip if it be a very "near thing," to squeeze the last ounce out of our mount. Horses, when ridden by a workman, will undoubtedly, under the whip, make a last effort which cannot be obtained by any other means of punishment. This effort, speaking in general terms, may make a difference of a length, perhaps even of two lengths, in some rare cases. Recollecting the risk we run of spoiling a horse's temper for the rest of his life by flogging him, we may take for granted that we should not use the whip if we have to trust to it to make up more than two lengths to secure the judge's verdict. A horse, as Edwin Martin, the well-known Newmarket trainer, once remarked to me, cannot at the end of a race go farther than a hundred yards at his very utmost speed without beginning to shorten his stride and go slower; hence we may conclude that our last resource, the whip, should not be used until we are within a hundred yards of the winning post. Practically speaking, the whip should be very rarely indeed "picked up" before the last thirty or forty yards, nor should more than two or three cuts be given. When a jockey begins to flog, as many of them do, two or three hundred yards from home, we need not be surprised at seeing the horse, after answering the call for ten or a dozen strides, go slower and slower as he nears the judge's box. The horse is then probably condemned as a rogue, and the jockey is praised as a resolute finisher. Some of our best jockeys now and then flourish the whip at the finish without hitting the horse, as a "bit of kid," or to make 
the animal travel faster than he is doing without punishing him.

Mr. Edwin Martin tells me that he teaches his boys to carry their sticks in the left hand, so that they may use the whip equally well with both hands. Unless a lad is left-handed, he will have no difficulty with the right. Agreeably to the remarks made on the use of the whip, it should, as a rule, be carried in the left on a right-hand course, and vice vers $\hat{a}$; for horses generally have a tendency to "bear" towards the outside of a course.

Bad as the spurs are, with respect to ruining a horse's temper and breaking his heart, their evil effects are as rothing compared with those of the whip. I may safely say that a large percentage of horses which have been once severely punished with the whip, are thereby rendered useless, as racehorses, for the remainder of their lives, whenever they have to contend in a close finish. Cecil, in his excellent little book, Stable Practice, remarks about the whip, that " not much benefit often results from it, except with game and indolent animals; and in using both that and the spurs, unless the horse is found to respond to the call, good feeling and prudence forbid their use. Inflicting pain - on an animal when he is doing his best, is not only wanton cruelty, but appears something like punishing him because he is going as fast as his powers will enable him. Horses have retentive memories, and there is no doubt many will cease to struggle at the moment they are called upon to do so, from reminiscences of former punishment."

The use of the whip with the crouching seat, is a subject I have not studied sufficiently to write much about, beyond stating that, in this case, the whip would in all probability have to be employed under-hand, and not over-hand, as is the usual English custom. The rule observed by all our best old-time jockeys, is that a rider in a race should 
strike his horse with the whip nowhere else except just behind the girth, unless when preventing him from swerving, etc. When he is hit in this manner, the side away from the whip hand will be hurt more than the other, so that the horse will not be so liable to swerve as he would be, were he hit in any other way. Besides, hitting him thus on the centre of the body will not "double him up," nor make him change his leg, as striking him on the flank or shoulder might do. A joskey who punishes a horse about the sheath, or rips his sides with the spurs, is a disgrace to his profession.

A novice should not use a whip ; for none but a good rider can sit still, hold his horse together with one hand and flog at the same time. Although spurs do not present these difficulties they are much less efficient than a whip in the hand of a "workman."

\section{EFFECT OF PUNISHMENT ON HORSES.}

Without wishing to be "hard" on a very meritorious class of men, I must say that a large number of horses are annually ruined for life by needless punishment. Jockeys are apt to attach too much weight to the opinion of the public, and, consequently, often " ride a horse out," rather than ease him, when pursuit is hopeless.

Although the view backers take of "cutting a horse to pieces" is very different to the one held by a humane owner ; still it is a difficult point to decide whether a jockey is always justified in punishing a horse to the utmost of his power, if he thinks that by so doing he has any chance of winning. If he knows that he has no chance, and persists in using whip and spurs, he ought never to get another mount. Regarding the matter as an old racing man, I hold that a jockey should not " knock about" a young promising horse or valuable old one, for 'an unimportant event, on the off chance of winning; 
and that he should be most particular not to "squeeze" one which has any suspicion of jadiness. Though it is too much to expect that a jockey should take a sentimental view of punishment; he ought to regard the interests of his employer, within honourable limits, and should be averse from ruining the noble animal by whose exertions he earns his bread. The most forcible argument I can use against punishment is that, in the large majority of cases, it defeats its own object. 


\section{CHAPTER XVIII.}

STEEPLECHASING.

Steeplechase riding-Grand National Steeplechase Course.

STEEPLECHASE RIDING.

BEFORE riding a chase, the jockey should go round and carefully examine the course, if it is strange to him, in order to find out the easiest and safest parts of the fences, which knowledge may be most useful to him when his horse is tired; to mark where the "taking off" and "landing" is soundest ; and to observe the nature of the ground, so that he may know when to travel fast, where the "going" is good, or when to take a pull at his horse, where it is heavy, or where, as may occur over a natural line of country, he may make a slight détour with advantage.

He should, above all things, make up his mind to go straight, and should never allow his horse the chance of even trying to refuse. If he knows that his mount is incapable of making a wilful mistake, he should merely regulate the pace, and should, on no account, interfere with his fencing; for a pull at his mouth, or a touch of the whip or spurs, at a critical moment, can only tend to make him shorten or lengthen his stride, and, consequently, to blunder. If the horse be dangerously impetuous, he should "drop his hands," speak soothingly to him, and sit as still as possible. If he be liable to chance his fences, and not jump big enough, the jockey should take a good hold of his head, and should rouse him 


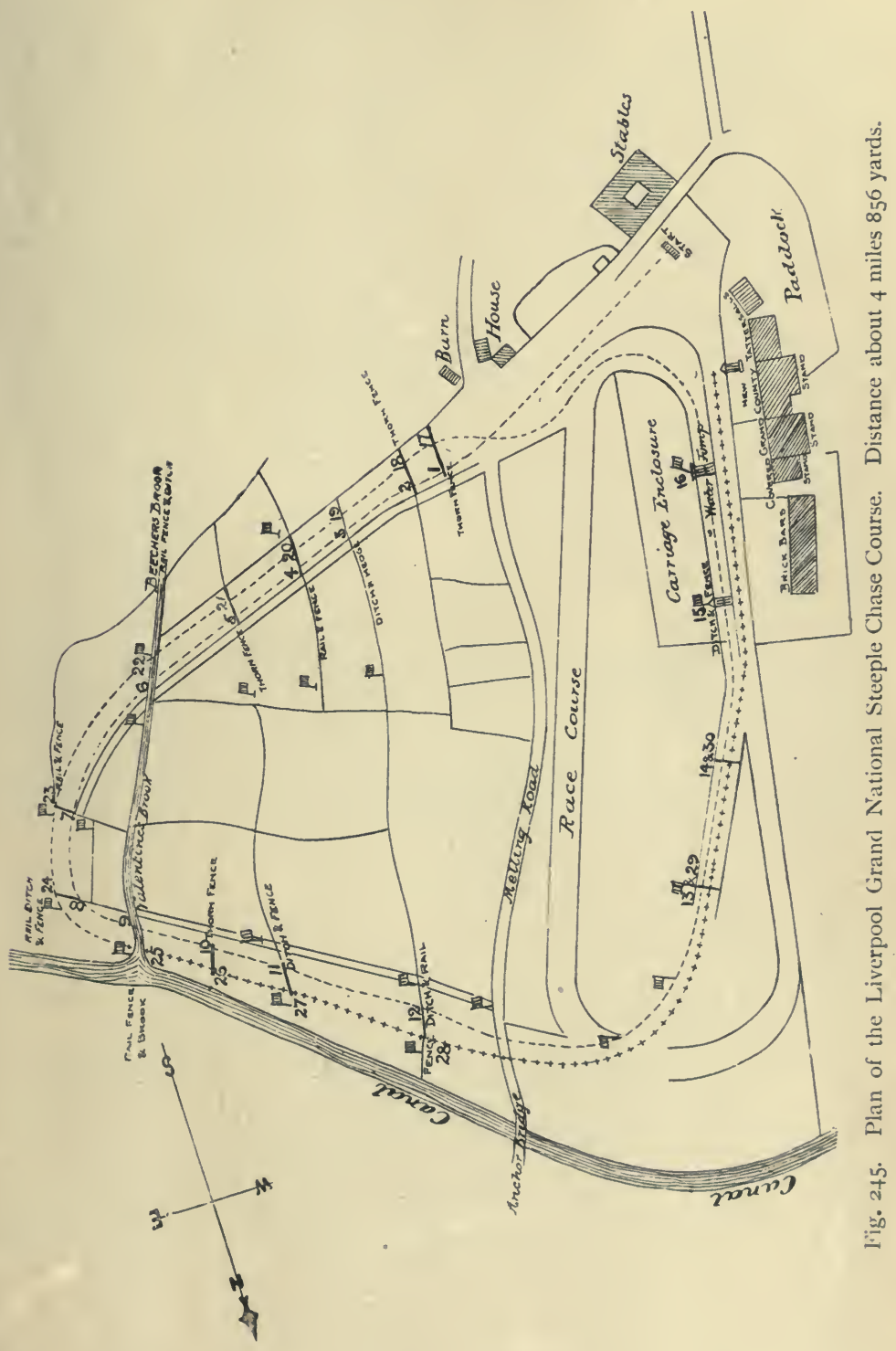


when approaching them. He should, however, avoid, unless obliged to do so, hitting the horse with the whip when in the act of jumping, as the sight of it is apt to distract his attention, and may make him blunder over the fence, or refuse, which he can easily do when the rider has only one hand on the reins. Pressure of the legs and the voice should always be used as a stimulus in preference to the spurs; and the spurs, to the whip. It sometimes happens, however, that in the last stride we instinctively feel that the horse is not going to jump big enough, whereupon our heels

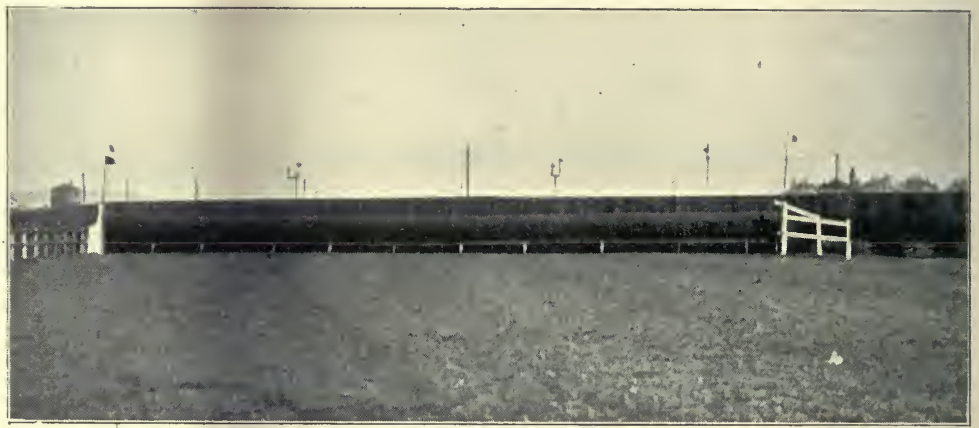

Fig. 246. Beecher's Brook (6th and 22nd fence).

close, or our whip comes down in response to the thought which flashes in a moment through our brain. These impulses have not always a good result with horses which have a "pain in their temper." A jockey should not allow a horse which is liable to refuse, to imagine, because the rider sits quietly and appears to trust to his honour, that he can stop or run out with impunity, for although all horses know when their rider funks, some of them seem to assume that he does so when such is not really the case. Most horses jump best when they are steadied a little, say about forty or fifty yards from their fences, and are then 


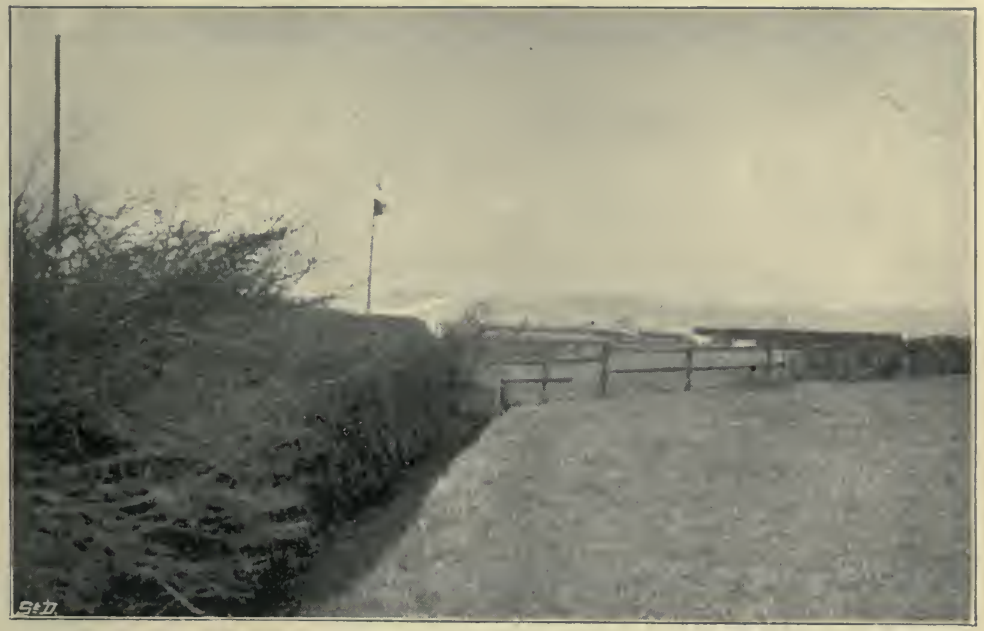

Fig. 247. Landing side of Beecher's Brook.

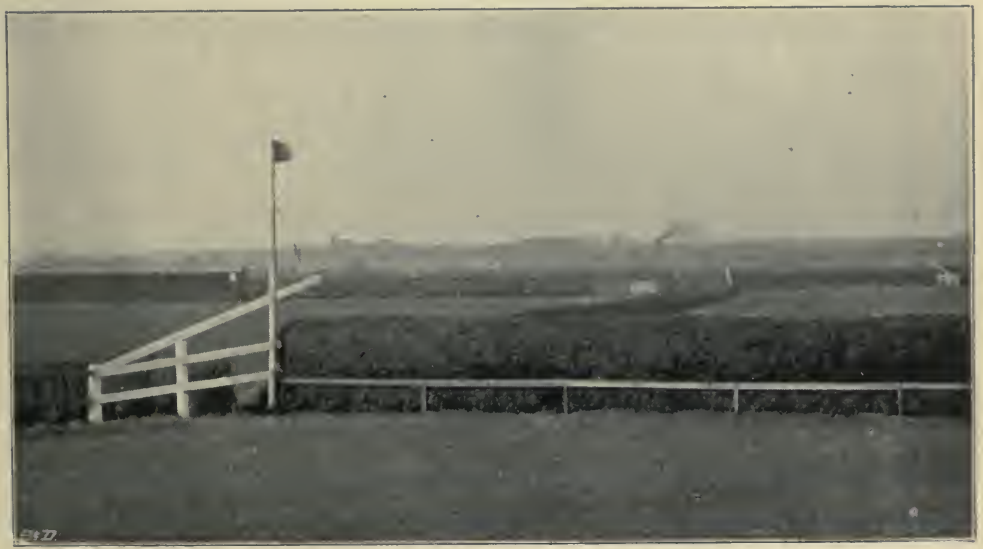

Fig. 248. 7th and 23rd fence. Stand in front of Valentine's Brook in the distance on the left. 
allowed to go their own pace at them. I am, of course, here referring to steeplechasing, and not to crossing country on occasions when the horseman can take his own time.

The horse's head should never be let loose. An extra pull should be taken, when going through heavy ground, so as to make him shorten his stride.

The rider should endeavour, as a rule, to get away in front for the first couple of fences. He will thus avoid being jostled, or "carried out," by any determined refuser which may happen to start; and will also have a clear

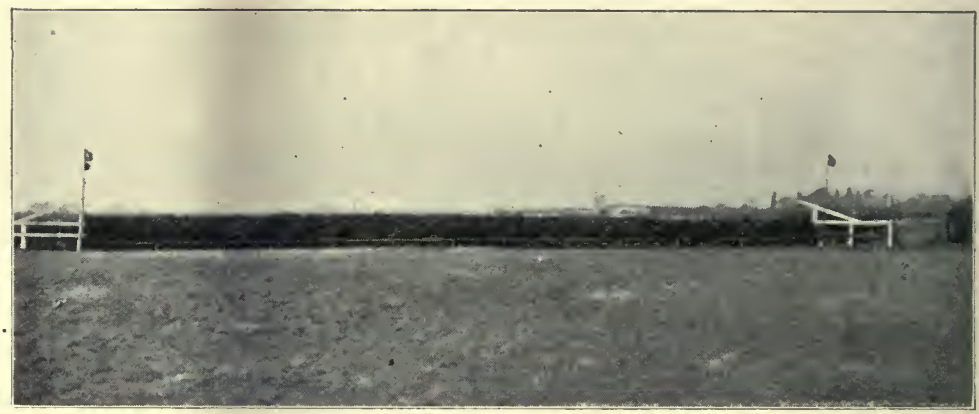

Fig. 249. Valentine's Brook fence (9th and $25^{\text {th }}$ ). Canal bridge in the distance.

view of his country, instead of it being obscured by a crowd in front of him. As the first two or three fences are generally low and easy, there is little risk in racing at them on a fresh horse, who, if he has any pretensions to the name of a steeplechaser, ought to permit this small liberty to be taken with him. When the rider finds his road is clear, he may settle down and ride as he thinks fit. If the ground is dusty, as very often happens in India, it is all-important to get well away at the drop of the flag.

A jockey shuuld take his own line, and should not ride close in the track of any other horse; for if he does so, he will, in the event of his leader making a mistake, run a 


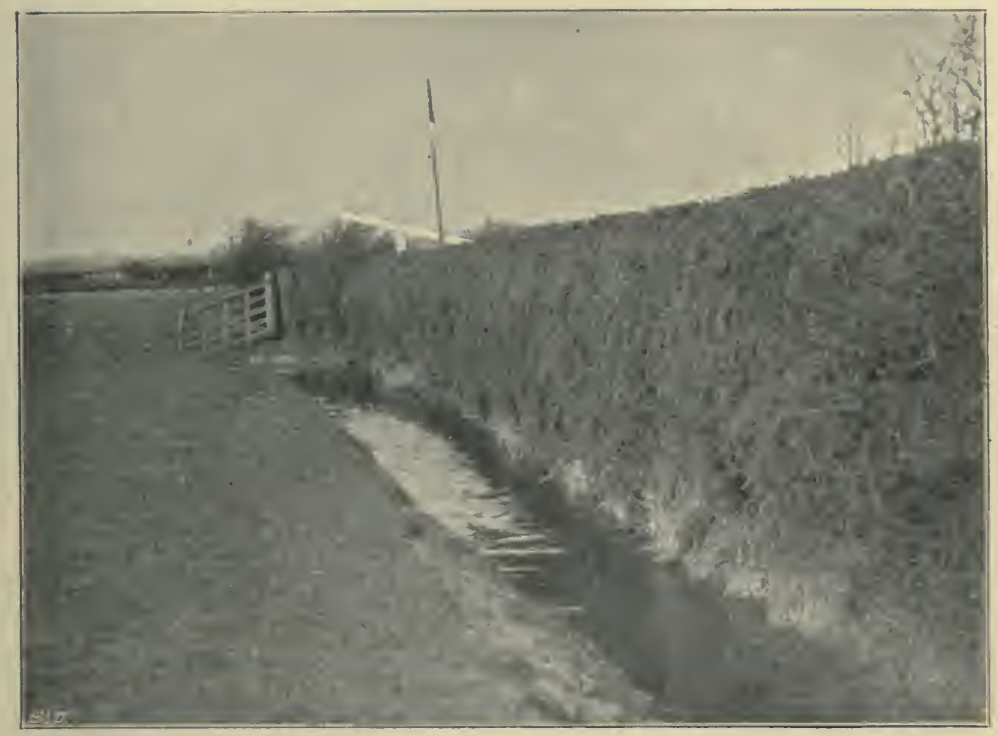

Fig. 250. Valentine’s Brook (landing side).

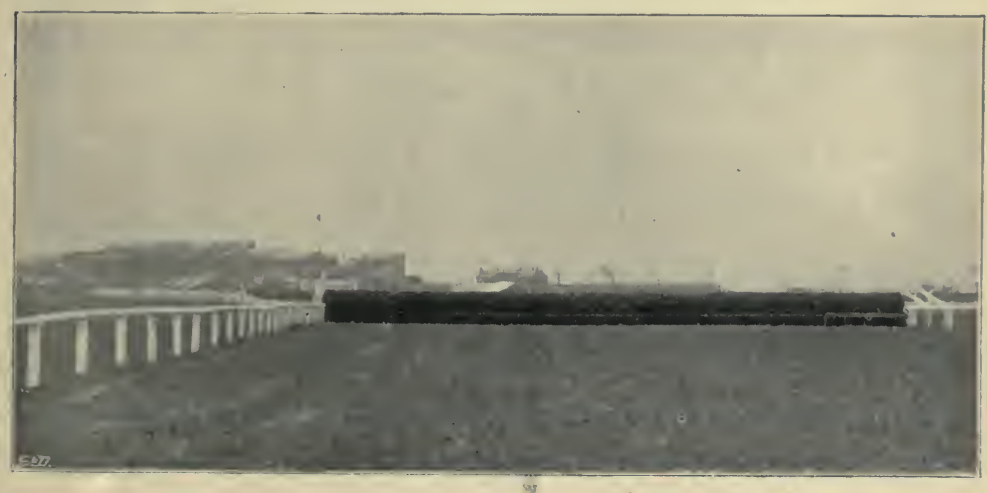

Fig. 25r. I $3_{\text {th }}$ and 29 th fence. Stands in the clistance on the left. 
great risk of coming to grief, with the off chance of jumping on and perhaps killing his man. Besides, his animal will not be able to see his fences properly if he has another right in front of him. If the horse has a fine turn of speed, but requires a lead, the rider may keep him thirty or forty yards behind any clever fencer which is going fast enough.

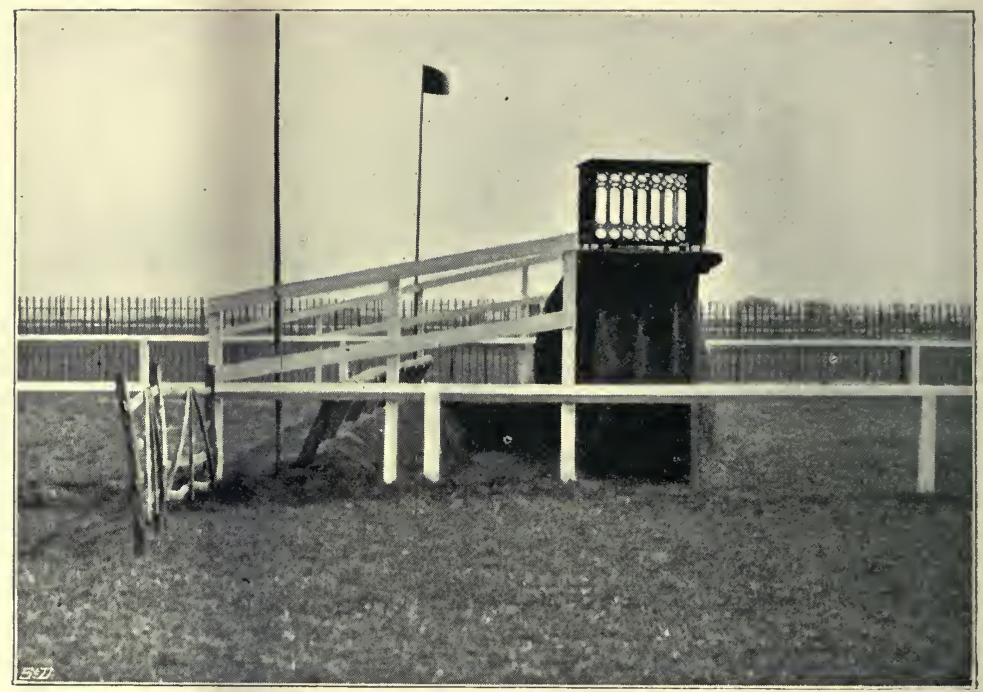

Fig. ${ }^{2} 5^{2}$. Side view of $\mathbf{I}_{5}$ th fence, at Old Distance Post.

When a man is on a horse which he can trust, and is free to take his own line, he should, within reasonable limits, keep as close as he can to the inside flags, so as to save ground. An inexperienced rider often loses a lot of distance by needlessly avoiding the inside of the course.

Unless the field is racing very fast, a jockey should moderate his pace somewhat when going at high fences. Of course he should go fast at water, so as to be able to clear it with ease; but he should be most careful to ride the horse up to his bridle, and get his hind quarters well under him 
by the pressure of the legs, and if need be, by a touch of the spurs, so that the animal may not overjump himself, and may get away again in his stride. Of the two faults

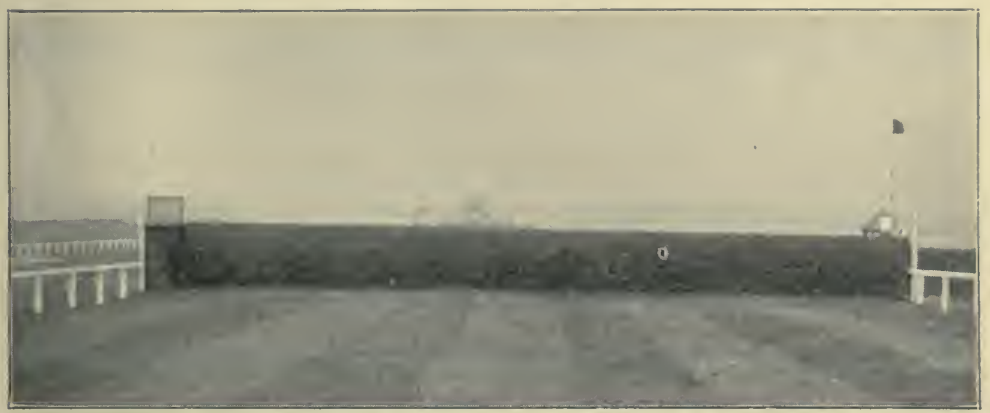

Fig. 253. View of $15^{\text {th }}$ fence, from landing side.

it is better to go too slow, with the horse properly in hand, than very fast with a loose rein at water.

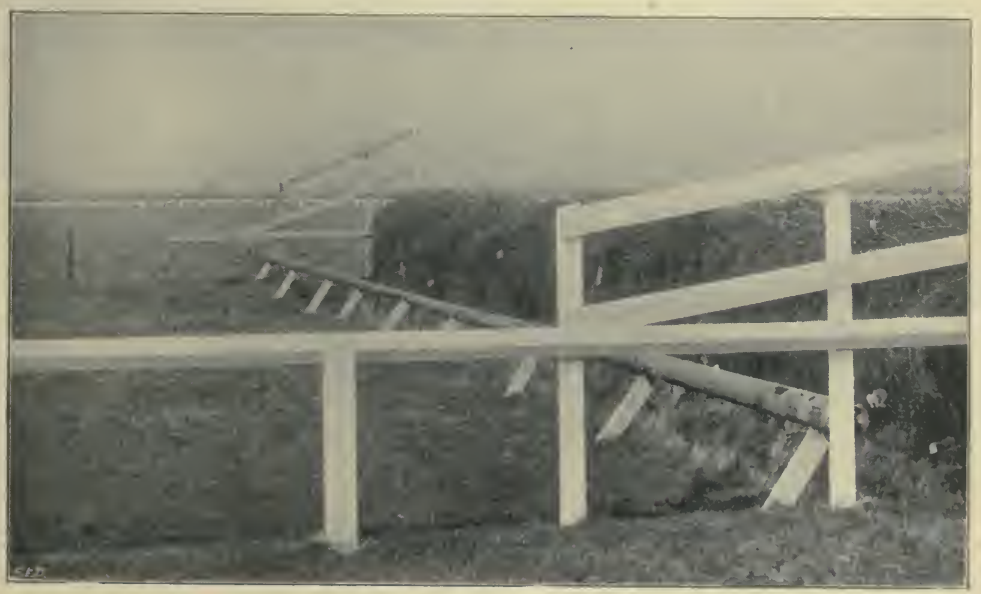

Fig. 254. Usual open ditch with guard rail.

If possible a man should avoid riding close, say half a length, behind an opponent in a chase when nearing a fence; 
for in such a case, the horse will be very apt to "take off " at the same instant the other does so, and consequently, to jump too soon. When galloping side by side, horses seem to like going stride for stride with each other. Besides this, the one that is a little behind may pay more attention to looking at his adversary than at the fence. I have seen on different

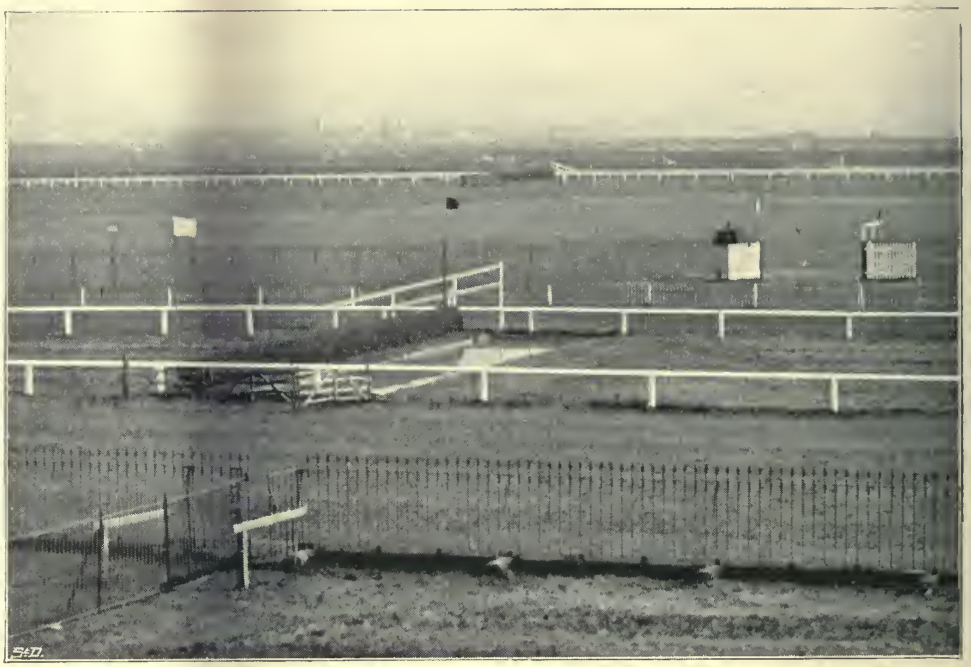

Fig. 255. Water jump in front of Grand Stand.

occasions horses come to grief in this manner and also from an opponent who has a slight lead, "rushing them" at their jumps with the intention of thus bringing them down.

If a horse be alongside another in a chase, it is usually much better to have him on one's near side than on the off ; for if horses refuse, they generally do so to the left, the cause for this often being the injudicious use of the whip on some previous occasion. The fact of a horse being on one's near side when coming to a fence, lessens the risk of his running 
into one ; and having him there may, also, prevent one's own horse refusing if he be that way inclined.

Stirrup leathers for riding across country should generally be a hole or two shorter than for ordinary riding.

Many of the remarks I have made on flat race riding, also apply to chasing.

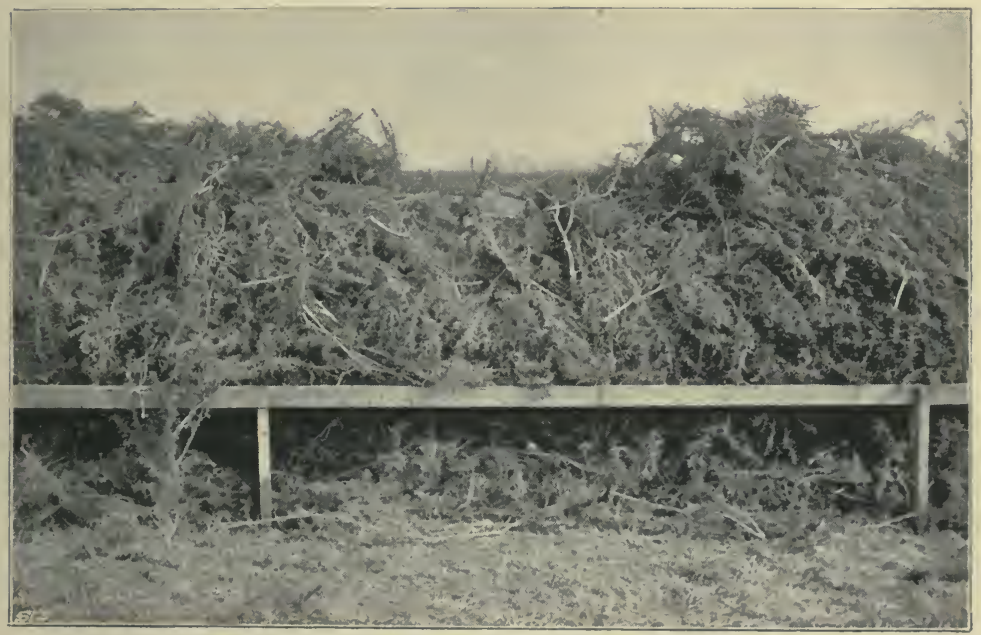

Fig. 256 . Ist and 17 th fence (taking-off side) after race.

GRAND NATIONAL STEEPLECHASE COURSE.

The following description of this course (Fig. 245), which is the best example of its kind in England, may prove useful to riders and trainers of 'cross country horses.

The course, which is a left-handed one, is about $2 \frac{1}{4}$ miles round, is very nearly level, and is all grass, with the exception of about 225 yards of light plough between the third and fourth jumps. The soil is sand with a thin covering of mould. The fences are about 2 I yards broad, and consist of thorn hedges built up with furze or fir twigs, and supplemented in 
several instances with ditches. There are altogether i6 obstacles, of which 14 are jumped twice, so that 30 have to be negotiated to complete the course. The two fences which are jumped only once are the big open ditch at the Old Distance Post, and the water jump. The start takes place a little in front of the right side of the paddock, and

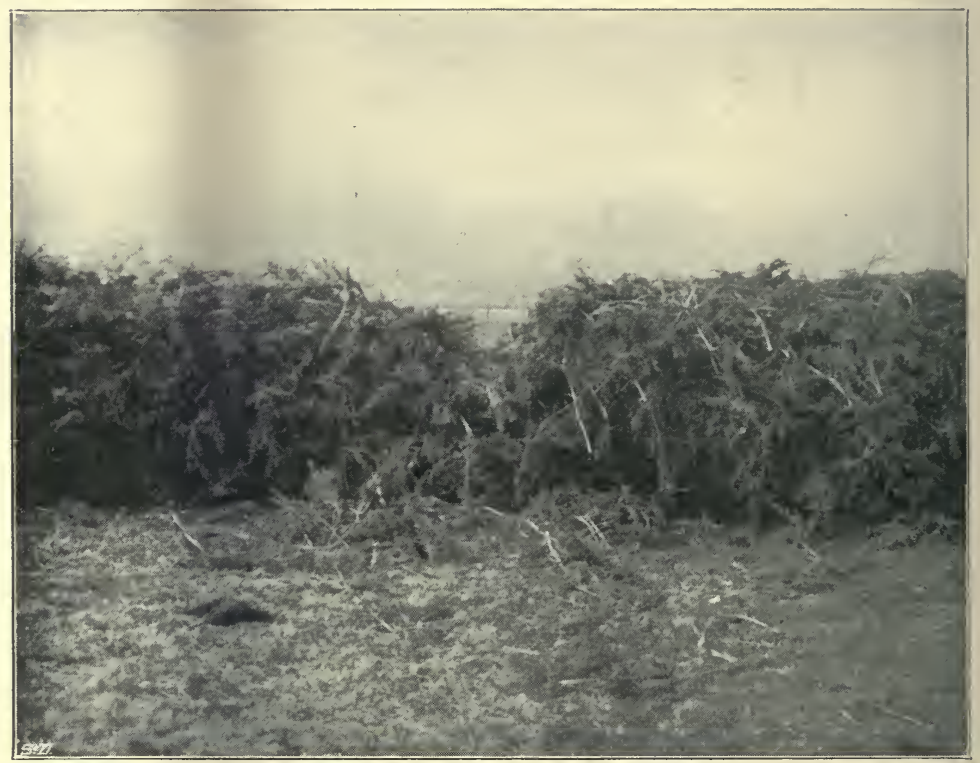

Fig. 257. Ist and 17 th fence (landing side) after the race.

the finish is in front of the junction between the New County Stand and Tattersall's Stand. The canal lies on the left hand side of the course, looking from the Stand; and two drains, Beecher's Brook and Valentine's Brook, run into it, more or less at right angles, from the higher ground on the right. The thirteenth, fourteenth, fifteenth and sixteenth jumps are within the race course enclosure; the remaining twelve being " in the country." 
All the obstacles, except the water jump, have guard rails varying in height from $2 \mathrm{ft}$. to $2 \mathrm{ft}$. $6 \mathrm{in}$. When there is a ditch on the taking off side, the rail is naturally placed in front of the ditch; but when there is no ditch on that side, the rail is put against the fence, to strengthen it. There is a white flag on the right of each fence, and a red one on

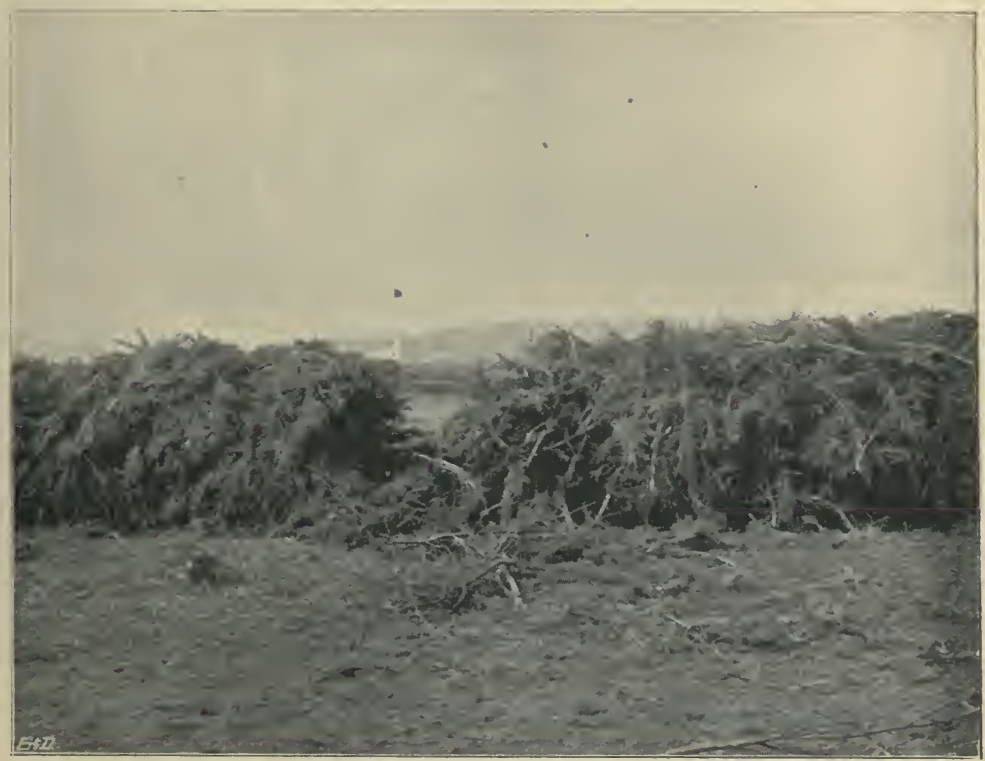

Fig. 258. 2nd and 18 th Fence (landing side) after the race.

the left. Above each of the flags at Beecher's Brook, there is a white flag bearing the letter B. At Valentine's B rook, the flags which are above the others, have a $\mathbf{V}$ on them.

The following details of the fences are from notes and measurements which I took during the Liverpool meeting in March, 1900. In them, I shall use the words "furze" or "fir," according to the nature of the twigs with which the respective hedges were built up. 
First and seventeenth fence, $5 \mathrm{ft} .4 \mathrm{in}$. high, no ditch, furze.

Second and eighteenth fence, 5 ft. 3 in. high, no ditch, fir.

Third and nineteenth fence, $4 \mathrm{ft}$. Io in. high, ditch in front, furze.

Fourth and twentieth fence, $5 \mathrm{ft}$. 6 in. high, no ditch, furze.

Fifth and twenty-first fence, $5 \mathrm{ft} .3$ in. high, no ditch, fir.

Sixth and twenty-second fence (Beecher's Brook, Fig. 246), $5 \mathrm{ft}$. high. Landing about is in. lower than take off. Dry

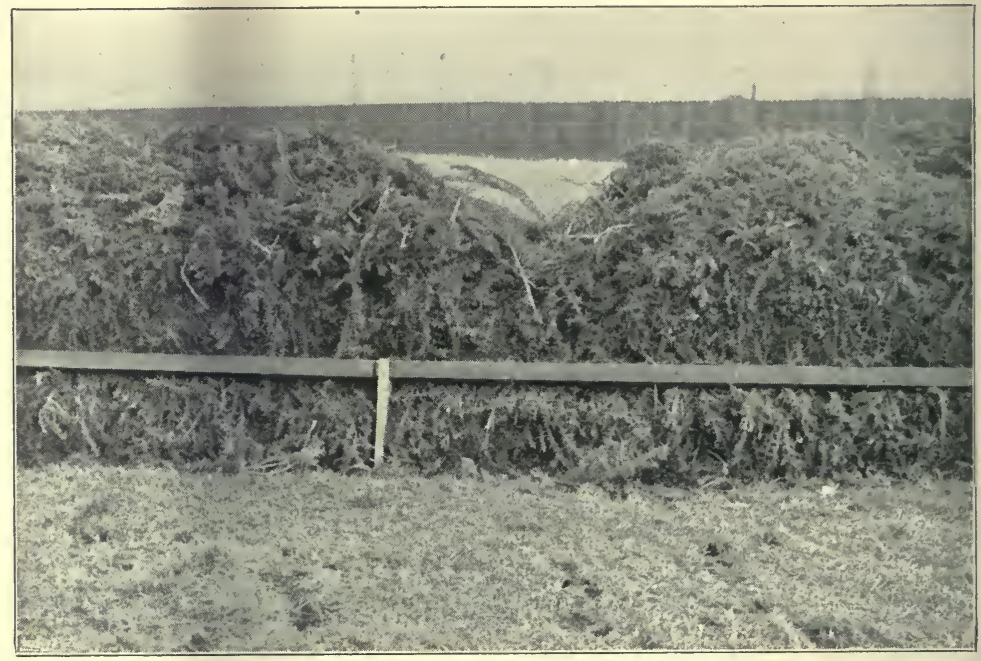

Fig. 259. Beecher's Brook (taking off side) after race.

ditch $3 \mathrm{ft}$. deep and $5 \mathrm{ft}$. 6 in. wide on landing side (Fig. 247). Base of fence about $5 \mathrm{ft}$. thick. Furze.

Seventh and twenty-third fence (Fig. 248), 5 ft. high with ground sloping downwards, no ditch, fir.

Eighth and twenty-fourth fence, $5 \mathrm{ft}$. high, ditch $5 \mathrm{ft}$. wide in front, furze.

Ninth and twenty-fifth fence (Valentine's Brook, Fig. 249), $5 \mathrm{ft}$. high and $5 \mathrm{ft}$. at base. Ditch on landing side (Fig. 250), full of water and $5 \mathrm{ft}$. wide. Fir. 
Tenth and twenty-sixth fence, $4 \mathrm{ft}$. 9 in. high on taking off side, and $5 \mathrm{ft} .4 \mathrm{in}$. on landing side, no ditch, fir.

Eleventh and twenty-seventh fence, $4 \mathrm{ft}$. 6 in. high ; ditch in front $3 \mathrm{ft}$. deep and $5 \mathrm{ft}$. wide; furze.

Twelfth and twenty-eighth fence, $5 \mathrm{ft}$. high; ditch on landing side, $4 \mathrm{ft}$. deep and $8 \mathrm{ft}$. wide ; fir.

Thirteenth and twenty-ninth fence (Fig. 25I), $5 \mathrm{ft}$. high, no ditch, furze.

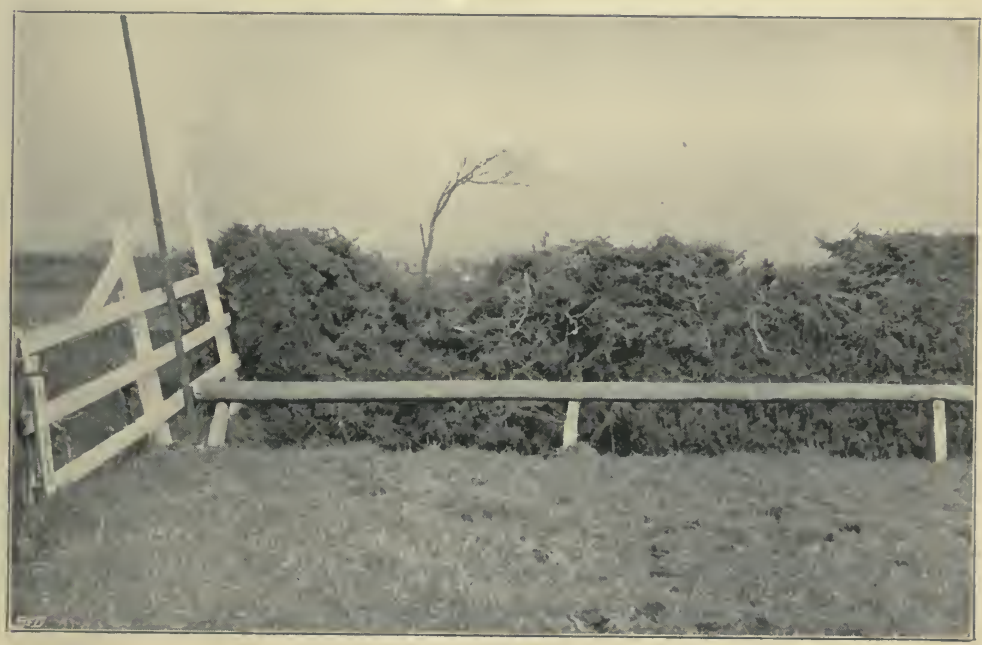

Fig. 260. 8th and 24th Fence (taking off side) after race.

Fourteenth and thirtieth fence, $5 \mathrm{ft}$. high and $4 \mathrm{ft}$. at base, no ditch, furze.

Fifteenth fence at Old Distance Post (Figs. 252 and 253), $5 \mathrm{ft}$. 2 in. high and $4 \mathrm{ft}$. 3 in. thick at base, with a ditch in front. Top of guard rail $5 \mathrm{ft}$. 6 in. away from fence. Furze. The usual guard rail in front of an open ditch (Fig. 254) generally slopes much more towards the fence than does this one. The superstructure on the right end of this fence was formerly the chair for the judge at the distance post in heat races. 
Sixteenth fence (water jump, Fig. 255). There is a hedge . $2 \mathrm{ft}$. $6 \mathrm{in}$. high and $2 \mathrm{ft}$. broad at base, in front of the water and standing about a yard back from it. The water measures about I I ft. across, and the whole affair is about I6 $\mathrm{ft}$. wide.

The day after the race was run, I took the photographs of which Figs. 256, 257, 258, 259 and 260 are reproductions, to show the damage done. As probably all the depicted gaps were the work of more than one horse, these illustrations unfortunately do not give an exact idea of the extent to which these fences could have been safely chanced by a single animal. 


\section{CHA PTER XIX.}

\section{RACING SADDLERY.}

Bridles-Martingales-Saddles-Stirrup Irons-Stirrup Leathers and WebsLead Cloths-Weight Jackets and Belts-Adjustment of Racing Gear.

\section{BRIDLES.}

UNLESS in very exceptional cases, an ordinary unjointed, jointed, or chain snaffle is the only kind of bit which should be used with a racehorse. The thin racing snaffle teaches him to pull, and the curb tends to make him raise his feet too high and bend his knees too much; in other words, to make him gallop "round." With a bad puller, a double bridle might be used, so that in the event of the rider not being able to hold him with the bridoon, he may have the bit reins ready to take up. Horses which can be held with a snaffle, gallop as a rule in far better form, from a racing point of view, in it than in a double bridle, even when the bridoon alone is used; the presence of the curb seeming to deter them from going boldly up to their bridle.

A double bridle is less objectionable for steeplechase riding than for the flat, on account of the greater necessity there is for obtaining command over the horse, and for "collecting" him, in the former, than in the latter business. When it has to be used in a race, the rider, having previously ascertained the exact length of curb-chain which suits his mount, should, before going to the starting post, see that the proper number of links, no more and no less, are taken up. 
Horses which carry the head too low can, as already advised, be ridden in a gag snaffle, or the cheekpieces of the head-stall of the snaffle may be taken up a little. One should be very careful not to adopt any method of arranging the bridle gear which might, in the slightest, check the horse's speed.

It is the fashion at the present time to use only one rein with the snaffle, even when a martingale is on (page 377 ).

\section{MARTINGALES.}

A running martingale will generally be required; for it is a powerful aid in steadying a horse in his gallop, in turning him, and in enabling the jockey to catch a firm "hold of his head." It is especially useful with young horses that are apt to "yaw" about, and with steeplechasers.

Although the standing martingale has been used with signally good effect for cross-country work, it is rarely employed in flat-racing. I have, however, seen many cases of races thrown away by jockeys not being able to hold their horses at false starts, when a standing martingale, properly adjusted, would have given them the power to control their mounts, and win comfortably. I have frequently used, both in training and in flat-racing, the standing. martingale with horses I have owned or have had charge of. After the flag has dropped, except in long races, the pace will generally be sufficient to hold a horse without the aid of any special appliance.

\section{SADDLES.}

The first point to be considered about racing saddles is that they should be long and roomy, as well as light. A two and a half pounds or three pounds saddle, all complete with irons, webs, girth and surcingle, ought not to be less than fifteen 
inches in length; though a six or seven pounds training or steeplechase one should be more than an inch longer.

The steeplechase saddle should fit as close as possible to the horse, without actually pressing on the vertebræ of the back, and all unnecessary stuffing and saddle cloths should be dispensed with, so as to avoid giving play to the saddle. It may be covered with doeskin in order to afford the rider a firm seat. Unless a very light one be used, it should be provided with spring bars for the stirrup leathers. The locks should be always left open. The confidence that the rider obtains from the knowledge that he runs no risk of being dragged, in the event of an accident, is certainly worth the addition of a pound or two to the weight of the tree, especially when it makes the saddle all the more comfortable for the horse.

Leaded saddles, which may be made to weigh a couple of stone, or even more, are very useful when dead weight has to be put up; or for trials, when the trainer does not want his jockeys to know more than he can help.

The ordinary steeplechase saddle is similar to the nine or ten pounds one which is used for training work; though it may be made as light as four pounds all complete. Some exceptionally strong riders, like what Mr. Garrett Moore was, are able to ride across country in a two pounds racing saddle, almost as well as they can do in one five times that weight. Apart from the question of comfort to man and horse, such a very light saddle can hardly be expected to last more than one journey "between the flags"; for even if the tree escapes being broken, the gullet plate will be almost certain to open out, and, consequently, to press on the withers.

The question of having spring bars or not, is simply one of weight. A saddle with them requires a moderately strong tree to bear the rivets for fastening them on. Hence, it cannot well be made under five pounds all complete. 


\section{STIRRUP IRONS}

of racing and steeplechase saddles should have plenty of room for the feet, so that there would be little chance of the rider being dragged in the event of a fall. Very light racing boots have no heels. As light stirrups of inferior material are apt to bend from the rider's weight, and consequently to catch on his feet, great care should be taken that none but those of the very best steel be used.

For racing saddles, the upper part of the eyes of the stirrup irons should be covered with leather, in order to prevent the iron from cutting the webs.

\section{STIRRUP LEATHERS AND WEBS.}

For steeplechasing, leathers are to be preferred to webs, as they are less liable to break.

\section{LEAD CLOTHS.}

A trainer should have weight cloths capable of containing different amounts, with their own actual weights respectively marked on them. One or two cloths weighted with leather up to four or five pounds, will come in useful; and there should be one, at least, capable of carrying not less than twenty-one pounds, so as to obviate the necessity of putting on two small ones; for the saddle will then have less play than it would have were the latter employed.

Each pocket of the weight cloth is, usually, secured by a strap and buckle for safety sake. The only objection to buckles is that they prevent the flaps of the saddle and those of the pannel from lying flat on the weight cloth. Instead of buckles, the pockets may be secured by loops through which passes a strap that is sewn to the rear part of the cloth, and is attached to a buckle on its front part, which lies beyond the saddle flap. If the buckle be to the rear, the rider, when using 
the whip, might hurt his knuckles against it. To prevent a weight cloth slipping off during a race, it may be secured, on each side, by a strap attached to the front part of the cloth, having at its end a loop through which the girth strap passes. This arrangement will prevent the cloth from slipping backwards. It has no tendency to slip forwards. Or the weight cloth may be kept in its place by straps at each end, which straps come over the flaps of the pannel and girth, and are then buckled together.

The leads should be thin and very pliable, and may be covered with washleather, on which it is convenient to mark their respective weights, which will average about half a pound. There should be a few light leads to make up exact weight. In order to obtain increased pliability, leads of half the ordinary thickness may be sewn up in pairs. Leads are covered with washleather, to prevent them from slipping out of the pockets of the cloth, and also to permit of their being provided with "tags," so that they may be readily removed, if required.

\section{WEIGHT JACKETS AND BELTS.}

Instead of a weight cloth, a weight jacket may be used, in case the trainer wants to keep a trial "dark." The jacket should be made to fit tightly, and should have pockets round the body to contain leads. In this way a stone or more may be carried. A shot belt may be used for the same purpose, around the waist; and should be supported by shoulder straps. For a steeplechase, a weight cloth is much to be preferred to a weight jacket; as the latter impedes, and often hurts, the rider by the leads striking against his sides. For a flat race, I think the jockey will ride to greater advantage with a weight jacket, than if all the lead was in a weight cloth. 


\section{ADJUSTMENT OF RACING GEAR.}

The running martingale, for ordinary racing purposes, should be of such a length that, when drawn straight up, the rings will reach to about four or five inches above the top of the withers. For steeplechasing, however high the horse may hold his head, it should never be so short as to make the pull of the reins to come below the withers.

The saddle should be placed just clear of the animal's shoulder blades and no more. For a training gallop it may be placed a little farther back, so as to lessen the strain on the fore legs, unless, indeed, the horse has a weak spot behind. The surcingle alone should pass through the loop of the running martingale, and its buckle should come low down so as not to press against the horse's side and hurt him. A pad, about a foot broad, and eight inches long, with about four inches down the centre unstuffed, will be useful with a light racing saddle, to prevent the gullet plate from pressing on the withers. If there be danger of this happening, and a pad be not at hand, one may be easily made for the occasion, by taking a flannel bandage, folding it in two, and then rolling it up very loosely from both ends, till the two rolls are within five or six inches of each other. This improvised pad may be placed over the withers and underneath the pommel of the saddle. The tapes of the bandage may be previously removed. If a bandage be not at hand, a rubber may be folded and used in the same manner. By this plan, the gullet plate will be kept off the withers. Even when the gullet plate does not come down too low, a thin woollen pad is generally used to protect them, when a racing saddle is put on. A large sponge makes a good pad. Two sponges, one at each side of the withers, would act better than one placed (as is usually done when a sponge is employed) on the top of the withers. 
It is advisable when girthing up a racing saddle, to have the girth one hole looser than it would be were there no surcingle, and to have the surcingle one hole tighter than the girth. This is done to prevent both "going" in the event of the animal unduly expanding his chest, an accident that not unfrequently happens.

Leathers for "steeplechasing should be twisted, just before the race, in the manner shown in Fig. 152.

As it sometimes happens that amateurs who are not particularly good horsemen attempt to ride over a country, I trust I may be pardoned by critical readers, if I remark that the best way to make a saddle less slippery than it would naturally be to an indifferent rider, is, before mounting, to rub over the seat and flaps a little finely powdered resin. This is infinitely more efficacious than wetting them, or the insides of the breeches, with water. I would not advise any such practice to be adopted for ordinary riding; but in a chase, especially when "the money is on," a man's first object should be to "remain" in his saddle.

New girths should not be put on for a race, as they will stretch considerably, and may allow the saddle to shift its position, or even to turn round. A silk girth should never be used, as it will be almost certain to hurt the horse. It is far better, instead of using a silk one, to put up a little extra weight in the form of a comfortable web girth, which should be comparatively broad.

A weight cloth should be placed well forward, with the leads equally divided on both sides. If there be an odd piece, it may be put in one of the pockets of the off side, if the race be on a right-handed course, and vice versti. To prevent the horse's sides from being hurt, no leads should be put into the pockets over which the girth passes. 


\title{
CHAPTER XX.
}

\section{KEEPING DOWN WEIGHT.}

\begin{abstract}
Objects - Theory of "Wasting" - Permanently Keeping Down Weight "Wasting" for Race Riding.
\end{abstract}

\section{OBJECTS.}

THE alternative of keeping down weight or giving up riding is often presented to hunting men, as well as to jockeys. In the latter case, the problem to be able to ride $8 \mathrm{st} .7 \mathrm{lb}$., is frequently impossible of solution, even by incurring serious danger to health. In the former, the effort, if judiciously carried out, will in the vast majority of cases be highly beneficial from a hygienic point of view; for certainly not one man in a hundred would weigh more than I4 st. when in the pink of condition, and even at that weight one ought to be able to see as much sport as an ordinary man would require, supposing that one was well mounted. An undue amount of fat in the rider is not only a burden to the horse which carries him, but it also diminishes a man's riding powers, and generally has a bad effect on his nerves. From a hunting and ordinary riding point of view, I shall assume that reduction of weight is not carried beyond a healthy limit. With jockeys, it has often to be pushed as far as human endurance will permit. In all cases, injudicious methods of "wasting" are liable to produce severe constitutional disturbance. In guarding against such an ill result, it is useful to understand the principles which regulate bodily supply and waste; for on these two factors depends 
the question we are at present considering. We may accept the truth of the statement, that the quantity of food or drink which every fat person consumes, is too large in proportion to the amount of exercise he takes. If this were not so, we would have instances of under-fed and hard-worked horses being too plump! It is almost needless to say that their nutrition is regulated in a manner similar to that of mankind. On the other hand, there are both men and horses that no amount of good food and idleness could make obese; because their organs of assimilation are abnormally inactive.

\section{THEORY OF "WASTING."}

The human body is a motor machine in which movement is produced and heat maintained by the oxidation of its structures (tissues); the oxygen for this purpose being absorbed into the body from the air taken into the lungs. As far as the production of heat is concerned, this oxidation is similar to the combustion of wood or coal in a fire; but the production of motion appears to be more or less a direct result of oxidation without the intermediate stage of heat, which we see in a steam engine. The principal products of the union of the tissues with oxygen are carbonic acid, water, and waste nitrogenous matter. In addition to the loss of substance from the continued process of oxidation, the weight of the body is further reduced by the escape of water which is passed out of the system in an unchanged condition. Carbonic acid gas is given off by the lungs and to a slight extent by the skin; and water is removed by the skin, lungs and kidneys. The excretion of waste nitrogenous matter is a more complex affair. Under conditions of health, almost all of this débris is removed from the tissues, by the blood, in the harmless form of urea, which is very soluble in water, and which is carried out of the body in a dissolved state in the urine. In health, a small percentage of 
uric acid is also found in the urine, combined with sodium and other bases. An average daily excretion of urea and uric acid would be, respectively 500 grains and 8 grains. It appears that uric acid is formed by the kidneys from urea. When the functions of nutrition and excretion become disturbed in certain ways, the urea in the blood becomes more or less replaced by other nitrogenous compounds which produce various distressing effects on the system, such as depression, feverishness, and gout. The chief factors in the production of an excess of these poisonous nitrogenous compounds in the body are: consumption of too much nitrogenous food; want of exercise ; indigestion; functional derangement of the kidneys and liver; deficiency in the supply of drinking water ; and individual idiosyncrasy.

Uric acid is so generally regarded as the chief poisonous form assumed by waste nitrogenous matter in the system, that a few remarks on its action may not be out of place. We learn from the researches of many reliable authorities that although urea is always present in healthy blood, uric acid is not found in that fluid. The blood of persons suffering from gout, on the contrary, always contains uric acid combined with sodium. Dr. Luff in his very valuable book on The Pathology and Treatment of Gout, shows that this disease is due to deficient excretion of uric acid by the kidneys. It is probable that in certain diseased conditions, uric acid is formed not only by the kidneys, but also by other organs. The uric acid which is thus passed into the blood, combines with sodium carbonate of that fluid, and forms sodium quadriurate, which is a very soluble compound. It would doubtless be rapidly carried out of the system without doing any harm, were it not for the fact that under ordinary conditions, it becomes quickly converted into sodium biurate, which is very sparingly soluble in blood, and consequently becomes deposited in various parts. This precipitation of 
sodium biurate in the tissues appears to be the exciting cause of gout. Dr. Luff has shown that the action of sodium biurate is mechanical, and is in no way poisonous. Also, he proves, that the mineral constituents of green vegetables (especially spinach, Brussels sprouts, winter cabbage, French beans, Savoy cabbage, turnip tops, turnips, lettuce, beetroot, and celery) and fruit taken as food, delay the conversion of the harmless quadriurate into the hurtful biurate, and that they increase the solubility of the latter. Green peas appear to have no good effect in this respect. Dr. Luff points out that the presence of oxalate of lime in tomatoes, rhubarb, and asparagus is apt to be irritating to the kidneys of gouty subjects, during its excretion in the crystalline form. He proved by experiment that an artificially prepared ash of the same composition as the natural ash of any of these green vegetables, has no good influence in the elimination of sodium biurate, and that the same may be said of salts of lithium, and salicylates. The mineral matter of meat diminishes the solubility of sodium biurate, and in this respect is injurious to gouty persons.

Scientific research has thrown but little light on the nature of the poison or poisons which, as we all know, are generated in the system by an excess of nitrogenous food, of which meat is the chief representative, and by fatigue. The poison or poisons in question are in all probability some waste nitrogenous product or products, none of which is uric acid. Experience, however, tells us that the consumption of green vegetables and fruit facilitates their elimination in a manner as effective as it is in the case of uric acid. Dr. Luff wisely draws attention to the fact that individual idiosyncrasy should be carefully studied with regard to the consumption of vegetables, some of which produce indigestion in certain persons.

To make up for the loss of substance caused by the oxidation of the tissues and by escape of water, the body 
needs water, food, and a continual supply of oxygen, which, as we have seen, is obtained by the lungs from the breathedin air. Water, which forms about three-quarters of the entire weight of the body, is necessary for the repair and development of the tissues; for the replenishment of the blood and other fluids of the system; for keeping down surplus heat by means of evaporation; and for removing injurious products out of the body. Ordinary food consists. of nitrogenous (albuminous) matter, starch, sugar, fat, mineral matter, and water. Albuminous matter is largely found in meat, fish, eggs, and cheese. Bread, potatoes and rice contain a high percentage of starch, which is present in all food grains. There is only a small proportion of starch in green vegetables, and practically none in fruit. A certain amount of albumen is required in food, in order to make up for the loss in nitrogenous matter which the tissues constantly experience. Sugar, starch, and fat in food can mutually replace each other to a great extent without injury to health.

Although a mixed diet is best for mankind, an exclusive meat diet would furnish us fairly well with all the materials. our body requires, and, for our present purpose, would have the great advantage of forming very little fat. Unfortunately, it possesses the serious drawback of over-loading the system with waste nitrogenous matter, which has a depressing and hurtful effect on the body. Hence the objection to. Banting, which was the plan of getting down weight by means of an almost exclusive meat diet, which a gentleman of that name proposed and practised many years ago. Although it obtained an extended trial, it naturally proved a failure.

The nitrogenous matter of white fish and cheese appears to have a less depressing effect on the system, than that of meat. Extracts of meat are particularly bad in this respect, although at first they have a stimulating influence. 
Fat, sugar, and starch readily form fat in the body. Starch has the further disadvantage from a weight reducing point of view, that many people, especially those who have passed their first youth, are unable to digest it easily, and from eating it are liable to suffer from rheumatism, as a consequence of dyspepsia. One of the chief reasons for toast being more digestible than bread, is that the process of toasting converts a portion of the starch into sugar, which is very easy of digestion. In the dilemma of getting ill from eating too much albumen, or of getting fat from relying too much on starch, sugar and fat, we may escape both difficulties by adopting a diet of ordinary mixed food, and reducing its amount to the required extent. Such a plan, though thoroughly sound, demands more self-denial than most men can exercise. A more workable alternative is to take advantage of the small fat-forming powers of nitrogenous food, and to use means for obviating the effects of its deleterious products, which we may do by the consumption of a sufficiency of green vegetables and fruit, neither of which unduly increase the weight. As the mineral matter of plants is more or less soluble, boiled vegetables will contain a much smaller proportion of it than raw vegetables or fruit. The mineral constituents of vegetables employed in soup, will of course be retained.

Water plays such an important part in the removal of deleterious substances from the system and in all other vital processes that undue curtailment in its consumption should not be resorted to, except in extreme cases, and then only for a comparatively brief period of time.

As all the movements of the body are produced by oxidation of the tissues, exercise will be accompanied by loss of weight proportionate to the severity of the work. Apart from its weight-reducing action, exercise increases the strength of the tissues and improves the general health, by quickening 
the circulation and breathing, both of which functions are engaged in the work of supplying the system with oxygen. This gas and water are the two great purifiers of the body.

Under ordinary "conditions of life, most of the force required for the production of movement and heat in the body is obtained from the starch, sugar and fat in the food; albumen being mainly concerned in the repair of nitrogenous tissue. Hence, exercise has little effect in increasing the amount of nitrogenous waste during health; but when the reserve of fat becomes exhausted in cases of starvation, the muscles and other nitrogenous tissues yield up their force-producing elements with the result that they suffer from a corresponding loss of substance, and the system becomes more or less loaded with nitrogenous waste products, which produce a depressing and hurtful influence on the bodily and mental powers. These ill results are particularly well marked in jockeys who trust more to sweats and Turkish baths than to long-continued exercise for reducing weight.

The mineral matter of the body consists of certain substances which, like the phosphate of lime of bones, are comparatively stable by reason of their being sparingly soluble; and others, like soda and potash, which, being easily dissolved in water, rapidly pass out of the body, and consequently require frequent replacement by means of food. In the human and animal body, soda and potash play a large part in nutrition, and are found in about equal quantities; but in plants, the percentage of potash far exceeds that of soda. As a large excess of potash is hurtful to health, and as it can be removed by soda, we find that people who subsist chiefly on plant food, require it to be supplemented by soda, which they usually obtain from common salt. Hence the large use of salt among the potato-eating peasantry of Ireland, and the rice-eating natives of India. Human beings who live mostly on meat, have little or no 
craving for salt. Herbivorous animals, like horses and cattle, and carnivorous animals, like dogs and cats, illustrate this principle in a similar manner. Therefore the quantity of added salt should vary proportionately to the amount of vegetable food consumed. "The due admixture of foodgrains belonging to different classes will secure the necessary mineral ingredients, provided an allowance of at least 230 grains of common salt be added to the daily ration of a man having a body weight of I05 lb." (Church). With a diet consisting chiefly of meat, the necessary amount of soda would of course be much less, say, from one-eighth to onesixteenth of an ounce, supposing that no bread, potatoes or other starchy food was eaten. Common salt (chloride of sodium) furnishes not only soda to the system, but also chlorine, which is one of the constituents of gastric juice.

With respect to medicine for getting down weight, we may rest assured that purgatives, such as Epsom salts, should be employed only when time is of supreme importance; because they reduce the strength, and any advantage that may be gained from their use in clearing the system of impurities may be obtained by other means which have little or no lowering action. In this respect, we are concerned principally with the question of guarding the body from the hurtful effects of an excess of waste nitrogenous products, which we may do by the judicious consumption of green vegetables and fruit. It is always well to have the advice of a doctor, as regards taking medicine. Sodium salicylate in doses of, say, I 5 grains two or three times a day, now and then, has often a good effect in relieving depression.

\section{PERMANENTLY KEEPING DOWN WEIGHT.}

Whether a man wants to keep light for ordinary purposes or for race riding, he cannot hope to continue the effort for a long time, unless he does so under healthy conditions; for if 
he persists in outraging hygienic laws, his constitution will become shattered, and his nerves unstrung, in which state it will be impossible for him to ride well, no matter how great his ability, and how extended his experience may be. In the first place, he should take abundance of exercise, should observe strict moderation as regards intoxicating drinks and food, and should not try to reduce his weight beyond a healthy limit. In ordinary cases, as for hunting, a man in the prime of life should take exercise equivalent to walking fifteen miles a day; should not eat oftener than twice a day (say, breakfast at halfpast eight and dinner at half-past five); and should not take more than three or three-and-a-half pints of fluid, of which light ale might constitute a pint, or light claret, half-a-pint. This would allow him two cups of tea or coffee for breakfast, two cups of tea in the middle of the day, and a pint or a pint and-a-half of beer or of, say, claret and water for dinner. The reputation which ordinary ale has as a fattening agent, is due far more to the quantity drunk than to the nature of the fluid, in a pint of which, the amount of fattening material would be inappreciable during a day's work. If tea is taken, it should be made very weak, and in that state is, I think, most palatable, when it is made in Russian fashion, by infusing a little less than half a teaspoonful of tea in a pint of boiling water, and drinking the tea with a slice of lemon in it, and sugar. The concession of a moderate amount of sugar and milk may be safely made, when extreme measures are not required. We must bear in mind that although a sufficiency of water (pure or combined, as in tea, coffee, beer, or light wine) is a necessity for health, an excess of it is a potent agent for putting on weight.

The diet should consist essentially of animal food (meat, poultry, game, fish, and non-fatty cheese), green vegetables and fruit, with a little common salt. To avoid thirst, the meat should be fresh, not salted. The best way to cook 
the meat is to roast or grill it; for its good qualities are preserved, and it is presented in a digestible form by either of these processes. Boiling deprives both meat and vegetables of a large portion of their health-giving mineral matter; and frying and stewing are apt to make the meat sodden with fat. The chief office of the stomach is to cause the digestion (solution) of albumen by means of the gastric juice, which does not act on starch. Consequently, when meat is impregnated with fat, more or less of its contained albumen is liable to be passed in an unchanged condition into the intestines. with the probable result of indigestion. As heat coagulates albumen, clear soup will be more or less free from this nourishing constituent, which is also practically absent from essences of meat. If soup be used, it should be allowed to cool after being made, and all the fat skimmed off. It can then be heated. As soup contains almost all the nitrogenous constituents of the meat which has been boiled in it, this meat should be eaten by the person who takes the soup, in preference to roast or grilled meat, which would furnish an undesirable addition of nitrogenous material. A very wholesome soup, known in Russia as shchi, is made by boiling meat with a large quantity of white-heart cabbage. If in frying, the pan be heated to redness before the meat is put into it and no dripping, butter, lard or other kind of fatty material be employed, the albumen on the outside of the meat will become quickly coagulated, and the interior portion of the meat will become more or less protected from the action of the fat in the pan. Hence this plan of frying is much superior from a health point of view, to the ordinary method. It is evident that with whole fish, the objection to frying is not so strong, as with cut-up meat.

The following may be regarded as proscribed articles of diet: Bread, cakes, potatoes, rice, cream, new milk, butter, fat, sweets, stews, minces, puddings, pastry, salt meat, spiced 
meat, salt fish, and everything containing an excess of fat, sugar or starch. To the list of vegetables given on page 435 , we may add endives, water-cress, mustard-and-cress, spring onions, leeks, ordinary onions, and scarlet runners. Among suitable fruits we have: strawberries, apples, pears, cherries, greengages, peaches, apricots, plums, gooseberries, and pineapples. As skim or separated milk consists of water, albumen (casein), and mineral matter, a little sugar, and only about one half per cent. of fat, no objection can be taken to its moderate use.

The chief difficulty in the adoption of the proposed diet, is the habit which most people have acquired of regarding bread, toast, or biscuit, as an indispensable article of food at breakfast time. A fair trial of fruit or green vegetables as a substitute for bread, will soon prove that this idea is a fallacy.

When getting down weight, it is well to be weighed every day, to see how the process of wasting proceeds. A Salter's spring balance which marks half-pounds up to $200 \mathrm{lbs}$, is a cheap, portable, and useful machine for this purpose; supposing that the person who uses it is not inordinately heavy.

A person who is out of health should not attempt reduction of weight, except under competent medical advice. If, when getting down weight according to the plan described in this chapter, a man feels the change of living to be too severe a trial on his strength or nerves, he will do well to "ease off" a little, until he has recovered.

An effective method of keeping down weight without alteration in the amount or nature of the food and drink, is to abstain from all fluids during meals, for two hours after them, and for a short time, say a quarter of an hour, before them. The chief objections to this plan are that it is apt to bring on constipation and rheumatism. In any case, it is more or less injurious to health. 
WASTING FOR RACE RIDING.

A jockey who wishes to keep down his weight for the season, can do so by strictly adhering to the regimen which has just been described, and by taking a large amount of exercise, as, for instance, walking twenty or twenty-five miles a day. By pursuing this system, a man in a month or six weeks will get down to within five or six pounds of his lightest riding weight, which, if necessary, can be attained by a couple of sweats and three-quarters or one ounce of Epsom salts. John Osborne and Edwin Martin used to waste by taking long walks without sweaters, and observing strict moderation in food, which system they found far better than that of violent purgatives and heavy sweats. Both of these fine horsemen have repeatedly got off a couple of stones in a fortnight or three weeks, and have felt all the better for it. Regular sweats depress a man so much and make him so nervous, that he cannot continue taking them in an effectual manner for a long period. Also, a jockey will find that after getting off five or six pounds by a single sweat, he will put nearly all the weight back again by eating even a moderate meal. Although the first few long walks without sweaters will not take much weight off, this work will rapidly waste down the superfluous flesh, if continued. As fluid of any sort puts up weight, a jockey will often be forced to exercise more abstinence in drinking, than is good for his health. I need hardly say that the less spirits he takes, the steadier will be his nerves. The system of long walks and abstinence as regards food and drink, requires so much fixity of purpose and self-denial, that it is easy to understand that it is unpopular among so-called fashionable jockeys.

If a man is too lazy to walk long distances every day, he should adopt a starvation diet; and if that is not sufficient, he will have to rely on sweats and physic. In this case, the 
training may commence with three Cockle's pills at night, and an ounce of Epsom salts next morning. On that day, while the physic is working, nothing beyond a quiet walk should be done; but on the next and succeeding days he should take a sweat, and about every third day, an ounce of salts the first thing in the morning. On the days physic is taken, a moderate walk without sweaters will be enough. The sweat may be arranged in the following fashion: A pair of long woollen stockings, and over them a pair of thick worsted socks and a pair of boots; three long drawers of "yellow sweating flannel," which is made for the purpose, and a pair of trousers, or if these sweating drawers be not available, a pair of drawers and a couple of pairs of thick cloth trousers; four yellow flannel body sweaters, or their equivalent in flannel shirts, with a waistcoat or two, a shooting coat and a greatcoat for the body; a pair of warm gloves; a large woollen comforter wrapped round and round the neck; and a couple of large cloth caps pulled down over the ears, will do as far as clothing is concerned. A pair of thick woollen socks, folded as if they were about to be put on the feet, are a capital substitute for gloves. Care should be taken that every part is protected from the air ; for even if the hands or neck be left bare, perspiration will be materially checked. With this amount of clothes on a warm day, most men will find that a sharp walk of eight miles will be as much as they can manage without overtaxing their strength. One should arrange if possible, to have the wind at one's back when returning home, so that it may not prevent one from sweating freely. The walk being finished, the man in training should lie down with a lot of rugs heaped over him and remain thus as long as he can, which usually will not be more than ten minutes or a quarter of an hour. During this time, the heavy oppressed feeling about the heart will be found to be very trying. Experto crede. 
After the rugs and clothes are taken off, the man should be quickly dried, and should then have a warm bath, after which he may have a cold douche, if his liver be in good order. He should not dress until he is thoroughly cool, and ought to forbear taking anything to drink, as long as he possibly can after a sweat; for the more heated the body is, the more rapidly will it absorb fluid.

In India and in other hot countries, a man cannot walk in clothing much more than half the distance he could accomplish in England under similar circumstances.

If a man has hacks to ride, and is unable to walk, he can take a sweat on horseback by putting on clothes as described, and then going for a sharp ride; but this, though pleasanter, will not be as effective as walking.

A sweat like that I have described, will take from four to six pounds off an ordinary man, provided that there is little or no wind, which very materially checks perspiration. When taking a sweat in hot climates, one should avoid the sun as much as practicable; for few things tend to make one so nervous, as hard exercise when exposed to its influence. Having one's nerves in good order is of far more consequence than being able to get the exact weight; a remark which applies particularly to men who ride their own horses, for jockeys have but little option in the matter, because owners are often foolishly exacting on this point. I am certain that on the flat, a jockey can ride fully five pounds better when he is fit and well, than he can do when he is weak from wasting. In steeplechasing, the difference is one of stones and not pounds.

A lamp bath is often taken instead of a regular sweat, if the jockey is lazy, or is not able to walk well. It can be arranged as follows: A lamp for the purpose, or three or four small saucers full of oil with lighted cotton wicks in them, are placed under a chair on which the man sits. It is well to have the 
seat of the chair made of wood and its under surface covered with zinc or tin, which will prevent it from being burned, and will also radiate the heat better than wood would do. He should have no clothes on, but should have several rugs and blankets wrapped round the chair and himself and brought tight round it, so that the heated air may not escape. A waterproof sheet considerably assists this operation. A little practice is required to teach one how to get the rugs and blankets fixed. If the hot air is properly kept in, the person taking the bath will, in about ten minutes, break out into a profuse perspiration. He may continue in this state for an hour, which will be as long as most men can bear. Portable baths are specially made for this purpose.

A lamp bath will take off little more than half the weight that a regular sweat will do; for its action is confined to the skin. In the other form of sweating, there is general waste, in the removal of which the lungs largely help, and thus the blood is kept pure. Under the influence of a lamp bath, the action of the heart becomes tumultuous after a short time, and the breathing laboured, on account of the lungs becoming gorged with impure blood, until faintness and marked distress ensues. By persisting in these sweats, the heart is liable to become permanently injured.

The action of a Turkish bath is similar to that of a lamp bath, except that it is not so severe.

I have known some men keep down their weight for race riding by taking plenty of exercise, and by rigidly abstaining from drinking more than a pint or a pint and a half of fluid during the twenty-four hours.

The more a man trusts to hard exercise and self-denial, the fitter will he be to ride. Sweats and physic should be employed only when time is narrowly limited, and the amount to be got off is very considerable.

A man can ride in a two or a two and a half pound saddle, 
about five pounds less than what he weighs in ordinary clothes.

If a jockey is in hard condition, he need allow nothing for wasting during a race on a hot day, because the horse will siveat as much into the saddle cloth or panel as the jockey is likely to lose.

The following is a safe rule to adopt for weighing out before a race. Everything, including the bridle, being in the scales, put half a pound on the opposite side, and if the jockey can draw his weight with this extra half-pound he is quite safe.

Weighing before a race is called "weighing out," and after a race it is termed "weighing in."

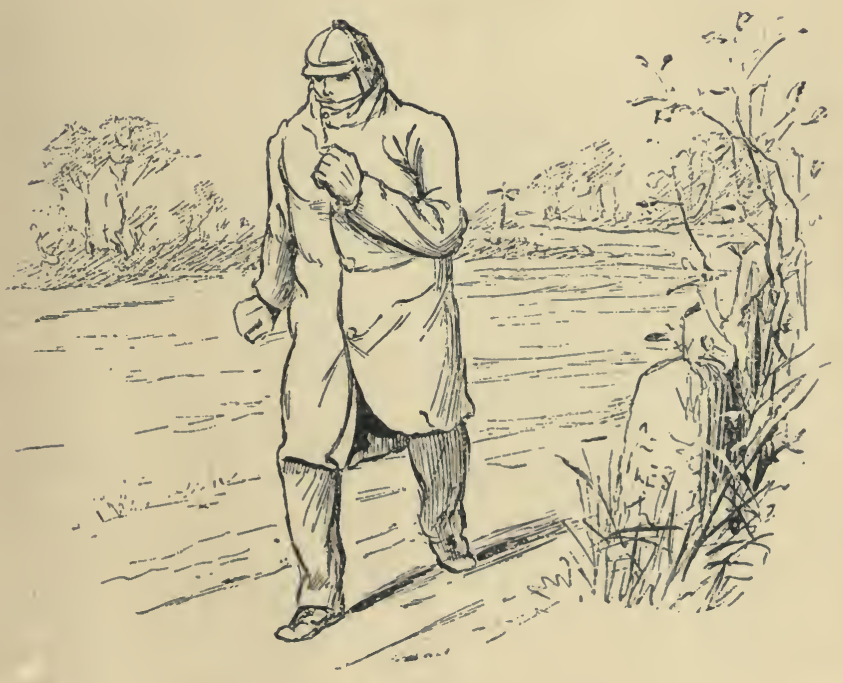




\section{CHAPTER XXI.}

\section{I L I T A R Y R I I I G.}

A CAVALRY soldier requires all the firmness of seat needed in hunting; for although in peace he will have to ride chiefly in the school and on parade, he may have to cross various forms of difficult country on service. As he is taught on the supposition that he has only his left hand on the reins, he ought to acquire a high degree of expertness in using the other aids (Chapters X. and XI.). In obtaining the necessary control and precision, he will have to carefully avoid allowing his horse on any occasion to keep behind the bridle; for an animal which does not go up to the bit, will be lacking in forward impulsion, and as a rule will be ready to jib and rear as a "defence." Also, school instruction should be made strictly subservient to outside work. Hence, in order to prevent a horse becoming a slave to school routine (routine, as the French call it), he should be made to devote his entire attention to the aids, and should not be permitted to give any part of it to landmarks inside the school. For instance, when a horse is going round the school ("going large"), it ought to be immaterial to him whether he is kept on the track or a yard or two away from it. Also, he ought to do the passage as well in any direction, as when his head is comparatively close to the wall, or is carried parallel to the track, supposing that the school is an open one.

I have already indicated (pp. I65, 225 and 226) that the plan of holding the reins crossed in one hand, as in Figs. I 59 . 
and 160 , enables a rider to give separate indications with either the near or off rein far more readily, than when the reins are simply drawn through the hand and kept apart only by the little finger, according to our military style (Fig. I67). Besides, the former method affords a much firmer hold on the reins, than the latter, and does not stiffen the hand.

Ordinary school movements should comprise those described in Chapter XI., and a change of the leading fore leg at the canter, which can be best obtained-say, if the off fore is leading-by touching the animal with the drawn-back right heel or spur, at the moment that the near fore comes on the ground (Fig. 19); pressing the off rein against the neck by carrying the left hand a little to the near side, and at the same time feeling the near rein by rotating the hand, so as to bring the palm upwards ; and leaning the body to the near side. The reversed aids will have to be employed for a change from the near fore to the off fore. Readers who have studied Chapters $\mathrm{X}$. and XI. will understand the rationale of these directions. Practice in doing the figure of 8 (see Illustrated Horse-Breaking) will greatly help in making this change. Although the turn on the haunches is a classical school movement, its well-marked tendency to make a horse rear, is a strong argument against its attempted execution. It consists of a turn on the inward hind leg as a fixed pivot. Hence, in a turn on the haunches, say, to the left, the rider has to lean back and to the left; apply his drawn-back right foot strongly to the horse's side; and turn him round to the left by means of the reins, without allowing him to raise his near hind off the ground. The more this turn is made on the inward hind leg as a moving pivot, the less danger will there be of making the animal rear. In this case, the turn will be more or less on the centre.

Readers who desire to study high school riding, will find that subject admirably explained in Barroil's Art Équestre. 
Officers and men are given good seats in our military riding schools; but no advance in the science of the aids has been made in these establishments since the battle of Waterloo, as far as I can find out. When I took my first lessons as a cadet in the Royal Artillery Riding School, Woolwich, forty years ago, the system of equitation was then the same as that practised as far back as the oldest soldier at that time could remember, and is the one now in vogue. We have seen that a knowledge of the application of the aids cannot be acquired without an acquaintance with the paces of the horse, about which forms of equine locomotion little or nothing was known forty or even thirty years ago. We accordingly find in the present Cavalry Drill book, the following wrong and unscientific method for the rein back: "Each man will feel both reins lightly, by turning the little fingers towards the breast; and will press both legs to the horse's sides to raise his forehand and keep his haunches under him; the rider must not have a dead pull on the horse's mouth, but should ease the reins after every step, and feel them again." By referring to page 247 , we can see that these directions of feeling both reins, raising the forehand, and keeping the horse's haunches under him in the rein back, are opposed to good horsemanship. In Cavalry Drill, the aids being limited to the hands and legs, no advantage is taken of the distribution of the rider's weight as an aid; and the leg which serves as an aid in regulating the lateral movements of the hind-quarters, acts by "closing" or by " a stronger pressure," and not by being drawn back, as ought to be done. The portion of the horse's side which would be acted upon by the closing of either leg, according to our cavalry practice, would be so close to the centre of gravity of the weight to be moved (that of the horse and rider), that such pressure would be useless, if not detrimental to the object in view. Also, when sitting upright 
in the saddle (as cavalry-men are directed to do), it would be impossible to press one leg, to any appreciable extent, stronger against one side of the horse than the other leg. Further, in the passage (p. 245), the moment when the horse's outward foreleg is brought across the inward foreleg and placed on the ground, is not utilised by our army riding masters. The military "shoulder-in" is a passage with the head turned the wrong way, and has as much sense in it, as making a sound horse walk lame. This false and absurd movement was evidently founded on a misconception of the French term, epaule en dedans, which is used in French riding schools to describe the passage with the tail towards the wall (croupe au mur), and the head and shoulders towards the inside of the school. Our drill book system of riding has the effect of making a horse deplorably routiné.

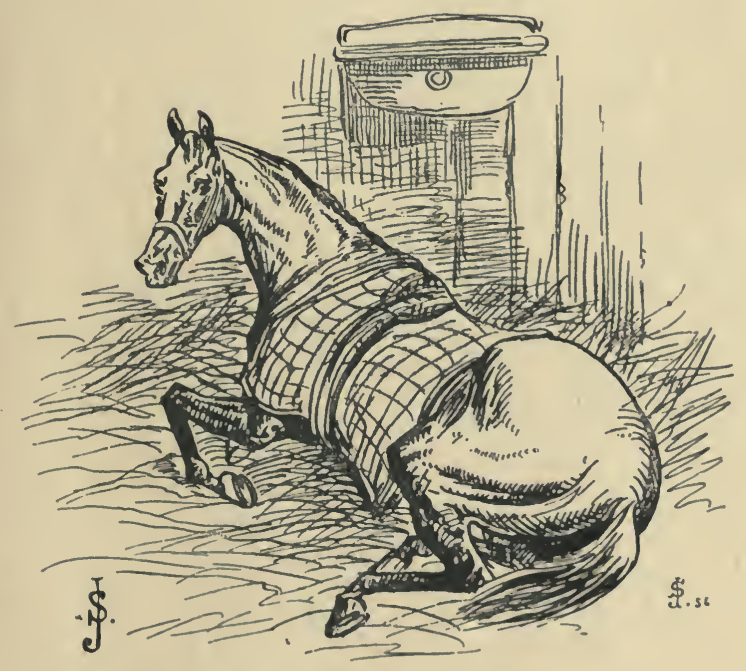




\section{N D E X.}

AIDS, THE, 207.

Alderson, Colonel, 105.

Amory's, Sir John, 296.

Annealed iron, 27-29.

Apology, 386.

Archer, Fred, 3, 6, 375, 393, 399.

Ash plant, 219.

Asteroid, 395.

Atherstone, 340.

Austrian officers' saddle, I33.

Australia, 2, 255.

Australians, 3, I73.

" BACK" OF SADDLE, I 24.

,, , weight-bearing surfaces of, I I 4, I I 7.

Backs, sore, I I6, I 30 .

Badgers, 3I I, 31 2, 336.

Balance, riding by, 6 .

Bandages, 348.

Bar plates, I 12.

Bare-backed riding, I 8 .

Barroil, 449.

Bars of a saddle, I I I, I I 2.

,, ,, the mouth, I8, 70.

,, , spring, I Io.

Bath, lamp, 445.

,, , Turkish, 446 .

Bearing-reins, 25.

Beaufort, Duke of, 349.

Beaufort's, Duke of, 320, 340.

Bedale, 320.

Beecher's Brook, 422.

Bellies of a tree, I I 2.

, on a saddle, 123.
Belts, weight, 429 .

Belvoir, 63, 298, 299, 322, 34I. foxes, $37 \mathrm{I}$.

Ben Morgan bit, 4I.

Bend Or, 395, 399.

Bending to the rein, I9.

Berks, South, 324.

Bicester and Warden Hill, 320.

Billets, 5 I.

Bit and bridoon, 24 .

, , choice of a, 106.

Bits, 24-48.

,, , cast, 27-29.

,, , materials for, 27.

Bitting, principles of, 24 .

Black Diamond, 393.

Blackmore Vale, 320.

Blackwell nose-net, 270.

Blencathra, 320.

Blood, 328.

"Blooding " a boy, 331.

Body, weight of, 208, 219.

Boers, I64.

Boots for horses, 348 .

,, , top, 344 .

Boring, 253.

Bottoms, 358 .

Boys learning to ride, 5 .

Breast-plates, I I I, I 45 .

Breeches, hunting, 34I.

Breeding horses, 307, 31 7 .

Bridle, adjustment of, Io3.

, , afraid to go up to, 25.

,, , description of, 24 .

,, , double, 29, 49, 106. 
Bridle gear, 24.

, , objects of a, 24 .

, parts of $a, 5 \mathrm{~J}$.

Bridling a horse, ror.

Bridles, 49

,, for racing, 425 .

Bridoon, 29. head, 5 I.

Brooks, 357.

Brown Brandy, 396.

Brush, giving fox's, 37 I.

Buckingham's covers for reins, 60 .

Buck-jumping, 255 .

, , saddle, I 35 .

Buckles and sewing, 51-54, 56 .

Bucks, 300.

Bullfinches, 354 .

Bumping up and down, 225.

Bullocks, 352.

Burns-Hartopp, Captain, 320.

Buttons, hunt, 340.

," on breeches, 342 .

CALEDONIAN HUNT CLUB, 340

Cambridgeshire Hill, 392.

Canes, riding, 2 I9.

Cannon, K., 393.

,, , M., 393.

,, , Tom, 374, 402.

Canter, 13, I 5, 17, 234.

,, , changing leg at, 449.

, , turning at, 23, 243.

Cantle, II 2.

plate, I 12.

Capping, 322.

Caps, hunting, 343 .

Carter, George, 337.

Cast bits, 27-29.

,, , saddle getting, 123 .

Cecil, 407.

Chaloner, 386.

Change of horses, 306.

Changing the pace, 23 I, 235, 236, 240.

leading fore leg, 449 .

Chapes, I 14 .

Chargers, 274.

Charnwood Forest, 3 I9.
Cheshire, 35I.

Chifney bit, $42,82,83$.

Chin-groove, $74,76$.

,, straps, 40, 4r, 66.

Christian, Dick, 266.

Circle curb hook, 86.

Clarke, Mr., 272.

Cloister, 283.

Coats, hunting, 338.

Collars, hunting, 340 .

Collecting a horse, 23 I.

Collection, over, 25, 26.

Colonials, 4 .

Colonies, 5I, I 26, I45, 227.

Control, 230.

Cooking food, 44I.

Cottesmore, 298.

Country, choice of a, 297 .

, , , riding over a, 278 .

Coventry, Lord, 323.

Covert, drawing a, 36r.

,, fund, 309.

Coverts, 336-338.

Cows, 352.

Craven, 320.

Crouching seat, I4, 375 .

Cruppers, I I I, I45.

Cub-hunting, 299.

Cubs, fox, 318.

Curb, definition of, 40 .

", chain, 40, 74, 84, 104 .

", ,, , curb without, 76 .

, , , position of, 104.

,, , position of, I03.

,, , use of, 107.

,, with sliding mouth-piece, 83 .

Curbs, 39-47.

,, , action of, 74, 107.

, , construction of, 77 .

,, , position of, IO3.

Custance, 3, 386 .

Cut-and-laid fences, 353 .

,, back pommel ("'head "), I2I.

DAMAGE FUND, 308.

Dartmore, 350.

Day, William, 38o, $3^{85}$. 
Deer, carted, 300.

Devon and Somerset, 296, 323.

Devonshire, 298.

Diet, 440, 44I, 442.

Dingles, 333 .

Dismounting, I8I.

Dixon, Mr. Scarth,' 309 .

Doe-skin covered saddle, I25.

“'Dogs,", calling hounds, \$349. , worrying sheep, 309-312.

Dollery, 283.

Doncaster, 386.

Double bridle, 29, 49, I06, 425 .

Dovedale, 402.

Drag-hunting, 297, 324 .

Dragged, getting, 140 .

Drink, 440, 442, 443.

Druid, 266.

Ds, II 4 .

Dubourg, Mr., 324 .

Dwyer, Major, 66, 76, 84 .

Dyke, 349.

\section{EARTH-STOPPERS, 322.}

East Essex, 320.

Equilibrium, instability of, I4, I6.

Eskdale, 320.

Essex, 350.

Evening hunt dress, 340.

Ewes, English and Welsh, 309.

Exercise, 437, 440.

Exmoor, 324, 350.

FALLING, 6, 288.

False, cantering, 237.

Farmers, 307-31 7, 369.

Felt for panels, I30.

Fences, 350-358, 369.

Fenn, Mr., 325.

Fernie's, Mr., 320.

Field money, 322.

Fields, Midland, 307 .

Finishing, 396.

Firr, Tom, 328, 336, 364 .

Flaps of a saddle, I I3, I 24-I 27.

Flock, I29, I 30.

Forage, 315, 316.
Forehand, raising the, 282, 288.

Foot, slope of, 277.

Fordham, George, 375, 392, 399.

Foxes, 308-312, 318, 319, 328, 33 I $338,352,370,37$ I.

Foxes, speed of, 350, 351.

Freeman, 395.

Frolic, 393.

Fronts (brow-bands), 54 .

Fruit, 439, 442.

Frying, 44I.

GALLOP, IO, I I, I 4, 238.

Gamekeepers, 319, 322.

Gardevisure, 392.

Garter straps, 342.

Gartree Hill, 299. ,, , farmer, 312.

Gates, 356, 365, 368 .

,, , opening, 365 .

Ghost, The, 402.

Gillard, Frank, 62, 323, 364 .

Gillson, 364 .

Girths, I 42, 43i.

,, , shortening, I 50.

Give and take, 224.

Gloves, 346.

Good Luck, 393.

Gorse, 336.

Gout, 434, 435 .

Grafton, 320 .

Grand Flaneur, 393.

Grand National fences, 4 I9.

Greatwood run, 37 I.

Greenwood, Colonel, I03, I04, I66, I68, I 8I, 398 .

Gridiron bit, 43 .

Grooms, 3I 5.

Guidance, 230.

Gullet, I I2, I 24, I 29.

,, lining, 124 .

,, , open, I 24, I 29.

,, plate, I I 2.

HANDCOCK'S MOUTH-COVERS, $3^{8 .}$

Hands, 227. 
Hands, position of, 220.

, , steady, keeping, 223, 224.

Hanwell, Major, 296.

Hard and sharp bridle, 30 .

Harness horses, 25, 26.

Harriers, 324.

Hats, hunting, 343 .

Haviers, 300.

Hayhoe, 405.

Head, Mr., 310.

, of a bridle, $5 \mathrm{I}$.

, , , , saddle, i 12.

,, , position of horse's, 18-23.

,, stall, $5 \mathrm{r}$.

, , throwing down the, 260.

,, ,, up ,, 26c.

Heavers, 303.

Hedges, 353-355.

Hieover, Harry, I06, 273.

Highland, Darcy, I 35 .

High Leicestershire, 349.

Hinds and does, hunting, 324 .

Hill, going up and down, 248.

Hiring hunters, 303 .

Holloas, 362-364.

Hoof, slope of, 277.

Horizon, 283

Horse hair, curled, I29.

Horse's mouth, i 8.

Horses, cruelty to, $366,407,408$.

, , harness, 25, 26.

,, , peculiarities of, 394 .

,, , wild, 9.

Hounds, buck, 323.

,, , deer, 325 .

,, , drag, 324 .

,, , fox, 323, 326 .

,, , pace, 359.

,, , stag, 323 .

, , with, 359 .

Hunt, joining a, 319.

, servants, presents to, $\mathbf{3 2 2}$.

Hunters, 303, 305, 306, 356 .

, , shoeing, 289.

Hunting, I, 3, 4, 106, 107, 295-37 I.

, as a sport, 295 .

, , benefit of, 307 .
Iunting box, 299.

,, clothes, 338 .

,, expressions, 348 .

,, men, 366 .

,, preliminaries, 295.

, $\quad$ riding gear, 348 .

,, season, 299.

, things, 338 .

Hutchens, Harry, I6.

" IMPECUNIOSUS," 326.

India, 51, 227, 381, 382, 438.

Ireland, 228, 349, 364, 438.

Irish horses, 229, 305, 353 .

Iron for bits, 27, 28 .

Iroquois, 395 .

JAW, WEIGHT-BEARING SURFACE OF, IO4.

Jibbing, 164 .

Jockeys, 2, 3, 381.

, , seat, 14, 16, 372-376.

Jones, Captain, 401 .

Jumping, 278.

, competitions, $\mathrm{I}$.

KEITH-FRASER, GENERAL, 134 .

Kicking, 26r, 304.

King-King, Captain, 296, 300, 323, $328,333,350,352,359,364,370$.

King's Messenger, 393.

Kirby Gate, 299.

Knee-rolls, I 13, 126, 127.

,, -ties, 343 .

Knight of the Garter, 395 .

Knuckling over behind, 277.

LAMBS AND FOXES, 309-312.

Lamp bath, 445 .

Langham-Reed, Mr., 55, 66, 67, 80, 8I , $82,84,86$, I 39.

Larking over jump, 5, 369.

Lead cloths, 428, 431 .

Leading with off fore, 237.

Leads, 429.

Leather-covered panels, I 30, I31.

Ledbury, 339. 
Leicestershire, 106, 298, 299, 305, $319,354,357,370$.

Leg up, getting a, I79.

Legs as an aid, 208, 2 Io.

Lifting a horse, 285 .

Lime, oxalate of, 435 .

Lip-straps, see "chin-straps."

Linen-covered panels, $\mathbf{1} 32$.

Lively, keeping the mouth, 83 .

Loates, S., 394, 400.

Long reins, driving with, 204-206.

Lonsdale, Lord, 306, 315, 320, 322, 362.

Lonsdale's girths, Lord, I 29. ,, martingale, Lord, 94.

Lord Clifden, 384, 395.

Luff, Dr., 434, 435 .

MACHINE, HORSE AS A, 9.

Malleable iron, 28, 29.

Mamluke bit, 46 .

Mange, 312, 318.

Manipur, 35 .

Manners, Lord Edward, 322.

Maories, 258.

Margarett, Mr. Steve, I26.

Marie Stuart, 386.

Market Harborough, 298.

Marriott, Mr., 266.

Martin Mr. Edwin, 377, 405, 406, 407, 443.

Martingale, Cheshire, 89 .

,, , fixed, 71, 89.

,, Irish, IOI.

,, , Lord Lonsdale's, 94.

,, , running, 94, 426, 430 .

,, , standing, 71, 89, 426 .

,, , webb, 96.

Martingales, 88-10I, 426.

Masters, 360, 36r, 362 .

Mawson, 284 .

Medicine, 439.

Meets, 359, 36o.

Melton Mowbray, 298, 307, 340.

,, $\quad$, $\quad$ corn dealer, 3 I 5 .

Melville, Whyte, I9, 280, 353, 367.

Merry Sunshire, 386 .
Meynell, 34I. ,, , Admiral, $35^{2}$.

Mid-Devon, 320.

Midlands, the, 298, 352 .

Military riding, 448 .

Milk, 442.

Miner, the 386 .

Moore, Mr. Garrett, 427.

,, , Mr. J. H., 58, 93, 222.

Morris, General, I2.

Mount, difficult to, 260 .

Mounting, I69-I8I.

Mouth, horse's, I8.

Mufti, hunting, 346.

Muscles, action of, 20, $2 \mathrm{I}$.

,, of the neck, 20, $2 \mathrm{I}$.

NEVER RUST BITS, 29.

New Forest, 300, 323, 324, 340.

,, Zealand, 2, 255, 258.

Newmarket, 392.

Nickel for bits, 29.

Nitrogenous matter, 433-438.

Nolan's saddle, I 34 .

North Cheshire, 344 .

Nose, blowing the, 275.

,, -band, action of, 65 .

,, , adjustment of, 106.

,, , Bucephalus, 62 .

,, , caveson, 6r.

,, double, 62 .

,, , Gillard's, 62.

,, , ordinary, 60.

,, , position of, Io6.

Nouveau Riche, 394.

Numdahs, I 44 .

Nutbush, 379.

OAKHAM, 298.

Off fore, leading with, 237.

Officers, 4.

Old Berkeley, 340, 34I.

One-handed riding, I64-167, 225-227, 29I , 448, 449.

Open channel, 129.

Ord, Mr. Richard, 307.

Orders, race riding, 403 . 
Osborne, John, 377, 384, 387, 393, 443.

Owen, Mr. E. M., 282.

Oxers, 355 .

PACE, JUDGING, 380.

Pace maker, 385 .

,, , making the, 385,386 .

Panels, I10, I27.

Passage, 244, 45 I.

Pax, 400 .

Pelham, Hanoverian, 48, 87 .

Pelhams, 48.

, , action of, 86 .

Persimmon, 386.

Philopena, 394 .

Picking objects off ground, 249.

Pig-skin, I24, I25.

Pigsticking, 2, 227, 228, 295.

Pink, 340.

Pins, hunting, 344 .

Poacher, a, 3II.

Point-pockets, II3.

Points of a tree, II2.

Polo, 2, 35, 9I, I87.

Pommel, II2.

, , cut back, I2I.

, , straight, I2I.

Port of a bit, 79, 80.

Posts and rails, 355 .

Poulett, Lord, 392.

Poultry and foxes, 308 .

Pratt, 386.

Provinces, the, 349 .

Pull up, to, 238.

Pullers, riding, 224, 267, 402.

Punishment, 292, 293, 407, 408.

Puppies, walking, 326 .

Puppy shows, 327.

Pytchley, 320, 340.

QUEEN'S, THE, 323.

Quorn, 298, 299, 306, 315, 320, 322.

RACE RIDING, 372-409.

Racing gear, 425 .
Racing gear, adjustment of, 430 .

Raddle, 3 I 2.

Rat-catcher, 346.

Rearing, 26I.

Red deer, 312.

,, man, 340.

Reiff, Lester, 393.

Rein, tying up a, 167 .

Reining back, 3, 247, 45 .

Reins, 55-60

, , changing the, 163 .

, , holding double, 158 .

,, , , single, I54.

, , , $\quad$ the, 153-167, 225, 226.

, in military style, holding, 164 , 226.

, in one hand, I64, 226.

" , two hands, 164 .

," , lacing, 60.

, , length of, 221.

", , long (driving), 204-206.

," , management of the, 6, 222, 376 .

,, , riding without, 204-206.

,, , shortening, 160.

", , slack, 227-229.

", , uses of the, 207.

Refusers, 288, 290-294.

Resin, 431.

Restiveness, 264.

Reversed indications, 225, 226

Rheumatism, 437.

Ride, beginning to, 5 .

Ridge and furrow, $352,356,357,367$.

Riding gear, hunting, 348 .

,, , general view of, I

,, straight, 364 .

Riot, 325 .

Ripley and Knap Hill, 324.

Robert the Devil, 395, 399.

Roberts, 4 .

Robinson, Jem, 375.

Roe, 300.

Rogers, Sam, 399.

Rogues, 390, 400.

Rossiter, 399.

Rothschild's, Baron, 323.

Rous, Admiral, 396. 
Running away, 267. , , making the, 386 .

Runs, 332, 37 I.

Rutland, Duke of, 322.

\section{SADDLE, Austrian officers', I 33 .}

, , bellies on seat of, I23.

, , buck-jumping, I35.

, cloths, I44, I48.

, , description of a, Iog.

, for heavy man, I I 9 .

," getting “cast," I23.

", , hunting, rog.

, , Keith-Fraser's, I34.

, , length of a, II7.

,, , measuring for a, I 35 .

", , military, I Io.

, muscle, II 4 .

, , position for a, I45.

,, , racing, 109, 426.

,$\quad$, riding in a light, 7 .

, , "spring" in, II9, I23.

, tree, I09, III, II6.

, , webs of, I22.

, , weight of hunting, I 20.

,, , width of, II 7 .

Saddlery, IO9-1 52, 425.

Saddles, I09-I 52, 426.

,, , covering of, I24.

,$\quad$, leaded, 427.

, , steeplechasing, 427 .

, , too short, II6.

, . , varieties of, Iog.

Saddling a horse, $\mathbf{1} 46$.

, , , race-horse, 430.

Safety bars, I 42.

Salicylate of sodium, 439.

Salt, 438, 439.

Samandal, 394.

Sandown water-jump, 285 .

Saunterer, 386, 387, 388.

Scarlet, 340.

Scent, 37 I.

School, riding, 448.

Scots Grey, 93.

Season, hunting, 299.

Seat, differences of, 187.
Seat, hunting, I89-20I.

,, , jockey's, I4, I6, 372-376.

,, , military, 203.

,, of a saddle, II 3 .

,, the, 187-203.

Second horsemen, 306 .

Segundo bit, 45 .

Serge-covered panels, I30, I3I.

Sewing for bridles, $5 \mathrm{I}-53,56$.

Sheep dip, 3 I 2.

Sherston, Major, 264.

Shires, the, 348.

Shooting men, 317 .

Short, Mr., 265.

Shoulder-in, 45I.

Shouldering, 270.

Showing the whip, 255 .

Shying, 273 .

Sir Bevys, 392.

Sitfast, I 17.

Skaters, 16.

Skirts of a saddle, II3.

Slack reins, 227-229.

Sliding mouth-piece curb, 4I, 83 .

"Slip, getting the," 389 .

Sloan, 38I, 394.

Slope of hoof, 277.

Smith, Capt. " Doggie," 364.

Snaffle, action of, 68-74.

,, , best form of, I08.

,, , chain, 33 .

,, , double-jointed, 30.

,, , , mouthed, 36 .

$,, \quad, \quad, \quad$ ringed, 33 .

, , gag, 35 .

,, , half-moon, 30 .

, in mouth, position of, I03.

,, , India-rubber, 38.

", , Newmarket, 38.

,, , single-jointed, 30 .

, , thin racing, 32 .

, , twisted, 32.

,, , unjointed, 30, Io8.

, , use of, 107.

Snaffles, 29-38.

"Snob," 339.

Sore backs, I I6, I 3 O. 
Sornette, 386.

Soup, 44I.

"Spectacles," Iо0.

Speed, I2, 14, 16, 21.

Spinal column, I I4.

Spring bars, I IO, 427.

,, hooks, 53 .

,, in saddle, II 9 .

Sprinters, 16.

Spurs, 208, 2 IO, 21 I, 345, 405.

Stabling for hunters, 299.

Stag hunting, 296, 300.

Standing in the stirrups, 373.

Staples, I I4

Starch, 436, 437.

Starting for a race, $378-380$. , , ,, run, 362, 364 .

Steel for bits, 27-29.

Steeplechase riding, 4 IO.

Steinbok, 325.

Stevens, Mr. John, 258.

Sticks, 208, 21 I, 218.

Stile, Midland, 356.

Stirrup irons, $139,428$.

, leathers, I37, I 50, I 52.

", , , buckles of, ${ }_{3} 38$.

" , , , twisting, I49.

Stirrups, feet home in, 196.

, , length of, 200.

," , measuring, 169 .

,$\quad$, riding without, 7 .

Stock driving, 227.

Stops on reins, 56 .

Straight head (ponmel), I2I. ,$\quad$, riding, 364 .

Stud-billets, 53 .

Stuffing of panel, I 29.

Stumbling, 275.

Stutterer, a, 391.

Subscriptions to hunts, 320-322.

Surcingles, I I I, I45, 430.

Sweat flaps, II 3 .

Sweating, 443.

Swerving, 246.

Swimming a horse, 249.

Swindells, Mr. F., 404.
TAR, 3I 2.

Tarporley Hunt Club, 340.

Taunton Vale, 34I.

Thorns, 336 .

Throat-latches, 54, 106.

Thurlow's bit, Lord, 44, 82.

Ties, hunting, 344 .

Timber, riding at, 288.

Timing trąining gallops, 382 .

Toast, 437.

Tomato, 405 .

Tongue over bit, 80, 271 .

Trees, saddle, I09, II I, II6.

Trot, 23I, 235.

., , turning at the, 22, 242.

Turning horse, 22, 23, 72, 98, 222, 223, 226, 240-243, 449.

Turning horse at canter, 23, 243.

, , , , trot, 22, 242.

, , , , walk, 22, 242.

Twist of a saddle, II 3 , II8.

UNITED, 340.

Unsteadiness, 273.

Urea, 433.

Uric acid, 434, 435 .

VALE OF WHITE HORSE, 320.

Valentine's Brook, 422.

Vegetables, 435, 439, 442 .

Vertebræ, II 4.

Vauban, 394.

Vices, horses with, 252-277.

Vine, 350.

Vixens, 299, 331-336.

Voice, 208, 220.

WAIST OF A SADDLE, II3, II4, II 8 .

Waistcoats, hunting, 344 .

Waiting, 383 .

, in front, 388 .

Walk, riding at a, 230.

, , turning at a, 242.

Walls, 356 .

Warburton, 3 I9.

Ward Union curb, 4I, 83. 
Wasting, 432-447.

Water, $368,436,437$. , , riding at, 288 .

Waterford, Lord, 344 .

Weatherall, 394.

Webb, Fred, 3 .

Webs of a saddle, $\mathbf{I 2 2}$.

Weighing, 442.

, in and out, 447.

Weight as an aid, rider's, 208, 219.

", hearing surfaces of horse's back, II4, II 7 .

, cloth, 428, 43I.

," , dead, 397.

", , distribution of horse's, I2, I8. ZEBRAS, 9.

, jackets, 429 .
Weight, keeping down, 432-447. , $\quad$ on horse, effect of, 384 .

Wellington, 4.

West Somerset, 340.

Whaddon Chase, 320.

Whippers-in, 322, 349.

Whip, jockey using, 21 5-219.

Whips, 208, 21 1-218, 349, 406.

Williams, General Owen, 338 .

Wire, 315.

Woodruff, Hiram, 403.

YATES, CAPTAIN PARK, 344.

TILE END. 


\section{BOOKS
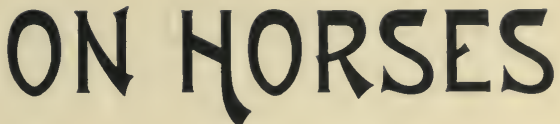

BY

M. HORACE HAYES, F.R.C.V.S.

(Late Captain "The Buffs").

Now Ready in I vol., Demy 8vo., Cloth. Price 16/- nett.

\section{Riding and Hunting.}

By CAPT. M. H. HAYES, F.R.C.V.S.

Fully Illustrated with upwards of 250 Reproductions of Photographs and Drawings.

Now Ready in I vol., Demy 8vo. Price 12 ; - nett.

\section{Stable Management and Exercise.}

A BOOK FOR HORSE OWNERS AND STUDENTS.

BY CAPT. M. HORACE HAYES, F.R.C.V.S.

Illustrated by numerous Reproductions of Photographs taken specially for this work.

"Captain Hayes-who may justly claim to be the first authority now living on all matters connected with the horse-is always welcome, and the more so because each successive volume is a monument of 'the reason why.' "-County Gentleman.

LONDON : HURST \& BLACKETT, LIMITED,

13, Great Marlborough Street. 
Second Edition. Super-Royal 8vo., Cloth, Gilt Top, Price 34/--

\section{Points of the Horse.}

A FAMILIAR TREATISE ON EQUINE CONFORMATION.

By CAPT. M. HORACE HAYES, F.R.C.V.S.

The present Edition has been thoroughly revised and contains numerous additions, including specially-written Chapters on the Breeds of English and Foreign Horses, with over Two Hundred beautiful Illustrations reproduced from Photographs, the larger number of which were taken by the Author and have never before been published.

"An elaborate and instructive compendium of sound knowledge on a subject of great moment to all owners of horses, by a writer of established authority on all matters connected with the horse."-Times.

"We hail the advent of a work on the subject by such a pastmaster of the arts hippic as Captain Horace Hayes, late of 'The Buffs,' and a Fellow of the Royal College of Veterinary Surgeons, the author of several of the most simple and thoroughly instructive treatises upon riding, breaking, and veterinary treatment of the horse."-Land aml Water.

Demy 8vo., Cloth. Price Io/6 nett.

\section{INFECTIVE DISEASES$$
==\text { OF ANIMALS. }
$$

Being Part I. of Friedberger and Frohner's Veterinary Pathology,

With a Chapter on Bacteriology by Dr. G. Newman, D.P.H.

Translated and Edited

By Capt. M. H. HAYES, F.R.C.V.S.

" Whether considered as a work of reference for busy practitioners, as a itext-book for students, or as a treatise on pathology in its widest significance, this volume meets every requirement, and is an invaluable addition to our literature."-Veterinary Record.

"With great satisfaction we welcome the appearance of this translation, Iwhich,for the first time places in the hands of English-speaking readers a worthy version of one part of Friedberger and Fröhner's great work. Captain Hayes' reputation is sufficient warrant for the excellence of the literary portion of the present issue. It would be presumptuous on our part to add one word on the value of the work as a source of information. Every one bows to the authority of the authors."-The Velerinarian.

LONDON: HURST \& BLACKETT, LIMITED, i3, Great Marlborough Street. 
Fifth Edition. Revised and Enlarged. Large Crown 8vo. Price 15/-.

\section{Veterinary Notes for Horse Owners.}

AN ILLUSTRATED MANUAL OF HORSE MEDICINE AND SURGERY, WRITTEN

IN SIMPLE LANGUAGE.

By CAPT. M. H. HAYES, F.R.C.V.S.

This Edition is revised throughout, considerably enlarged, and incorporates the substance of the Author's "Soundness and Age of Horses."

The chief new matter in this edition is-articles on Contracted Heels, Donkey's Foot Disease, Forging or Clicking, Rheumatic Joint Disease, Abscess, Dislocation of the Shoulder Joint, Inflammation of the Mouth and Tongue, Flatulent Distention of the Stomach, Twist of the Intestines, Relapsing Fever, Cape Horse Sickness, Horse Syphilis, Rabies, Megrims, Staggers, Epilepsy, Sunstroke, Poisoning, Castration by the Ecraseur, and Mechanism of the Foot (in Chapter on Shoeing). Field.

"Is a thoroughly practical work and may be recommended with confidence."-The

"Is a valuable addition to our stable literature; and the illustrations, tolerably numerous, are excellent beyond the reach of criticism."-Saturday Reviev.

"Leaves nothing to be desired on the score of lucidity and comprehensiveness."Veterinary Journal.

"A necessary guide for horse-owners, especially those who are far removed from immediate professional assistance."-The Times.

\section{The Horsewoman. Large Crown 8vo. Price Io/6.}

\section{By MRS. HAYES. Edited by CAPT. M. H. HAYES.}

\section{A PRACTICAL GUIDE TO SIDE-SADDLE RIDING.}

\section{With Numerous Illustrations and Drawings from Photographs by OSWALD BROWN.}

"A large amount of sound, practical instruction, very judiciously and pleasantly imparted."-The Times.

"This is the first occasion on which a practical horseman and a practical horsewoman lave collaborated in bringing out a book on riding for ladies. "The result is in every way satisfactory, and, no matter how well a lady may ride, she will gain much valuable information from a perusal of 'The Horsewoman.' The book is happily free from selflaudatory passages."-The Field.

Large Crown 8vo. Price 10,6 nett.

\section{Among \\ Horses \\ in \\ Russia.}

By CAPT. M. H. HAYES, F.R.C.V.S.

With Fifty=three lllustrations from Photographs taken chiefly by the Author.

LONDON : HURST \& BLACKETT, LIMITED, 13, Great Marlborough Street. 
Imperial I6mo. Second Edition, Price 21/-.

\section{ILLUSTRATED . . HORSE=BREAKING.}

By Capt. M. H. HAYES, F.R.C.V.S.

This Edition has been entirely re-written; the amount of the letterpress more than doubled; and 75 reproductions of Photographs have been added.

'It is a characteristic of all Capt. Hayes' books on horses that they are eminently practical, and the present one is no exception to the rule. A work which is entitled to high praise as being far and away the best reasoned-out one on breaking under a new system we have seen."-The Field

Fifth Edition. Revised. Crown 8vo. Price 6/-.

\section{Training and}

\section{Horse Management in India.}

By Capt. M. H. HAYES, F.R.C.V.S.

"A useful guide in regard to horses anywhere. Concise, practical, and portable."-Saturday Revieze.

"We entertain a very high opinion of Capt. Hayes' book on 'Horse Training and Management in India,' and are of opinion that no better guide could be placed in the hands of either amateur horseman or veterinary surgeon newly arrived in that important division of our empire."-Veterinary fournal.

\section{Crown 8vo. Price 5/-. \\ AMONG HORSES \\ - IN SOUTH AFRICA. \\ By Capt. M. H. HAYES, F.R.C.V.S.}

LONDON : HURST \& BLACKETT, LIMITED.

i3, Great Marlborough Street. 




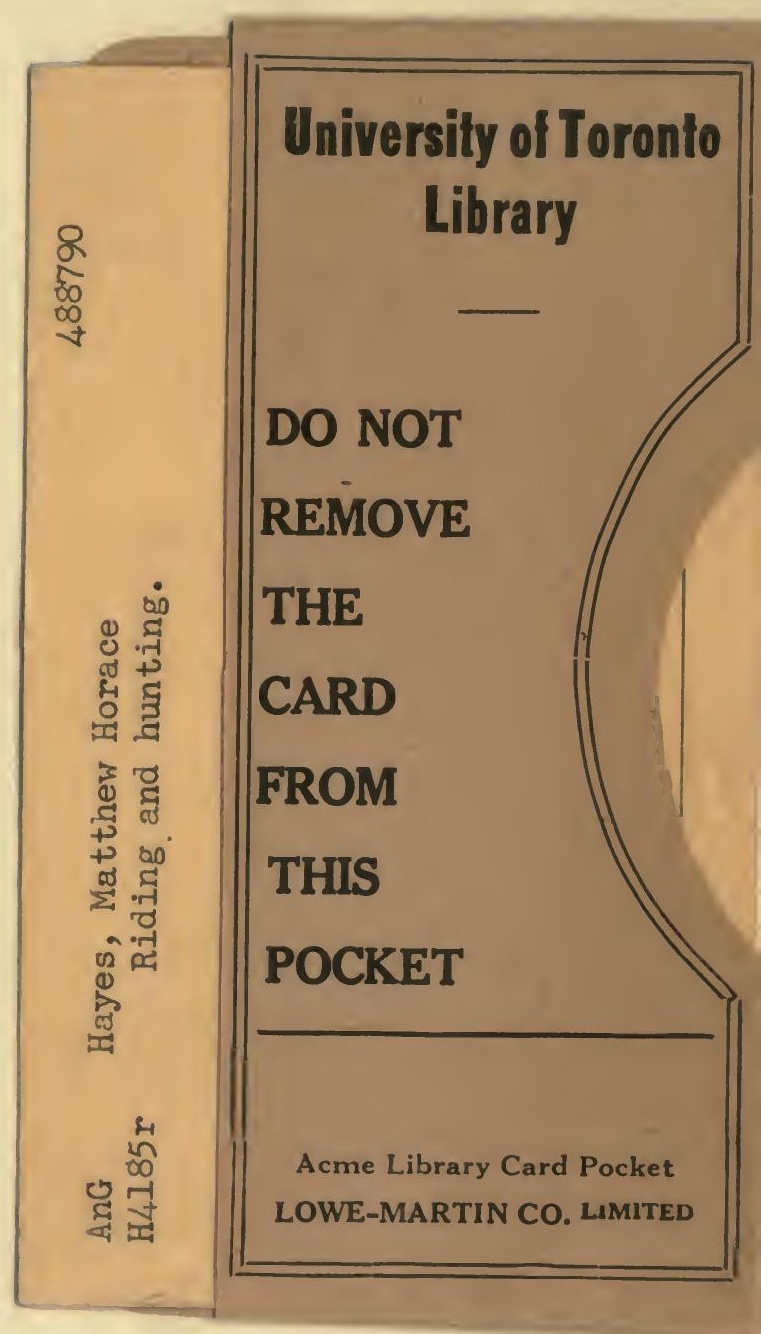


